\title{
Three-Dimensional Stability Analyses of Soil-Nailed Slopes by Finite Element Method
}

\author{
Kerry D. Stauffer
}

Follow this and additional works at: https://researchrepository.wvu.edu/etd

\section{Recommended Citation}

Stauffer, Kerry D., "Three-Dimensional Stability Analyses of Soil-Nailed Slopes by Finite Element Method" (2015). Graduate Theses, Dissertations, and Problem Reports. 6719.

https://researchrepository.wvu.edu/etd/6719

This Dissertation is protected by copyright and/or related rights. It has been brought to you by the The Research Repository @ WVU with permission from the rights-holder(s). You are free to use this Dissertation in any way that is permitted by the copyright and related rights legislation that applies to your use. For other uses you must obtain permission from the rights-holder(s) directly, unless additional rights are indicated by a Creative Commons license in the record and/ or on the work itself. This Dissertation has been accepted for inclusion in WVU Graduate Theses, Dissertations, and Problem Reports collection by an authorized administrator of The Research Repository @ WVU.

For more information, please contact researchrepository@mail.wvu.edu. 


\title{
Three-Dimensional Stability Analyses of Soil-Nailed Slopes by Finite Element Method
}

\author{
Kerry D. Stauffer, M.S., P.E., P.S. \\ Dissertation submitted to the \\ Benjamin M. Statler College of Engineering and Mineral Resources \\ at West Virginia University \\ in partial fulfillment of the requirements \\ for the degree of \\ Doctor of Philosophy \\ in \\ Civil and Environmental Engineering \\ Hema J. Siriwardane, Ph.D., Chair \\ H. Ilkin Bilgesu, Ph.D. \\ Raj K. Gondle, Ph.D. \\ Udaya B. Halabe, Ph.D. \\ John D. Quaranta, Ph.D.
}

Department of Civil and Environmental Engineering Morgantown, West Virginia

2015

Keywords: Soil Nailing; Finite Element Method; Three-Dimensional Slope Stability 


\title{
ABSTRACT \\ Three-Dimensional Stability Analyses of Soil-nailed Slopes by Finite Element Method
}

\author{
Kerry D. Stauffer
}

Modern computer capabilities enable complex slope stability problems to be analyzed using the finite element method (FEM), including three-dimensional slopes. This research presents the results of analyzing two- and three-dimensional, unreinforced and soil-nailed, reinforced slopes. Previously performed two-dimensional slopes were modeled as three-dimensional slopes in an effort to validate the modeling technique. The Shear Strength Reduction (SSR) Method was used throughout this study to determine the Factor of Safety (FOS). Both two- and three-dimensional FEM models compared well with conventional, two-dimensional Limit-Equilibrium (L-E) results. Overall, results show that the FEM is an extremely diverse and robust alternative to conventional, L-E slope stability analyses, especially when complex site geometries or conditions exist.

When modeling two-dimensional, unreinforced soil slopes using FEM, the most efficient and accurate element type that provides an acceptable failure mechanism is the CPE4 (4-noded bilinear quadrilateral) element in conjunction with either the MohrCoulomb or Drucker-Prager soil failure yielding criteria. When modeling threedimensional, unreinforced soil slopes using FEM, the most efficient and accurate element type that provides an acceptable failure mechanism is the C3D8 (8-noded linear brick) element in conjunction with the Mohr-Coulomb soil failure yielding criteria. Although the Drucker-Prager soil yielding criteria assumptions seem to offer more potential for three-dimensional applications, this study found no significant benefit from its use.

For unreinforced slopes, three-dimensional, unit-width FEM models provide identical results to FEM slope models with depth, when end conditions are not considered. For soil-nailed reinforced slopes, three-dimensional, unit-width FEM models yield FOS values marginally higher than two-dimensional FEM and L-E models for all slope angles. Unit-width FEM models provide designers with a valuable tool for performing parametric studies and preliminary design.

Three-dimensional FEM models of soil-nailed reinforced slopes can be used to effectively determine the soil nail orientation that yields the highest FOS, also known as the optimum soil nail orientation. For slopes with a level backfill, the optimum soil nail orientation (in degrees measured downward from horizontal) can be first approximated using the equation $58^{\circ}-0.6 \beta$, where $\beta$ is the slope angle in degrees. Three-dimensional FEM models can also be used to effectively determine the most efficient soil nail length. For slope heights of about 10 meters, the most efficient soil nail length can be first approximated using a soil nail length to slope height ratio equal to 1.0.

A maximum vertical soil nail spacing of 2.4 meters and 1.9 meters is recommended for soil-nailed slopes with slope angles less than or equal to $60^{\circ}$ and greater than $60^{\circ}$, respectively. A maximum horizontal soil nail spacing less than 1.9 meters is recommended for soil-nailed slopes for all slope angles. When performing three-dimensional FEM modeling of reinforced slopes, the FOS value is relatively 
insensitive to a soil's Elastic Modulus, Unit Weight, and Poisson's Ratio value. The most significant soil parameters are the Angle of Friction and the Cohesion. Further, the results of this study indicate that regardless of the soil type, there is no significant increase in the FOS of soil-nailed reinforced slopes with slope angles less than $80^{\circ}$.

Three-dimensional FEM models can be used effectively to evaluate unreinforced and soil-nailed reinforced slopes that have a surcharge load and can be used to estimate slope deformation, even prior to failure. In addition, pre-tensioned soil nails can be modeled using an FEM approach. Fully modeled, three-dimensional FEM slope stability analyses yield FOS values that are slightly lower than either traditional two-dimensional L-E models or three-dimensional FEM unit-width models that use a "worst case" section technique. Overall, three-dimensional FEM slope stability modeling is superior to other methods due to its capabilities and versatility. 


\section{ACKNOWLEDGEMENT}

\section{Three-Dimensional Stability Analysis of Soil-nailed Slopes by Finite Element Method \\ Kerry D. Stauffer}

I would like to express my sincere appreciation to Dr. Hema J. Siriwardane for his time, guidance, and willingness to work with me as a nontraditional graduate student over these past few years. I would not have been able to complete this work without him.

Also, I extend much gratitude to Dr. H. Ilkin Bilgesu, Dr. Raj K. Gondle, Dr. Udaya B. Halabe, and Dr. John D. Quaranta for their patience, time, and willingness to serve on my graduate committee.

I would like to thank E. Franklin Hart for his consistent push and encouragement throughout this research. I would like to communicate my love and appreciation to my wife, Susie, and my four children, Hannah, Blake, Joshua, and Caleb for their patience over all these years.

Last, but certainly not least, I would like to thank my Heavenly Father for all the blessings in life, for through Him all things are possible. 


\section{TABLE OF CONTENTS}

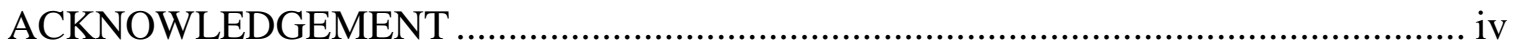

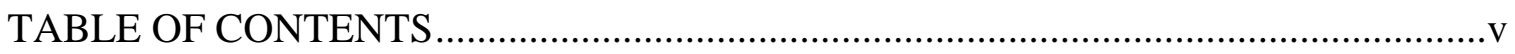

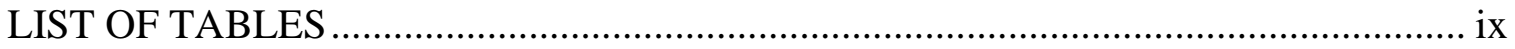

LIST OF FIGURES .................................................................................... xii

CHAPTER 1: INTRODUCTION ......................................................................

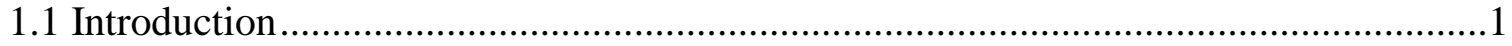

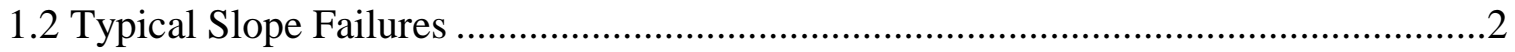

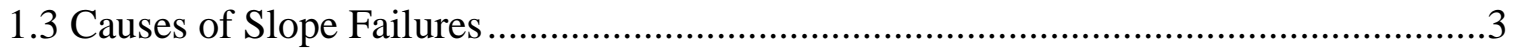

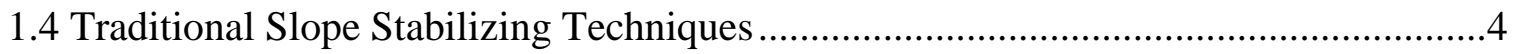

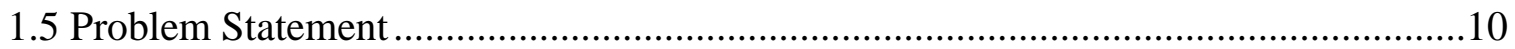

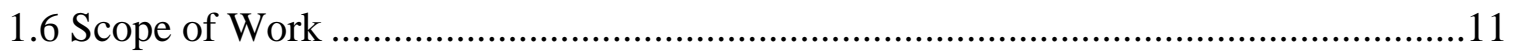

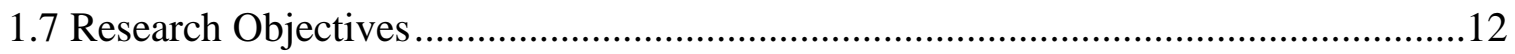

CHAPTER 2: SOIL NAILING: A COMPREHENSIVE REVIEW ..............................13

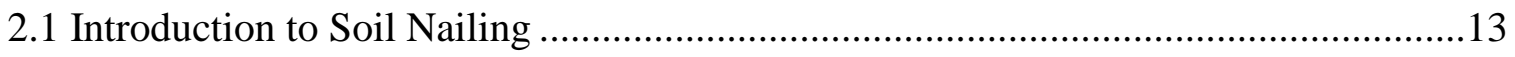

2.2 Construction and Components of a Soil Nail Wall................................................15

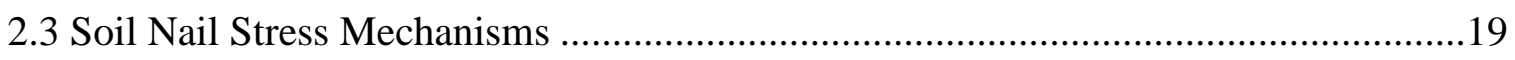

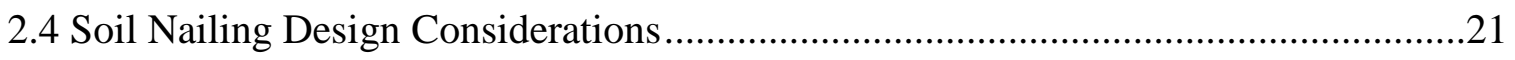

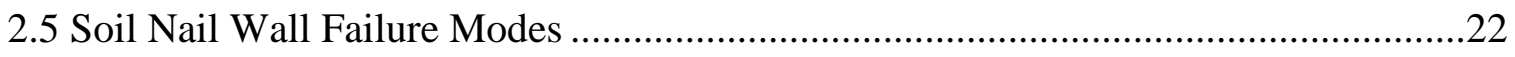

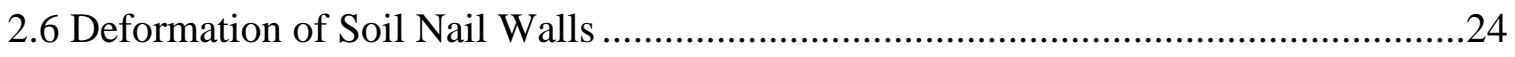

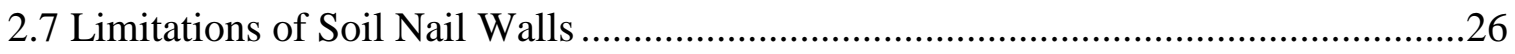

2.8 Use of Finite Element Method (FEM) and Limit-Equilibrium (L-E) in Evaluating Soil Nail Walls..................................................................26

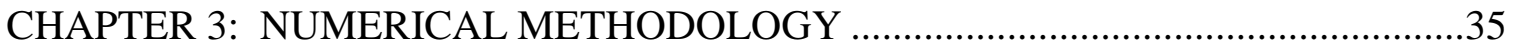

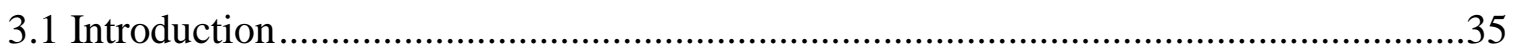

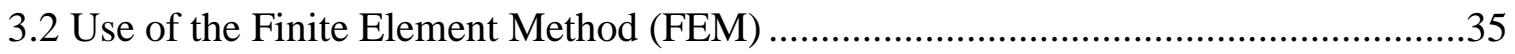

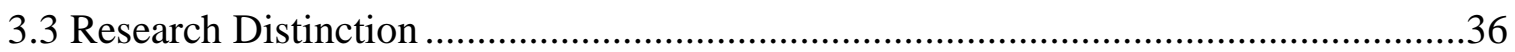

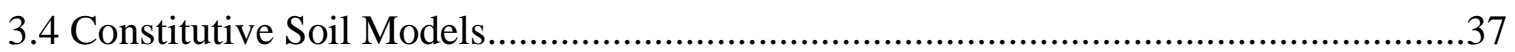

3.4.1 Comparison of Drucker-Prager and Mohr-Coulomb Soil Models ..........................37

3.4.2 Linear Drucker-Prager Soil Model ............................................................... 40 
3.4.3 Comparison of Drucker-Prager Model with Mohr-Coulomb Model.......................42

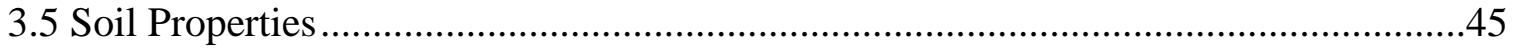

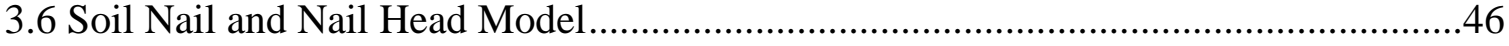

3.6.1 Constitutive Material Model for the Soil Nail and Nail Head ...............................46

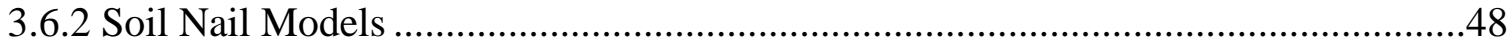

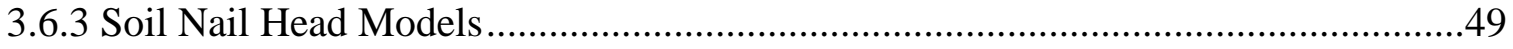

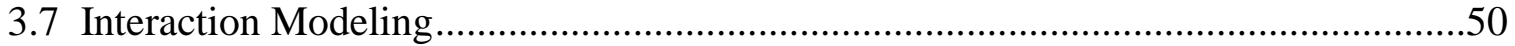

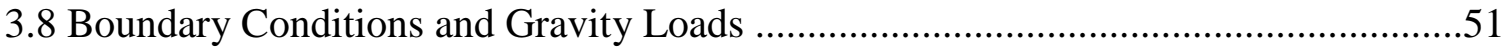

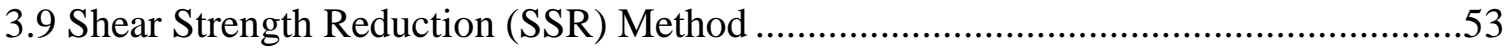

CHAPTER 4: TWO-DIMENSIONAL MODELING STUDIES ...................................55

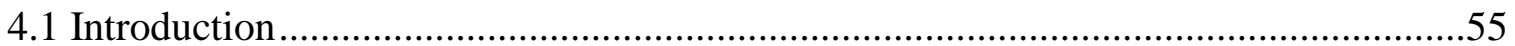

4.2 Two-Dimensional Limit Equilibrium Evaluation of Unreinforced Slopes..................55

4.3 Selection of Element Type in Two-Dimensional Finite Element Model ....................57

4.4 Two-Dimensional Modeling for Reinforced Slopes.............................................59

4.5 Two-Dimensional Limit-Equilibrium Evaluation of Reinforced Slopes ....................59

CHAPTER 5: THREE-DIMENSIONAL MODELING STUDIES ..............................61

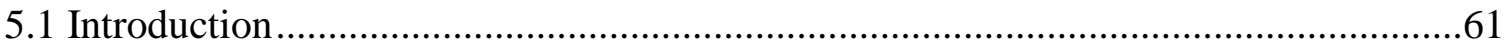

5.2 Influence of Depth in Three-Dimensional Analysis of Unreinforced Slopes..............61

5.3 Selection of Element Type in Three-Dimensional Finite Element Model .................62

5.4 Comparison of Three-Dimensional FEM with Two-Dimensional FEM and Limit Equilibrium Models for Unreinforced Slopes.....................................64

5.5 Three-Dimensional Modeling of Reinforced Slopes ..............................................64

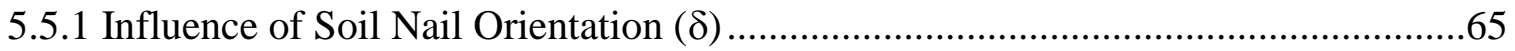

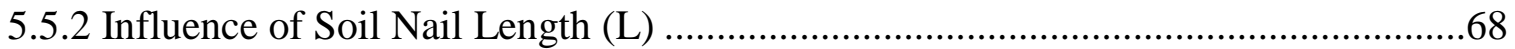

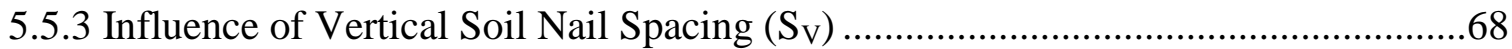

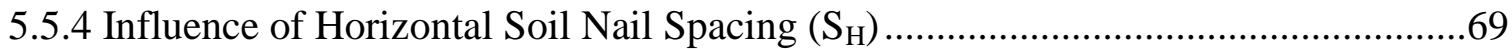

5.5.5 Horizontal Soil Nail Spacing $\left(\mathrm{S}_{\mathrm{H}}\right)$ - Sensitivity of Soil Properties ........................71

5.5.6 Influence of Surcharge Location $(\mathrm{x})$ and Magnitude $(\mathrm{q})$........................................72

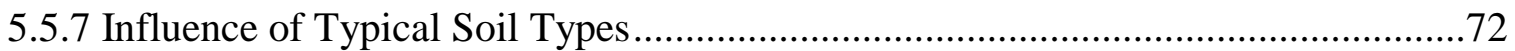

5.5.8 Influence of Rainwater Infiltration on Slope Stability........................................73

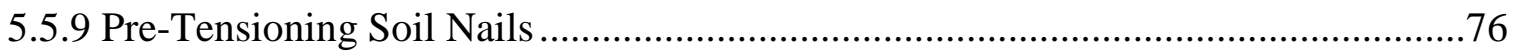

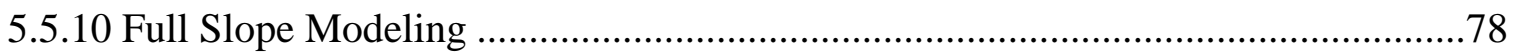


CHAPTER 6: TWO-DIMENSIONAL MODELING RESULTS AND

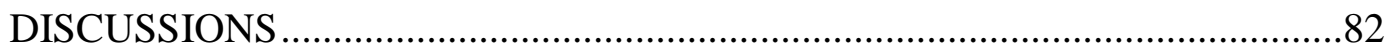

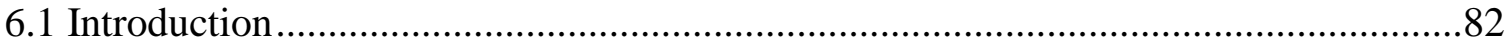

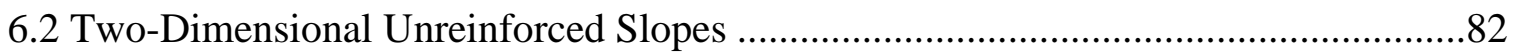

6.3 Two-Dimensional Limit Equilibrium Results for Unreinforced Slopes.....................83

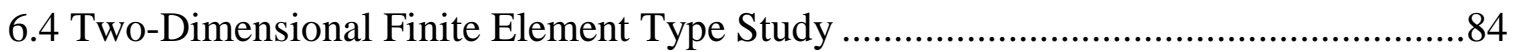

6.4.1 Comparison of Element Types for Two-Dimensional Mohr-Coulomb

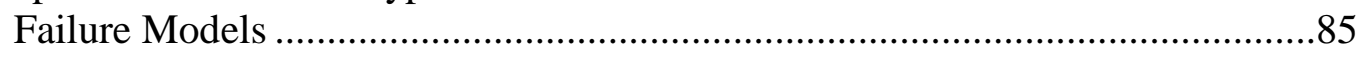

6.4.2 Comparison of Element Types for Two-Dimensional Drucker-Prager

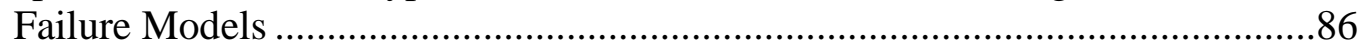

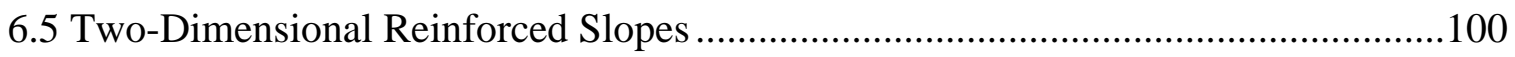

CHAPTER 7: THREE-DIMENSIONAL MODELING RESULTS AND

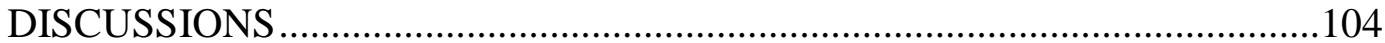

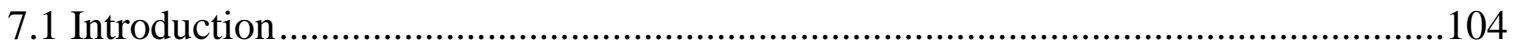

7.2 Influence of Depth in Three-Dimensional Analysis of Unreinforced Slopes ............104

7.3 Three-Dimensional Finite Element Type Study .................................................. 106

7.3.1 Comparison of Element Types for Three-Dimensional MohrCoulomb Failure Models .................................................................................10

7.3.2 Comparison of Element Types for Three-Dimensional Drucker-

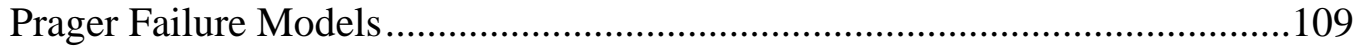

7.4 Three-Dimensional FEM Comparison to Two-Dimensional FEM and Limit Equilibrium Results for Unreinforced Slopes ......................................125

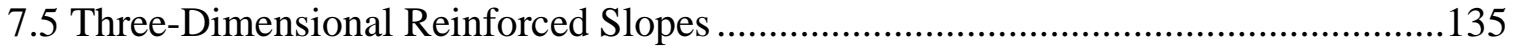

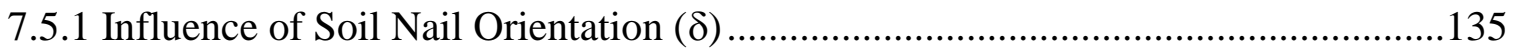

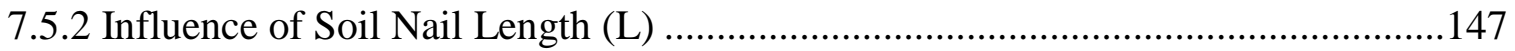

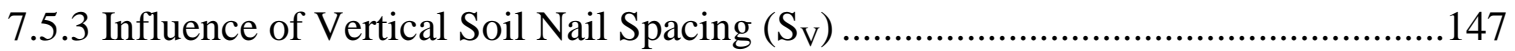

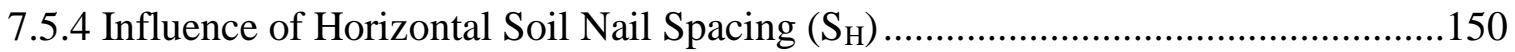

7.5.5 Influence of Surcharge Location (x) and Magnitude (q) ....................................174

7.5.6 Surcharge Location (x) and Magnitude (q) - Two-Dimensional L-E

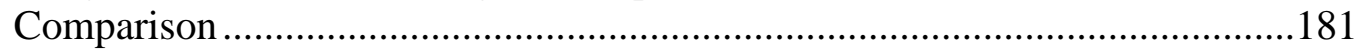

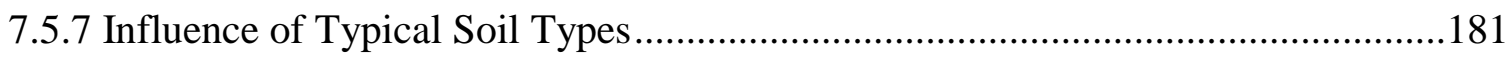

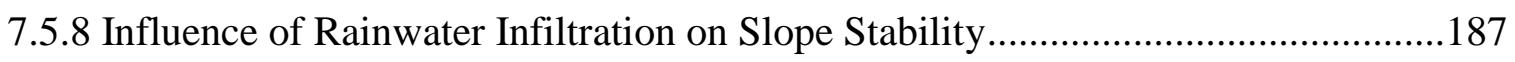

7.5.9 Influence of Pre-Tensioned Soil Nails on Vertical Deformation............................188

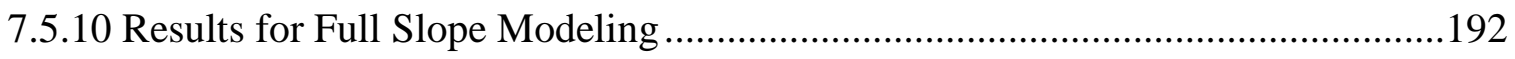


CHAPTER 8: SUMMARY AND CONCLUSIONS .................................................203

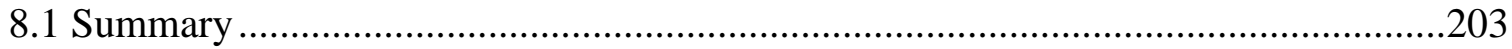

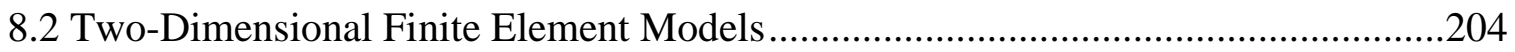

8.2.1 Analysis of Two-Dimensional Reinforced Slopes.............................................207

8.3 Three-Dimensional Finite Element Models............................................................207

8.3.1 Influence of Depth in Three-Dimensional Analysis of Unreinforced

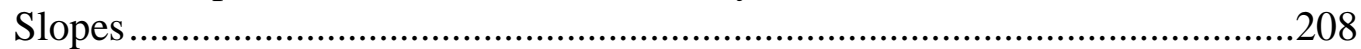

8.3.2 Three-Dimensional Element Type Study ....................................................208

8.3.3 Comparison of Three-Dimensional FEM with Two-Dimensional L-E Analysis for Unreinforced Slopes ...........................................................211

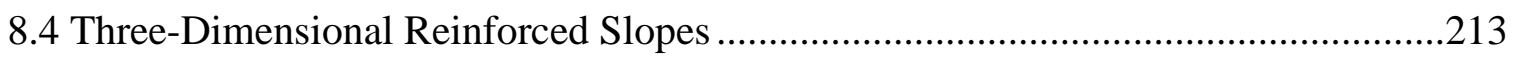

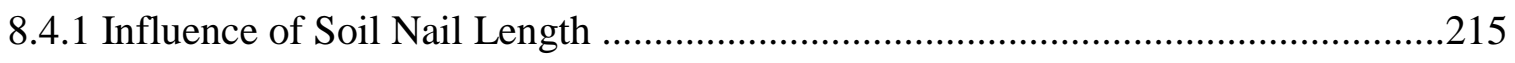

8.4.2 Influence of Vertical Spacing of Soil Nails ........................................................216

8.4.3 Influence of Horizontal Spacing of Soil Nails ...................................................217

8.4.4 Influence of Surcharge Location and Magnitude..............................................219

8.4.5 Influence of Typical Soil Properties and Rainwater Infiltration ...........................220

8.4.6 Influence of Pre-Tensioned Soil Nails .................................................................222

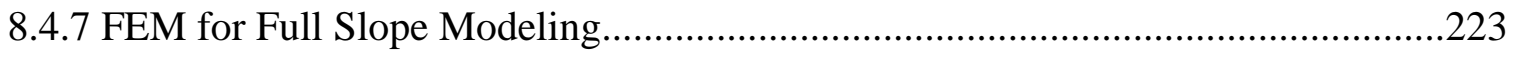

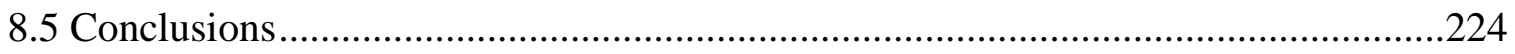

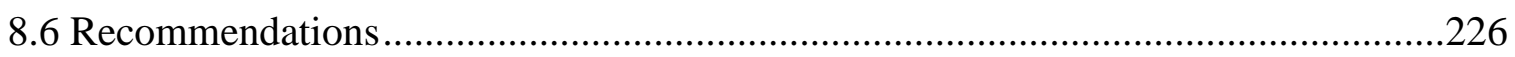

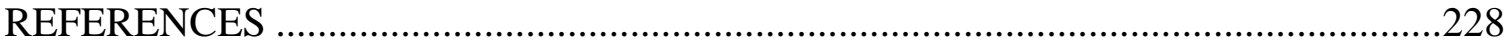

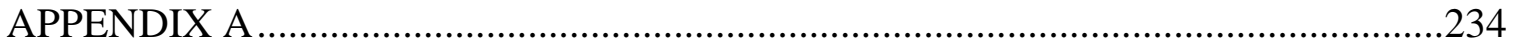




\section{LIST OF TABLES}

Table 1.1 Types of Slope Movements (Varnes, 1978) .....................................................

Table 2.1 Typical Soil Nail Construction and Component Properties............................ 18

Table 2.2 Values of $(\delta \mathrm{h} / \mathrm{H})_{\mathrm{i}}$ and $\mathrm{C}$ as Functions of Soil Conditions

(Lazarte et al., 2003)

Table 2.3 The Optimal Nail Orientation for Soil-nailed Slopes with Various Geometric Conditions using Two-Dimensional FEM (from Fan and Luo, 2008)

Table 2.4 The Optimal Nail Orientation for Soil-nailed Slopes with Various Geometric Conditions using Two-Dimensional LimitEquilibrium (from Rotte et. al., 2011)

Table 3.1 Comparison of Mohr-Coulomb and Drucker-Prager Soil Models

Table 3.2 Matching of Drucker-Prager and Mohr-Coulomb Soil Properties (Abaqus, 2011)

Table 3.3 Benchmark Mohr-Coulomb Soil Properties ("Soil 1”).................................. 45

Table 3.4 Equivalent Benchmark Drucker-Prager Soil Properties ................................ 46

Table 3.5 Soil Nail and Nail Head Mechanical Properties (Tamboli, 1997) ................... 47

Table 4.1 Available Options for Two-Dimensional Plane Strain Element

Selection in Abaqus 58

Table 5.1 Available Options for Three-Dimensional Element Selection in Abaqus

Table 5.2 Optimum Soil Nail Orientation Values for Various Slope Angles.................. 68

Table 5.3 Soil Properties used in Horizontal Soil Nail Spacing Study 70

Table 5.4 Soil Types and Associated M-C Property Ranges Encountered on Soil Nailing Projects

Table 5.5 Soil Properties Used in Full Slope Modeling Study 79

Table 6.1 FOS Results for Two-Dimensional FEM and L-E Models 84 
Table 6.2 Comparison of Two-Dimensional Element Type for Mohr-

Coulomb Model

Table 6.3 Comparison of Two-Dimensional Element Type for Drucker-

Prager Model.

Table 6.4 Comparison of Two-Dimensional FEM and L-E Results for

Reinforced Benchmark Slope

Table 7.1 Comparison of Three-Dimensional Element Type for Mohr-

Coulomb Model

Table 7.2 Comparison of Three-Dimensional Element Type for DruckerPrager Model.

Table 7.3 Comparison of FOS for 3-D FEM, 2-D FEM, and L-E for Unreinforced Slopes.

Table 7.4 Optimum Soil Nail Orientation Values for Various Slope Angles

Table 7.5 Slope and Soil Variables used in Soil Nail Horizontal Spacing

$\left(\mathrm{S}_{\mathrm{H}}\right)$ Study -Influence of Soil Properties

Table 7.6 FOS Values for Fully Modeled Slopes and Comparable Section Methods.

Table 8.1 Results Summary for Two-Dimensional Element Selection Study........... 206

Table 8.2 Results Summary for Three-Dimensional Element Selection Study...........210

Table 8.3 Comparison of 3-D FEM with 2-D L-E Results for Unreinforced Slopes.....

Table A.1 Summary Table of Default PEEQ Plot Values and Recommendation for 2-D Element Selection Study using M-C Yielding Criteria.

Table A.2 Summary Table of Default PEEQ Plot Values and Recommendation for 2-D Element Selection Study using D-P Yielding Criteria .236

Table A.3 Comparison of 2-D Element Type for M-C - Uniform Deformation Factor and PEEQ Limits

Table A.4 Comparison of 2-D Element Type for D-P - Uniform Deformation Factor and PEEQ Limits..........................................238

Table A.5 Summary Table of Default PEEQ Plot Values and Recommendation for 3-D Element Selection Study using M-C Yielding Criteria. 
Table A.6 Summary Table of Default PEEQ Plot Values and Recommendation for 2-D Element Selection Study using D-P Yielding Criteria................240

Table A.7 Comparison of Three-Dimensional Element Type for Mohr-Coulomb -Uniform Deformation Factor and PEEQ Limits..........241

Table A.8 Comparison of Three-Dimensional Element Type for Drucker-Prager - Uniform Deformation Factor and PEEQ Limits...........242 


\section{LIST OF FIGURES}

Figure 1.1 Slope Stabilization by Earthworks …................................

Figure 1.2 Drainage Layer used to Enhance Slope Stability.......................6

Figure 1.3 Mechanical Behavior of a Reinforced Earth Slope.......................9

Figure 2.1 Schematic of Typical Soil Nail Construction............................14

Figure 2.2 Soil Nail Project at Bluestone Lake, Hinton, WV ........................16

Figure 2.3 Schematic of Typical Soil Nail Cross-Section..........................17

Figure 2.4 Components of a Soil Nail (Porterfield et. al., 1994).....................19

Figure 2.5 Mechanism of Tension Mobilization in Soil Nail Wall....................21

Figure 2.6 Ex. 2: Homogeneous Slope with a Foundation Layer

(Griffiths and Lane, 1999).....................................28

Figure 2.7 Geometry of Soil-Nailed Reinforced Benchmark Model with Base

(Wanstreet, 2007).............................................28

Figure 2.8 Equivalent Plastic Strain Contours - one nail at toe of slope

(Wanstreet, 2007)...........................................29

Figure 2.9 Equivalent Plastic Strain Contours - three nail case

(Wanstreet, 2007)...............................................29

Figure 2.10 Schematic of Slope and Soil Nail Parameters

Used by Fan and Luo (2008)...................................

Figure 3.1 Mohr-Coulomb Failure Criteria......................................38

Figure 3.2 Cross-Section of Mohr-Coulomb and Drucker-Prager

Yield Surface in Deviatoric Plane.................................39

Figure 3.3 Drucker-Prager Failure Criteria.....................................40

Figure 3.4a FE Model of a Typical Soil-nailed Slope - Full View.....................47

Figure 3.4b FE Model of a Typical Soil-nailed Slope - Exploded View................48

Figure 3.5 FE Model Interactions Schematic.....................................51 
Figure 3.6 Boundary Conditions Used for Two-Dimensional Models...............52

Figure 3.7 Boundary Conditions Used for Three-Dimensional Models...............52

Figure 4.1 Geometry of Two-Dimensional Benchmark Model

(Wanstreet, 2007)....................................57

Figure 4.2 Mesh Geometry of Two-Dimensional Benchmark Model

using 6-Noded Modified Quadratic Plane Strain

Triangular (CPE6M) Elements (Wanstreet, 2007)

Figure 4.3 Two-Dimensional, Reinforced Benchmark Model

(Wanstreet, 2007)..........................................59

Figure 5.1 Three-Dimensional, Unreinforced Soil Slope with Increasing Depth.....62

Figure 5.2 Schematic of Soil Nailing Design Variables..........................65

Figure 5.3 Schematic of Soil Nail Intersection with Failure Surface...............66

Figure 5.4 Three-Dimensional, Soil Nail Reinforced Soil Slope

$\left(90^{\circ}\right.$ Slope Shown)

Figure 5.5 Vertical Nail Spacing $\left(\mathrm{S}_{\mathrm{V}}\right)$ Methodology

$\left(90^{\circ}\right.$ Slope Shown with $\left.\mathrm{S}_{\mathrm{V}}=2.0 \mathrm{~m}\right)$

Figure 5.6 Horizontal Nail Spacing $\left(\mathrm{S}_{\mathrm{H}}\right)$ Methodology

$\left(90^{\circ}\right.$ Slope Shown) .71

Figure 5.7 Point of Interest for Evaluation of Pre-Tensioned, Soil-nailed Slope.....77

Figure 5.8 Full Slope Model No. 1 (Effect of End Conditions)..................80

Figure 5.9 Full Slope Model No. 2 (Non-Planar, 90 Corner, 5-meter Radius).......81

Figure 5.10 Full Slope Model No. 3 (Non-Planar, 90 Corner, 25-meter Radius).....81

Figure 6.1 Deformed Mesh for Two-Dimensional Benchmark Model..............83

Figure 6.2 PEEQ Contours for Two-Dimensional Benchmark Model..............83

Figures 6.3 - 6.18 Plastic Strains for Two-Dimensional Mohr-Coulomb Elements

Figure 6.3: Plastic strains for CPE3 elements (2D) .................88

Figure 6.4: Plastic strains for CPE3H elements (2D) .................88

Figure 6.5: Plastic strains for CPE4 elements (2D) ...................88

Figure 6.6: Plastic strains for CPE4H elements (2D).................89 
Figure 6.7: Plastic strains for CPE4R elements (2D)................89

Figure 6.8: Plastic strains for CPE4RH elements (2D)..............89

Figure 6.9: Plastic strains for CPE4I elements (2D)...................90

Figure 6.10: Plastic strains for CPE4IH elements (2D)...............90

Figure 6.11: Plastic strains for CPE6 elements (2D)................90

Figure 6.12: Plastic strains for CPE6H elements (2D)..............91

Figure 6.13: Plastic strains for CPE6M elements (2D)................91

Figure 6.14: Plastic strains for CPE6MH elements (2D)...............91

Figure 6.15: Plastic strains for CPE8 elements (2D)................92

Figure 6.16: Plastic strains for CPE8H elements (2D)..............92

Figure 6.17: Plastic strains for CPE8R elements (2D)...............99

Figure 6.18: Plastic strains for CPE8RH elements (2D).............. 93

Figures 6.19-6.34 Plastic Strains for Two-Dimensional Drucker-Prager Elements

Figure 6.19: Plastic strains for CPE3 elements (2D).................94

Figure 6.20: Plastic strains for CPE3H elements (2D)................94

Figure 6.21: Plastic strains for CPE4 elements (2D) ..................94

Figure 6.22: Plastic strains for CPE4H elements (2D)...............95

Figure 6.23: Plastic strains for CPE4R elements (2D)................95

Figure 6.24: Plastic strains for CPE4RH elements (2D)................95

Figure 6.25: Plastic strains for CPE4I elements (2D)..................96

Figure 6.26: Plastic strains for CPE4IH elements (2D)................96

Figure 6.27: Plastic strains for CPE6 elements (2D).................96

Figure 6.28: Plastic strains for CPE6H elements (2D)................97

Figure 6.29: Plastic strains for CPE6M elements (2D).................97

Figure 6.30: Plastic strains for CPE6MH elements (2D)..............97

Figure 6.31: Plastic strains for CPE8 elements (2D) .................98

Figure 6.32: Plastic strains for CPE8H elements (2D)................98

Figure 6.33: Plastic strains for CPE8R elements (2D)............... 98

Figure 6.34: Plastic strains for CPE8RH elements (2D)...............99

Figure 6.35 PEEQ Contours for Two-Dimensional,

Reinforced Benchmark Model - 1 Nail...........................101

Figure 6.36 PEEQ Contours for Two-Dimensional,

Reinforced Benchmark Model - 2 Nails............................101

Figure 6.37 PEEQ Contours for Two-Dimensional,

Reinforced Benchmark Model - 3 Nails...............................102

Figure 6.38 L-E Results for Two-Dimensional,

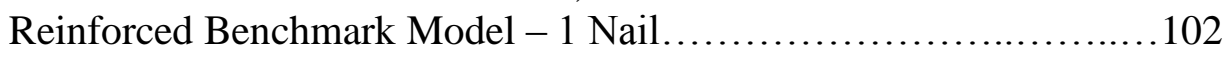

Figure 6.39 L-E Results for Two-Dimensional,

Reinforced Benchmark Model - 2 Nails.........................103 
Figure 6.40 L-E Results for Two-Dimensional,

Reinforced Benchmark Model - 3 Nails............................103

Figure 7.1 Three-Dimensional, Unreinforced Soil Slope with 2 meter Depth.........105

Figure 7.2 Three-Dimensional, Unreinforced Soil Slope with 10 meter Depth.......105

Figure 7.3 Three-Dimensional, Unreinforced Soil Slope with 50 meter Depth.......106

Figures 7.4 - 7.24 Plastic Strains for Three-Dimensional Mohr-Coulomb Elements

Figure 7.4: Plastic strains for C3D4 elements (3D)...................111

Figure 7.5: Plastic strains for C3D4H elements (3D)..................111

Figure 7.6: Plastic strains for C3D6 elements (3D)...................111

Figure 7.7: Plastic strains for C3D6H elements (3D)...................112

Figure 7.8: Plastic strains for C3D8 elements (3D) .................112

Figure 7.9: Plastic strains for C3D8H elements (3D) .................112

Figure 7.10: Plastic strains for C3D8R elements (3D).................113

Figure 7.11: Plastic strains for C3D8RH elements (3D)..............113

Figure 7.12: Plastic strains for C3D8I elements (3D)...............113

Figure 7.13: Plastic strains for C3D8IH elements (3D)...............114

Figure 7.14: Plastic strains for C3D10 elements (3D)................114

Figure 7.15: Plastic strains for C3D10H elements (3D)..............114

Figure 7.16: Plastic strains for C3D10M elements (3D)...............115

Figure 7.17: Plastic strains for C3D10MH elements (3D).............115

Figure 7.18: Plastic strains for C3D10I elements (3D)................115

Figure 7.19: Plastic strains for C3D15 elements (3D) .................116

Figure 7.20: Plastic strains for C3D15H elements (3D)................116

Figure 7.21: Plastic strains for C3D20 elements (3D)................116

Figure 7.22: Plastic strains for C3D20H elements (3D)...............117

Figure 7.23: Plastic strains for C3D20R elements (3D)...............117

Figure 7.24: Plastic strains for C3D20RH elements (3D).............117

Figures 7.25 - 7.45 Plastic Strains for Three-Dimensional Drucker-Prager Elements

Figure 7.25: Plastic strains for C3D4 elements (3D).................118

Figure 7.26: Plastic strains for C3D4H elements (3D).................118

Figure 7.27: Plastic strains for C3D6 elements (3D).................118

Figure 7.28: Plastic strains for C3D6H elements (3D).................119

Figure 7.29: Plastic strains for C3D8 elements (3D)..................119

Figure 7.30: Plastic strains for C3D8H elements (3D).................119

Figure 7.31: Plastic strains for C3D8R elements (3D).................120

Figure 7.32: Plastic strains for C3D8RH elements (3D)..............120

Figure 7.33: Plastic strains for C3D8I elements (3D) .................120

Figure 7.34: Plastic strains for C3D8IH elements (3D).................121

Figure 7.35: Plastic strains for C3D10 elements (3D).................121

Figure 7.36: Plastic strains for C3D10H elements (3D)...............121

Figure 7.37: Plastic strains for C3D10M elements (3D)..............122

Figure 7.38: Plastic strains for C3D10MH elements (3D)..............122 
Figure 7.39: Plastic strains for C3D10I elements (3D)................122

Figure 7.40: Plastic strains for C3D15 elements (3D) ................123

Figure 7.41: Plastic strains for C3D15H elements (3D)..............123

Figure 7.42: Plastic strains for C3D20 elements (3D)...............123

Figure 7.43: Plastic strains for C3D20H elements (3D)..............124

Figure 7.44: Plastic strains for C3D20R elements (3D).............124

Figure 7.45: Plastic strains for C3D20RH elements (3D)............124

Figure 7.46 L-E Results for Two-Dimensional Unreinforced Slope - 26.5 ${ }^{\circ} \ldots \ldots \ldots . .126$

Figure 7.47 PEEQ Contour Plot for Two-Dimensional FEM

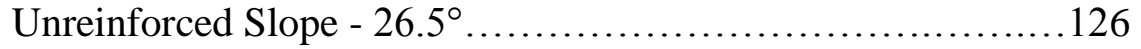

Figure 7.48 PEEQ Contour Plot for Three-Dimensional FEM

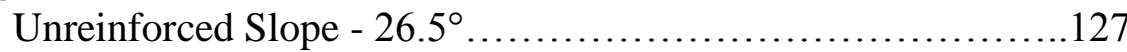

Figure 7.49 L-E Results for Two-Dimensional Unreinforced Slope - 50..........127

Figure 7.50 PEEQ Contour Plot for Two-Dimensional FEM

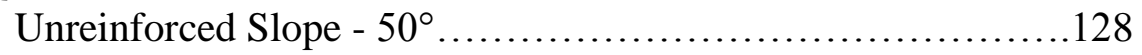

Figure 7.51 PEEQ Contour Plot for Three-Dimensional FEM

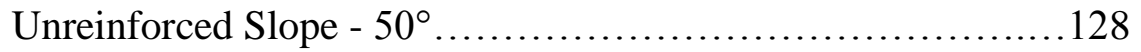

Figure 7.52 L-E Results for Two-Dimensional Unreinforced Slope $-60^{\circ} \ldots \ldots \ldots \ldots . .129$

Figure 7.53 PEEQ Contour Plot for Two-Dimensional FEM

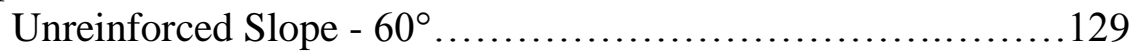

Figure 7.54 PEEQ Contour Plot for Three-Dimensional FEM

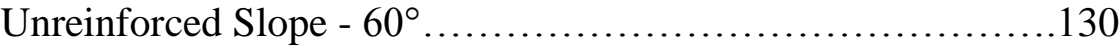

Figure 7.55 L-E Results for Two-Dimensional Unreinforced Slope - 70 ............130

Figure 7.56 PEEQ Contour Plot for Two-Dimensional FEM

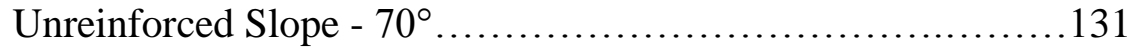

Figure 7.57 PEEQ Contour Plot for Three-Dimensional FEM

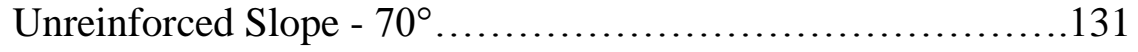

Figure 7.58 L-E Results for Two-Dimensional Unreinforced Slope - 80............132

Figure 7.59 PEEQ Contour Plot for Two-Dimensional FEM

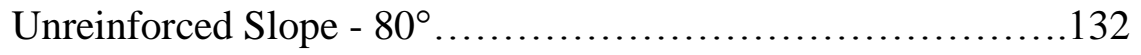


Figure 7.60 PEEQ Contour Plot for Three-Dimensional FEM

Unreinforced Slope - $80^{\circ}$

Figure 7.61 L-E Results for Two-Dimensional Unreinforced Slope - $90^{\circ}$

Figure 7.62 PEEQ Contour Plot for Two-Dimensional FEM

Unreinforced Slope - $90^{\circ}$

Figure 7.63 PEEQ Contour Plot for Three-Dimensional FEM

Unreinforced Slope - $90^{\circ}$

Figure 7.64 Schematic of Slope and Soil Nail Parameters Used in Soil Nail Orientation $(\delta)$ Study..............................136

Figure 7.65 Influence of Soil Nail Orientation $(\delta)$ on FOS for Varying Slope Angles $(\beta)$ - based on 3-D FEM.................138

Figure 7.66 L-E Results for Two-Dimensional Reinforced Slope $-26.5^{\circ}$

Figure 7.67 PEEQ Contour Plot for Three-Dimensional FEM

Reinforced Slope $-26.5^{\circ}$

Figure 7.68 L-E Results for Two-Dimensional Reinforced Slope $-40^{\circ}$.

Figure 7.69 PEEQ Contour Plot for Three-Dimensional FEM

Reinforced Slope $-40^{\circ}$

Figure 7.70 L-E Results for Two-Dimensional Reinforced Slope $-50^{\circ}$.

Figure 7.71 PEEQ Contour Plot for Three-Dimensional FEM

Reinforced Slope $-50^{\circ}$

Figure 7.72 L-E Results for Two-Dimensional Reinforced Slope $-60^{\circ}$.

Figure 7.73 PEEQ Contour Plot for Three-Dimensional FEM

Reinforced Slope $-60^{\circ}$

Figure 7.74 L-E Results for Two-Dimensional Reinforced Slope $-70^{\circ}$.

Figure 7.75 PEEQ Contour Plot for Three-Dimensional FEM

Reinforced Slope $-70^{\circ}$

Figure 7.76 L-E Results for Two-Dimensional Reinforced Slope $-80^{\circ}$.

Figure 7.77 PEEQ Contour Plot for Three-Dimensional FEM

Reinforced Slope $-80^{\circ}$ 
Figure 7.78 L-E Results for Two-Dimensional Reinforced Slope $-90^{\circ}$ 146

Figure 7.79 PEEQ Contour Plot for Three-Dimensional FEM

Reinforced Slope $-90^{\circ}$.

Figure 7.80 Schematic of Slope and Soil Nail Parameters

Used in Soil Nail Length (L) Study

Figure 7.81 Influence of Soil Nail Length (L) on FOS for

Varying Slope Angles $(\beta)$ - based on 3-D FEM

Figure 7.82 Schematic of Slope and Soil Nail Parameters

Used in Vertical Soil Nail Spacing $\left(\mathrm{S}_{\mathrm{V}}\right)$ Study

Figure 7.83 Influence of Vertical Soil Nail Spacing $\left(\mathrm{S}_{\mathrm{V}}\right)$ on FOS for

Varying Slope Angles $(\beta)$ based on 3-D FEM.

Figure 7.84 Influence of Horizontal Nail Spacing $\left(\mathrm{S}_{\mathrm{H}}\right)$ on FOS for

Varying Slope Angles $(\beta)$ based on 3-D FEM - Soil 1

Figure 7.85 Influence of Horizontal Nail Spacing $\left(\mathrm{S}_{\mathrm{H}}\right)$ on FOS for

Varying Slope Angles $(\beta)$ based on 3-D FEM - Soil 2.........154

Figure 7.86 Influence of Horizontal Nail Spacing $\left(\mathrm{S}_{\mathrm{H}}\right)$ on FOS for

Varying Slope Angles $(\beta)$ based on 3-D FEM - Soil 3.........155

Figure 7.87 Typical PEEQ Contours for Horizontal Soil Nail Spacing

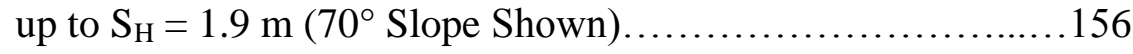

Figure 7.88 Typical PEEQ Contours for Horizontal Soil Nail Spacing of $S_{H} \geq 2.0 \mathrm{~m}\left(70^{\circ}\right.$ Slope Shown $)$

Figure 7.89 Influence of Elastic Modulus (E) \& Horizontal Nail Spacing $\left(\mathrm{S}_{\mathrm{H}}\right)$ on FOS for a $70^{\circ}$ Slope Angle $(\beta)-$ Soil $1 \ldots \ldots \ldots \ldots \ldots \ldots . . \ldots 158$

Figure 7.90 Influence of Poisson's Ratio $(\mu) \&$ Horizontal Nail Spacing $\left(\mathrm{S}_{\mathrm{H}}\right)$ on FOS for a $70^{\circ}$ Slope Angle $(\beta)$ - Soil 1 .

Figure 7.91 Influence of Soil Unit Weight $(\gamma) \&$ Horizontal Nail Spacing $\left(\mathrm{S}_{\mathrm{H}}\right)$ on FOS for a $70^{\circ}$ Slope Angle $(\beta)$ - Soil $1 \ldots \ldots \ldots \ldots \ldots \ldots . \ldots 160$

Figure 7.92 Influence of Cohesion (c) \& Horizontal Nail Spacing $\left(\mathrm{S}_{\mathrm{H}}\right)$ on FOS for a $70^{\circ}$ Slope Angle $(\beta)$ - Soil $1 \ldots \ldots \ldots \ldots \ldots \ldots 1$

Figure 7.93 Influence of Angle of Friction $(\phi) \&$ Horizontal Nail Spacing $\left(\mathrm{S}_{\mathrm{H}}\right)$ on FOS for a $70^{\circ}$ Slope Angle $(\beta)$ - Soil $1 \ldots \ldots \ldots \ldots \ldots \ldots \ldots . \ldots 162$ xviii 
Figure 7.94 Influence of Dilation Angle $(\psi)$ \& Horizontal Nail Spacing $\left(\mathrm{S}_{\mathrm{H}}\right)$ on FOS for a $70^{\circ}$ Slope Angle $(\beta)$ - Soil 1

Figure 7.95 Influence of Dilation Angle $(\psi)$ on FOS for Select Horizontal Nail Spacing $\left(\mathrm{S}_{\mathrm{H}}\right)$ for a $70^{\circ}$ Slope Angle $(\beta)$ - Soil $1 \ldots \ldots \ldots \ldots . . . . . .169$

Figure 7.96 Influence of Dilation Angle $(\psi)$ on FOS for Select Horizontal Nail Spacing $\left(\mathrm{S}_{\mathrm{H}}\right)$ for a $70^{\circ}$ Slope Angle $(\beta)$ - Soil $2 \ldots \ldots \ldots \ldots \ldots . \ldots 170$

Figure 7.97 Influence of Dilation Angle $(\psi)$ on FOS for Select Horizontal Nail Spacing $\left(\mathrm{S}_{\mathrm{H}}\right)$ for a $70^{\circ}$ Slope Angle $(\beta)-$ Soil 3..............171

Figure 7.98 Influence of Combined Cohesion (c) - Friction $(\phi) \&$ Horizontal

Nail Spacing $\left(\mathrm{S}_{\mathrm{H}}\right)$ on FOS for a $70^{\circ}$ Slope Angle $(\beta)$ - Soil $1 \ldots 173$

Figure 7.99 Schematic of Slope and Soil Nail Parameters Used in

Surcharge Location (x) and Magnitude (q) Study...

Figure 7.100 Influence of Surcharge Position (X) and Magnitude (q)

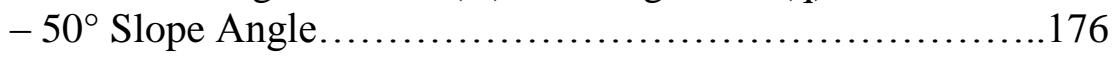

Figure 7.101 Influence of Surcharge Position (X) and Magnitude (q) $-60^{\circ}$ Slope Angle...................................... 177

Figure 7.102 Influence of Surcharge Position (X) and Magnitude (q) $-70^{\circ}$ Slope Angle................................... 178

Figure 7.103 Influence of Surcharge Position (X) and Magnitude (q) - $80^{\circ}$ Slope Angle.............................................. 179

Figure 7.104 Influence of Surcharge Position (X) and Magnitude (q) $-90^{\circ}$ Slope Angle 180

Figure 7.105 3-D FEM and 2-D L-E FOS Results for Surcharge Location and Magnitude $-70^{\circ}$ Slope Angle.

Figure 7.106 L-E Two-Dimensional Critical Surface for Reinforced Slope with Surcharge $-70^{\circ}$ Slope $(x=0 ; q=50 \mathrm{kPa})$ .184

Figure 7.107 FEM Three-Dimensional PEEQ Contours for Reinforced Slope with Surcharge $-70^{\circ}$ Slope $(x=0 ; q=50 \mathrm{kPa}) \ldots \ldots \ldots \ldots \ldots . . .184$

Figure 7.108 L-E Two-Dimensional Critical Surface for Reinforced Slope with Surcharge $-70^{\circ}$ Slope $(x=15 ; q=250 \mathrm{kPa})$... 
Figure 7.109 FEM Three-Dimensional PEEQ Contours for Reinforced Slope with Surcharge $-70^{\circ}$ Slope $(x=15 ; \mathrm{q}=250 \mathrm{kPa})$

Figure 7.110 Influence of Typical Cohesive Soil Property Values on FOS. 186

Figure 7.111 Influence of Unit Weight on FOS..................................188

Figure 7.112 Schematic of Slope and Soil Nail Parameters Used in Pre-Tensioned Study. ....

Figure 7.113 Vertical Deformation Results for Pre-Tensioned Soil Nails

Figure 7.114 PEEQ Contour Plot for Pre-Tensioned Soil Nails with Low Pre-Tension Force.

Figure 7.115 PEEQ Contour Plot for Pre-Tensioned Soil Nails with High Pre-Tension Force

Figure 7.116 Schematic of Full Slope Model No. 1 Geometry

- Elevation View.

Figure 7.117 2-D "Equivalent” Cross-Section Schematic for Comparison to Full Slope Models.

Figure 7.118 2-D L-E Reinforced Slope Result for Comparison to Full Slope Models.

Figure 7.119 PEEQ Contour Plot for 3-D FEM, Unit-Width Reinforced Slope for Comparison to Full Slope Models............................196

Figure 7.120a PEEQ Contour Plot for 3-D FEM, Unreinforced Full Slope Model No. 1 (Entire Slope).

Figure 7.120b PEEQ Contour Plot for 3-D FEM, Unreinforced Full Slope Model No. 1 (View Cut Section - X Axis).

Figure 7.121 PEEQ Contour Plot for 3-D FEM, Reinforced Full Slope Model No. 1 (Entire Slope).

Figure 7.122 Soil Nail Pattern for 3-D FEM, Reinforced Full Slope Model No. 1 (PEEQ Contour Plot; View Cut Section - X Axis). 198

Figure 7.123a PEEQ Contour Plot for 3-D FEM, Unreinforced Full Slope Model No. 2 (Entire Slope). 
Figure 7.123b PEEQ Contour Plot for 3-D FEM, Unreinforced Full Slope Model No. 2 (View Cut Section - Y Axis).

Figure 7.124 Soil Nail Pattern for 3-D FEM, Reinforced Full Slope Model No. 2

(PEEQ Contour Plot $)$ )..................................200

Figure 7.125 PEEQ Contour Plot for 3-D FEM, Reinforced Full Slope Model No. 2 (Entire Slope)

Figure 7.126a PEEQ Contour Plot for 3-D FEM, Unreinforced Full Slope Model No. 3 (Entire Slope). .201

Figure 7.126b PEEQ Contour Plot for 3-D FEM, Unreinforced Full Slope Model No. 2 (View Cut Section - Y \& Z Axis).................201

Figure 7.127 Soil Nail Pattern for 3-D FEM, Reinforced Full Slope Model No. 3 (Plan View).

Figure 8.1 Combined Results for Optimum Soil Nail Orientations of Various Slope Angles... .214

Figure A.1 M-C CPE4 (2D) elements - PEEQ; Uniform.......................236

Figure A.2 M-C CPE4H (2D) elements - PEEQ; Uniform......................236

Figure A.3 M-C CPE6M (2D) elements - PEEQ; Uniform......................236

Figure A.4 D-P CPE4 (2D) elements - PEEQ; Uniform.........................237

Figure A.5 D-P CPE4H (2D) elements - PEEQ; Uniform.......................237

Figure A.6 D-P CPE6M (2D) elements - PEEQ; Uniform.......................237

Figure A.7 M-C C3D8 (3D) elements - PEEQ; Uniform......................240

Figure A.8 M-C C3D8H (3D) elements - PEEQ; Uniform......................240

Figure A.9 M-C C3D10M (3D) elements - PEEQ; Uniform....................240

Figure A.10 D-P C3D8 (3D) elements - PEEQ; Uniform........................241

Figure A.11 D-P C3D8H (3D) elements - PEEQ; Uniform.......................241

Figure A.12 D-P C3D10M (3D) elements - PEEQ; Uniform....................241 


\section{CHAPTER 1: INTRODUCTION}

\subsection{Introduction}

Slope stability issues continue to be a recurrent problem in geotechnical engineering. Every year as much as $\$ 2$ billion in landslide damage occurs in the United States, (Sanderson, 2011). While many of these landslides take place in uninhabited areas, slope failures are also common on geotechnical/construction projects. In response, varying techniques such as earthworks, retaining walls, and reinforced earth systems have been successfully used to obtain and maintain a satisfactory level of performance on these slopes (Duncan and Wright, 2005). Over the past 30 years, the process of soil nailing has gained popularity and confidence for use in slope stabilization and strengthening (Zhou et al., 2013; Shaw-Shong, 2005). Its rapid growth can be attributed to its flexibility in design, its relative ease of construction, and expense, when compared to traditional slope stabilization methods.

Although the technology to model and analyze slope stability has steadily improved, precise slope stability modeling will continue to be a challenge. This is primarily due to the intrinsic difficulties and uncertainties in geotechnical material characterization and response. In addition, many projects require the need to construct slopes that are steeper, have greater surcharge loads, and may have complex site geometries. While most limit equilibrium computer programs were developed to undertake slope stability problems with respect to soil strength and shear stresses, factors of safety, and pore pressures, the deformation behavior of soil slopes is often overlooked or conservatively accounted for in design (Lazarte et al., 2003; Thompson et al., 1990). In recent years, the finite element method (FEM) has been used successfully to handle both stress and deformation considerations for complex site conditions (Halabian et al., 2012; Abdulrahman, 2006; Ann et al., 2004). 


\subsection{Typical Slope Failures}

There are a number of different ways that a slope may fail. Varnes (1978) was the first to publish a generally accepted classification of slope movements, and this work is still referenced and used today. According to Varnes (1978), slope movements can be placed into five main categories: falls, topples, slides, spreads, and flows (as well as a complex or compound category). Falls can be described as sudden movements of relatively large sections of soil or rock that tend to separate along discontinuities such as joints, fractures, and bedding planes. Toppling failure can best be identified by the forward rotation about a particular point. These soil and rock failures are often the result of the forces applied by adjacent sections or by the hydrostatic pressure resulting from water-filled tension cracks (Varnes, 1978).

Slides, which are often more associated with "soil" failures, as recognized on many construction projects, can either be classified as rotational or translational. Rotational slides can occur in natural slopes or in constructed slopes with homogeneous materials that possess Cohesion. Rotational slides are sliding masses that tend to exhibit a circular failure surface that rotates about an imaginary axis. Translational movements (slides) often occur within inclined layered soils that possess a weak layer or zone. The sliding mass moves across the weak surface until equilibrium is restored. Lateral spread failures occur on relatively flat terrain and can result in both tensile and shear cracks on the surface. The main cause of these types of failures is the liquefaction of saturated, Cohesionless material that loses its shear strength during vibration. Most lateral spreads occur as the result of earthquake incidents but may also be related to blasting or other manmade vibrations (Cornforth, 2005; Varnes, 1978).. 
Flows are typically a fast moving mass of loose soil, rock, organic matter, and water that behaves more like a viscous fluid. Flow slides are commonly evident in steep gullies and slopes and are easily identified by their "debris fan" at the bottom of the slope. They are often triggered by heavy periods of precipitation or rapid snowmelt (Cornforth, 2005; Varnes, 1978).

Table 1.1 Types of Slope Movements (Varnes, 1978)

\begin{tabular}{|c|c|c|c|c|}
\hline \multirow{3}{*}{\multicolumn{2}{|c|}{ TYPE OF MOVEMENT }} & \multicolumn{3}{|c|}{ TYPE OF MOVEMENT } \\
\hline & & \multirow[b]{2}{*}{ BEDROCK } & \multicolumn{2}{|c|}{ ENGINEERING SOILS } \\
\hline & & & Predominantly Coarse & Predominantly Fine \\
\hline & FALLS & Rock Fall & Debris fall & Earth fall \\
\hline & TOPPLES & Rock topple & Debris topple & Earth topple \\
\hline \multirow{2}{*}{ SLIDES } & ROTATIONAL & \multirow{2}{*}{ Rock slide } & \multirow{2}{*}{ Debris slide } & \multirow{2}{*}{ Earth slide } \\
\hline & TRANSLATIONAL & & & \\
\hline \multicolumn{2}{|c|}{ LATERAL SPREADS } & Rock spread & Debris spread & Earth spread \\
\hline \multicolumn{2}{|r|}{ FLOWS } & $\begin{array}{l}\text { Rock flow } \\
\text { (deep creep) }\end{array}$ & $\begin{array}{l}\text { Debris flow } \\
\text { (soil creep) }\end{array}$ & $\begin{array}{l}\text { Earth flow } \\
\text { (soil creep) }\end{array}$ \\
\hline \multicolumn{2}{|c|}{ COMPLEX } & nation of tw & ore principal types & movement \\
\hline
\end{tabular}

\subsection{Causes of Slope Failures}

Due to complexities in slope failures, in most cases, it is difficult to identify a single cause. However, simply stated, the shear strength of the soil, along some surface, has been exceeded by the induced shear stresses. Further, for a given slope, if equilibrium was ever attained and then lost, either the shear strength within the slope was decreased or the induced shear stresses were increased. Some common mechanisms that lead to a decrease in shear strength are: increased pore pressure; cracking; swelling; development of slickensides; 
decomposition of clayey rock fills; creep under sustained loads; leaching; strain softening; weathering; and cyclic loading (Duncan and Wright, 2005). Increases in shear stress may be induced by the following: surcharge loads or water pressures at the top of the slope; increase in the soil's water content; excavation at the bottom of the slope; drop in water level at the base of a slope (rapid-drawdown); and earthquake loading (Duncan and Wright, 2005). Often times several of these mechanisms work simultaneously, making it even more challenging to isolate any single factor or how that factor directly contributed to a slope failure. However, many slope failures can be linked to water and/or the presence of clay.

\subsection{Traditional Slope Stabilizing Techniques}

There have been many successful slope stabilization methods. Among these include earthworks, erosion control measures, dewatering techniques, various chemical treatments, retaining walls, and reinforced earth systems. Earthworks are often the most simple and economical way of slope stabilization. They generally involve removal of the upper portion of the slope, benching, or flattening the slope in order to improve stability (Cornforth, 2005). Figure 1.1 presents slope stabilization by earthworks. Unloading the upper portion of a slope by reducing the slope height, using benches, or flattening the slope face are all common remediation alternatives for failed slopes in an effort to greatly reduce the driving forces. Earthworks are often the preferred method due to economics and ease of employment; however, space constraints often limit its use.

Erosion control measures include the use of geosynthetics, riprap, shotcrete, concrete block systems, and vegetation. The primary goal of these techniques is to maintain a uniformly-graded slope and ensure that erosion does not cause a steepened slope, or portions 
of, leading to a shear failure or flow-type slide. Geotextile fabrics, geosynthetic-rolled mats, or cellular grids are the most common types of geosynthetics used (Shukla, 2011). Riprap, which may be grouted or non-grouted, can be an effective method when placed on slopes. Shotcrete is a concrete-like coating that is applied pneumatically at a high velocity and essentially "coats" the surface of the slope. Similarly, precast concrete block units are often a very flexible erosion control measure that can even be placed underwater, if necessary. Finally, as a slope erosion control measure, seeding, hydroseeding, or other vegetative covers can be an economical choice, where applicable.
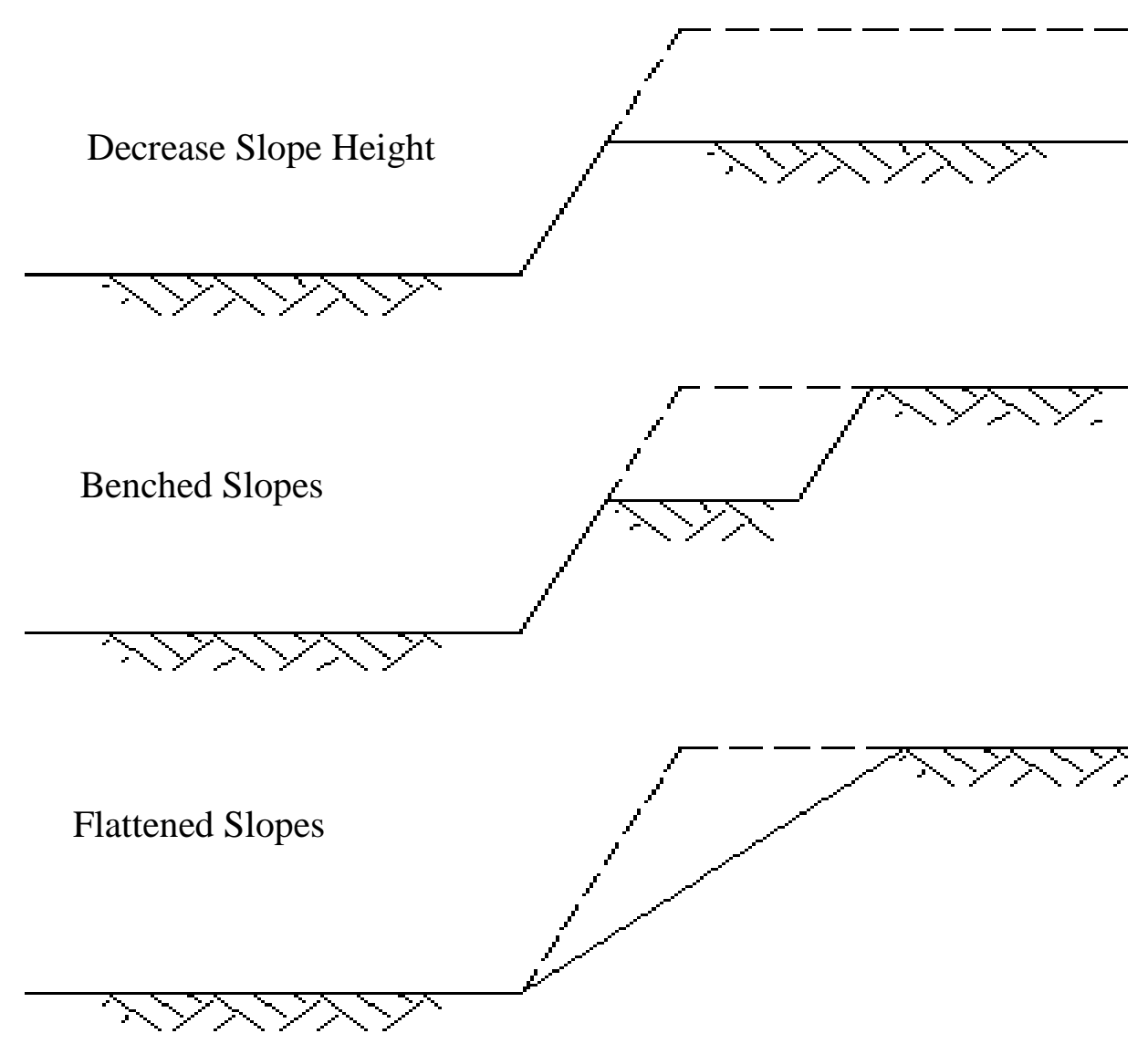

Figure 1.1 Slope Stabilization by Earthworks 
Often times, slope stability may be greatly increased by dewatering techniques. Since soil strength depends on the effective stresses developed in the soil, decreasing the pore pressures along the slip surface increases the stability of the slope. Drains placed within a slope may be horizontal, vertical, blanket drains, or constructed at any angle necessary to induce drainage by gravity flow. Figure 1.2 illustrates the use of drainage layers for slope stability.

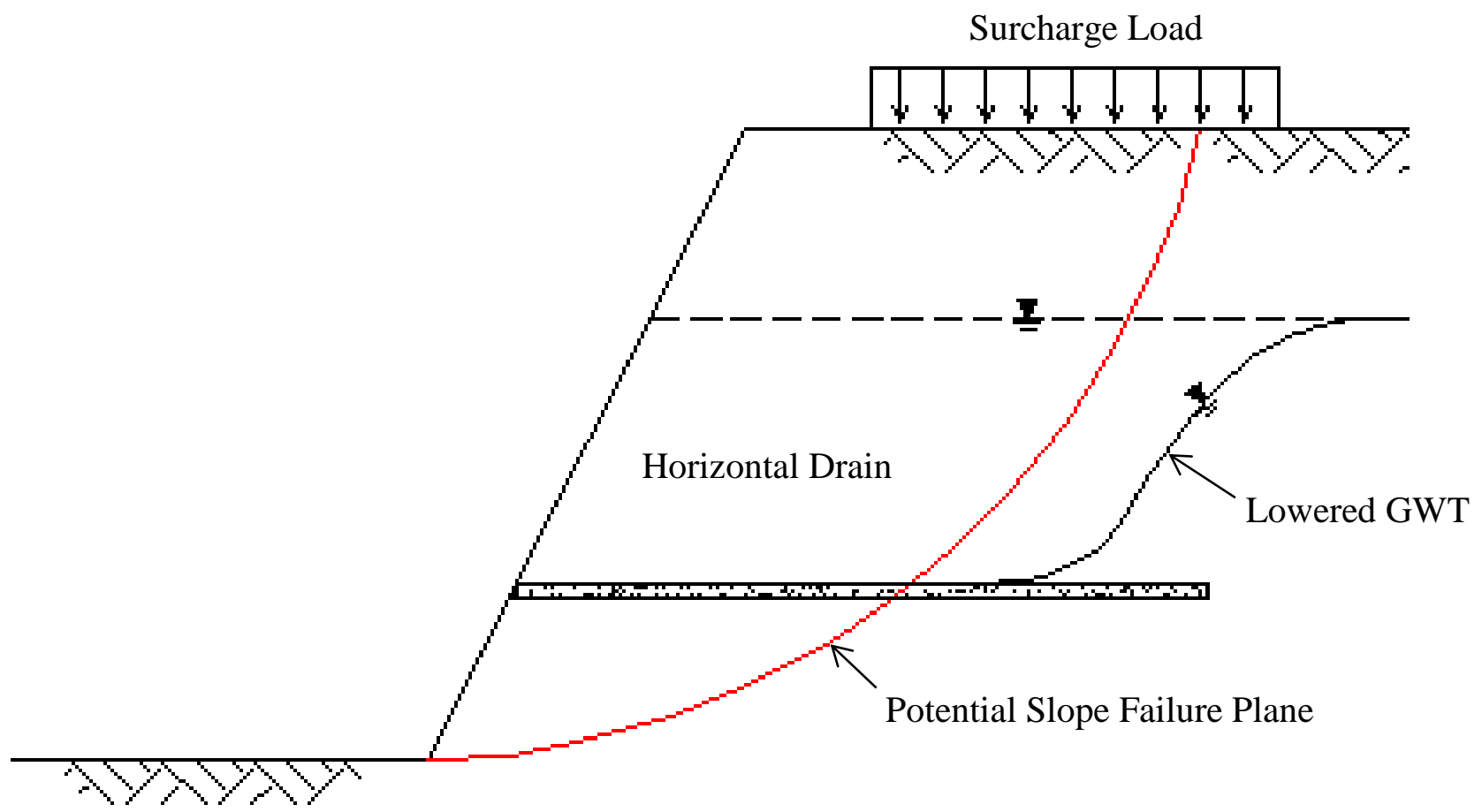

Figure 1.2 Drainage Layer used to Enhance Slope Stability

Chemical treatments can be used to increase the shear strength of the ground on and adjacent to slopes. The use of chemical admixtures for soil stabilization is generally accomplished by the addition of a cementing agent to the soil. This is either done by mechanical mixing and compaction or by allowing the chemical to permeate the void spaces 
within the soil. Admixture stabilization can fill voids, bind particles, break down soil particles and form cement, and interact with soil particle surfaces to change the soil's interparticle forces and structure. More specifically, chemical admixtures and treatments can be used for volume stability, strength, and hydraulic conductivity among others. This technique can be used on newly constructed earth fills or on existing slopes by drilling and injection methods (Cornforth, 2005; Abramson, 2002).

A variety of retaining walls has been used to solve slope stability problems for many years. Retaining walls are especially useful where space constraints limit the design. Retaining walls can be grouped into four broad categories: gravity, piling, cantilever, and anchored (Cornforth, 2005; Duncan and Wright, 2005). A gravity type of retaining wall uses its own weight to hold back earth against sliding and overturning. These walls are typically thicker at the base than at the top and they generally slope towards the retained earth slightly as they increase in height. This group includes mass concrete walls, many interlocking systems of concrete, masonry, or gabion baskets filled with rock (McCarthy, 2007). Piling retaining walls are usually used in tight spaces and are often used as temporary earth retention during construction. Typical designs incorporate about two-thirds of the piling below ground with one-third cantilever above ground. Piling walls may be driven sheet pile walls that are usually made of steel, but driven H-piles with wood lagging or similar construction would also fall into this group (Cornforth, 2005). A cantilever retaining wall is commonly of uniform thickness and tied directly to the foundation. The foundation is designed wide enough to incorporate a block or width of soil behind the wall to help in the resistance by adding to the overall weight of the system. These walls typically require significant steel reinforcing in both the foundation and the wall itself that tie the two 
together such that a true cantilever is developed. This group may include concrete retaining walls and segmental retaining walls, when aided by geosynthetics Cornforth, 2005).

For practical purposes, any of the wall types previously mentioned can be classified as an anchored retaining wall. Anchored walls utilize cables, metal or plastic strips, or other devices that are most often tied back into rock or the soil in the non-active zone. Some anchored walls, called counterfort retaining walls, have anchors that tie the top of the wall back to the base of the foundation, which can also be an effective technique to provide additional strength and stability to the wall system. While anchored retaining walls are more technically challenging and more difficult to construct, they are often a viable solution when large lateral loads are expected or where the wall itself is otherwise too weak (Cornforth, 2005).

Reinforced earth slopes and retaining systems have gained much confidence and popularity in recent years. A reinforced soil slope can be defined as a compacted fill embankment that incorporates the use of horizontally placed reinforcement, either geosynthetics or other, to enhance the stability of the soil structure. This broad definition encompasses many and varied applications. Simply put, when confined, soil is relatively strong in compression but weak in tension. Thus, resistance to tensile strain can be provided by reinforcement. The reinforcement works with the compacted soil by friction or mechanical interlock to create a stable mass that has enhanced geotechnical properties. Mechanically, as illustrated in Figure 1.3, the weight of the soil mass [W] in the active zone is resisted by the shear strength of the soil $[\tau]$ along the failure plane and the sum of the tensile forces generated by the reinforcement layer(s) $\left[\mathrm{F}_{\mathrm{i}}\right]$. In order for a reinforced earth slope/wall to be effective, the reinforcement length [L] must be of sufficient length in the 
resistant zone to transfer the calculated tensile force from the reinforcement into the soil (Liu and Evett, 2008; Cornforth, 2005).

One common type of reinforced soil slope is called a mechanically stabilized earth wall (MSE wall or MSEW). It is generally accepted that the distinction between the two is in the slope of the outer surface. MSE walls contain those reinforced structures with outer slopes greater than or equal to $70^{\circ}$. In either case, they both require a relatively large space behind the wall or outward face to obtain enough wall width for internal and external stability (Elias et al., 2001).

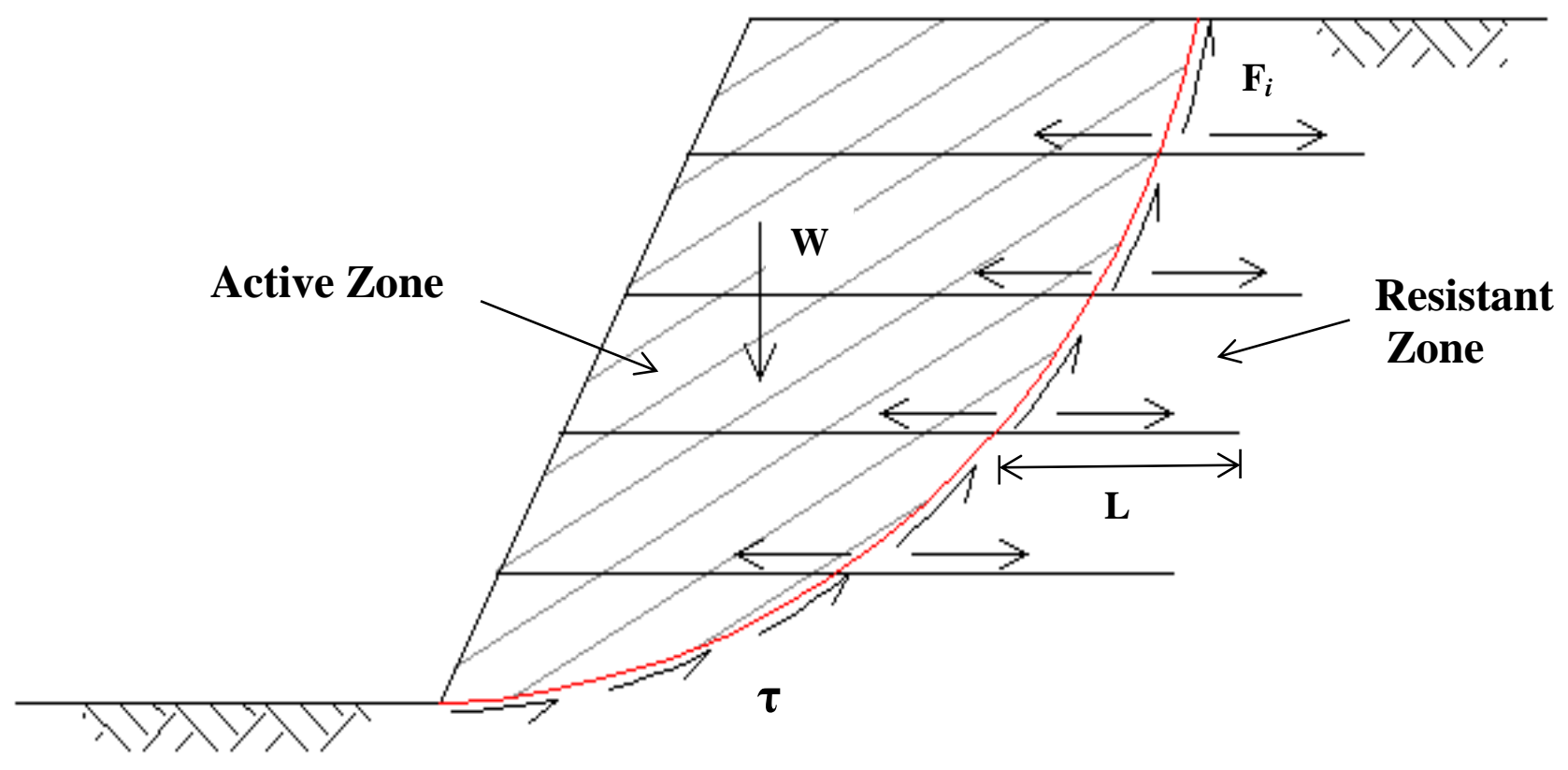

Figure 1.3 Mechanical Behavior of a Reinforced Earth Slope 


\subsection{Problem Statement}

In recent years, the technology to model and analyze slope stability has appreciably improved and there are many Limit-Equilibrium (L-E) computer programs that have been developed for the design and analysis of soil nail walls (Slide, 2012; Geoslope, 2008; Andrew et al., 2010; Banjerjee et al., 1998). Soil nailing has gained rapid popularity over the last two decades due to its versatility and effectiveness. However, accurate slope stability modeling will continue to be a challenge due to the fundamental complexities in geotechnical material characterization and response, especially in the third dimension. Most geotechnical engineers attempt to utilize a "worst case", two-dimensional section approach for solving slope stability problems. Further, most L-E computer programs do not take into account any deformation behavior and the concept of pre-tensioning soil nails would be beyond their capabilities. Thus, most design practices conservatively estimate deformation/settlement of soil-nailed walls, and pre-tensioning levels are based on experience and generally "safe" assumptions (Ling and Liu, 2009; Barley and Mothersille, 2006; Lazarte et al., 2003). This leads many researchers and engineers to the use of numerical modeling techniques (Zhou et. al., 2013; Rotte and Viswanadham, 2013; Halabian et. al., 2012; Singh and Babu, 2010; Gitirana et. al., 2008; Fan and Luo, 2008; Abdulrahman, 2006; Shiu and Chang, 2005; Griffiths and Lane, 1999).

In this study, a FEM computer program will be used to analyze and evaluate twoand three-dimensional unreinforced and soil-nailed reinforced slopes. Specifically, the work in this study extends the two-dimensional work performed in the published literature (Rotte et. al., 2011; Wanstreet, 2007; Fan and Luo, 2007; Griffiths and Lane, 1999). In addition, 
FEM element types will be investigated and several soil nailing parametric studies will be completed in order to provide design recommendations for soil-nailed slopes.

\subsection{Scope of Work}

A literature review was conducted to investigate the history, construction considerations, and design concepts for soil nailing as well as the current use of the FEM to evaluate soil-nailed reinforced slopes. In order to validate the proposed modeling technique, two-dimensional models were developed using the finite element computer program 'ABAQUS' (2011) for an unreinforced, benchmark soil slope, previously performed by others (Wanstreet, 2007; Griffiths and Lane, 1999). Once this was accomplished, several two- and three-dimensional finite element types were evaluated for unreinforced slopes based on their computational efficiency (processing time), accuracy (FOS result as compared to the benchmark slope), and suitability of the failure surface (as compared to the benchmark slope). Both the Mohr-Coulomb and Drucker-Prager soil yielding criteria were evaluated.

Next, three-dimensional FEM soil-nailed reinforced slope models for various slope angles were used in parametric design studies including: soil nail orientation, soil nail length, soil nail vertical spacing, soil nail horizontal spacing, and the effect of soil properties on the overall Factor of Safety (FOS). In addition, the effect of surcharge loads on the FOS and the use of pre-tensioned soil nails to reduce deformation was studied. Finally, the use of three-dimensional FEM to fully model soil-nailed reinforced slopes was investigated. For comparison, two-dimensional FEM and L-E results were used where possible. 


\subsection{Research Objectives}

The primary objectives of this study were to:

- Review existing literature of soil nailing and slope stability analysis and procedures including the FEM

- Perform finite element analysis for both two and three-dimensional models

- Study the accuracy and efficiency of two-dimensional and three-dimensional finite element types for modeling soil in slope stability models

- Study the influence of soil nail orientation, soil nail length, and soil nail vertical and horizontal spacing on Factor of Safety (FOS)

- Study the influence of varying soil properties including the effect of rainwater infiltration on FOS

- Study the influence of surcharge location and magnitude on FOS

- Study the potential for three-dimensional FEM modeling of pre-tensioned soilnailed slopes

- Perform three-dimensional full slope modeling of soil nail reinforced slopes

- Compare findings of FEM with generally accepted limit-equilibrium methods or previous research studies, where available 


\section{CHAPTER 2: SOIL NAILING: A COMPREHENSIVE REVIEW}

\subsection{Introduction to Soil Nailing}

Soil nailing has become a viable, effective, and economical option as an earth retention system in recent years (Cornforth, 2005; Singla, 1999). Among the common applications of soil nailing are: temporary and permanent excavation support; repair and construction of retaining wall systems; stabilization of tunnel portals; stabilization of slopes; lateral support and resistance to overturning of walls; construction and retrofitting of bridge abutments with complex boundaries; resistance of hydraulic uplift; and stabilization of landslide areas.

Soil nailing is a ground improvement method used for reinforcing, stabilizing and retaining excavations and deep cuts in existing soils by introducing closely spaced, parallel, passive inclusions. The inclusions, called "nails", are installed into slopes or excavated soil as construction proceeds from top to bottom. The nails are then grouted to create a stable mass of soil. This process creates a coherent reinforced section that is itself stable and able to retain the ground behind it due to the increase in the overall shear strength of the in-situ soil. The reinforcements are passive and develop their reinforcing action through nailground interactions as the ground deforms both during and following construction (Tuozzolo, 2003).

Soil nailing appears to be similar to other stabilization methods of reinforced fill, such as Mechanically Stabilized Earth (MSE) walls. However, there are major differences in the construction, especially since the nails are inserted directly into an existing mass of earth as opposed to being installed with the structural fill. The construction process commences at the top and proceeds downwards such that the upper nails are loaded first, 
followed by subsequently lower layers (See Figure 2.1). For reinforced fills, the lower reinforcements are loaded first as a consequence of constructing by layers from the bottom up.

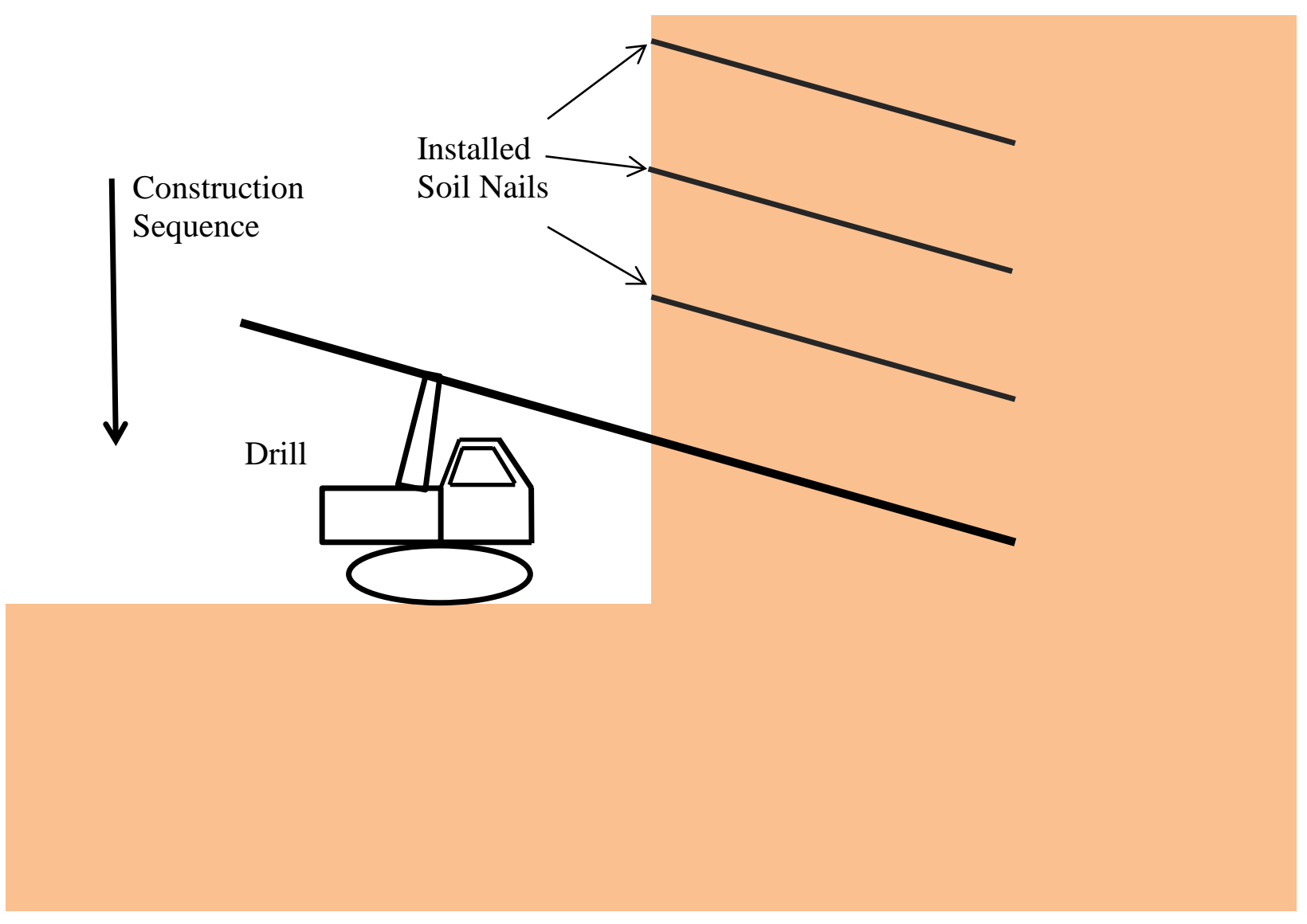

Figure 2.1 Schematic of Typical Soil Nail Construction

Soil nailing, in the form that we use today, began in France in 1972 where the first soil-nailed wall was constructed (Lazarte, 2003). The wall was reported to have been 60 feet high and faced with reinforced concrete. Two major soil nailing research programs were initiated shortly after the project's completion. In Germany from 1975 to 1981, the 
University of Karlsruhe and the Bauer Construction company completed the first major research program on soil nail walls. This research was directly followed by a very comprehensive research project called CLOUTERRE (Plumelle et. al., 1990). In the United States, the first documented soil-nailed wall was constructed in Portland, Oregon, in 1976, for the support of a hospital foundation excavation. It was reported that the wall was 45 feet high and that soil nailing reduced the construction time by 50\% (Byrne et. al, 1998).

Since this time, soil nailing has been used on a variety of stabilization projects. Especially over the past few years, designers and contractors have realized that soil nailing can be very cost effective, less disruptive, and can usually be constructed in less time than conventional retaining wall systems (Halabian et al., 2012; Tuozzolo, 2003; Singla, 1999). In addition, research has shown that soil nailing can be used effectively to mitigate active slope areas (Turner and Jensen, 2005).

\subsection{Construction and Components of a Soil Nail Wall}

The basic construction sequence for a soil nail wall system includes subsequent applications of excavating the bench to the desired depth for each soil nail layer, installing the soil nail, and applying shotcrete or other facing material. Excavation may be performed with common excavation equipment and a relatively level working platform that has enough space to accommodate conventional drilling equipment is desired. Typically, a three to sixfoot cut is made to begin initial leveling for the nailing operation. The height of this cut is dependent on the spacing of the soil nails and the "stand-up" capacity of the soil (Porterfield et al., 1994). Once the bench is complete, boreholes that are usually four to eight inches in diameter can be drilled into the soil mass at the selected dip angle (orientation). Whenever 
possible, the use of open-hole placement (no casing) of the nail bar is preferred and is by far the most common method practiced. This technique, along with the borehole orientation, affords the grout placement by either gravity or low pressure which provides adequate bond strength and makes soil nailing feasible or cost effective. The drilling can be accomplished using rotary, percussion or rotary/percussion equipment and whenever possible, hollowstem augers are used (Lazarte, 2003). Figure 2.2 displays the construction on a typical soil nail project.

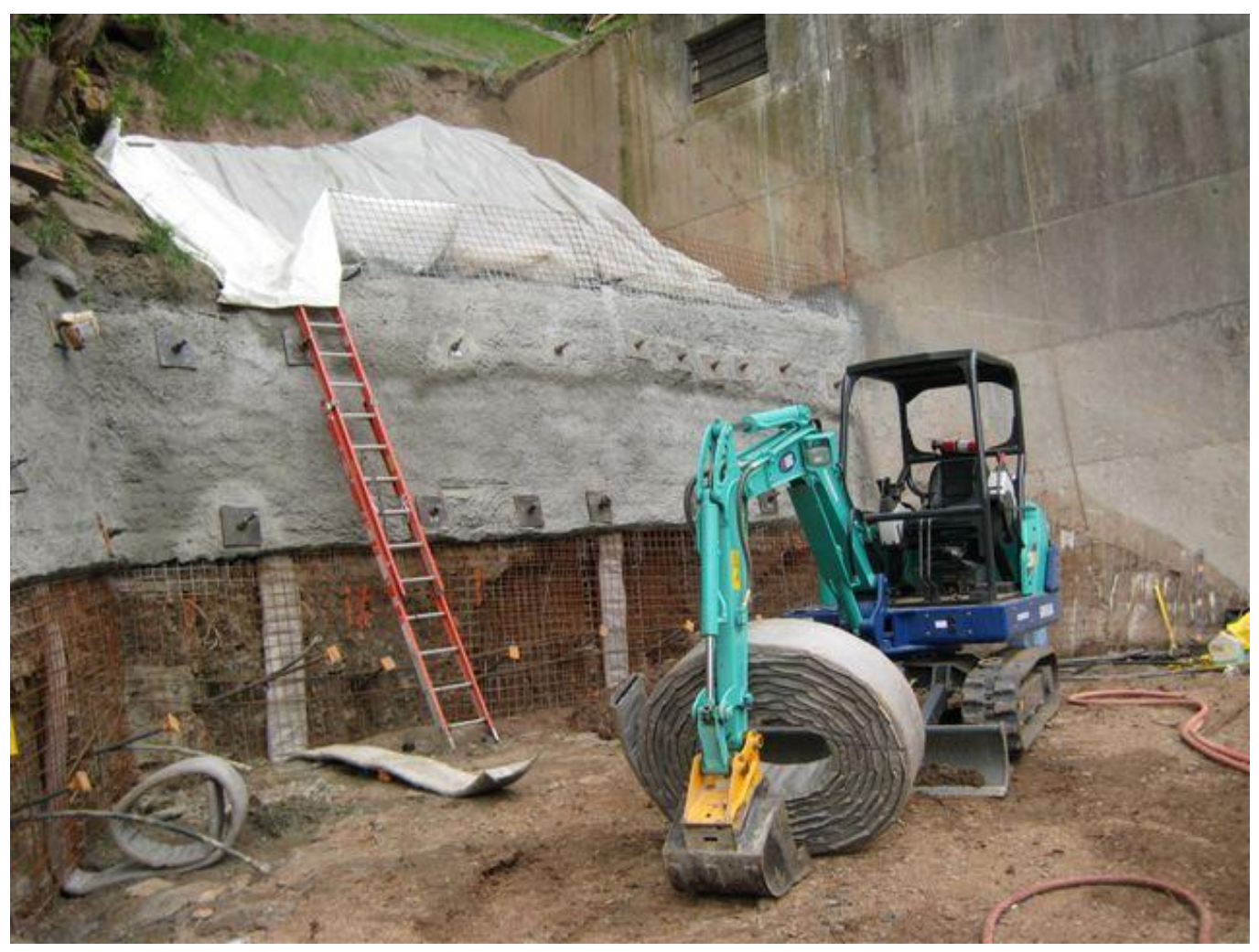

Figure 2.2 Soil Nailing Project at Bluestone Lake, Hinton, WV

The primary structural elements of a soil nailing wall system include tensionresisting nail bars, a suitable grout mixture, a structural retaining element or facing material, and of course, the in-situ ground itself. The nails are placed in pre-drilled holes and grouted in-place. Common bar diameters in the U.S. include sizes from No. 8 through No. 14 in 
lengths approaching 60 feet. Where longer bars are needed, they may be appropriately spliced using couplers and welding techniques. Centralizers, as illustrated in Figure 2.3, are normally required every 8 to 10 feet around the nail bars to maintain the annular gap between the nail bar and the sides of the borehole (Kutschke et al., 2007). The primary function of the grout that is placed around the soil nail bar is to transfer the stress from the ground to the nail, as well as to provide some corrosion resistance for the nail bar. Research has shown that the characteristics of the grout have a significant effect on the ultimate bond strength of the soil-grout interface and thus the soil nail system all together (Zhou et al., 2009).

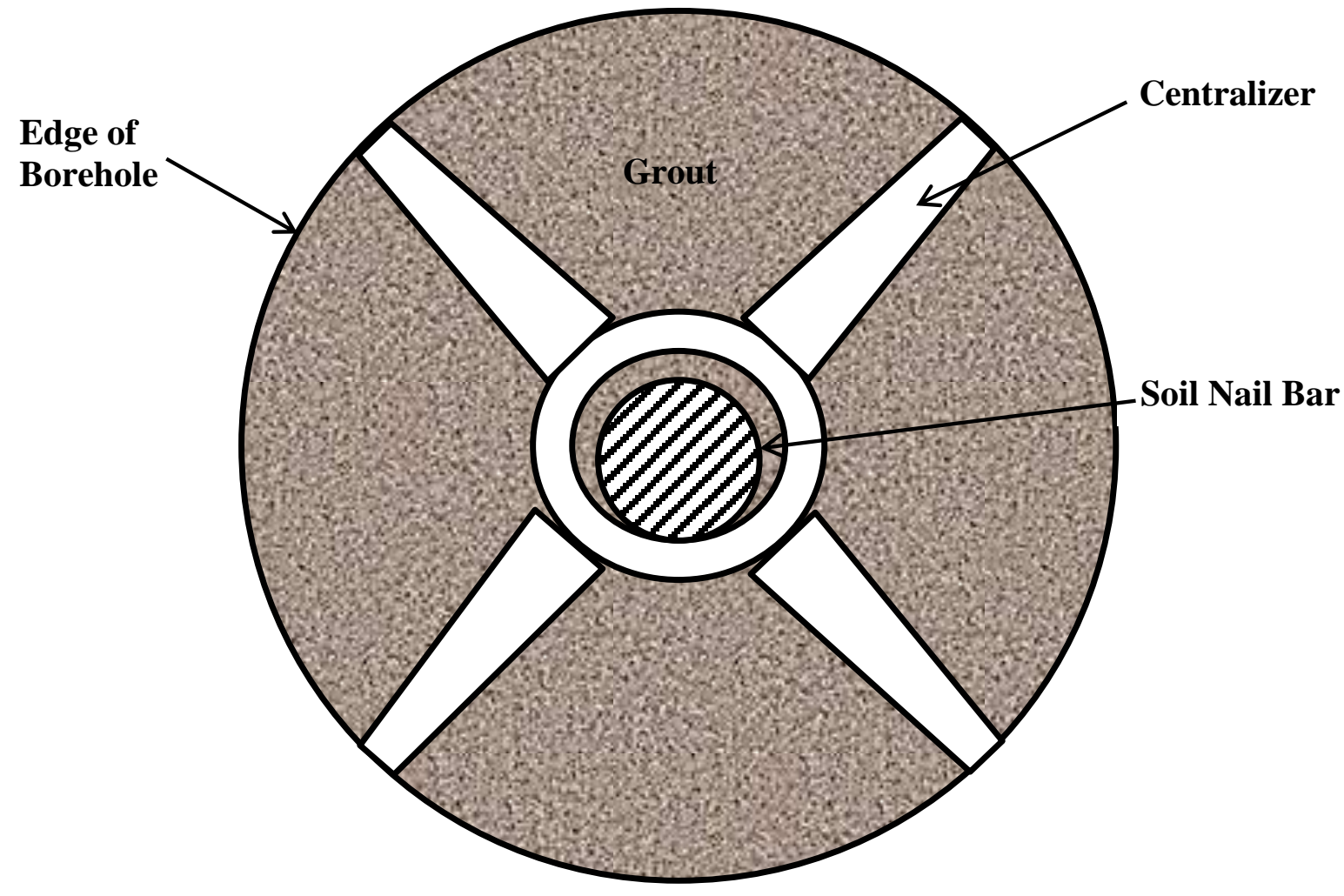

Figure 2.3 Schematic of Typical Soil Nail Cross-Section

The primary components on the exterior of the soil mass include the facing material, wire mesh reinforcement, the soil nail "head" (hex nut and tapered washer) and the bearing 
plate, which varies in size and thickness. Depending on the service life of the wall, the facing material may be temporary or permanent. Facing material is typically an applied layer of reinforced shotcrete, which provides overall structural connectivity and supports the soil mass against lateral expansion. Soil nails are generally installed in regular patterns with vertical and horizontal spacing from about three to eight feet. A vertical spacing of six feet is often used since that is the common width of the welded wire mesh used as the facing material reinforcement (Kutschke et al., 2007). Another key issue on many soil nailing projects is drainage control. Typically, a vertical geocomposite strip drain is secured to the excavation face. These drains are spliced together, due to the top down construction, and either collected by footing drains at the bottom of the excavation or they are directed toward weep holes left in the wall face (Tuozzolo, 2003). Table 2.1 and Figure 2.4 present some typical soil nail construction materials and methods currently used for drilled and grouted soil nail construction.

Table 2.1 Typical Soil Nail Construction and Component Properties

\begin{tabular}{|c|c|}
\hline Component/Item & Typical Property \\
\hline Drilled Borehole Diameter & $4 "-8 "$ \\
\hline Soil Nail Diameter & $\begin{array}{c}\# 8-\# 14 \text { Bar Sizes } \\
(25 \mathrm{~mm}-43 \mathrm{~mm})\end{array}$ \\
\hline Soil Nail Length & $\leq 60^{\prime}$ \\
\hline Soil Nail Tensile Strength & $\begin{array}{c}\text { Grade 60/Grade } 75 \\
(420 \mathrm{MPa} / 520 \mathrm{MPa})\end{array}$ \\
\hline Soil Nail Vertical and Horizontal Spacing & $3^{\prime}-8^{\prime}$ \\
\hline Bearing Plate Size & $3 / 4 " \times 8 " / 10 "$ (Square) \\
\hline Centralizer Spacing & $8^{\prime}-10^{\prime}$ \\
\hline Minimum Grout Strength & $\begin{array}{l}3000 \mathrm{psi} \\
(21 \mathrm{MPa})\end{array}$ \\
\hline
\end{tabular}




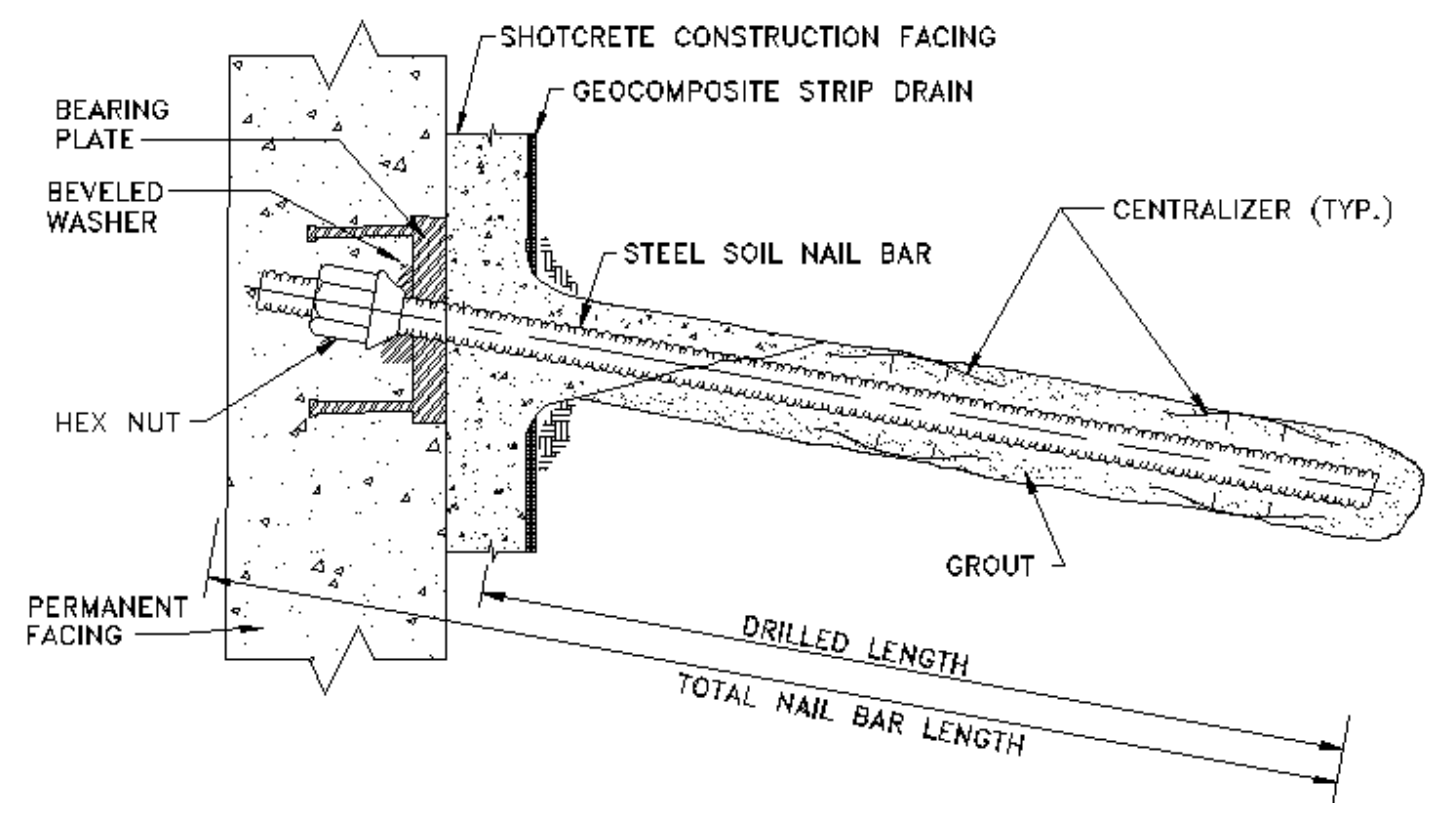

Figure 2.4 Components of Soil Nail (after Porterfield et al., 1994)

Lastly, the reinforced soil mass contributes greatly to the success of soil nail wall systems. Soil nailing is possible in a wide range of soils including: clays, sandy soils, weathered rock, and heterogeneous and stratified soils. However, soils that are loose and/or saturated are generally unsuitable for soil nailing, including rubble or miscellaneous fills (Lazarte, 2003).

\subsection{Soil Nail Stress Mechanisms}

In order to contribute effectively to improve slope stability, soil nails must be able to transfer tensile forces that develop between the grout and ground interface and also handle the shear and bending stresses, both caused by the soil mass that is deformable. When the soil along the front face is excavated, the soil nails develop tension due to the outward wall movement. The soil nails mobilize bond strength between the grout and the surrounding 
soil. The bond strength is mobilized progressively along the entire soil nail with a certain distribution that is affected by several factors. As the bond strength is mobilized, tensile forces increase within the nail. Similar to ground anchors, the load-transfer mechanism and the ultimate pull-out resistance of the nail bars depend on several factors including the soil type and strength, and the installation technique used, which includes the drilling method, size and shape of the drilled hole and the grouting method (Lazarte et al., 2003).

According to Byrne et al. (1998), the maximum tensile force developed in the soil nail does not generally occur at the interface of the active and passive (resistant) zone within the soil mass (See Figure 2.5). In addition, the distribution of these forces, along with the location of the maximum tensile force, varies along the wall section, as with the location of the failure surface. It is believed that the maximum tensile forces occur approximately 0.3 to 0.4 wall heights $(\mathrm{H})$ behind the front face for the upper part of the wall and about 0.15 to $0.2 \mathrm{H}$ behind the front face for the lower part of the wall (Lazarte et al., 2003; Plumelle et al., 1990; Byrne et al., 1998). Thus, nail tensions develop gradually as the excavation proceeds to greater depths. Research has also found that most of the tensile loading occurs during the first three excavation steps following a nails installation (Byrne, et al., 1998).

In addition to tension, a deformed soil mass also causes shear and bending stresses within the soil nail. The effect of the loaded nail can be likened to a laterally loaded pile; however, the shear and bending forces are only mobilized after relatively large displacements have occurred. Based on published literature, only about $10 \%$ of the overall slope stability is reported to be effected by the shear and bending strength of a soil nail and is therefore generally disregarded during design (Lazarte et al., 2003). 


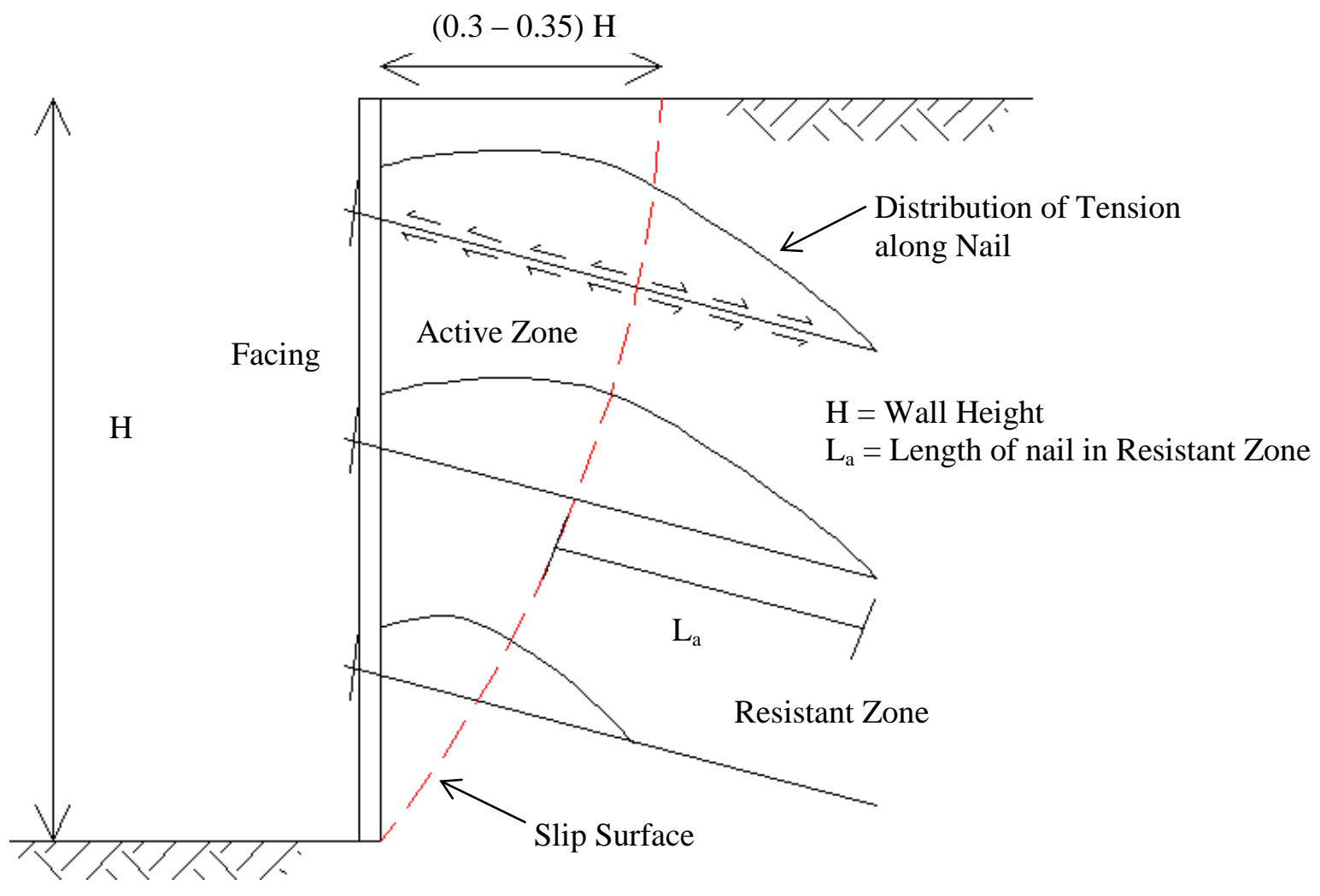

Figure 2.5 Mechanism of Tension Mobilization in Soil Nail Wall

\subsection{Soil Nailing Design Considerations}

To effectively design a soil nailing wall system, there are several basic considerations. Overall, the primary concern is to guarantee that lateral stability is achieved by the effective mobilization of the soil nail interaction and that ground movements are resisted, according to appropriate factors of safety for a given project (Banerjee et al., 1998; Sakr and Kimmerling, 1995). For the specified structure, geometry including depth and cut slope orientation, ground profile, surcharge loadings, and the location of the potential sliding surface should be determined (Shaw-Shong, 2005; Tuozzolo, 2003; Byrne et al., 1998). After the sliding surface is identified, the necessary resisting soil nail tensile force(s) can be calculated. The reinforcement type is then selected, including the cross-sectional area, 
length, orientation, grid pattern, and nail spacing, both horizontally and vertically (Lazarte, 2003; Tuozzolo, 2003; Byrne et al., 1998). Calculations are then performed to verify the local stability at each reinforcement level with acceptable factors of safety. Next, the global stability of the nailed-soil structure and the surrounding ground is verified with an acceptable factor of safety for the cases during and after excavation. Stability analyses are performed to verify that the proposed soil nail wall is able to resist the destabilizing forces induced by the excavation, service loads, and seismic loads for each of the potential failure modes. Factors that control external stability include the wall height, soil stratigraphy behind and under the wall, the width of the nailed zone, and the soil, nail, and interface strengths. Then, the system of forces acting on the facing is analyzed with respect to the lateral earth pressures and the nail forces at the connections. Finally, the facing is designed for the specified architectural and durability criteria. It is also important that appropriate corrosion protection relevant to specific site conditions be considered for permanent structures. Finally, the drainage system should be considered for site-specific conditions (Lazarte, 2003; Tuozzolo, 2003; Byrne et al., 1998).

\subsection{Soil Nail Wall Failure Modes}

The failure mechanisms associated with soil nail wall systems can generally be lumped into three broad categories: external failure modes; internal failure modes; and facing connection failure modes. External failure modes refer to the development of potential failure surfaces passing through or behind the soil nails. These failure surfaces may or may not intersect the installed nails. If the failure surface intersects one or more soil nails, the intersected nails contribute to the stability of the soil mass by providing an 
external stabilizing force. It should be noted that the external stability analysis is generally an important aspect in the design of soil nail walls due to the potential impact or consequence if an external failure occurred. The external failure modes typically considered for soil nail wall systems include: a global failure mode, a sliding failure mode, and a bearing failure mode also known as basal heave (Byrne et al., 1998; Lazarte, 2003).

Internal failure modes generally refer to the failure between the soil and the nail bars and/or the grout. Typical failure modes include: nail pullout failure, slippage of the bargrout interface, tensile failure of the nail, or bending and shear of the nails. Nail pullout failure is a failure along the soil-grout interface due to either insufficient intrinsic bond strength and/or an insufficient nail length to resist the induced tensile stress. Sometimes, the bar-grout interface slips. This is predominantly due to the lack of mechanical interlock of the grout between the protrusions of the nail bar surface. For this reason, threaded nail bars are often recommended. The nail can also fail in tension if it is under-designed in tensile strength. While soil nails are designed primarily for tension, sometimes they must function to resist bending and shear stresses, especially at/along the intersection of the slip surface with the soil nail (Lazarte, 2003; Singla, 1999; Elias and Juran, 1991).

Soil nail wall systems can also fail at the surface within the facing and facing nailhead connections. The facing material may exhibit a flexural failure if excessive bending stresses are present. This failure mode should be considered separately for both temporary and permanent facings and remediation may be possible depending on the severity of the failure. Punching shear failure is when the stresses at the soil nail bearing plate overcome the strength of the facing material and underlying soil. The plate and nail bar end "punch" through the facing material and penetrate some distance into the underlying soil. Similar to 
the previous failure mode, this mode should be evaluated for both temporary and permanent facings. In some types of soil nail construction, headed-studs are welded onto the bearing plates in an effort to increase the bond strength between the soil nail and the permanent facing material. If these stresses are high, the studs fail in tension (Lazarte, 2003; Rotte and Viswanadham, 2013).

\subsection{Deformation of Soil Nail Walls}

Wall deformation can be a controlling factor for many soil nail projects, especially those used around structures. Some amounts of both horizontal and vertical movements are inevitable due to the shear and bending forces of the soil nails and the lateral pressure of the soil (Kutschke et al., 2007; Ling and Liu, 2009). Both vertical and horizontal deformations are likely to be of the same order of magnitude at the wall crest but several factors affect the displacement of the facing. These include: the rate of construction; nail orientation, spacing, and stiffness; lift height; soil stiffness and bearing capacity; global factor of safety; nail length $(\mathrm{L}) /$ wall height $(\mathrm{H})$ ratio; and the magnitude and location of a surcharge loading, if present (Byrne et al., 1996; Plumelle et al., 1990). When an adequate factor of safety is used and where the $\mathrm{L} / \mathrm{H}$ ratio and surcharge loadings are negligible, deformation is likely to be about $0.1 \%$ to $0.4 \%$ of the wall height (Plumelle et al., 1990; Lazarte et al., 2003). Lazarte et al. (2003) present that the maximum horizontal $\left(\delta_{\mathrm{h}}\right)$ and vertical $\left(\delta_{\mathrm{v}}\right)$ wall displacement at the top of the wall can be estimated by the formula (Lazarte, 2003):

$$
\delta_{h}=\left(\frac{\delta_{h}}{H}\right)_{i} \cdot H
$$


Where:

$(\delta \mathrm{h} / \mathrm{H})_{\mathrm{i}}=$ a ratio dependent on the soil conditions " $\mathrm{i}$ " in Table 2.2; and $\mathrm{H}=$ wall height

Table 2.2 Values of $\left(\delta_{\mathrm{h}} / \mathrm{H}\right)_{\mathrm{i}}$ and $\mathrm{C}$ as Functions of Soil Conditions (Lazarte et al., 2003)

\begin{tabular}{|c|c|c|c|}
\hline$\underline{\text { Variable }}$ & $\frac{\text { Weathered Rock }}{\text { and Stiff Soil }}$ & $\underline{\text { Sandy Soil }}$ & $\frac{\text { Fine-Grained }}{\underline{\text { Soil }}}$ \\
\hline$\delta_{\mathrm{h}} / \mathrm{H}$ and $\delta_{\mathrm{v}} / \mathrm{H}$ & $1 / 1,000$ & $1 / 500$ & $1 / 333$ \\
\hline $\mathrm{C}$ & 1.25 & 0.8 & 0.7 \\
\hline
\end{tabular}

They report that the size of the zone of influence where noticeable ground deformation may take place is defined by a horizontal distance behind the soil nail wall $\left(\mathrm{D}_{\mathrm{DEF}}\right)$ and can be estimated with (Lazarte, 2003):

$$
\frac{D_{D E F}}{H}=C(1-\tan \alpha)
$$

Where:

$$
\begin{aligned}
& \alpha=\text { the wall batter angle; and } \\
& \mathrm{C}=\text { coefficient indicated in Table } 2.2
\end{aligned}
$$

In most soil nail wall projects, the associated movements are relatively small. Since the design parameters that have been developed to address soil nail wall deformation are limited, the estimates that result from the equations above are often used as design values (Lazarte, 2003). When deformation estimates appear to be unacceptable, a modified design which addresses slope angle, nail lengths, overall factors of safety, and perhaps even the addition of ground anchors usually follows. If it is observed that horizontal deflections have met or exceeded $0.5 \% \mathrm{H}$, a construction change may be warranted, as this normally represents an upper limit of acceptable performance (Lazarte, 2003). 


\subsection{Limitations of Soil Nail Walls}

There are some limitations to the method of soil nailing wall systems (Tuozzolo, 2003). Soil nailing techniques cannot be used where soils do not have sufficient friction or Cohesion to develop an adequate bond between the nails and the soil. Certain soils, like soft clays or rubble fills, are not suitable for soil nailing wall systems. Soil nails cannot be installed below the groundwater table. Other concerns include: the presence of underground easements and utilities, the effect on adjacent structures due to unacceptable horizontal ground movements, the deterioration of the shotcrete facing over time, and the exclusive use of a specialty contractor necessary to complete the work (Tuozzolo, 2003; Byrne et al., 1998).

\subsection{Use of Finite Element Method (FEM) and Limit-Equilibrium (L-E) in Evaluating Soil Nail Walls}

There have been several research studies completed in the area of soil nailing with the benefit of the FEM in recent years (Zhou et. al., 2013; Rotte and Viswanadham, 2013; Halabian et. al., 2012; Singh and Babu, 2010; Fan and Luo, 2008; Wanstreet, 2007; Abdulrahman, 2006; Shiu and Chang, 2005; Ann et. al., 2004; Griffiths and Lane, 1999). Many of these studies utilize a two-dimensional approach. Specifically, the work in this study will expand the two-dimensional work completed by Wanstreet (2007) and Griffiths and Lane (1999).

Griffiths and Lane's work (1999) demonstrated that the FEM approach was indeed a "reliable and robust method for assessing the factor of safety of slopes". They studied at least six different slope/soil conditions and performed two-dimensional FEM analysis in 
order to determine the Factor of Safety (FOS). They correlated the FOS from the FEM analysis to more traditionally accepted limit equilibrium techniques. One part of their research that is particularly relevant to the present study is presented in Figure 2.6.

In this particular example (Griffiths and Lane (1999) -Example 2), a twodimensional, homogeneous, $2: 1\left(26.6^{\circ}\right)$ slope with a foundational layer was studied. The results clearly show the deformed mesh and failure circle that resulted from the analysis. Griffiths and Lane (1999) have shown one of the main advantages to the FEM approach being that no extra effort is required to obtain the location and shape of the critical failure surface. When performing this example using traditional limit equilibrium (L-E) methods, one must frequently force the failure surface to pass through the toe of the circle to obtain the most accurate solution. Their work proposed that this was not necessary using FEM (Griffiths and Lane, 1999).

In 2007, Wanstreet built upon Griffiths and Lane's work and evaluated the use of FEM on a similarly modeled slope with the addition of soil nail inclusions, see Figure 2.7. Wanstreet (2007) studied the influence of mesh density along with the length, location, orientation and the number of nails used. The results for unreinforced slopes showed strong correlations between FEM and limit equilibrium methods for determining FOS. In addition, results for the reinforced (soil-nailed) slopes indicated that the FEM was an effective method for the design/analysis of soil nailing applications. Specifically, Wanstreet (2007) reports that the FOS/stability of a soil-nailed slope was greatly impacted by the location and orientation of the soil nail(s). Figures 2.8 and 2.9 present some of Wanstreet's (2007) results, as expressed by the equivalent plastic strain (PEEQ) contour for the soil slope. The 
benefit of one soil nail, and the added benefit of additional soil nails was evident (modeled using a two-dimensional FEM approach).

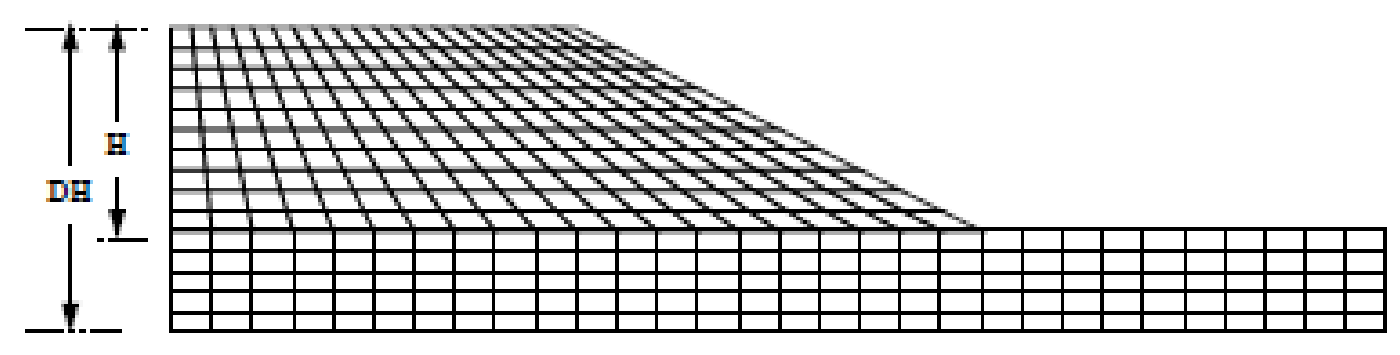

(a)

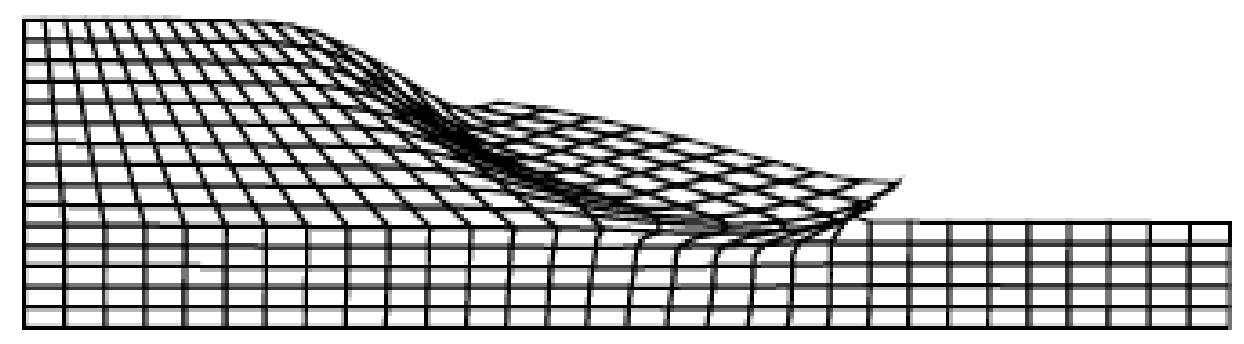

(b)

Figure 2.6 Ex. 2: Homogeneous Slope with a Foundation Layer (Griffiths and Lane, 1999)

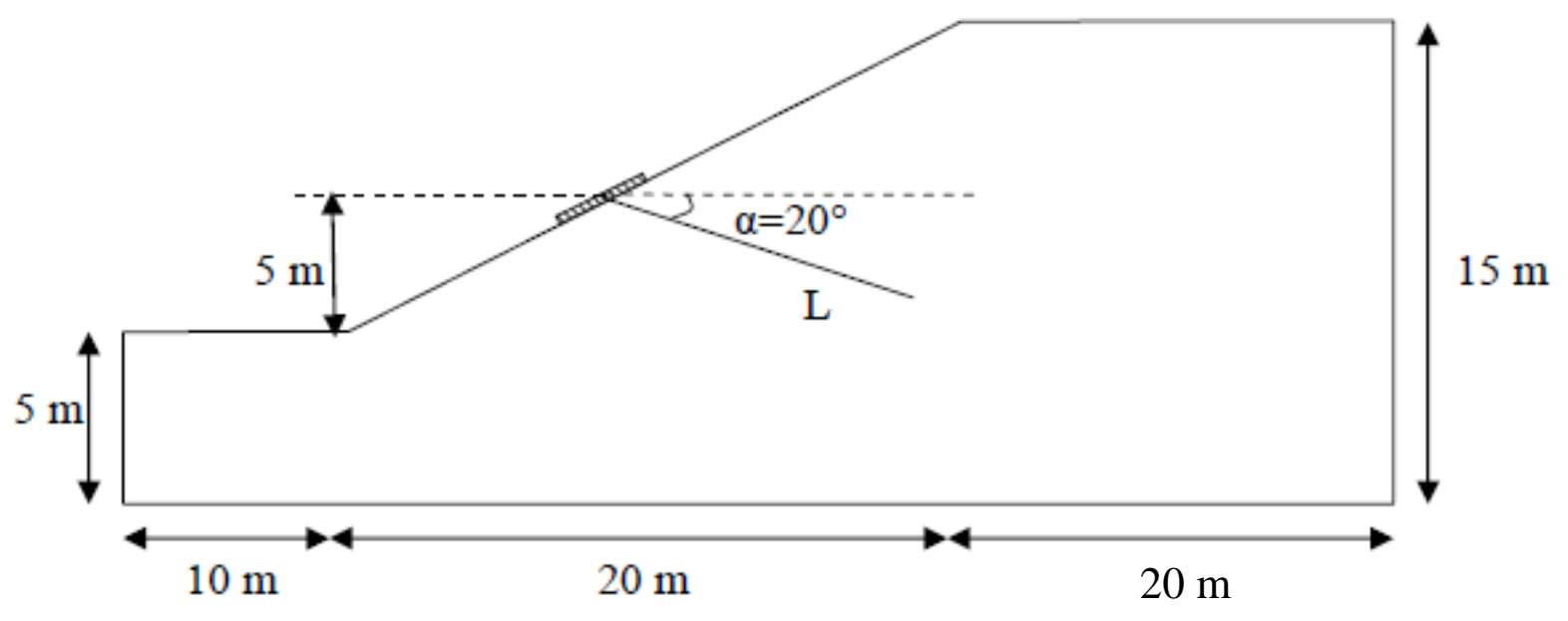

Figure 2.7 Geometry of Soil-Nailed Reinforced Benchmark Model with Base (Wanstreet, 2007) 


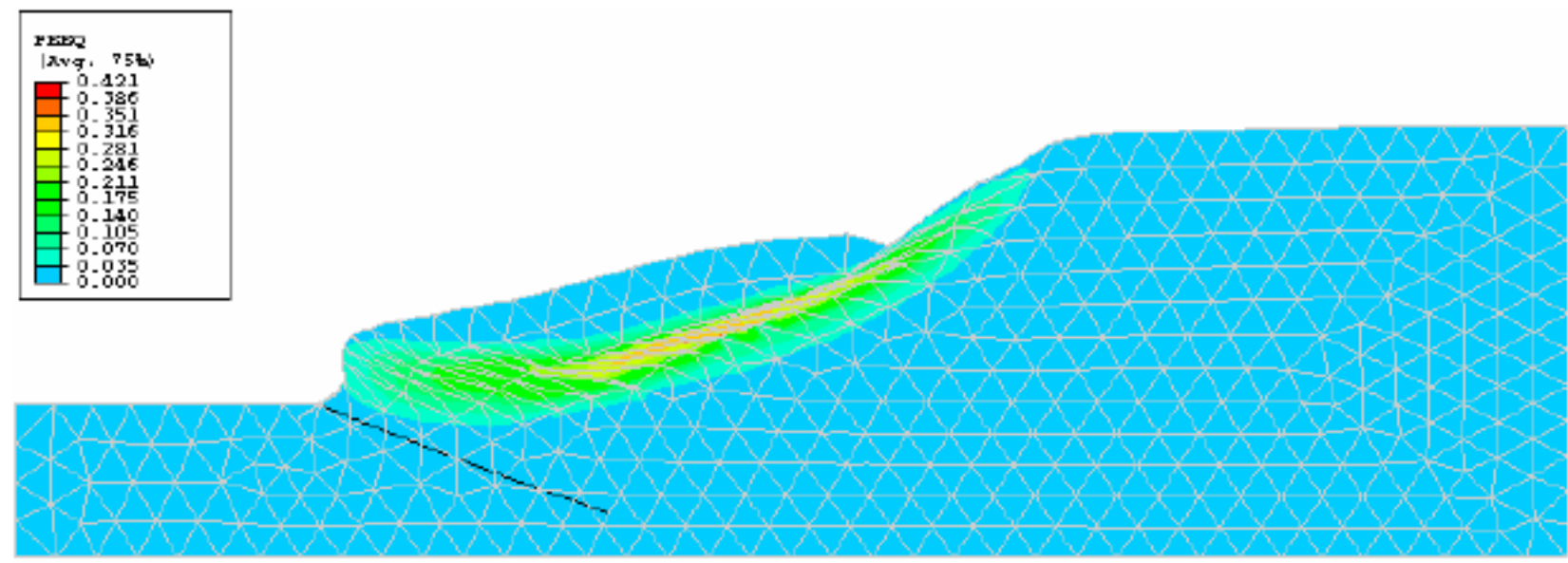

Figure 2.8 Equivalent Plastic Strain Contours - one nail at toe of slope (Wanstreet, 2007)

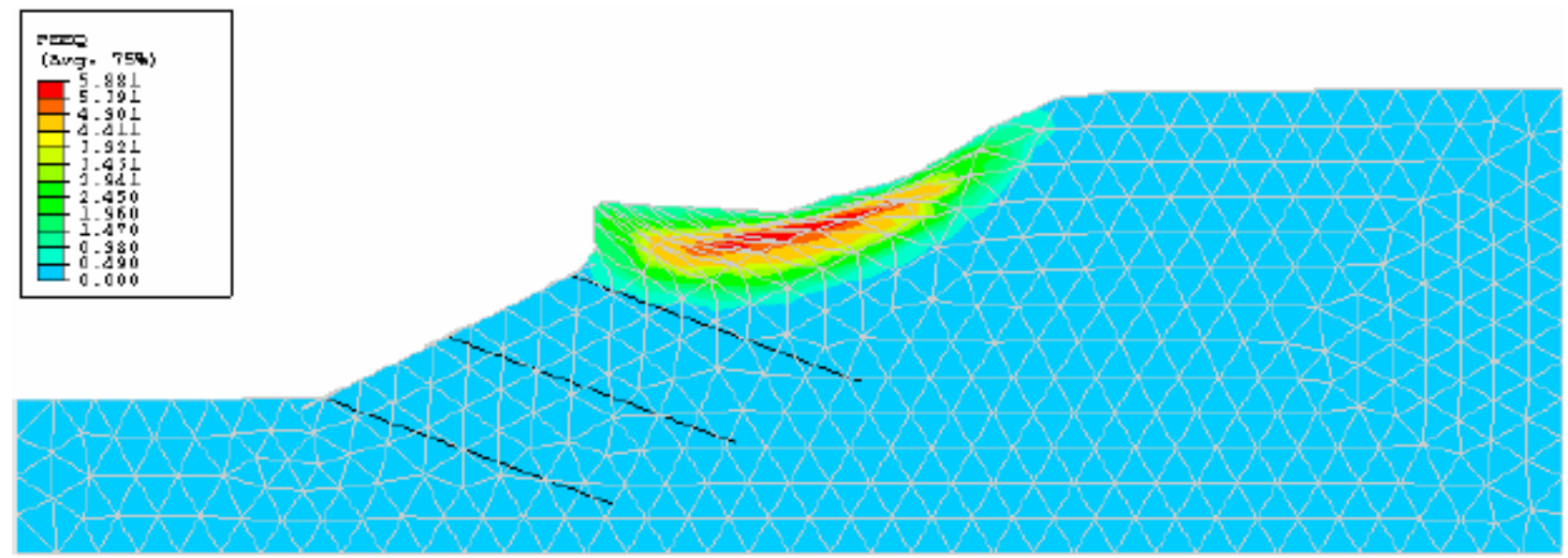

Figure 2.9 Equivalent Plastic Strain Contours - three nail case (Wanstreet, 2007)

Several others have studied soil-nailed slopes using FEM. Zhang, Song, and Chen (1999) studied the horizontal deformation of a $90^{\circ}$, soil-nailed slope. Their work used a unit width, three-dimensional model that included construction staging to model the construction sequence of a soil nailing application. They utilized 20 -node isoparametric finite elements to model a 9-meter high vertical excavation constructed in five stages (excavation levels). They evaluated the horizontal deflection versus depth at the different stages of construction. In addition, they studied the effect of nail length and vertical spacing on the horizontal 
deflection. Their study proved and reported some logical concepts about most soil nailing applications: 1. The horizontal deflection decreased with increasing depth and that it was very small at depths greater than the excavation depth; 2. That the horizontal deflection increased with excavation depth; and 3. Ground movements are at a maximum adjacent to the cut surface and a minimum a distance away from the cut surface.

Another study of interest to this study was that completed by Fan and Luo (2008). They published two-dimensional studies that included soil nail orientation, length, and vertical spacing. Primarily, their study presented Factors of Safety for various slope angles considering those factors previously mentioned. They utilized six-node triangular isoparametric elements in an attempt to reproduce the CLOUTERRE project (Plumelle et. al., 1990). With respect to soil nail orientation, they presented that the optimum orientation varied with the angle of the slope face and does change slightly with the slope of the retained material, or "backslope angle". Table 2.3 below presents a reproduction of these results. Figure 2.10 presents a schematic of the slope studied.

Table 2.3 The Optimal Nail Orientation for Soil-nailed Slopes with Various Geometric Conditions using Two-Dimensional FEM (from Fan and Luo, 2008)

\begin{tabular}{|c|c|c|c|}
\hline$\frac{\text { Slope Angle }}{(\boldsymbol{\beta})}$ & $\frac{\text { Backslope Angle }}{\left(\boldsymbol{\alpha}=\mathbf{0}^{\circ}\right)}$ & $\frac{\text { Backslope Angle }}{\left(\boldsymbol{\alpha = 1 0 ^ { \circ } )}\right.}$ & $\frac{\text { Backslope Angle }}{\left(\boldsymbol{\alpha}=\mathbf{2 0 ^ { \circ } )}\right.}$ \\
\hline $40^{\circ}$ & $40^{\circ}$ & $50^{\circ}$ & $65^{\circ}$ \\
\hline $50^{\circ}$ & $30^{\circ}$ & $40^{\circ}$ & $58^{\circ}$ \\
\hline $60^{\circ}$ & $23^{\circ}$ & $30^{\circ}$ & $47^{\circ}$ \\
\hline $70^{\circ}$ & $16^{\circ}$ & $20^{\circ}$ & $30^{\circ}$ \\
\hline $80^{\circ}$ & $8^{\circ}$ & $10^{\circ}$ & $20^{\circ}$ \\
\hline $90^{\circ}$ & $0^{\circ}$ & $0^{\circ}$ & $10^{\circ}$ \\
\hline
\end{tabular}


When considering soil nail length, generally they reported that the soil nail length in the bottom third of the excavation had a major influence on the Factor of Safety of soilnailed slopes as compared to the upper and middle thirds. Once again, this was slightly affected by the backslope angle. In addition, they reported that the effect of the soil nails length was "more significant" as the slope angle was steeper, regardless of the backslope angle. Fan and Luo (2008) also evaluated the vertical spacing of soil nails and presented that the vertical spacing was not a major factor with respect to the FOS as long as the position of the upper and lower most nail remained constant. Yet, for steeper slope angles $\left(>70^{\circ}\right)$, they reported a variation in the Factor of Safety of $3-9 \%$ using a smaller vertical spacing in the lower half of the nailed slope.

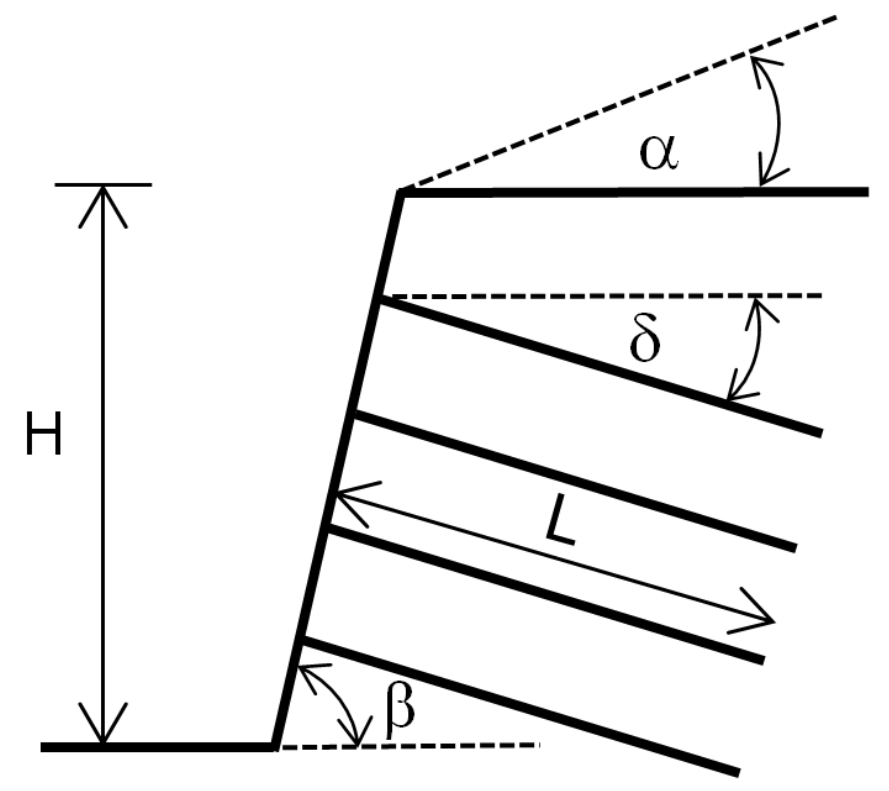

Where: Slope Height $(\mathrm{H})=10$ meters

Soil Nail Length $(\mathrm{L})=$ Varied

Backslope Angle $(\alpha)=0^{\circ}, 10^{\circ}$, and $20^{\circ}$

Slope Angle $(\beta)$ was varied from $40^{\circ}$ to $90^{\circ}$

Soil Nail Orientation $(\delta)$ was varied from $0^{\circ}$ to $60^{\circ}$

Figure 2.10 Schematic of Slope and Soil Nail Parameters Used by Fan and Luo (2008) 
Rotte et. al. (2011) performed several parametric soil nail studies in terms of Factor of Safety (FOS) using a Limit-Equilibrium (L-E) procedure. Specifically, they studied the effect of slope geometry, including slope angle and backslope angle, soil nail orientation, soil nail length, soil nail pattern, soil nail horizontal spacing, and the effect of a rising water surface within the slope. They evaluated a 7.2 meter and 10.2 meter high slope at slope angles of $63.43^{\circ}, 71.56^{\circ}, 78.7^{\circ}$, and $90^{\circ}$ with backslope angles of $0^{\circ}, 10^{\circ}$, and $20^{\circ}$. Table 2.4 presents their results pertaining to slope angle (geometry), soil nail orientation, and backslope angle.

Table 2.4 The Optimal Nail Orientation for Soil-nailed Slopes with Various Geometric Conditions using Two-Dimensional Limit-Equilibrium (from Rotte et. al., 2011)

\begin{tabular}{|c|c|c|c|}
\hline$\frac{\text { Slope Angle }}{(\boldsymbol{\beta})}$ & $\frac{\text { Backslope Angle }}{\left(\boldsymbol{\alpha}=\mathbf{0}^{\circ}\right)}$ & $\frac{\text { Backslope Angle }}{\left(\boldsymbol{\alpha = 1 0 ^ { \circ } )}\right.}$ & $\frac{\text { Backslope Angle }}{\left(\boldsymbol{\alpha}=\mathbf{2 0 ^ { \circ } )}\right.}$ \\
\hline $63.43^{\circ}$ & $24^{\circ}$ & $25^{\circ}$ & $26^{\circ}$ \\
\hline $71.56^{\circ}$ & $17^{\circ}$ & $20^{\circ}$ & $22^{\circ}$ \\
\hline $78.7^{\circ}$ & $10^{\circ}$ & $13^{\circ}$ & $15^{\circ}$ \\
\hline $90^{\circ}$ & $0^{\circ}$ & $0^{\circ}$ & $2^{\circ}$ \\
\hline
\end{tabular}

When studying nail length, Rotte et. al. (2011) report that the most effective nail length, based on a pattern approach, is dependent on the type of failure considered. When considering maximum deflection, longer soil nails in the upper portion of the slope proved more effective. When overall stability (sliding) was considered, longer soil nails applied to the lower portion of the slope more effectively increased the FOS. Further, they evaluated a 7.2 meter high, $63.43^{\circ}$ slope with a horizontal back slope for various nail length to slope height ratios of $0.85,0.8,0.7$, and 0.6 while also varying the soil nail orientations from $0^{\circ}$ to 
$30^{\circ}$. They report a general increase in the overall FOS with an increase in soil nail length. For soil nail lengths of $0.85 \mathrm{H}$ and $0.8 \mathrm{H}$, the FOS value reached a maximum value at soil nail orientations of $24^{\circ}$ and $25^{\circ}$, respectively. Rotte et. al. (2011) also studied horizontal nail spacing's of 1.2 meters, 1.5 meters, 1.8 meters, and 2 meters. They report that the overall stability of a soil-nailed slope is significantly affected by the horizontal soil nail spacing. In addition, Rott et. al. (2011) studied the effect of a rising water surface within a soil-nailed slope. They report that the presence of water significantly reduces the soil nail to soil interface (bond) strength and, due to saturation, also increases the unit weight of the soil in the active zone. Both of these factors reduce the overall FOS for soil-nailed slopes (Rotte et. al., 2011).

Using three-dimensional FEM, Halabian et. al. (2012) evaluated earth pressure distributions during and after soil nail wall construction. Included in their study was the effect of slope angle, soil nail orientation, soil nail length, soil nail pattern, and the effect of soil strength properties. They used continuum quadratic tetrahedral elements and an elastic, perfectly plastic Mohr-Coulomb failure criterion to represent the soil. Their study also incorporated construction stages with soil excavation, borehole drilling, soil nail placement and facing construction. For a 7-meter high slope with a $90^{\circ}$ slope angle (vertical slope face), they found that soil nail orientations in the range of $0^{\circ}$ to $15^{\circ}$ results in decreased lateral earth pressures. They report that using soil nail lengths up to 9 meters does lower lateral earth pressures, but using soil nails longer than 9 meters has little effect on the lateral earth pressures. Further, they report that longer soil nails in the upper portion of the soil nail wall have more influence on the horizontal deformation of the soil nail wall while using longer soil nails in the lower portion are more important towards the overall slope stability. 
Using horizontally placed soil nails, they also confirm the logical deduction that the lateral earth pressures, soil nail tensile forces and horizontal slope deformation decreased with a decreasing slope angle. When considering soil strength properties, they report that the lateral earth pressures, and thus the horizontal deformation along the wall facing, decreased as either the Cohesion or Angle of Friction increased. Finally, they report that a staggered soil nail pattern can reduce lateral earth pressures and soil nail tensile forces and increase the global FOS of about $35 \%$ over a square pattern.

Zhou et. al. (2012) used three-dimensional FEM to back-analyze a soil-nailed slope under a surcharge load. They studied the internal deformation and the soil nail tensile forces during the surcharge load application. Particularly, their study evaluated the effect of surface grillage constraints at the soil nail heads. Overall, they report notable agreement between field and numerical modeling results. They found that soil nails can increase the overall stability when used on loose fill slopes under a surcharge load. Further, they report that the surface grillage and structure near the top portion of a soil-nailed wall is vital in the overall performance of a soil-nailed slope under surcharge loads, “..., particularly when an extreme surcharge loading is applied." (Zhou et. al., 2012)

Finally, Singh and Babu (2010) used two-dimensional FEM to study the effect of including soil hardening models when modeling soil nail walls. They recommend the use of advanced, hardening soil models for soil nail walls constructed in soft soils and when lateral wall displacements are critical. In addition, they report that the inclusion and consideration of the soil nail stiffness was important when evaluating the soil nail facing. 


\section{CHAPTER 3: NUMERICAL METHODOLOGY}

\subsection{Introduction}

Due to the rapid advances in computer technology, the use of numerical modeling for the analysis and evaluation of soil slopes has greatly improved (Zhou et. al., 2013; Rotte and Viswanadham, 2013; Halabian et. al., 2012; Singh and Babu, 2010; Gitirana et. al., 2008; Fan and Luo, 2008; Abdulrahman, 2006; Shiu and Chang, 2005; Griffiths and Lane, 1999). Finite Element Method (FEM) has proven to be a valuable tool to more accurately evaluate soil behavior and performance with respect to strain and deformation, as well as soil stresses (Zhou et. al., 2013; Rotte and Viswanadham, 2013; Halabian et. al., 2012; Singh and Babu, 2010; Zhang et. al., 1999). In this study, the FEM computer program 'ABAQUS' (2011) was utilized to analyze two- and three-dimensional slopes, both unreinforced and reinforced with soil nails.

\subsection{Use of the Finite Element Method (FEM)}

The history of the FEM, also known as finite element analysis (FEA), goes back to R. Courant (1943) and Turner et al. (1956), who used numerical analysis and variational calculus to obtain approximate solutions while studying vibration systems and complex structures, respectively (Clough, 1990). For several years, the computational power required to efficiently use FEM on a large-scale was limited to government and major industrial leaders (Chen and Han, 2007; Hutton, 2004); however, today's technology has evolved such that the average computer processor can effectively utilize FEM methods with confidence in a broad and diverse range of fields. In addition, both linear and non-linear 
systems which take into account plastic deformation and geometric nonlinearities can be analyzed (Abaqus, 2011, Hutton, 2004).

To begin an FEA, structures are divided into separate elements by creating a gridlike geometry, called a mesh, using nodal points. The frequency of the nodal points, and thus the "density" of the created mesh, is selected based on the precision and quantity of information desired for a particular area of interest. Material properties and associated behaviors are then assigned to the elements along with any external loads and boundary conditions present in the model.

\subsection{Research Distinction}

Various finite element types were evaluated for accuracy and efficiency for a previously solved two-dimensional soil slope reported in published literature (Wanstreet, 2007; Griffiths and Lane, 1999). Results from this study were compared with results from Limit-Equilibrium (L-E) slope stability analyses in an effort to validate the subsequent numerical models. In this study, many finite element types were evaluated in two- and three-dimensional slope stability analyses. After this, three-dimensional modeling was used for parametric studies to evaluate the influence on Factor of Safety (FOS) for several aspects of soil-nailed slopes, including: soil nail orientation; soil nail length; soil nail vertical spacing, soil nail horizontal spacing; the effect of varying soil properties; and surcharge location and magnitude. This research was distinct in that it utilized both two- and threedimensional methods and identified the advantages and disadvantages of three-dimensional slope stability modeling of unreinforced and reinforced, soil-nailed slopes. This research also identified the potential advantages of employing a three-dimensional finite element approach to pre-tensioned soil nails and fully modeling slopes. 


\subsection{Constitutive Soil Models}

Two relatively equivalent soil material models were used in this study. First, the Mohr-Coulomb soil model (Coulomb, 1776) was used. In geotechnical practice, this model is widely accepted and most often used (Duncan and Wright, 2005; Mitchell and Soga, 2005). In addition to the Mohr-Coulomb model, the Drucker-Prager soil model (Drucker and Prager, 1952) was also evaluated. Many two-dimensional studies have incorporated the use of the Mohr-Coulomb failure criterion (Wanstreet, 2007; Shiu and Chang, 2005; Ann et al, 2004; Griffiths and Lane, 1999). However, due to the differences in the yield surface, as discussed below, the Drucker-Prager model was evaluated for its suitability and potential advantages in three-dimensional numerical modeling. More details of these two models can be found elsewhere (Chen and Han, 2007).

\subsubsection{Comparison of Drucker-Prager and Mohr-Coulomb Soil Models}

The Drucker-Prager soil model has much in common with the more prevalently used Mohr-Coulomb theory. A summary of the similarities and differences are presented in Table 3.1 (Abaqus, 2011; Chen and Han, 2007). Both models include isotropic hardening or

Table 3.1 Comparison of Mohr-Coulomb and Drucker-Prager Soil Models

\begin{tabular}{|c|c|c|}
\hline Property/Description & Mohr-Coulomb & Drucker-Prager \\
\hline Origin & $\begin{array}{c}\text { Generalized Version } \\
\text { of Tresca Criterion }\end{array}$ & $\begin{array}{c}\text { Simple Modification } \\
\text { of Von Mises Criterion }\end{array}$ \\
\hline $\begin{array}{c}\text { Accounts for } \\
\text { Hydrostatic Pressure }\end{array}$ & Yes & Yes \\
\hline $\begin{array}{c}\text { Shape of Failure Curve in } \\
\text { Deviatoric Planes }\end{array}$ & Hexagon & Circle \\
\hline $\begin{array}{c}\text { Includes Isotropic } \\
\text { Hardening/Softening }\end{array}$ & Yes & Yes \\
\hline $\begin{array}{c}\text { Failure Dependent on } \\
\text { Intermediate Principal Stress }\end{array}$ & No & Yes \\
\hline
\end{tabular}


softening, as well as the capacity to manage separate friction and dilation angles. (The Angle of Dilation is the material property relating the ratio of plastic volume change to the plastic shear strain upon shearing.) The yield behavior of both models depends on the hydrostatic pressure, which in practical terms implies that they become stronger as the confining pressure increases, and vice-versa (Salgado, 2006). In addition, the inelastic behavior is generally accompanied by volume change in which the flow rule may include inelastic dilation. However, unlike the Drucker-Prager model, the Mohr-Coulomb model assumes that failure is independent of the value of the intermediate principal stress.

The well-known Mohr-Coulomb failure criterion can be expressed as (Das, 2013):

$$
\tau_{f}=c+\sigma \tan \phi
$$

Where:

$$
\begin{aligned}
& \tau_{f}=\text { Shear Stress } \\
& c=\text { Cohesion } \\
& \phi=\text { Angle of Friction } \\
& \sigma=\text { Normal Stress }
\end{aligned}
$$

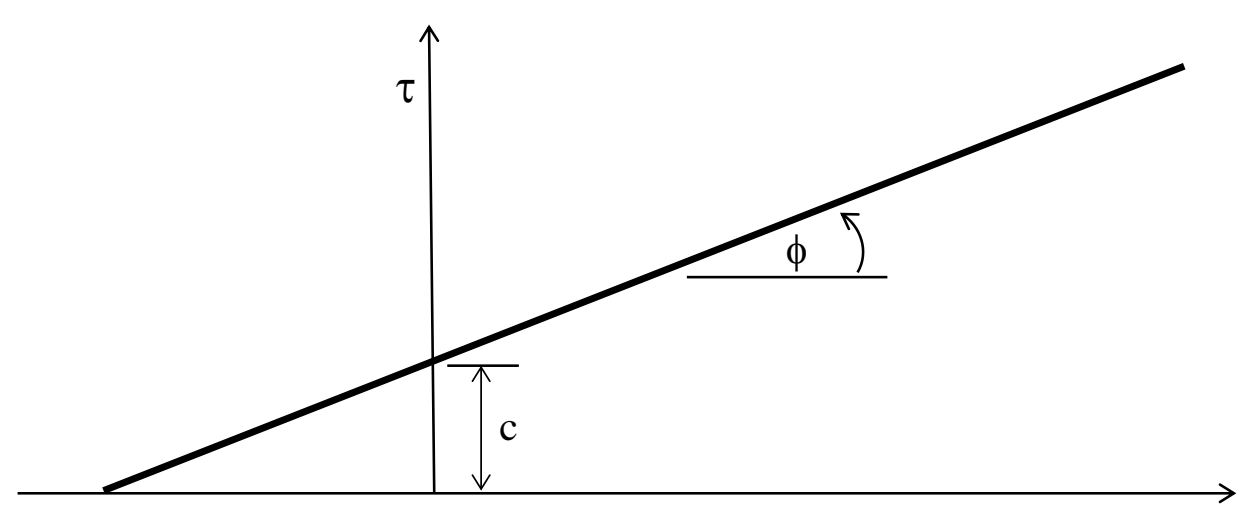

Figure 3.1 Mohr-Coulomb Failure Criteria 
For general states of stress, the model is more conveniently written in terms of three stress invariants as (Abaqus, 2011):

$$
F=R_{m c} q-p \cdot \tan \phi-c=0
$$

Where:

$$
\begin{aligned}
& R_{m c}(\theta, \phi)=\frac{1}{\sqrt{3} \cos \phi} \sin \left(\theta+\frac{\pi}{3}\right)+\frac{1}{3} \cos \left(\theta+\frac{\pi}{3}\right) \tan \phi \\
& \theta=\text { Deviatoric Polar Angle } \quad q=\text { Mises Equivalent Stress } \\
& p=\text { Equivalent Pressure Stress } \quad \phi \text { and } c \text { (as previously defined) }
\end{aligned}
$$

The primary difference in the Mohr-Coulomb and Drucker-Prager models is the shape of the resulting yield surface. The Drucker-Prager model results in a smooth, potentially non-circular yield surface in the deviatoric plane. When the Drucker-Prager is made to circumscribe (match) the Mohr-Coulomb hexagon, the two surfaces coincide. A two-dimensional cross-section of the respective yield surfaces is presented in Figure 3.2.

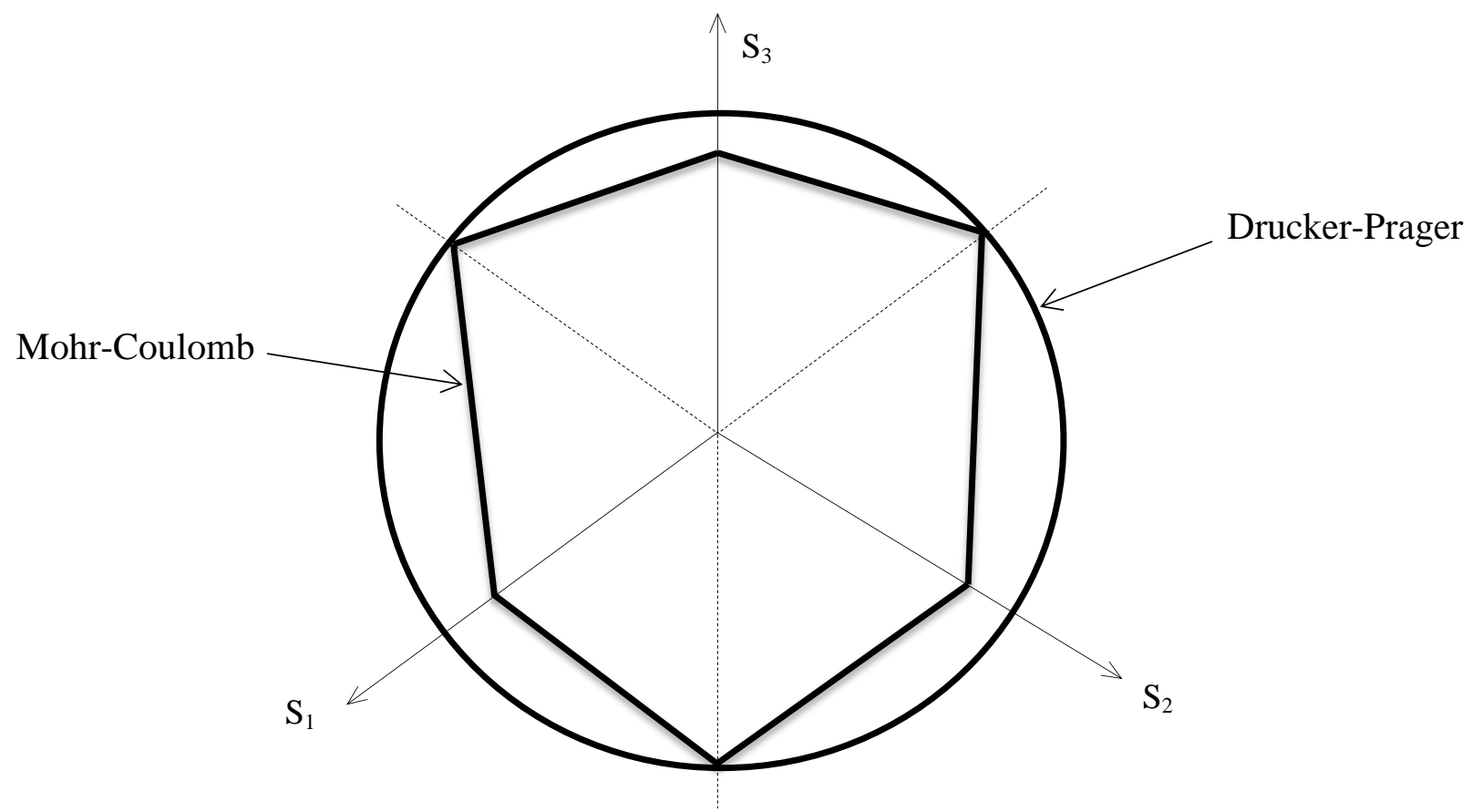

Figure 3.2 Cross-Sections of Mohr-Coulomb and Drucker-Prager Yield Surface in Deviatoric Plane 


\subsubsection{Linear Drucker-Prager Soil Model}

The Linear Drucker-Prager soil model was also used in this study. The yield surface for the Linear Drucker-Prager soil model can be written as (Abaqus, 2011):

$$
F=t-p \cdot \tan \beta-c^{\prime}=0
$$

Where:

$$
\begin{aligned}
& t=\text { Deviatoric Stress Measure } \\
& p=\text { Equivalent Pressure Stress } \\
& \beta=\text { Angle of Friction } \\
& c^{\prime}=\text { Cohesion }
\end{aligned}
$$

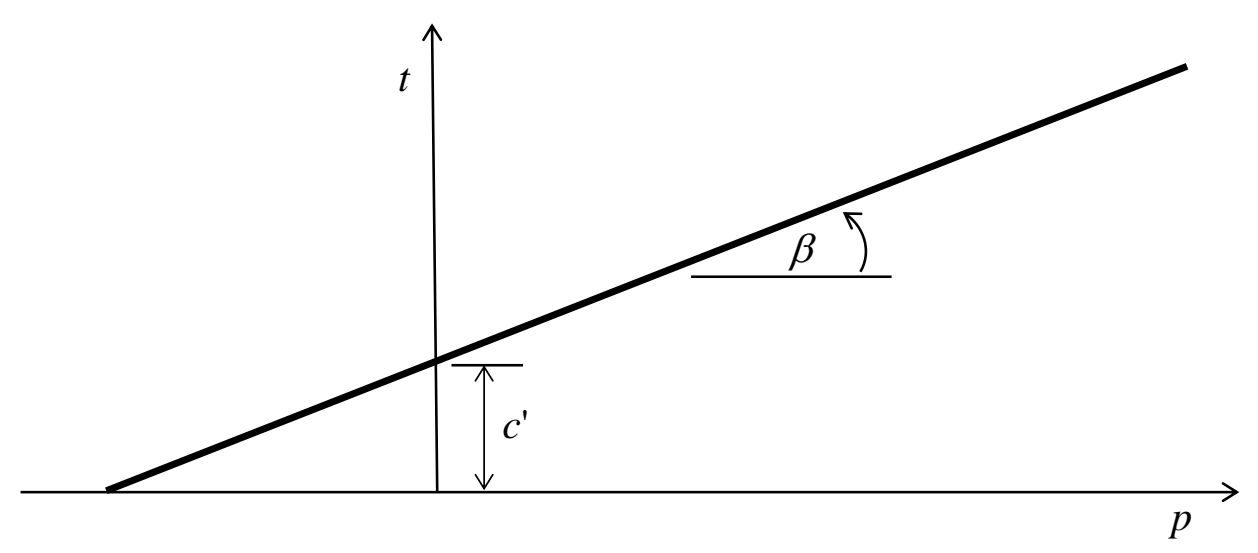

Figure 3.3 Drucker-Prager Failure Criteria

In this study, the soil was modeled as an initially isotropic, homogeneous material with a non-associative plastic flow rule (Mitchel and Soga, 2005; Griffiths and Lane, 1999). The input parameters included the following: 
Unit Weight:

$$
\gamma=\text { Unit Weight, }\left(\mathrm{kN} / \mathrm{m}^{3}\right)
$$

Elastic:

$$
\begin{aligned}
& \mathrm{E}=\text { Elastic Modulus },(\mathrm{kPa}) \\
& \mu=\text { Poisson's Ratio }
\end{aligned}
$$

$$
\begin{aligned}
& \text { Drucker-Prager Material Properties: } \\
& \qquad \begin{aligned}
c^{\prime} & =\text { Cohesion, }(\mathrm{kPa}) \\
\beta & =\text { Angle of Friction, (degrees) } \\
\psi & =\text { Dilation Angle, } \text { (degrees) }
\end{aligned}
\end{aligned}
$$

Some discussion is warranted on the non-associative plastic flow assumption followed in this study. For a soil undergoing plastic strain, dilatancy is the main property that must be considered as it determines the volume behavior of soil during yielding (Houlsby, 1991; Mitchel and Soga, 2005). If the ratio between the dilation angle and the Angle of Friction is greater than 1.0, then the soil compacts. If the ratio is less than or equal to 1.0 , then the soil may initially compact, followed by dilation. Manzari and Nour (2000) studied the significance of soil dilatancy with respect to slope stability and reported that higher dilation angle values lead to larger stability numbers.

While it is understood that the actual volume change of a soil during shearing is highly variable, the modeling of such variation, even by FEA using sophisticated computer processing, would be a daunting task. Most designers either choose to set the dilation angle equal to the Angle of Friction (assuming a fully associative plastic flow rule), or equal to zero (assuming a non-associative plastic flow rule). As previously stated, a non-associative plastic flow rule was assumed in this study. This assumption implies that the material stiffness matrix is not symmetric (Wanstreet, 2007; Griffiths and Lane, 1999). 


\subsubsection{Comparison of Drucker-Prager Model with Mohr-Coulomb Model}

This study utilized both the Mohr-Coulomb and Linear Drucker-Prager soil models. Since both models were used and will be evaluated and compared, an attempt was made to match the soil properties. Abaqus (2011) recommends that the user either match according to a plane strain condition or, for materials with relatively low friction angles, by using triaxial test results. For plane strain condition (Abaqus 2011); the plastic strain increment based on the linear Drucker-Prager flow potential can be expressed as:

$$
d \varepsilon^{p l}=d \bar{\varepsilon}^{p l} \frac{1}{\left(1-\frac{1}{3} \tan \psi\right)} \frac{\partial}{\partial \sigma}(t-p \tan \psi)
$$

where:

$$
\begin{aligned}
& d \bar{\varepsilon}^{p l}=\text { Equivalent plastic strain increment } \\
& t=\text { Deviatoric Stress } \\
& p=\text { Equivalent Pressure Stress } \\
& \psi=\text { Dilation Angle }
\end{aligned}
$$

Since only plane strain problems were considered, it can be assumed that the deviatoric stress is equal to the equivalent pressure $(t=q)$.

Thus:

$$
d \varepsilon^{p l}=d \bar{\varepsilon}^{p l} \frac{1}{\left(1-\frac{1}{3} \tan \psi\right)}\left(\frac{\partial q}{\partial \sigma}-\tan \psi \frac{\partial p}{\partial \sigma}\right)
$$

Writing this expression in terms of principal stresses leads to:

$$
d \varepsilon_{1}^{p l}=d \bar{\varepsilon}^{p l} \frac{1}{\left(1-\frac{1}{3} \tan \psi\right)}\left(\frac{1}{2 q}\left(2 \sigma_{1}-\sigma_{2}-\sigma_{3}\right)+\frac{1}{3} \tan \psi\right)
$$


where:

$$
\begin{aligned}
& d \bar{\varepsilon}^{p l}=\text { Equivalent plastic strain increment } \\
& \sigma_{i}=\text { Principle Stresses in } i \text {-plane } \\
& \psi=\text { Dilation Angle }
\end{aligned}
$$

Similar expressions may be written for $d \varepsilon^{p l}{ }_{2}$ and $d \varepsilon^{p l}{ }_{3}$. Assuming plane strain in the 1direction, at the limit load, $d \varepsilon^{p l}{ }_{1}=0$. Thus, this provides the constraint:

$$
\sigma_{1}=\frac{1}{2}\left(\sigma_{2}+\sigma_{3}\right)-\frac{1}{3} \tan \psi \cdot q
$$

And, using this constraint, one can rewrite $q$ and $p$ in terms of the principal stresses in the plane of deformation, $\sigma_{2}$ and $\sigma_{3}$, as:

$$
q=\frac{3 \sqrt{3}}{2 \sqrt{9-\tan ^{2} \psi}}\left(\sigma_{2}-\sigma_{3}\right)
$$

and,

$$
p=-\frac{1}{2}\left(\sigma_{2}+\sigma_{3}\right)+\frac{\tan \psi}{2 \sqrt{3\left(9-\tan ^{2} \psi\right)}}\left(\sigma_{2}-\sigma_{3}\right)
$$

With these expressions, the Drucker-Prager yield surface can be written in terms of $\sigma_{2}$ and $\sigma_{3}$, as:

$$
\frac{9-\tan \beta \tan \psi}{2 \sqrt{3\left(9-\tan ^{2} \psi\right)}}\left(\sigma_{2}-\sigma_{3}\right)+\frac{1}{2} \tan \beta\left(\sigma_{2}+\sigma_{3}\right)-d=0
$$

As illustrated in Figure 3.2, the Mohr-Coulomb yield surface in the deviatoric plane is then:

$$
\sigma_{2}-\sigma_{3}+\sin \phi\left(\sigma_{2}+\sigma_{3}\right)-2 c \cos \phi=0
$$


and by comparison,

$$
\begin{aligned}
& \sin \phi=\frac{\tan \beta \sqrt{3\left(9-\tan ^{2} \psi\right)}}{9-\tan \beta \tan \psi} \\
& \cos \phi=\frac{\sqrt{3\left(9-\tan ^{2} \psi\right)}}{9-\tan \beta \tan \psi} d
\end{aligned}
$$

So, for associative flow rule $(\psi=\beta)$, the relationship is obtained as:

$$
\tan \beta=\frac{\sqrt{3} \sin \phi}{\sqrt{1+\frac{1}{3} \sin ^{2} \phi}}
$$

and,

$$
c^{\prime}=\frac{\sqrt{3} \cos \phi}{\sqrt{1+\frac{1}{3} \sin ^{2} \phi}} C
$$

And for a non-associative flow rule $\left(\psi=0^{\circ}\right)$, as assumed in this study, the relationship is defined by (Abaqus, 2001):

$$
\tan \beta=\sqrt{3} \sin \phi
$$

and

$$
c^{\prime}=(\sqrt{3} \cos \phi) c
$$

Note that the discrepency between the fully and non-associative relationships for the Drucker-Prager model increases as the Mohr-Coulomb friction angle increases, but the difference is only slight for friction angles less than $30^{\circ}$. Table 3.2 presents the resulting Drucker-Prager friction angles of both associative and non-associative flow rules for varying Mohr-Coulomb friction angles. 
Table 3.2 Matching of Drucker-Prager and Mohr-Coulomb Soil Properties (Abaqus, 2011)

\begin{tabular}{|c|c|c|}
\hline $\begin{array}{c}\text { Mohr-Coulomb } \\
\text { Friction Angle, } \phi\end{array}$ & $\begin{array}{c}\text { Drucker-Prager } \\
\text { Friction Angle, } \beta \\
\text { (Associative Flow) }\end{array}$ & $\begin{array}{c}\text { Drucker-Prager } \\
\text { Friction Angle, } \beta \\
\text { (Non-Associative Flow) }\end{array}$ \\
\hline $10^{\circ}$ & $16.7^{\circ}$ & $16.7^{\circ}$ \\
\hline $20^{\circ}$ & $30.2^{\circ}$ & $30.6^{\circ}$ \\
\hline $30^{\circ}$ & $39.8^{\circ}$ & $40.9^{\circ}$ \\
\hline $40^{\circ}$ & $46.2^{\circ}$ & $48.1^{\circ}$ \\
\hline $50^{\circ}$ & $50.5^{\circ}$ & $53.0^{\circ}$ \\
\hline
\end{tabular}

\subsection{Soil Properties}

With the exception of the parametric soil property evaluation, the soil properties used in this study match those of previously studied numerically solved slopes (Wanstreet, 2007; Griffiths and Lane, 1999; Shiu and Chang, 2005). Table 3.3 presents these values. Similarly, the "equivalent" Drucker-Prager soil properties that were used in this study are presented in Table 3.4 and were determined using Equations 3.17 and 3.18. The soil properties used were considered to be homogeneous throughout the models.

Table 3.3 Benchmark Mohr-Coulomb Soil Properties (“Soil 1")

\begin{tabular}{|c|c|c|c|c|c|}
\hline $\begin{array}{c}\text { Unit Weight } \\
(\gamma)\end{array}$ & $\begin{array}{c}\text { Elastic } \\
\text { Modulus } \\
(\mathrm{E})\end{array}$ & $\begin{array}{c}\text { Angle of } \\
\text { Friction } \\
(\phi)\end{array}$ & $\begin{array}{c}\text { Cohesion } \\
(\mathrm{c})\end{array}$ & $\begin{array}{c}\text { Poisson's } \\
\text { Ratio } \\
(\mu)\end{array}$ & $\begin{array}{c}\text { Dilation* } \\
\text { Angle } \\
(\psi)\end{array}$ \\
\hline $20.2 \mathrm{kN} / \mathrm{m}^{3}$ & $100,000 \mathrm{kPa}$ & $19.6^{\circ}$ & $3 \mathrm{kPa}$ & 0.3 & $0^{\circ}$ \\
\hline
\end{tabular}

* Dilation Angle $(\psi)$ equal to zero assumes a non-associative plastic flow rule. 
Table 3.4 Equivalent Benchmark Drucker-Prager Soil Properties

\begin{tabular}{|c|c|c|c|c|c|}
\hline $\begin{array}{c}\text { Unit Weight } \\
(\gamma)\end{array}$ & $\begin{array}{c}\text { Elastic } \\
\text { Modulus } \\
(\mathrm{E})\end{array}$ & $\begin{array}{c}\text { Angle of } \\
\text { Friction } \\
(\beta)\end{array}$ & $\begin{array}{c}\text { Cohesion } \\
\left(\mathrm{c}^{\prime}\right)\end{array}$ & $\begin{array}{c}\text { Poisson's } \\
\text { Ratio } \\
(\mu)\end{array}$ & $\begin{array}{c}\text { Dilation* } \\
\text { Angle } \\
(\psi)\end{array}$ \\
\hline $20.2 \mathrm{kN} / \mathrm{m}^{3}$ & $100,000 \mathrm{kPa}$ & $30.2^{\circ}$ & $4.9 \mathrm{kPa}$ & 0.3 & $0^{\circ}$ \\
\hline
\end{tabular}

* Dilation Angle $(\psi)$ equal to zero assumes a non-associative plastic flow rule.

\subsection{Soil Nail and Nail Head Model}

While the soil nail and nail head stresses associated with reinforced slope stability analysis were not a focus of this research, proper modeling of nail components were necessary in order to accurately capture slope stability behavior. The soil nail and nail head modeling procedures employed in this study were adapted from previous research (Wanstreet, 2007) and expanded to include three-dimensional modeling capabilities. Specific modeling details for the soil nail and nail head is presented below. Figures 3.4a and 3.4b present the basic components of a soil-nailed slope as modeled in this research using FEM.

\subsubsection{Constitutive Material Model for the Soil Nail and Nail Head}

Linear elastic behavior was assumed for the soil nail and soil nail head in all finite element modeling procedures as the nail stresses were below the material yield strengths. This assumption has been shown to be adequate in capturing the behavior of reinforced earth slopes (Wanstreet 2007). The mechanical properties employed were obtained from 
Tamboli (1997) for typical structural steel, and are listed in Table 3.5 below. These soil nail parameters were assumed homogeneous and constant throughout all models.

Table 3.5 Soil Nail and Nail Head Mechanical Properties (Tamboli, 1997)

\begin{tabular}{|c|c|c|}
\hline $\begin{array}{c}\text { Unit Weight } \\
(\gamma)\end{array}$ & $\begin{array}{c}\text { Elastic } \\
\text { Modulus } \\
(\mathrm{E})\end{array}$ & $\begin{array}{c}\text { Poisson's } \\
\text { Ratio } \\
(\mu)\end{array}$ \\
\hline $76.98 \mathrm{kN} / \mathrm{m}^{3}$ & $200 \mathrm{GPa}$ & 0.30 \\
\hline
\end{tabular}

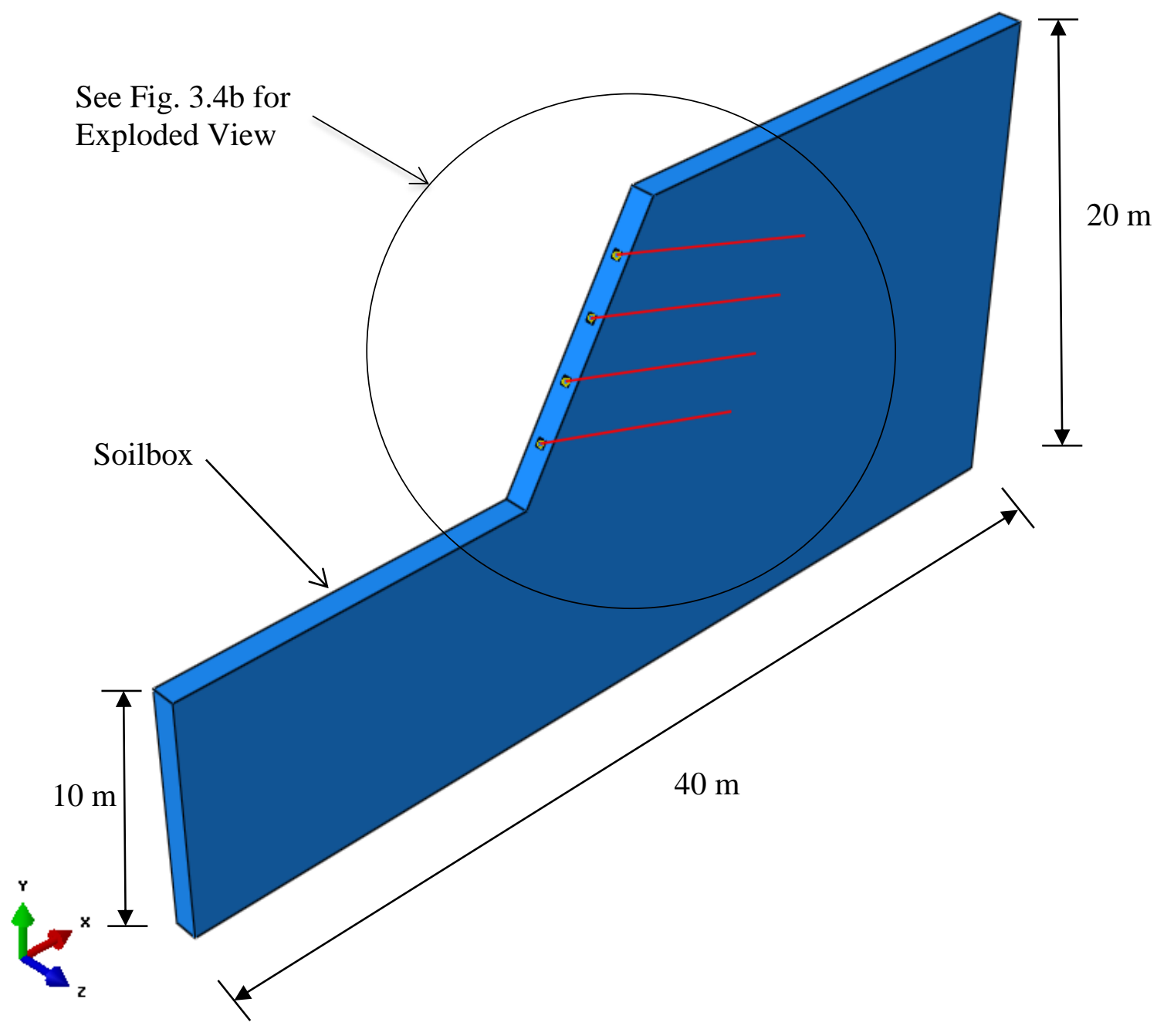

Figure 3.4a FE Model of a Typical Soil-Nailed Slope - Full View 


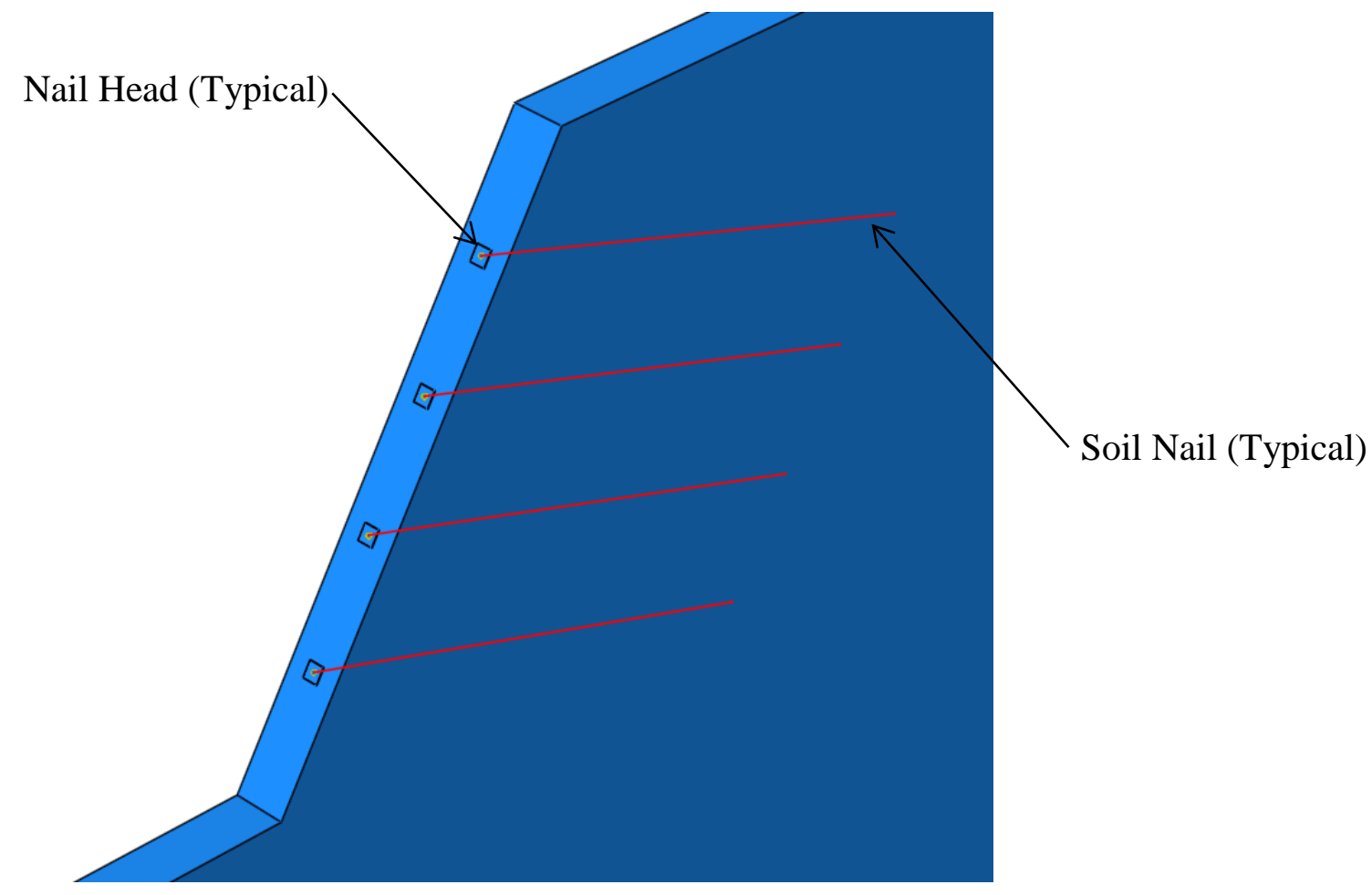

Figure 3.4b FE Model of a Typical Soil-Nailed Slope - Exploded View

\subsubsection{Soil Nail Models}

The two-dimensional soil nail length and diameter was set at 10 meters and 10 millimeters, respectively, following Wanstreet (2007). Since the soil nails employed in this study were inherently slender, due to their relatively high aspect ratio (i.e. length/depth), linear beam elements were used to model the soil nails. Element selection for twodimensional models consisted of a two-node linear Timoshenko beam, known in the Abaqus/Standard User's Manual (Abaqus, 2007) as a B21 element (Oñate, 2013). The B21 element is an extremely versatile element, capable of capturing axial, flexural, and shear 
deformations. However, it should be noted that, because of the high aspect ratios associated with typical soil nail dimensions, shear deformations are negligible for these elements. For two-dimensional models, a global seeding size of 2.0 was employed. Global seeding size approximates the length of each element edge and thus the size of the element by placing nodes to subdivide parts into elements; the smaller the finite element (mesh) seeding size, the finer the mesh. This translates to element lengths of 2.0 meters for the two-dimensional soil nails.

For the three-dimensional models, a more realistic 30-millimeter diameter soil nail (equivalent to a \#10 size rebar) was used (Kutschke et al., 2007). The element selection consisted of a two-node linear beam in space, known in the Abaqus/Standard User's Manual as a B31 element. The B31 element is essentially an extension of the B21 element into three dimensions, with the inclusion of torsional deformation capabilities. In addition, the B31 element is capable of capturing twisting deformations due to both St. Venant torsion (i.e. pure torsion) and warping torsion (Oñate, 2013). However, since the cross-sections for the soil nails in this study are all circular, all associated warping constants were set equal to zero, and warping deformations were effectively neglected. In order to obtain a more detailed, finer mesh, the three-dimensional models throughout this study used an approximate global seeding size of 1.0, translating into 1.0 meter element lengths for the three-dimensional soil nails.

\subsubsection{Soil Nail Head Models}

The soil nail heads employed in this study have relatively low thicknesses when compared with their respective lengths and widths. For two-dimensional models, the soil 
nail heads were 1.6 meters wide by 5 millimeters thick, following Wanstreet (2007). Therefore, planar elements were used to model all nail head components. Element selection for these components consisted of 8-node quadratic plane strain elements, known in the Abaqus/Standard User's Manual as a CPE8. Due to their higher-order interpolation of associated deformations, these elements can accurately capture the behavior of nail head assemblies, even at relatively low mesh densities (Oñate, 2013). For the two-dimensional nail head modeling in this study, an approximate global seeding size of 0.08 was used to generate the associated mesh layouts, following Wanstreet (2007).

The three-dimensional soil nail heads used in this study were set at a more realistic, and conservative, 0.3 meters square by 20 millimeters thick (Kutschke et al., 2007). In addition, 8-noded linear brick elements were employed, known in the Abaqus/Standard User's Manual as a C3D8 element. While these elements only offer linear interpolation of deformations (as opposed to the higher-order CPE8 elements), a global seeding size of 0.05 was employed, thereby increasing the mesh density in an effort to ensure that results were both accurate and comparable with the two-dimensional modeling. The finite element mesh serves two purposes. It subdivides the geometry into elements and represents the solution field to which the numerical solution is obtained. Although a finer mesh requires greater processing power, it also yields more detailed information (Hutton, 2004).

\subsection{Interaction Modeling}

Three different interactions were included for appropriate modeling of the soil nail and soil nail head assembly. To model the interaction between the soil nail and soil slope, fully-bonded behavior (embedded elements) was assumed. Soil nail heads were also tied to the slope face, which essentially bonds two regions together, even though the meshes 
created on the surfaces of the regions may be different. Finally, the soil nail ends were coupled to the outer surface of the soil nail head. Figure 3.5 illustrates these interactions.

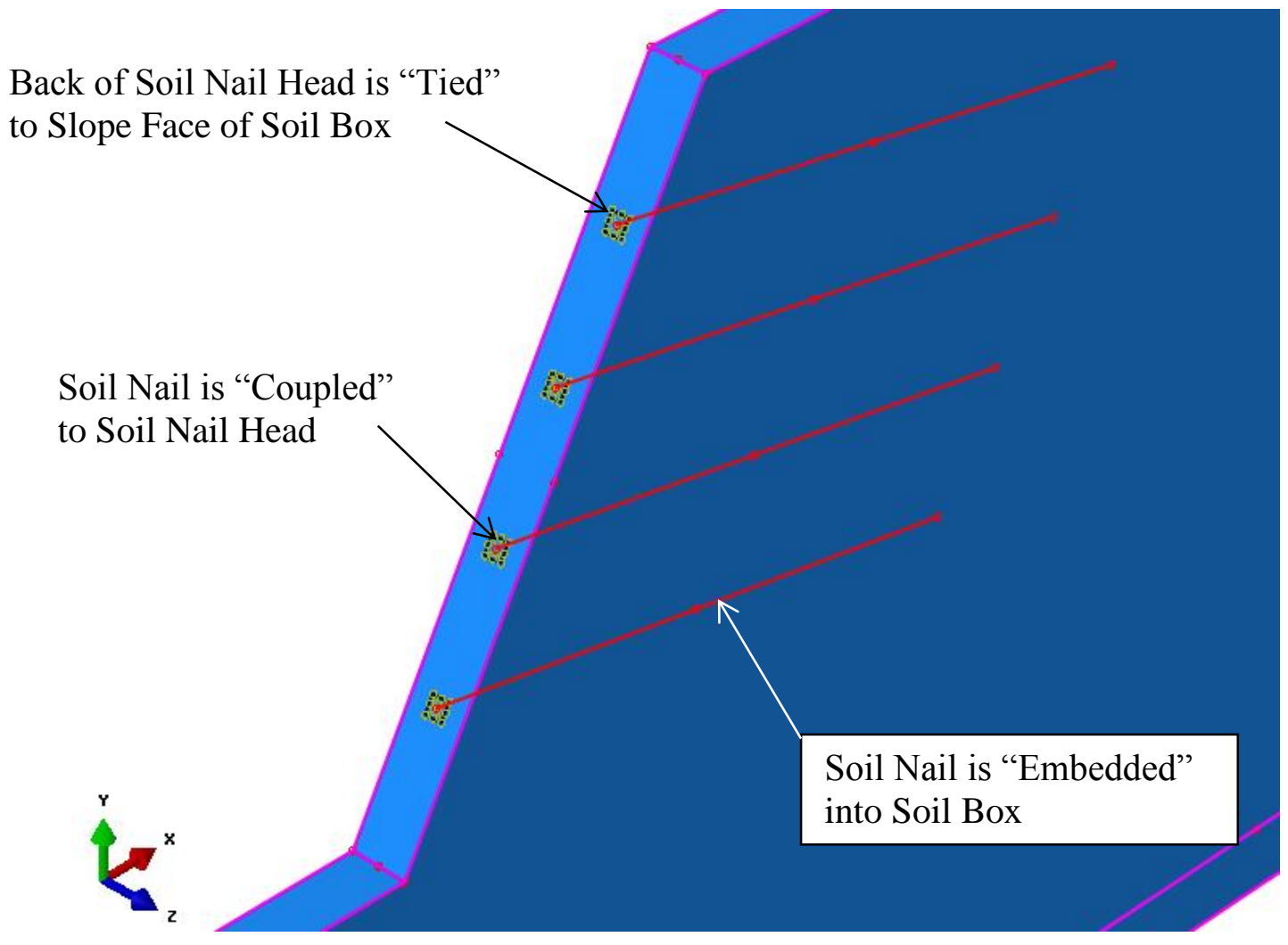

Figure 3.5 FE Model Interactions Schematic

\subsection{Boundary Conditions and Gravity Loads}

The boundary conditions used for this study are similar for the two- and threedimensional models, as shown in Figures 3.6 and 3.7, respectively. For all studies, the Ydirection was assigned to the plane running with the vertical slope faces; the $\mathrm{X}$-direction was assigned to the plane running with the base of the slopes; and for the three-dimensional models, the Z-direction added depth to the models in a direction normal to both the $\mathrm{X}$ and $\mathrm{Y}$ directions. Completely fixed (Encastre) boundaries were used for the bottom of the embankment in both directions ( $\mathrm{X}$ and $\mathrm{Y}$ ) for the two-dimensional studies and in all three 
directions (X, Y, and $\mathrm{Z}$ ) for the three-dimensional studies. The vertical ends, as well as the sides for 3-D modeling, were assumed to be fixed only in the normal directions. There were no restraints ("Free") on the top and sloped faces of the models.

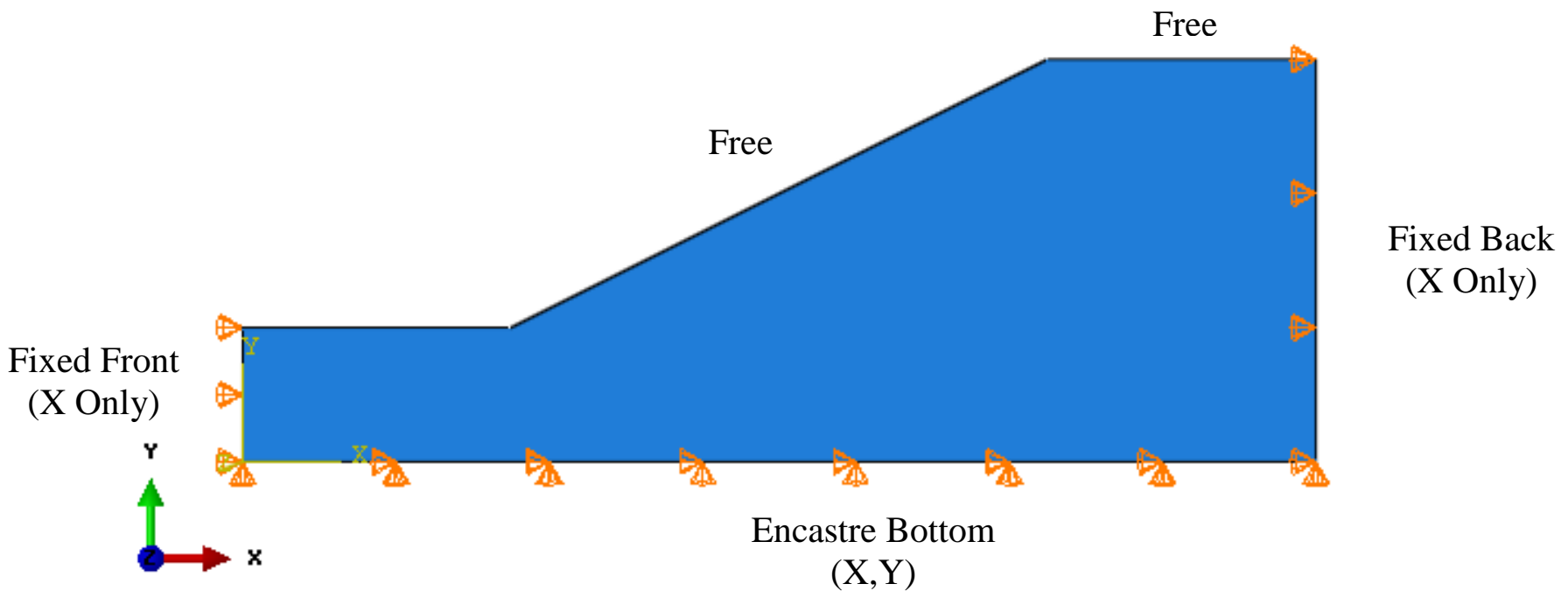

Figure 3.6 Boundary Conditions Used for Two-Dimensional Models

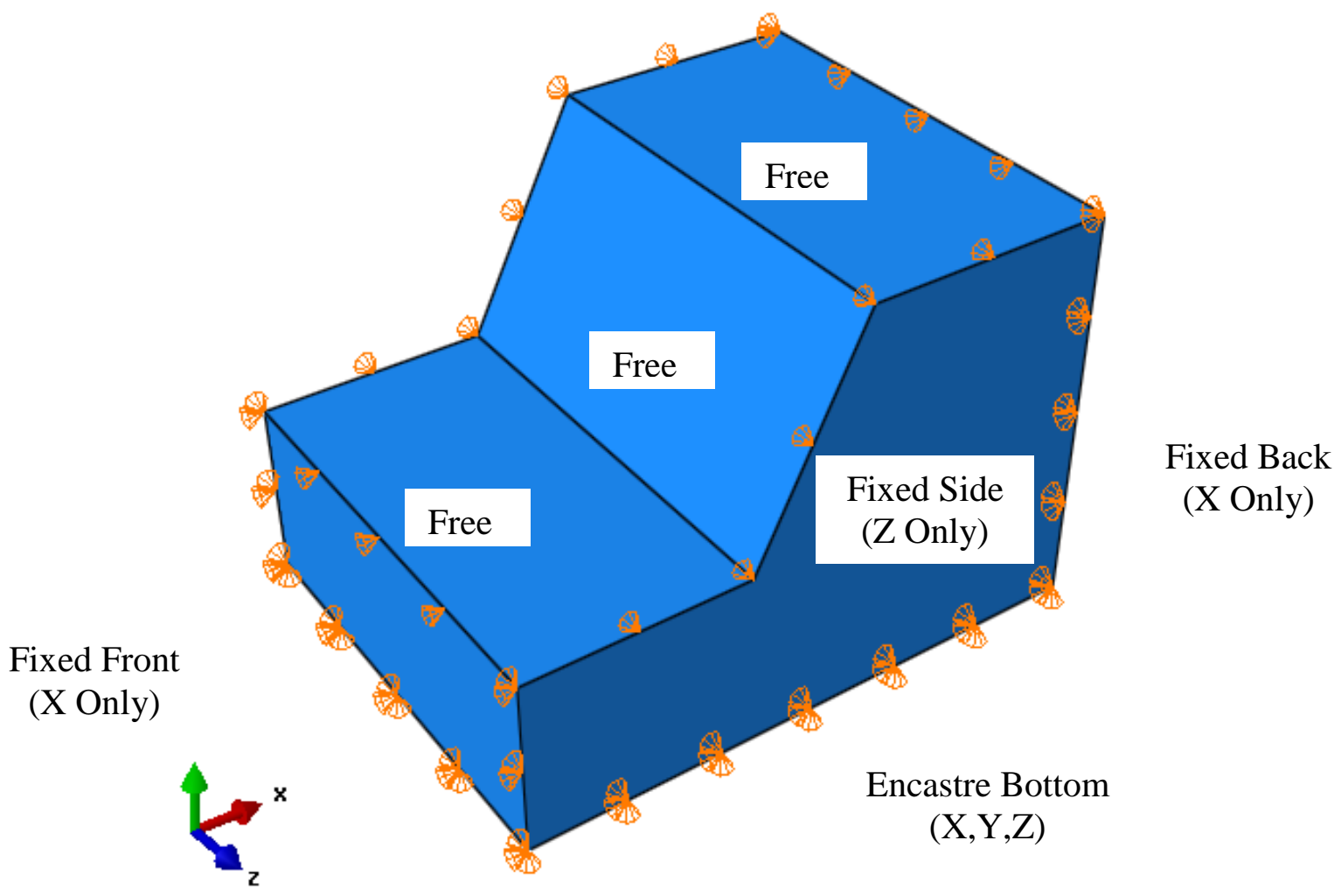

Figure 3.7 Boundary Conditions Used for Three-Dimensional Models 
For all of the slope models in this study, a gravitational force was applied as a downward pressure over the entire model equal to 1 kilonewton $(\mathrm{kN})$ (Wanstreet, 2007; Griffiths and Lane, 1999). This load was modeled within a general static step as an amplituded, ramp load. In this type of analysis, the initial stresses are generated due to the unit load applied. According to Griffiths and Lane (1999), applying a unit load to an initially stress-free slope is a reliable method to account for the self-weight of the soil. This is referred to as a standard gravity "turn-on" procedure. Further, Griffiths and Lane (1999) state that the "turn-on" procedure involves, “...integrals over each element of the form:

$$
p^{e}=\gamma \int_{V^{e}} N^{T} d V^{e}
$$

Where, $\mathrm{N}$ is the shape function of the element and the superscript e refers to the element number. This integral evaluates the volume of each element, multiplies by the total unit weight of the soil and distributes the net vertical force consistently to all the nodes. These element forces are assembled into a global gravity force vector that is applied to the finite element mesh in order to generate the initial stress state of the problem."

\subsection{Shear Strength Reduction (SSR) Method}

For several years now designers have practiced the Shear Strength Reduction (SSR) method to evaluate slope stability (Wei and Chen, 2010; Wanstreet, 2007; Chen et. al., 2007; Curran et. al., 2006; Griffiths and Lane, 1999; Dawson et. al., 1999; Duncan, 1996; Matsui and San, 1992). The SSR technique is a practical and effective way to evaluate the stability of soil slopes, both unreinforced and reinforced, and was used in the vast majority of the modeling work in this study. The SSR process is accomplished whereby the strength of a soil slope is systematically increased or reduced until the balance of equilibrium/non- 
equilibrium is obtained. Upon this threshold, a Factor of Safety (FOS) is derived, as presented below, with the use of Equations 3.20 through 3.23. This technique assumes elasto-plastic material behavior.

The Factor of Safety (FOS), expressed using the Mohr-Coulomb yield criterion as presented in Equation 3.1, can be expressed as (Duncan, 1996):

$$
\frac{\tau}{F O S}=\frac{c}{F O S}+\frac{\tan \phi}{F O S}
$$

This expression can also be written as:

$$
\frac{\tau}{F O S}=c^{*}+\tan \phi^{*}
$$

where,

$$
c^{*}=\frac{c}{F O S}
$$

and,

$$
\phi^{*}=\arctan \left(\frac{\tan \phi}{F O S}\right)
$$

Using these equations, and the following steps, a FOS can easily be obtained (Duncan, 1996):

Step 1. Create an FE model of the selected slope and assign the appropriate strength and deformation soil material properties. Compute the model and note the total slope deformation.

Step 2. (Assuming the slope is stable...) Using Equations 3.22 and 3.23, increase the FOS value in order to obtain decreased soil strength properties to assign to the FE model and re-compute the model.

Step 3. Repeat Step 2 until the FE model does not obtain a converged solution. (The FOS value obtained that is just above the non-converged solution is recorded as the slope's FOS.)

(Note that if the slope is initially unstable, the FOS is decreased in Step 2 and 3, whereby the strength properties are increased until the FE solution converges.) 


\section{CHAPTER 4: TWO-DIMENSIONAL MODELING STUDIES}

\subsection{Introduction}

As discussed in Chapter 2, this research builds upon the work completed by Wanstreet (2007) where two-dimensional FEM was used to study the influence of mesh density, along with the length, location, orientation and the number of nails used. This problem was replicated in this study. The model geometry is presented in Figure 4.1. The soil slope was modeled using 6-noded modified quadratic plane strain triangular (CPE6M) elements with an approximate global seeding size of 1.3. Mohr-Coulomb soil properties were used as presented in Table 3.3. (This soil type was named "Soil 1" for the remainder of this study.) The mesh geometry of the benchmark model is presented in Figure 4.2 (Wanstreet, 2007).

In addition to the benchmark model, with a $26.5^{\circ}$ slope, additional slope angles of $50^{\circ}, 60^{\circ}, 70^{\circ}, 80^{\circ}$, and $90^{\circ}$ were modeled. The FOS results' from this study were used for comparison to matching two-dimensional L-E models and three-dimensional FEM models. Besides the slope angles, no other parameters were altered from the benchmark model.

\subsection{Two-Dimensional Limit Equilibrium Evaluation of Unreinforced Slopes}

In an effort to validate the benchmark model, and other models in this study, a limitequilibrium slope stability computer program was used. Generally, two-dimensional, limitequilibrium (L-E) modeling has gained popularity over the last couple decades because L-E software typically provides a simple, user-friendly interface with acceptable results regarding overall FOS (Curran et. al., 2006; Hammah et. al., 2005). The slope stability 
software system developed by Rocscience, Inc., of Toronto, Ontario, called "Slide" is routinely used to perform two-dimensional slope stability analysis (Duncan et. al., 2008).

Slide (2012) is a two-dimensional, L-E slope stability program used to investigate the FOS of slopes including both circular and non-circular failure surfaces. Slide evaluates a slopes stability using vertical slice equilibrium methods such as Fellenius, Simplified Bishop, Janbu, Spencer, and Morgenstern-Price. Soil failure criteria options include: MohrCoulomb, Hoek-Brown, Barton-Bandis and others. However, the Drucker-Prager failure criterion is not an option. Slide will perform analyses considering external loads and reinforced slopes, such as soil-nailed slopes (Slide, 2012). The Slide slope stability computer program was used for comparative studies in this research.

For the study of unreinforced slopes, two-dimensional L-E models were developed for slope angles of $26.5^{\circ}, 50^{\circ}, 60^{\circ}, 70^{\circ}, 80^{\circ}$, and $90^{\circ}$. After the slope geometries were developed, the material properties were assigned using the benchmark model MohrCoulomb soil properties (Soil 1 - See Table 3.3). Once the model was developed, the Slide program analyzed and yielded a minimum FOS. The Simplified Bishop method was used for all the two-dimensional, limit-equilibrium models evaluated in this research. The Simplified Bishop method is a method of slices that uses a circular failure surface and conservatively assumes that the forces on the sides of the slices are horizontal; therefore, there are no shear stresses between the slices. For the Simplified Bishop method, both moment equilibrium, about the center of the failure circle, and vertical equilibrium are satisfied. Duncan and Wright (2005) report that the Simplified Bishop method provides relatively accurate FOS values and that it has proven to be more accurate than the Ordinary Method of Slices for an effective stress analysis. In addition, close agreement between the 
Simplified Bishop method and L-E methods that fully satisfy static equilibrium (e.g. Spencer, Morgenstern and Price, Chen and Morgenstern, and Sarma) have been confirmed (Duncan and Wright, 2005; Abramson et. al., 2002).

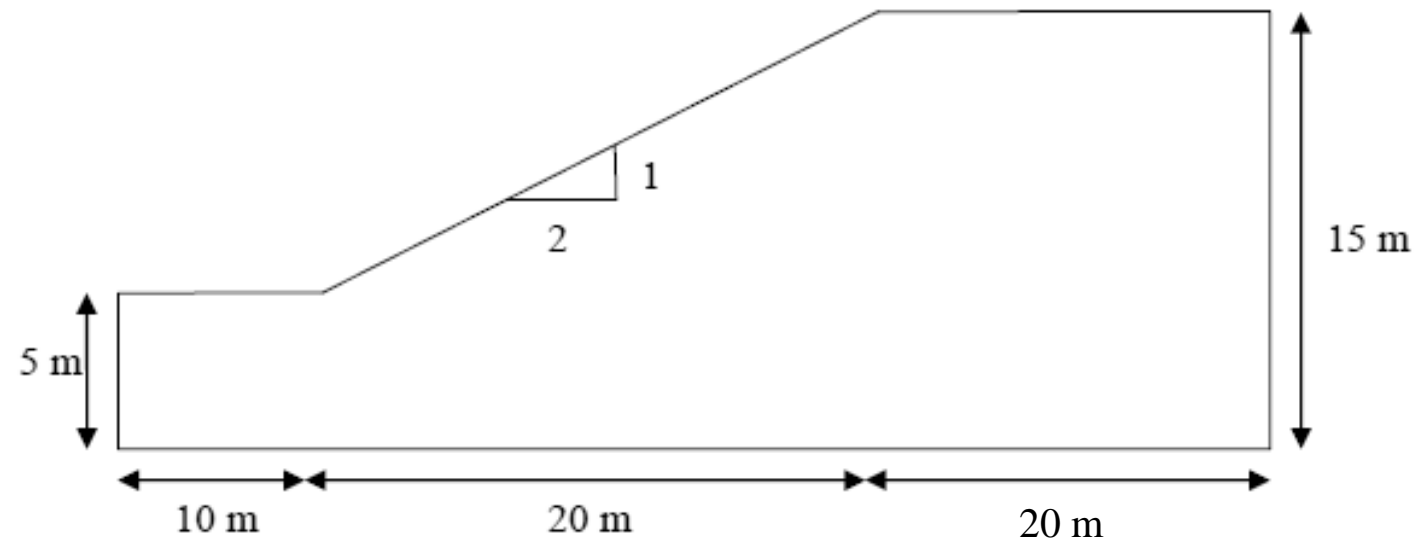

Figure 4.1 Geometry of Two-Dimensional Benchmark Model (Wanstreet, 2007)

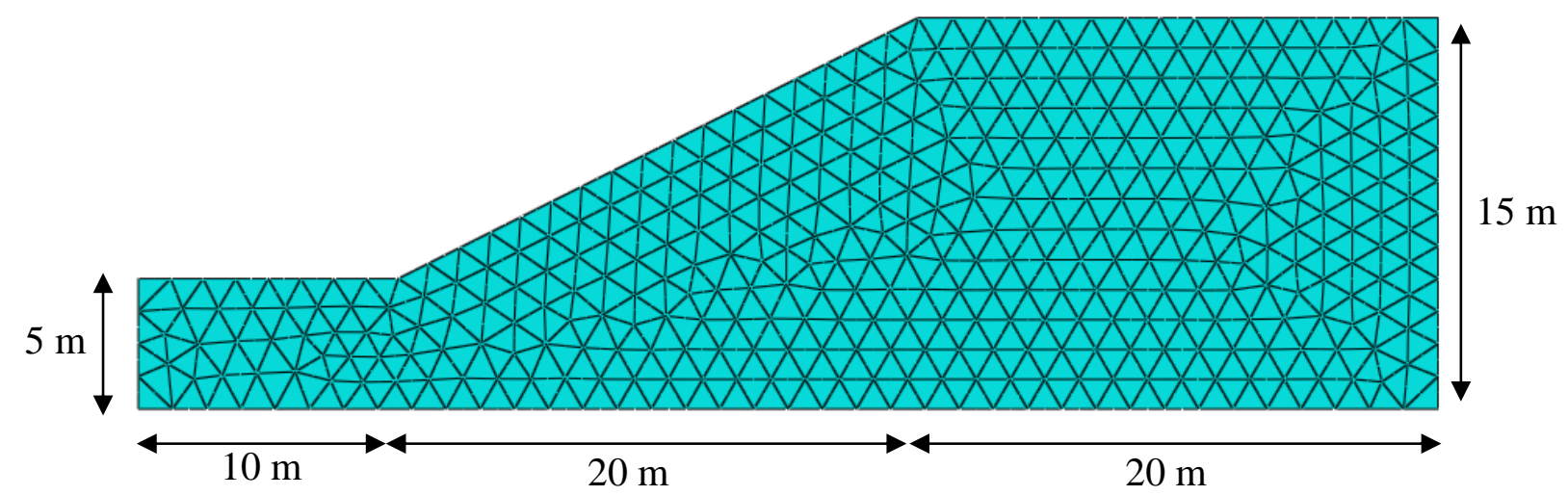

Figure 4.2 Mesh Geometry of Two-Dimensional Benchmark Model using 6-Noded Modified Quadratic Plane Strain Triangular (CPE6M) Elements (Wanstreet, 2007)

\subsection{Selection of Element Type in Two-Dimensional Finite Element Model}

Selecting the appropriate element type is crucial to the accuracy and efficiency of FEM modeling. Some FEM computer programs have a limited element type selection 
available. Abaqus (2011) provides many different options for selecting an element type. One of the primary objectives of this research was to evaluate and define the most suitable element types for slope stability modeling. Sixteen different plane strain element types were evaluated for accuracy, efficiency, and failure surface suitability using both Mohr-Coulomb and Drucker-Prager yielding criteria. Table 4.1 below presents the different element types investigated in this study along with a brief element description. Using the two-dimensional benchmark model previously discussed, each available element type was assigned to model the soil and evaluated.

Table 4.1 Available Options for Two-Dimensional Plane Strain Element Selection in Abaqus

\begin{tabular}{|c|c|c|}
\hline No. & $\begin{array}{c}\text { Element } \\
\text { Type }\end{array}$ & $\begin{array}{c}\text { Element } \\
\text { Description }\end{array}$ \\
\hline 1 & CPE3 & 3-noded linear triangle \\
\hline 2 & CPE3H & 3-noded linear triangle, Hybrid, Constant Pressure \\
\hline 3 & CPE4 & 4-noded bilinear quadrilateral \\
\hline 4 & CPE4H & 4-noded Bilinear Quadrilateral, Hybrid, Constant Pressure \\
\hline 5 & CPE4R & 4-noded Bilinear Quadrilateral, Reduced Integration, Hourglass Control \\
\hline 6 & CPE4RH & 4-noded Bilinear Quadrilateral, Hybrid, Constant Pressure, Reduced Integration, \\
\hline 7 & CPE4I & 4-noded Bilinear Quadrilateral, Incompatible Modes \\
\hline 8 & CPE4IH & 4-noded Bilinear Quadrilateral, Hybrid, Linear Pressure, Incompatible Modes \\
\hline 9 & CPE6 & 6-noded Quadratic Triangle \\
\hline 10 & CPE6H & 6-noded Quadratic Triangle, Hybrid, Linear Pressure \\
\hline 11 & CPE6M & 6-noded Modified Quadratic Triangle \\
\hline 12 & CPE6MH & 6-noded Modified Quadratic Triangle, Hybrid, Linear Pressure \\
\hline 13 & CPE8 & 8-noded Biquadratic Quadrilateral \\
\hline 14 & CPE8H & 8-noded Biquadratic Quadrilateral, Hybrid, Linear Pressure \\
\hline 15 & CPE8R & 8-noded Biquadratic Quadrilateral, Reduced Integration \\
\hline 16 & CPE8RH & 8-noded Biquadratic Quadrilateral, Hybrid, Linear Pressure, \\
\hline
\end{tabular}




\subsection{Two-Dimensional Modeling for Reinforced Slopes}

Two-dimensional, reinforced slopes were created in this study in an effort to reproduce, and build upon, the work completed by Wanstreet (2007). As presented in Figure 4.3 below, this study reproduced the benchmark slope used by Wanstreet (2007) in which the CPE6M finite element type was used to model the soil. For reinforcement, the models included the use of one, two, and three soil nails. These reinforcements were placed at 2 meter, vertical intervals, beginning with the first soil nail at the toe of the slope. The soil nail orientation used was $20^{\circ}$ and the soil nails were 10 meters in length.

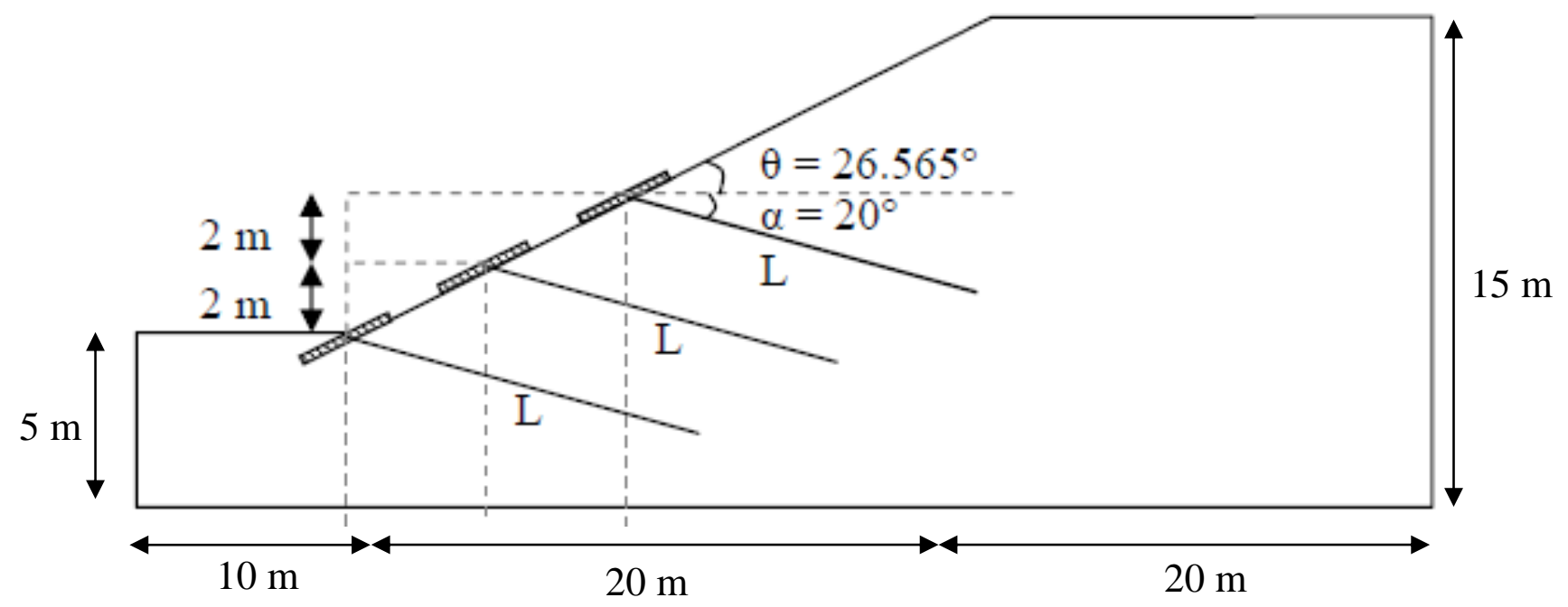

Figure 4.3 Two-Dimensional, Reinforced Benchmark Model (Wanstreet, 2007)

\subsection{Two-Dimensional Limit-Equilibrium Evaluation of Reinforced Slopes}

The two-dimensional, limit-equilibrium computer program Slide was also used to model reinforced slopes. According to the Slide User's Manual (Slide, 2012), Slide can analyze several types of reinforced (supported) soil systems, including an option for soil- 
nailed reinforced slopes. Slide was used in this research in order to compare results to twoand three-dimensional FEM models reinforced with soil nails. As noted in the Slide documentation (Slide, 2012), the Soil Nail option assumes:

- A Soil Nail is assumed to be fully bonded along its entire length

- The Soil Nail support type in Slide is equivalent to Grouted Tieback support with Bond Length $=100 \%$.

- The Soil Nail support type in Slide is differentiated from the Grouted Tieback for user convenience. However, the user should be aware that, as far as the Slide implementation is concerned, a Grouted Tieback with Bond Length $=100 \%$ would behave exactly the same as a Soil Nail, all other parameters being equal.

- A Soil Nail is NOT equivalent to the Grouted Tieback with Friction support type.

In addition, Slide offers the user several strength parameters in the Soil Nail option. The soil nail tensile capacity is defined as the maximum tensile capacity for one soil nail. Slide assumes the tensile capacity for steel and the default value of $100 \mathrm{kN}$ was used. The plate capacity is the maximum load which can be handled by the soil nail head/nail head assembly. Once again, the default value of $100 \mathrm{kN}$ was used in this study. It should be noted that Slide always assumes that the applied force is parallel to the orientation of the soil nail (Slide, 2012). Lastly, the pullout strength is defined as a force per unit length which determines the pullout or stripping force that the soil nail can withstand. The default value of $50 \mathrm{kN} / \mathrm{m}$ was used in this study. The default values represent typical conditions encountered on soil nailing projects based on material property values of steel and soil nail sizes (Slide, 2012). 


\section{CHAPTER 5: THREE-DIMENSIONAL MODELING STUDIES}

\subsection{Introduction}

To begin the three-dimensional modeling, a model based on the results from the twodimensional work was developed. Several options were explored and studied including the incorporation of the Drucker-Prager constitutive soil model in lieu of the Mohr-Coulomb model. Initially, it was thought that the Drucker-Prager model might perform more efficiently in three-dimensional modeling due to the smoother yield surface in the deviatoric plane, as discussed in Section 3.4 (See Figure 3.2). In addition, the large number of element types available for a three-dimensional stress/strain analysis needed to be evaluated in order to develop an appropriate model to progress with parametric studies and more complex three-dimensional, soil-nailed slopes.

Once a suitable model was developed, the effects of nail orientation, length, vertical soil nail spacing, horizontal soil nail spacing, surcharge magnitude and position, the effect of soil properties, the effect of pre-tensioning soil nails, and fully modeled slopes were studied. As with the two-dimensional models, an approximate global seeding size of 1.3 was used for all the three-dimensional models in this study.

\subsection{Influence of Depth in Three-Dimensional Analysis of Unreinforced Slopes}

Much of the three-dimensional, parametric investigations presented in this research utilizes a unit-width, finite element model. Due to the consistent model geometry and boundary conditions, as well as the homogeneous soil properties used in most of the threedimensional modeling performed in these studies, this approach provides an efficient and dependable alternative to full-scale modeling. In order to validate the use of a unit-width 
approach, a $26.5^{\circ}[2(\mathrm{H}): 1(\mathrm{~V})]$ unreinforced soil slope, with section $(\mathrm{X}-\mathrm{Y})$ dimensions as used on the benchmark slope presented in Figure 4.1, was modeled using an increasing depth (Z-direction) from 1 to 50 meters (See Figure 5.1). Three-dimensional, 8-noded linear brick (C3D8) stress elements were assigned to the soil elements used for this study. As discussed in Chapter 7, modeling results showed no variance in the Factor of Safety or failure surface with an increase in slope depth, only in the amount of time necessary for processing the results. Thus, many of the three-dimensional parametric studies performed in this research utilized a unit-width approach.

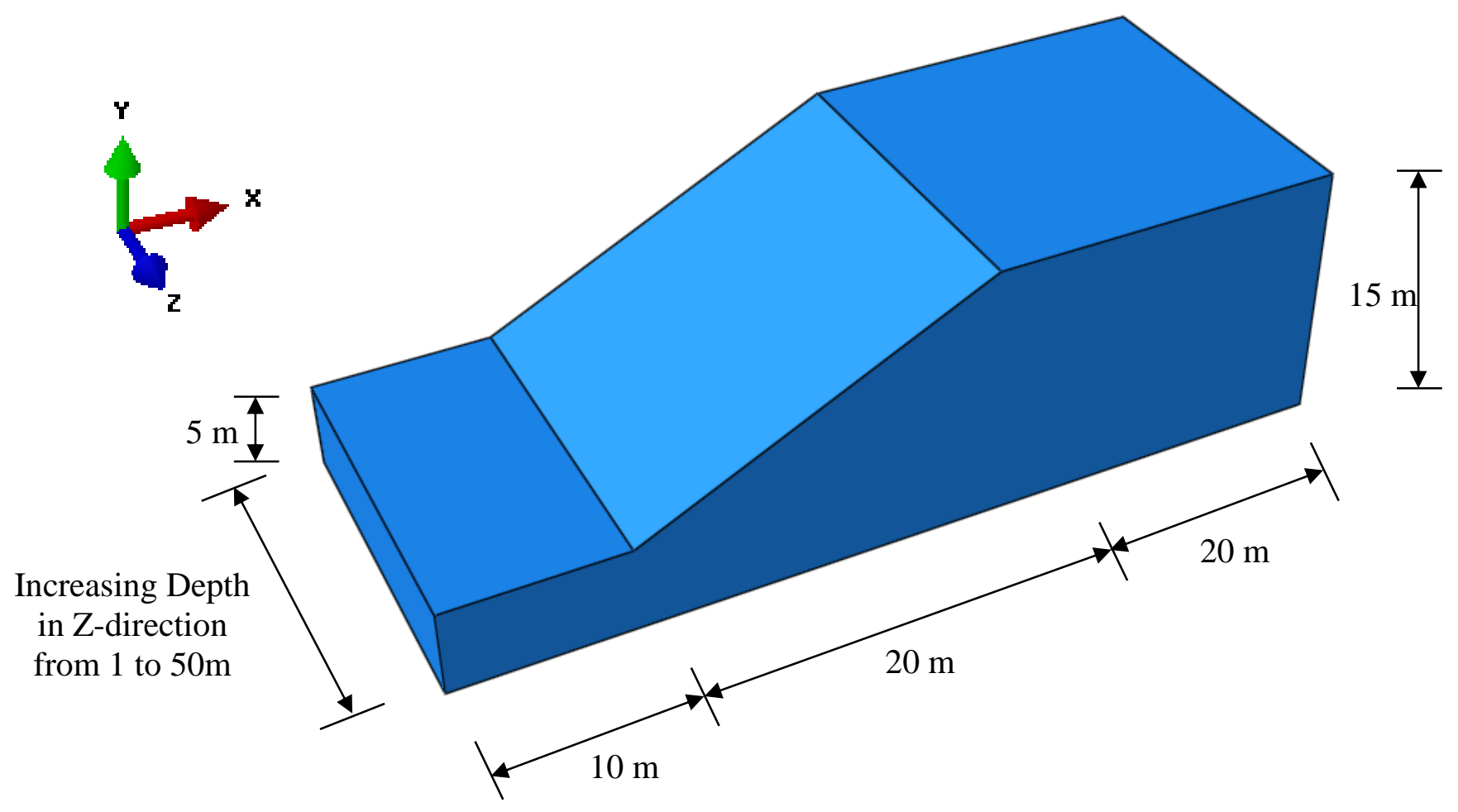

Figure 5.1 Three-Dimensional, Unreinforced Soil Slope with Increasing Depth

\subsection{Selection of Element Type in Three-Dimensional Finite Element Model}

While some FEM computer programs are very limited as to element type for threedimensional work, Abaqus (2011) offers twenty-one, three-dimensional finite element type 
options. Once again, by modeling the benchmark slope presented in Figure 4.1, with a unitwidth, the 21 available element types were evaluated for accuracy, efficiency, and failure surface suitability for both the Mohr-Coulomb and Drucker-Prager yield criteria. Table 5.1 presents the different element types used along with a brief element description.

Table 5.1 Available Options for Three-Dimensional Element Selection in Abaqus

\begin{tabular}{|c|c|c|}
\hline No. & $\begin{array}{c}\text { Element } \\
\text { Type }\end{array}$ & $\begin{array}{c}\text { Element } \\
\text { Description }\end{array}$ \\
\hline 1 & C3D4 & 4-noded Linear Tetrahedron \\
\hline 2 & $\mathrm{C} 3 \mathrm{D} 4 \mathrm{H}$ & 4-noded Linear Tetrahedron, Hybrid, Linear Pressure \\
\hline 3 & C3D6 & 6-noded Linear Triangular Prism \\
\hline 4 & $\mathrm{C} 3 \mathrm{D} 6 \mathrm{H}$ & 6-noded Linear Triangular Prism, Hybrid, Constant Pressure \\
\hline 5 & C3D8 & 8-noded Linear Brick \\
\hline 6 & $\mathrm{C} 3 \mathrm{D} 8 \mathrm{H}$ & 8-noded Linear Brick, Hybrid, Constant Pressure \\
\hline 7 & C3D8R & 8-noded Linear Brick, Reduced Integration, Hourglass Control \\
\hline 8 & C3D8RH & $\begin{array}{c}\text { 8-noded Linear Brick, Hybrid, Constant Pressure, Reduced Integration, } \\
\text { Hourglass Control }\end{array}$ \\
\hline 9 & C3D8I & 8-noded Linear Brick, Incompatible Modes \\
\hline 10 & C3D8IH & 8-noded Linear Brick, Hybrid, Linear Pressure, Incompatible Modes \\
\hline 11 & C3D10 & 10-noded Quadratic Tetrahedron \\
\hline 12 & $\mathrm{C} 3 \mathrm{D} 10 \mathrm{H}$ & 10-noded Quadratic Tetrahedron, Hybrid, Constant Pressure \\
\hline 13 & C3D10M & 10-noded Modified Quadratic Tetrahedron \\
\hline 14 & C3D10MH & 10-noded Modified Quadratic Tetrahedron, Hybrid with Linear Pressure \\
\hline 15 & C3D10I & 10-noded General Purpose Tetrahedron w/Improved Surface Stress Formulation \\
\hline 16 & C3D15 & 15-Node Quadratic Triangular Prism \\
\hline 17 & C3D15H & 15-Node Quadratic Triangular Prism, Hybrid, Linear Pressure \\
\hline 18 & C3D20 & 20-Node Quadratic Brick \\
\hline 19 & $\mathrm{C} 3 \mathrm{D} 20 \mathrm{H}$ & 20-Node Quadratic Brick, Hybrid, Linear Pressure \\
\hline 20 & C3D20R & 20-Node Quadratic Brick, Reduced Integration \\
\hline 21 & C3D20RH & 20-Node Quadratic Brick, Hybrid, Linear Pressure, Reduced Integration \\
\hline
\end{tabular}




\subsection{Comparison of Three-Dimensional FEM with Two-Dimensional FEM and Limit Equilibrium Models for Unreinforced Slopes}

Unreinforced, three-dimensional slopes were modeled using FEM. The result of this modeling was used to compare with two-dimensional FEM and limit equilibrium (L-E) methods. To begin, the $26.5^{\circ}$ benchmark slope, with dimensions as presented in Figure 4.1, was modeled as a three-dimensional, unreinforced FEM slope using a unit-width. Subsequent FEM models were constructed with varying slope angles of $50^{\circ}, 60^{\circ}, 70^{\circ}, 80^{\circ}$, and $90^{\circ}$. For these models, to eliminate any possible boundary condition issues, the total height was increased to 20 meters, providing an additional 5 meters of foundation (similar to that presented in Figure 5.4). Soil 1, Mohr-Coulomb soil properties were used as presented in Table 3.3. In addition, C3D8 element types were used for the FEM models and the SSR method was utilized to obtain a FOS.

Two-dimensional FEM and L-E models, with matching dimensions and soil properties, were developed for comparison. Two-dimensional FEM models were discussed in Section 4.2. Two-dimensional L-E models were developed using the computer program Slide (2012), as discussed in Section 4.2. The Slide (2012) computer program also generated FOS's for each slope.

\subsection{Three-Dimensional Modeling of Reinforced Slopes}

In this study, three-dimensional FEM modeling was used to evaluate the influence of several parameters of soil-nailed reinforced slopes, including: soil nail orientation; soil nail length; vertical soil nail spacing; horizontal soil nail spacing (including the influence of selected soil properties); surcharge location and magnitude; and the evaluation of typical 
soil properties. Figure 5.2 presents several of the soil nailing design parameters evaluated in this study. In addition, deformation was analyzed for pre-tensioned soil nails and two fully modeled soil slopes were analyzed. As previously described, the SSR method was used to determine the FOS in all cases.

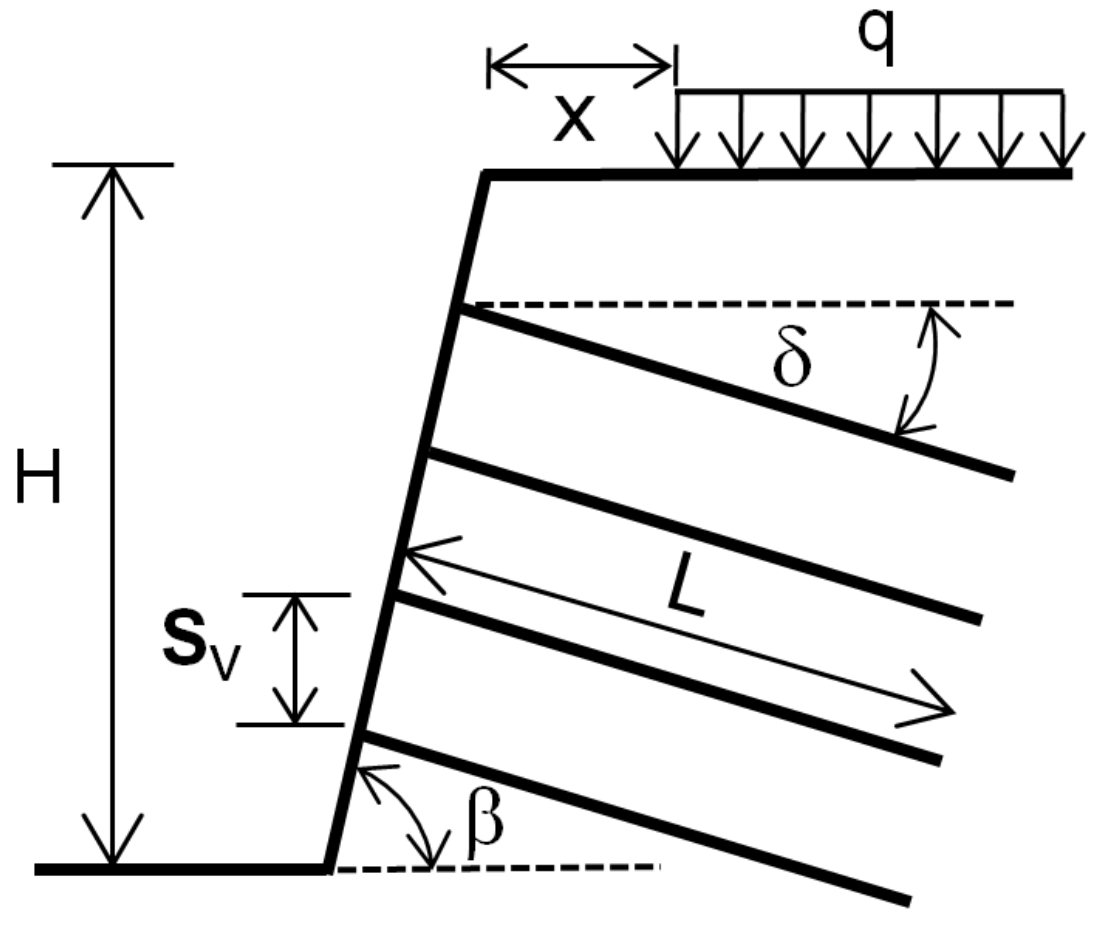

Where:
$\mathrm{H}=$ Slope Height
$\mathrm{S}_{\mathrm{V}}=$ Vertical Soil Nail Spacing
$\beta=$ Slope Angle
$\mathrm{D}=$ Soil Nail Orientation
$\mathrm{L}=$ Soil Nail Length
$\mathrm{x}=$ Dist. from Top of Slope to Surcharge Load
$q=$ Surcharge Load

Figure 5.2 Schematic of Soil Nailing Design Variables

\subsubsection{Influence of Soil Nail Orientation $(\delta)$}

In order for a soil nail to function efficiently, it must be constructed at an orientation ( $\delta)$ that effectively intersects the failure surface into the stable, Resistant Zone, as discussed 
in Section 2.3 (See Figure 5.3). To study nail orientation, 10 meter high $(\mathrm{H})$, threedimensional soil slope models were developed for slope angles $(\beta)$ of $90^{\circ}, 80^{\circ}, 70^{\circ}, 60^{\circ}$, $50^{\circ}, 40^{\circ}$, and $26.5^{\circ}$, using Soil 1, Mohr-Coulomb soil properties, as presented in Table 3.3. Four soil nails were placed, beginning at a vertical height 2 meters from the base of the slope, at a 2 meter vertical spacing $\left(\mathrm{S}_{\mathrm{V}}\right)$ (See Figures 5.2 and Figure 5.4). A soil nail length (L) of 10 meters was used for this study and no other lengths were evaluated. The soil nail orientation $(\delta)$ was varied from $0^{\circ}$ to $50^{\circ}$ in order to determine the orientation that corresponded with the highest FOS for the selected slope(s). This orientation was the “optimum" soil nail orientation.

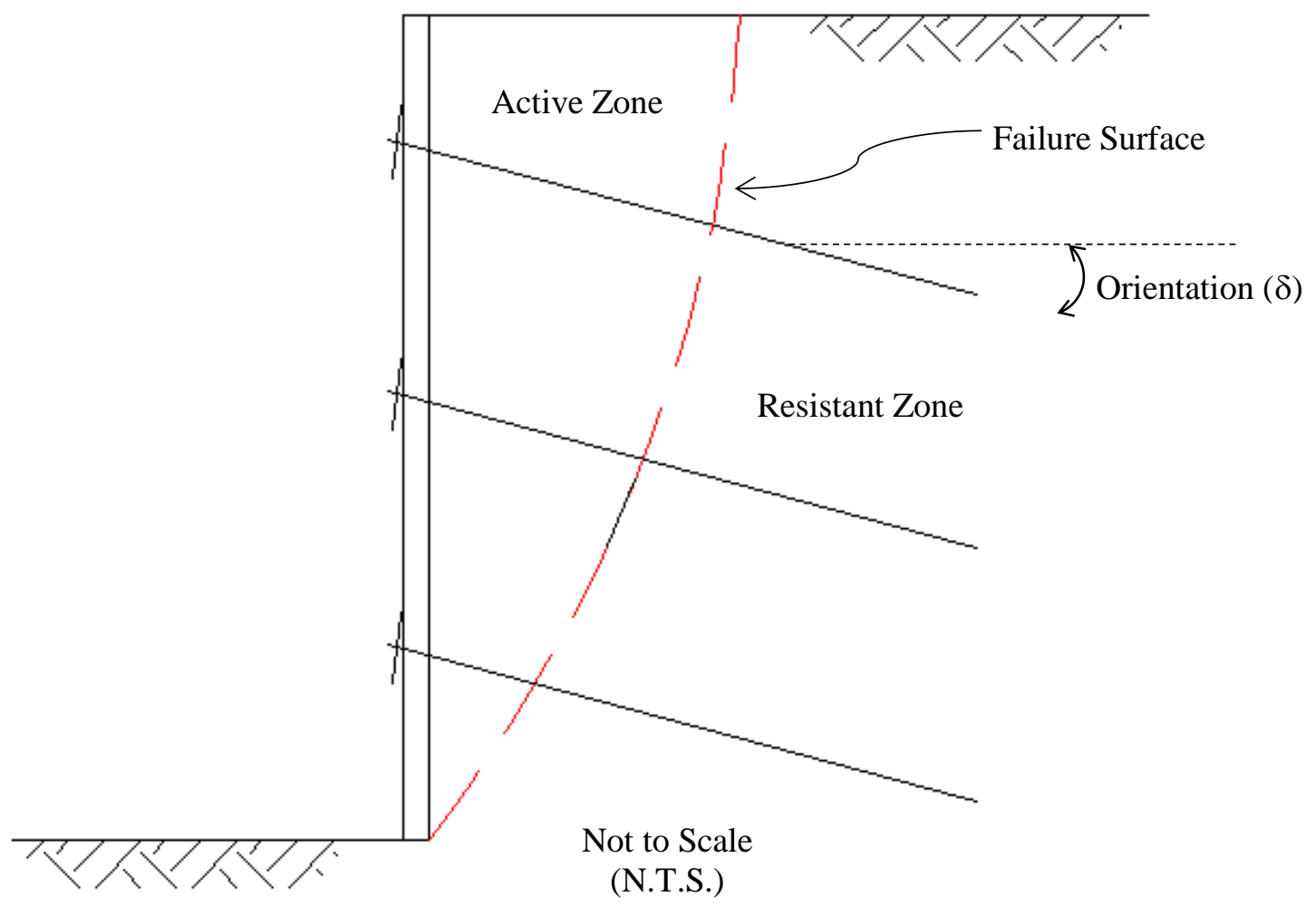

Figure 5.3 Schematic of Soil Nail Intersection with Failure Surface 


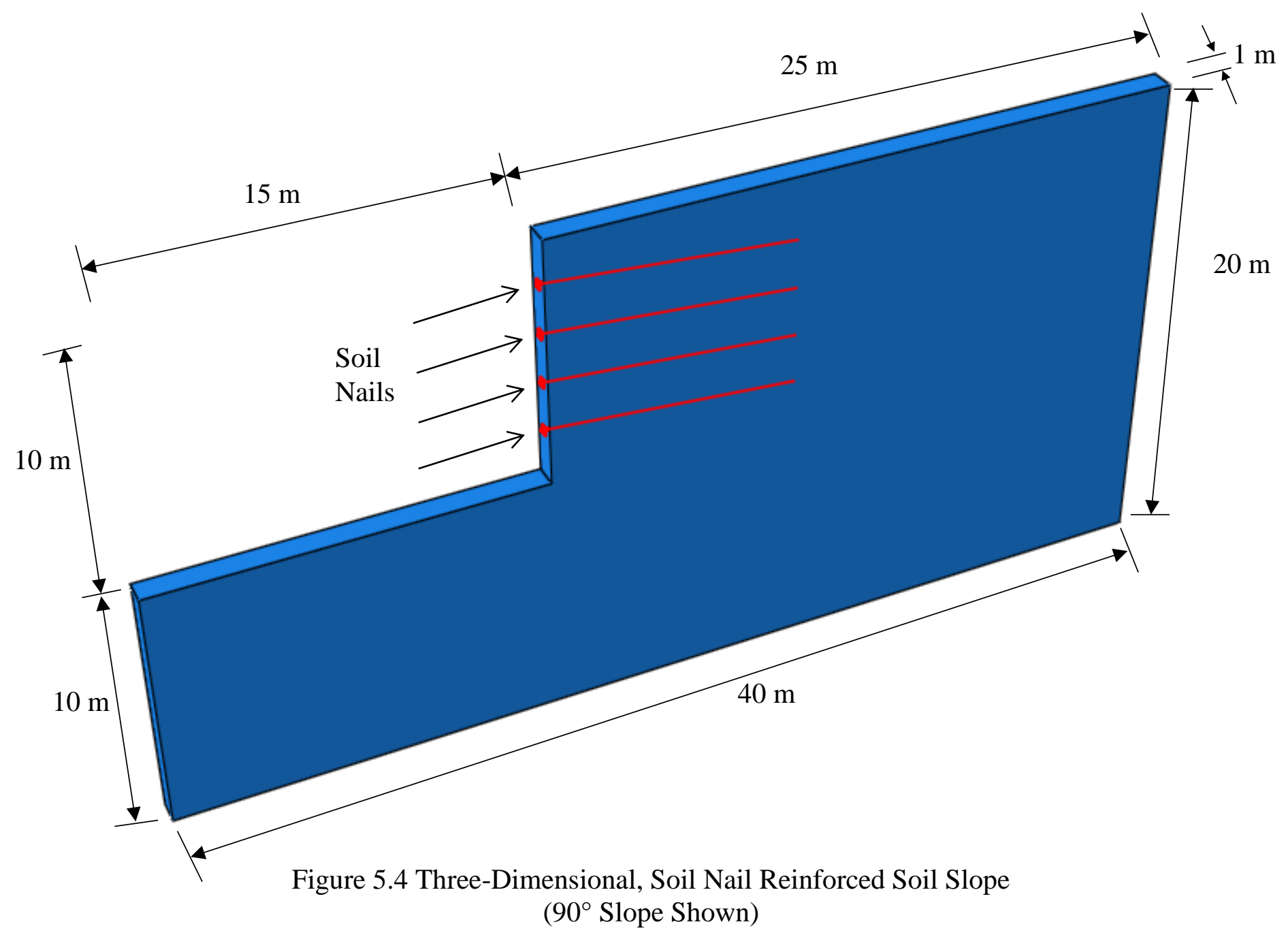

To supplement this study, the computer program SLIDE was used to develop twodimensional, limit-equilibrium models, with equal dimensions, reinforced with soil nails. These models were also completed for slope angles of $90^{\circ}, 80^{\circ}, 70^{\circ}, 60^{\circ}, 50^{\circ}, 40^{\circ}$, and $26.5^{\circ}$. The nails were placed so as to replicate the FEM model(s), for comparative results. Details for the soil nail properties were as presented in Section 4.5 


\subsubsection{Influence of Soil Nail Length (L)}

The influence of soil nail length (L) on the FOS was also evaluated in this study. A 10 meter high $(\mathrm{H})$, three-dimensional slope was developed for various slope angles $(\beta)$ from $90^{\circ}$ down to $26.5^{\circ}$ using Soil 1 (See Figure 5.2). Four soil nails were placed, beginning at a vertical height 2 meters from the base of the slope, at a 2 meter vertical spacing $\left(\mathrm{S}_{\mathrm{V}}\right)$ (See Figure 5.5). In this study, the nail length was varied from 0 (Unreinforced) to 20 meters for each slope angle. The nails were placed at the soil nail orientation that yielded the highest factor of safety ("optimum" soil nail orientation), as determined from the results of the previous study. Table 5.2 presents the soil nail orientations used in this study.

Table 5.2 Optimum Soil Nail Orientation Values for Various Slope Angles

\begin{tabular}{|c|c|}
\hline $\begin{array}{c}\text { Slope Angle } \\
(\boldsymbol{\beta})\end{array}$ & $\begin{array}{c}\text { Optimum } \\
\text { Soil Nail } \\
\text { Orientation } \\
\left(\boldsymbol{\delta}_{\text {OPT. }}\right)\end{array}$ \\
\hline $26.5^{\circ}$ & $35^{\circ}$ \\
\hline $40^{\circ}$ & $34^{\circ}$ \\
\hline $50^{\circ}$ & $25^{\circ}$ \\
\hline $60^{\circ}$ & $18^{\circ}$ \\
\hline $70^{\circ}$ & $15^{\circ}$ \\
\hline $80^{\circ}$ & $10^{\circ}$ \\
\hline
\end{tabular}

\subsubsection{Influence of Vertical Soil Nail Spacing $\left(\mathrm{S}_{\mathrm{V}}\right)$}

The influence of vertical soil nail spacing $\left(\mathrm{S}_{\mathrm{V}}\right)$ on FOS was also investigated in this study. Ten meter long soil nails were placed using the orientations as presented in Table 5.2. The vertical spacing of soil nails was increased from 0.5 meters to 5.0 meters. The first soil nail was placed at a vertical distance of 1.0 meter from the toe of the slope for all 
models. Soil 1 was used for this study and slope angles were once again varied from $90^{\circ}$ to

$26.5^{\circ}$. Figure 5.5 presents the methodology used for this study.

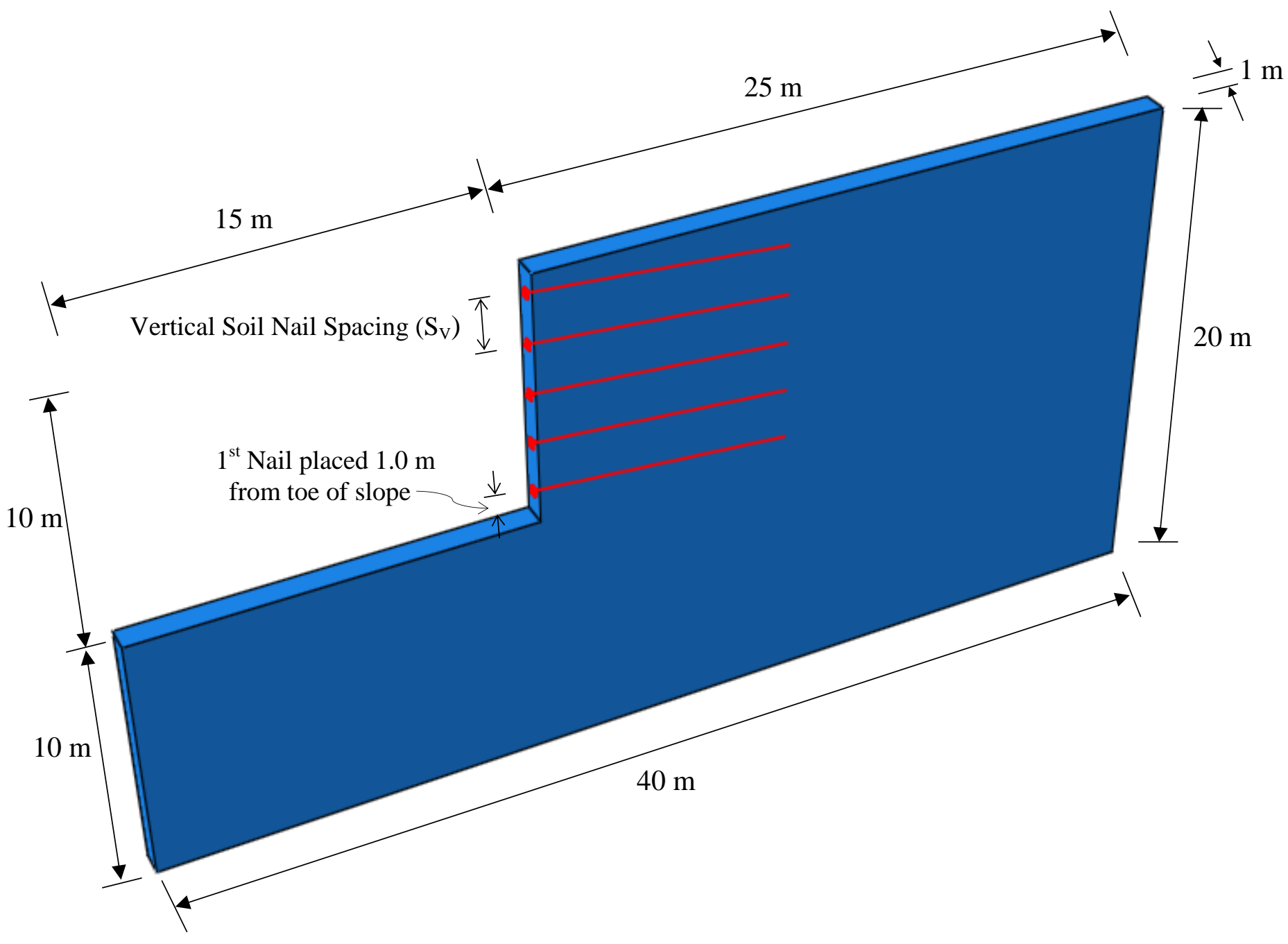

Figure 5.5 Vertical Nail Spacing $\left(\mathrm{S}_{\mathrm{V}}\right)$ Methodology

$\left(90^{\circ}\right.$ Slope Shown with $\left.\mathrm{S}_{\mathrm{V}}=2.0 \mathrm{~m}\right)$

\subsubsection{Influence of Horizontal Soil Nail Spacing $\left(\mathrm{S}_{\mathrm{H}}\right)$}

While two-dimensional modeling is often deemed sufficient, it simply cannot address the concept of horizontal soil nail spacing $\left(\mathrm{S}_{\mathrm{H}}\right)$. This study evaluated the FOS for soil-nailed reinforced slopes considering the horizontal spacing between lines of nails $\left(\mathrm{S}_{\mathrm{H}}\right)$. For this study, five, 10-meter long soil nails were placed along the centerline of the slope 
face using a vertical spacing of 2 meters. The first (lowest) soil nail was placed 1.0 meter vertically from the toe of the slope (See Figure 5.5). Slope angles were varied from $90^{\circ}$ to $50^{\circ}$. For each slope angle studied, the soil nails were placed at the orientations as presented in Table 5.2 and Soil 1 was used.

The horizontal spacing was accomplished by increasing the depth of the model, as previously discussed and as illustrated in Figure 5.1, while the position of the nail "column" remained constant along the centerline of the slope (See Figure 5.6). Due to the symmetrical boundary conditions, as described above, the horizontal nail spacing is equivalent to twice the distance from the centerline of the slope to the edge of the model in the Z-direction (also the depth of the slope in the Z-direction). The horizontal spacing was evaluated from 0.5 meters to 5 meters.

To cover a wider range of soil properties, besides Soil 1, two additional soils ("Soil 2" and "Soil 3"), were evaluated in an attempt to extend the results in this study. The properties of Soils 1, 2, and 3 are presented in Table 5.3.

Table 5.3 Soil Properties used in Horizontal Soil Nail Spacing Study

\begin{tabular}{|c|c|c|c|c|c|c|c|}
\hline Soil & $\begin{array}{c}\text { Yield } \\
\text { Criteria }\end{array}$ & $\begin{array}{c}\text { Unit } \\
\text { Weight } \\
(\gamma)\end{array}$ & $\begin{array}{c}\text { Young's } \\
\text { Modulus } \\
(\mathrm{E})\end{array}$ & $\begin{array}{c}\text { Angle of } \\
\text { Friction } \\
(\phi)\end{array}$ & $\begin{array}{c}\text { Cohesion } \\
(\mathrm{c})\end{array}$ & $\begin{array}{c}\text { Poisson's } \\
\text { Ratio } \\
(\mu)\end{array}$ & $\begin{array}{c}\text { Dilation } \\
\text { Angle } \\
(\psi)\end{array}$ \\
\hline Soil 1 & Mohr-Coulomb & $20.2 \mathrm{kN} / \mathrm{m}^{3}$ & $100,000 \mathrm{kPa}$ & $19.6^{\circ}$ & $3 \mathrm{kPa}$ & 0.3 & $0^{\circ}$ \\
\hline Soil 2 & Mohr-Coulomb & $21.6 \mathrm{kN} / \mathrm{m}^{3}$ & $21,000 \mathrm{kPa}$ & $31^{\circ}$ & $10 \mathrm{kPa}$ & 0.4 & $0^{\circ}$ \\
\hline Soil 3 & Mohr-Coulomb & $15.0 \mathrm{kN} / \mathrm{m}^{3}$ & $2,000 \mathrm{kPa}$ & $18^{\circ}$ & $35 \mathrm{kPa}$ & 0.4 & $0^{\circ}$ \\
\hline
\end{tabular}




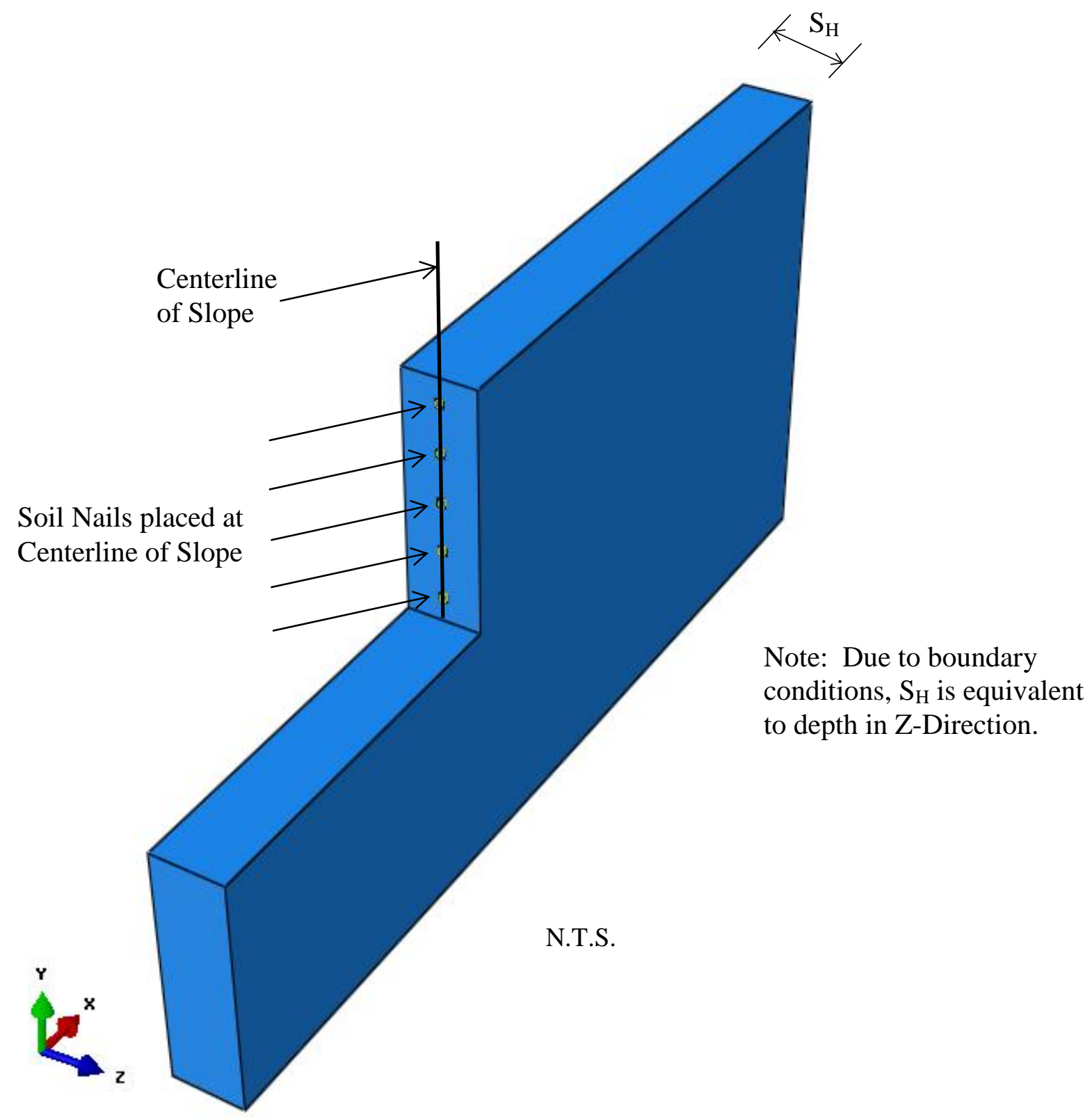

Figure 5.6 Horizontal Nail Spacing $\left(\mathrm{S}_{\mathrm{H}}\right)$ Methodology (90 Slope Shown)

\subsubsection{Horizontal Soil Nail Spacing $\left(\mathrm{S}_{\mathrm{H}}\right)$ - Sensitivity of Soil Properties}

This study investigated the influence of soil properties and horizontal soil nail spacing $\left(\mathrm{S}_{\mathrm{H}}\right)$ on the FOS. Several soil parameters were evaluated separately to identify their contribution, and sensitivity, towards the overall stability of the reinforced slope(s). Among those studied included the Elastic Modulus (E), Poisson's Ratio ( $\mu$ ), Unit Weight $(\gamma)$, 
Cohesion (c), Angle of Friction $(\phi)$, and the Dilation Angle $(\psi)$. The FOS was determined as each of these properties was varied, while the others remained constant. For this study, five, 10-meter long soil nails were placed along the centerline of the slope face using a vertical soil nail spacing $\left(\mathrm{S}_{\mathrm{V}}\right)$ of 2 meters. The first (lowest) soil nail was placed 1.0 meter vertically from the toe of the slope (See Figure 5.5). This study was performed for Soil 1 and a $70^{\circ}$ slope angle. The soil nails were placed at a $15^{\circ}$ orientation.

\subsubsection{Influence of Surcharge Location (x) and Magnitude (q)}

With many soil nailing projects, surcharge loads are frequently present. This study evaluated the influence of the location (x) and magnitude of surcharge loads (q) applied to the top of soil-nailed slopes on the FOS (See Figure 5.2). For this study, five, 10-meter long soil nails were placed using a vertical spacing of 2.0 meters, as presented in Figure 5.5. Slope angles were varied from $90^{\circ}$ to $50^{\circ}$ and the soil nails were placed at the orientations as presented in Table 5.2. Soil 1 was used for all models in this study. From the top of the slope, the surcharge loads were placed at a location (x), beginning with $\mathrm{x}=0$ meters (surcharge load covering the entire top of slope), then at $2 \mathrm{~m}, 4 \mathrm{~m}, 6 \mathrm{~m}, 8 \mathrm{~m}, 10 \mathrm{~m}$, and $15 \mathrm{~m}$, for surcharge magnitudes (q) of $10 \mathrm{kPa}, 50 \mathrm{kPa}, 100 \mathrm{kPa}, 250 \mathrm{kPa}$, and $500 \mathrm{kPa}$.

\subsubsection{Influence of Typical Soil Types}

One of the important factors when assessing the use of soil nails for a project is the type of soil, and associated soil properties. Table 5.4 presents practical upper and lower limits of Mohr-Coulomb soil properties for three types of soils that are suitable for soil nailing applications. These properties were obtained from various sources (Das, 2013; 
McCarthy, 2007; MnDOT, 2007; NAVFAC, 1986). For this model, a 10 meter high (H), three-dimensional soil slope reinforced with soil nails spaced at 1.5 meters horizontally was evaluated. The vertical spacing and soil nail length used were 2.0 meters and 10.0 meters, respectively. The soil nail orientations were as presented in Table 5.2.

For this study, the soil properties listed in Table 5.4 were grouped together in low and high value sets, respectively, in an effort to obtain "soft" and "stiff" conditions. It is understood that this methodology creates soil properties that may be unrealistic for most practical slope problems; however, it should systematically cover the range of soil property combination possibilities that may be encountered. FOS's using the SSR method were determined for slope angles from $90^{\circ}$ to $50^{\circ}$.

Table 5.4 Soil Types and Associated M-C Property Ranges Encountered on Soil Nailing Projects

\begin{tabular}{|c|c|c|c|c|c|}
\hline Soil Type & $\begin{array}{c}\text { Unit Weight } \\
(\gamma) \\
\mathrm{kN} / \mathrm{m}^{3}\end{array}$ & $\begin{array}{c}\text { Elastic Modulus } \\
(\mathrm{E}) \\
\mathrm{kPa}\end{array}$ & $\begin{array}{c}\text { Angle of } \\
\text { Friction } \\
(\phi) \\
\text { degrees }\end{array}$ & $\begin{array}{c}\text { Cohesion } \\
(\mathrm{c}) \\
\mathrm{kPa}\end{array}$ & $\begin{array}{c}\text { Poisson's } \\
\text { Ratio } \\
(\mu)\end{array}$ \\
\hline $\begin{array}{c}\text { Clay } \\
\text { (Soft to Firm) }\end{array}$ & $15.0-21.8$ & $2,000-100,000$ & $18-31^{\circ}$ & $10-35$ & $0.4-0.5$ \\
\hline $\begin{array}{c}\text { Silt } \\
\text { (Soft to Firm) }\end{array}$ & $15.7-19.6$ & $2,000-20,000$ & $18-37^{\circ}$ & $0-20$ & $0.3-0.4$ \\
\hline $\begin{array}{c}\text { Sandy Clay } \\
\text { (Soft to Firm) }\end{array}$ & $15.0-21.8$ & $25,000-250,000$ & $31-34^{\circ}$ & $10-20$ & $0.2-0.4$ \\
\hline
\end{tabular}

\subsubsection{Influence of Rainwater Infiltration on Slope Stability}

In many cases, slopes fail during periods of heavy rainfall. Rainfall infiltration and associated rise in groundwater levels during periods of heavy rainfall cause a decrease in 
soil strength within slopes. Rainfall infiltration also adds to the driving force by increasing the unit weight of soil. An accurate determination of the groundwater condition for most slope stability analysis/projects is paramount, especially where excavations are proposed and soil nailing is involved (Claugue and Stead, 2012; Littlejohn, 1985).

Drained and undrained conditions in soils should be considered to incorporate the effect of groundwater movement within a soil on the shear strength. A drained soil implies a condition under which water is able to flow into or out of a soil in the length of time that the soil is subjected to a change in load, whereby there is no change in the pore water pressure within the soil. In an undrained condition there is a change in the pore water pressure that is equal in magnitude and sign to the change in load (Duncan and Wright, 2005).

The total stress is the same for undrained and drained conditions. Effective stress can be expressed as the total stress minus the pore water pressure. In simple terms, the source of a soil's shear strength comes from the strength of its interparticle bonds, its frictional resistance to sliding, and by its resistance of adjacent particles to resist displacement and reorientation. The magnitude of effective stress relate directly to the shear strength (Mitchell and Soga, 2005).

An overconsolidated soil is one that has been subjected to an effective stress that is higher than the present effective stress. Overconsolidated clays have relatively higher densities and shear strengths than normally consolidated clays as a general rule. Therefore, overconsolidated clay slopes are more stable (Mitchell and Soga, 2005).

Using the Mohr-Coulomb failure criterion, as presented in Equation 3.1, laboratory strength values for a total stress analysis yield an Angle of Friction $(\phi)$ equal to zero with a 
constant shear strength that is equal to the Cohesion intercept (c). Total stress analysis results are independent of the confining pressure. For an effective stress analysis, the strength envelope for normally consolidated clays yields the Cohesion (c) as zero and the Angle of Friction $(\phi)$ is greater than zero. For overconsolidated clays the Cohesion (c) is greater than zero and the Angle of Friction $(\phi)$ is less than the Angle of Friction $(\phi)$ obtained for the normally consolidated test (Liu and Evett, 2008; Das, 2013).

The behavior of a partially saturated soil is primarily governed by the water content and associated degree of saturation. Load changes, which produce changes in the total normal stress, yield unequal changes in the intergranular (effective) stress and the pore water pressure, since some amount of both air and water are present in the void spaces. For soils with degrees of saturation in the range of $70 \%$ and lower, a change in the total stress results in virtually no change in the pore water pressure and the increase comes through a countering increase in the effective stress. When degrees of saturation approach $100 \%$, equilibrium is of course satisfied by the resulting change in the pore water pressure, as previously discussed for undrained conditions (Duncan and Wright, 2005).

Many slopes fail during periods of heavy rainfall. Accurate slope stability analyses/projects must give appropriate consideration to groundwater levels, including the changes incurred by heavy rainfall events. In addition, appropriate laboratory testing for the determination of accurate strength properties, considering both drained and undrained behavior, must be achieved (Littlejohn, 1985).

In order to study the influence of rainwater infiltration on slope stability, a soil's Cohesion (c), Angle of Friction $(\phi)$, and Unit Weight $(\curlyvee)$ must be considered. For this study, a $70^{\circ}$ unreinforced slope was modeled using Soil 1, as presented in Table 3.3. In addition, 
the same $70^{\circ}$ slope was modeled with soil nail reinforcements. Five, 10-meter long soil nails were placed along the centerline of the slope face using a vertical $\left(\mathrm{S}_{\mathrm{V}}\right)$ and horizontal $\left(\mathrm{S}_{\mathrm{H}}\right)$ soil nail spacing of 2 meters and 1.5 meters, respectively. The first (lowest) soil nail was placed 1.0 meter vertically from the toe of the slope. The soil nails were placed at a $15^{\circ}$ orientation. C3D8 linear brick elements using Mohr-Coulomb failure criterion were used for the soil model.

\subsubsection{Pre-Tensioning Soil Nails}

In addition to being an effective method for stabilizing many slopes, soil nails are also used to stabilize deep, vertical excavations adjacent to existing structures (Chow and Tan, 2011). However, traditional soil nailing that employs "passive" inclusions can generally result in vertical and/or horizontal deformations that are unacceptable (Park and Kim, 2006; Choi et. al., 2004). With this in mind, much like soil anchor technology, soil nails can be conventionally installed and then pre-tensioned to reduce deformation (Park and Kim, 2006; Choi et. al., 2004). On projects where deformations must be controlled, a small pre-tensioned force is used to "tighten" the soil nail components and the facing materials.

In this study, pre-tensioned soil nails were modeled by using thermally induced contractions. The steel soil nails were given a coefficient of thermal expansion equal to 1.17 E-5 per degree Celsius (Marotta et. al., 2011). Using the soil nail's cross-sectional area and Elastic Modulus, the induced force at various temperature differentials was determined. The calculations assumed elastic deformation only. The temperatures used equated to forces up to 10 meganewtons $(\mathrm{MN})$. While this magnitude of force is well beyond the practical range for soil nails, it demonstrates the technique used to employ this tool in practice when actual 
steel sizes, steel yield strengths, slope geometries, surcharge location and magnitudes, and other project variables are known.

In this study, a $90^{\circ}, 10$ meter high slope, with dimensions as presented in Figure 5.7, was reinforced with five, 10-meter long soil nails placed using a vertical spacing of 2.0 meters at a $5^{\circ}$ orientation. This reinforced slope was used to evaluate the deformation of a point at the top of the slope (See Figure 5.7). The slope was evaluated with and without a surcharge load. For the surcharge load case, the surcharge magnitude (q) was set equal to $250 \mathrm{kPa}$ to cover the entire top surface $(\mathrm{x}=0)$. Soil 1 was used for all models in this study.

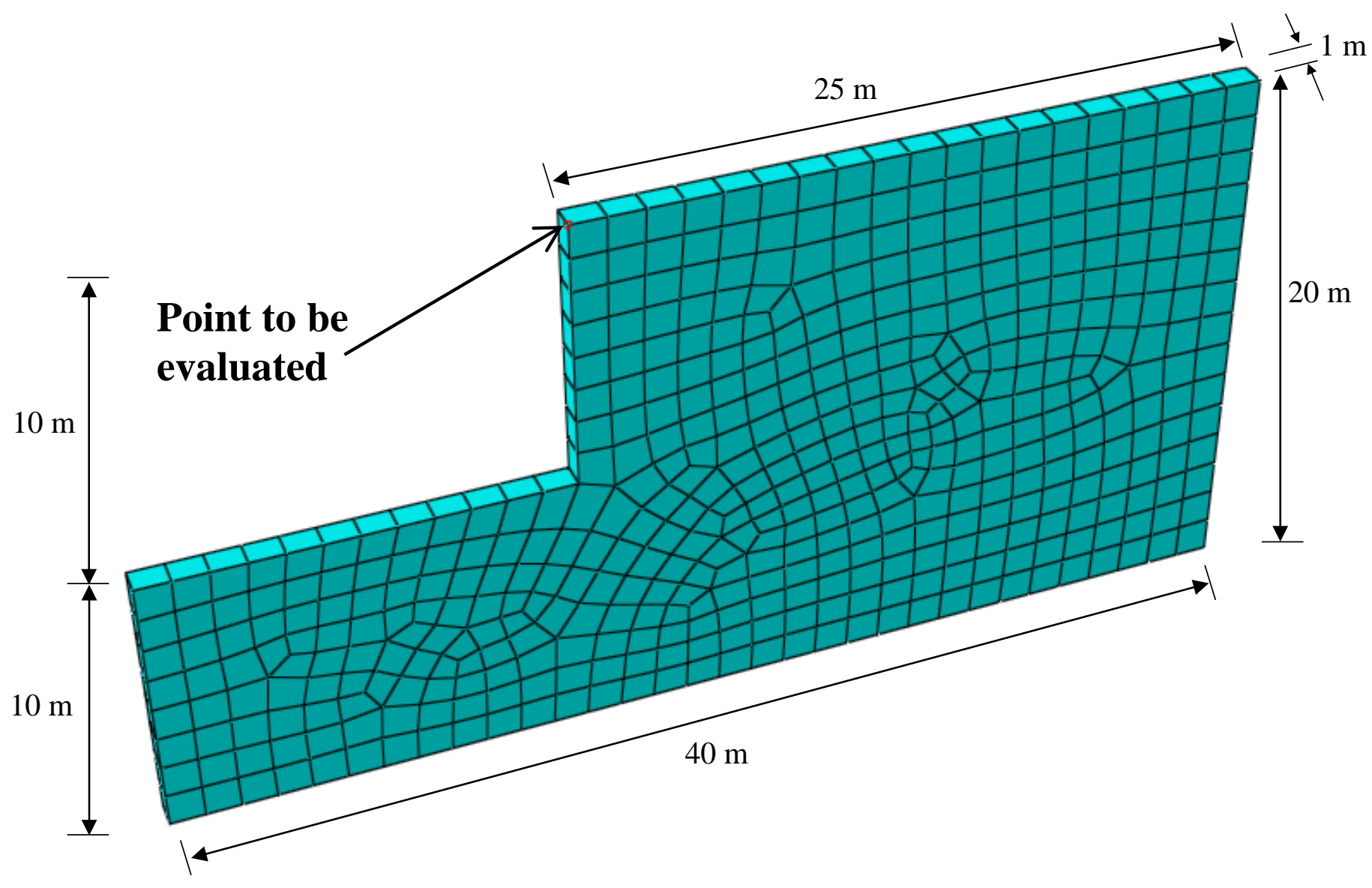

Figure 5.7 Point of Interest for Evaluation of Pre-Tensioned, Soil-nailed Slope 


\subsubsection{Full Slope Modeling}

Perhaps one of the greatest strengths of finite element modeling in civil engineering is its ability to replicate real world conditions, especially when complex site geometries are involved. For many years, conventional geotechnical engineering has used a "worst case", two-dimensional approach for changing or complex site geometries; "worst case" presumably being the two-dimensional slope section that would yield the lowest FOS value. This approach offers no consideration to geometrical irregularities across a site, to "end" conditions, such as slopes that reduce in height or flatten considerably, or to non-planar slopes that change direction (in plan view). This study demonstrates the usefulness of FEM modeling of full slopes, rather than a section selected to represent the "worst case" for the entire slope. Three slopes were evaluated unreinforced and reinforced with soil nails and FOS values were obtained using the SSR method. These results were compared with: 1.) a three-dimensional slope using a FEM, unit-width approach; and 2.) a two-dimensional slope using the Slide (2012), L-E computer program. Both of these comparative slopes were modeled using the "worst case" conditions (i.e. the largest " $H$ " value present). The full, three-dimensional slopes, as well as the FEM, unit-width slope in this study, were modeled using 10-noded quadratic tetrahedral (C3D10) elements. The soil used in this study was selected as a Soft Clay. The specific soil properties are presented in Table 5.5.

The first slope (Full Slope Model No. 1) considered the effect of end conditions for a slope that reduces in height (from $\mathrm{H}=10 \mathrm{~m}$ to $\mathrm{H}=0 \mathrm{~m}$ ) on both sides. This type of slope is common in practice as the site makes an elevation transition. The dimensions are presented in Figure 5.8. The front-face slope angle is $90^{\circ}$ and the side-slopes follow a $1(\mathrm{H}): 1(\mathrm{~V})$ angle. Ten meter long $(\mathrm{L})$ soil nails were placed at 1.5-meter and 2.0-meter horizontal $\left(\mathrm{S}_{\mathrm{H}}\right)$ 
and vertical spacing $\left(\mathrm{S}_{\mathrm{V}}\right)$, respectively. The first row of soil nails were placed at a vertical distance of 1.0 meter vertically from the toe of the slope at an optimum orientation $\left(5^{\circ}\right)$ for a $90^{\circ}$ slope angle.

Table 5.5 Soil Properties Used in Full Slope Modeling Study

\begin{tabular}{|c|c|c|c|c|c|}
\hline$\underline{\text { Soil Type }}$ & $\begin{array}{c}\text { Unit Weight } \\
(\gamma) \\
\mathrm{kN} / \mathrm{m}^{3}\end{array}$ & $\begin{array}{c}\text { Elastic Modulus } \\
(\mathrm{E}) \\
\mathrm{kPa}\end{array}$ & $\begin{array}{c}\text { Angle of } \\
\text { Friction } \\
(\phi) \\
\text { degrees }\end{array}$ & $\begin{array}{c}\text { Cohesion } \\
(\mathrm{c}) \\
\mathrm{kPa}\end{array}$ & $\begin{array}{c}\text { Poisson's } \\
\text { Ratio } \\
(\mu)\end{array}$ \\
\hline Soft Clay & 15.0 & 2,000 & $18^{\circ}$ & 10 & 0.4 \\
\hline
\end{tabular}

The second slope (Full Slope Model No. 2) modeled in this study imitates an elevated site with a rounded, $90^{\circ}$ corner in plan view (see Figure 5.9). Corners are often necessary, depending on site conditions, for efficient site development designs. For this model, a 5.0-meter radius was used on a $90^{\circ}$ slope face, as presented in Figure 5.9. Ten meter long $(\mathrm{L})$ soil nails were placed at 1.5-meter and 2.0-meter horizontal $\left(\mathrm{S}_{\mathrm{H}}\right)$ and vertical spacing $\left(\mathrm{S}_{\mathrm{V}}\right)$, respectively. The first row of soil nails was placed at a vertical distance of 1.0 meter, vertically, from the toe of the slope at an optimum orientation $\left(5^{\circ}\right)$ for a $90^{\circ}$ slope angle. For slopes that turn with relatively small radii, it is often necessary to adjust soil nail construction. Practically, this can be accomplished by either a small translation or orientation offset. These adjustments are also often necessary to avoid underground utility services (e.g. water, sewer, or electrical). For this model a small translational offset was used to avoid soil nail intersections. 
The third slope (Full Slope Model No. 3) modeled in this study also replicates an elevated site with a rounded, $90^{\circ}$ corner in plan view. However, Full Slope Model No. 3 utilizes an overall larger model size and provides a sufficient radius (25.0 meters) to avoid any difficulties associated with the intersection of soil nails. Figure 5.10 presents the model dimensions for Full Slope Model No. 3. It was also modeled unreinforced and reinforced with soil nails. The other modeling parameters, including the soil-nailing details, are identical to those described for Full Slope Model No. 2.

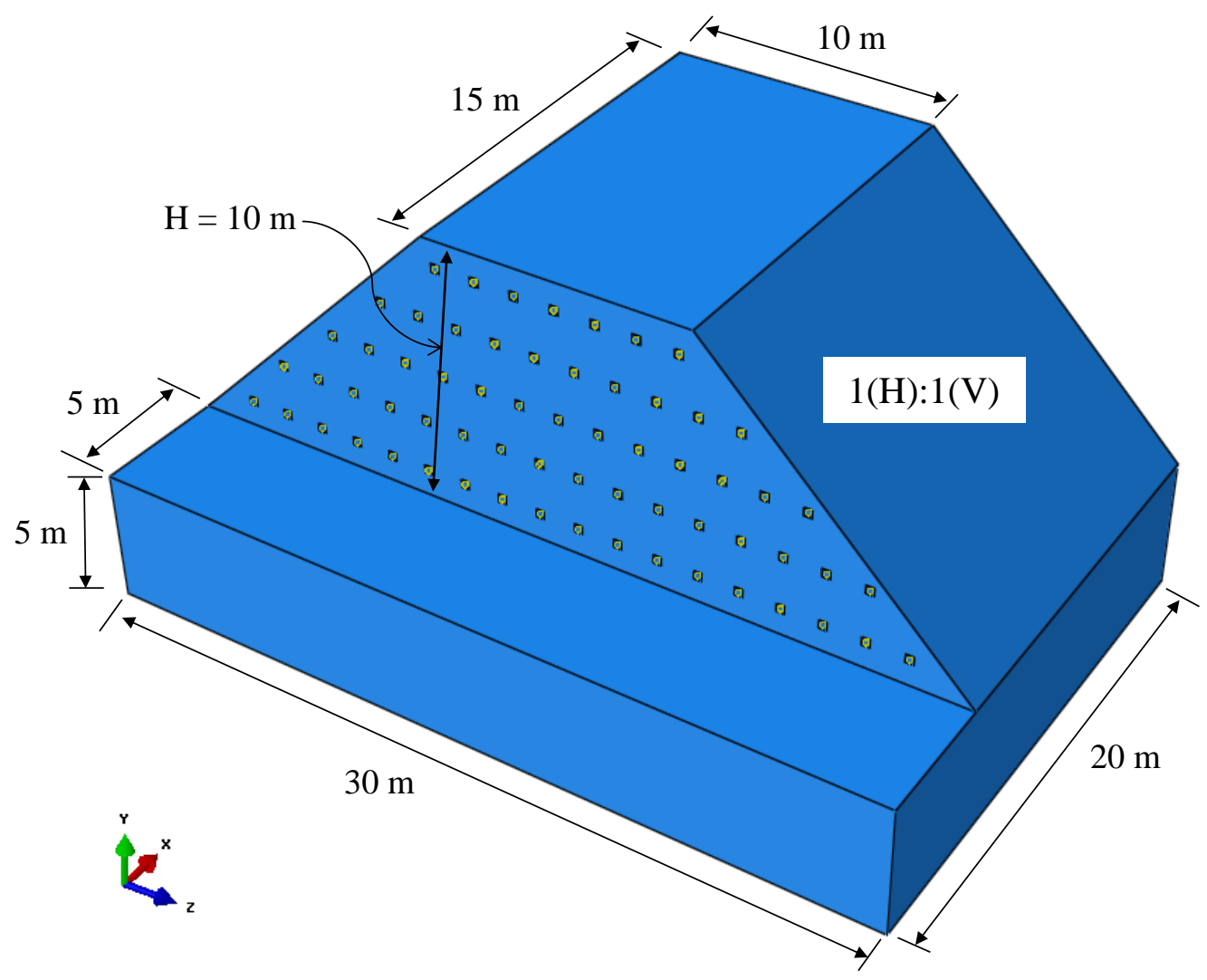

Figure 5.8 Full Slope Model No. 1 (Effect of End Conditions) 


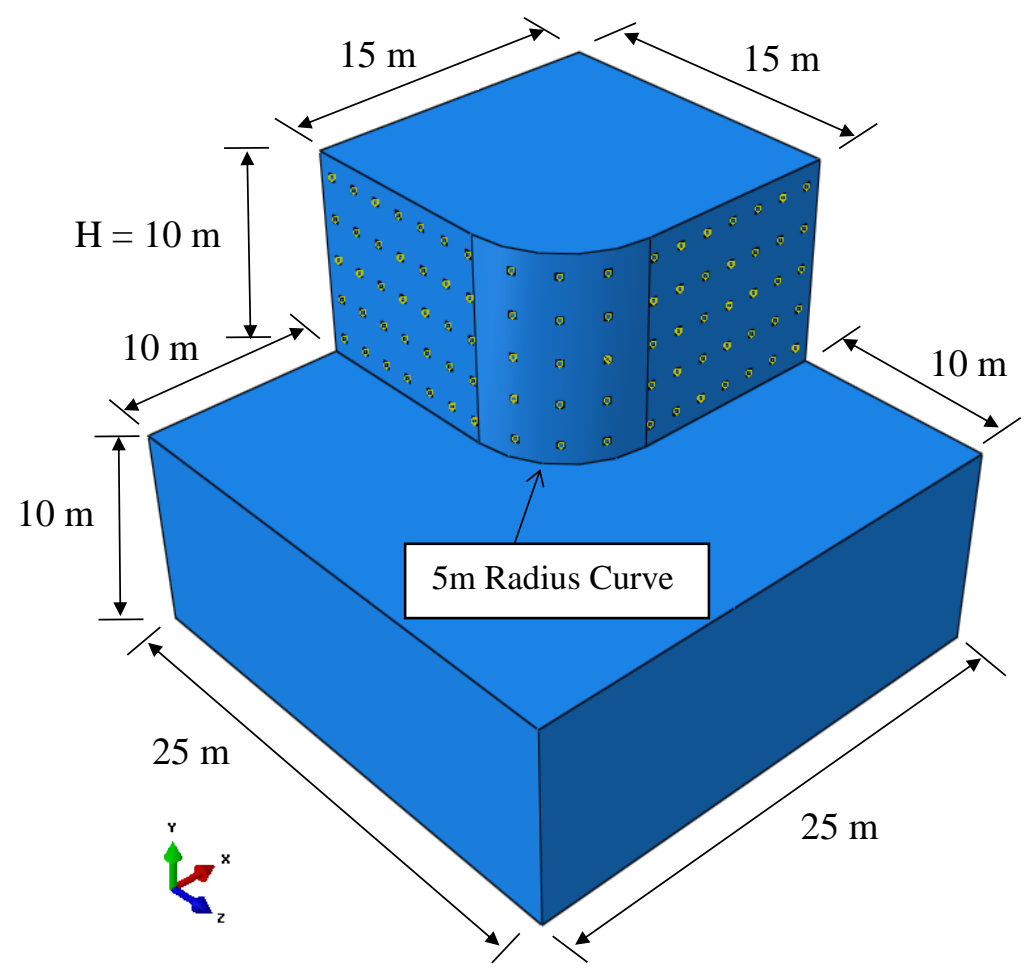

Figure 5.9 Full Slope Model No. 2 (Non-Planar, $90^{\circ}$ Corner, 5-meter Radius)

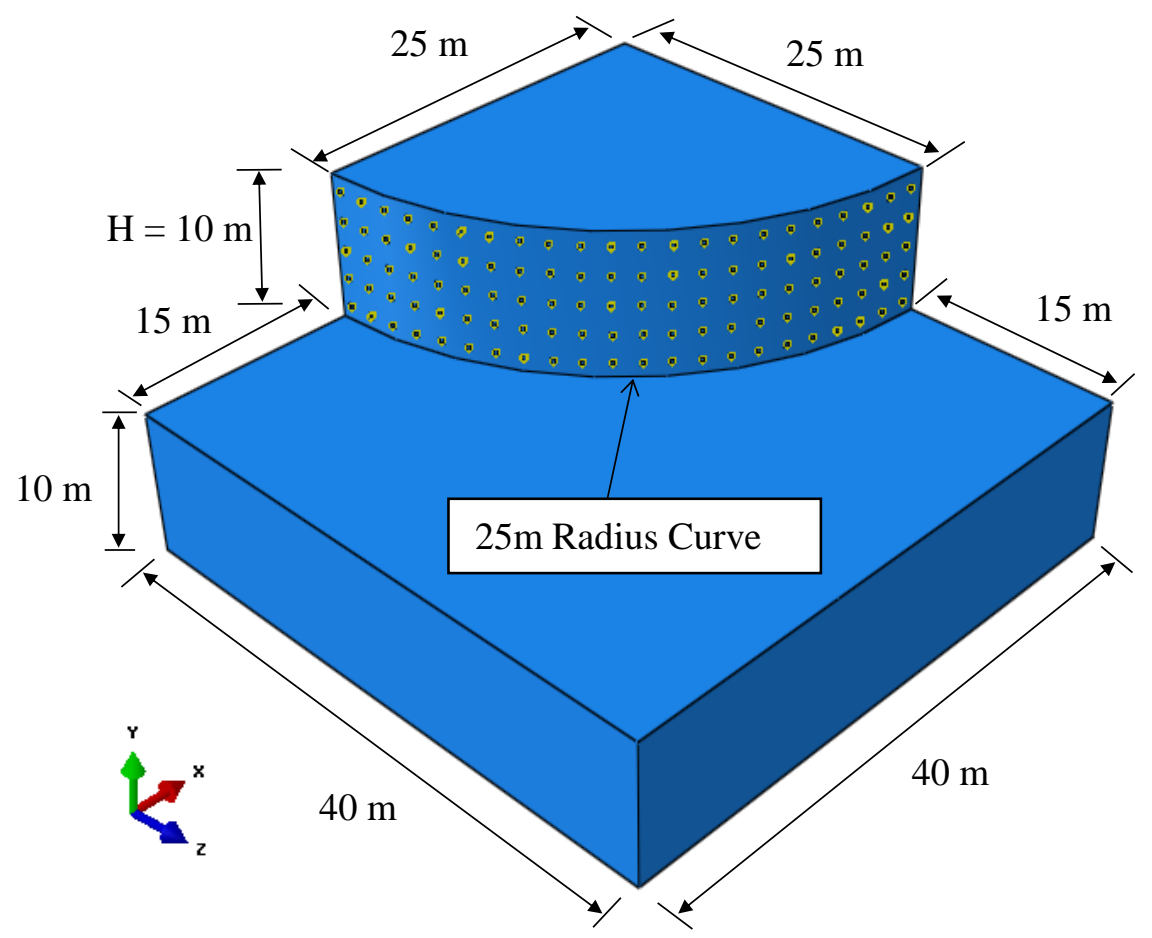

Figure 5.10 Full Slope Model No. 3 (Non-Planar, 90 Corner, 25-meter Radius) 


\section{CHAPTER 6: TWO-DIMENSIONAL MODELING RESULTS AND DISCUSSIONS}

\subsection{Introduction}

This study was used to evaluate the stability of both unreinforced and reinforced slopes using a two-dimensional FEM approach. The FOS was determined using the Shear Strength Reduction (SSR) method, as discussed in Section 3.9, for all the two-dimensional models. Some results for unreinforced and reinforced slopes were compared to currently accepted LimitEquilibrium (L-E) approaches, and where possible, to previously published work.

\subsection{Two-Dimensional Unreinforced Slopes}

Two-dimensional slopes were studied for both unreinforced and reinforced slopes in order to compare results to previous studies. Both FEM and L-E models were completed on a $26.5^{\circ}[2(\mathrm{H}): 1(\mathrm{~V})]$, benchmark slope (See Figure 4.1). This slope has been investigated by Wanstreet (2007) and Griffiths and Lane (1999). In addition, this research investigated the selection of finite element types in two-dimensional FEM modeling.

As previously stated, the two-dimensional slope modeling of Wanstreet (2007) was continued in this study. The starting point was the redevelopment of the two-dimensional, $26.5^{\circ}[2(\mathrm{H}): 1(\mathrm{~V})]$ unreinforced, benchmark slope. The slope was modeled by using 6-noded modified quadratic plane strain triangular (CPE6M) elements with Mohr-Coulomb yielding criteria soil properties as presented in Table 3.3. Figures 6.1 and 6.2 below present the results of the deformed mesh and the equivalent plastic strain contours (PEEQ), respectively. These results match those of Wanstreet (2007) and Griffiths and Lane (1999), resulting in a FOS value equal to 1.00 . 


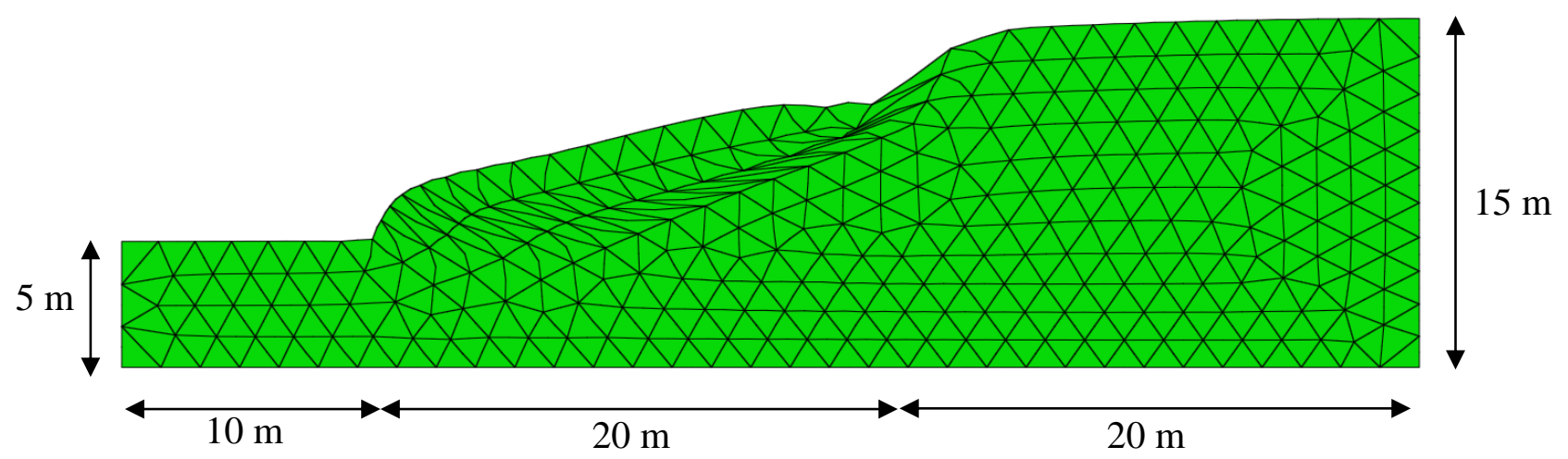

Figure 6.1 Deformed Mesh for Two-Dimensional Benchmark Model

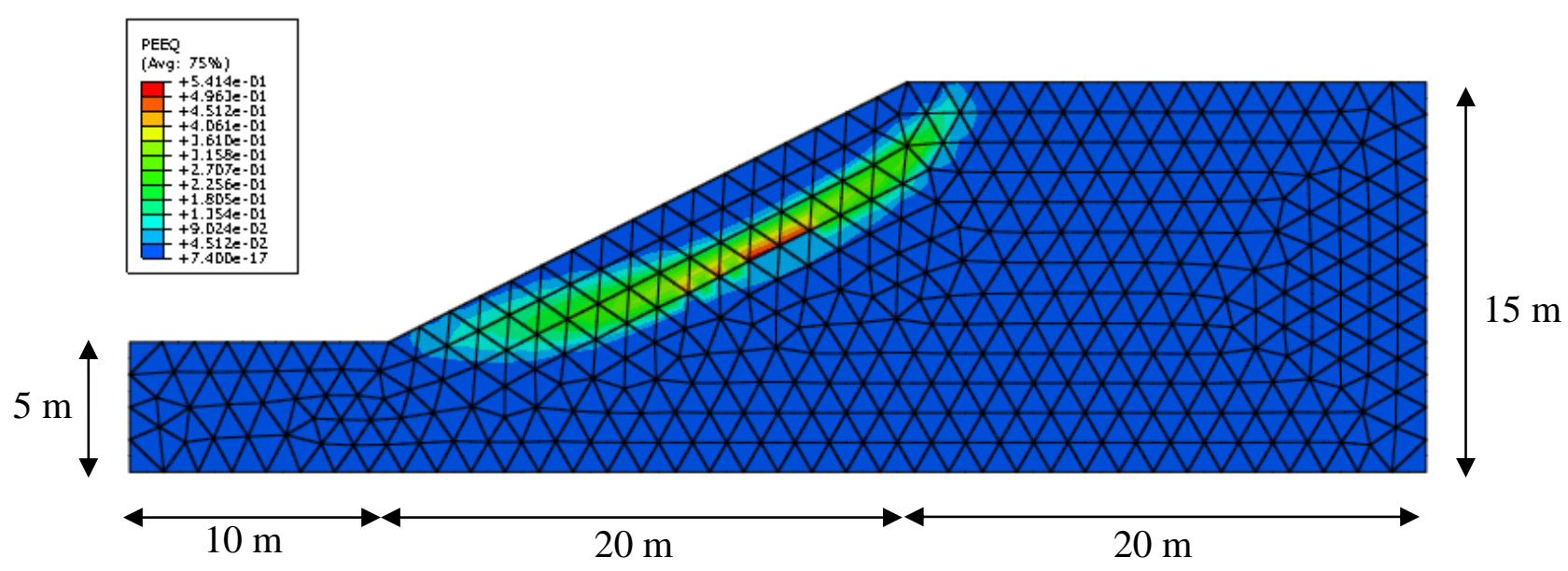

Figure 6.2 PEEQ Contours for Two-Dimensional Benchmark Model

Additional slope angles of $50^{\circ}, 60^{\circ}, 70^{\circ}, 80^{\circ}$, and $90^{\circ}$ were also modeled using twodimensional FEM. The resulting FOS values for each slope angle is presented in Table 6.1. As evident from Table 6.1, the FOS results using two-dimensional FEM closely match the results using two-dimensional L-E methods.

\subsection{Two-Dimensional Limit Equilibrium Results for Unreinforced Slopes}

Two-dimensional, L-E analyses are routinely performed and the results are generally accepted in geotechnical practice. In this study, two-dimensional L-E results were used for 
comparison to two- and three-dimensional FEM modeling results. Unreinforced slope angles of $26.5^{\circ}, 50^{\circ}, 60^{\circ}, 70^{\circ}, 80^{\circ}$, and $90^{\circ}$ were modeled. Table 6.1 presents the results for comparison with two-dimensional FEM. In addition, for easy comparison to two- and threedimensional FEM, the resulting FOS values, PEEQ plots (FEM) and failure circles (L-E), along with the discussion, are contained in Section 7.4 and within Figures 7.46 through 7.63.

Table 6.1 FOS Results for Two-Dimensional FEM and L-E Models

\begin{tabular}{|c|c|c|}
\hline $\begin{array}{c}\text { Slope Angle } \\
(\boldsymbol{\beta})\end{array}$ & $\begin{array}{c}\text { 2-D FEM } \\
\text { FOS }\end{array}$ & $\begin{array}{c}\text { 2-D L-E } \\
\text { FOS }\end{array}$ \\
\hline $26.5^{\circ}$ & 1.00 & 0.99 \\
\hline $50^{\circ}$ & 0.55 & 0.54 \\
\hline $60^{\circ}$ & 0.45 & 0.43 \\
\hline $70^{\circ}$ & 0.38 & 0.38 \\
\hline $80^{\circ}$ & 0.30 & 0.29 \\
\hline $90^{\circ}$ & 0.23 & 0.18 \\
\hline
\end{tabular}

\subsection{Two-Dimensional Finite Element Type Study}

Sixteen different element types were used to model the geometry and soil properties for the benchmark problem. The primary goal of this analysis was to determine the most efficient and accurate element type(s) that generated an acceptable circular failure surface. Efficiency was determined by the amount of time it took to process the model. Accuracy was measured by the proximity of the FOS to 1.00 , and the decision for acceptance of the failure circle was primarily based on the position of the failure "zone" with respect to the previously performed benchmark model results (Wanstreet, 2007; Griffiths and Lane, 1999), as compared using the PEEQ visualization plots. 
Using the sixteen available element options in Abaqus (2011), models were created and evaluated that utilized both the Mohr-Coulomb and Drucker-Prager soil yielding criteria, as presented in Table 3.3 and Table 3.4, respectively. The results of the twodimensional Mohr-Coulomb models are presented in Table 6.2. The results of the twodimensional Drucker-Prager models are presented in Table 6.3. Within these tables, the processing time $\left(\mathrm{t}_{\mathrm{CPU}}\right)$ and percentage completion are associated with the $\mathrm{FOS}(\mathrm{s})$ presented. Likewise are the PEEQ visualization plots presented in Figures 6.3 through 6.18 and Figures 6.19 through 6.34, for Mohr-Coulomb and Drucker-Prager models, respectively. The PEEQ visualization plots were developed using Abaqus (2011) default values for Deformation Factor and PEEQ color contour limits for each model. The computer used for this study was a Dell Optiplex 790, Intel ${ }^{\circledR}$ Core $^{\mathrm{TM}}$ i7-2600 CPU @ 3.40 GigaHertz (GHz) with 4.00 Gigabytes (GB) of Installed memory (RAM).

\subsubsection{Comparison of Element Types for Two-Dimensional Mohr-Coulomb Failure Models}

For the Mohr-Coulomb models, the CPE3 group provided the fastest results that yielded a reasonably acceptable failure surface (Figures 6.3 and 6.4); however, the accuracy proved to be poor. For the purpose of this study, a "group" refers to all the element choices of the same basic element type. The FOS for both the CPE3 and the CPE3H element models was 1.23 .

The CPE4 group was efficient, with processing speeds of $\leq 7.0$ seconds. Element types CPE4, CPE4H, CPE4R and CPE4RH also generated accurate FOS's (0.98 to 1.03) and an acceptable failure surface (See Figures 6.5 to 6.8). From Figure 6.9 and 6.10, it is 
clear that neither of the last two elements types in this group, CPE4I and CPE4IH, produced acceptable failure surfaces, although the FOS for the CPE4I element type was 0.95.

The CPE6 group (Figures 6.11 to 6.14), except for the CPE6MH model, all produced acceptable failure surfaces and accurate results, as FOS's ranged from 0.97 to 1.00 . In addition, this entire group generated these results in 9.0 to 22.3 seconds. The CPE6MH model did not generate an acceptable failure surface.

None of the 4 slopes modeled with the CPE8 group yielded an acceptable failure surface (See Figures 6.15 through 6.18), and processing times and FOS's were scattered. Processing times ranged from 19.0 to 44.4 seconds and FOS's ranged from 0.71 to 0.97 .

From this study, using the Mohr-Coulomb failure criteria, the element types that proved to be most efficient, accurate, and produce an acceptable failure surface included element types from the CPE4 and CPE6 groups. Specifically, the CPE4, CPE4H, and the CPE6M (of which the benchmark model with a FOS $=1.00$ was based upon) element types performed very well in all aspects considered.

\subsubsection{Comparison of Element Types for Two-Dimensional Drucker-Prager Failure Models}

For the Drucker-Prager models, the CPE3 group once again provided the fastest processing times, only requiring 1.7 and 1.9 seconds for the $\mathrm{CPE} 3$ and $\mathrm{CPE} 3 \mathrm{H}$ element models, respectively. Further, the accuracy provided FOS's of 0.97 ; however, the generated failure surfaces were not acceptable (Figures 6.19 and 6.20).

The CPE4 group had mixed results (See Figures 6.21 through 6.26). While the entire group, except for the CPE4I and CPE4IH element models, exhibited acceptable failure surfaces, the CPE4R and CPE4RH models were inaccurate, with FOS's of 1.37. The 
CPE4 and CPE4H element models did perform well in all areas. They processed in 3.5 and 3.8 seconds, respectively, and both yielded a FOS equal to 0.96 .

As is evident from the information in the table below, the CPE6 group performed well against all three selection criteria. All of the failure surfaces were acceptable (See Figures 6.27 through 6.30). The FOS's were accurate, ranging from 0.94 to 0.98 , and the processing speeds were all below 8.9 seconds.

The CPE8 group generated mixed results (Figures 6.31 through 6.34). The CPE8 and CPE8R element models yielded processing times of 3.2 and 6.2 seconds, respectively, with reasonably accurate FOS's of 0.94 and 0.93 . In addition, they both exhibited acceptable failure surfaces. The $\mathrm{CPE} 8 \mathrm{H}$ and $\mathrm{CPE} 8 \mathrm{RH}$ models yielded long processing times, inaccurate results and unacceptable failure surfaces.

Using the Drucker-Prager yielding criteria, the CPE6 group performed best overall. Specifically, the CPE6, CPE6H, CPE6M, and the CPE6MH element types performed well. Once again, the CPE4 and CPE4H element types also performed very well, being the most efficient, with accurate and acceptable results.

From the results of this two-dimensional FEM element type study on an unreinforced slope, including both Mohr-Coulomb and Drucker-Prager yielding criteria, the CPE4 and CPE4H element types provide the most efficient, accurate and acceptable results. In addition, the differences between the results for Mohr-Coulomb and Drucker-Prager for most element types are negligible.

Element types were also compared using uniform Deformation Factors and PEEQ contour limits. This was performed for select elements using Mohr-Coulomb and DruckerPrager yielding criteria. The results of this study are presented in Appendix A. 
Table 6.2 Comparison of Two-Dimensional Element Type for Mohr-Coulomb Model

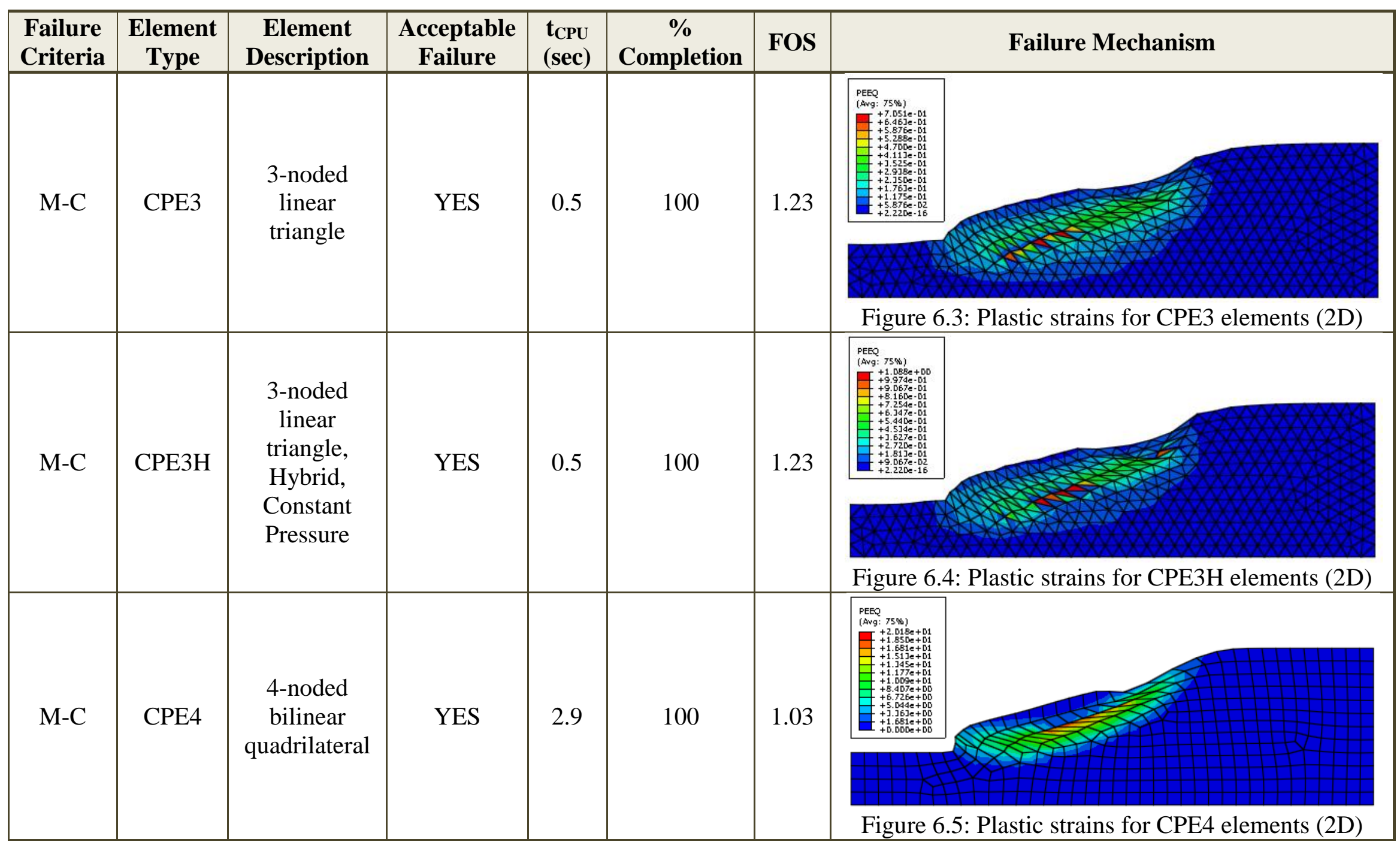


Table 6.2 (Continued)

\begin{tabular}{|c|c|c|c|c|c|c|c|}
\hline $\begin{array}{l}\text { Failure } \\
\text { Criteria }\end{array}$ & $\begin{array}{c}\text { Element } \\
\text { Type }\end{array}$ & $\begin{array}{c}\text { Element } \\
\text { Description }\end{array}$ & $\begin{array}{c}\text { Acceptable } \\
\text { Failure }\end{array}$ & $\begin{array}{l}\mathbf{t}_{\mathrm{CPU}} \\
(\mathrm{sec})\end{array}$ & $\begin{array}{c}\% \% \\
\text { Completion }\end{array}$ & FOS & Failure Mechanism \\
\hline $\mathrm{M}-\mathrm{C}$ & CPE4H & $\begin{array}{c}\text { 4-noded } \\
\text { Bilinear } \\
\text { Quadrilateral, } \\
\text { Hybrid, } \\
\text { Constant } \\
\text { Pressure }\end{array}$ & YES & 3.0 & 100 & 1.01 & 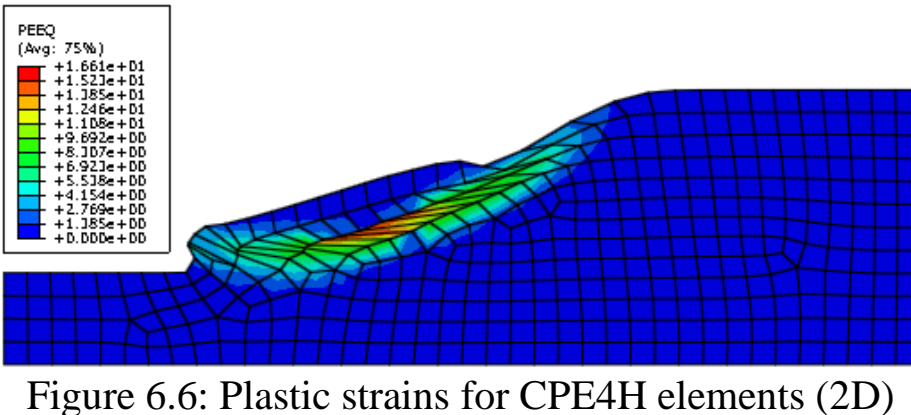 \\
\hline $\mathrm{M}-\mathrm{C}$ & CPE4R & $\begin{array}{c}\text { 4-noded } \\
\text { Bilinear } \\
\text { Quadrilateral, } \\
\text { Reduced } \\
\text { Integration, } \\
\text { Hourglass } \\
\text { Control }\end{array}$ & YES & 6.6 & 91.5 & 0.98 & 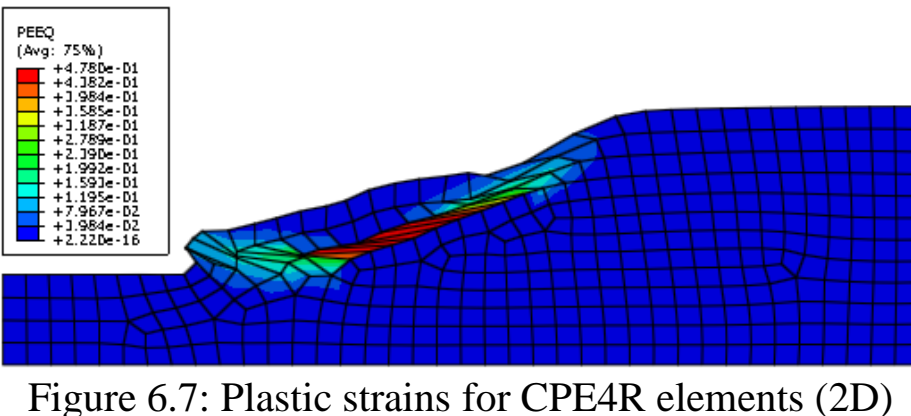 \\
\hline $\mathrm{M}-\mathrm{C}$ & CPE4RH & $\begin{array}{c}\text { 4-noded } \\
\text { Bilinear } \\
\text { Quadrilateral, } \\
\text { Hybrid, } \\
\text { Constant } \\
\text { Pressure, } \\
\text { Reduced } \\
\text { Integration } \\
\text { Hourglass } \\
\text { Control }\end{array}$ & YES & 6.0 & 90.9 & 0.98 & 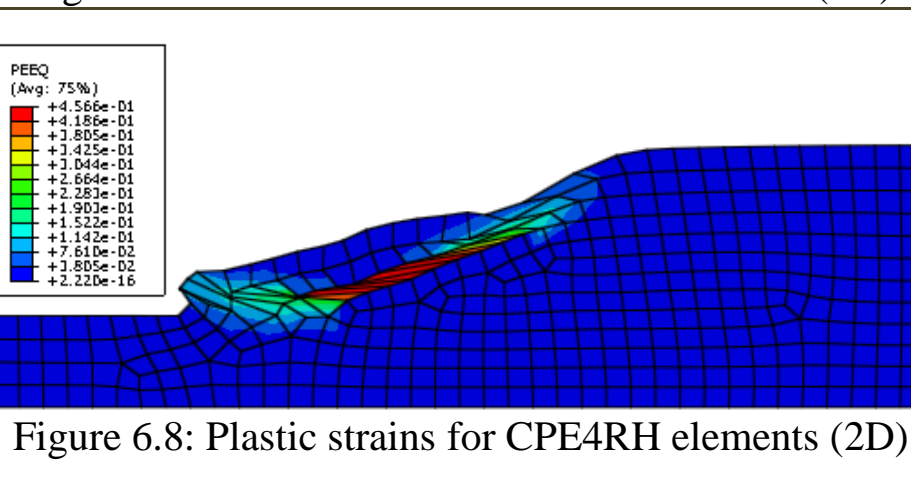 \\
\hline
\end{tabular}


Table 6.2 (Continued)

\begin{tabular}{|c|c|c|c|c|c|c|c|}
\hline $\begin{array}{l}\text { Failure } \\
\text { Criteria }\end{array}$ & $\begin{array}{c}\text { Element } \\
\text { Type }\end{array}$ & $\begin{array}{c}\text { Element } \\
\text { Description }\end{array}$ & $\begin{array}{c}\text { Acceptable } \\
\text { Failure }\end{array}$ & $\begin{array}{l}\mathbf{t}_{\mathrm{CPU}} \\
(\mathrm{sec})\end{array}$ & $\begin{array}{c}\% \\
\text { Completion }\end{array}$ & FOS & Failure Mechanism \\
\hline $\mathrm{M}-\mathrm{C}$ & CPE4I & $\begin{array}{c}\text { 4-noded } \\
\text { Bilinear } \\
\text { Quadrilateral, } \\
\text { Incompatible } \\
\text { Modes }\end{array}$ & $\mathrm{NO}$ & 7.0 & 68.4 & 0.95 & 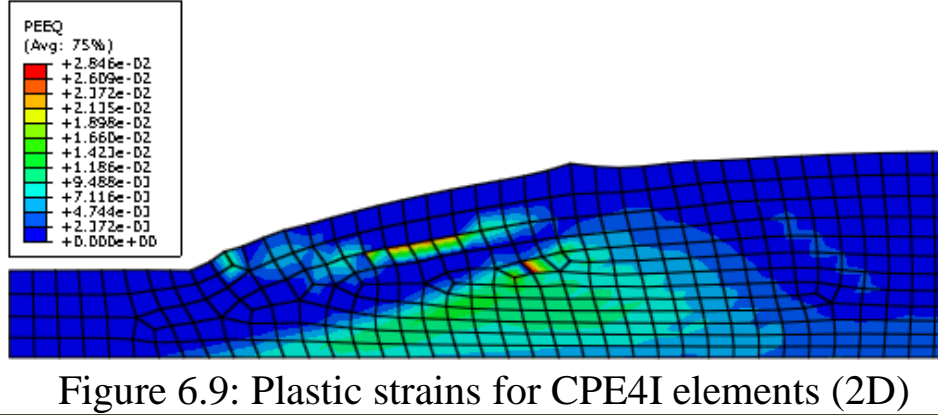 \\
\hline $\mathrm{M}-\mathrm{C}$ & CPE4IH & $\begin{array}{l}\text { 4-noded } \\
\text { Bilinear } \\
\text { Quadrilateral, } \\
\text { Hybrid, } \\
\text { Linear } \\
\text { Pressure, } \\
\text { Incompatible } \\
\text { Modes }\end{array}$ & NO & 6.6 & 15.6 & 0.66 & 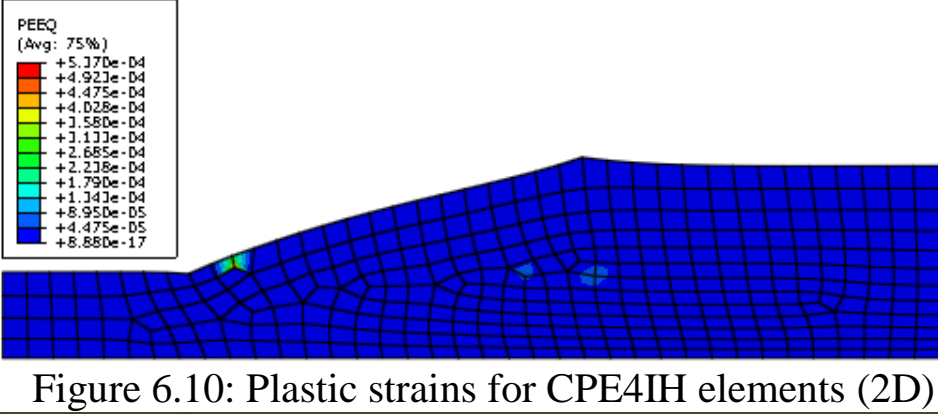 \\
\hline $\mathrm{M}-\mathrm{C}$ & CPE6 & $\begin{array}{l}\text { 6-noded } \\
\text { Quadratic } \\
\text { Triangle }\end{array}$ & YES & 12.6 & 89.2 & 0.97 & 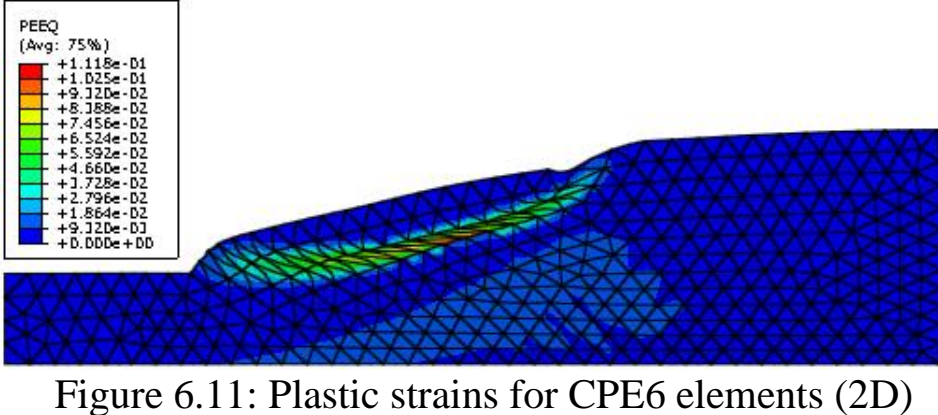 \\
\hline
\end{tabular}


Table 6.2 (Continued)

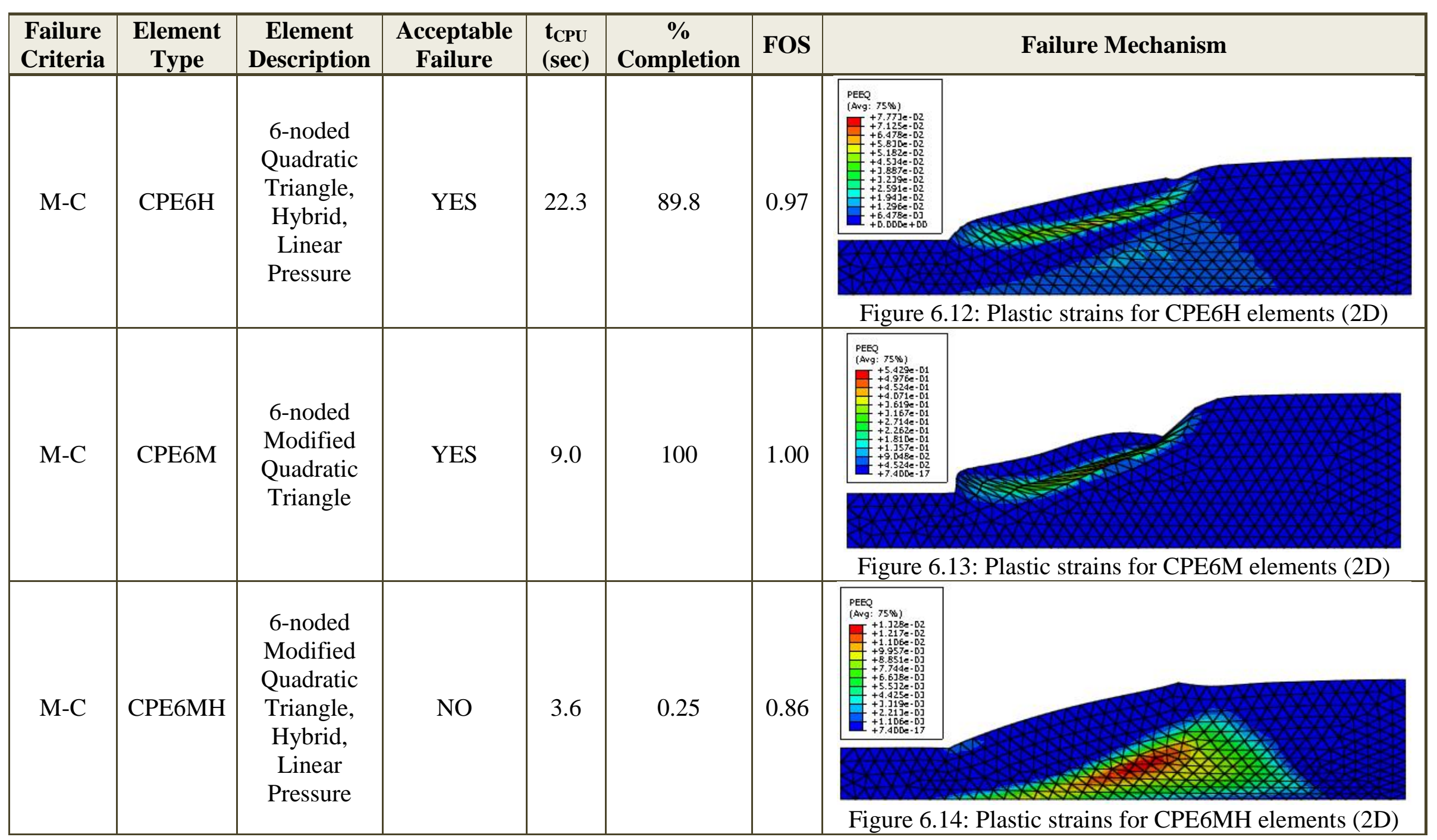


Table 6.2 (Continued)

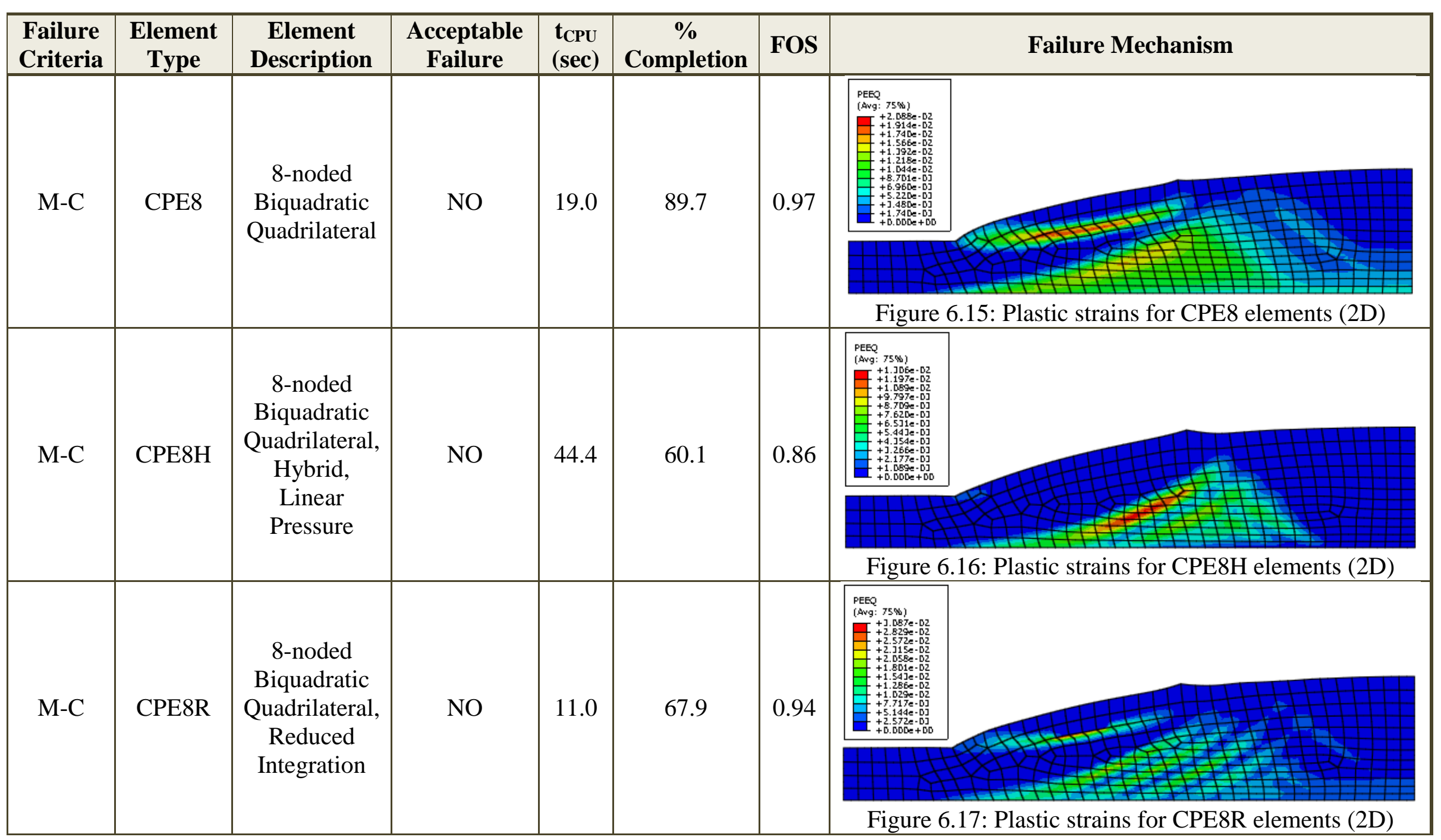


Table 6.2 (Continued)

\begin{tabular}{|c|c|c|c|c|c|c|c|c|}
\hline $\begin{array}{l}\text { Failure } \\
\text { Criteria }\end{array}$ & $\begin{array}{c}\text { Element } \\
\text { Type }\end{array}$ & $\begin{array}{c}\text { Element } \\
\text { Description }\end{array}$ & $\begin{array}{c}\text { Acceptable } \\
\text { Failure }\end{array}$ & $\begin{array}{l}\mathbf{t}_{\mathrm{CPU}} \\
(\mathrm{sec})\end{array}$ & $\begin{array}{c}\% \\
\text { Completion }\end{array}$ & FOS & & Failure Mechanism \\
\hline $\mathrm{M}-\mathrm{C}$ & CPE8RH & $\begin{array}{c}\text { 8-noded } \\
\text { Biquadratic } \\
\text { Quadrilateral, } \\
\text { Hybrid, } \\
\text { Linear } \\
\text { Pressure, } \\
\text { Reduced } \\
\text { Integration }\end{array}$ & NO & 33.9 & 36.1 & 0.71 & 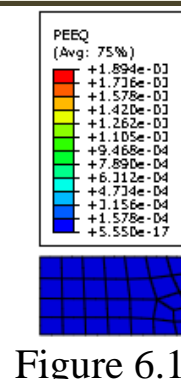 & Plastic strains for CPE8RH elements (2D) \\
\hline
\end{tabular}


Table 6.3 Comparison of Two-Dimensional Element Type for Drucker-Prager Model

\begin{tabular}{|c|c|c|c|c|c|c|c|}
\hline $\begin{array}{l}\text { Failure } \\
\text { Criteria }\end{array}$ & $\begin{array}{c}\text { Element } \\
\text { Type }\end{array}$ & $\begin{array}{c}\text { Element } \\
\text { Description }\end{array}$ & $\begin{array}{c}\text { Acceptable } \\
\text { Failure }\end{array}$ & $\begin{array}{l}\mathbf{t}_{\mathrm{CPU}} \\
(\mathrm{sec})\end{array}$ & $\begin{array}{c}\% \\
\text { Completion } \\
\end{array}$ & FOS & Failure Mechanism \\
\hline D-P & CPE3 & $\begin{array}{l}\text { 3-noded } \\
\text { linear } \\
\text { triangle }\end{array}$ & NO & 1.7 & 84.8 & 0.97 & 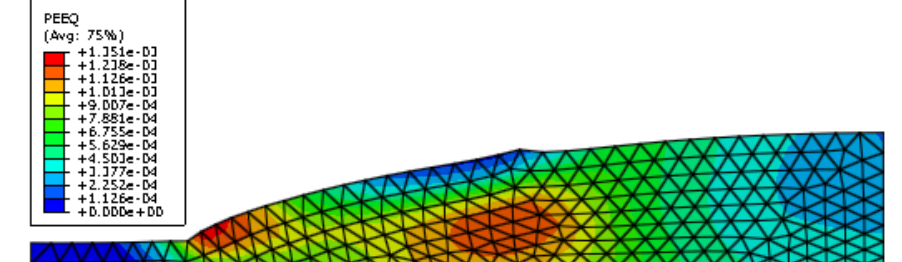 \\
\hline & & & & & & & Figure 6.19: Plastic strains for CPE3 elements (2D) \\
\hline D-P & CPE3H & $\begin{array}{c}\text { 3-noded } \\
\text { linear } \\
\text { triangle, } \\
\text { Hybrid, } \\
\text { Constant } \\
\text { Pressure }\end{array}$ & NO & 1.9 & 84.8 & 0.97 & 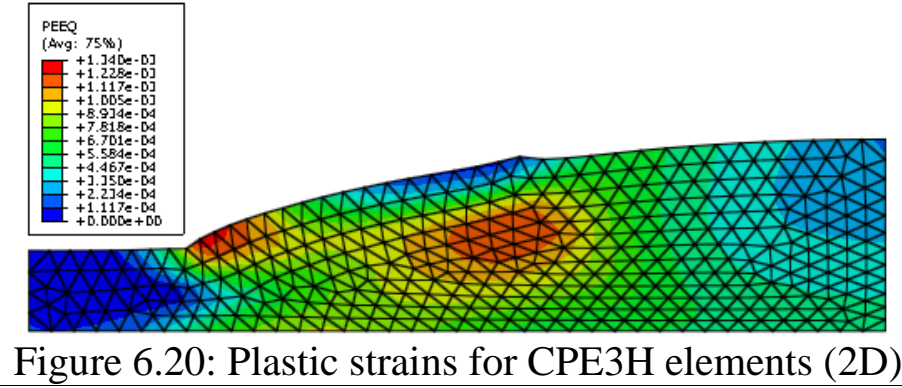 \\
\hline D-P & CPE4 & $\begin{array}{l}\text { 4-noded } \\
\text { bilinear } \\
\text { quadrilateral }\end{array}$ & YES & 3.5 & 75.2 & 0.96 & 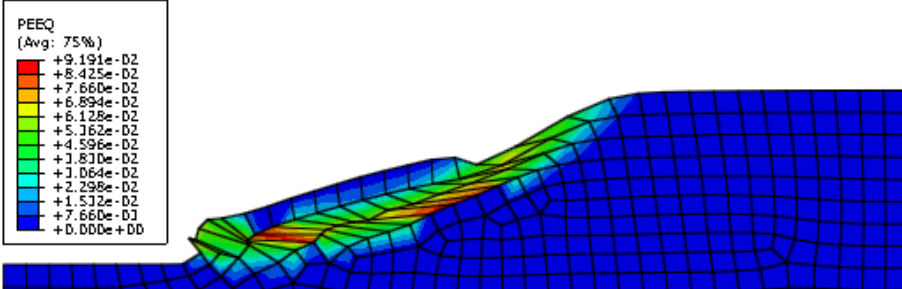 \\
\hline & & & & & & & Figure 6.21: Plastic strains for CPE4 elements (2D) \\
\hline
\end{tabular}


Table 6.3 (Continued)

\begin{tabular}{|c|c|c|c|c|c|c|c|}
\hline $\begin{array}{l}\text { Failure } \\
\text { Criteria }\end{array}$ & $\begin{array}{c}\text { Element } \\
\text { Type }\end{array}$ & $\begin{array}{c}\text { Element } \\
\text { Description }\end{array}$ & $\begin{array}{c}\text { Acceptable } \\
\text { Failure }\end{array}$ & $\begin{array}{l}\mathbf{t}_{\mathrm{CPU}} \\
(\mathrm{sec})\end{array}$ & $\begin{array}{c}\% \\
\text { Completion }\end{array}$ & FOS & Failure Mechanism \\
\hline D-P & CPE4H & $\begin{array}{c}\text { 4-noded } \\
\text { Bilinear } \\
\text { Quadrilateral, } \\
\text { Hybrid, } \\
\text { Constant } \\
\text { Pressure }\end{array}$ & YES & 3.8 & 75.2 & 0.96 & 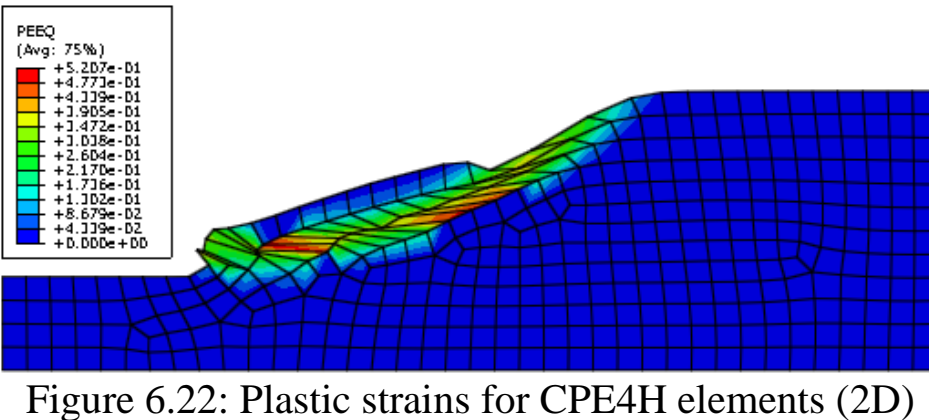 \\
\hline D-P & CPE4R & $\begin{array}{c}\text { 4-noded } \\
\text { Bilinear } \\
\text { Quadrilateral, } \\
\text { Reduced } \\
\text { Integration, } \\
\text { Hourglass } \\
\text { Control }\end{array}$ & YES & 2.5 & 100 & 1.37 & 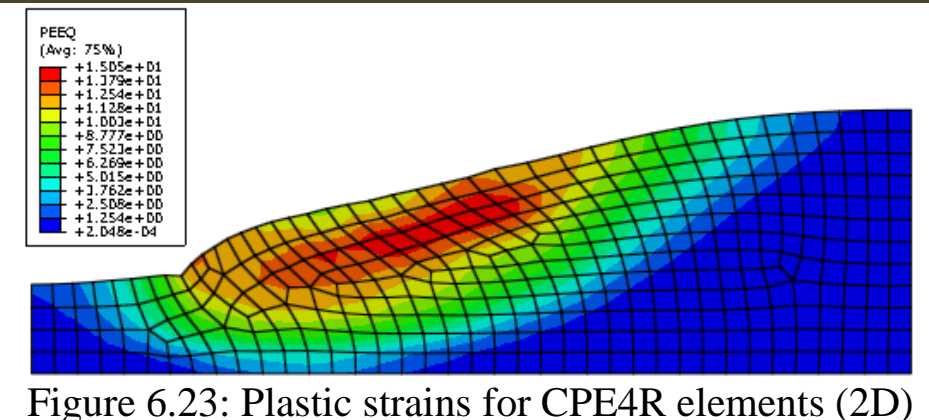 \\
\hline D-P & CPE4RH & $\begin{array}{c}\text { 4-noded } \\
\text { Bilinear } \\
\text { Quadrilateral, } \\
\text { Hybrid, } \\
\text { Constant } \\
\text { Pressure, } \\
\text { Reduced } \\
\text { Integration } \\
\text { Hourglass } \\
\text { Control }\end{array}$ & YES & 2.7 & 100 & 1.37 & 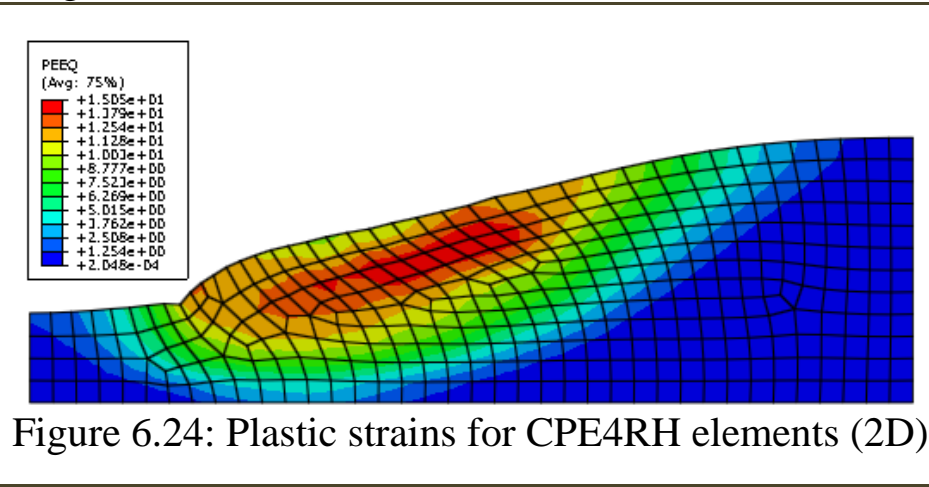 \\
\hline
\end{tabular}


Table 6.3 (Continued)

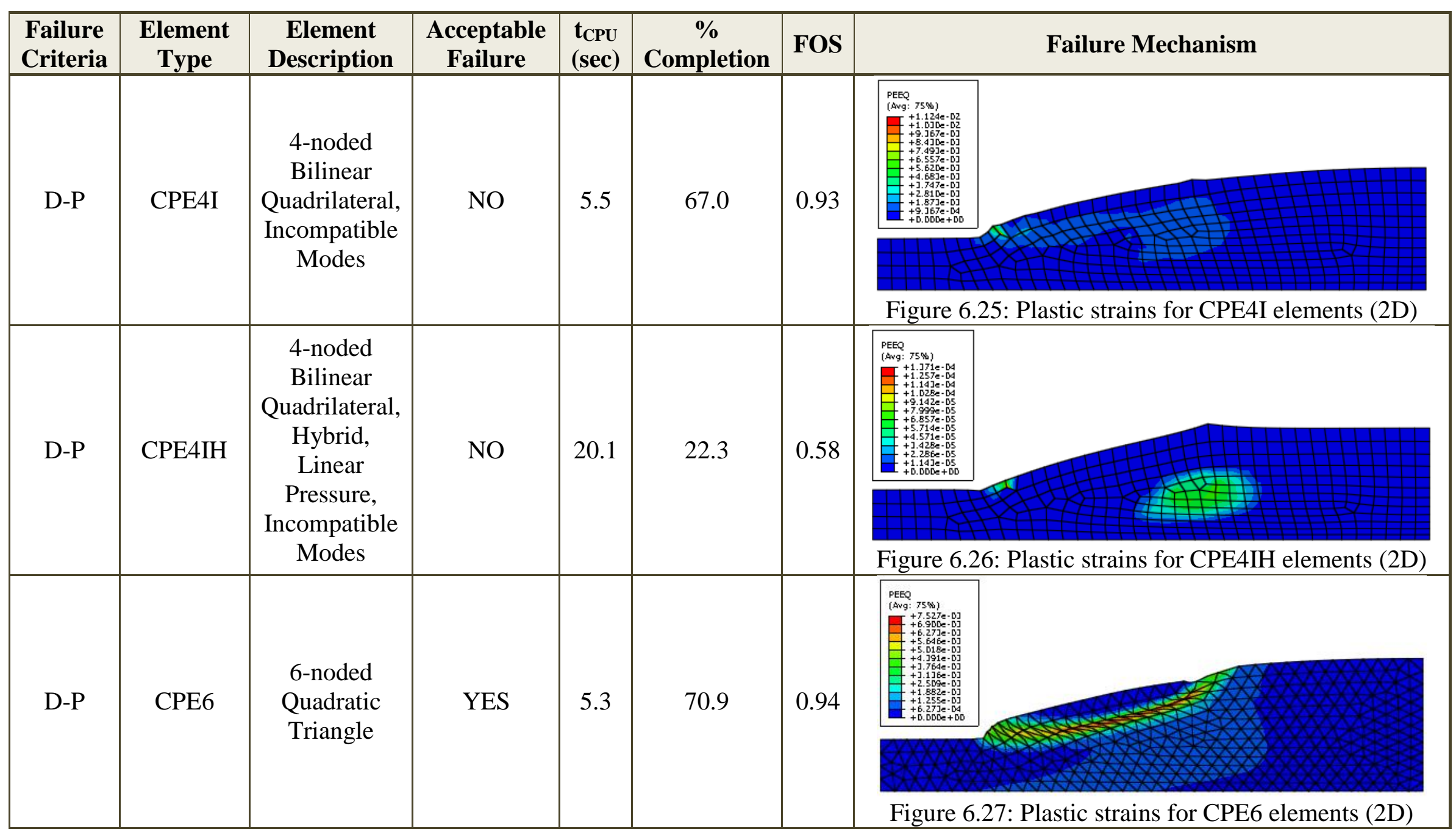


Table 6.3 (Continued)

\begin{tabular}{|c|c|c|c|c|c|c|c|}
\hline $\begin{array}{l}\text { Failure } \\
\text { Criteria }\end{array}$ & $\begin{array}{c}\text { Element } \\
\text { Type }\end{array}$ & $\begin{array}{c}\text { Element } \\
\text { Description }\end{array}$ & $\begin{array}{c}\text { Acceptable } \\
\text { Failure } \\
\end{array}$ & $\begin{array}{l}\mathbf{t}_{\mathrm{CPU}} \\
(\mathrm{sec}) \\
\end{array}$ & $\begin{array}{c}\% \\
\text { Completion } \\
\end{array}$ & FOS & Failure Mechanism \\
\hline D-P & СРE6H & $\begin{array}{c}\text { 6-noded } \\
\text { Quadratic } \\
\text { Triangle, } \\
\text { Hybrid, } \\
\text { Linear } \\
\text { Pressure }\end{array}$ & YES & 8.9 & 70.9 & 0.94 & 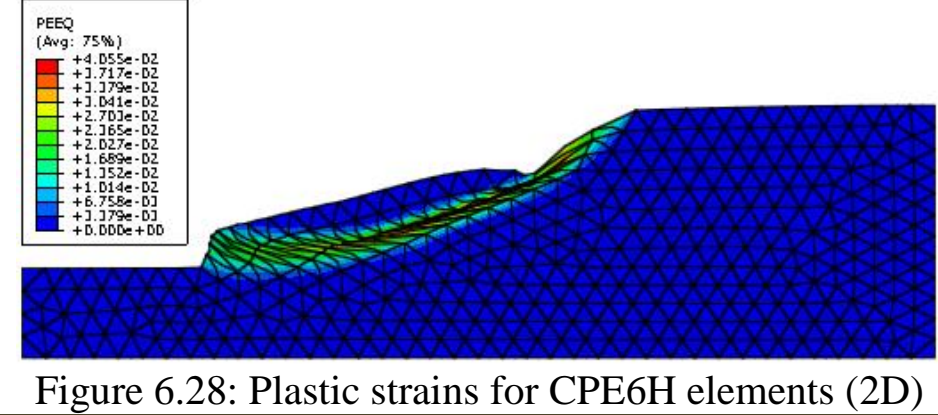 \\
\hline D-P & CPE6M & $\begin{array}{l}\text { 6-noded } \\
\text { Modified } \\
\text { Quadratic } \\
\text { Triangle }\end{array}$ & YES & 5.5 & 71.9 & 0.96 & 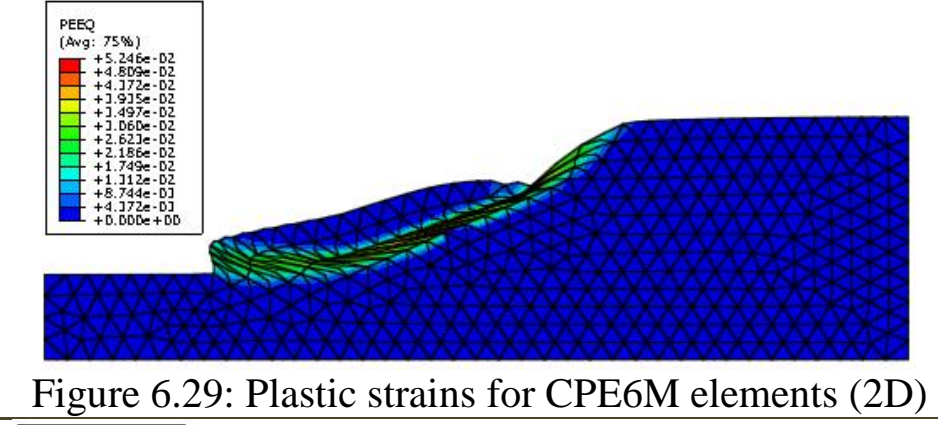 \\
\hline D-P & CPE6MH & $\begin{array}{c}\text { 6-noded } \\
\text { Modified } \\
\text { Quadratic } \\
\text { Triangle, } \\
\text { Hybrid, } \\
\text { Linear } \\
\text { Pressure }\end{array}$ & YES & 4.0 & 25.0 & 0.98 & 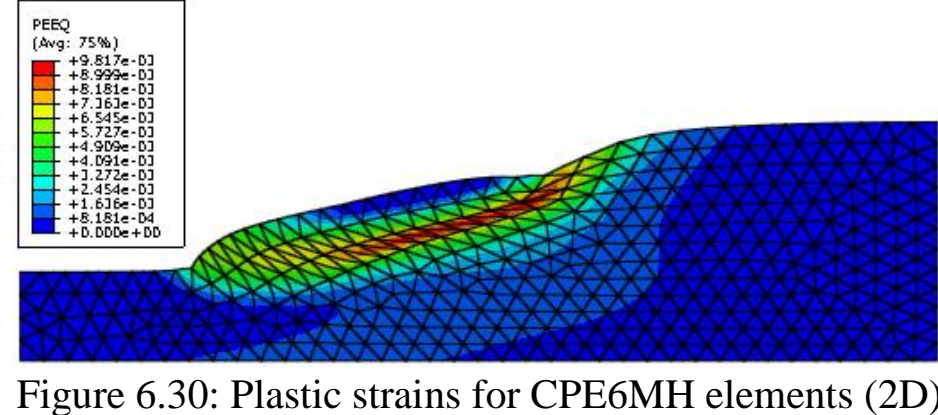 \\
\hline
\end{tabular}


Table 6.3 (Continued)

\begin{tabular}{|c|c|c|c|c|c|c|c|}
\hline $\begin{array}{l}\text { Failure } \\
\text { Criteria }\end{array}$ & $\begin{array}{c}\text { Element } \\
\text { Type }\end{array}$ & $\begin{array}{c}\text { Element } \\
\text { Description }\end{array}$ & $\begin{array}{c}\text { Acceptable } \\
\text { Failure }\end{array}$ & $\begin{array}{l}\mathbf{t}_{\text {CPU }} \\
(\mathbf{s e c}) \\
\end{array}$ & $\begin{array}{c}\% \\
\text { Completion }\end{array}$ & FOS & Failure Mechanism \\
\hline D-P & CPE8 & $\begin{array}{c}\text { 8-noded } \\
\text { Biquadratic } \\
\text { Quadrilateral }\end{array}$ & YES & 3.2 & 71.9 & 0.94 & 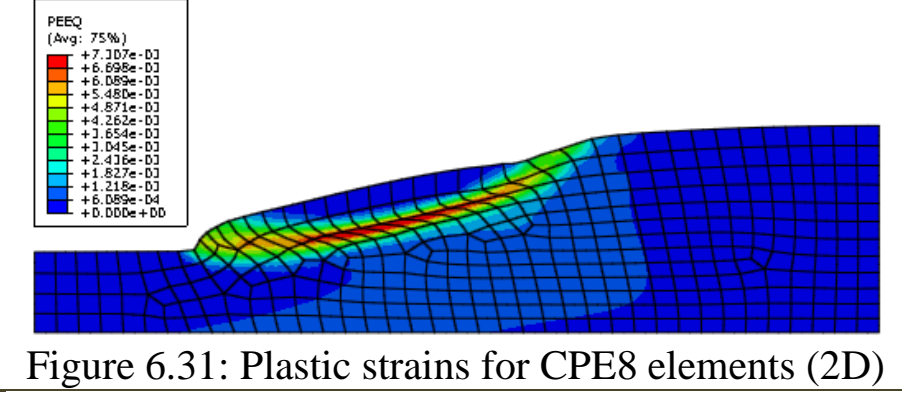 \\
\hline D-P & CPE8H & $\begin{array}{c}\text { 8-noded } \\
\text { Biquadratic } \\
\text { Quadrilateral, } \\
\text { Hybrid, } \\
\text { Linear } \\
\text { Pressure }\end{array}$ & NO & 43.8 & 55.8 & 0.86 & 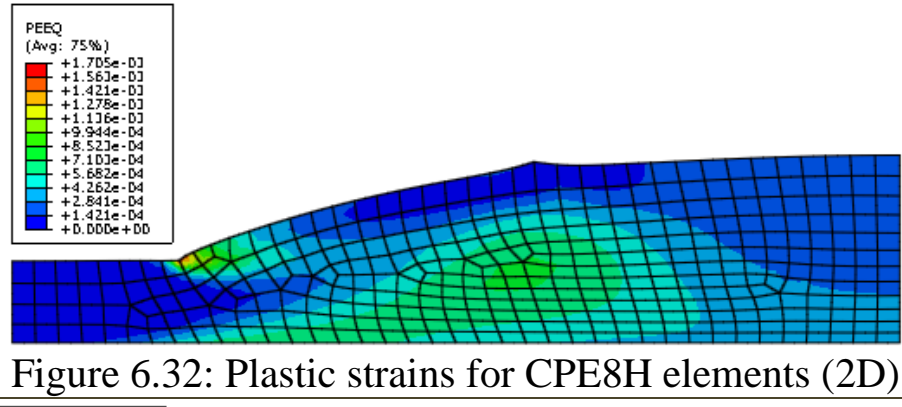 \\
\hline D-P & CPE8R & $\begin{array}{c}\text { 8-noded } \\
\text { Biquadratic } \\
\text { Quadrilateral, } \\
\text { Reduced } \\
\text { Integration }\end{array}$ & YES & 6.2 & 65.6 & 0.93 & 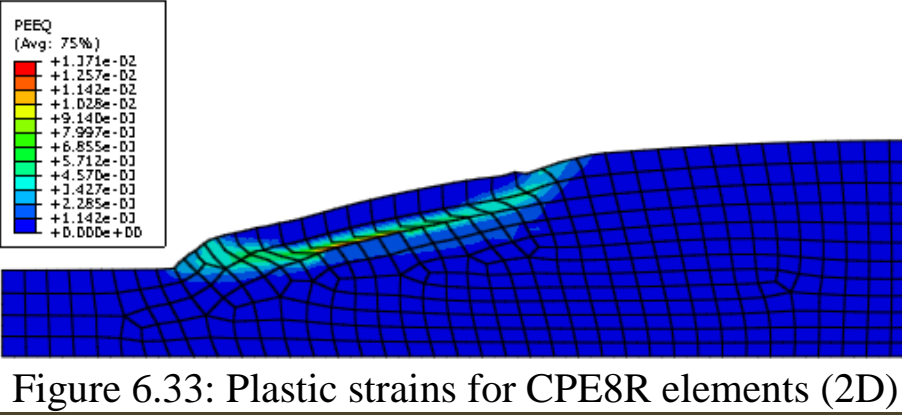 \\
\hline
\end{tabular}


Table 6.3 (Continued)

\begin{tabular}{|c|c|c|c|c|c|c|c|}
\hline $\begin{array}{l}\text { Failure } \\
\text { Criteria }\end{array}$ & $\begin{array}{c}\text { Element } \\
\text { Type }\end{array}$ & $\begin{array}{c}\text { Element } \\
\text { Description }\end{array}$ & $\begin{array}{c}\text { Acceptable } \\
\text { Failure }\end{array}$ & $\begin{array}{l}\mathbf{t}_{\text {CPU }} \\
(\mathbf{s e c})\end{array}$ & $\begin{array}{c}\% \\
\text { Completion }\end{array}$ & FOS & Failure Mechanism \\
\hline D-P & CPE8RH & $\begin{array}{l}\text { 8-noded } \\
\text { Biquadratic } \\
\text { Quadrilateral, } \\
\text { Hybrid, } \\
\text { Linear } \\
\text { Pressure, } \\
\text { Reduced } \\
\text { Integration }\end{array}$ & NO & 34.1 & 42.7 & 0.72 & 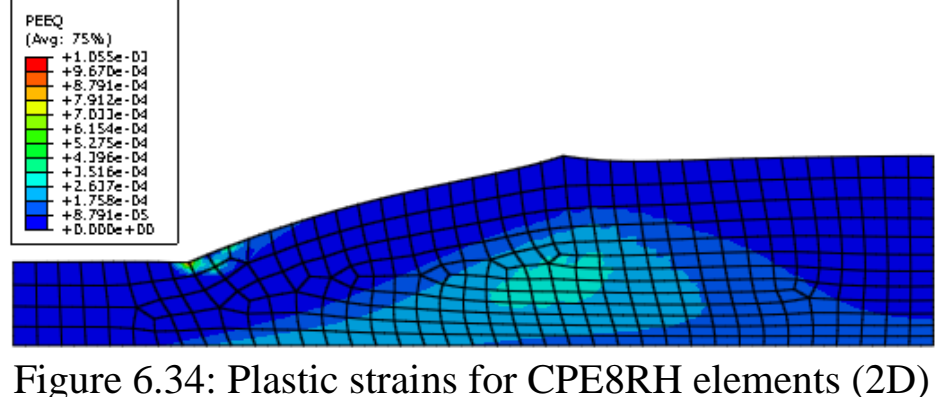 \\
\hline
\end{tabular}




\subsection{Two-Dimensional Reinforced Slopes}

As with unreinforced slopes, research toward soil-nailed reinforced slopes began with the reproduction of the benchmark slope studied by Wanstreet (2007). For the soil slope in this study, a Mohr-Coulomb soil failure criterion was used along with CPE6M element types. In the one-nail case, the nail was placed at the toe of the slope. In the twoand three- nail cases, the nails were placed using a vertical spacing of 2.0 meters. All nails were 10 meters in length and placed at a $20^{\circ}$ orientation.

For comparison, two-dimensional, limit-equilibrium (L-E) models were also developed. As discussed in Section 4.5, the Slide (2012) L-E computer program was used to model soil slopes reinforced with soil nails. Given the assumptions stated in Section 4.5, three soil-nailed, reinforced slopes were developed to replicate the dimensions and soil parameters used in the FEM study. Table 6.4 displays the computed FOS results for each FEM and L-E case. In addition, Figures 6.35 through 6.37 presents the PEEQ contour plots for the three FEM models and Figures 6.38 through 6.40 present the critical circle for the L-E models.

As presented, it is easy to see the similarities in the FOS values and the potential failure circles for all three cases. Note that the one-nail case does not alter the FOS or the position of the failure circle in either the FEM or the L-E analysis, as the single soil nail does not intersect the failure circle. In the two- and three-nail cases, it is easy to see the positive effect of the soil nails as the potential failure circle is displaced to a position above the soil nail reinforcements (to the unreinforced area of the slope). 
Table 6.4 Comparison of Two-Dimensional FEM and L-E Results for Reinforced Benchmark Slope

\begin{tabular}{|c|c|c|}
\hline No. Soil Nails & FEM FOS & L-E FOS \\
\hline 1 & 0.99 & 0.99 \\
\hline 2 & 1.06 & 1.04 \\
\hline 3 & 1.16 & 1.11 \\
\hline
\end{tabular}

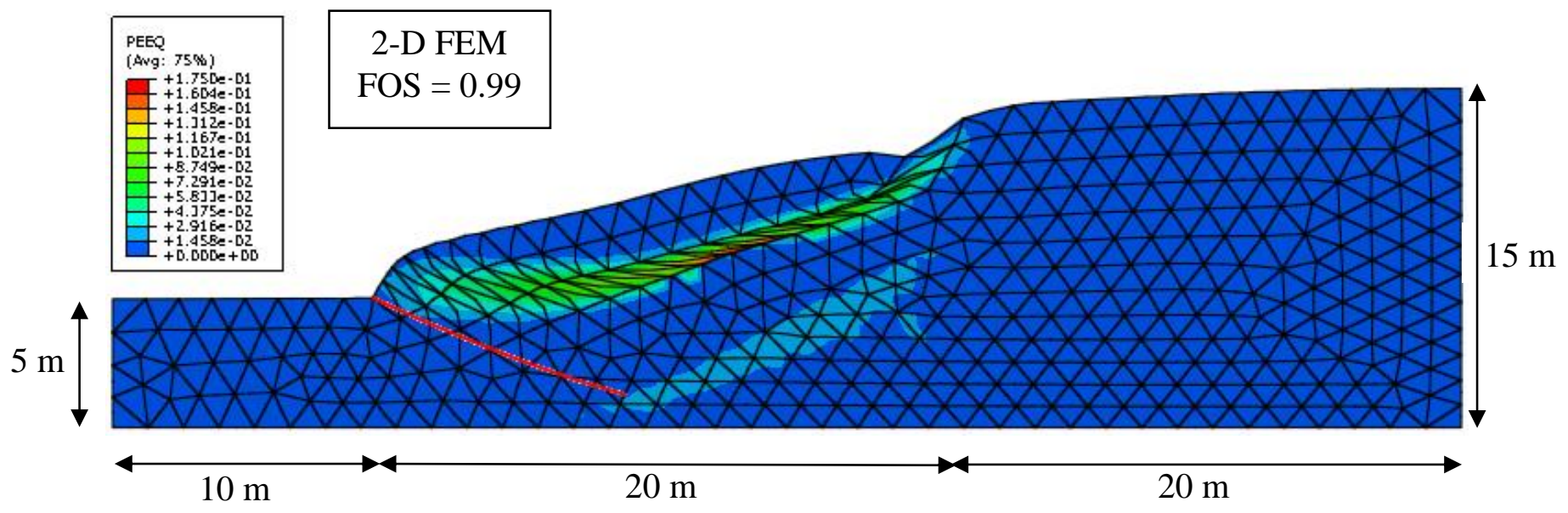

Figure 6.35 PEEQ Contours for Two-Dimensional, Reinforced Benchmark Model - 1 Nail

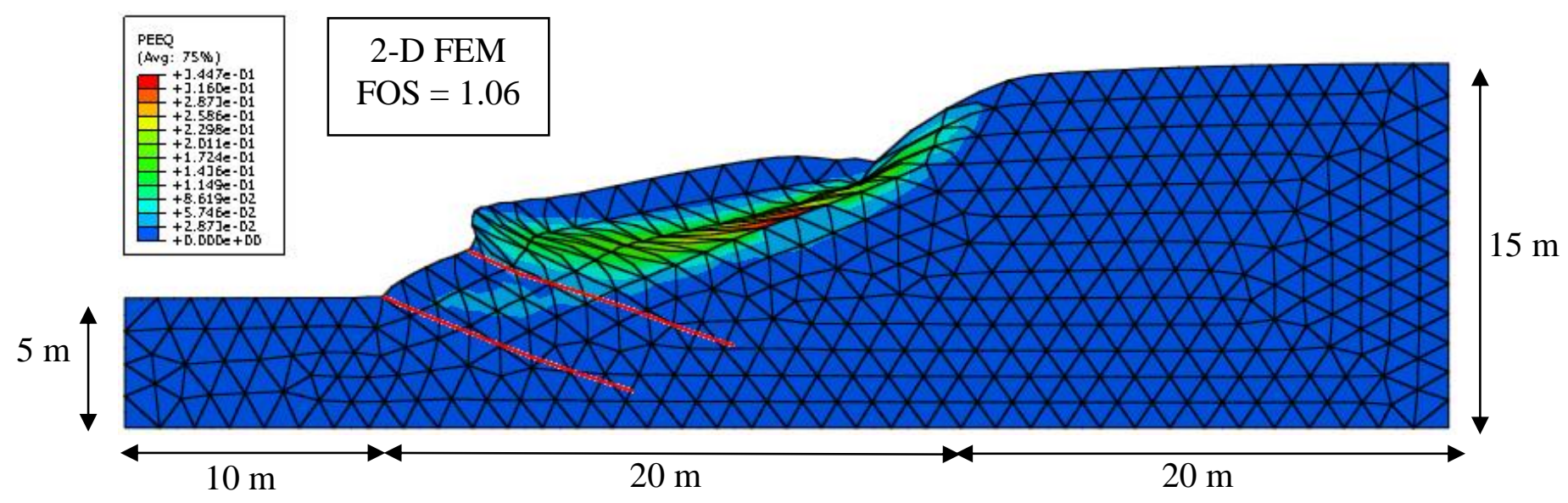

Figure 6.36 PEEQ Contours for Two-Dimensional, Reinforced Benchmark Model - 2 Nails 


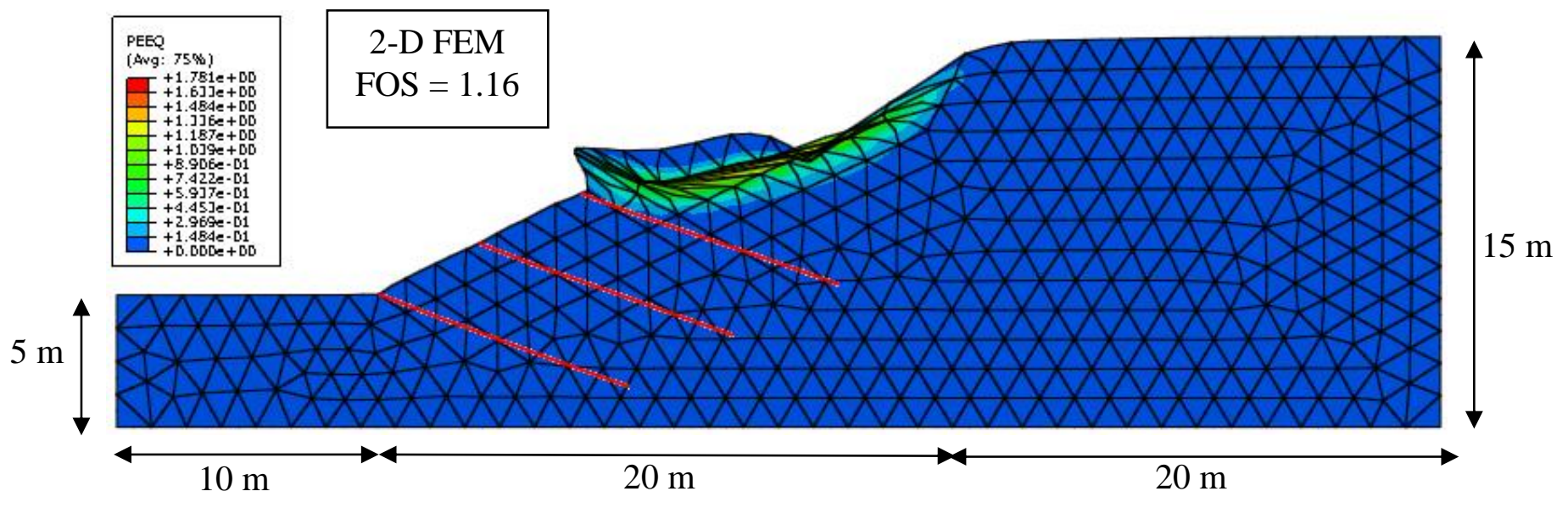

Figure 6.37 PEEQ Contours for Two-Dimensional, Reinforced Benchmark Model - 3 Nails
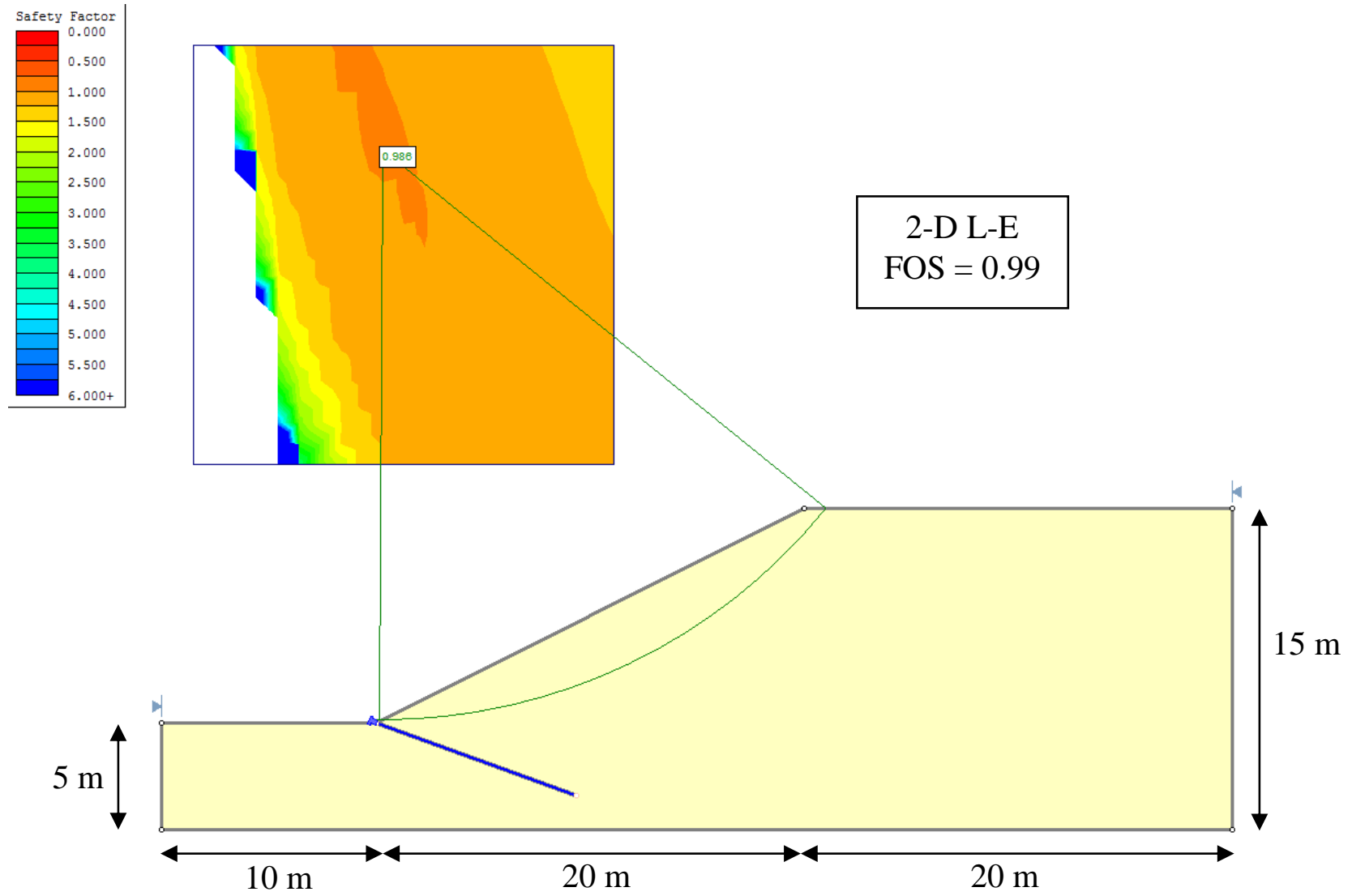

Figure 6.38 L-E Results for Two-Dimensional, Reinforced Benchmark Model - 1 Nail 


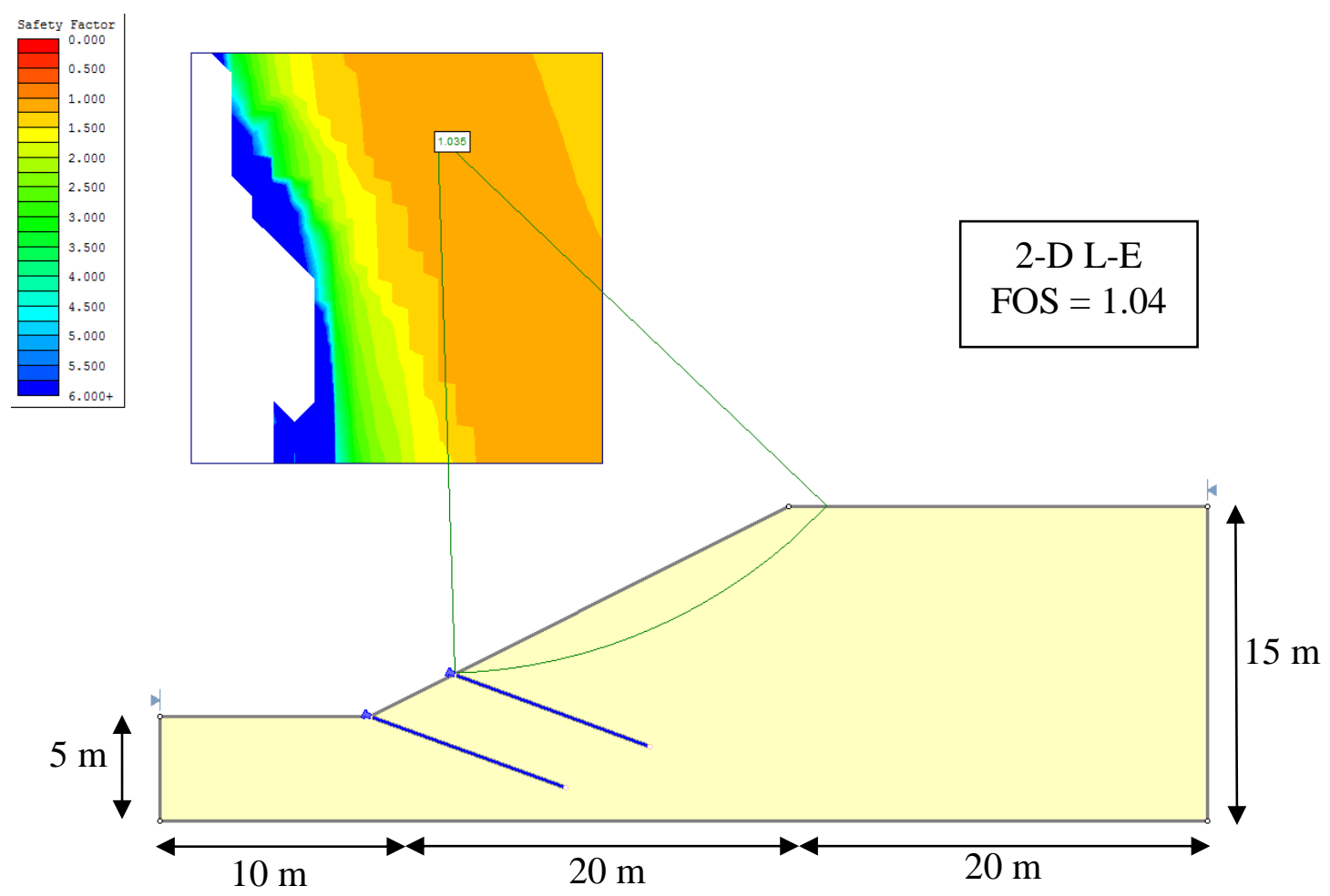

Figure 6.39 L-E Results for Two-Dimensional, Reinforced Benchmark Model - 2 Nails

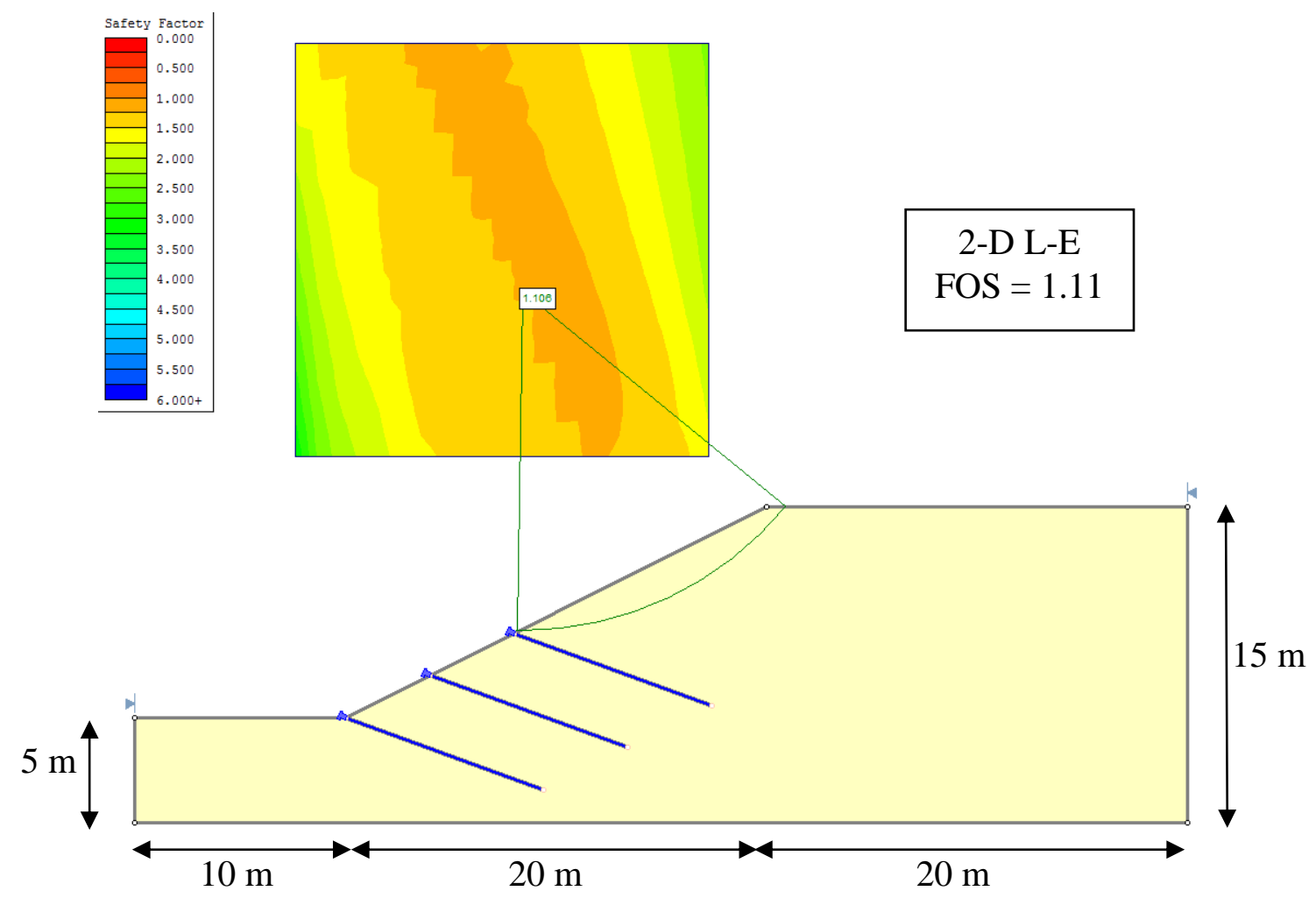

Figure 6.40 L-E Results for Two-Dimensional, Reinforced Benchmark Model - 3 Nails 


\section{CHAPTER 7: THREE-DIMENSIONAL MODELING RESULTS AND DISCUSSIONS}

\subsection{Introduction}

This study was used to evaluate the stability of both unreinforced and reinforced slopes using a three-dimensional FEM approach. For most models, the Factor of Safety (FOS) was determined using the Shear Strength Reduction (SSR) method, as discussed in Section 3.9. Due to the limited amount of field data available, results were related back to FEM and L-E, twodimensional results, and where possible to previously published work.

\subsection{Influence of Depth in Three-Dimensional Analysis of Unreinforced Slopes}

As discussed in Section 5.2, a unit-width depth was used for parametric studies in this research. In order to validate this approach, the depth of the benchmark model was increased from a unit width ( 1 meter) to depths of: 2 meters, 3 meters, 4 meters, 5 meters, 7.5 meters, 10 meters, 15 meters, 20 meters, 30 meters, 40 meters, and 50 meters. Threedimensional, 8-noded linear brick (C3D8) stress elements were assigned to the soil elements used for this study using Mohr-Coulomb failure criteria.

Three-dimensional FEM modeling results showed no variance in the FOS or failure surface at any of the depths investigated. However, it did take significant more time to process the larger models. The FOS values in all depth cases was consistently equal to 1.04 and the equivalent plastic strain (PEEQ) contour plots appeared identical throughout all depth cases. PEEQ visualizations for selected depths are presented in Figures 7.1 to 7.3. 


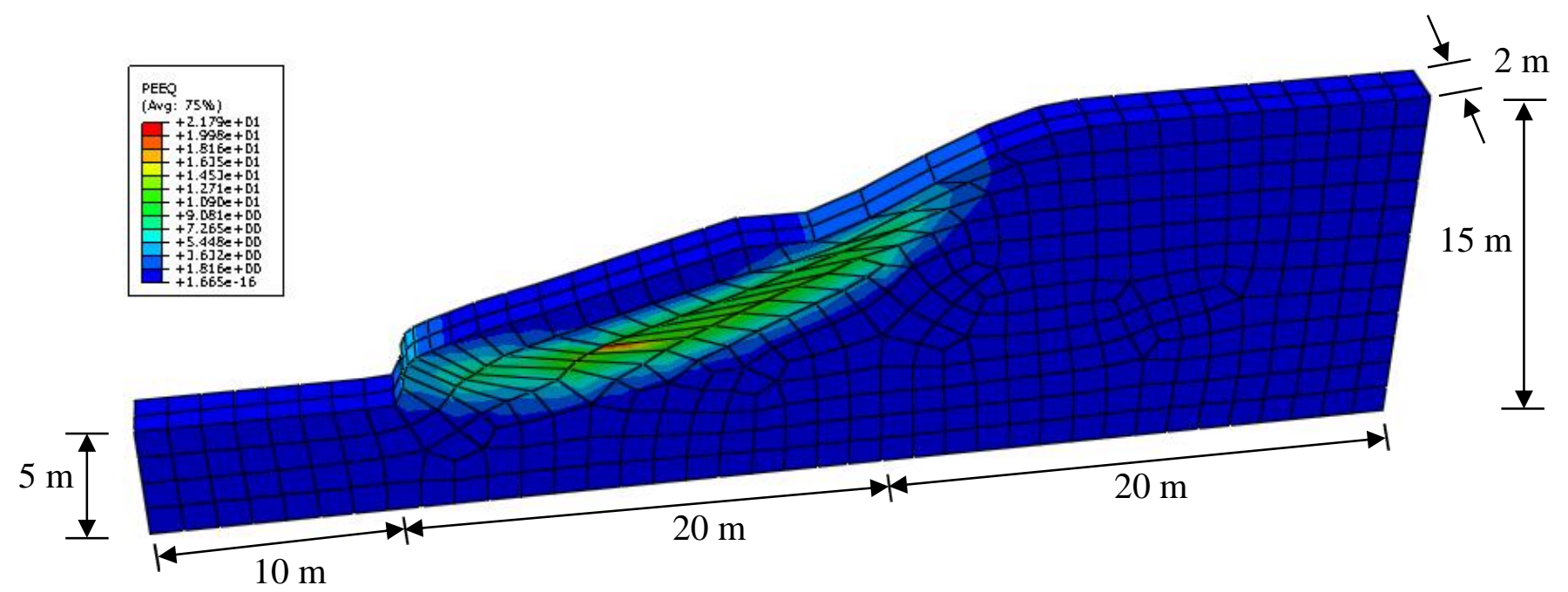

Figure 7.1 Three-Dimensional, Unreinforced Soil Slope with 2 meter Depth

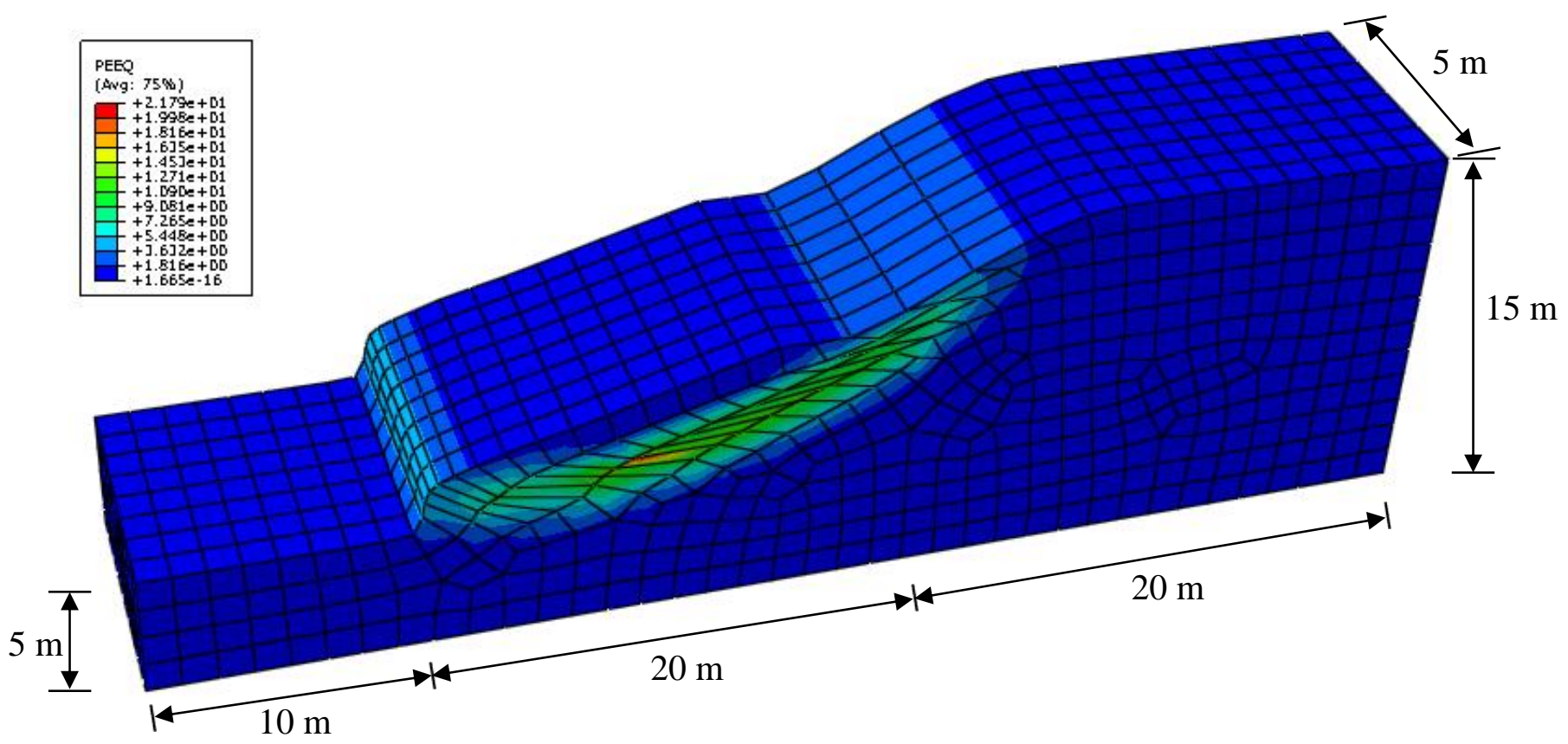

Figure 7.2 Three-Dimensional, Unreinforced Soil Slope with 10 meter Depth 


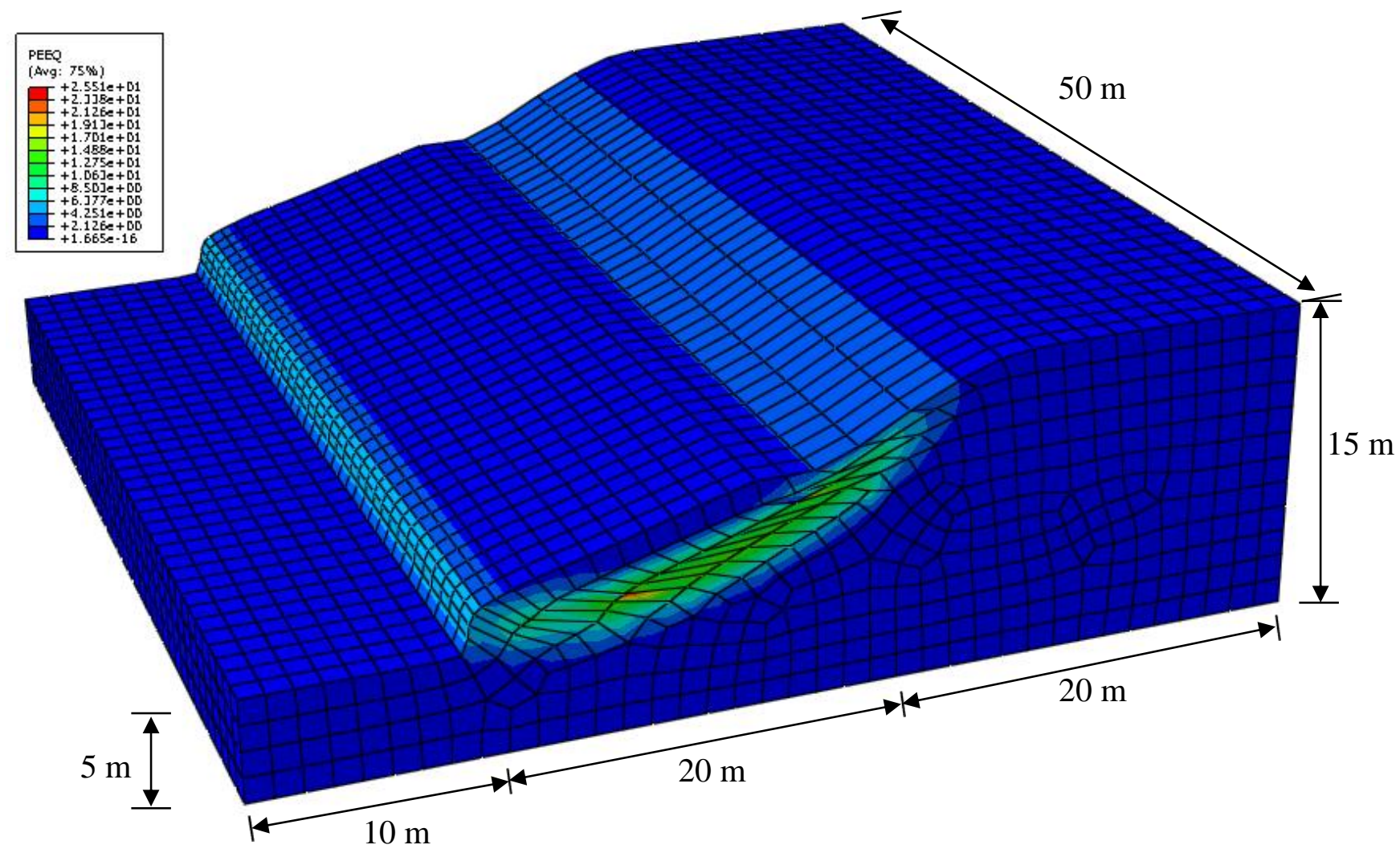

Figure 7.3 Three-Dimensional, Unreinforced Soil Slope with 50 meter Depth

\subsection{Three-Dimensional Finite Element Type Study}

Similar to the two-dimensional FEM element type study, this study also investigated three-dimensional FEM element types for unreinforced slopes. The evaluation of element type for FEM of soil slopes is paramount to the accuracy and efficiency of FEA. Using the twenty-one available element options in Abaqus, Mohr-Coulomb and Drucker-Prager models were created and evaluated using the geometry and soil properties used for the benchmark slope (See Figure 4.1). A unit-width depth was used for this study. As before, the primary goal of this analysis was to determine the most efficient and accurate element type(s) that generated an acceptable circular failure surface. The criteria used to evaluate these three were identical to the two-dimensional element type analyses. 
Using the twenty-one available element options, models were created and evaluated that utilized both the Mohr-Coulomb and Drucker-Prager soil yielding criteria, as presented in Table 3.3 and Table 3.4, respectively. The results of the three-dimensional MohrCoulomb models are presented in Table 7.1. The results of the three-dimensional DruckerPrager models are presented in Table 7.2. Within these tables, the processing time $\left(t_{\mathrm{CPU}}\right)$ and percentage completion are associated with the FOS(s) presented. Likewise are the PEEQ visualization plots presented in Figures 7.4 through 7.24 and Figures 7.25 through 7.45, for Mohr-Coulomb and Drucker-Prager models, respectively. The PEEQ visualization

plots were developed using Abaqus (2011) default values for Deformation Factor and PEEQ color contour limits for each model. The computer used for this study was a Dell Optiplex 790, Intel ${ }^{\circledR}$ Core ${ }^{\mathrm{TM}}$ i7-2600 CPU @ 3.40 GigaHertz (GHz) with 4.00 Gigabytes (GB) of Installed memory (RAM).

\subsubsection{Comparison of Element Types for Three-Dimensional Mohr-Coulomb Failure Models}

For the Mohr-Coulomb models, there were two element types in the C3D4 group. The C3D4 element type processed in 1.2 seconds and exhibited a suitable failure surface; however, it yielded an inaccurate FOS equal to 1.22. The C3D4H element model processed in 89.2 seconds, did not exhibit a suitable failure surface, and also yielded an inaccurate FOS of 0.86 (See Figures 7.4 and 7.5).

The two element type options for the C3D6 group both generated acceptable failure surfaces and efficient processing times but resulted in inaccurate FOS's (See Figure 7.6 and 7.7). The C3D6 and C3D6H element types processed in 0.7 and 0.8 seconds but yielded a FOS of 1.22 and 1.20 , respectively. 
The C3D8 group was generally strong in all three criteria. All but two element types (C3D8I and C3D8IH) yielded acceptable failure surfaces (See Figures 7.8 through 7.13) with processing times under 9.2 seconds. In addition, besides the two element options mentioned, this group was also very accurate producing FOS's from 1.00 to 1.04. The C3D8I and C3D8IH posted processing times of 48.8 and 23.8 seconds with FOS's equal to 0.95 and 0.67 , respectively.

The C3D10 group gave mixed results. Generally, processing times were high, from 21.9 to 1050.3 seconds. The C3D10 and C3D10M element types exhibited acceptable failure surfaces (Figures 7.14 and 7.16) and accurate results with FOS's of 0.97 and 0.99 , respectively. The $\mathrm{C} 3 \mathrm{D} 10 \mathrm{H}, \mathrm{C} 3 \mathrm{D} 10 \mathrm{MH}$, and C3D10I element types did not give acceptable failure surfaces (See Figures 7.15, 7.17, and 7.18), and FOS's ranged from 0.63 to 0.79.

There were two options in the C3D15 group, the C3D15 and the C3D15H (See Figures 7.19 and 7.20). The C3D15 element type processed in 56.0 seconds, and yielded a FOS equal to 0.98 with an acceptable failure surface. The C3D15H element type processed in 166.2 seconds, yielded a FOS of 0.82, and did not exhibit an acceptable failure surface.

The final three-dimensional element group was the C3D20 group. Except for the basic C3D20 element type, none of the element types produced acceptable failure surfaces (See Figures 7.21 through 7.24). The C3D20 element type processed in 91.2 seconds and provided an accurate FOS equal to 0.98. The C3D20H, C3D20R, and the C3D20RH element types processed in times ranging from 58.0 to 334.4 seconds, and yielded FOS's that ranged from 0.71 to 0.96 .

From this three-dimensional FEM study, using the Mohr-Coulomb failure criteria, the element types that proved to be most efficient, accurate, and produce an acceptable 
failure surface included element types exclusively from the C3D8 group. Within this group, the basic C3D8 element type performed very well, processing a FOS of 1.04 in 2.5 seconds, with an acceptable failure surface.

7.3.2 Comparison of Element Types for Three-Dimensional Drucker-Prager Failure Models

To begin the three-dimensional, Drucker-Prager models, the C3D4 group, which included just the C3D4 and C3D4H element types, did not exhibit acceptable failure surfaces (Figures 7.25 and 7.26). Processing times were 7.4 and 53.4 seconds for FOS's of 0.94 and 0.96 , respectively.

The C3D6 group also just had two options, the C3D6 and C3D6H. While the failure surfaces were marginally acceptable (See Figures 7.27 and 7.28), processing times were low at 0.6 and 0.8 seconds, respectively, with both yielding a FOS's equal to 1.06.

The largest, C3D8 group, generated favorable results, overall. With the exception of the C3D8IH element type, all of the element types in this group produced acceptable failure surfaces (Figures 7.29 through 7.34) with processing times that ranged from 2.9 to 16.0 seconds and accurate FOS's ranging from 0.95 to 1.02 . The C3D8IH element type processed in 42.3 seconds and yielded a FOS equal to 0.60 .

The C3D10 group once again had mixed results. Generally, processing times were again high, from 41.7 to 546.9 seconds. The C3D10 and C3D10M element types once again exhibited acceptable failure surfaces (Figures 7.35 and 7.37) and somewhat accurate results since both yielded a FOS of 0.94. The C3D10H, C3D10MH, and C3D10I element types did not have acceptable failure surfaces (See Figures 7.36, 7.38, and 7.39), and FOS's ranged from 0.61 to 0.92 . 
Both options for the C3D15 group, the C3D15 and the C3D15H, produced acceptable failure surfaces (See Figures 7.40 and 7.41). The C3D15 and C3D15H element types processed in 33.4 and 39.1 seconds, respectively, and both yielded a FOS of 0.94.

The only element type in the C3D20 group that exhibited an acceptable failure surface was the basic C3D20 element type (See Figures 7.42 through 7.45). It processed in 67.5 seconds with a FOS equal to 0.94. The C3D20H, C3D20R, and the C3D20RH element types processed in times ranging from 33.7 to 322.5 seconds, and yielded FOS's that ranged from 0.66 to 0.93 .

Using the Drucker-Prager yielding criteria for three-dimensional, unreinforced slope, once again the C3D8 group performed best overall. Specifically, the C3D8, C3D8H, C3D8R, and C3D8I element types all proved to be efficient and accurate with acceptable failure surfaces. In addition, the C3D6 and C3D6H element types were very fast with acceptable failure surfaces. However, both the C3D6 and C3D6H element types yielded FOS values equal to 1.06 , which is marginal with respect to accuracy.

From the results of this three-dimensional FEM element type study on an unreinforced slope, including both Mohr-Coulomb and Drucker-Prager yielding criteria, the C3D8 element type provided the most efficient, accurate and acceptable results. While the differences between the results for Mohr-Coulomb and Drucker-Prager were noticeable for some element types in this three-dimensional study, most element type's yielded similar results.

Element types were also compared using uniform Deformation Factors and PEEQ contour limits. This was performed for select elements using Mohr-Coulomb and DruckerPrager yielding criteria. The results of this study are presented in Appendix A. 
Table 7.1 Comparison of Three-Dimensional Element Type for Mohr-Coulomb Model

\begin{tabular}{|c|c|c|c|c|c|c|c|}
\hline $\begin{array}{l}\text { Failure } \\
\text { Criteria }\end{array}$ & $\begin{array}{c}\text { Element } \\
\text { Type }\end{array}$ & $\begin{array}{c}\text { Element } \\
\text { Description }\end{array}$ & $\begin{array}{c}\text { Accepta } \\
\text { ble } \\
\text { Failure }\end{array}$ & $\begin{array}{l}\mathbf{t}_{\mathrm{CPU}} \\
(\mathrm{sec})\end{array}$ & $\begin{array}{c}\% \\
\text { Completion }\end{array}$ & FOS & Failure Mechanism \\
\hline $\mathrm{M}-\mathrm{C}$ & C3D4 & $\begin{array}{l}\text { 4-noded } \\
\text { Linear } \\
\text { Tetrahedron }\end{array}$ & YES & 1.2 & 100 & 1.22 & 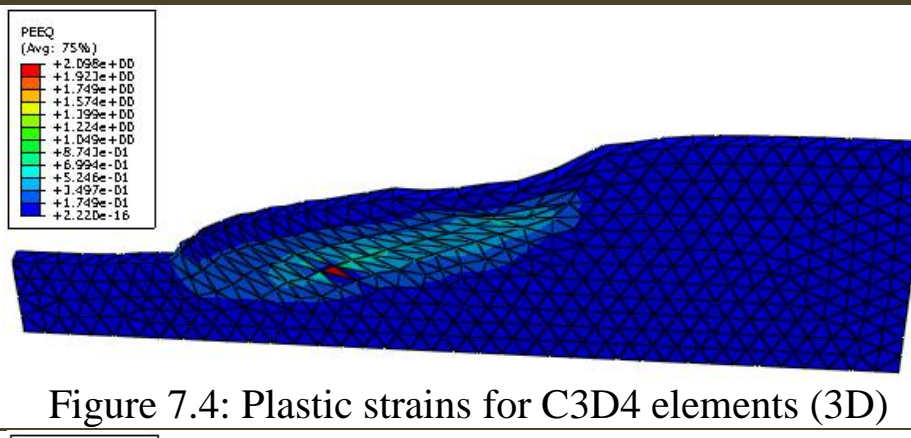 \\
\hline $\mathrm{M}-\mathrm{C}$ & C3D4H & $\begin{array}{l}\text { 4-noded } \\
\text { Linear } \\
\text { Tetrahedron, } \\
\text { Hybrid, } \\
\text { Linear } \\
\text { Pressure }\end{array}$ & NO & 89.2 & 72.9 & 0.86 & 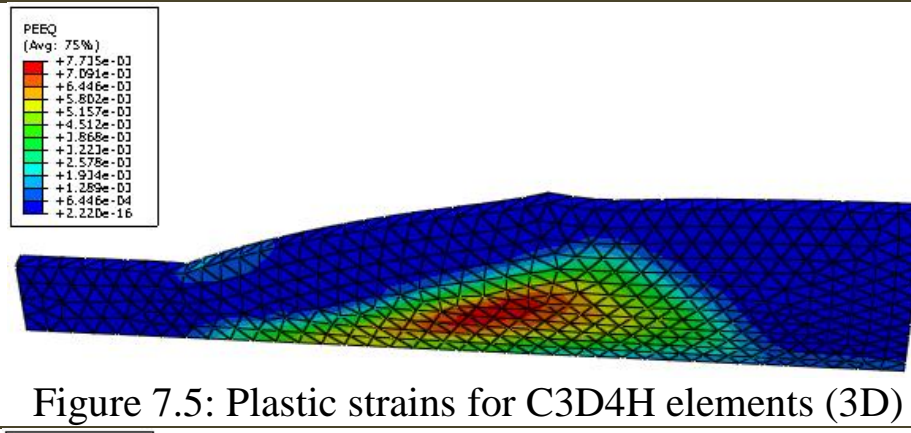 \\
\hline $\mathrm{M}-\mathrm{C}$ & C3D6 & $\begin{array}{l}\text { 6-noded } \\
\text { Linear } \\
\text { Triangular } \\
\text { Prism }\end{array}$ & YES & 0.7 & 100 & 1.22 & 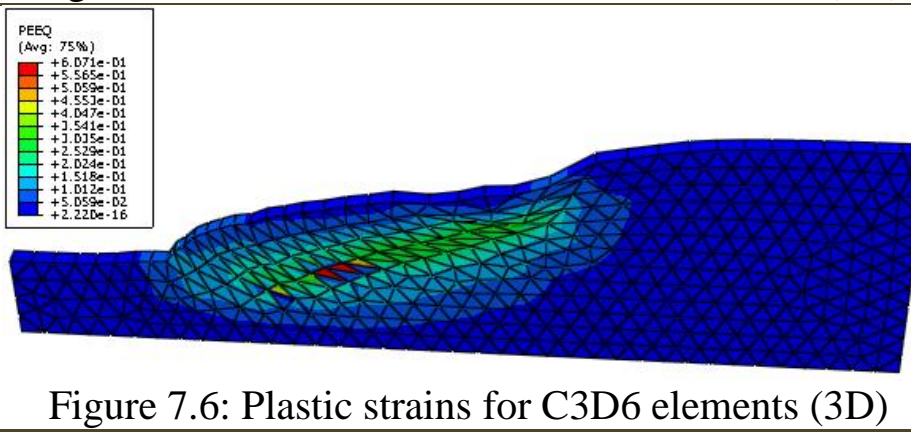 \\
\hline
\end{tabular}


Table 7.1 (Continued)

\begin{tabular}{|c|c|c|c|c|c|c|c|}
\hline $\begin{array}{l}\text { Failure } \\
\text { Criteria }\end{array}$ & $\begin{array}{c}\text { Element } \\
\text { Type }\end{array}$ & $\begin{array}{c}\text { Element } \\
\text { Description }\end{array}$ & $\begin{array}{c}\text { Acceptable } \\
\text { Failure } \\
\end{array}$ & $\begin{array}{l}\mathbf{t}_{\mathrm{CPU}} \\
(\mathrm{sec})\end{array}$ & $\begin{array}{c}\% \\
\text { Completion }\end{array}$ & FOS & Failure Mechanism \\
\hline $\mathrm{M}-\mathrm{C}$ & C3D6H & $\begin{array}{l}\text { 6-noded } \\
\text { Linear } \\
\text { Triangular } \\
\text { Prism, } \\
\text { Hybrid, } \\
\text { Constant } \\
\text { Pressure }\end{array}$ & YES & 0.8 & 100 & 1.20 & 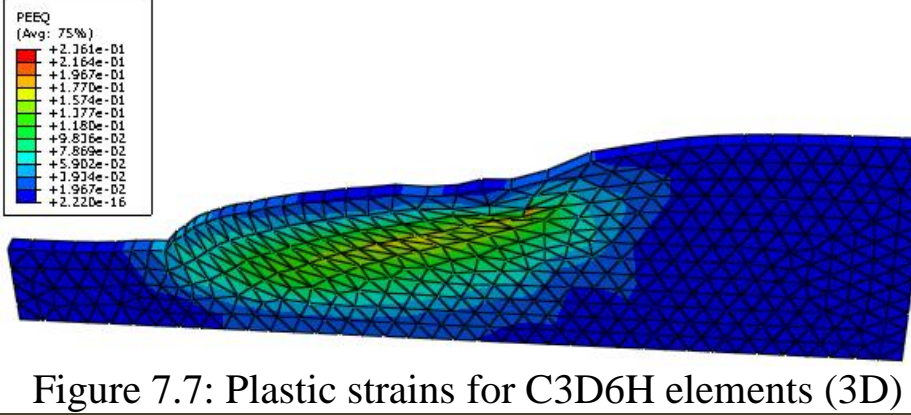 \\
\hline $\mathrm{M}-\mathrm{C}$ & C3D8 & $\begin{array}{l}\text { 8-noded } \\
\text { Linear } \\
\text { Brick }\end{array}$ & YES & 2.5 & 100 & 1.04 & 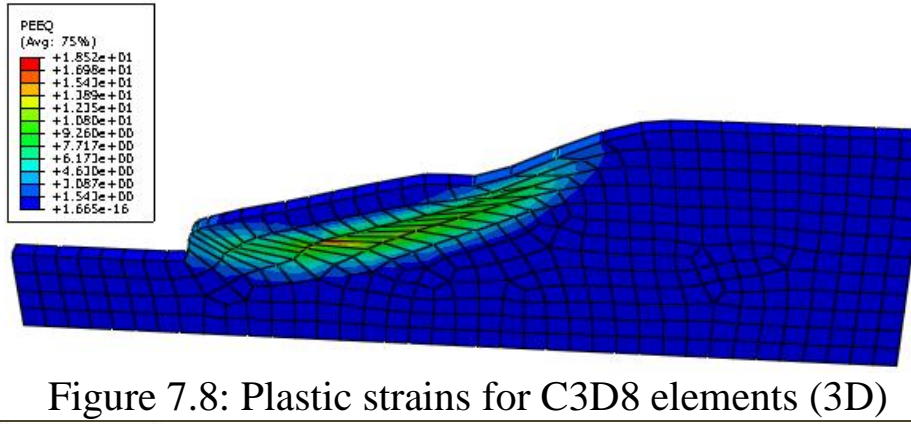 \\
\hline $\mathrm{M}-\mathrm{C}$ & $\mathrm{C} 3 \mathrm{D} 8 \mathrm{H}$ & $\begin{array}{l}\text { 8-noded } \\
\text { Linear } \\
\text { Brick, } \\
\text { Hybrid, } \\
\text { Constant } \\
\text { Pressure }\end{array}$ & YES & 9.2 & 100 & 1.00 & 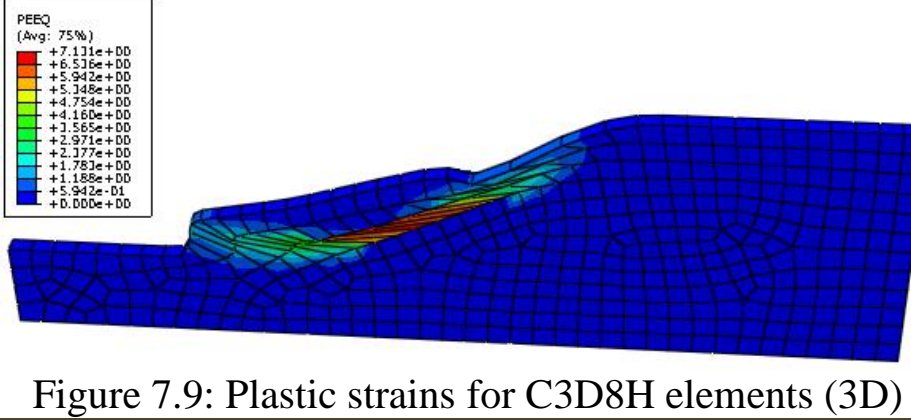 \\
\hline
\end{tabular}


Table 7.1 (Continued)

\begin{tabular}{|c|c|c|c|c|c|c|c|}
\hline $\begin{array}{l}\text { Failure } \\
\text { Criteria }\end{array}$ & $\begin{array}{c}\text { Element } \\
\text { Type }\end{array}$ & \begin{tabular}{c|} 
Element \\
Description
\end{tabular} & $\begin{array}{c}\text { Acceptable } \\
\text { Failure }\end{array}$ & $\begin{array}{l}\mathbf{t}_{\mathrm{CPU}} \\
(\mathrm{sec})\end{array}$ & $\begin{array}{c}\% \% \\
\text { Completion }\end{array}$ & FOS & Failure Mechanism \\
\hline $\mathrm{M}-\mathrm{C}$ & C3D8R & $\begin{array}{c}\text { 8-noded } \\
\text { Linear } \\
\text { Brick, } \\
\text { Reduced } \\
\text { Integration, } \\
\text { Hourglass } \\
\text { Control }\end{array}$ & YES & 4.9 & 100 & 1.01 & 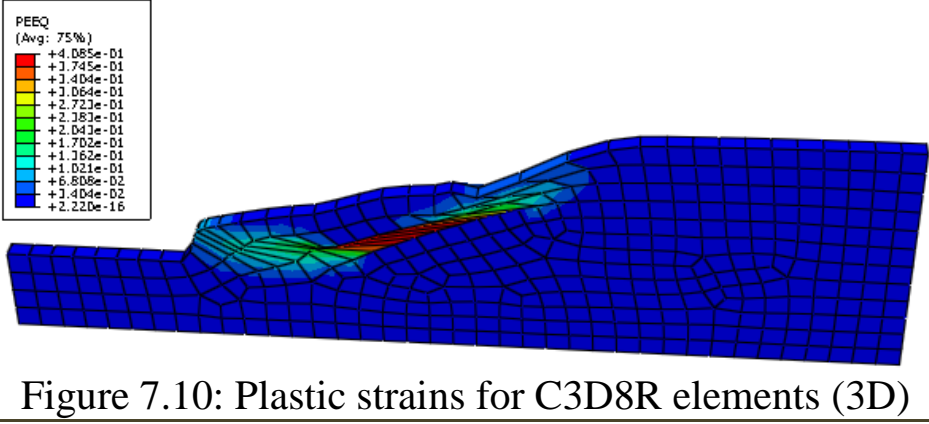 \\
\hline $\mathrm{M}-\mathrm{C}$ & C3D8RH & $\begin{array}{c}\text { 8-noded } \\
\text { Linear } \\
\text { Brick, } \\
\text { Hybrid, } \\
\text { Constant } \\
\text { Pressure, } \\
\text { Reduced } \\
\text { Integration, } \\
\text { Hourglass } \\
\text { Control } \\
\end{array}$ & YES & 5.5 & 100 & 1.01 & 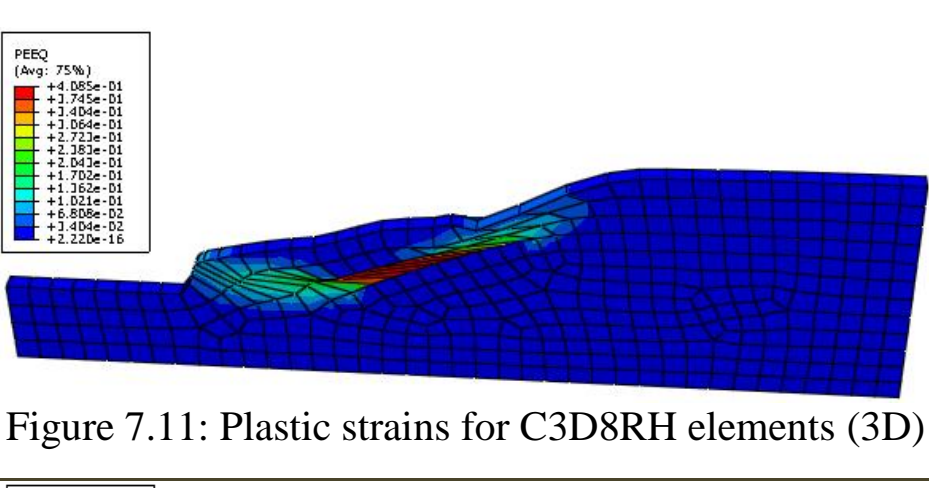 \\
\hline $\mathrm{M}-\mathrm{C}$ & C3D8I & $\begin{array}{c}\text { 8-noded } \\
\text { Linear } \\
\text { Brick, } \\
\text { Incompatible } \\
\text { Modes }\end{array}$ & $\mathrm{NO}$ & 48.8 & 84.2 & 0.95 & 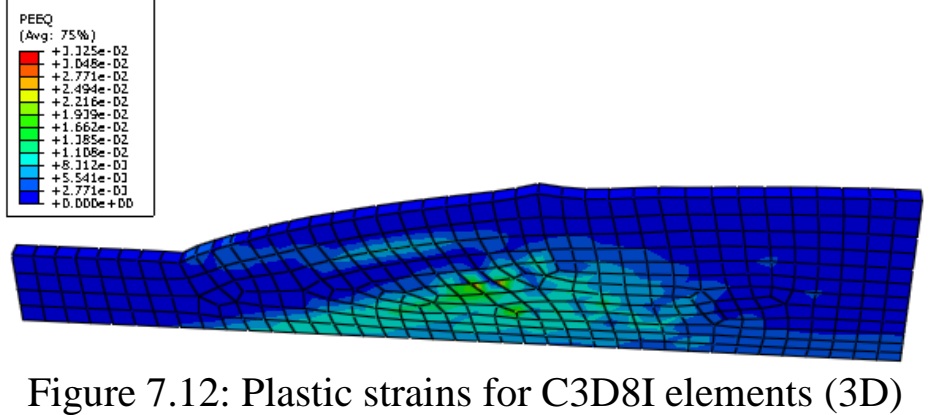 \\
\hline
\end{tabular}


Table 7.1 (Continued)

\begin{tabular}{|c|c|c|c|c|c|c|c|}
\hline $\begin{array}{l}\text { Failure } \\
\text { Criteria }\end{array}$ & $\begin{array}{c}\text { Element } \\
\text { Type }\end{array}$ & \begin{tabular}{c|} 
Element \\
Description
\end{tabular} & $\begin{array}{c}\text { Acceptable } \\
\text { Failure }\end{array}$ & $\begin{array}{l}\mathbf{t}_{\mathrm{CPU}} \\
(\mathrm{sec})\end{array}$ & $\begin{array}{c}\% \\
\text { Completion }\end{array}$ & FOS & Failure Mechanism \\
\hline $\mathrm{M}-\mathrm{C}$ & C3D8IH & $\begin{array}{l}\text { 8-noded } \\
\text { Linear } \\
\text { Brick, } \\
\text { Hybrid, } \\
\text { Linear } \\
\text { Pressure, } \\
\text { Incompatible } \\
\text { Modes }\end{array}$ & $\mathrm{NO}$ & 23.8 & 15.7 & 0.67 & 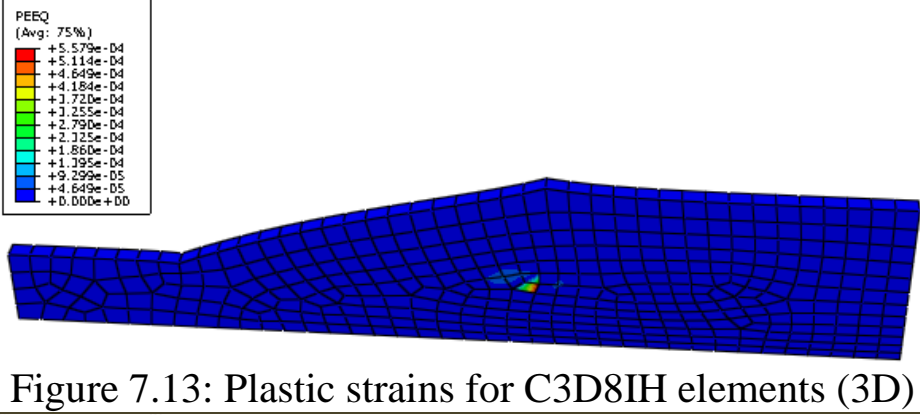 \\
\hline $\mathrm{M}-\mathrm{C}$ & C3D10 & $\begin{array}{c}\text { 10-noded } \\
\text { Quadratic } \\
\text { Tetrahedron }\end{array}$ & YES & 82.7 & 85.2 & 0.97 & 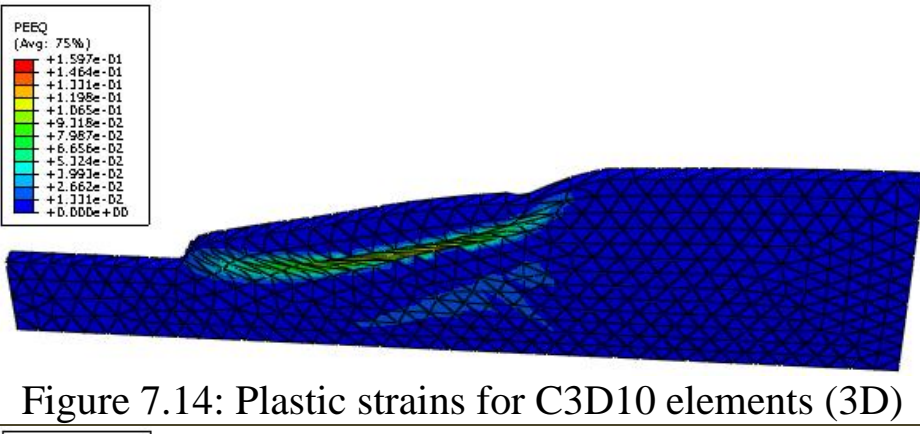 \\
\hline $\mathrm{M}-\mathrm{C}$ & $\mathrm{C} 3 \mathrm{D} 10 \mathrm{H}$ & $\begin{array}{c}\text { 10-noded } \\
\text { Quadratic } \\
\text { Tetrahedron, } \\
\text { Hybrid, } \\
\text { Constant } \\
\text { Pressure }\end{array}$ & NO & 338.3 & 35.2 & 0.63 & 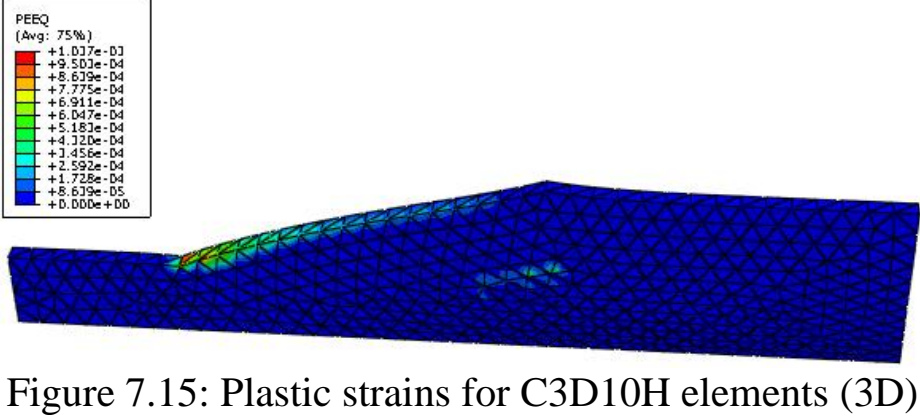 \\
\hline
\end{tabular}


Table 7.1 (Continued)

\begin{tabular}{|c|c|c|c|c|c|c|c|}
\hline $\begin{array}{l}\text { Failure } \\
\text { Criteria }\end{array}$ & $\begin{array}{l}\text { Element } \\
\text { Type }\end{array}$ & $\begin{array}{c}\text { Element } \\
\text { Description }\end{array}$ & $\begin{array}{c}\text { Acceptable } \\
\text { Failure }\end{array}$ & $\begin{array}{l}\mathbf{t}_{\mathrm{CPU}} \\
(\mathbf{s e c})\end{array}$ & $\begin{array}{c}\% \\
\text { Completion }\end{array}$ & FOS & Failure Mechanism \\
\hline $\mathrm{M}-\mathrm{C}$ & C3D10M & $\begin{array}{l}\text { 10-noded } \\
\text { Modified } \\
\text { Quadratic } \\
\text { Tetrahedron }\end{array}$ & YES & 125.0 & 88.4 & 0.99 & 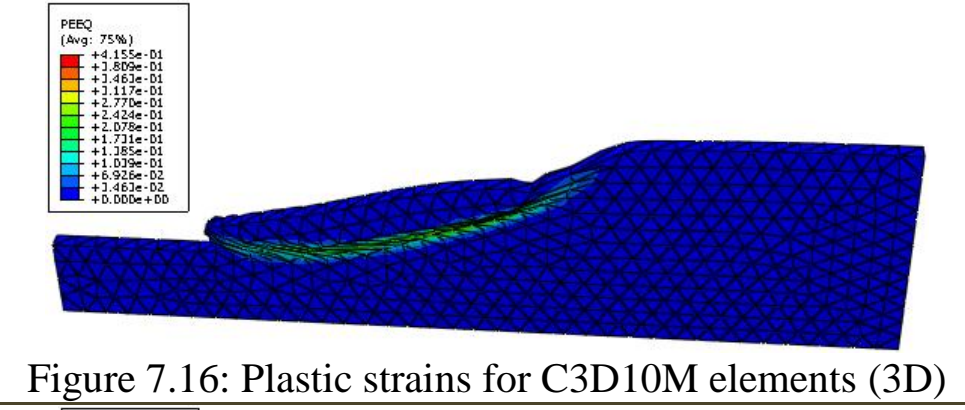 \\
\hline $\mathrm{M}-\mathrm{C}$ & C3D10MH & $\begin{array}{c}\text { 10-noded } \\
\text { Modified } \\
\text { Quadratic } \\
\text { Tetrahedron, } \\
\text { Hybrid with } \\
\text { Linear } \\
\text { Pressure }\end{array}$ & NO & 1050.3 & 41.9 & 0.72 & 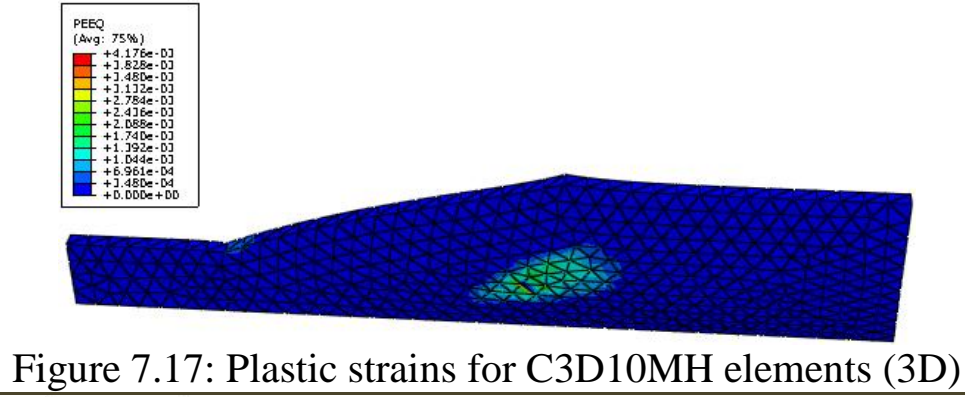 \\
\hline $\mathrm{M}-\mathrm{C}$ & C3D10I & $\begin{array}{l}\text { 10-noded } \\
\text { General } \\
\text { Purpose } \\
\text { Tetrahedron } \\
\text { w/Improved } \\
\text { Surface } \\
\quad \text { Stress } \\
\text { Formulation }\end{array}$ & NO & 21.9 & 25.0 & 0.79 & 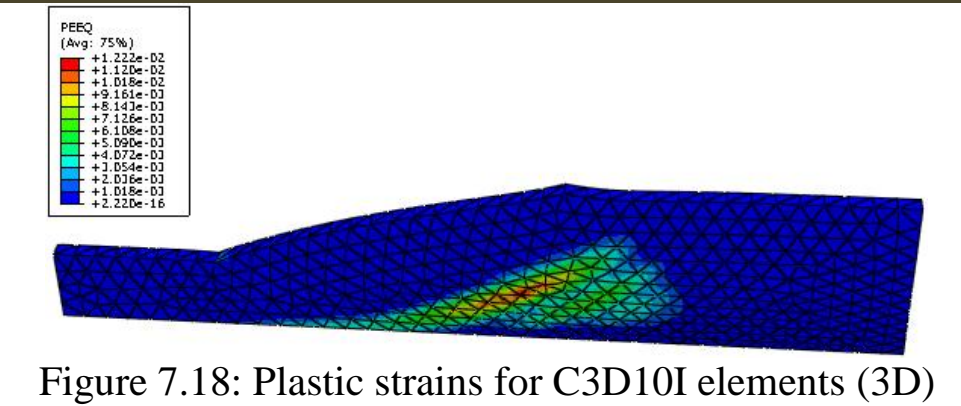 \\
\hline
\end{tabular}


Table 7.1 (Continued)

\begin{tabular}{|c|c|c|c|c|c|c|c|}
\hline $\begin{array}{l}\text { Failure } \\
\text { Criteria }\end{array}$ & $\begin{array}{c}\text { Element } \\
\text { Type }\end{array}$ & $\begin{array}{c}\text { Element } \\
\text { Description }\end{array}$ & $\begin{array}{c}\text { Acceptable } \\
\text { Failure }\end{array}$ & $\begin{array}{l}\mathbf{t}_{\mathrm{CPU}} \\
(\mathrm{sec}) \\
\end{array}$ & $\begin{array}{c}\% \\
\text { Completion }\end{array}$ & FOS & Failure Mechanism \\
\hline $\mathrm{M}-\mathrm{C}$ & C3D15 & $\begin{array}{c}\text { 15-Node } \\
\text { Quadratic } \\
\text { Triangular } \\
\text { Prism }\end{array}$ & YES & 56.0 & 86.7 & 0.98 & 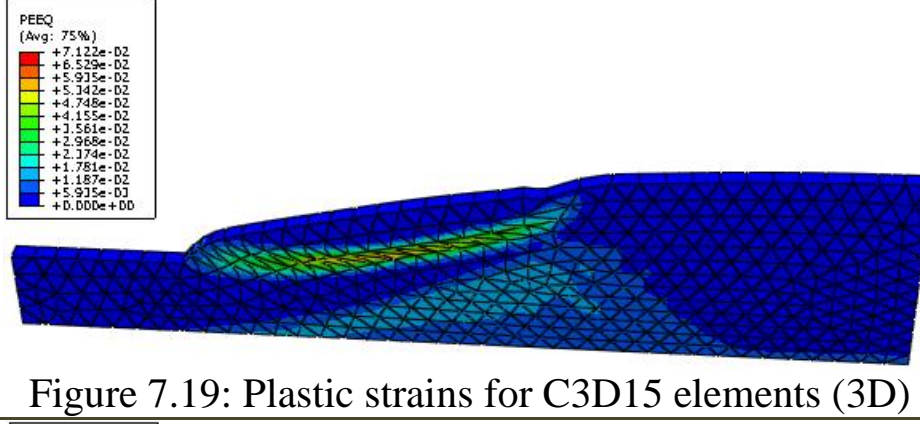 \\
\hline $\mathrm{M}-\mathrm{C}$ & C3D15H & $\begin{array}{c}\text { 15-Node } \\
\text { Quadratic } \\
\text { Triangular } \\
\text { Prism, } \\
\text { Hybrid, } \\
\text { Linear } \\
\text { Pressure }\end{array}$ & NO & 166.2 & 53.0 & 0.82 & 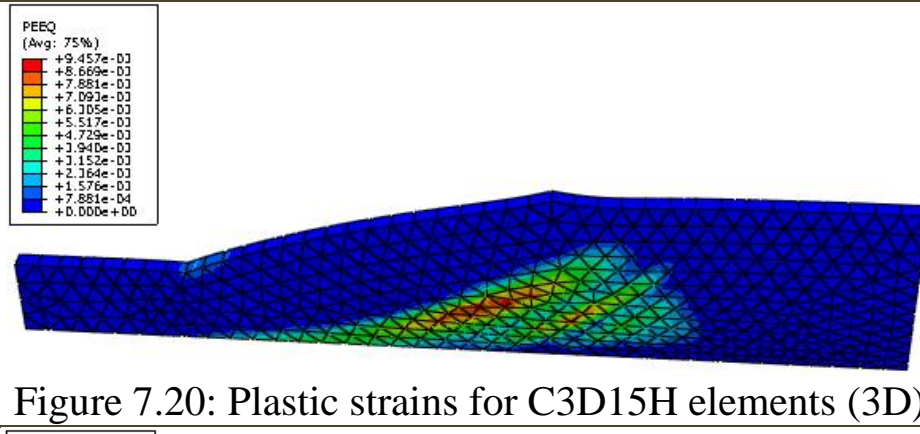 \\
\hline $\mathrm{M}-\mathrm{C}$ & C3D20 & $\begin{array}{c}\text { 20-Node } \\
\text { Quadratic } \\
\text { Brick }\end{array}$ & YES & 91.2 & 91.2 & 0.98 & 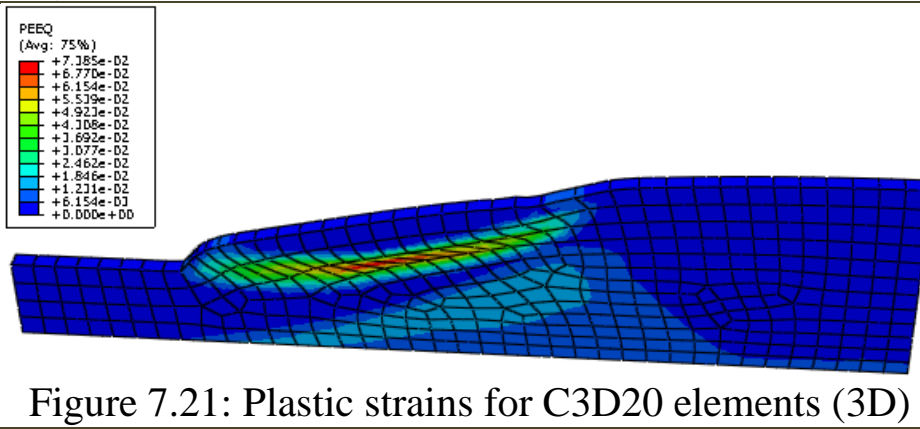 \\
\hline
\end{tabular}


Table 7.1 (Continued)

\begin{tabular}{|c|c|c|c|c|c|c|c|}
\hline $\begin{array}{l}\text { Failure } \\
\text { Criteria }\end{array}$ & $\begin{array}{c}\text { Element } \\
\text { Type }\end{array}$ & $\begin{array}{c}\text { Element } \\
\text { Description }\end{array}$ & $\begin{array}{c}\text { Acceptable } \\
\text { Failure }\end{array}$ & $\begin{array}{l}\mathbf{t}_{\mathrm{CPU}} \\
(\mathrm{sec})\end{array}$ & $\begin{array}{c}\% \% \\
\text { Completion }\end{array}$ & FOS & Failure Mechanism \\
\hline $\mathrm{M}-\mathrm{C}$ & $\mathrm{C} 3 \mathrm{D} 20 \mathrm{H}$ & $\begin{array}{c}\text { 20-Node } \\
\text { Quadratic } \\
\text { Brick, } \\
\text { Hybrid, } \\
\text { Linear } \\
\text { Pressure }\end{array}$ & NO & 334.4 & 57.8 & 0.79 & 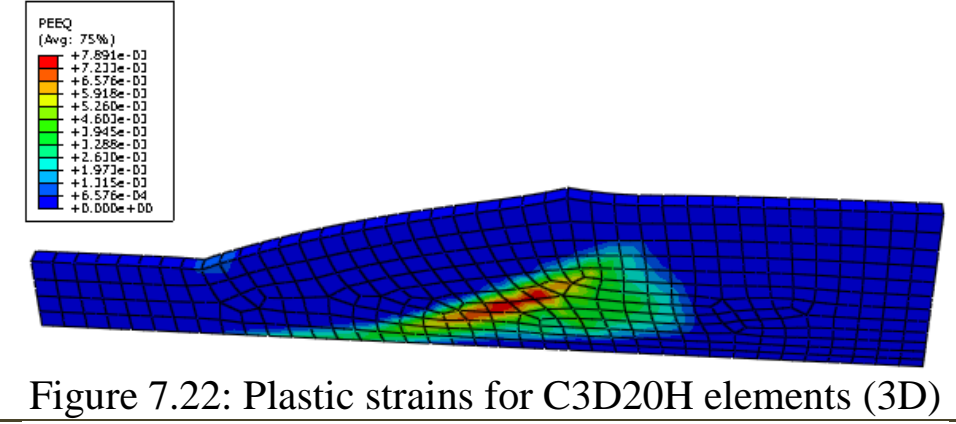 \\
\hline $\mathrm{M}-\mathrm{C}$ & C3D20R & $\begin{array}{l}\text { 20-Node } \\
\text { Quadratic } \\
\text { Brick, } \\
\text { Reduced } \\
\text { Integration }\end{array}$ & $\mathrm{NO}$ & 58.0 & 70.8 & 0.96 & 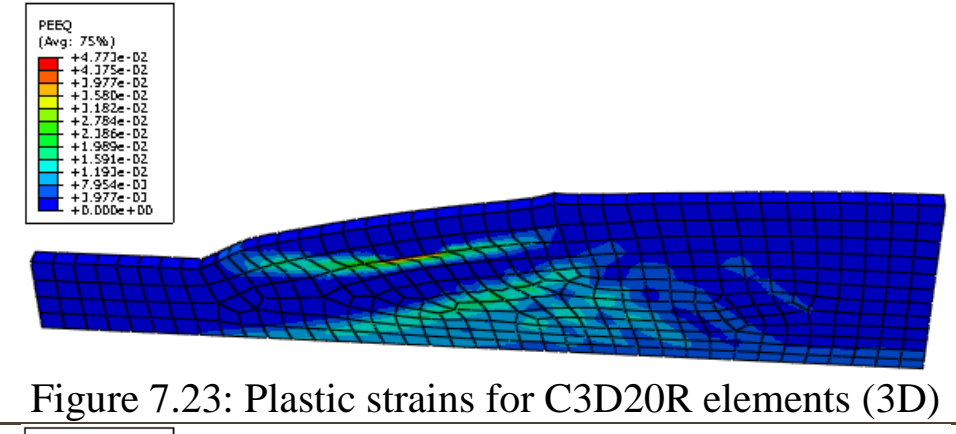 \\
\hline $\mathrm{M}-\mathrm{C}$ & C3D20RH & $\begin{array}{l}\text { 20-Node } \\
\text { Quadratic } \\
\text { Brick, } \\
\text { Hybrid, } \\
\text { Linear } \\
\text { Pressure, } \\
\text { Reduced } \\
\text { Integration }\end{array}$ & NO & 144.8 & 24.3 & 0.71 & 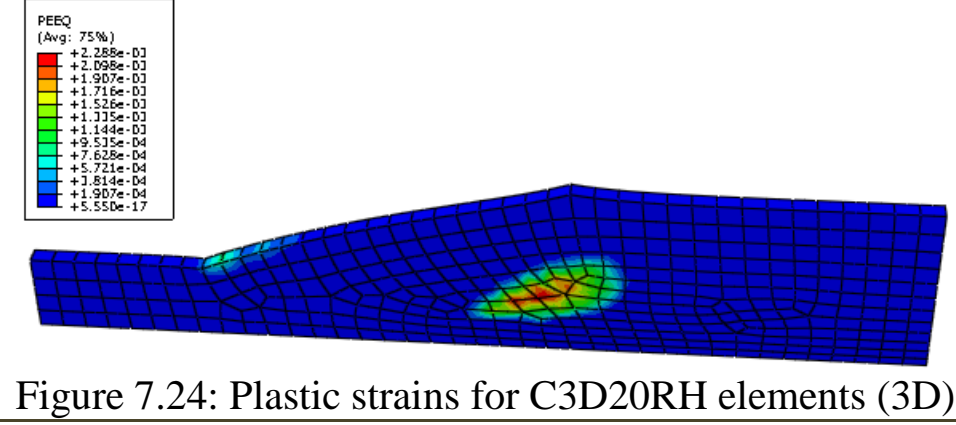 \\
\hline
\end{tabular}


Table 7.2 Comparison of Three-Dimensional Element Type for Drucker-Prager Model

\begin{tabular}{|c|c|c|c|c|c|c|c|}
\hline $\begin{array}{l}\text { Failure } \\
\text { Criteria }\end{array}$ & $\begin{array}{c}\text { Element } \\
\text { Type }\end{array}$ & $\begin{array}{c}\text { Element } \\
\text { Description }\end{array}$ & $\begin{array}{c}\text { Acceptable } \\
\text { Failure }\end{array}$ & $\begin{array}{l}\mathbf{t}_{\mathrm{CPU}} \\
(\mathrm{sec})\end{array}$ & $\begin{array}{c}\% \% \\
\text { Completion }\end{array}$ & FOS & Failure Mechanism \\
\hline D-P & C3D4 & $\begin{array}{l}\text { 4-noded } \\
\text { Linear } \\
\text { Tetrahedron }\end{array}$ & NO & 7.4 & 75.5 & 0.94 & 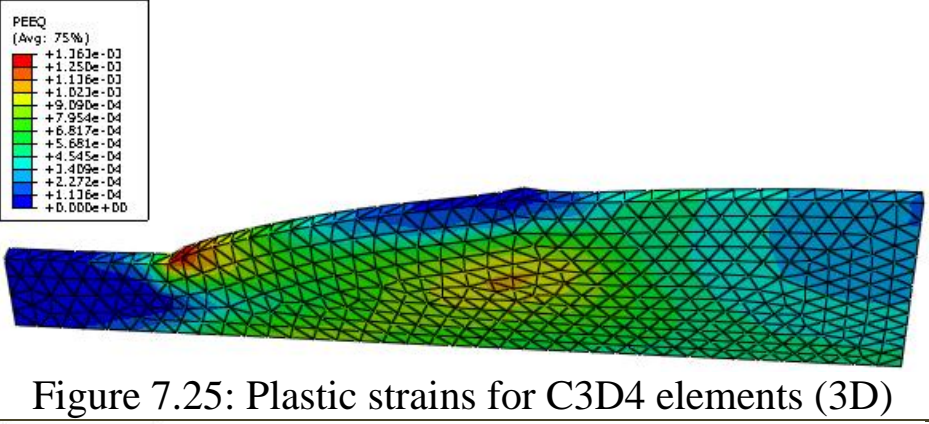 \\
\hline D-P & $\mathrm{C} 3 \mathrm{D} 4 \mathrm{H}$ & $\begin{array}{c}\text { 4-noded } \\
\text { Linear } \\
\text { Tetrahedron, } \\
\text { Hybrid, } \\
\text { Linear } \\
\text { Pressure }\end{array}$ & NO & 53.4 & 79.3 & 0.96 & 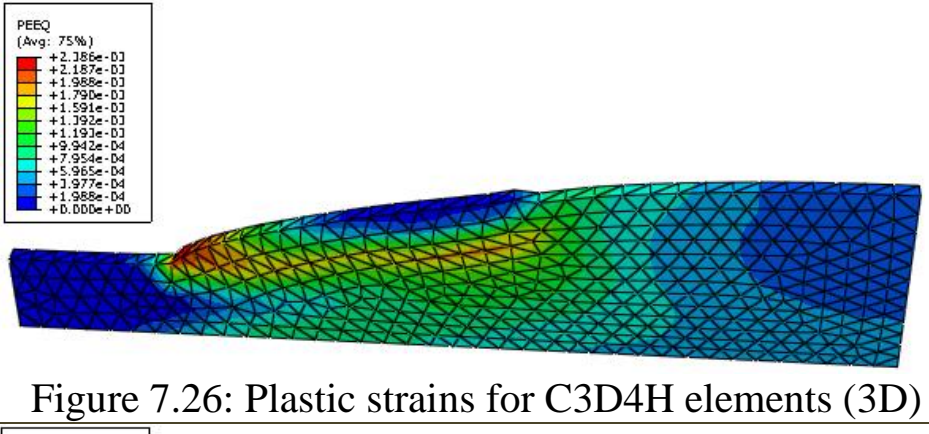 \\
\hline D-P & C3D6 & $\begin{array}{l}\text { 6-noded } \\
\text { Linear } \\
\text { Triangular } \\
\text { Prism }\end{array}$ & YES & 0.6 & 100 & 1.06 & 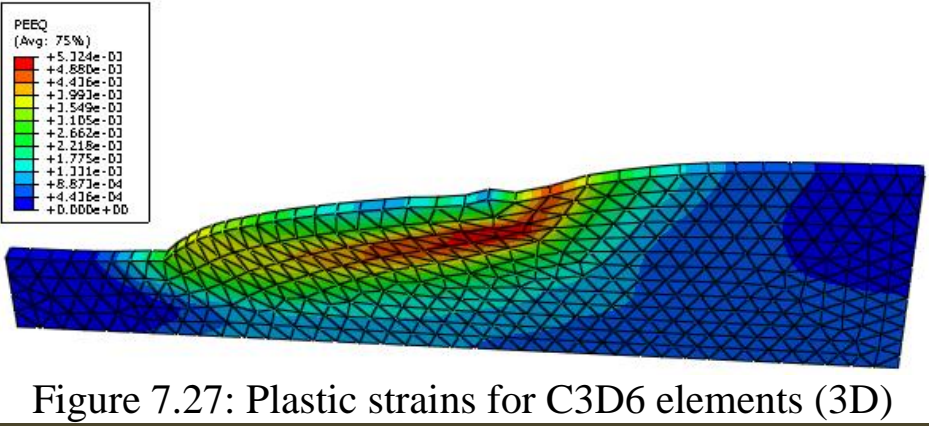 \\
\hline
\end{tabular}


Table 7.2 (Continued)

\begin{tabular}{|c|c|c|c|c|c|c|c|}
\hline $\begin{array}{l}\text { Failure } \\
\text { Criteria }\end{array}$ & $\begin{array}{c}\text { Element } \\
\text { Type }\end{array}$ & $\begin{array}{c}\text { Element } \\
\text { Description }\end{array}$ & $\begin{array}{c}\text { Acceptable } \\
\text { Failure }\end{array}$ & $\begin{array}{l}\mathbf{t}_{\mathrm{CPU}} \\
(\mathrm{sec})\end{array}$ & $\begin{array}{c}\% \% \\
\text { Completion }\end{array}$ & FOS & Failure Mechanism \\
\hline D-P & C3D6H & $\begin{array}{c}\text { 6-noded } \\
\text { Linear } \\
\text { Triangular } \\
\text { Prism, } \\
\text { Hybrid, } \\
\text { Constant } \\
\text { Pressure }\end{array}$ & YES & 0.8 & 100 & 1.06 & 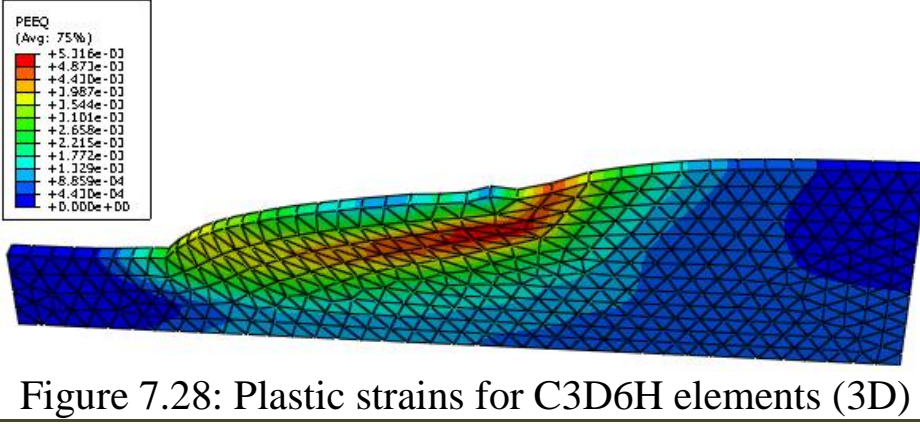 \\
\hline D-P & C3D8 & $\begin{array}{l}\text { 8-noded } \\
\text { Linear } \\
\text { Brick }\end{array}$ & YES & 7.5 & 81.9 & 0.97 & 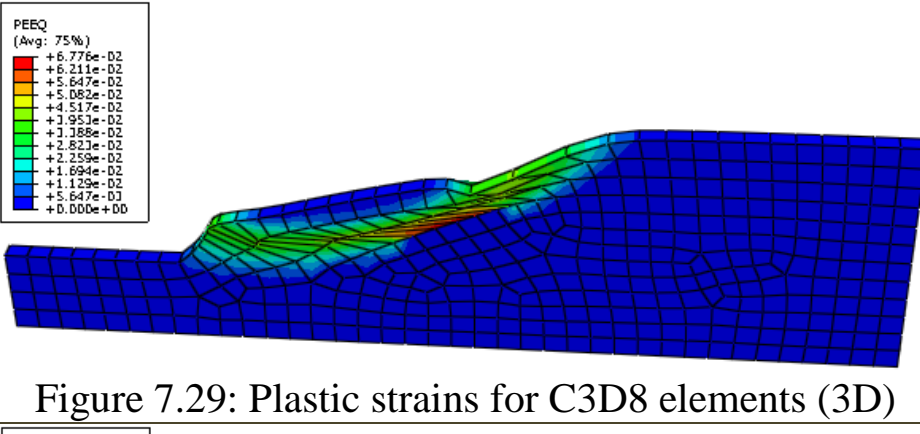 \\
\hline D-P & C3D8H & $\begin{array}{c}\text { 8-noded } \\
\text { Linear } \\
\text { Brick, } \\
\text { Hybrid, } \\
\text { Constant } \\
\text { Pressure }\end{array}$ & YES & 8.6 & 81.9 & 0.97 & 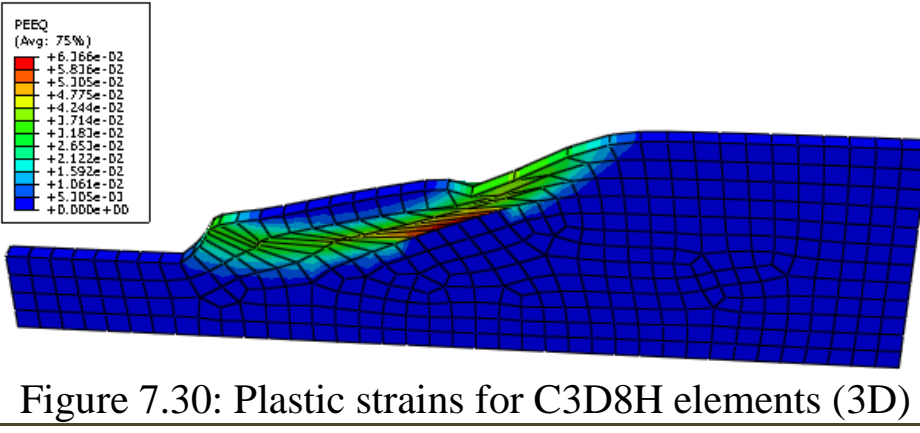 \\
\hline
\end{tabular}


Table 7.2 (Continued)

\begin{tabular}{|c|c|c|c|c|c|c|c|}
\hline $\begin{array}{l}\text { Failure } \\
\text { Criteria }\end{array}$ & $\begin{array}{c}\text { Element } \\
\text { Type }\end{array}$ & $\begin{array}{c}\text { Element } \\
\text { Description }\end{array}$ & $\begin{array}{c}\text { Acceptable } \\
\text { Failure }\end{array}$ & $\begin{array}{l}\mathbf{t}_{\mathrm{CPU}} \\
(\mathrm{sec})\end{array}$ & $\begin{array}{c}\% \% \\
\text { Completion }\end{array}$ & FOS & Failure Mechanism \\
\hline D-P & C3D8R & $\begin{array}{l}\text { 8-noded } \\
\text { Linear } \\
\text { Brick, } \\
\text { Reduced } \\
\text { Integration, } \\
\text { Hourglass } \\
\text { Control }\end{array}$ & YES & 2.9 & 100 & 1.02 & 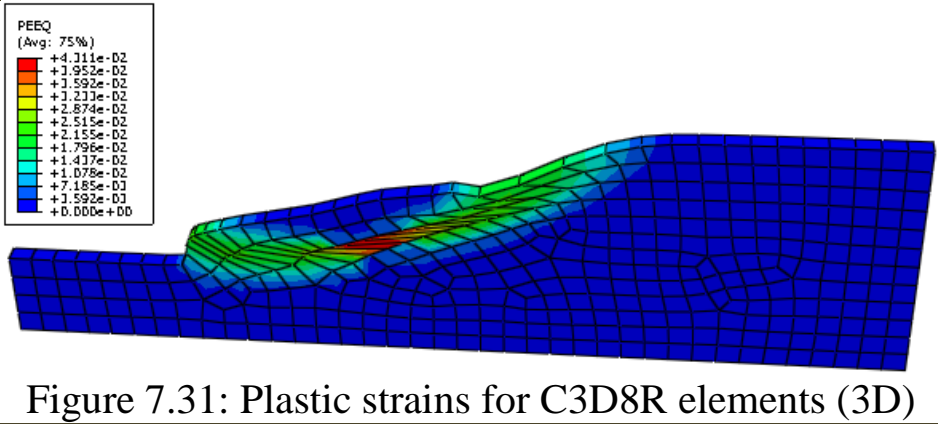 \\
\hline D-P & C3D8RH & $\begin{array}{c}\text { 8-noded } \\
\text { Linear } \\
\text { Brick, } \\
\text { Hybrid, } \\
\text { Constant } \\
\text { Pressure, } \\
\text { Reduced } \\
\text { Integration, } \\
\text { Hourglass } \\
\text { Control } \\
\end{array}$ & YES & 16.0 & 75.9 & 0.95 & 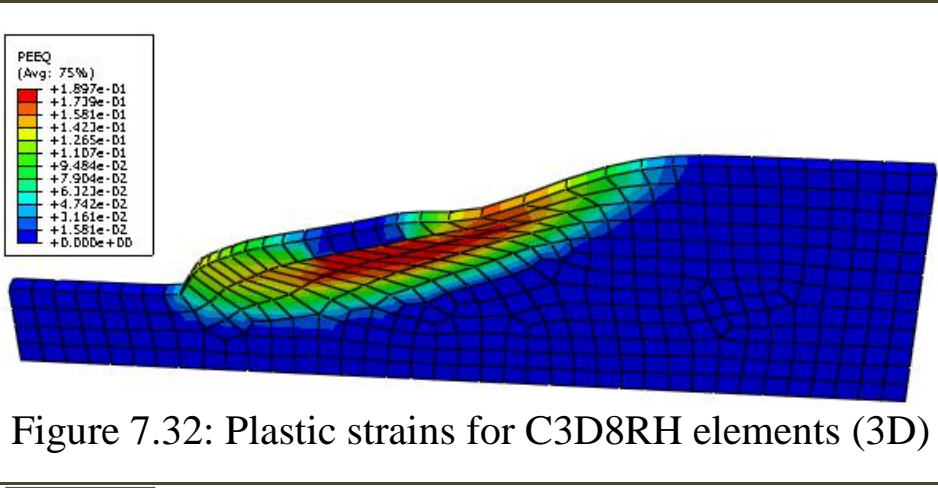 \\
\hline D-P & C3D8I & $\begin{array}{c}\text { 8-noded } \\
\text { Linear } \\
\text { Brick, } \\
\text { Incompatible } \\
\text { Modes }\end{array}$ & YES & 3.2 & 100 & 1.02 & 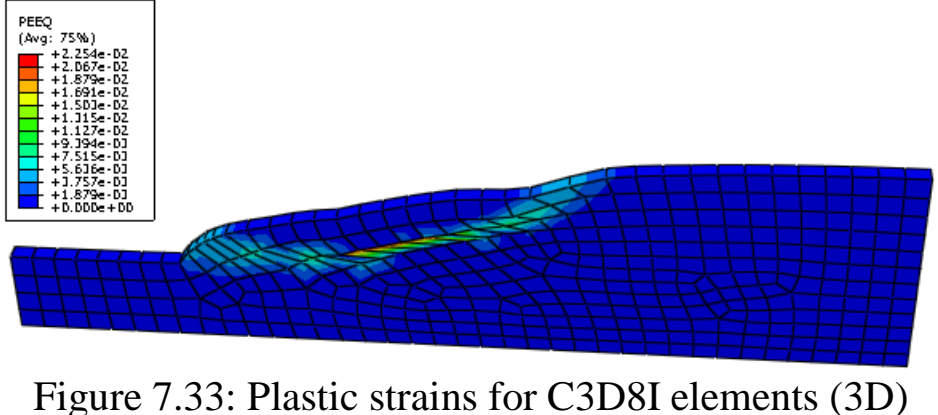 \\
\hline
\end{tabular}


Table 7.2 (Continued)

\begin{tabular}{|c|c|c|c|c|c|c|c|}
\hline $\begin{array}{l}\text { Failure } \\
\text { Criteria }\end{array}$ & $\begin{array}{c}\text { Element } \\
\text { Type }\end{array}$ & \begin{tabular}{c|} 
Element \\
Description
\end{tabular} & $\begin{array}{c}\text { Acceptable } \\
\text { Failure }\end{array}$ & $\begin{array}{l}\mathbf{t}_{\mathrm{CPU}} \\
(\mathrm{sec})\end{array}$ & $\begin{array}{c}\% \% \\
\text { Completion }\end{array}$ & FOS & Failure Mechanism \\
\hline D-P & C3D8IH & $\begin{array}{l}\text { 8-noded } \\
\text { Linear } \\
\text { Brick, } \\
\text { Hybrid, } \\
\text { Linear } \\
\text { Pressure, } \\
\text { Incompatible } \\
\text { Modes } \\
\end{array}$ & $\mathrm{NO}$ & 42.3 & 23.9 & 0.60 & 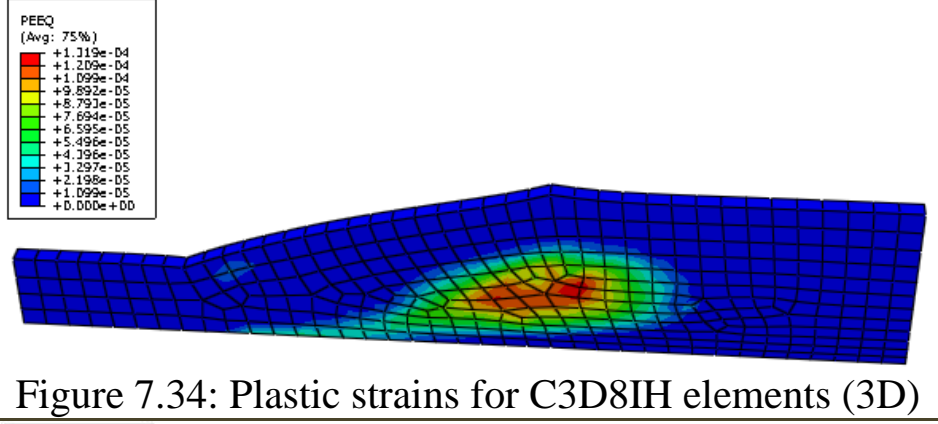 \\
\hline D-P & C3D10 & $\begin{array}{c}\text { 10-noded } \\
\text { Quadratic } \\
\text { Tetrahedron }\end{array}$ & YES & 41.7 & 70.9 & 0.94 & 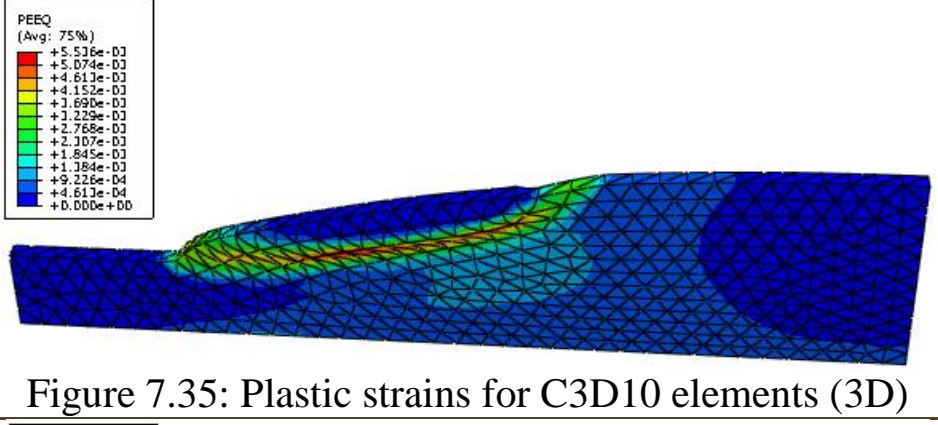 \\
\hline D-P & C3D10H & $\begin{array}{c}\text { 10-noded } \\
\text { Quadratic } \\
\text { Tetrahedron, } \\
\text { Hybrid, } \\
\text { Constant } \\
\text { Pressure }\end{array}$ & $\mathrm{NO}$ & 269.1 & 40.3 & 0.61 & 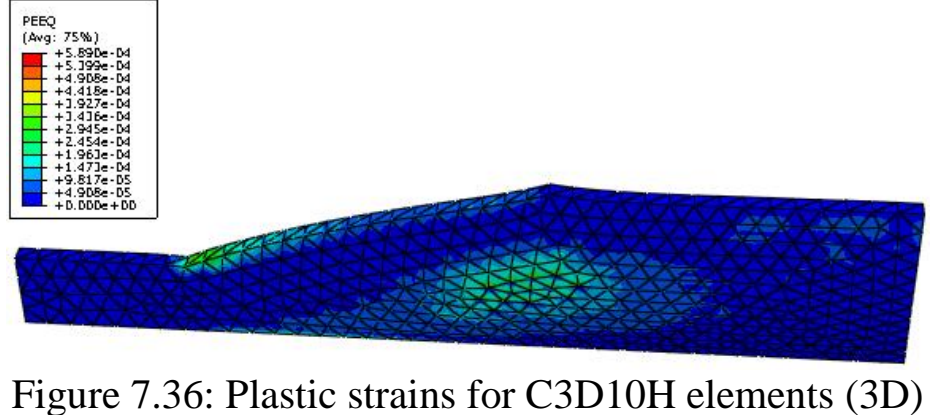 \\
\hline
\end{tabular}


Table 7.2 (Continued)

\begin{tabular}{|c|c|c|c|c|c|c|c|}
\hline $\begin{array}{l}\text { Failure } \\
\text { Criteria }\end{array}$ & $\begin{array}{c}\text { Element } \\
\text { Type }\end{array}$ & $\begin{array}{c}\text { Element } \\
\text { Description }\end{array}$ & $\begin{array}{c}\text { Acceptable } \\
\text { Failure }\end{array}$ & $\begin{array}{l}\mathbf{t}_{\text {CPU }} \\
(\mathbf{s e c})\end{array}$ & $\begin{array}{c}\% \% \\
\text { Completion }\end{array}$ & FOS & Failure Mechanism \\
\hline D-P & C3D10M & $\begin{array}{l}\text { 10-noded } \\
\text { Modified } \\
\text { Quadratic } \\
\text { Tetrahedron }\end{array}$ & YES & 52.8 & 69.0 & 0.94 & 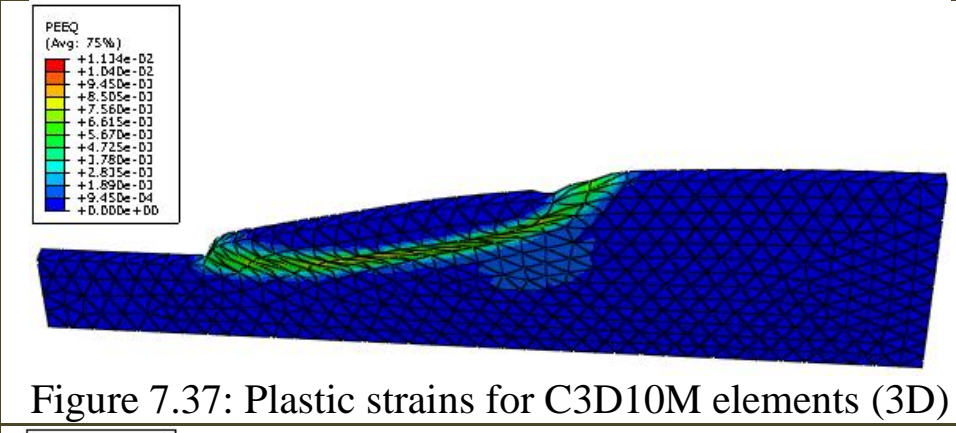 \\
\hline D-P & C3D10MH & $\begin{array}{c}\text { 10-noded } \\
\text { Modified } \\
\text { Quadratic } \\
\text { Tetrahedron, } \\
\text { Hybrid with } \\
\text { Linear } \\
\text { Pressure }\end{array}$ & $\mathrm{NO}$ & 546.9 & 62.9 & 0.92 & 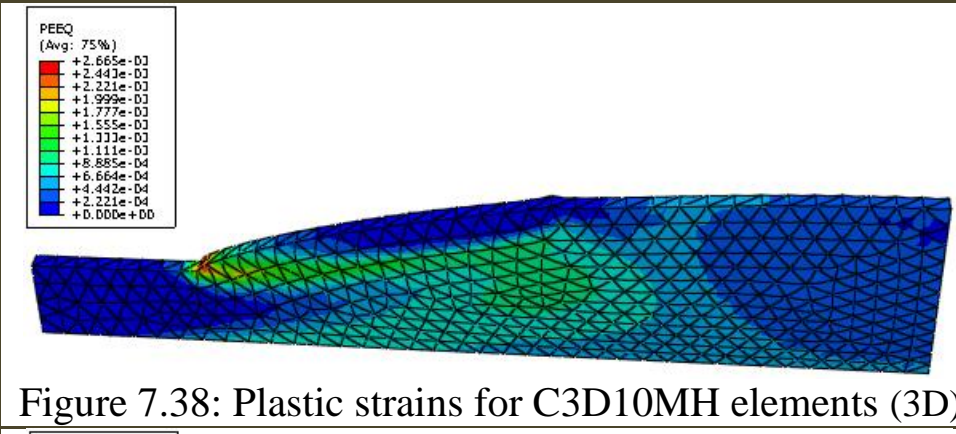 \\
\hline D-P & C3D10I & $\begin{array}{l}\text { 10-noded } \\
\text { General } \\
\text { Purpose } \\
\text { Tetrahedron } \\
\text { w/Improved } \\
\text { Surface } \\
\quad \text { Stress } \\
\text { Formulation }\end{array}$ & NO & 478.8 & 25.7 & 0.70 & 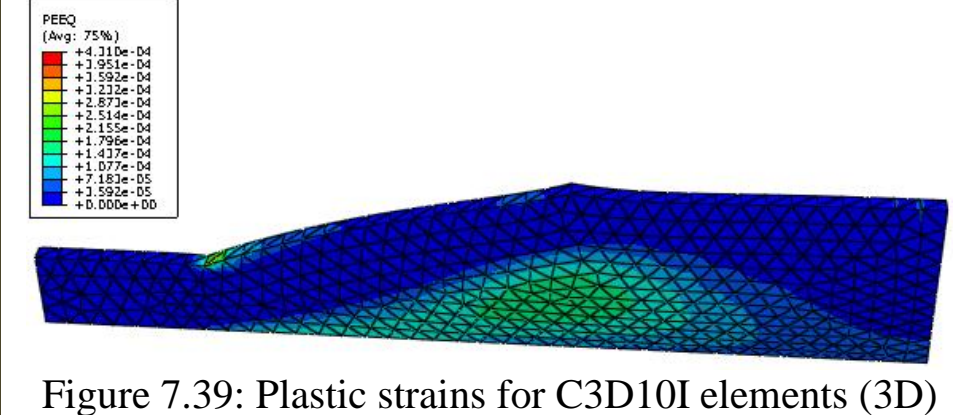 \\
\hline
\end{tabular}


Table 7.2 (Continued)

\begin{tabular}{|c|c|c|c|c|c|c|c|}
\hline $\begin{array}{l}\text { Failure } \\
\text { Criteria }\end{array}$ & $\begin{array}{c}\text { Element } \\
\text { Type }\end{array}$ & $\begin{array}{c}\text { Element } \\
\text { Description }\end{array}$ & $\begin{array}{c}\text { Acceptable } \\
\text { Failure }\end{array}$ & $\begin{array}{l}\mathbf{t}_{\mathrm{CPU}} \\
(\mathrm{sec})\end{array}$ & $\begin{array}{c}\% \% \\
\text { Completion }\end{array}$ & FOS & Failure Mechanism \\
\hline D-P & C3D15 & $\begin{array}{c}\text { 15-Node } \\
\text { Quadratic } \\
\text { Triangular } \\
\text { Prism }\end{array}$ & YES & 33.4 & 71.2 & 0.94 & 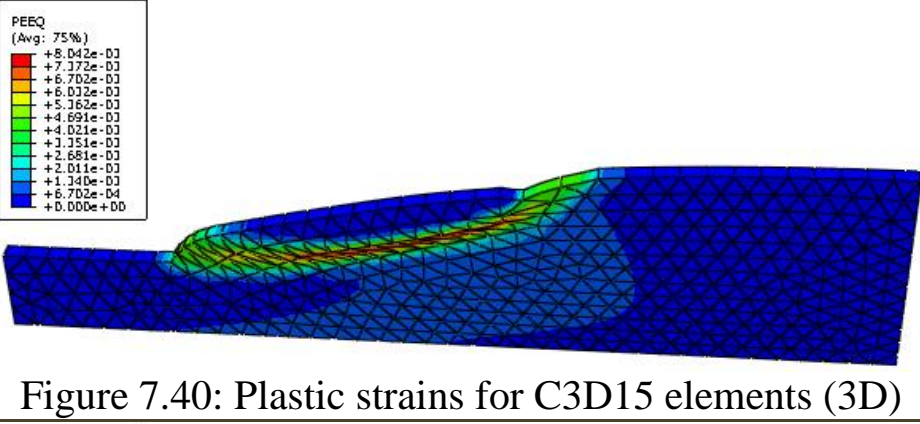 \\
\hline D-P & C3D15H & $\begin{array}{c}\text { 15-Node } \\
\text { Quadratic } \\
\text { Triangular } \\
\text { Prism, } \\
\text { Hybrid, } \\
\text { Linear } \\
\text { Pressure }\end{array}$ & YES & 39.1 & 71.2 & 0.94 & 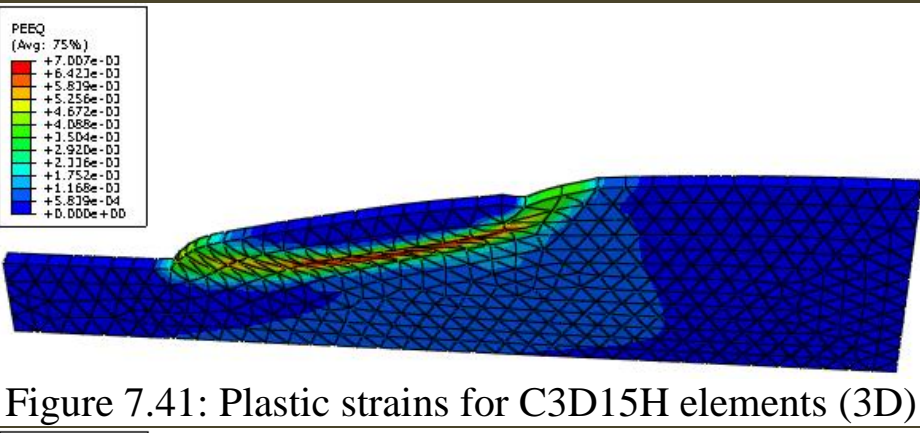 \\
\hline D-P & C3D20 & $\begin{array}{c}\text { 20-Node } \\
\text { Quadratic } \\
\text { Brick }\end{array}$ & YES & 67.5 & 72.5 & 0.94 & 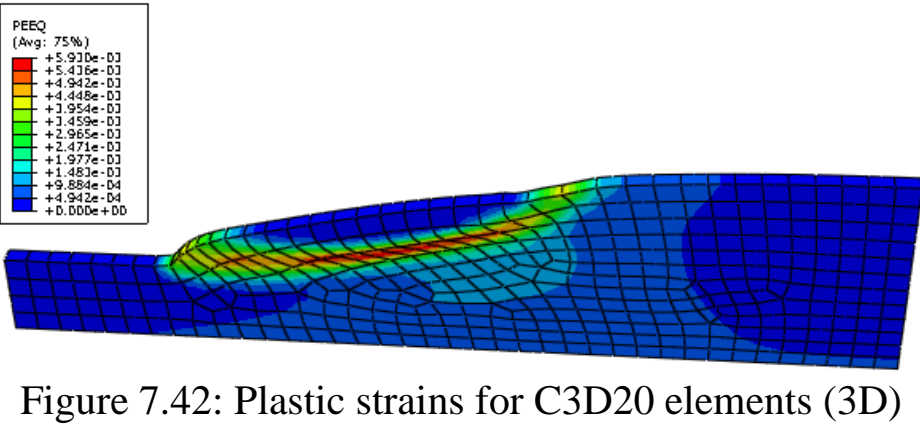 \\
\hline
\end{tabular}


Table 7.2 (Continued)

\begin{tabular}{|c|c|c|c|c|c|c|c|}
\hline $\begin{array}{l}\text { Failure } \\
\text { Criteria }\end{array}$ & $\begin{array}{c}\text { Element } \\
\text { Type }\end{array}$ & $\begin{array}{c}\text { Element } \\
\text { Description }\end{array}$ & $\begin{array}{c}\text { Acceptable } \\
\text { Failure }\end{array}$ & $\begin{array}{l}\mathbf{t}_{\mathrm{CPU}} \\
(\mathrm{sec})\end{array}$ & $\begin{array}{c}\% \% \\
\text { Completion }\end{array}$ & FOS & Failure Mechanism \\
\hline D-P & $\mathrm{C} 3 \mathrm{D} 20 \mathrm{H}$ & $\begin{array}{c}\text { 20-Node } \\
\text { Quadratic } \\
\text { Brick, } \\
\text { Hybrid, } \\
\text { Linear } \\
\text { Pressure }\end{array}$ & $\mathrm{NO}$ & 322.5 & 55.8 & 0.82 & 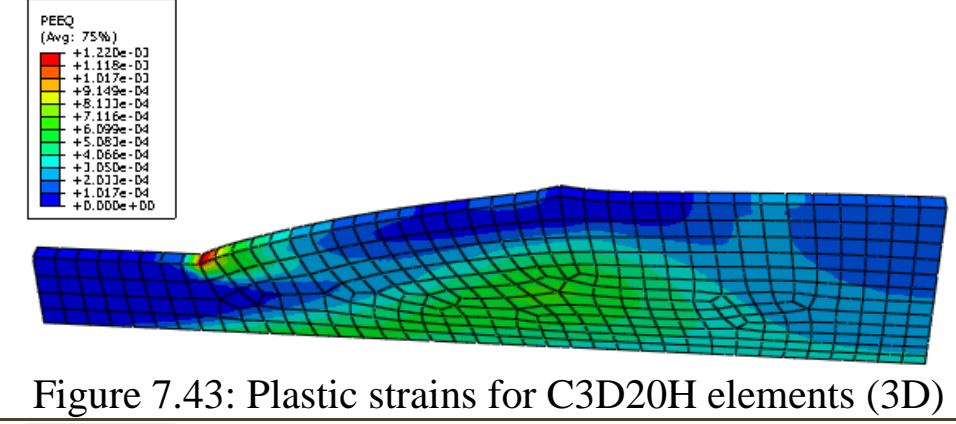 \\
\hline D-P & C3D20R & $\begin{array}{l}\text { 20-Node } \\
\text { Quadratic } \\
\text { Brick, } \\
\text { Reduced } \\
\text { Integration }\end{array}$ & $\mathrm{NO}$ & 33.7 & 68.3 & 0.93 & 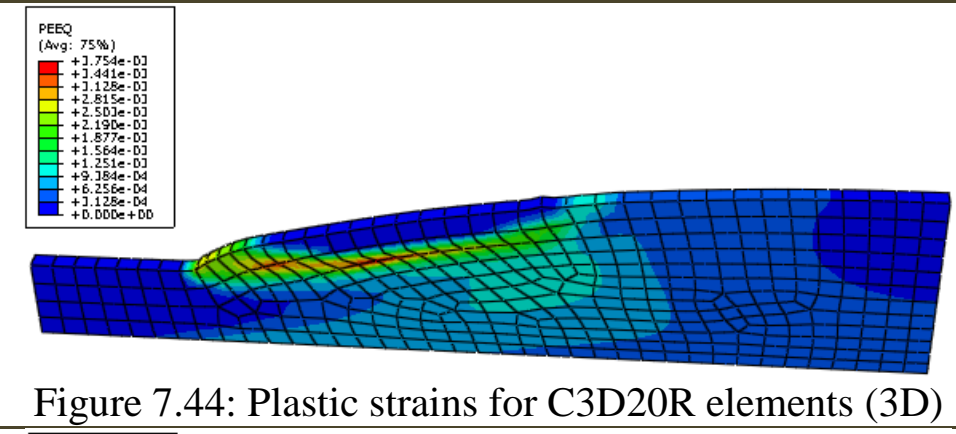 \\
\hline D-P & C3D20RH & $\begin{array}{l}\text { 20-Node } \\
\text { Quadratic } \\
\text { Brick, } \\
\text { Hybrid, } \\
\text { Linear } \\
\text { Pressure, } \\
\text { Reduced } \\
\text { Integration }\end{array}$ & NO & 46.5 & 31.2 & 0.66 & 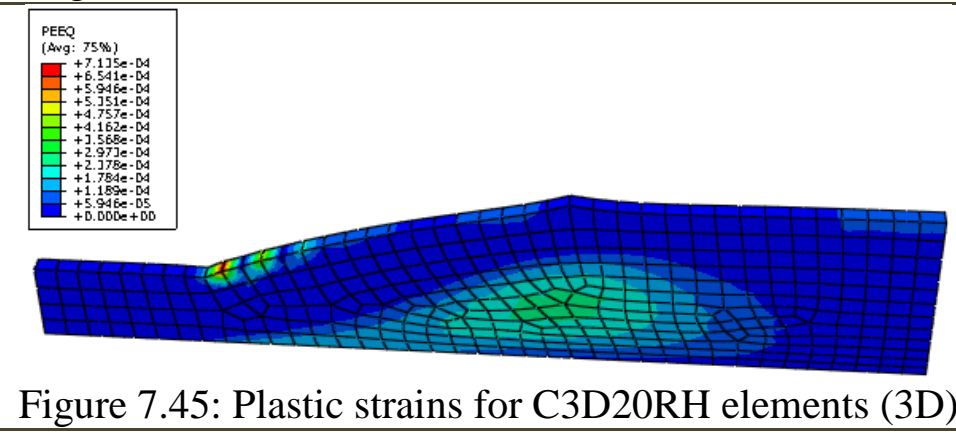 \\
\hline
\end{tabular}




\subsection{Three-Dimensional FEM Comparison to Two-Dimensional FEM and Limit Equilibrium Results for Unreinforced Slopes}

Three-dimensional FEM models were developed for unreinforced slopes with slope angles of $26.5^{\circ}, 50^{\circ}, 60^{\circ}, 70^{\circ}, 80^{\circ}$, and $90^{\circ}$, as presented in Section 5.4. In addition, twodimensional FEM and L-E models were completed for comparison, as presented in Sections 4.1 and 4.2, respectively. Table 7.3 contains the computed FOS values for the threedimensional FEM and two-dimensional FEM and L-E models. In addition, Figures 7.46 through 7.63 presents the results of the three-dimensional FEM, two-dimensional FEM and two-dimensional L-E models for each slope angle studied. PEEQ plots were used for the FEM models and critical failure circles are shown for the L-E analyses.

As is evident in Table 7.3, the three-dimensional FEM modeling consistently produced slightly higher FOS values compared to the two-dimensional FEM and L-E results. As discussed in Section 6.2, two-dimensional FEM and two-dimensional L-E results closely matched. However, all of the results were within a small margin. Since the C3D8 finite element type, which was chosen based on all of the criteria listed in previous sections, was used in nearly all of the three-dimensional FEM modeling in this research, the three-dimensional FEM results are expected to give slightly higher FOS values.

Table 7.3 Comparison of FOS for 3-D FEM, 2-D FEM, and L-E for Unreinforced Slopes

\begin{tabular}{|c|c|c|c|}
\hline Slope Angle $(\boldsymbol{\beta})$ & 3-D FEM FOS & 2-D FEM FOS & 2-D L-E FOS \\
\hline $26.5^{\circ}$ & 1.04 & 1.00 & 0.99 \\
\hline $50^{\circ}$ & 0.57 & 0.55 & 0.54 \\
\hline $60^{\circ}$ & 0.46 & 0.45 & 0.43 \\
\hline $70^{\circ}$ & 0.40 & 0.38 & 0.38 \\
\hline $80^{\circ}$ & 0.33 & 0.30 & 0.29 \\
\hline $90^{\circ}$ & 0.26 & 0.23 & 0.18 \\
\hline
\end{tabular}




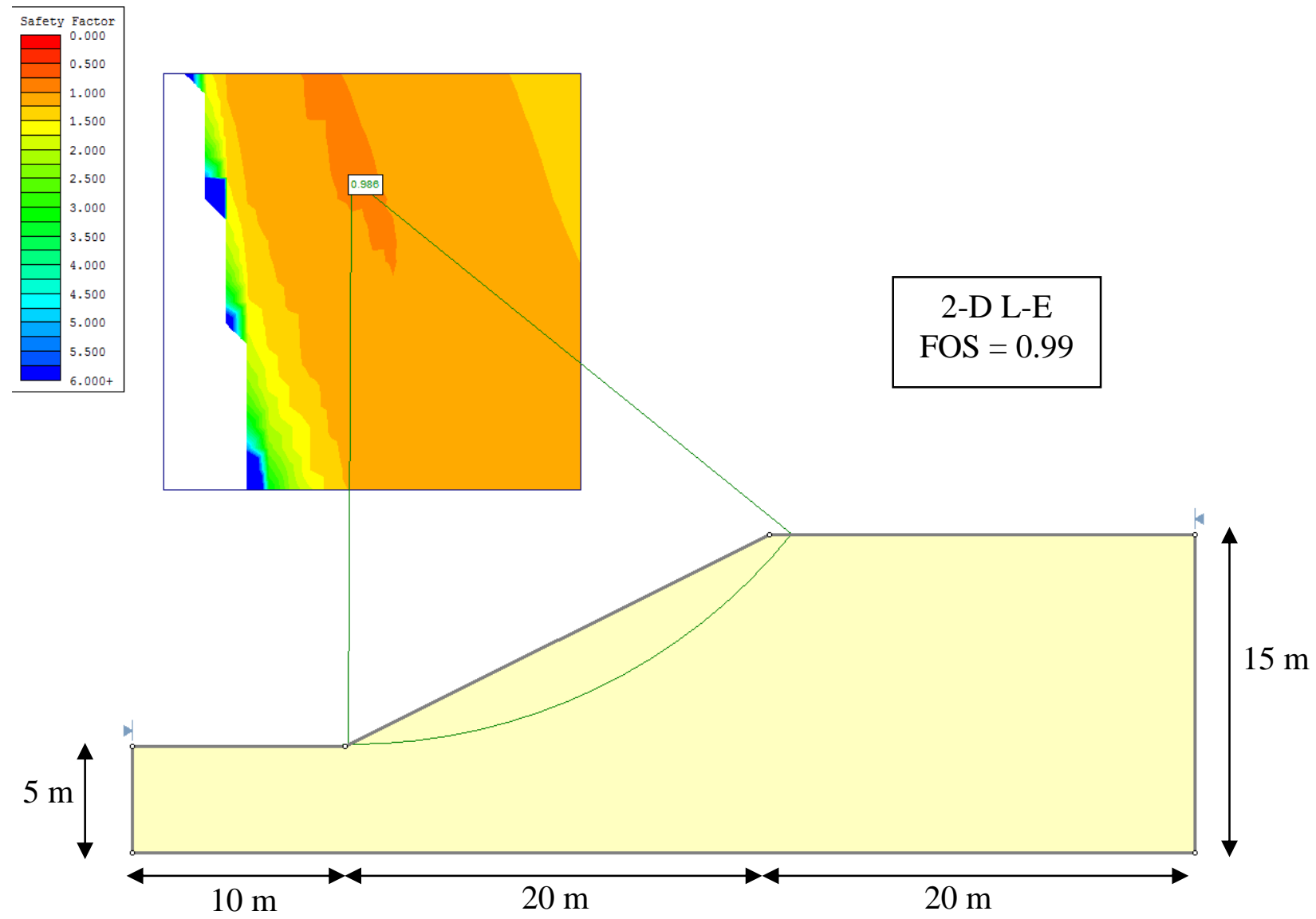

Figure 7.46 L-E Results for Two-Dimensional Unreinforced Slope - 26.5

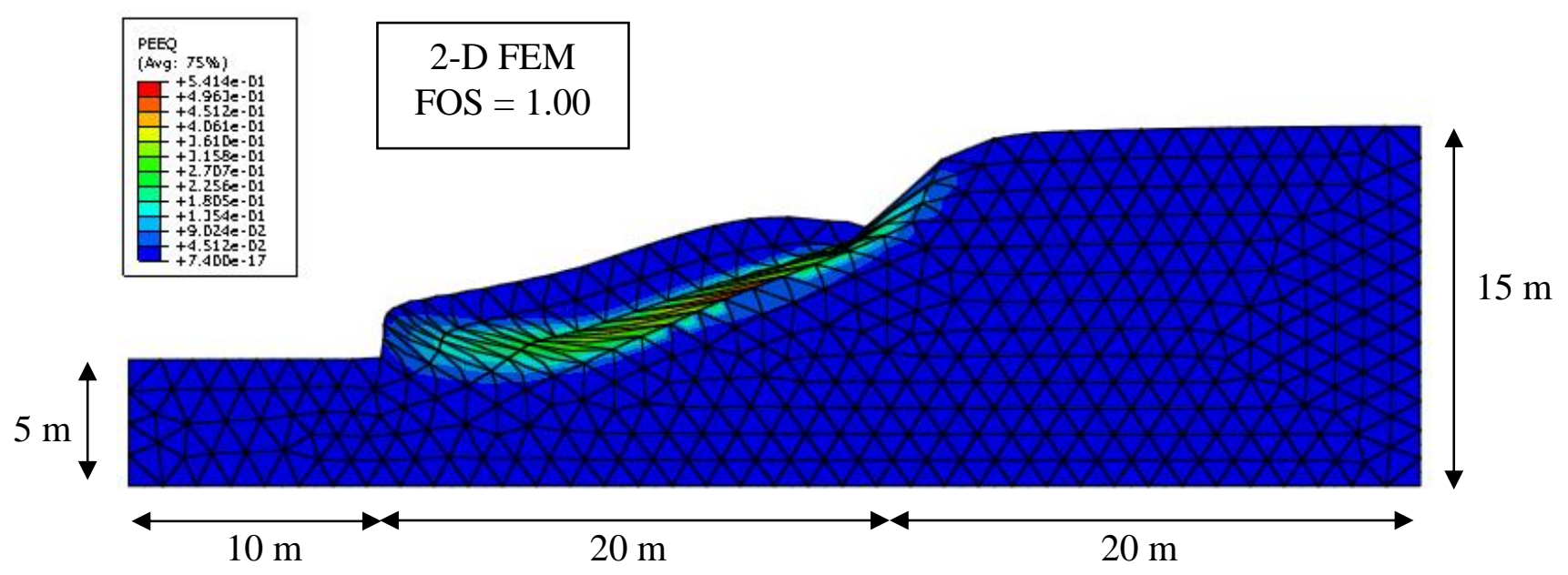

Figure 7.47 PEEQ Contour Plot for Two-Dimensional FEM Unreinforced Slope - 26.5 


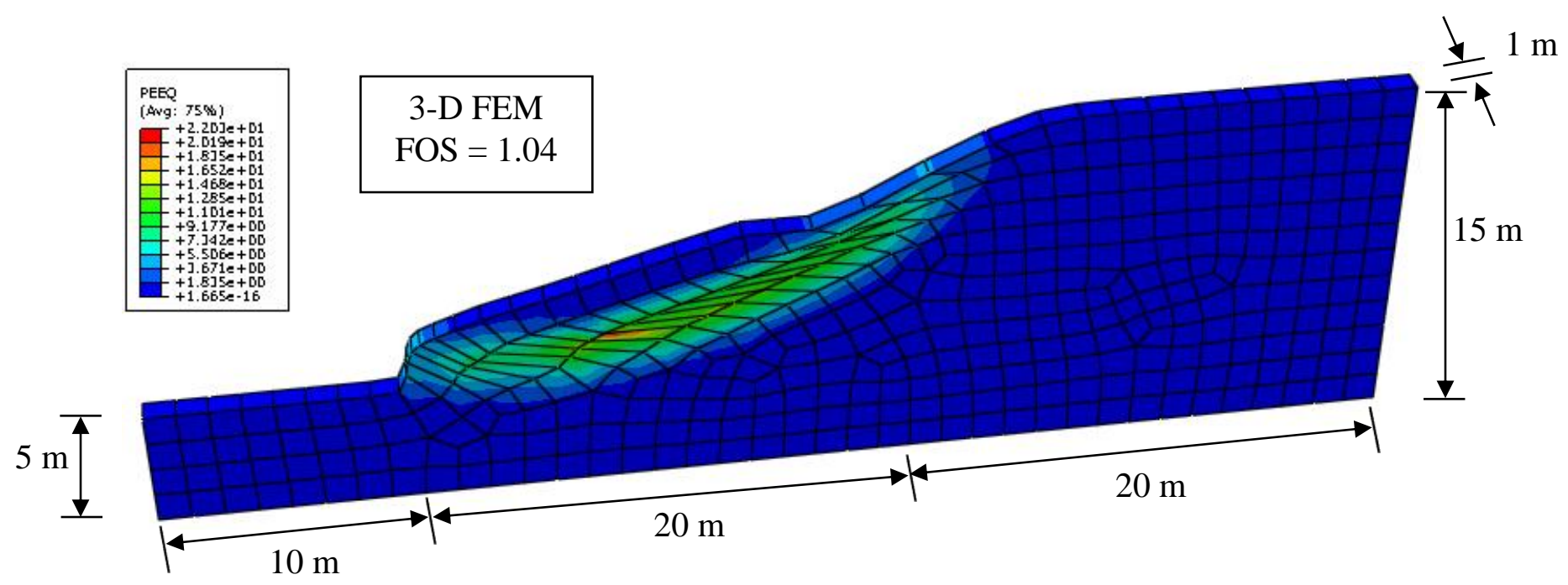

Figure 7.48 PEEQ Contour Plot for Three-Dimensional FEM Unreinforced Slope - $26.5^{\circ}$
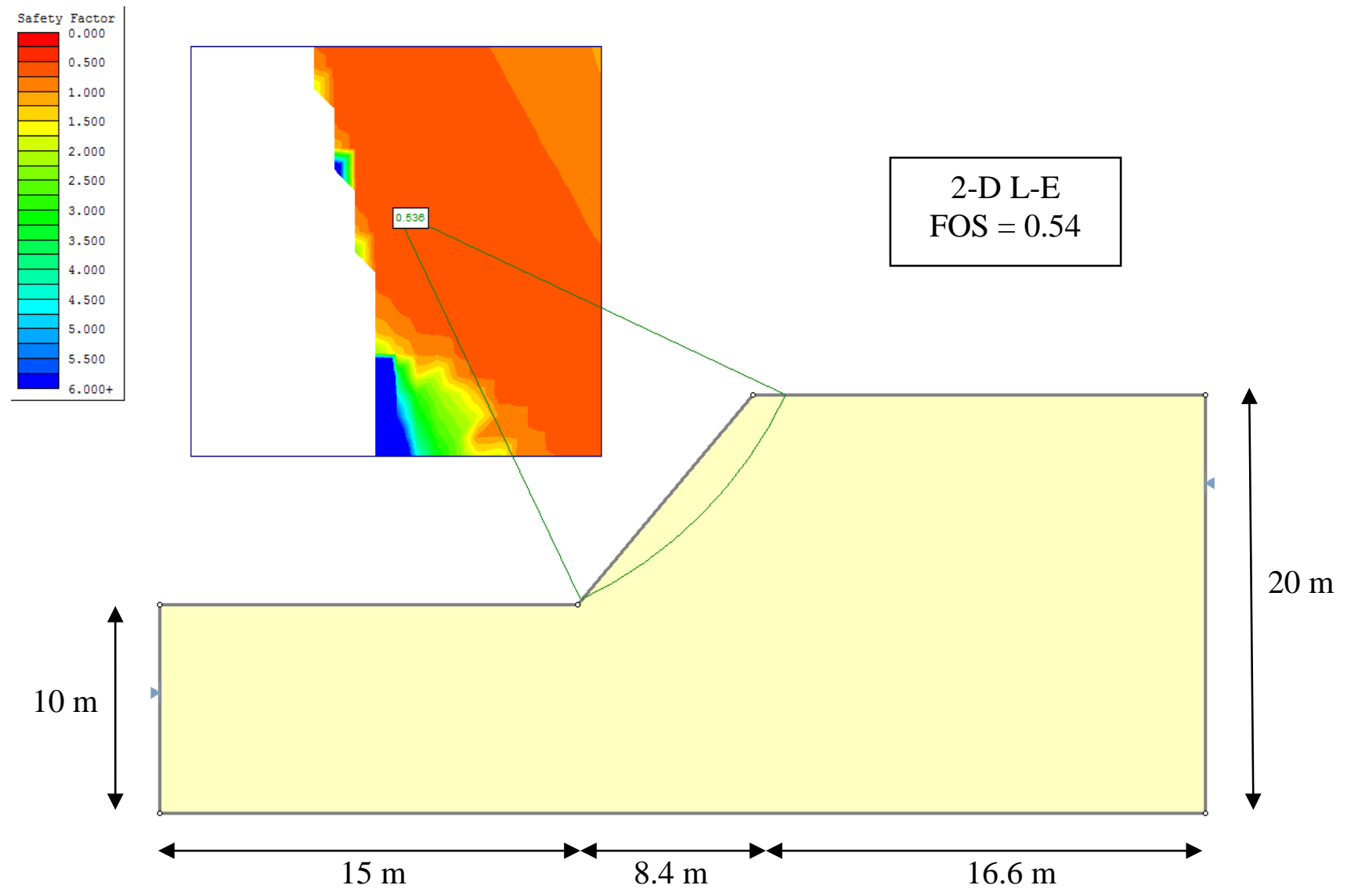

Figure 7.49 L-E Results for Two-Dimensional Unreinforced Slope - 50 


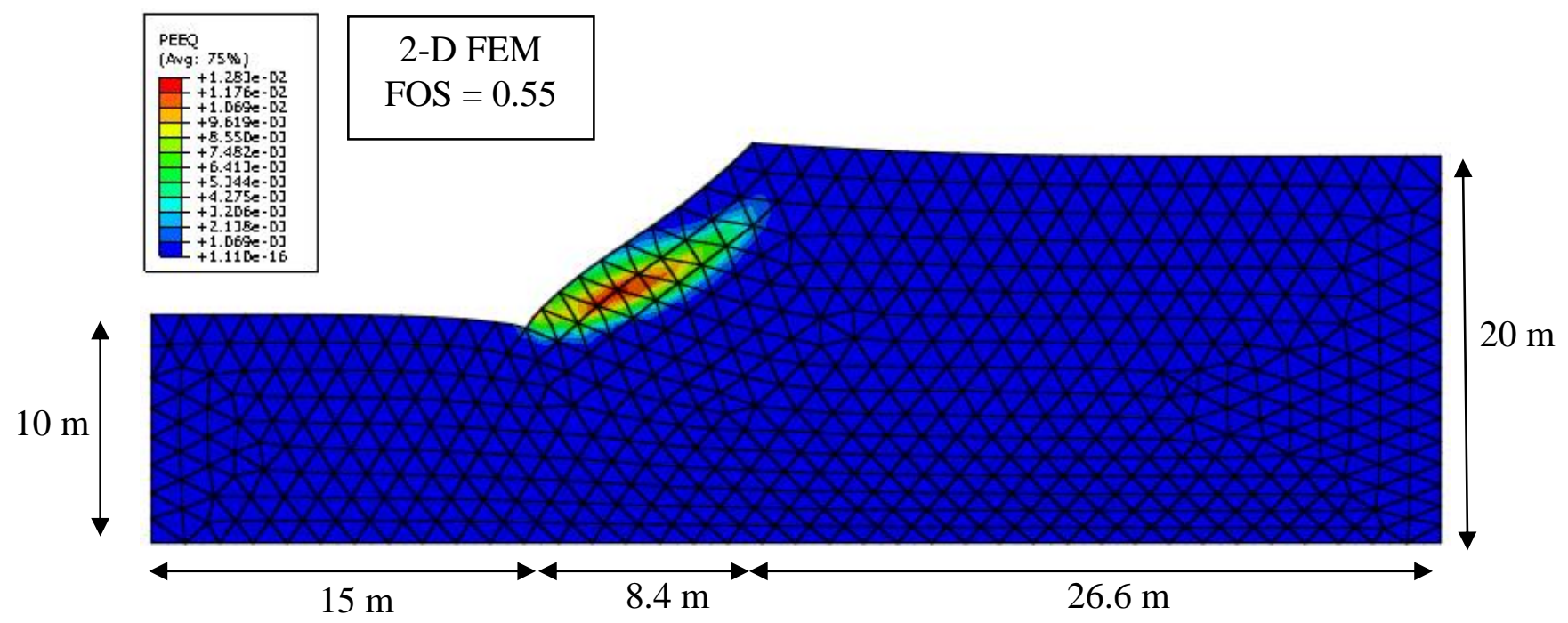

Figure 7.50 PEEQ Contour Plot for Two-Dimensional FEM Unreinforced Slope - 50

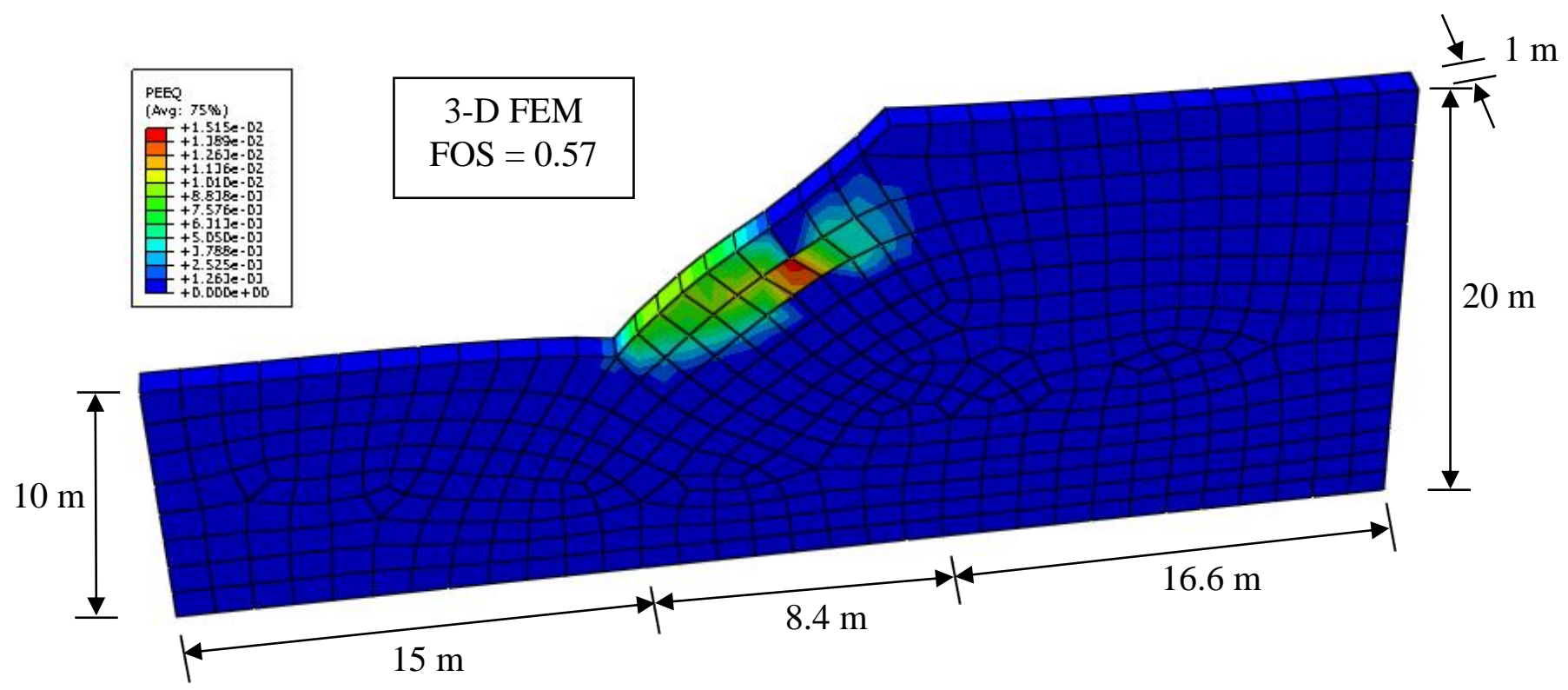

Figure 7.51 PEEQ Contour Plot for Three-Dimensional FEM Unreinforced Slope - 50 


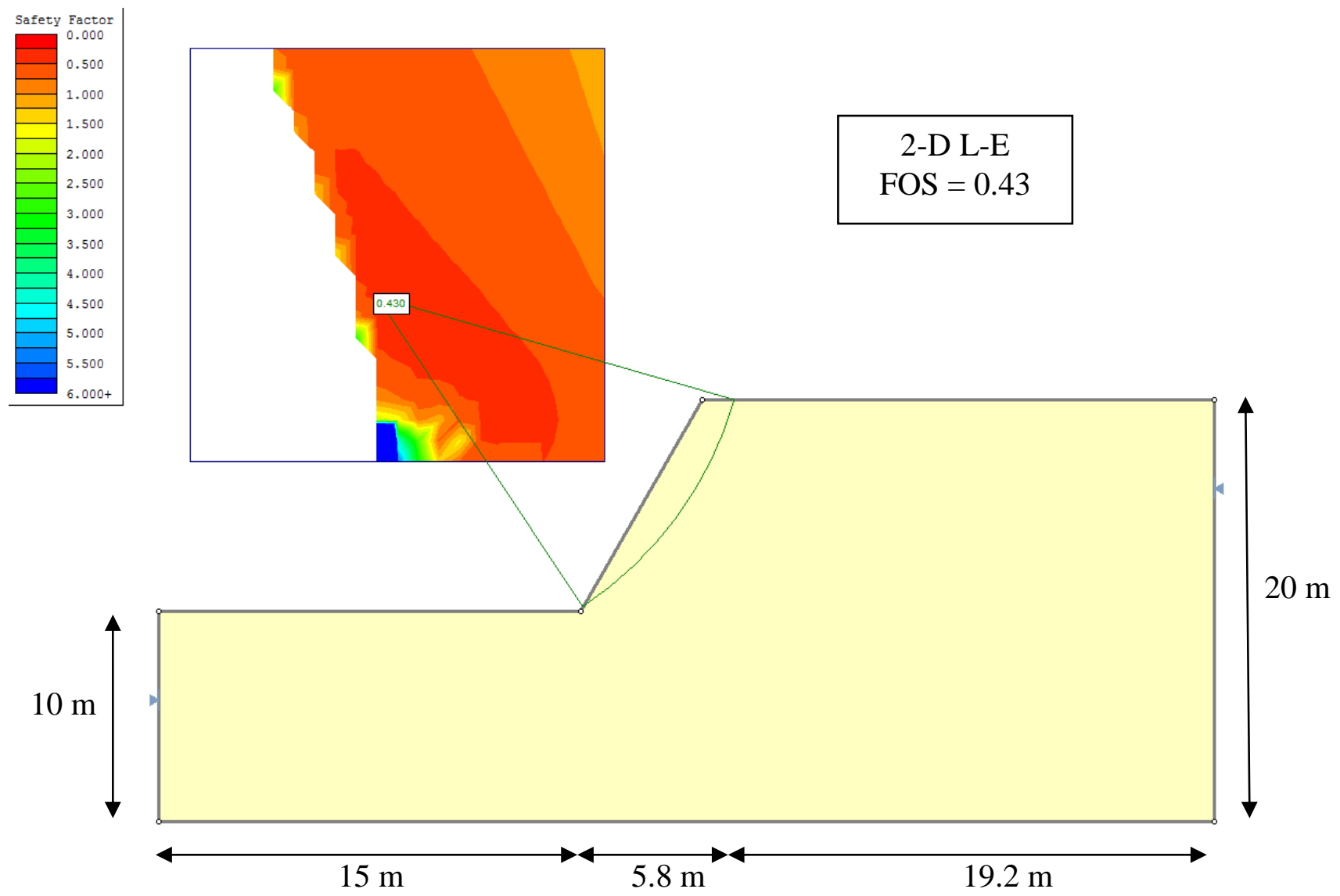

Figure 7.52 L-E Results for Two-Dimensional Unreinforced Slope - $60^{\circ}$

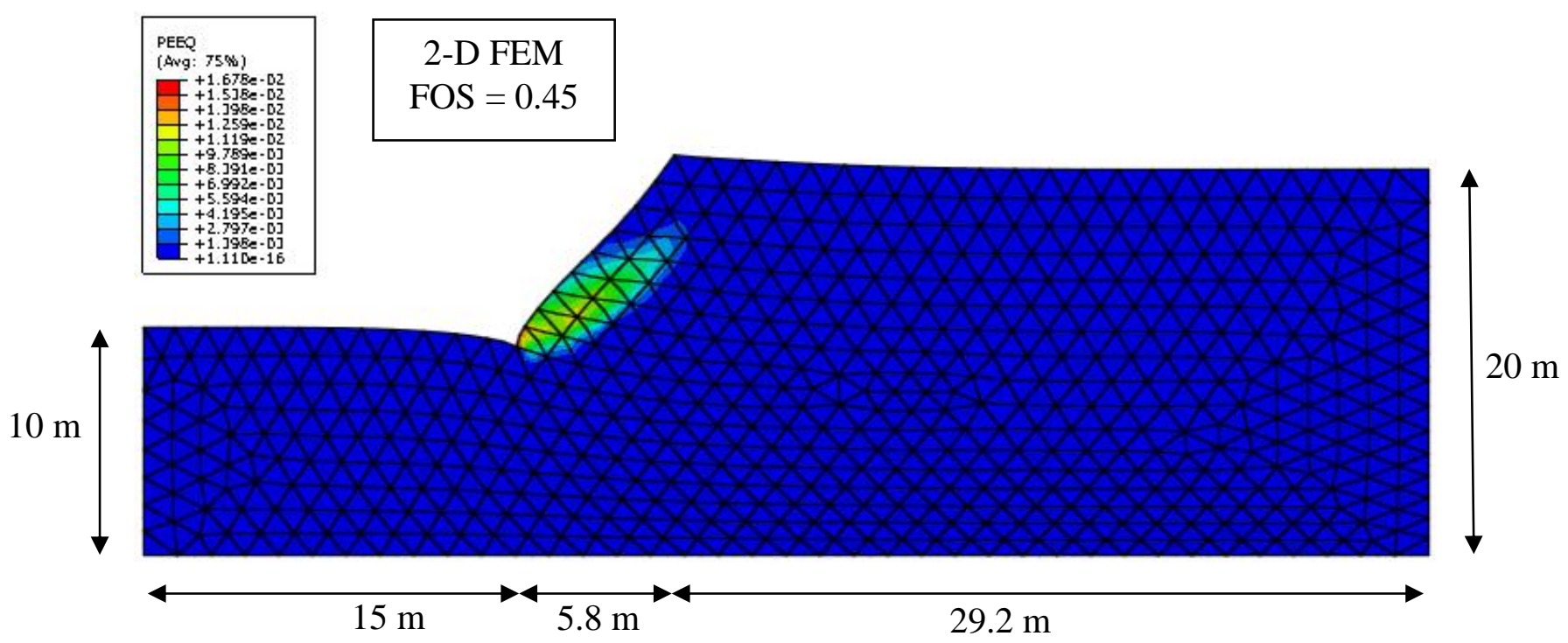

Figure 7.53 PEEQ Contour Plot for Two-Dimensional FEM Unreinforced Slope - $60^{\circ}$ 


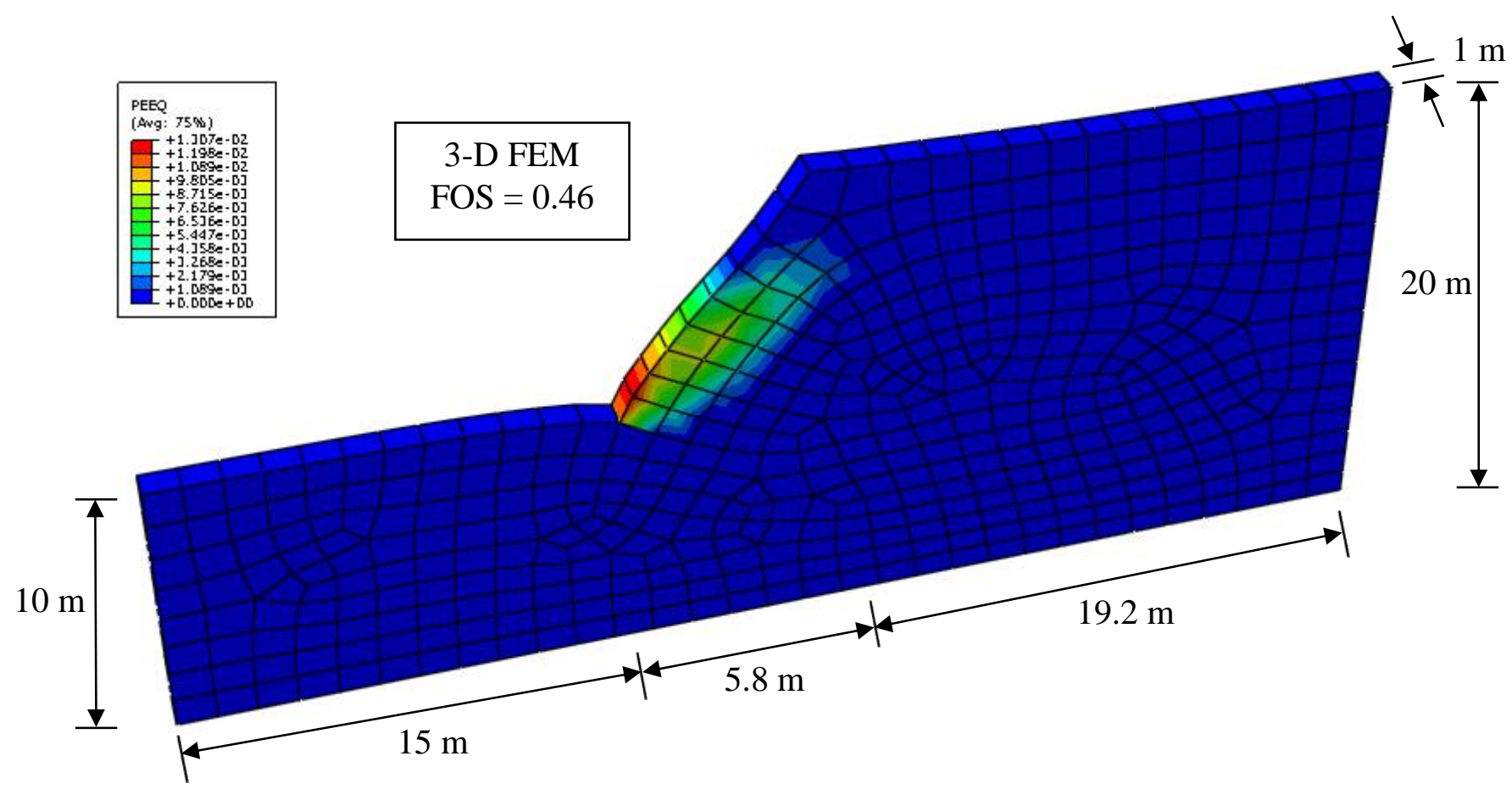

Figure 7.54 PEEQ Contour Plot for Three-Dimensional FEM Unreinforced Slope - $60^{\circ}$

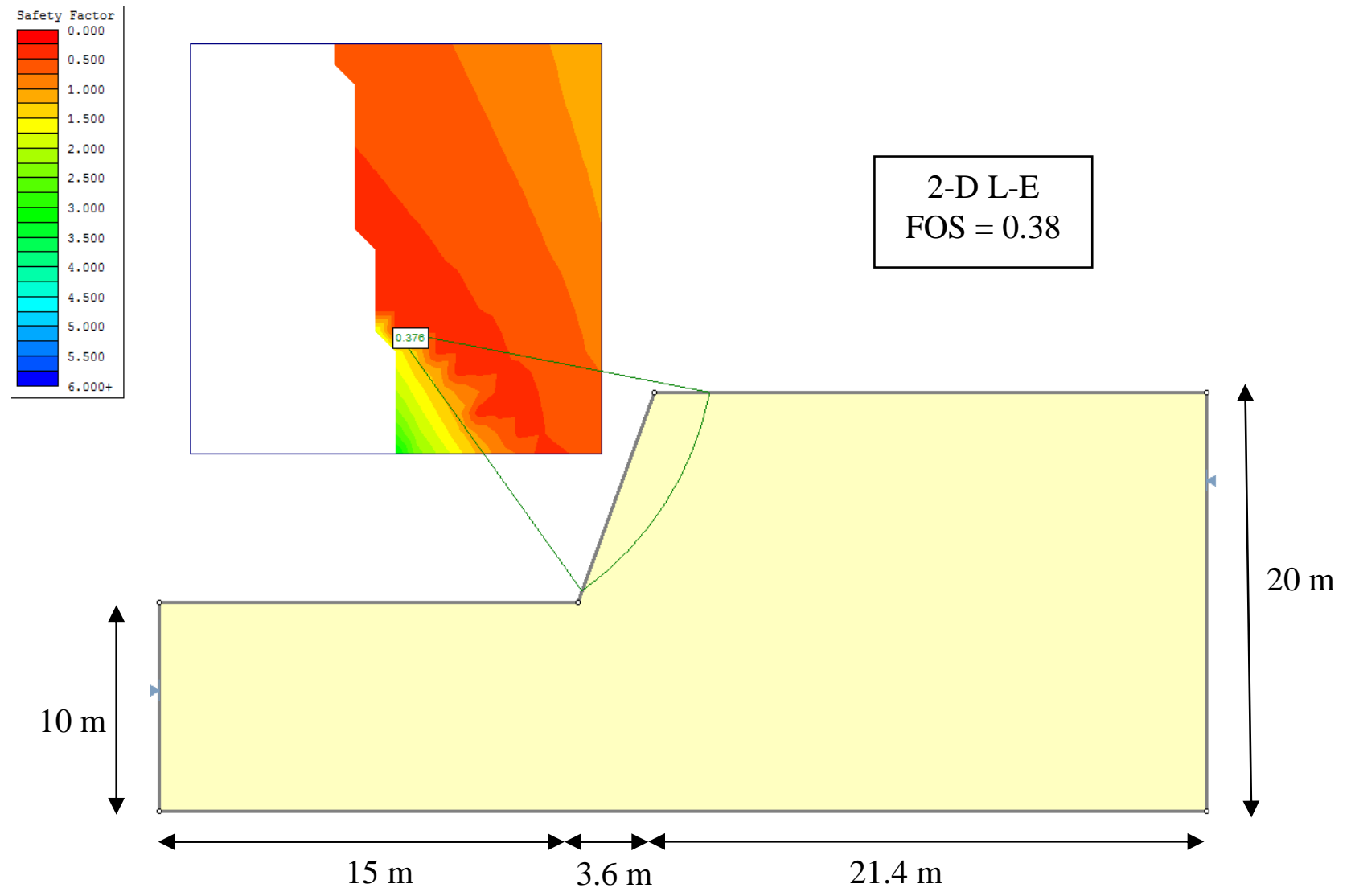

Figure 7.55 L-E Results for Two-Dimensional Unreinforced Slope - 70 


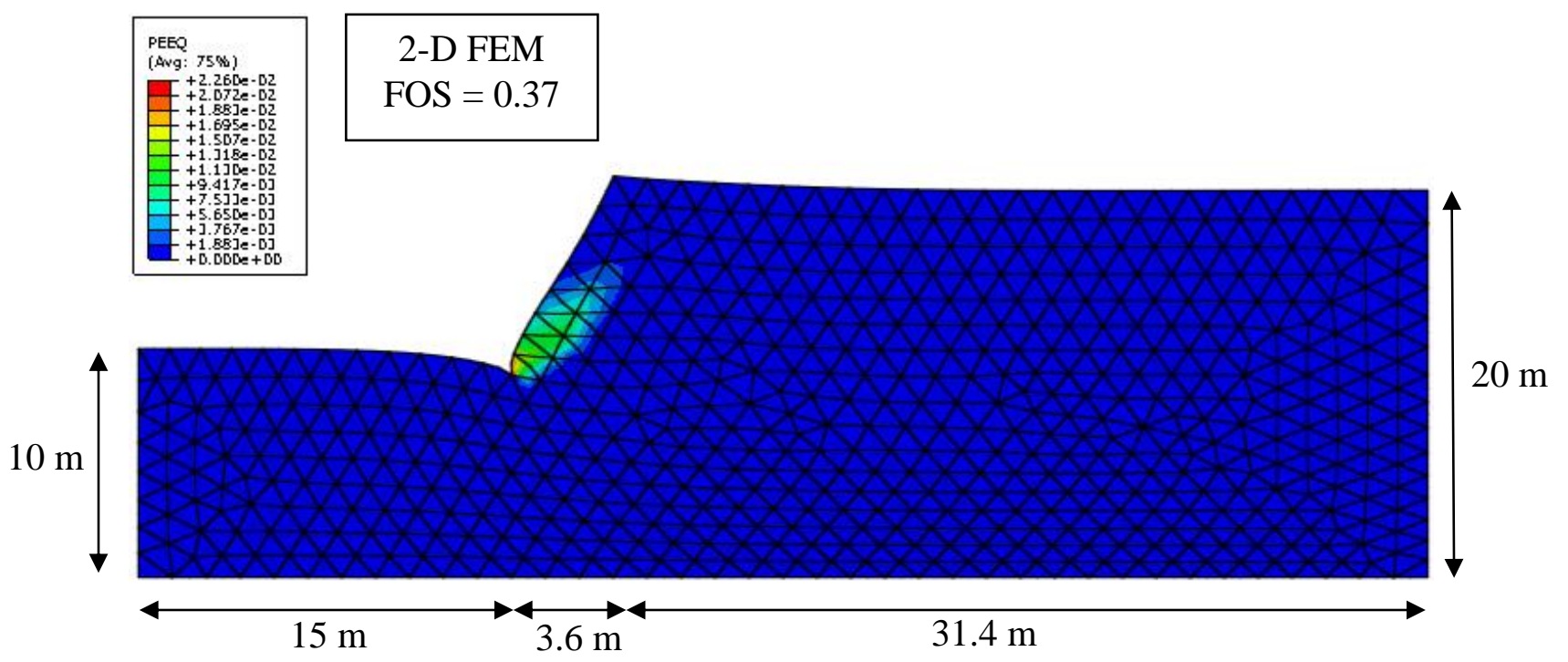

Figure 7.56 PEEQ Contour Plot for Two-Dimensional FEM Unreinforced Slope - 70

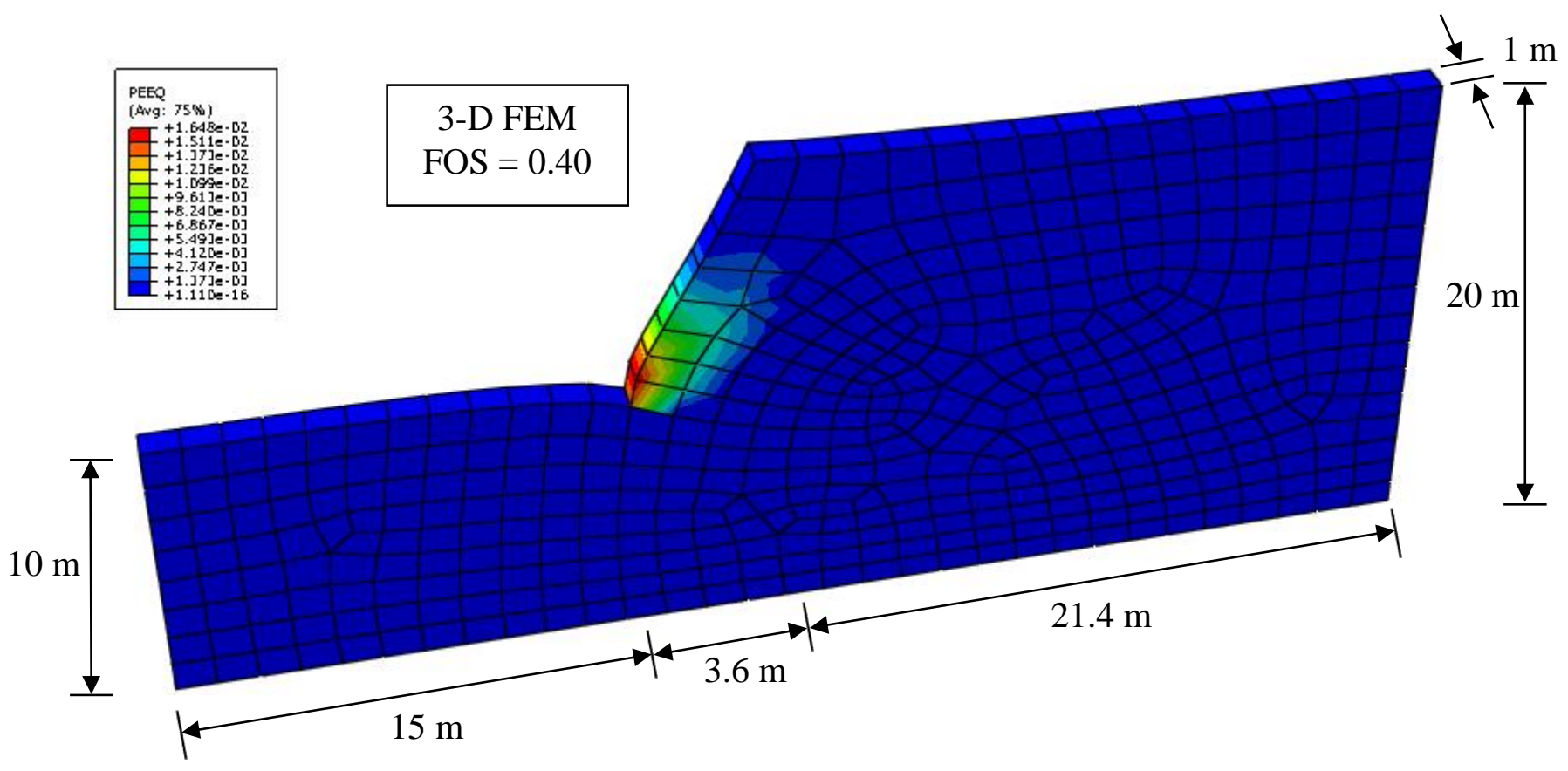

Figure 7.57 PEEQ Contour Plot for Three-Dimensional FEM Unreinforced Slope - 70 


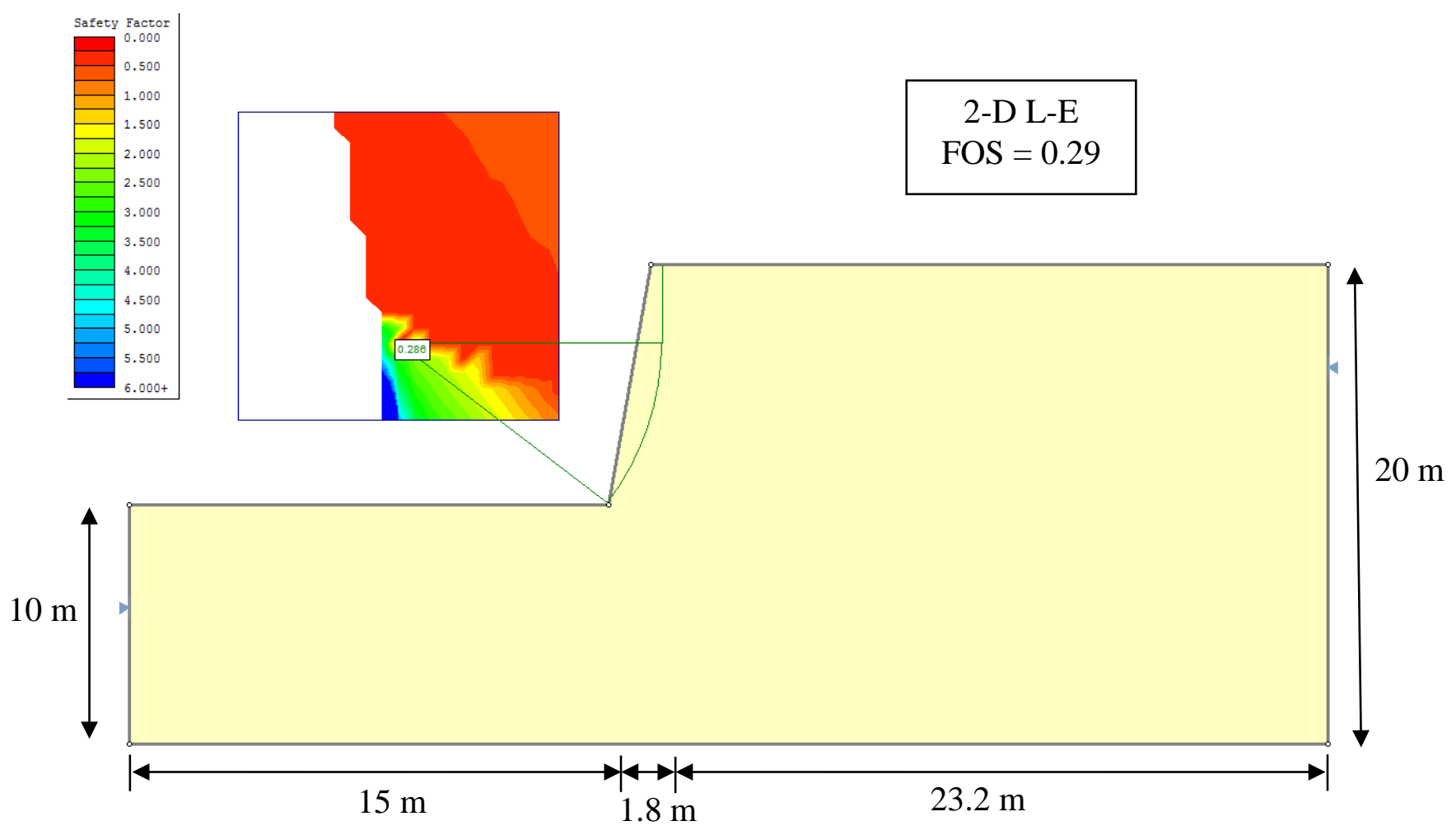

Figure 7.58 L-E Results for Two-Dimensional Unreinforced Slope - $80^{\circ}$

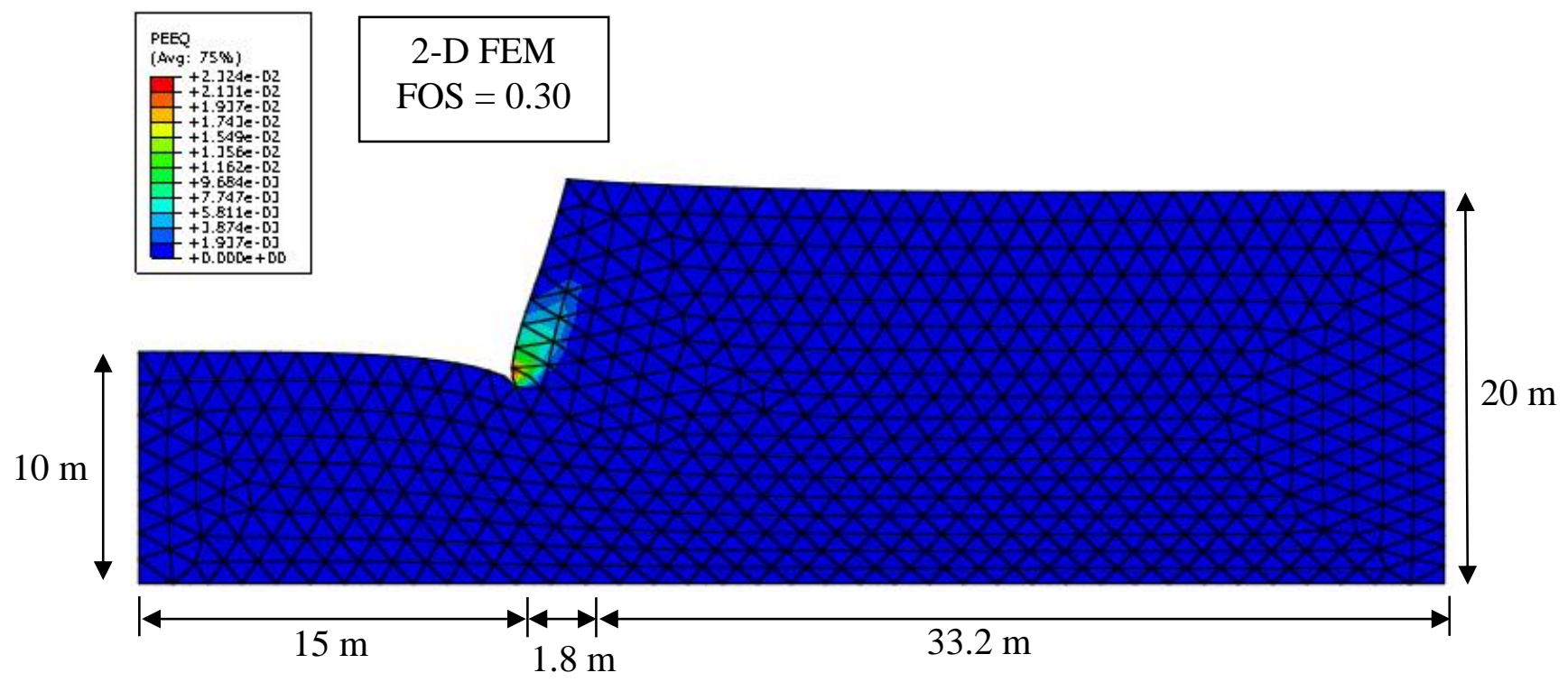

Figure 7.59 PEEQ Contour Plot for Two-Dimensional FEM Unreinforced Slope - $80^{\circ}$ 


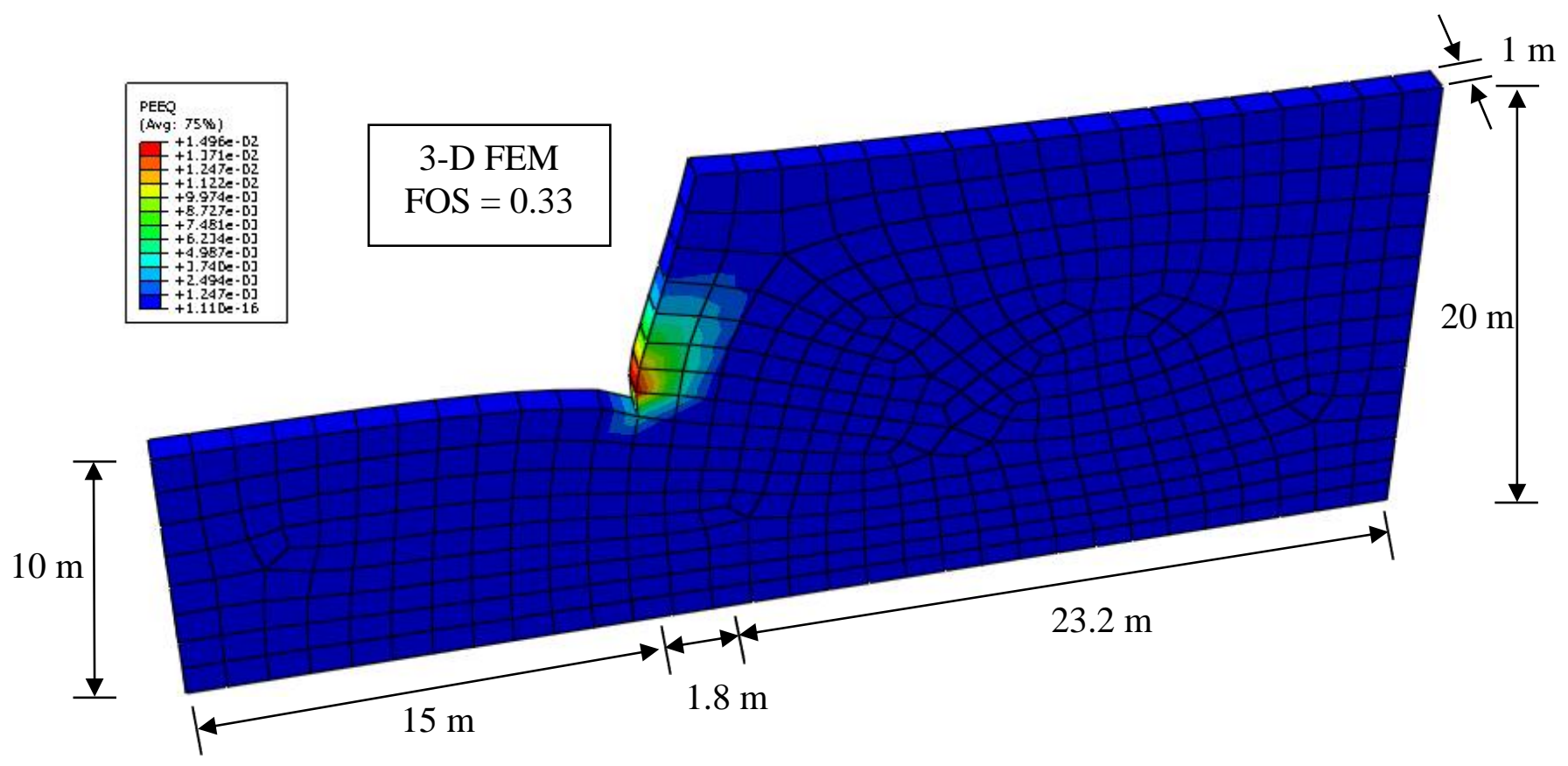

Figure 7.60 PEEQ Contour Plot for Three-Dimensional FEM Unreinforced Slope - 80

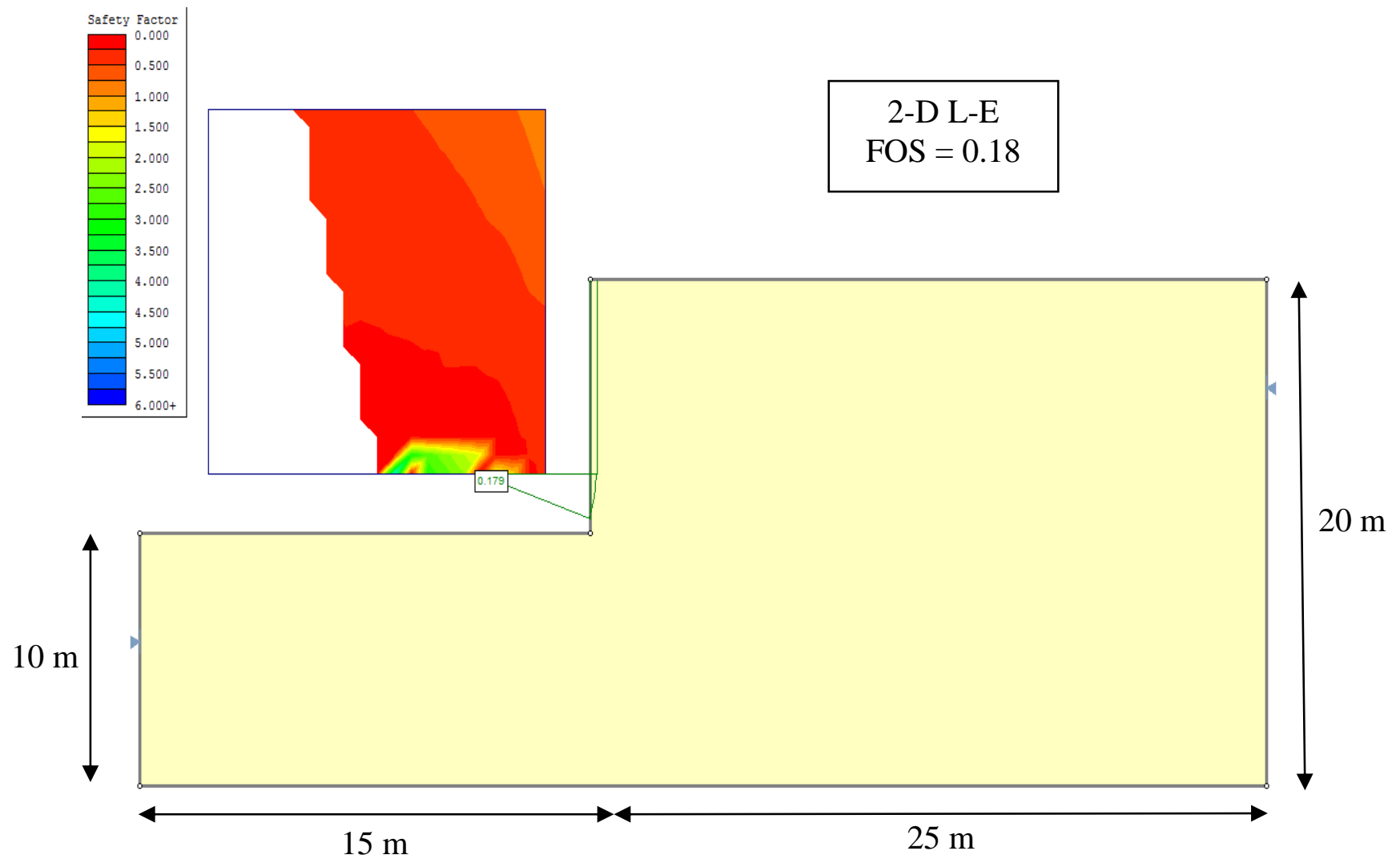

Figure 7.61 L-E Results for Two-Dimensional Unreinforced Slope - 90 


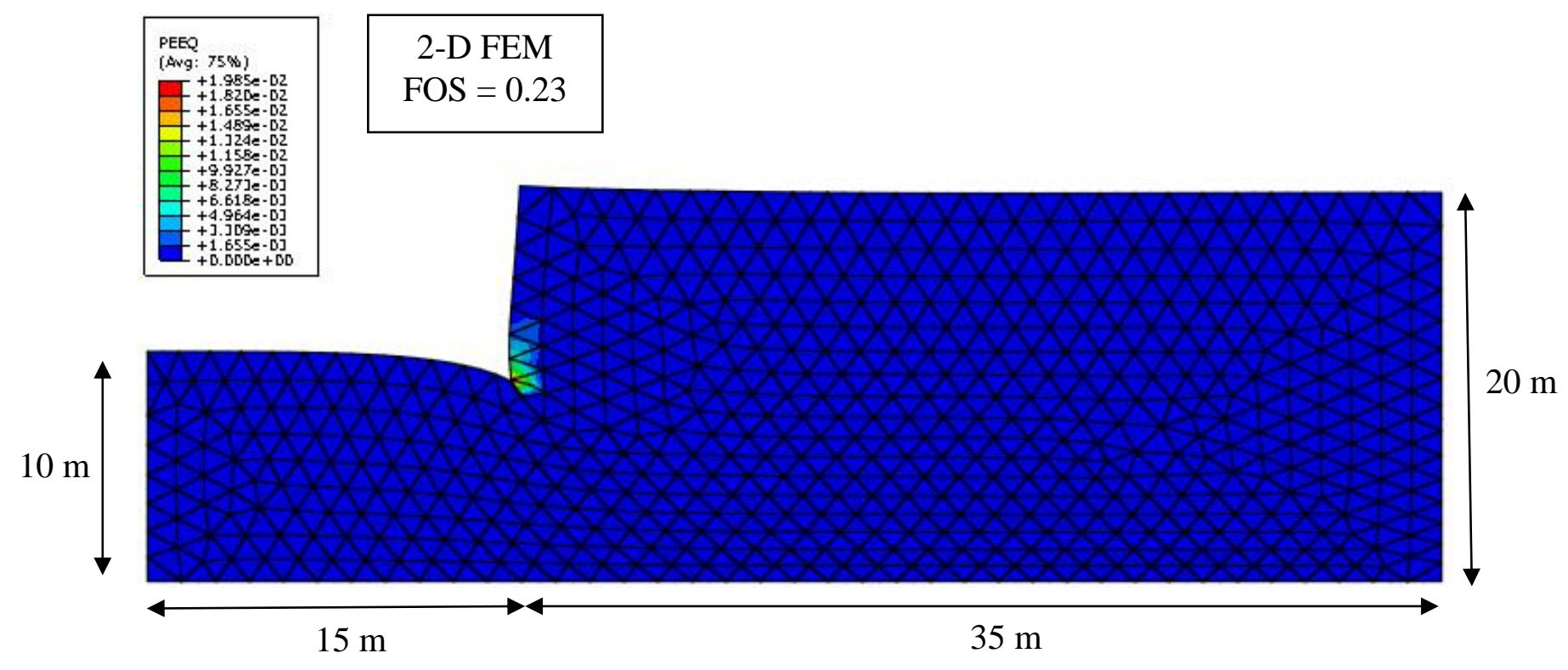

Figure 7.62 PEEQ Contour Plot for Two-Dimensional FEM Unreinforced Slope - 90

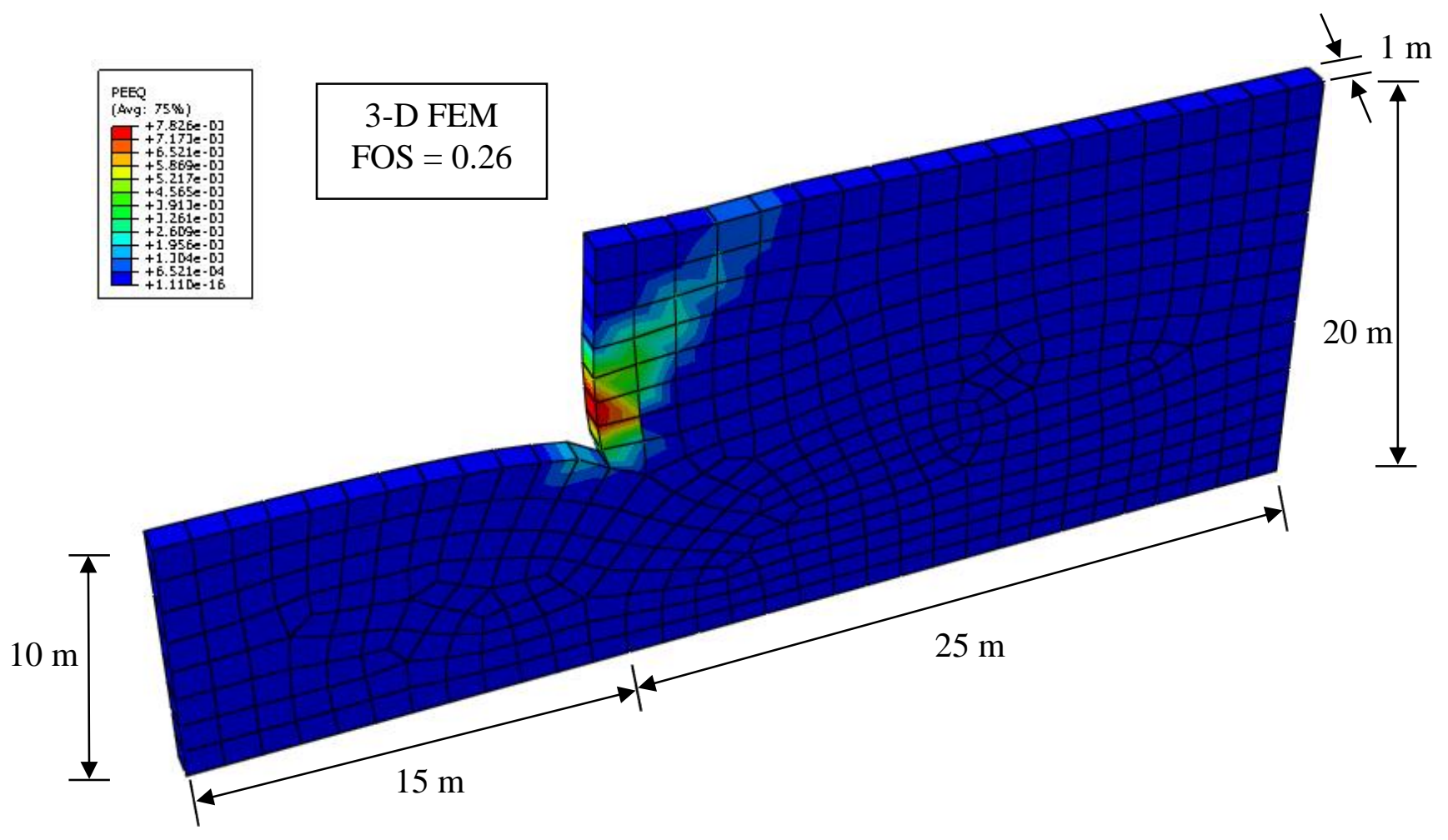

Figure 7.63 PEEQ Contour Plot for Three-Dimensional FEM Unreinforced Slope - 90 


\subsection{Three-Dimensional Reinforced Slopes}

Three-dimensional reinforced slopes were investigated using FEM. Parametric studies were completed to evaluate the effect of: soil nail orientation, soil nail length, vertical soil nail spacing, horizontal soil nail spacing, the effect of surcharge location and magnitude, and the effect of various soil properties. Slopes reinforced with pre-tensioned soil nails were modeled using three-dimensional FEM. Finally, two slopes were fully modeled using three-dimensional FEM. The first slope was modeled with a decreasing slope height in order to include the effect of end conditions. The second fully modeled slope included a $90^{\circ}$ corner in plan view.

Where possible, three-dimensional FEM results were compared to previously published work. In other cases, similar two-dimensional L-E models were developed for comparison. As discussed in Section 4.2 and 4.5, the Slide (2012), two-dimensional L-E computer program was used. The two-dimensional models were developed to match the geometry and soil parameters used in the three-dimensional FEM models.

\subsubsection{Influence of Soil Nail Orientation $(\delta)$}

As discussed in Section 5.5.1, the influence of soil nail orientation was investigated. A 10 meter high $(\mathrm{H})$, three-dimensional soil slope model was developed for slope angles $(\beta)$ of $90^{\circ}, 80^{\circ}, 70^{\circ}, 60^{\circ}, 50^{\circ}, 40^{\circ}$, and $26.5^{\circ}$. Considering the results of the three-dimensional element type study, a C3D8 element type using Mohr-Coulomb failure criteria was used for modeling of the soil slope. The Mohr-Coulomb soil properties for Soil 1 were used, as presented in Table 3.3. Four soil nails were placed at a 2.0-meter vertical spacing $\left(\mathrm{S}_{\mathrm{V}}\right)$ (See Figure 5.2). A soil nail length (L) of 10.0 meters was used for this study and no other 
lengths were evaluated. Figure 7.64 presents a schematic of the slope and soil nail variables used in the soil nail orientation $(\delta)$ study.

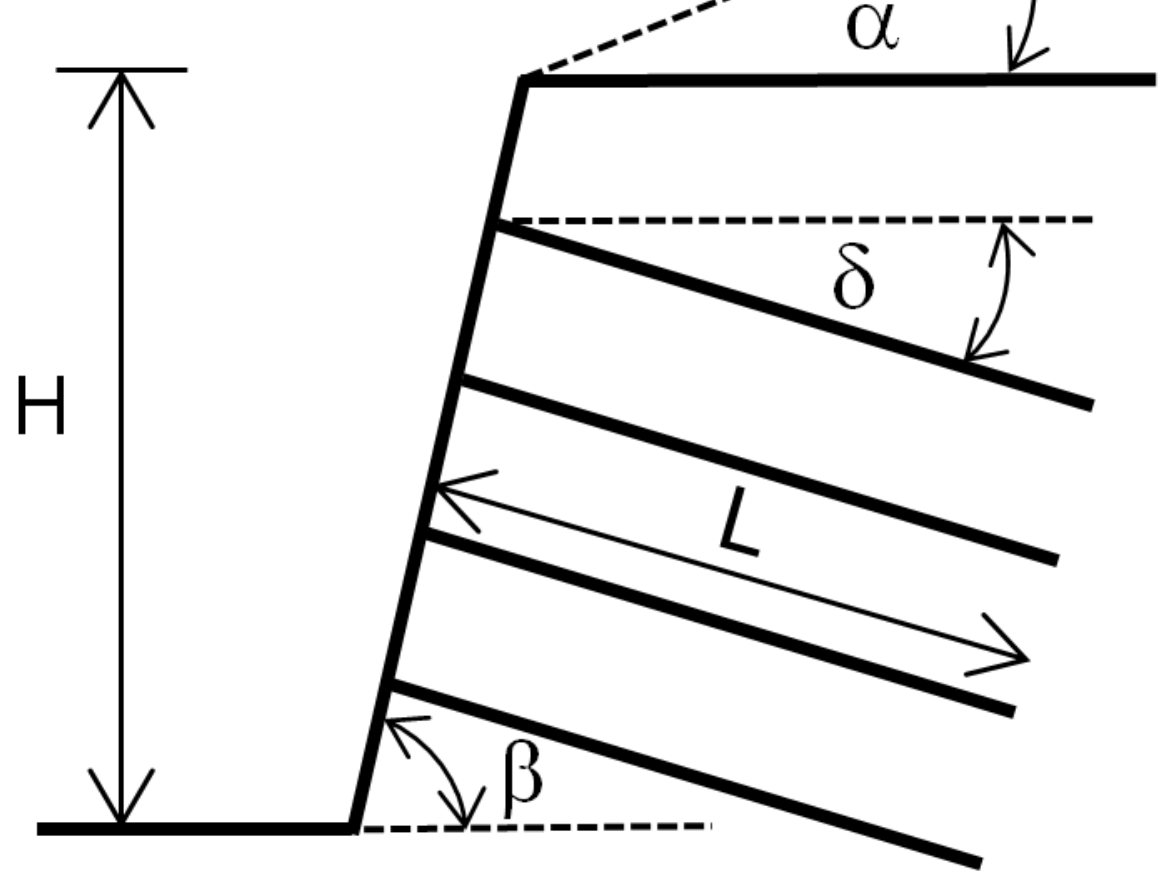

Where: Slope Height $(\mathrm{H})=10$ meters

Soil Nail Length $(\mathrm{L})=10$ meters

Backslope Angle $(\alpha)=0^{\circ}$

Slope Angle $(\beta)$ was varied from $26.5^{\circ}$ to $90^{\circ}$

Soil Nail Orientation $(\delta)$ was varied from $0^{\circ}$ to $50^{\circ}$

Figure 7.64 Schematic of Slope and Soil Nail Parameters Used in Soil Nail Orientation ( $\delta$ ) Study 
Figure 7.65 presents the three-dimensional FEM results of the influence of soil nail orientation on FOS values for various slope angles from $90^{\circ}$ down to $26.5^{\circ}$. The soil nail orientation $(\delta)$ was varied from $0^{\circ}$ to $50^{\circ}$ in order to determine the orientation that corresponded with the highest FOS for the selected slope(s). This orientation is the "optimum" soil nail orientation $\left(\delta_{\mathrm{OPT}}\right)$. For each slope angle studied, the optimum orientation is presented in Table 7.4. It should be noted that for each slope angle, models were completed for values on each side of the optimum values in order to solidify the results presented in the table. In addition, the two-dimensional FEM results from Fan and Luo (2008) and Rotte et. al. (2011) with a horizontal backslope angle $\left(\alpha=0^{\circ}\right)$, which is geometrically similar to this study, are presented in Table 7.4 for comparison.

The results are within $6^{\circ}$ for slope angles from $40^{\circ}$ to $90^{\circ}$. No comparative results were found for a $26.5^{\circ}$ slope angle. It is noted that there appears to be a larger discrepancy in the calculated FOS values, especially for the lower slope angles (i.e. slope angles of $50^{\circ}$, $40^{\circ}$, and $26.5^{\circ}$ ). However, the results of this study in conjunction with the results from Fan and Luo (2008) and Rotte et. al. (2011) provides a strong correlation between the optimum soil nail orientation $\left(\delta_{\mathrm{OPT}}\right)$ and the slope angle $(\beta)$. At the least, this relationship could provide a starting orientation when designing soil-nailed walls. 


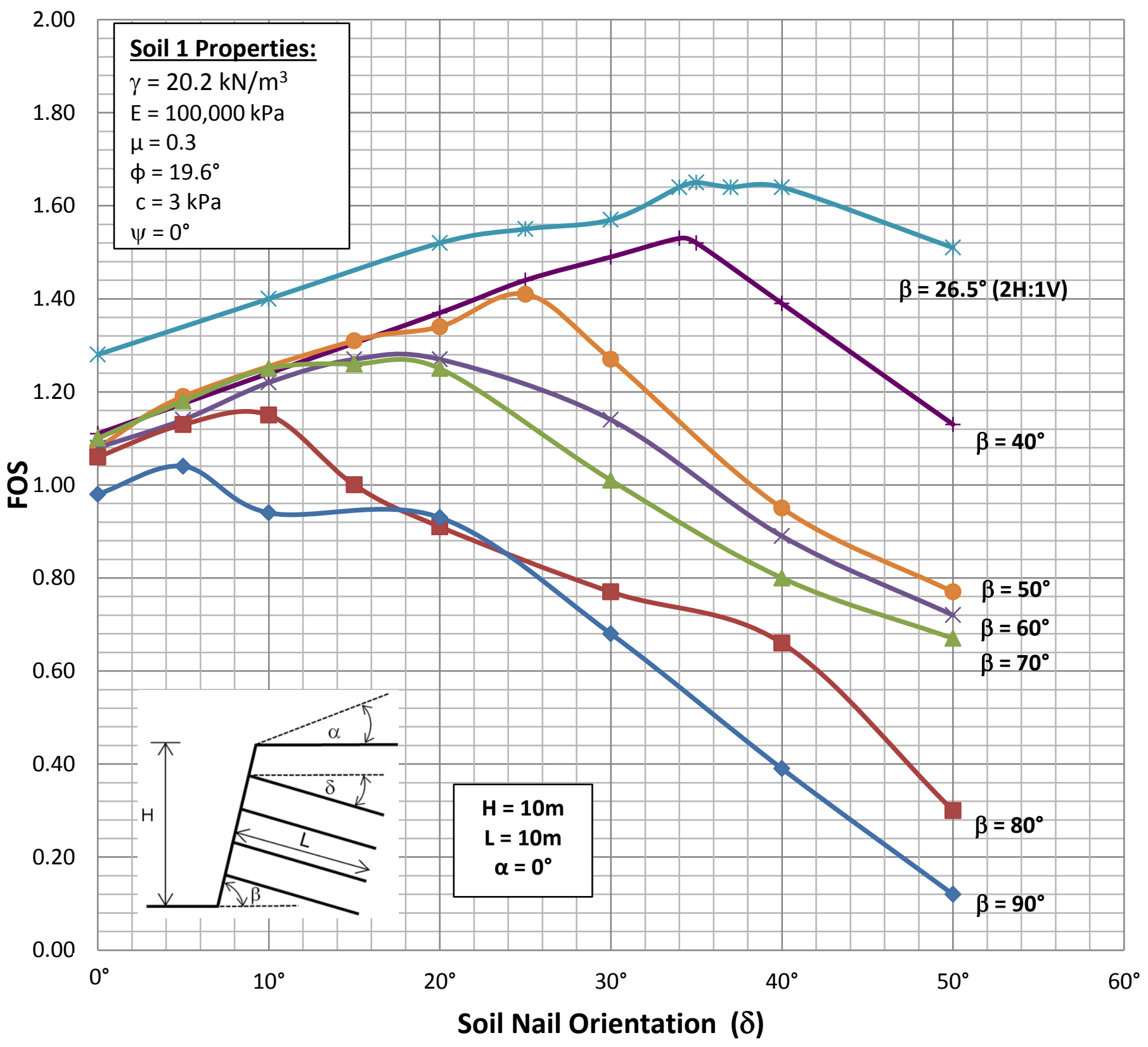

Figure 7.65 Influence of Soil Nail Orientation $(\delta)$ on FOS for Varying Slope Angles $(\beta)$ - based on 3-D FEM 
For comparison, L-E models were also completed that replicated the geometry and characteristics of the three-dimensional FEM models. Optimum soil nail orientations, as presented in Table 7.4, were used. Table 7.4 also presents the FOS values from both the three-dimensional FEM and two-dimensional L-E models. With the exception of a $90^{\circ}$ slope angle, the three-dimensional FEM FOS values are consistently higher than the twodimensional L-E models. In addition, the discrepancy in the FOS values is generally larger as the slope angle decreases. PEEQ plots for the three-dimensional FEM models and critical circle plots for the two-dimensional L-E models are presented in Figures 7.66 through 7.79 .

Table 7.4 Optimum Soil Nail Orientation Values for Various Slope Angles

\begin{tabular}{|c|c|c|c|c|c|}
\hline $\begin{array}{c}\text { Slope } \\
\text { Angle } \\
(\boldsymbol{\beta})\end{array}$ & $\begin{array}{c}\text { 3-D FEM } \\
\boldsymbol{\delta}_{\text {OPT. }}\end{array}$ & $\begin{array}{c}\text { *Fan and Luo } \\
(\mathbf{2 0 0 8}) \\
\boldsymbol{\delta}_{\text {OPT. }}\end{array}$ & $\begin{array}{c}* * \text { Rotte et.al. } \\
(\mathbf{2 0 1 1}) \\
\boldsymbol{\delta}_{\text {OPT. }}\end{array}$ & $\begin{array}{c}\text { 3-D FEM } \\
\text { FOS }\end{array}$ & $\begin{array}{c}\text { 2-D L-E } \\
\text { FOS }\end{array}$ \\
\hline $26.5^{\circ}$ & $35^{\circ}$ & Not Studied & Not Studied & 1.65 & 1.47 \\
\hline $40^{\circ}$ & $34^{\circ}$ & $40^{\circ}$ & Not Studied & 1.53 & 1.40 \\
\hline $50^{\circ}$ & $25^{\circ}$ & $30^{\circ}$ & Not Studied & 1.41 & 1.27 \\
\hline $60^{\circ}$ & $18^{\circ}$ & $23^{\circ}$ & $\begin{array}{c}24^{\circ} \\
\left(\beta=63.43^{\circ}\right)\end{array}$ & 1.27 & 1.20 \\
\hline $70^{\circ}$ & $15^{\circ}$ & $16^{\circ}$ & $\begin{array}{c}17^{\circ} \\
\left(\beta=71.56^{\circ}\right)\end{array}$ & 1.26 & 1.17 \\
\hline $80^{\circ}$ & $10^{\circ}$ & $8^{\circ}$ & $\begin{array}{c}10^{\circ} \\
\left(\beta=78.7^{\circ}\right)\end{array}$ & 1.15 & 1.14 \\
\hline $90^{\circ}$ & $5^{\circ}$ & $0^{\circ}$ & $0^{\circ}$ & 1.04 & 1.08 \\
\hline
\end{tabular}

*Fan and Lou (2008) Optimum Soil Nail Orientation $\left(\delta_{\mathrm{OPT}}\right)$ with a Backslope Angle $(\alpha)=0^{\circ}$ $* *$ Rotte et. al. (2011) Optimum Soil Nail Orientation $\left(\delta_{\text {OPT }}\right)$ with a Backslope Angle $(\alpha)=0^{\circ}$ - Note that the Rotte et.al. Slope Angle's $(\beta)$ are dissimilar for all but $\beta=90^{\circ}$. 


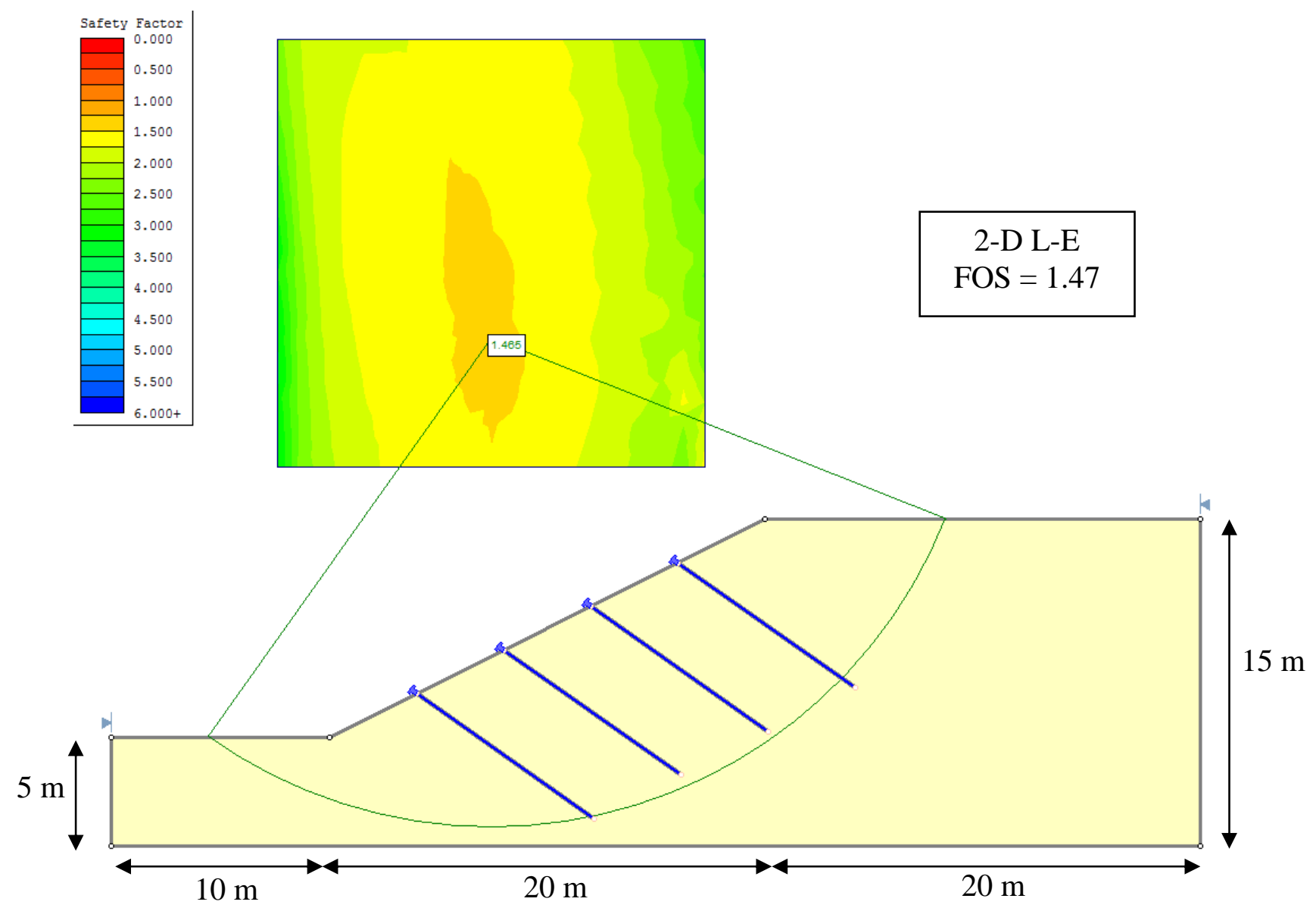

Figure 7.66 L-E Results for Two-Dimensional Reinforced Slope $-26.5^{\circ}$

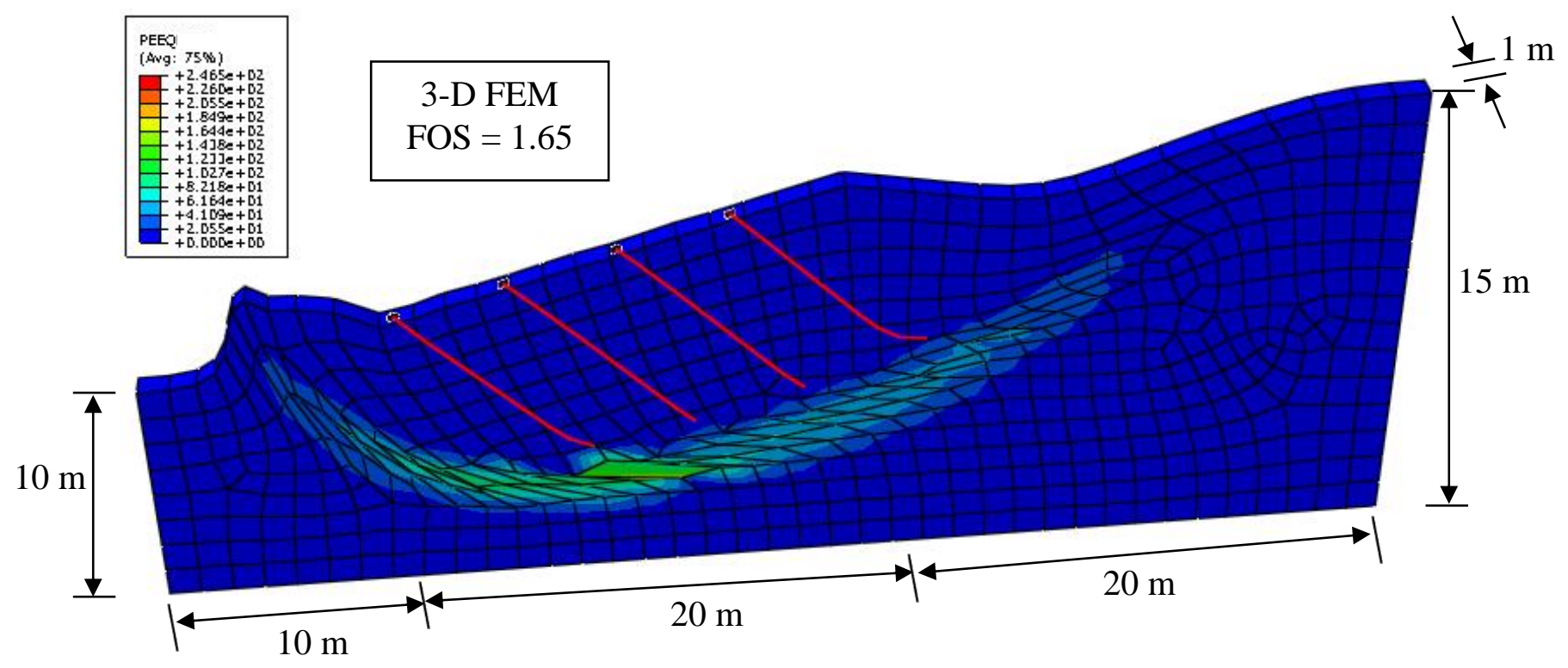

Figure 7.67 PEEQ Contour Plot for Three-Dimensional FEM Reinforced Slope $-26.5^{\circ}$ 

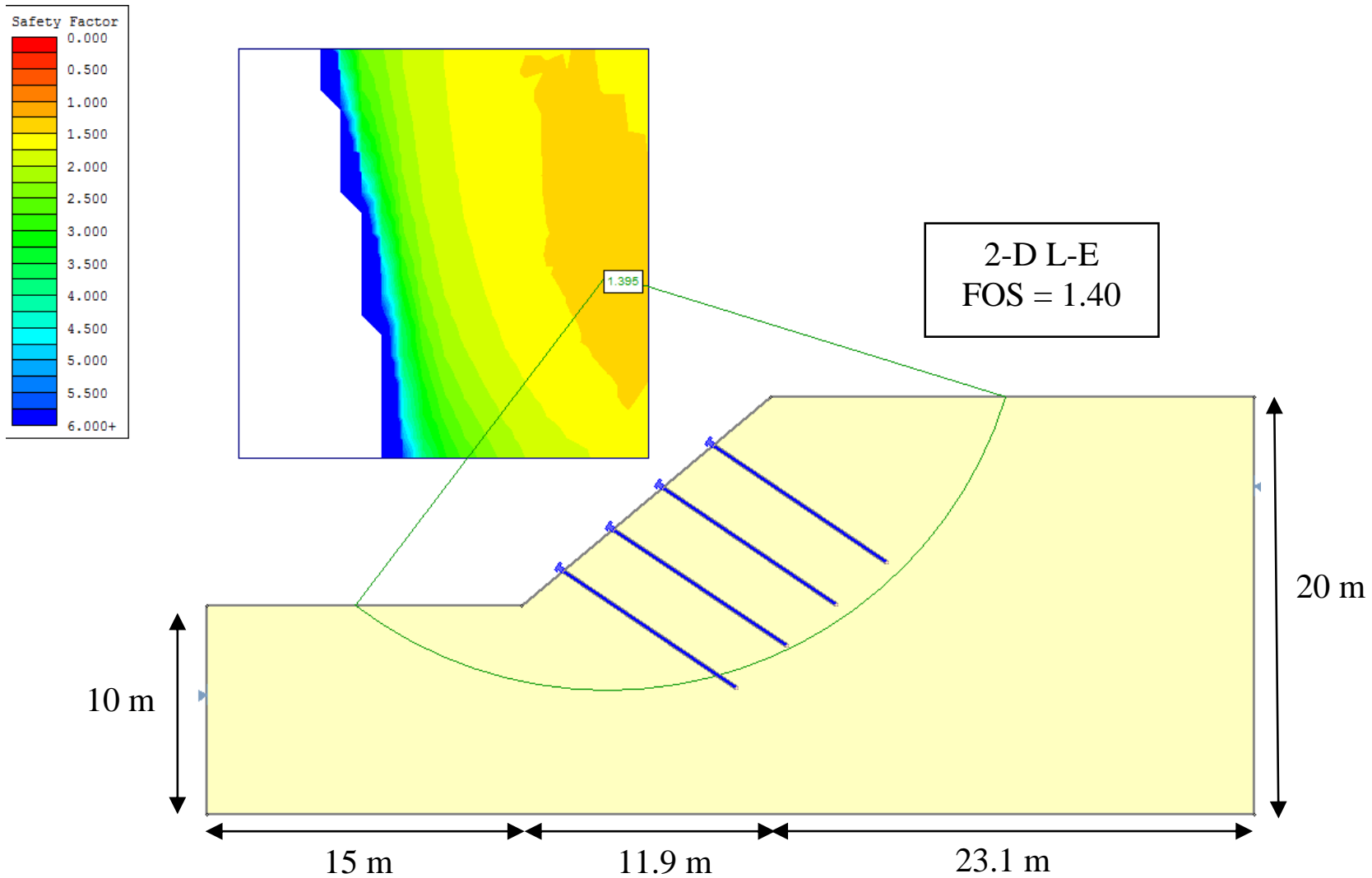

Figure 7.68 L-E Results for Two-Dimensional Reinforced Slope $-40^{\circ}$

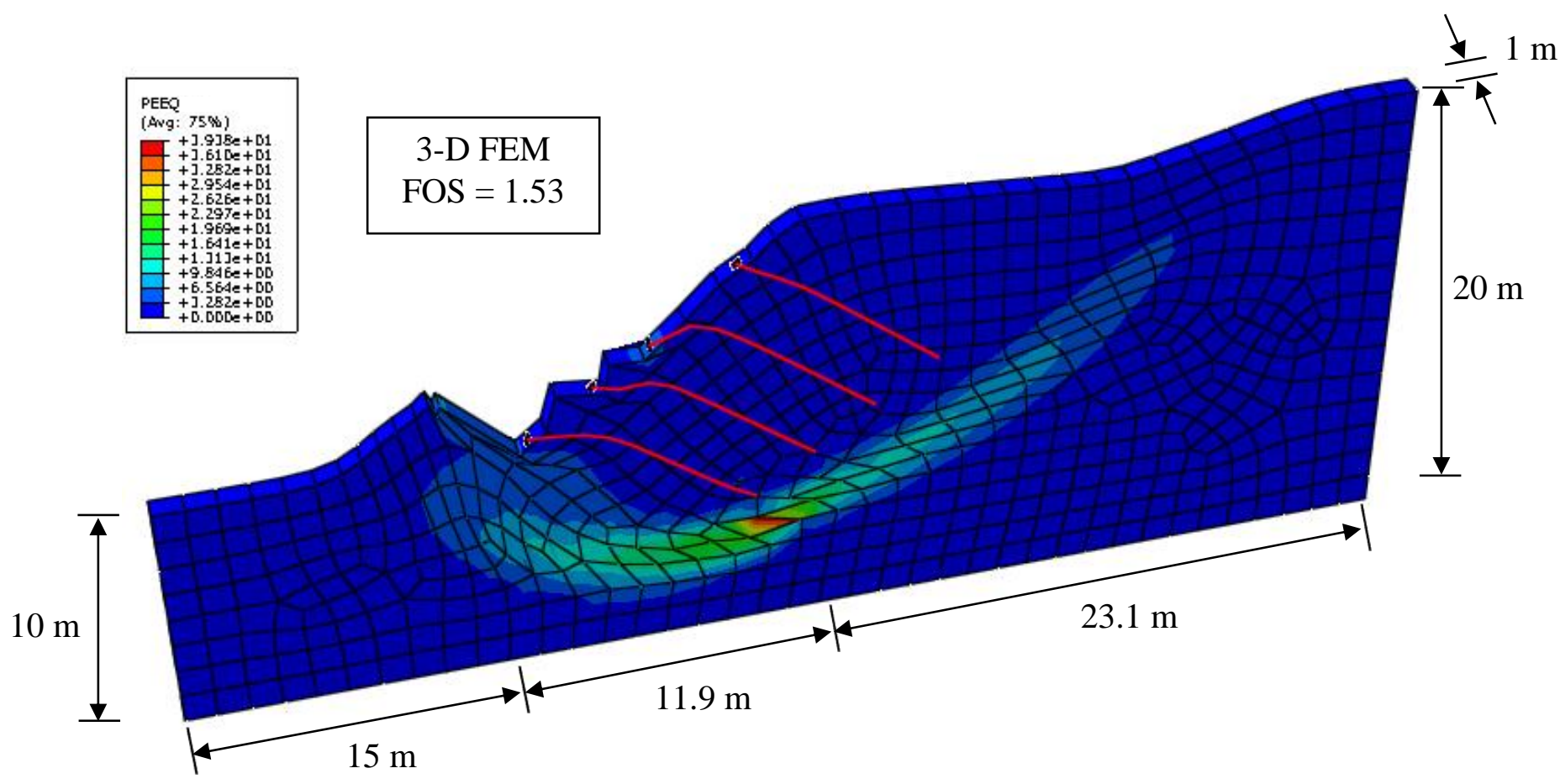

Figure 7.69 PEEQ Contour Plot for Three-Dimensional FEM Reinforced Slope $-40^{\circ}$ 


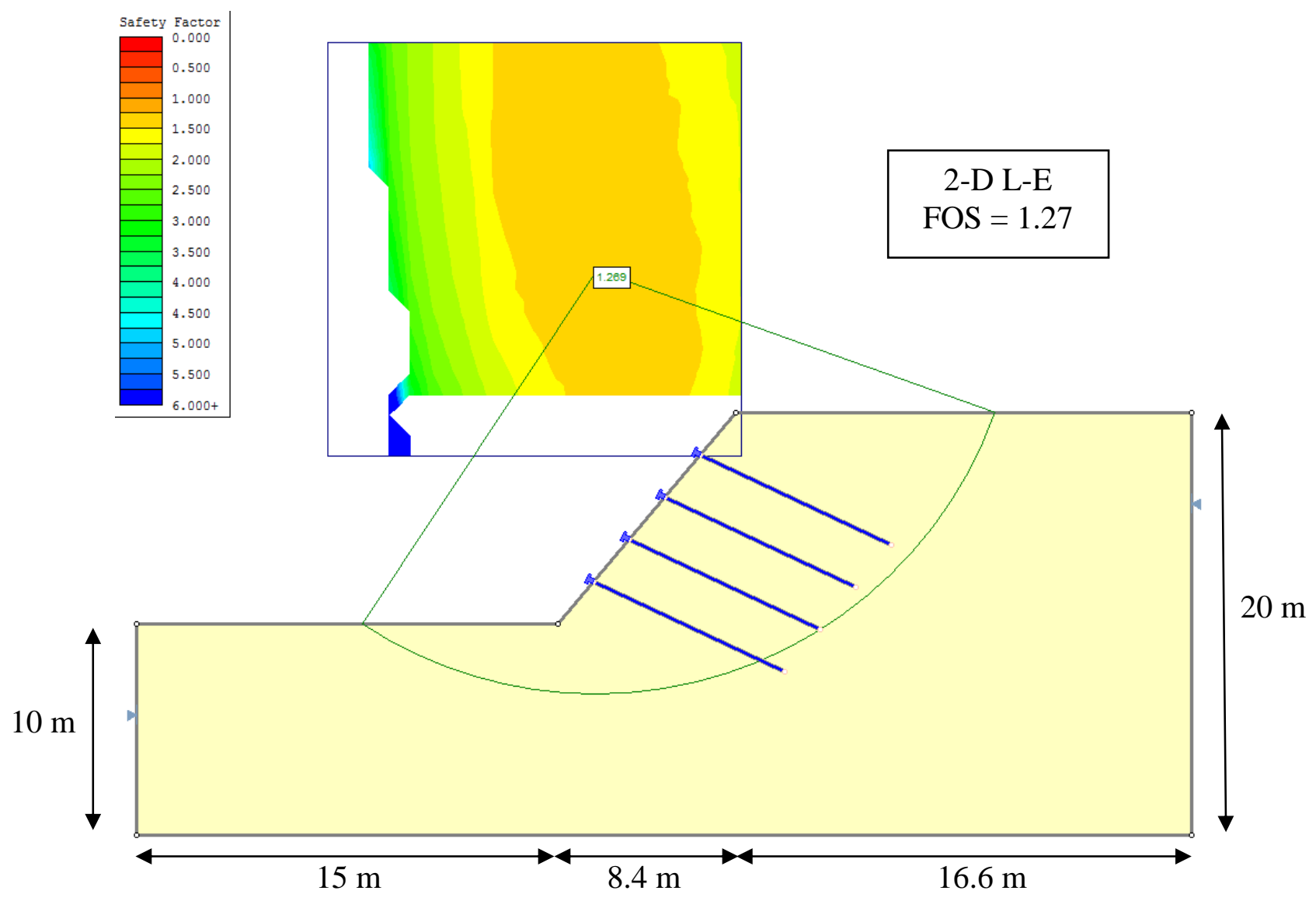

Figure 7.70 L-E Results for Two-Dimensional Reinforced Slope $-50^{\circ}$

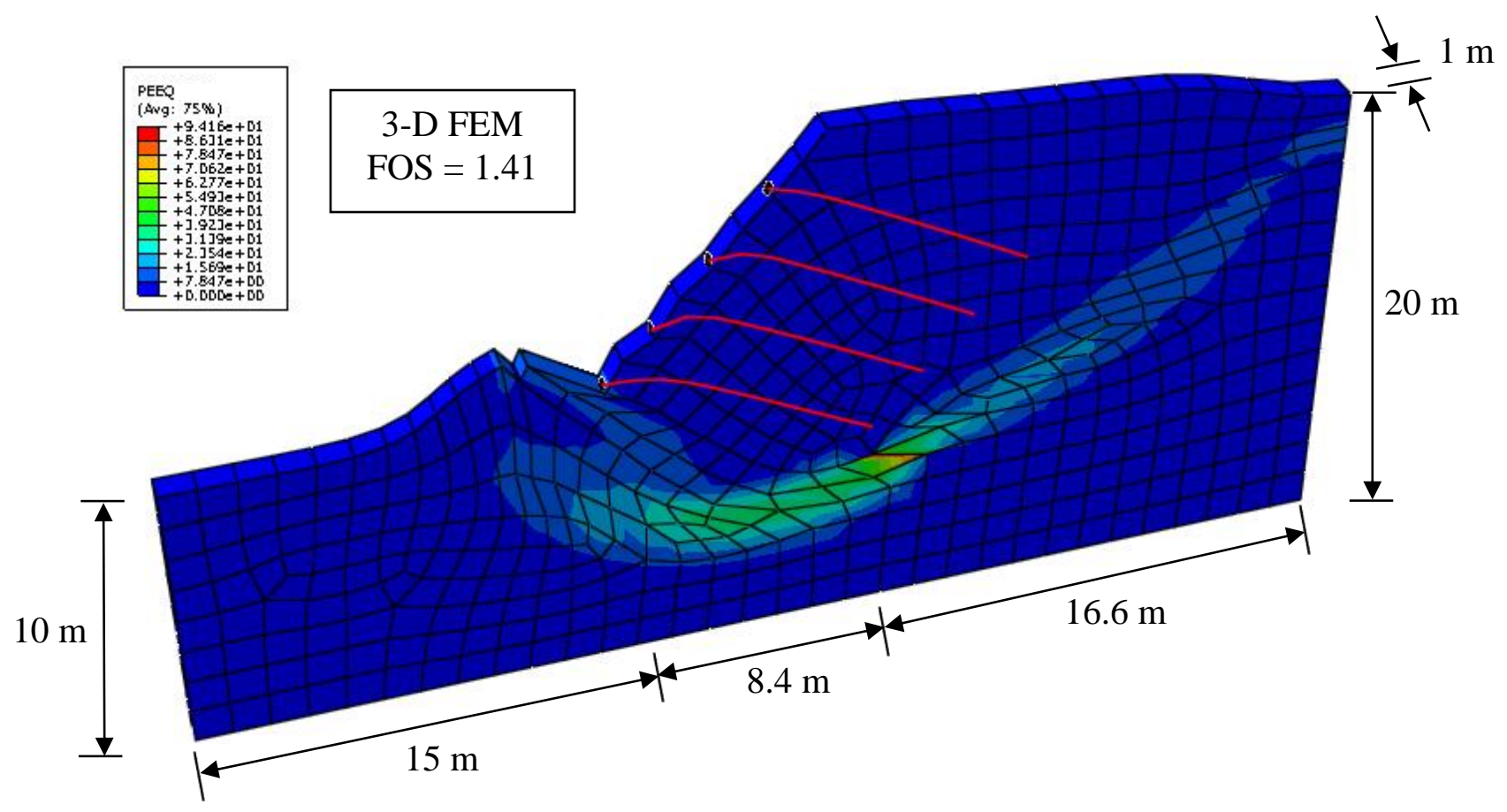

Figure 7.71 PEEQ Contour Plot for Three-Dimensional FEM Reinforced Slope $-50^{\circ}$ 


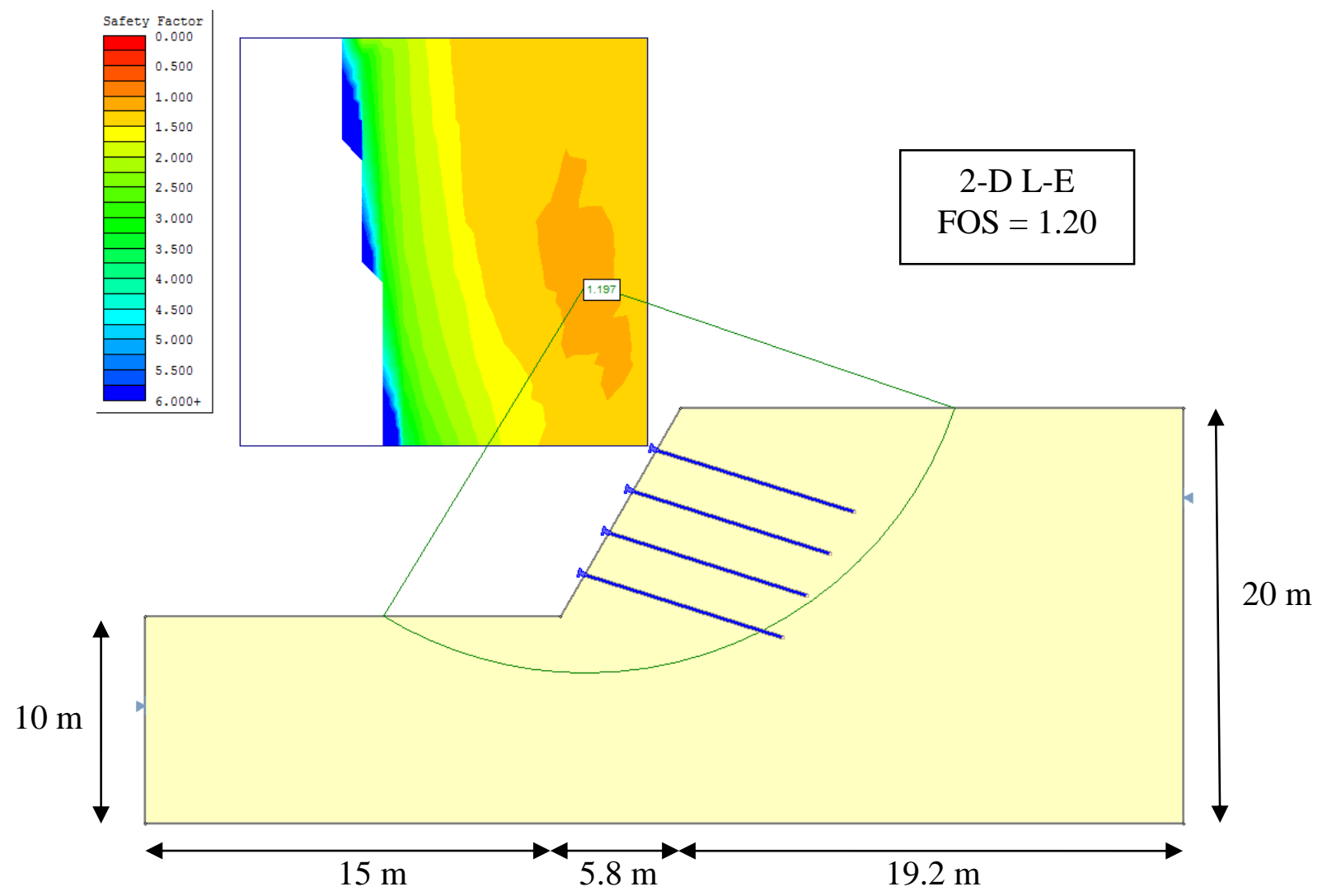

Figure 7.72 L-E Results for Two-Dimensional Reinforced Slope $-60^{\circ}$

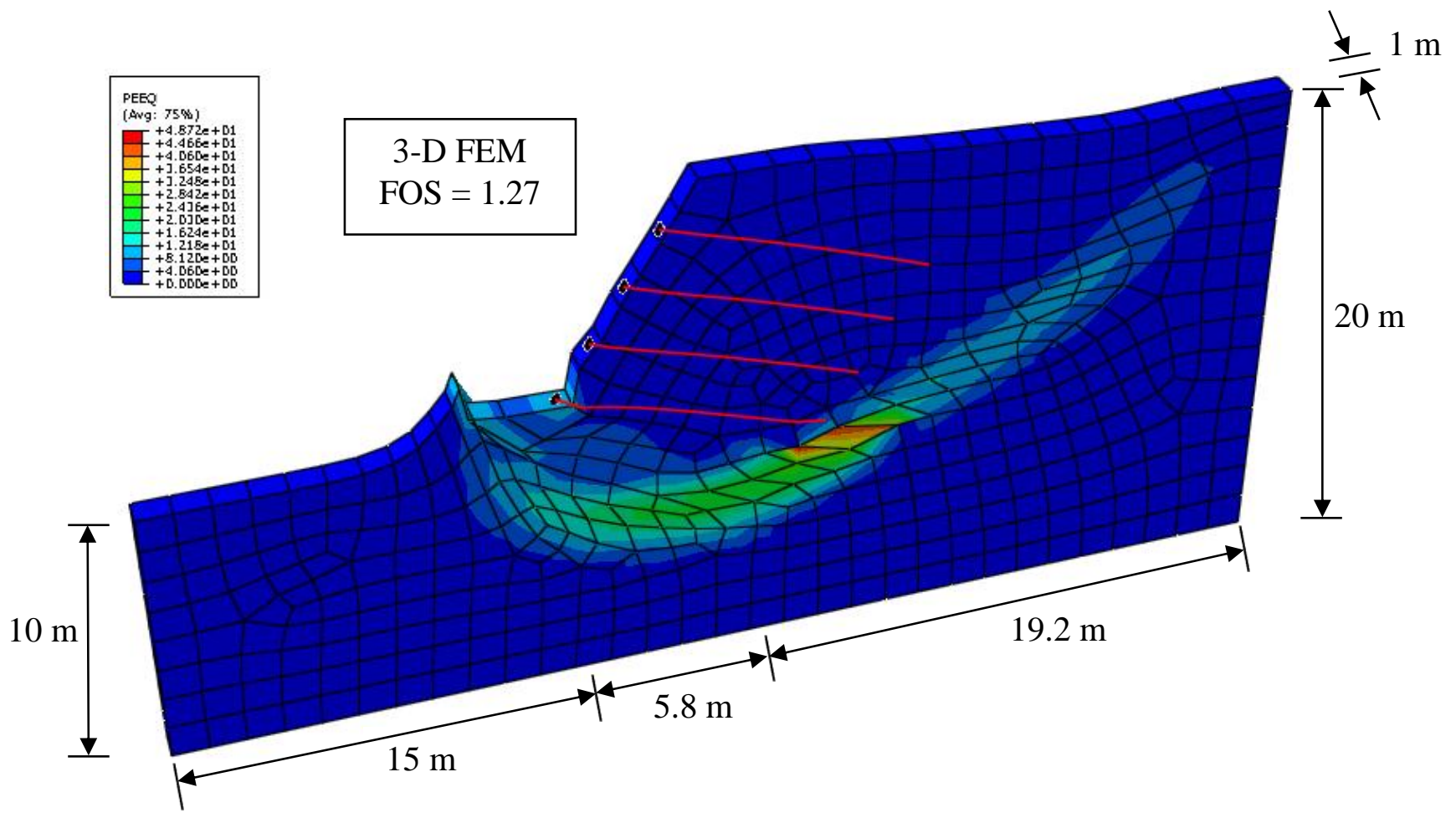

Figure 7.73 PEEQ Contour Plot for Three-Dimensional FEM Reinforced Slope - $60^{\circ}$ 


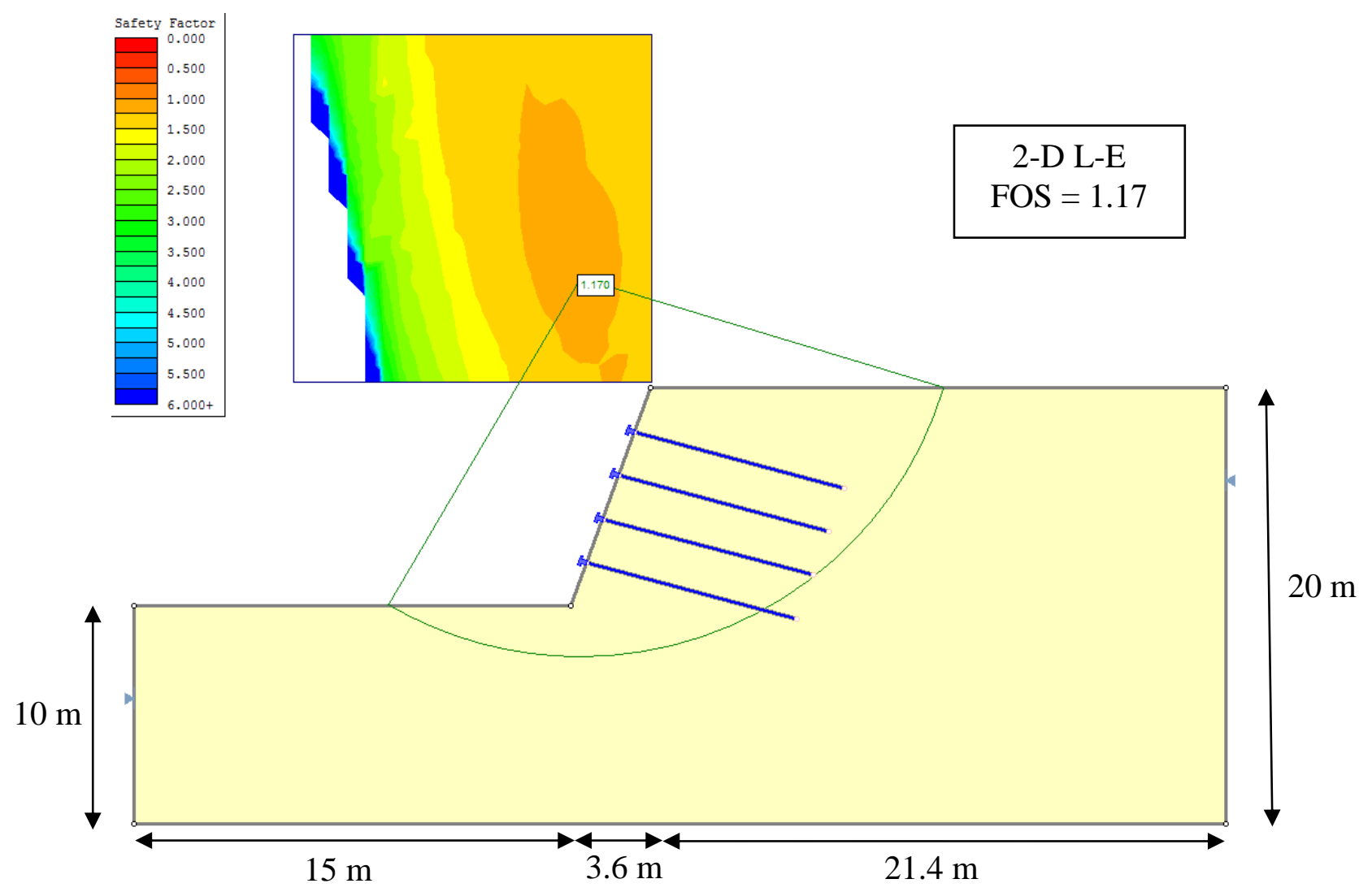

Figure 7.74 L-E Results for Two-Dimensional Reinforced Slope - 70

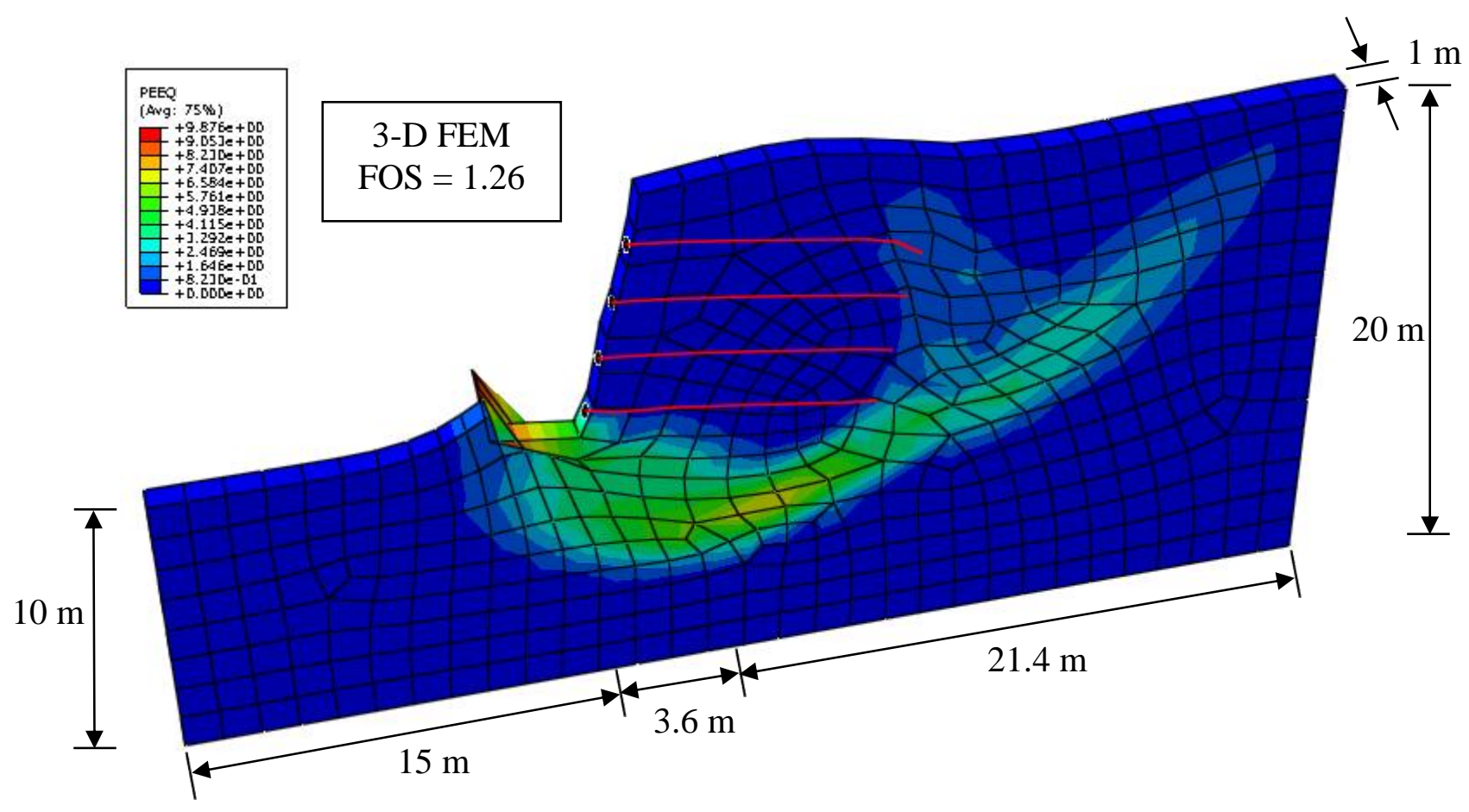

Figure 7.75 PEEQ Contour Plot for Three-Dimensional FEM Reinforced Slope - 70 


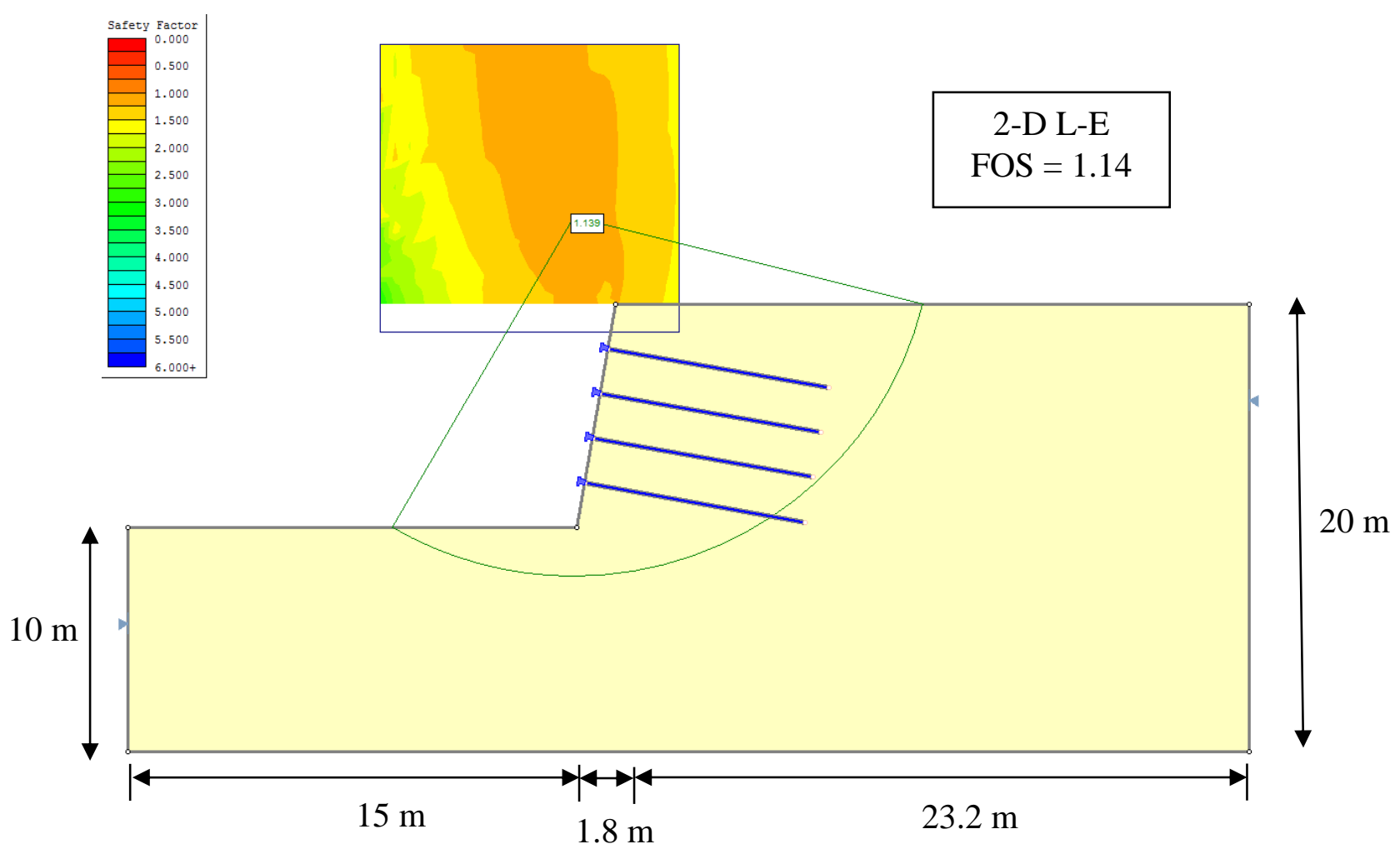

Figure 7.76 L-E Results for Two-Dimensional Reinforced Slope $-80^{\circ}$

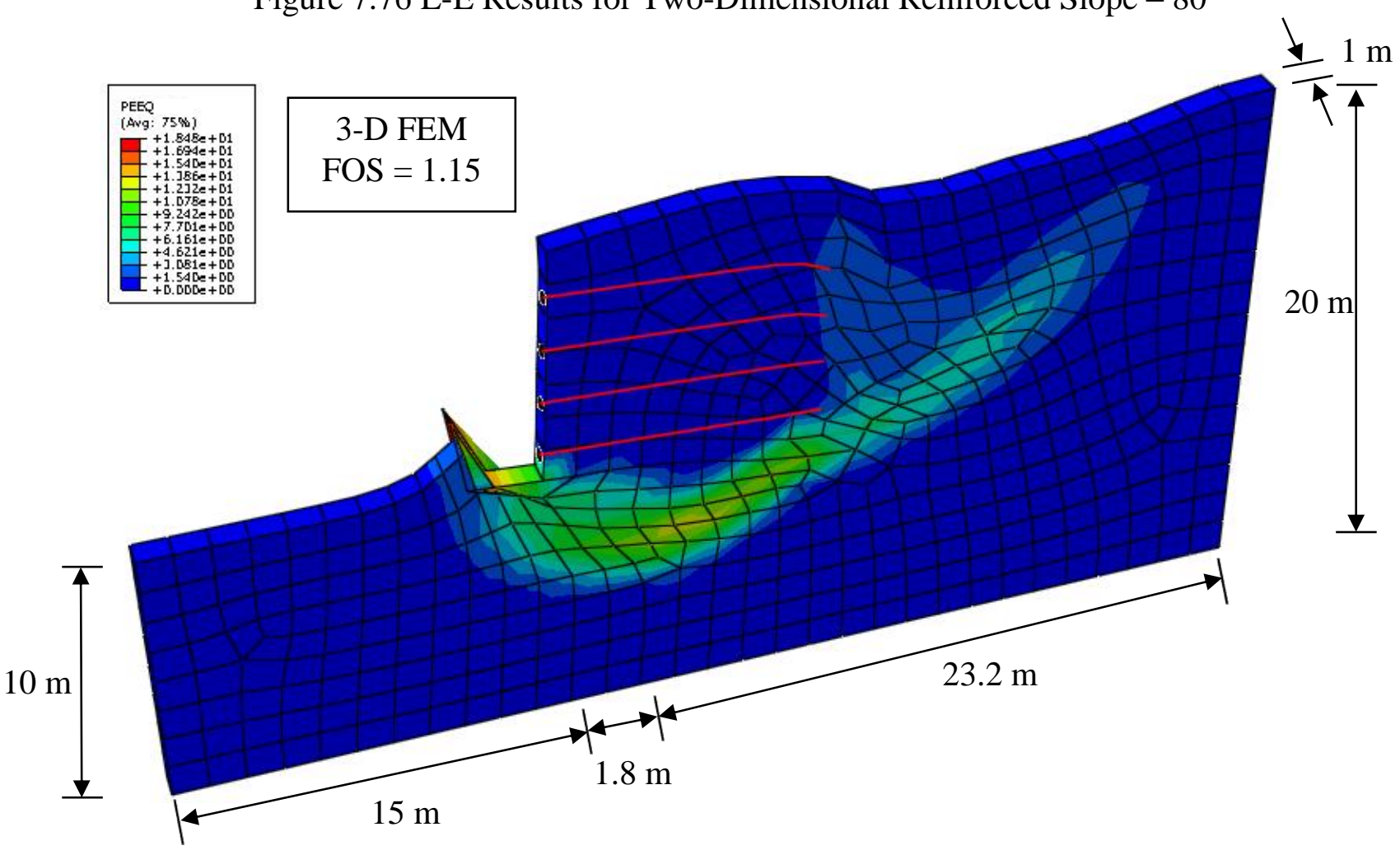

Figure 7.77 PEEQ Contour Plot for Three-Dimensional FEM Reinforced Slope - $80^{\circ}$ 


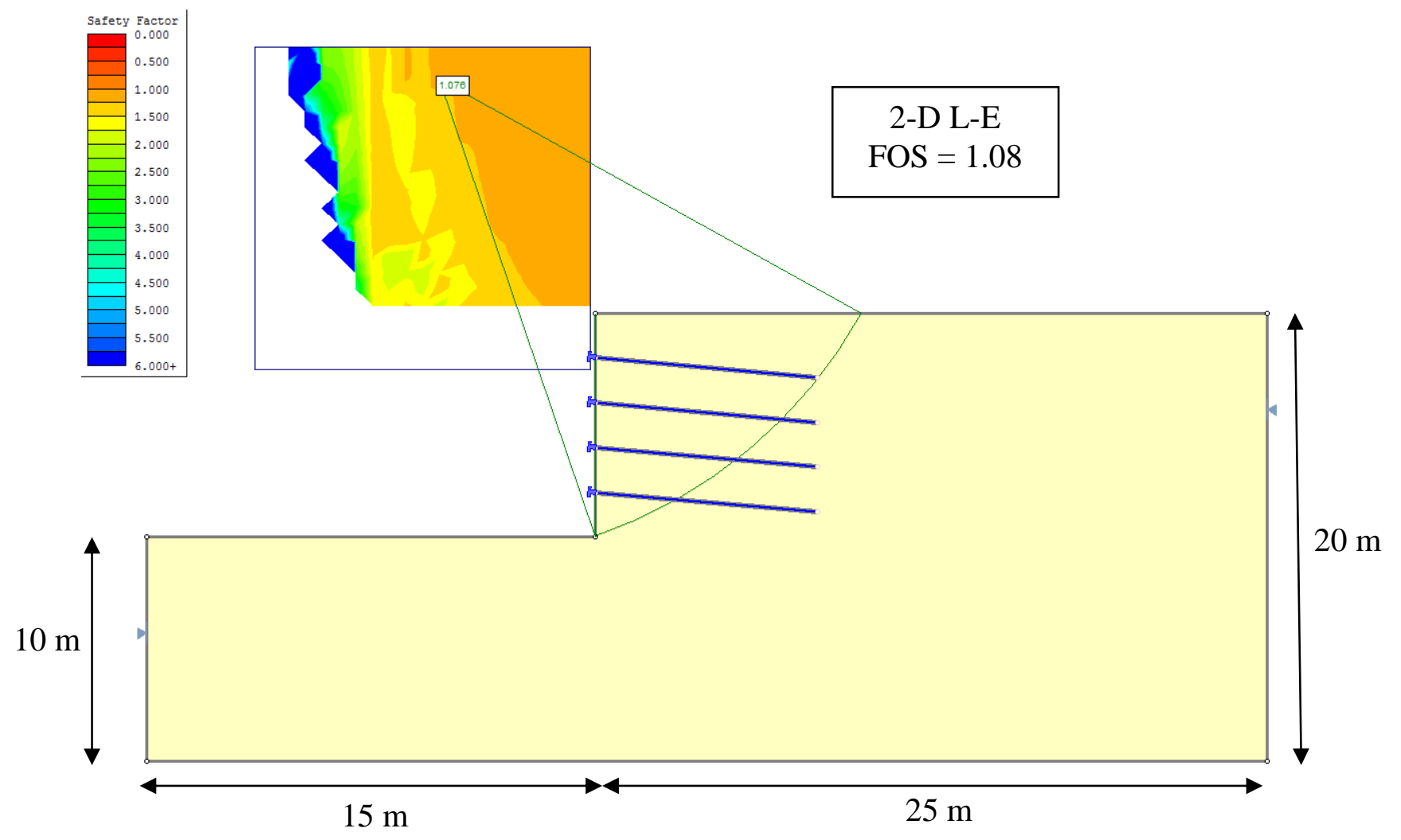

Figure 7.78 L-E Results for Two-Dimensional Reinforced Slope - 90

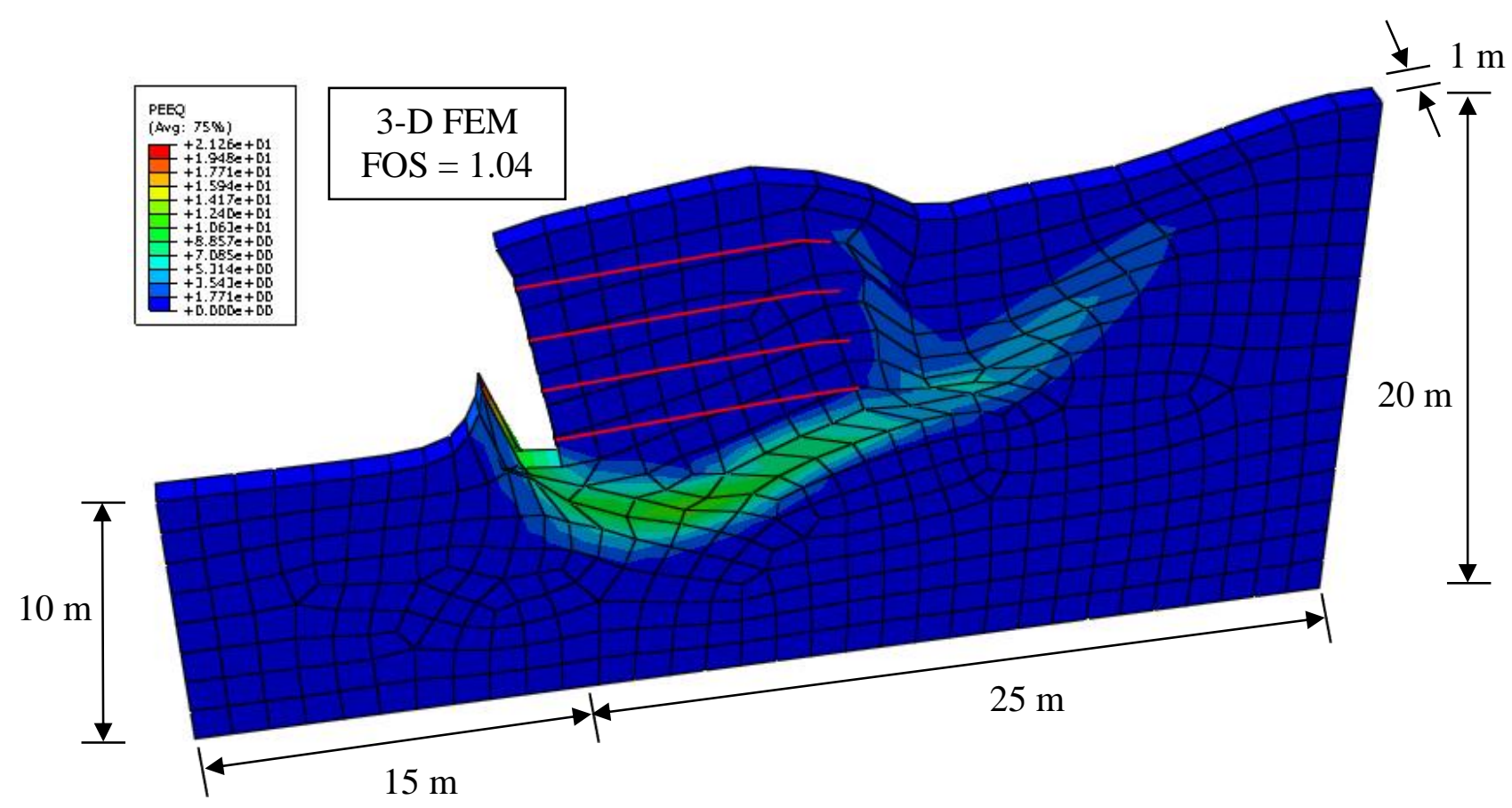

Figure 7.79 PEEQ Contour Plot for Three-Dimensional FEM Reinforced Slope $-90^{\circ}$ 


\subsubsection{Influence of Soil Nail Length (L)}

The influence of soil nail length (L) on the FOS was evaluated by using threedimensional FEM models in this study. A 10 meter high $(\mathrm{H})$, three-dimensional slope was developed for various slope angles $(\beta)$ from $90^{\circ}$ to $26.5^{\circ}$ using Soil 1 with Mohr-Coulomb yielding criteria and C3D8 element types. Four soil nails were placed at a 2.0-meter vertical spacing $\left(\mathrm{S}_{\mathrm{V}}\right)$. In this study, the nail length was varied from 0 (Unreinforced) to 20.0 meters for each slope angle. The nails were placed at the optimum soil nail orientation, as presented in Table 7.4. Figure 7.80 presents the slope and soil nail variables used in the soil nail length (L) study.

The results of this study are presented in Figure 7.81. By analyzing the slope of the data presented in Figure 7.81, steady gains in FOS values are clearly evident on all slope angles up to a certain length, where increases in length from this point on are not advantageous. This point is considered the most efficient soil nail length. For the $26.5^{\circ}$ and $90^{\circ}$ slope, this value is around 12.5 meters. For slope angles of $50^{\circ}, 60^{\circ}, 70^{\circ}$ and $80^{\circ}$, the most efficient soil nail length is about 10 meters.

\subsubsection{Influence of Vertical Soil Nail Spacing $\left(\mathrm{S}_{\mathrm{V}}\right)$}

The influence of vertical soil nail spacing $\left(\mathrm{S}_{\mathrm{V}}\right)$ on FOS was investigated using the model presented in Figure 5.3. A 10 meter high $(\mathrm{H})$, three-dimensional slope was developed for various slope angles $(\beta)$ from $90^{\circ}$ to $26.5^{\circ}$ using Soil 1 with Mohr-Coulomb yielding criteria and C3D8 element types. Ten meter long soil nails were placed using the optimum orientations as presented in Table 5.2. The first soil nail was placed at a vertical distance of 1.0 meter from the toe of the slope for all models, as presented in Figure 5.5. The vertical 
spacing of the soil nails was increased from 0.5 meters to 5.0 meters. Figure 7.82 presents a schematic of the slope and soil nail variables used in the vertical soil nail spacing $\left(\mathrm{S}_{\mathrm{V}}\right)$ study.

The results of the influence of vertical soil nail spacing $\left(\mathrm{S}_{\mathrm{V}}\right)$ on FOS values for various slope angles $(\beta)$ are presented in Figure 7.83 . For the $26.5^{\circ}$ slopes, decreases in the FOS values were mild beyond a vertical spacing of $S_{V}=2.5$ meters. For the $50^{\circ}$ and $60^{\circ}$ slopes, after a slight decrease in the FOS value from $S_{V}=0.5$ meters to $S_{V}=1.0$ meters, the FOS once again remained steady until $\mathrm{S}_{\mathrm{V}}=2.5$ meters and then began to decrease significantly. For the $70^{\circ}, 80^{\circ}$, and $90^{\circ}$ slopes, the FOS values were nearly constant until a vertical spacing of $S_{V}=2.0$ meters, where the rapid decrease in the FOS values began.

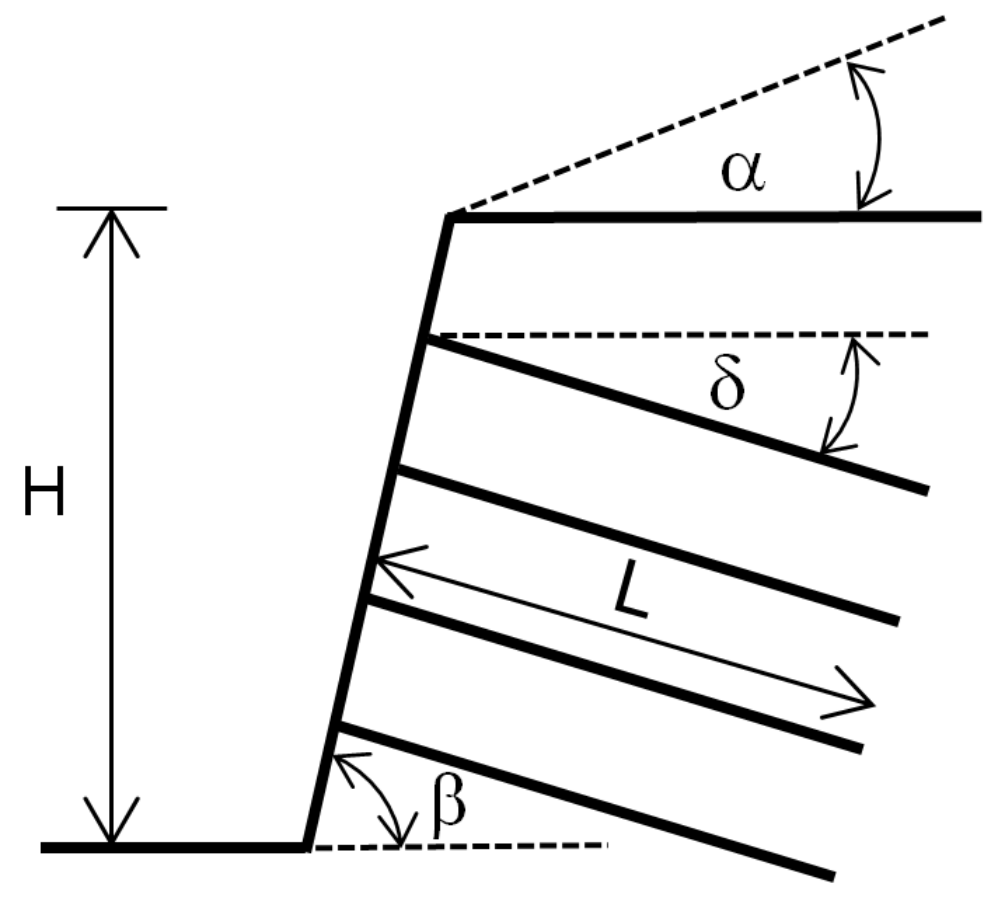

Where: Slope Height $(\mathrm{H})=10$ meters

Backslope Angle $(\alpha)=0^{\circ}$

Soil Nail Orientation $(\delta)$ was set at optimum (See Table 7.4)

Slope Angle ( $\beta$ ) was varied from $26.5^{\circ}$ to $90^{\circ}$

Soil Nail Length (L) was varied from 0 meters to 20 meters

Figure 7.80 Schematic of Slope and Soil Nail Parameters Used in Soil Nail Length (L) Study 


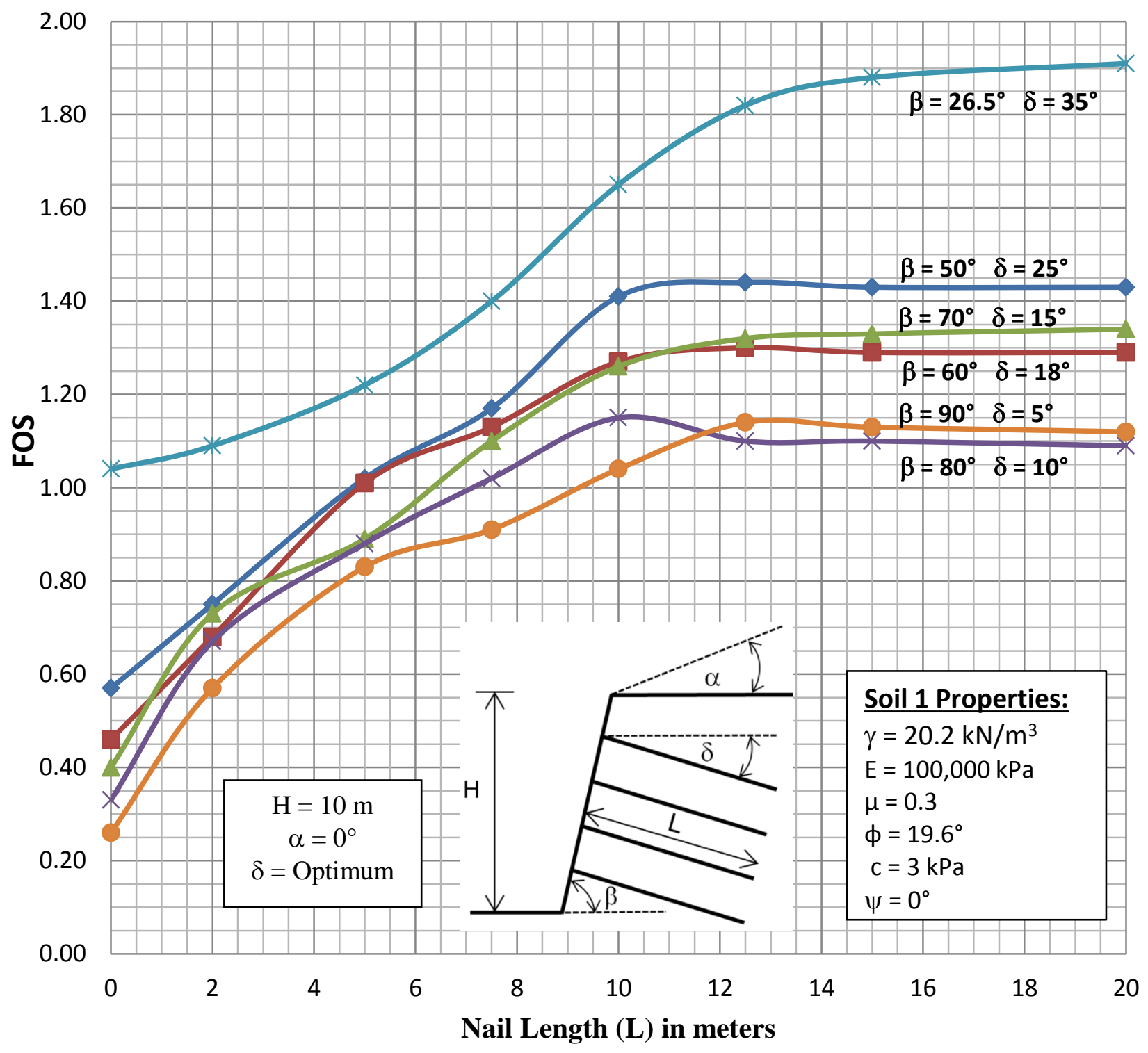

Figure 7.81 Influence of Soil Nail Length (L) on FOS for Varying Slope Angles ( $\beta$ ) - based on 3-D FEM 


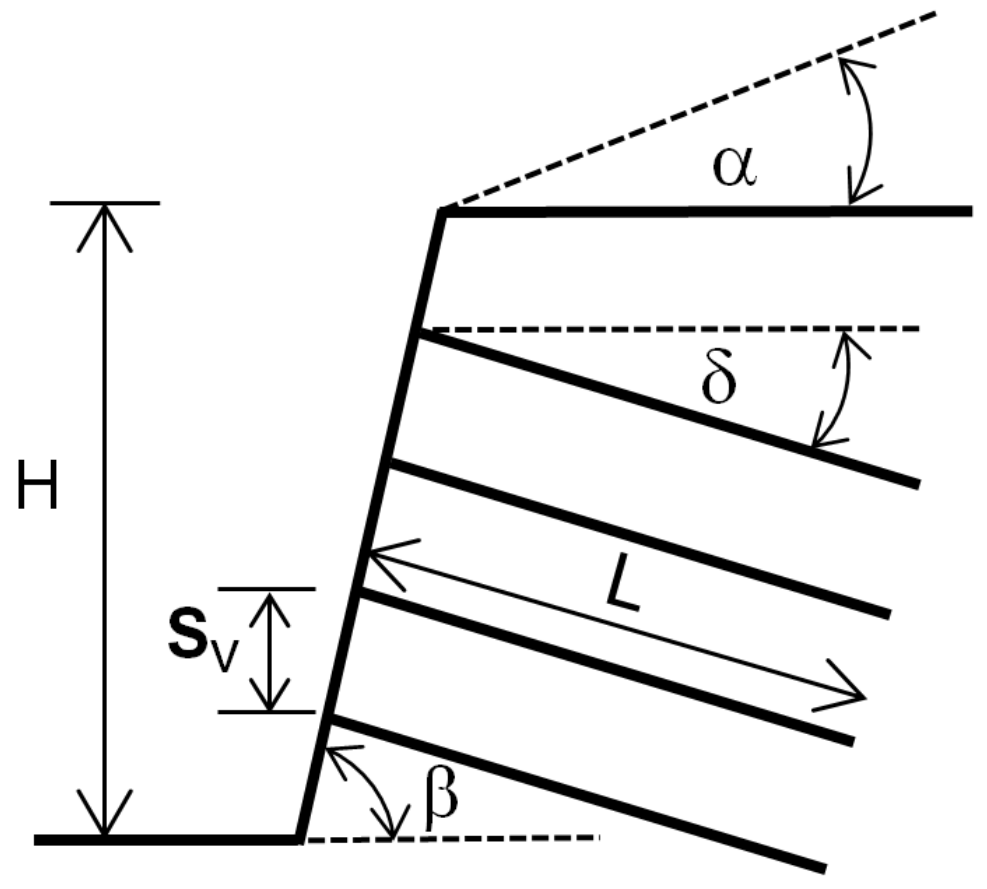

Where: Slope Height $(\mathrm{H})=10$ meters

Backslope Angle $(\alpha)=0^{\circ}$

Soil Nail Length $(\mathrm{L})=10$ meters

Soil Nail Orientation $(\delta)$ was set at optimum (See Table 7.4)

Slope Angle $(\beta)$ was varied from $26.5^{\circ}$ to $90^{\circ}$

Soil Nail Vertical Spacing was varied from 0.5 meters to 5.0 meters

Figure 7.82 Schematic of Slope and Soil Nail Parameters Used in Vertical Soil Nail Spacing $\left(\mathrm{S}_{\mathrm{V}}\right)$ Study

\subsubsection{Influence of Horizontal Soil Nail Spacing $\left(\mathrm{S}_{\mathrm{H}}\right)$}

The results of the influence of horizontal soil nail spacing $\left(\mathrm{S}_{\mathrm{H}}\right)$ on the FOS of threedimensional FEM slopes were investigated. A 10 meter high $(\mathrm{H})$, three-dimensional slope was developed for various slope angles $(\beta)$ from $90^{\circ}$ to $50^{\circ}$ using Mohr-Coulomb yielding criteria and C3D8 element types. Three different soils were used; Soil 1, Soil 2, and Soil 3, as presented in Table 5.3. For this study, five, 10-meter long (L) soil nails were placed along the centerline of the slope face using a vertical spacing $\left(\mathrm{S}_{\mathrm{V}}\right)$ of 2.0 meters. The first soil nail was placed 1.0-meter vertically from the toe of the slope (See Figure 5.5). For each 
slope angle studied, the soil nails were placed at the optimum orientations for the respective slope angles $(\beta)$, as presented in Table 5.2. The horizontal spacing $\left(\mathrm{S}_{\mathrm{H}}\right)$ was evaluated from 0.5 meters to 5.0 meters. Horizontal soil nail spacing $\left(\mathrm{S}_{\mathrm{H}}\right)$ was accomplished by increasing the depth of the model, as illustrated in Figure 5.1, while the position of the nail "column" remained constant along the centerline of the slope (See Figure 5.6).

The results for Soil 1, Soil 2, and Soil 3 are presented in Figures 7.84 through 7.86. The results of all three plots shared similar characteristics; initial FOS values remained consistent out to about $S_{H}=1.9$ meters, followed by a drop in FOS to $S_{H}=2.0$ meters, followed by a steady decrease in FOS out to $S_{H}=5.0$ meters. The reduction in the FOS from $S_{H}=1.9$ meters to $S_{H}=2.0$ meters is more evident in Soil 1 and Soil 2 than in Soil 3 . Soil 3 exhibits a slight drop from $S_{H}=1.9$ meters to $S_{H}=2.0$ meters, and a generally steady drop throughout the entire range studied. Also, at a horizontal spacing of $S_{H}=5.0$ meters, the reinforced slopes offer only a marginally higher FOS as compared to an unreinforced slope.

Typical results of the horizontal soil nail spacing $\left(\mathrm{S}_{\mathrm{H}}\right)$ study, expressed as PEEQ contour plots, are presented as Figures 7.87 and 7.88. Figure 7.87 presents a typical failure mode up to $S_{H}=1.9$ meters, and Figure 7.88 presents a typical failure mode occurring for a horizontal soil nail spacing of $\mathrm{S}_{\mathrm{H}}=2.0$ meters and greater. It is clear that the mode of failure changes from a circular failure to localized failure between the columns of soil nails, as one would expect. For illustrative purposes, a $70^{\circ}$ slope was chosen. 


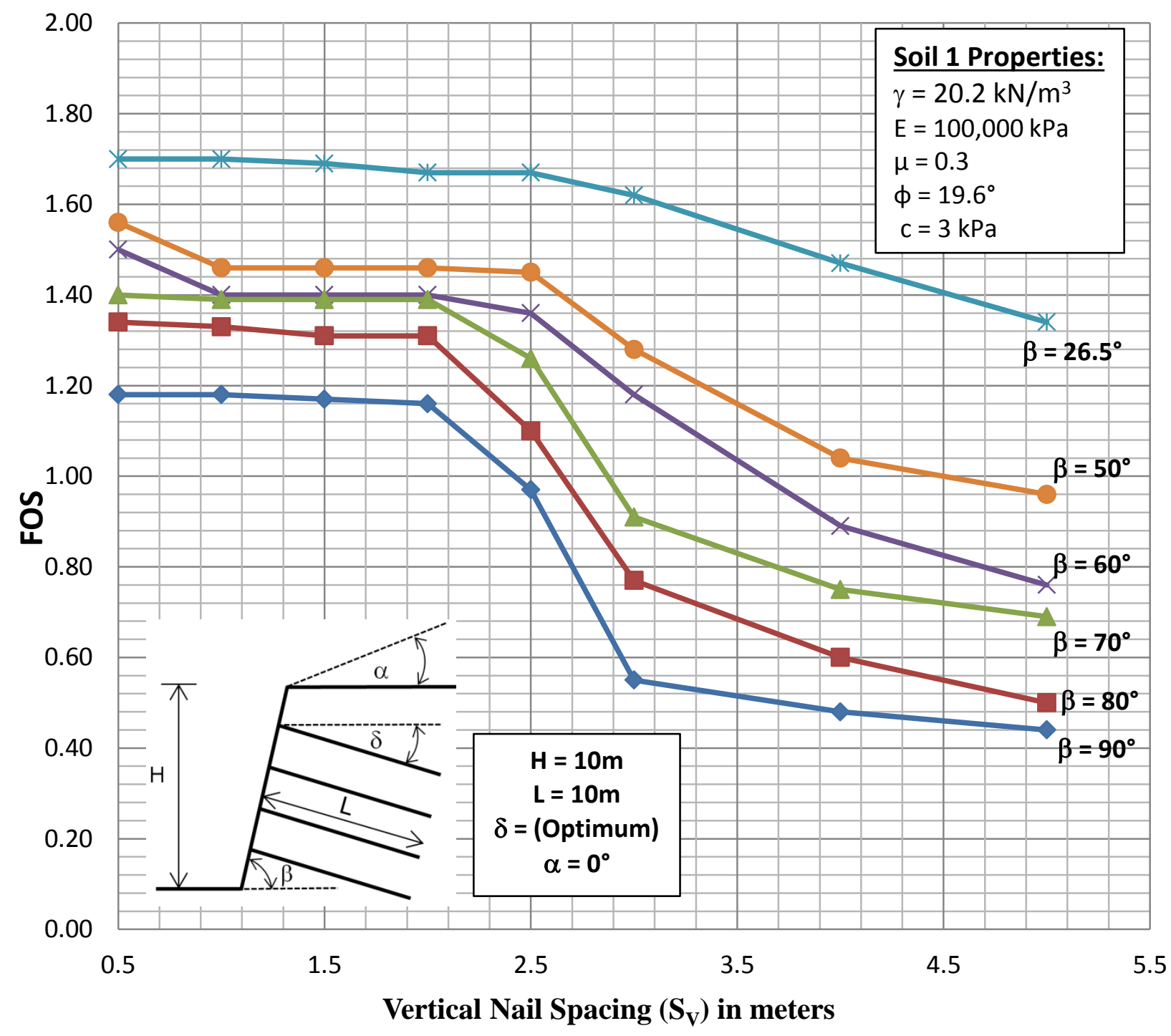

Figure 7.83 Influence of Vertical Soil Nail Spacing $\left(\mathrm{S}_{\mathrm{V}}\right)$ on FOS for Varying Slope Angles ( $\beta$ ) based on 3-D FEM 


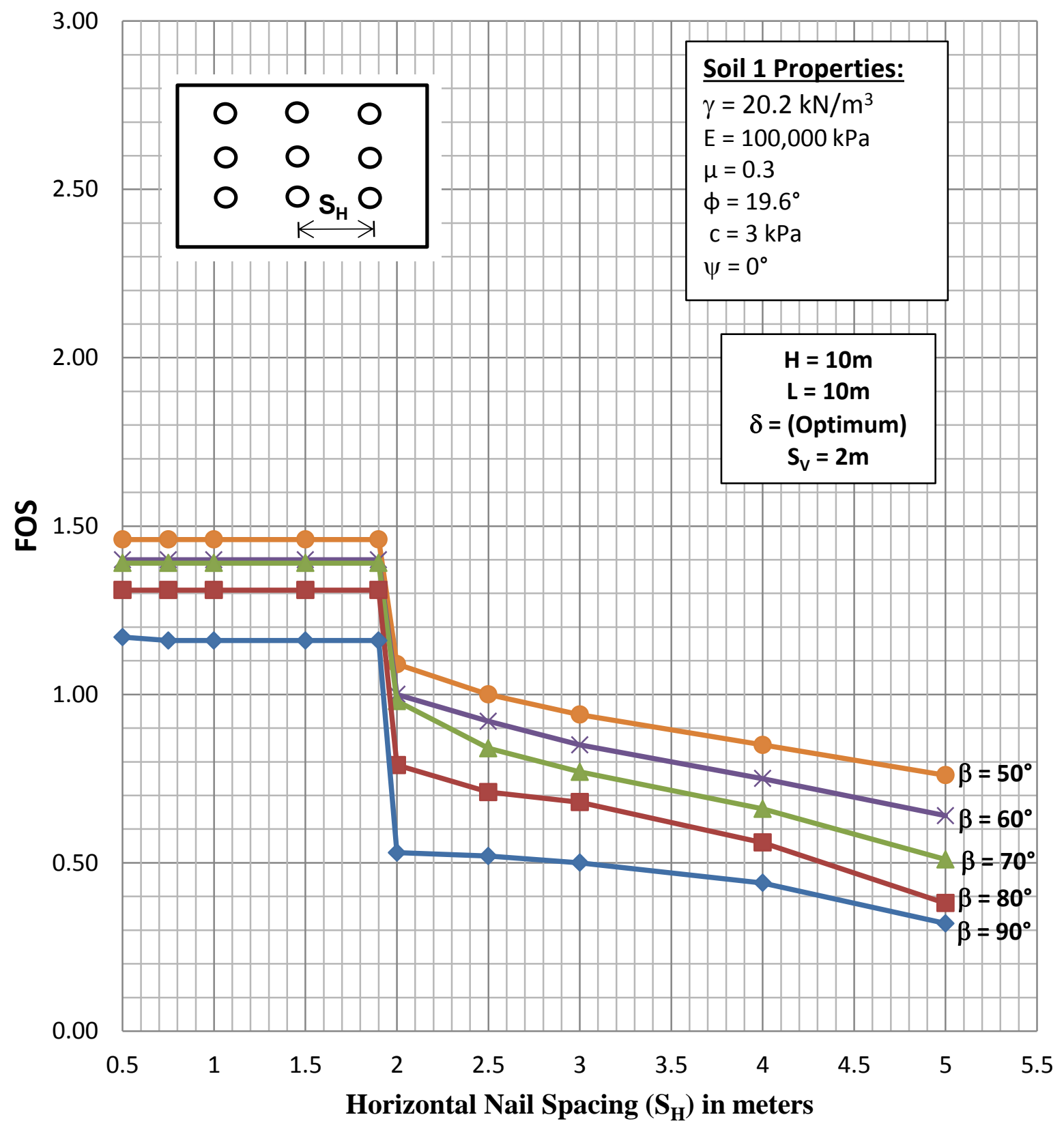

Figure 7.84 Influence of Horizontal Nail Spacing $\left(\mathrm{S}_{\mathrm{H}}\right)$ on FOS for Varying Slope Angles ( $\beta$ ) based on 3-D FEM - Soil 1 


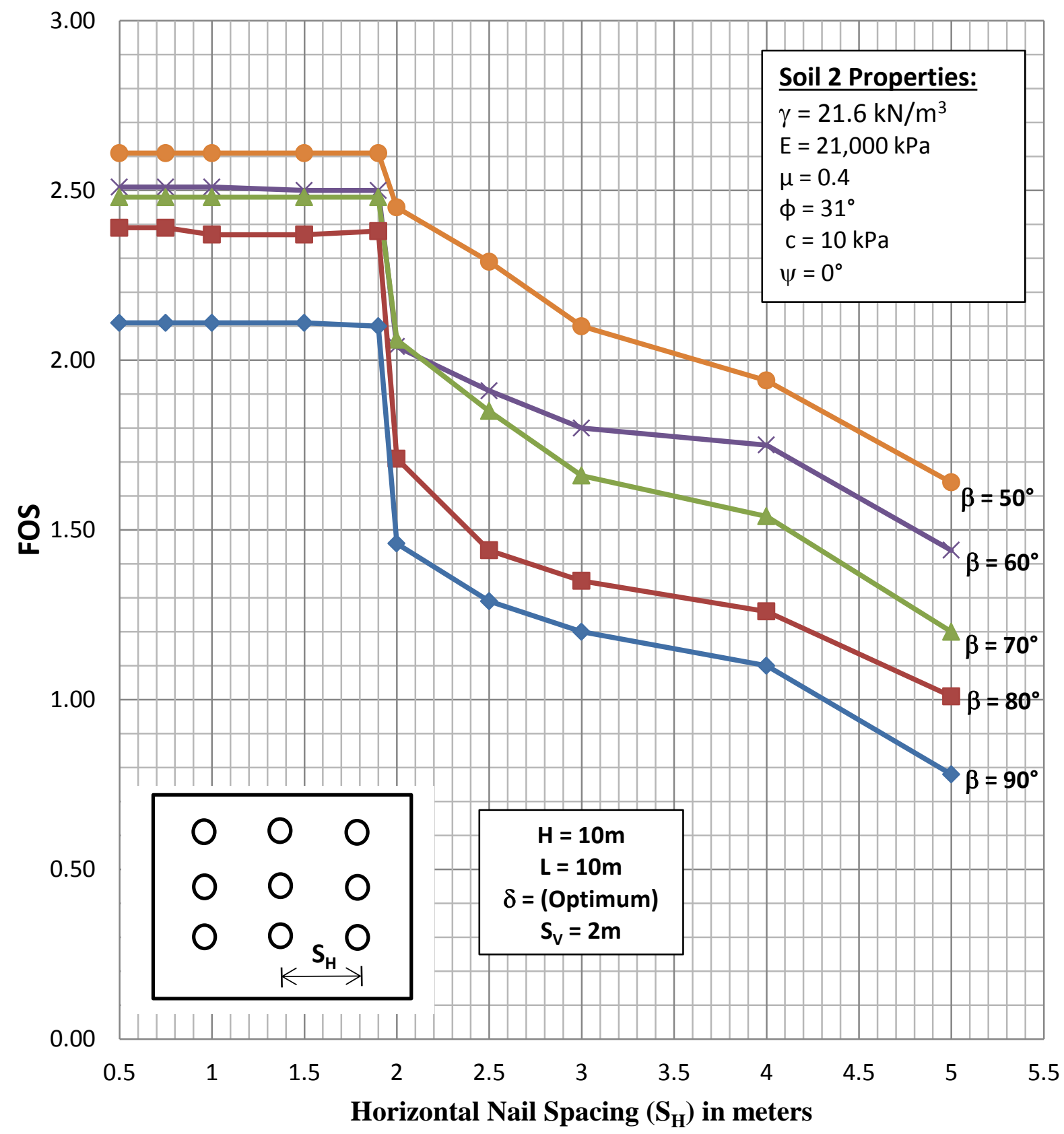

Figure 7.85 Influence of Horizontal Nail Spacing $\left(\mathrm{S}_{\mathrm{H}}\right)$ on FOS for Varying Slope Angles ( $\beta$ ) based on 3-D FEM - Soil 2 


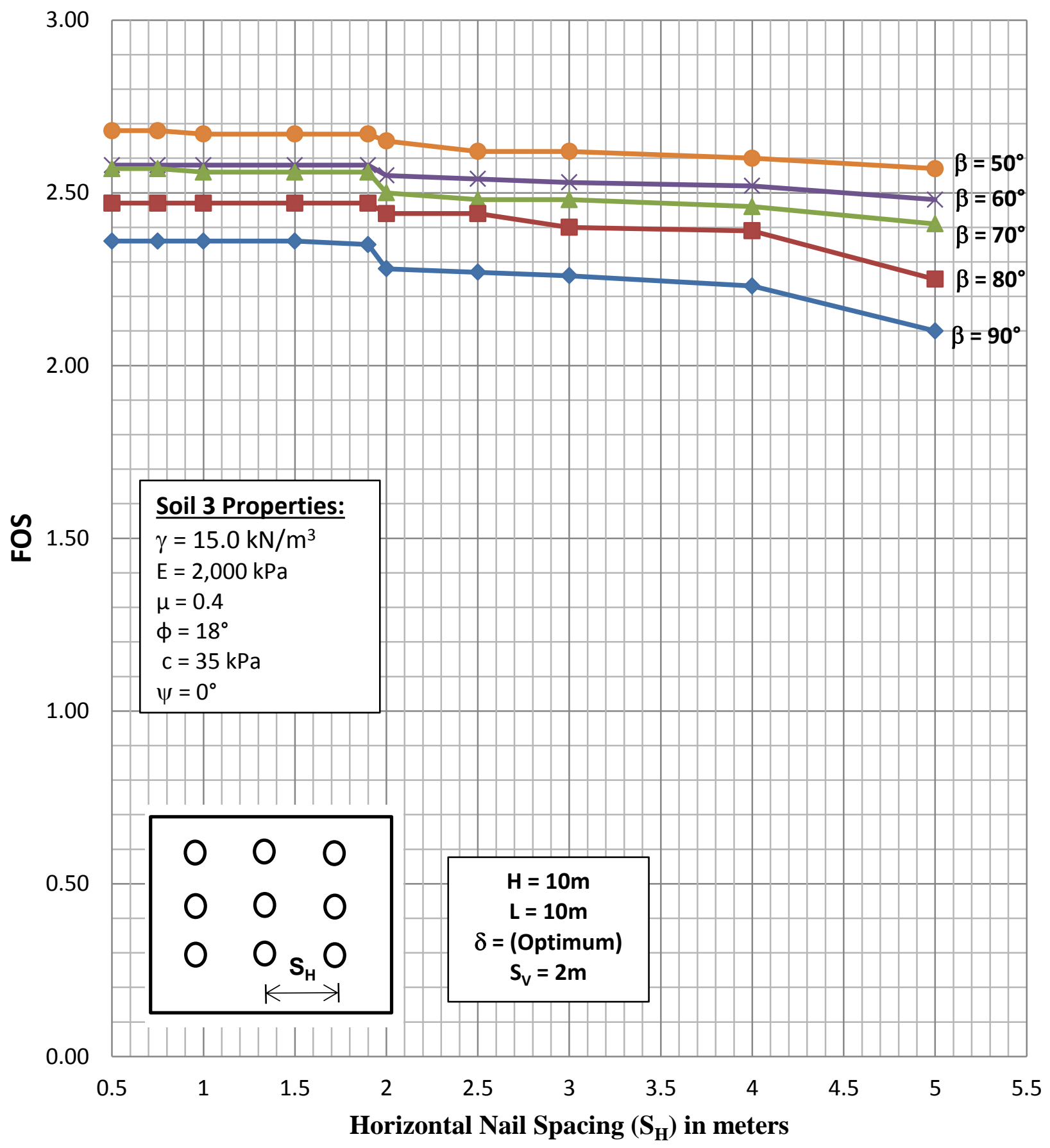

Figure 7.86 Influence of Horizontal Nail Spacing $\left(\mathrm{S}_{\mathrm{H}}\right)$ on FOS for Varying Slope Angles ( $\beta$ ) based on 3-D FEM - Soil 3 


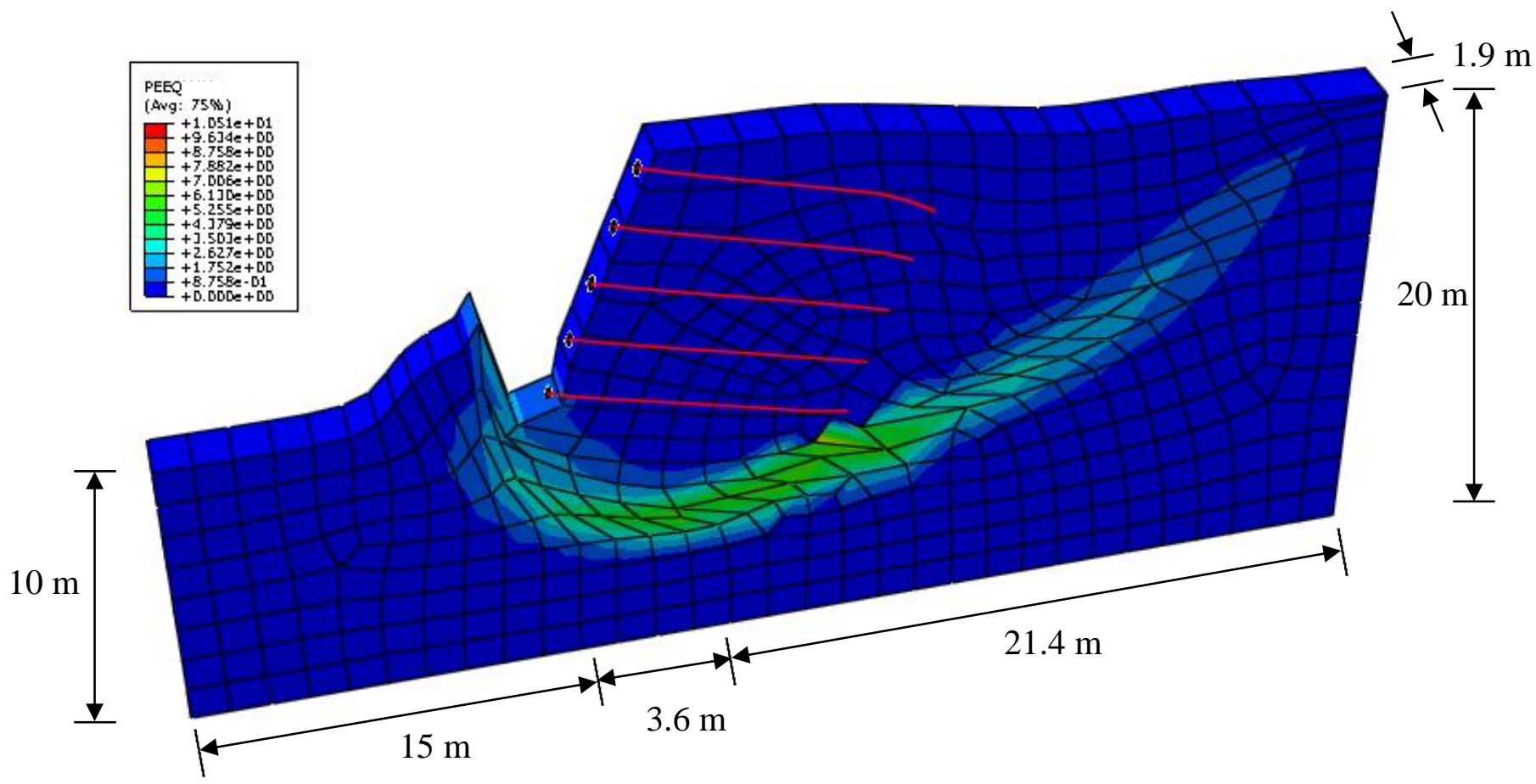

Figure 7.87 Typical PEEQ Contours for Horizontal Soil Nail Spacing up to $S_{H}=1.9 \mathrm{~m}$ (70 ${ }^{\circ}$ Slope Shown)

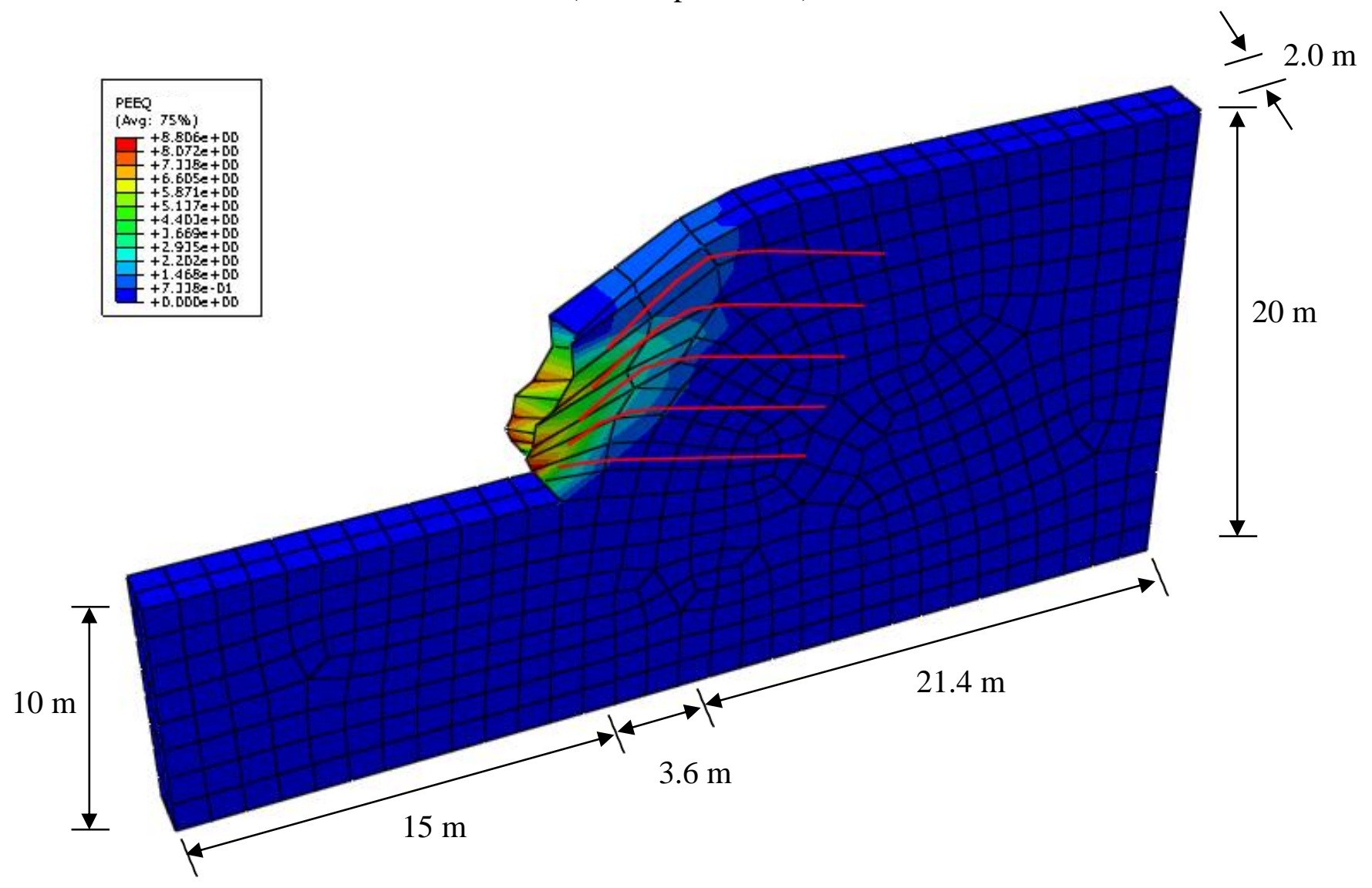

Figure 7.88 Typical PEEQ Contours for Horizontal Soil Nail Spacing of $S_{H} \geq 2.0 \mathrm{~m}$ $\left(70^{\circ}\right.$ Slope Shown) 
Since the drop in FOS was quite extreme between $\mathrm{S}_{\mathrm{H}}=1.9$ meters and $\mathrm{S}_{\mathrm{H}}=2.0$ meters (See Figures 7.84 and 7.85), a sensitivity study was performed in an attempt to clarify these results. The objective was to identify the key soil parameter(s) that were driving these results. Among those studied included the Elastic Modulus (E), the Unit Weight $(\gamma)$, Poisson's Ratio ( $\mu$ ), Angle of Friction $(\phi)$, Cohesion (c), and the Dilation Angle $(\psi)$. The FOS was determined as each of these properties was varied, within a reasonable range, while the others remained constant. In this study, Soil 1 and a $70^{\circ}$ slope angle $(\beta)$ was utilized. Table 7.5 presents the soil and slope parameters used in this study. Figures 7.89 through 7.94 present these results.

Table 7.5 Slope and Soil Variables used in Soil Nail Horizontal Spacing $\left(\mathrm{S}_{\mathrm{H}}\right)$ Study Influence of Soil Properties

\begin{tabular}{|c|c|}
\hline Slope/Soil Parameter & Value \\
\hline Slope Angle $(\beta)$ & $70^{\circ}$ \\
\hline Slope Height $(\mathrm{H})$ & $10 \mathrm{~m}$ \\
\hline Soil Nail Length $(\mathrm{L})$ & $10 \mathrm{~m}$ \\
\hline Soil Nail Orientation $(\delta)$ & $15^{\circ}($ Optimum $)$ \\
\hline Soil Nail Vertical Spacing $\left(\mathrm{S}_{\mathrm{V}}\right)$ & $2 \mathrm{~m}$ \\
\hline Soil Nail Horizontal Spacing $\left(\mathrm{S}_{\mathrm{H}}\right)$ & Varies $(0.5 \mathrm{~m}$ to $5.0 \mathrm{~m})$ \\
\hline Soil Unit Weight $(\gamma)$ & $20.2 \mathrm{kN} / \mathrm{m}^{3}$ \\
\hline Soil Elastic Modulus $(\mathrm{E})$ & $100,000 \mathrm{kPa}$ \\
\hline Soil Poisson's Ratio $(\mu)$ & 0.3 \\
\hline Soil Yielding Criteria & Mohr-Coulomb \\
\hline Soil Friction Angle $(\phi)$ & $19.6^{\circ}$ \\
\hline Soil Cohesion $(\mathrm{c})$ & $3.0 \mathrm{kPa}$ \\
\hline Soil Dilation Angle $(\psi)$ & $0^{\circ}$ \\
\hline
\end{tabular}




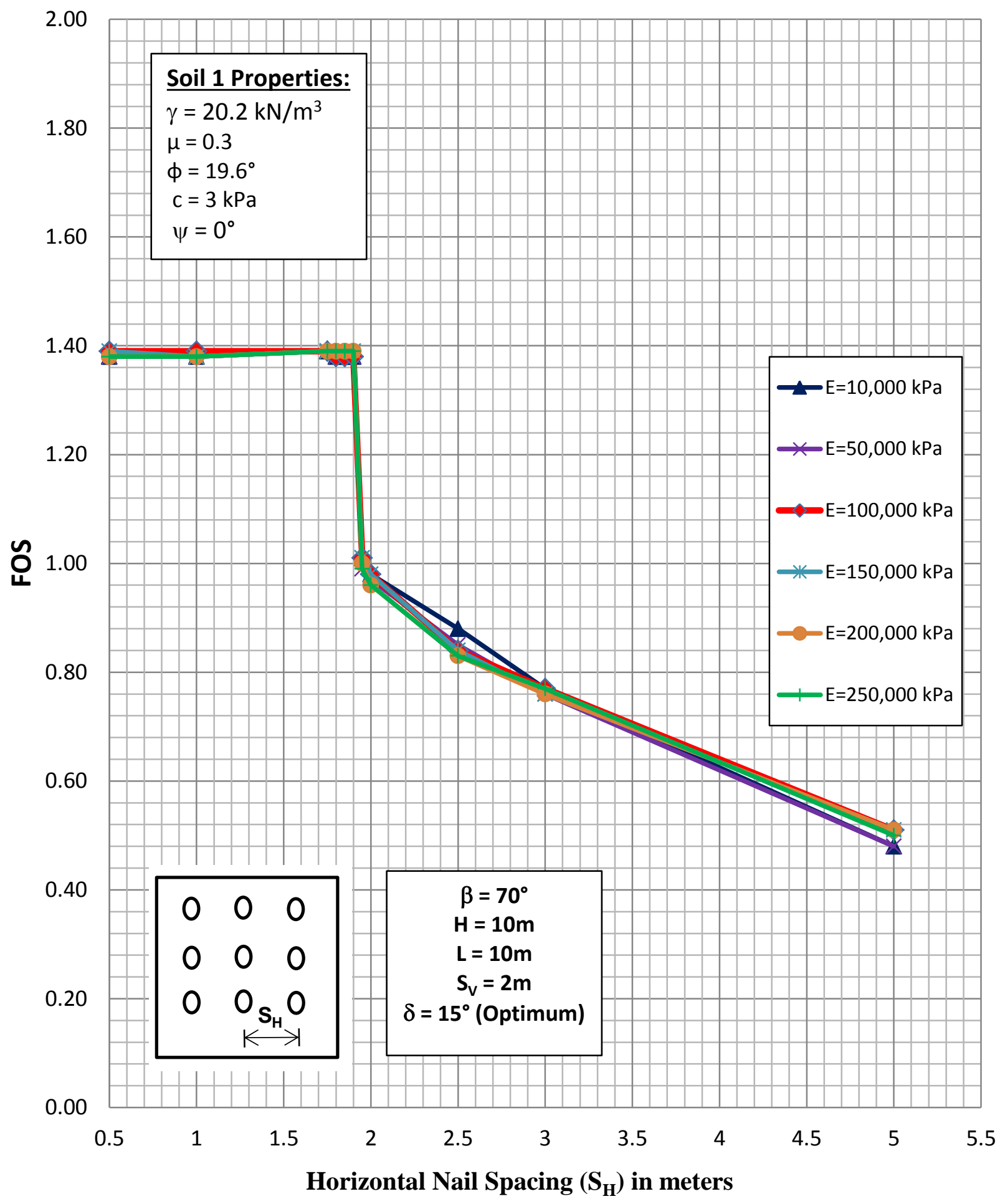

Figure 7.89 Influence of Elastic Modulus (E) \& Horizontal Nail Spacing $\left(\mathrm{S}_{\mathrm{H}}\right)$ on FOS for a $70^{\circ}$ Slope Angle $(\beta)$ - Soil 1 


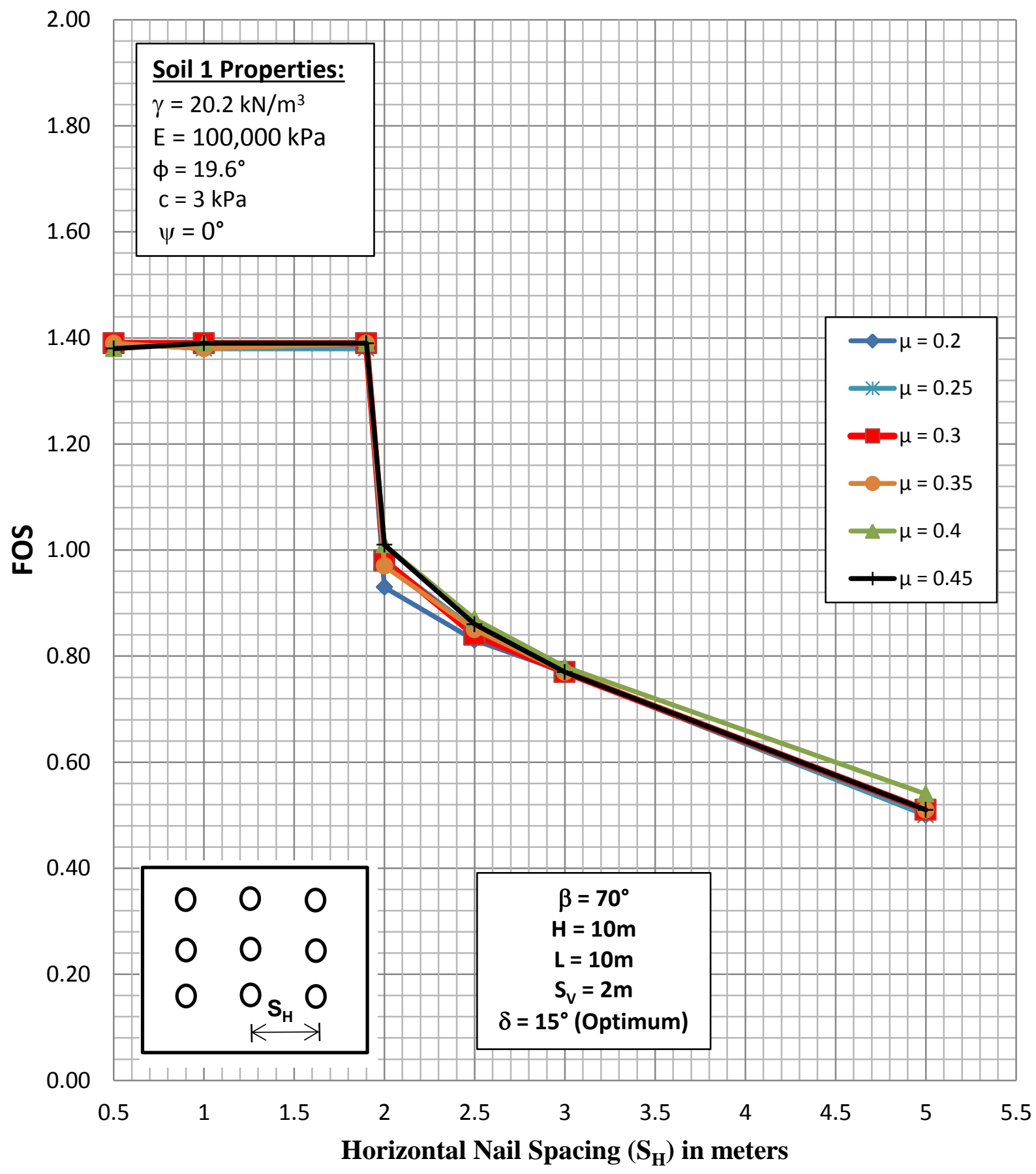

Figure 7.90 Influence of Poisson's Ratio $(\mu) \&$ Horizontal Nail Spacing $\left(\mathrm{S}_{\mathrm{H}}\right)$ on FOS for a $70^{\circ}$ Slope Angle $(\beta)$ - Soil 1 


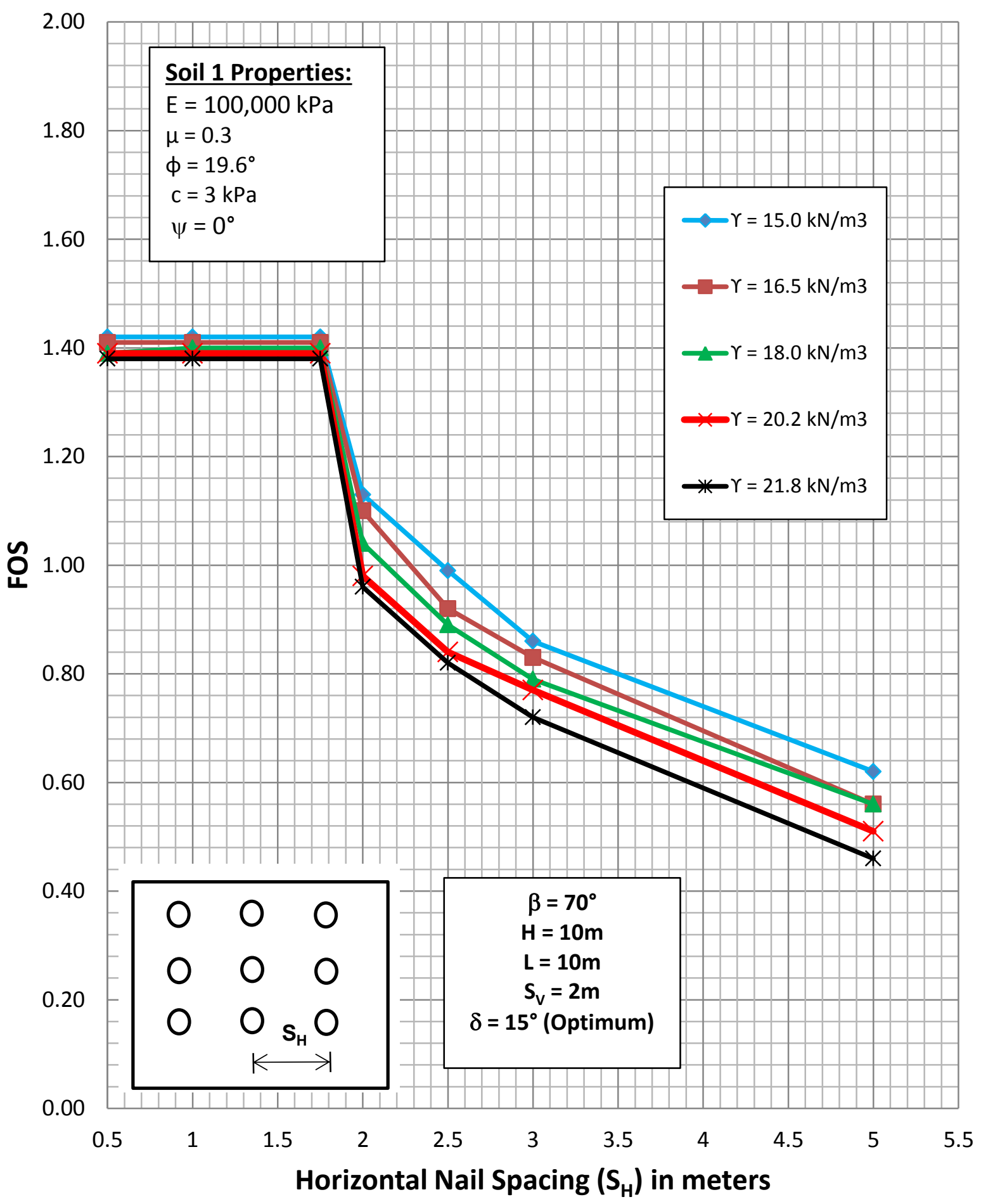

Figure 7.91 Influence of Soil Unit Weight $(\gamma) \&$ Horizontal Nail Spacing $\left(\mathrm{S}_{\mathrm{H}}\right)$ on FOS for a $70^{\circ}$ Slope Angle ( $\beta$ ) - Soil 1 


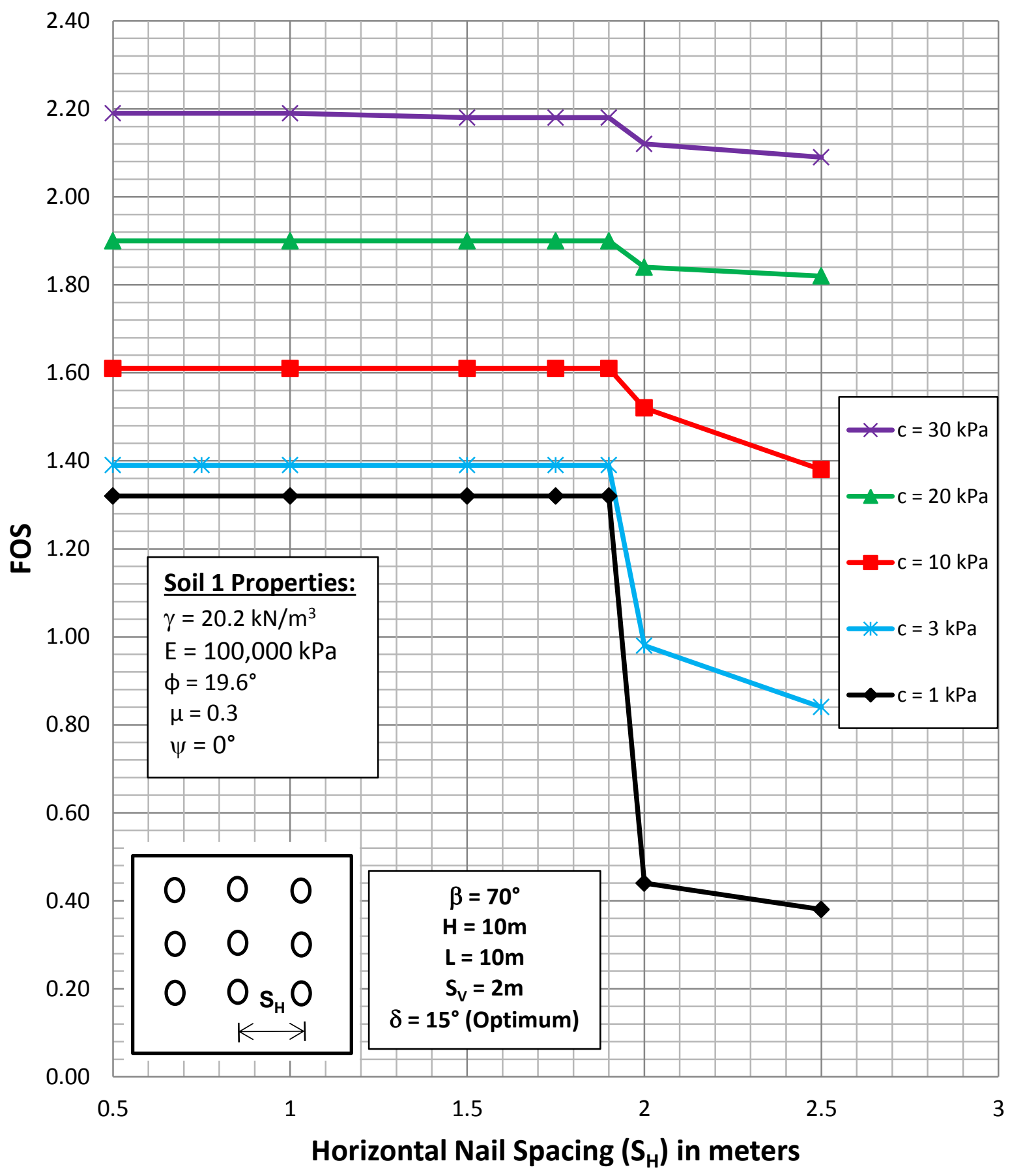

Figure 7.92 Influence of Cohesion (c) \& Horizontal Nail Spacing $\left(\mathrm{S}_{\mathrm{H}}\right)$ on FOS for a $70^{\circ}$ Slope Angle ( $\beta$ ) - Soil 1 


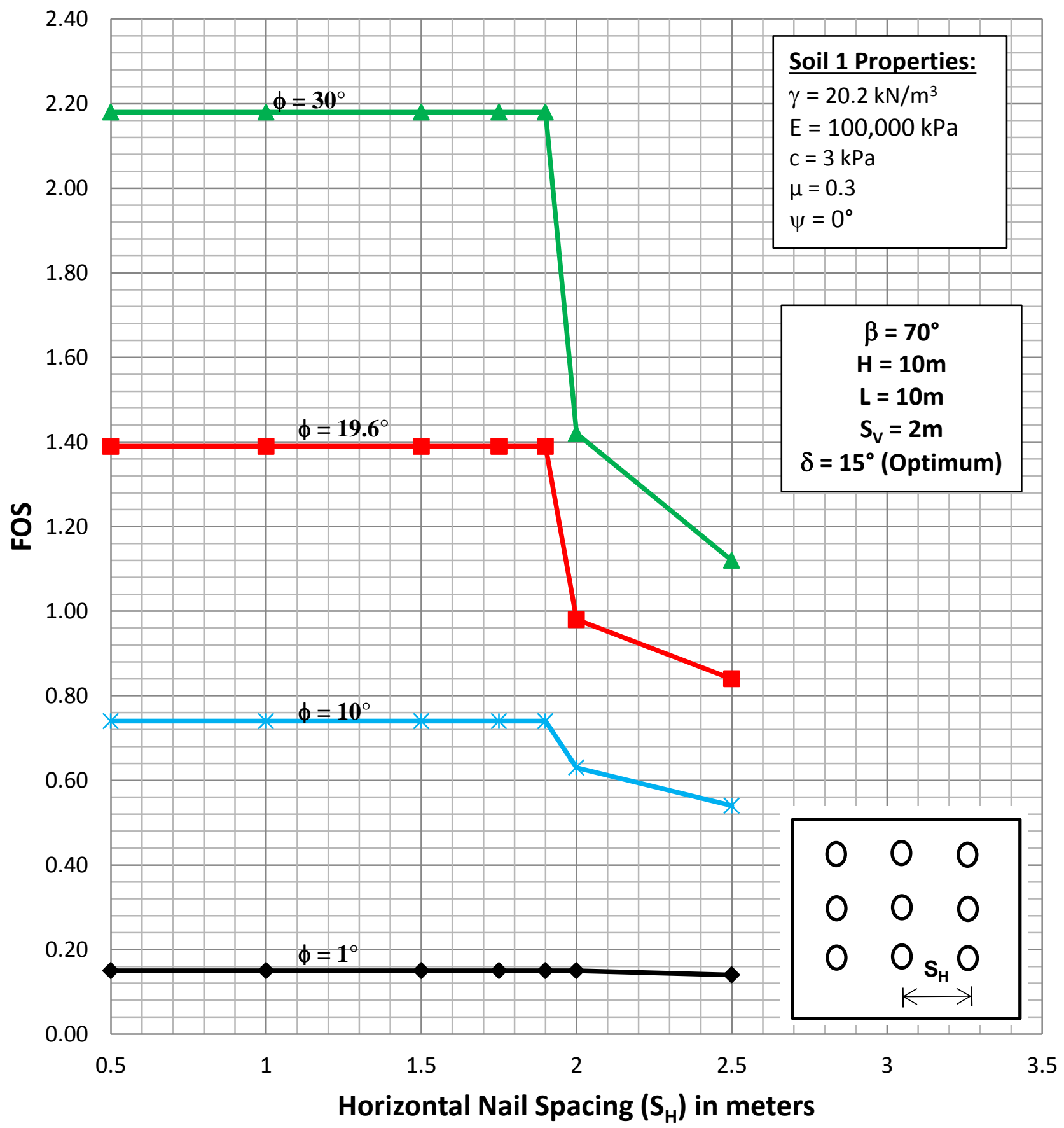

Figure 7.93 Influence of Angle of Friction $(\phi)$ \& Horizontal Nail Spacing $\left(\mathrm{S}_{\mathrm{H}}\right)$ on FOS for a $70^{\circ}$ Slope Angle $(\beta)$ - Soil 1 


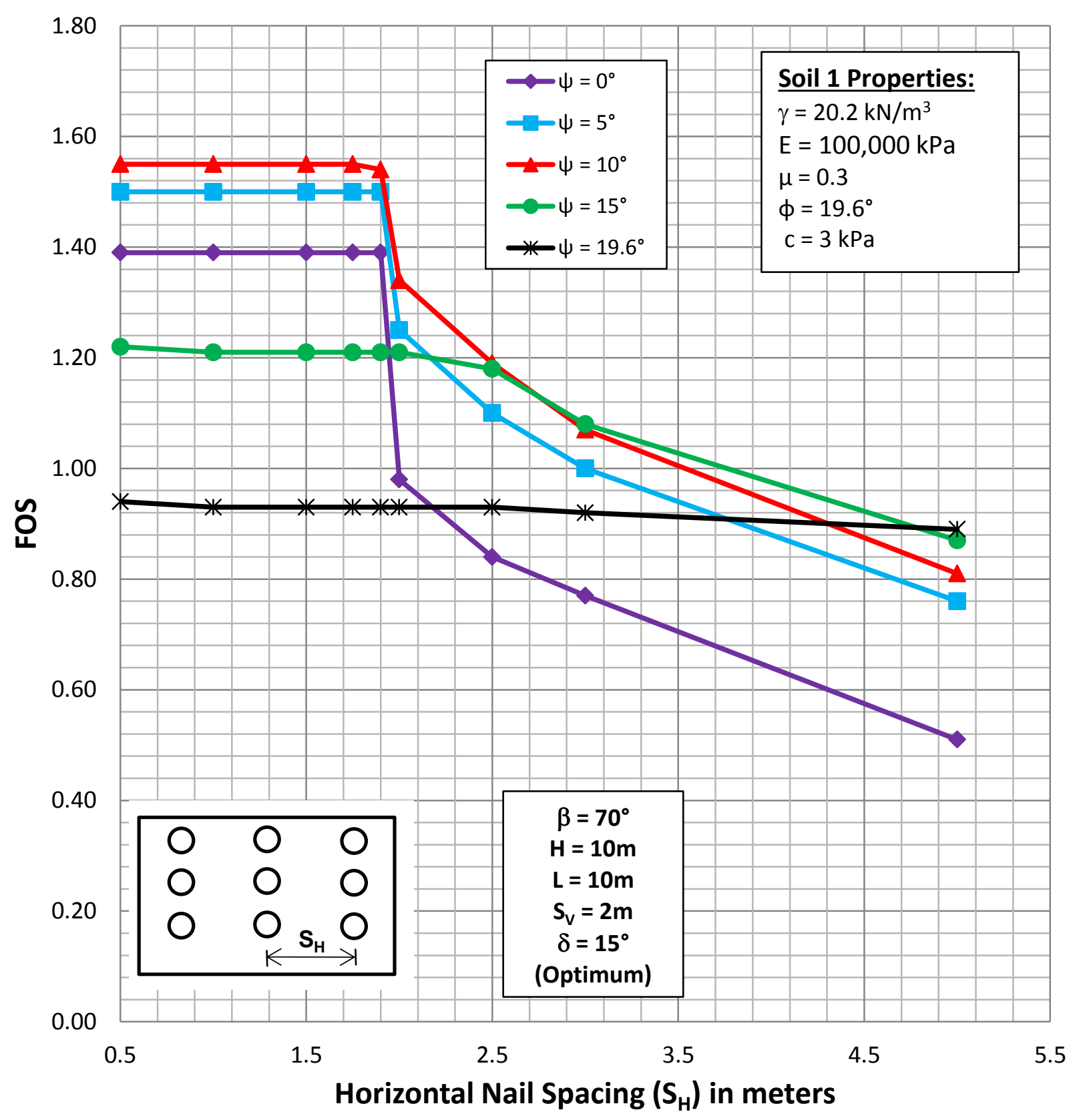

Figure 7.94 Influence of Dilation Angle $(\psi)$ \& Horizontal Nail Spacing $\left(\mathrm{S}_{\mathrm{H}}\right)$ on FOS for a $70^{\circ}$ Slope Angle $(\beta)$ - Soil 1 
From the results of this study, it is apparent that neither the Elastic Modulus (E) nor the Poisson's Ratio $(\mu)$ has a significant effect on the overall FOS (See Figures 7.89 and 7.90). Also, the large drop in FOS, at horizontal soil nail spacing from $\mathrm{S}_{\mathrm{H}}=1.9$ meters to $\mathrm{S}_{\mathrm{H}}=2.0$ meters, was still present. The Elastic Moduli used in this study was varied from $10,000 \mathrm{kPa}$ to $250,000 \mathrm{kPa}$ and the Poisson's Ratio value was varied from 0.2 to 0.45 . From a horizontal soil nail spacing of $S_{H}=2.0$ meters to $S_{H}=5.0$ meters, there was a steady, highly uniform decrease in the FOS present for both soil properties $\mathrm{E}$ and $\mu$.

The Unit Weight $(\gamma)$ soil parameter was varied from $15.0 \mathrm{kN} / \mathrm{m}^{3}$ to $21.8 \mathrm{kN} / \mathrm{m}^{3}$ (See Figure 7.91). At a horizontal soil nail spacing from $S_{H}=0.5$ meters to $S_{H}=1.9$ meters, like the results for $\mathrm{E}$ and $\mu$, the FOS for all the Unit Weight $(\gamma)$ values followed a consistently close and parallel group. In addition, and similar to the $\mathrm{E}$ and $\mu$ results, the large drop in FOS between the horizontal soil nail spacing values of $S_{H}=1.9$ meters to $S_{H}=2.0$ meters was still present. Further, there was also a steady decline in FOS beyond a horizontal soil nail spacing of $S_{H}=2.0$ meters. In addition, the lower Unit Weights $(\gamma)$ consistently yielded slightly higher FOS values than the higher Unit Weights $(\gamma)$ studied. This behavior peaked at the maximum horizontal soil nail spacing $\left(\mathrm{S}_{\mathrm{H}}=5\right.$ meters $)$ evaluated for this study with a discrepancy of 0.16 .

From Figure 7.92, it can be seen that the Cohesion (c) value plays a major role in the overall magnitude of the FOS as well as the magnitude of the FOS value decrease that occurs between a horizontal soil nail spacing values of $\mathrm{S}_{\mathrm{H}}=1.9$ meters and $\mathrm{S}_{\mathrm{H}}=2.0$ meters. Cohesion values were varied from $1.0 \mathrm{kPa}$ to $30 \mathrm{kPa}$. FOS values for this range of Cohesion values varied as much as 0.87 on the lower horizontal soil nail spacing values $\left(\mathrm{S}_{\mathrm{H}}=0.5\right.$ meters to $\mathrm{S}_{\mathrm{H}}=1.9$ meters) to as much as 1.71 at the maximum one $\left(\mathrm{S}_{\mathrm{H}}=5\right.$ meters). In 
addition, while there was still a decrease in FOS between the $S_{H}=1.9$ meter and $S_{H}=2.0$ meter horizontal soil nail spacing values for all the Cohesion values studied, it was evident that an inverse relationship existed between the magnitude of the drop and the Cohesion value. The larger the Cohesion value, the smaller the decrease in the FOS.

The Mohr-Coulomb Angle of Friction $(\phi)$ was varied from $1^{\circ}$ to $30^{\circ}$ in this study in order to evaluate its impact on the FOS associated with horizontal soil nail spacing. As presented in Figure 7.93, and similar to the Cohesion parameter, it is evident that the Angle of Friction also plays a major role in the shape and overall magnitude of the FOS. Further, the overall FOS values varied significantly for the range of friction angle values studied. For a friction angle $\left(\phi=1^{\circ}\right)$, a FOS value of about 0.14 to 0.15 resulted, regardless of the horizontal nail spacing $\left(\mathrm{S}_{\mathrm{H}}\right)$. This low value is comparable to an unreinforced slope. With an Angle of Friction $\left(\phi=1^{\circ}\right)$, an unreinforced slope yields a FOS value of about 0.10 . An Angle of Friction $\left(\phi=30^{\circ}\right)$ increased the FOS value up to 2.18 for horizontal soil nail spacing values $S_{H}=0.5$ meters to $S_{H}=1.9$ meters, but dropped to a FOS value of 1.12 for a horizontal nail spacing of $S_{H}=5$ meters. As evident in Figure 7.93, there was still a decrease in FOS between the $\mathrm{S}_{\mathrm{H}}=1.9$ meter and $\mathrm{S}_{\mathrm{H}}=2.0$ meter horizontal soil nail spacing values for all the Angle of Friction values studied. Further, it was evident that a direct relationship existed between the magnitude of the drop in the FOS values and the Angle of Friction value. The larger the Angle of Friction value, the larger the decrease in the FOS.

Although a non-associative plastic flow assumption $\left(\psi=0^{\circ}\right)$ was used in this study, as discussed in Section 3.4, for completeness, the Dilation Angle ( $\psi)$ was also studied. The Dilation Angle $(\psi)$ was varied from $0^{\circ}$ to $19.6^{\circ}$ in order to evaluate its impact on the FOS associated with horizontal soil nail spacing and the results are presented in Figure 7.94. It is 
evident that the dilation angle does have an impact on the overall FOS. As the dilation angle varied from $\psi=0^{\circ}$ to $\psi=10^{\circ}$, the FOS generally increased. The increase in FOS lessened as the dilation angle approached $\psi=10^{\circ}$. Similar to other soil parameters studied, within this dilation angle range $\left(\psi=0^{\circ}\right.$ to $\left.\psi=10^{\circ}\right)$, the FOS remained steady at a horizontal soil nail spacing from $S_{H}=0.5$ meters to $S_{H}=1.9$ meters and demonstrated a significant decrease in the FOS between the $\mathrm{S}_{\mathrm{H}}=1.9$ meter and $\mathrm{S}_{\mathrm{H}}=2.0$ meter. However, as the dilation angle increased above $\psi=10^{\circ}$, the overall FOS simply decreased. In addition, the consistent pattern of a steady FOS out to a horizontal soil nail spacing of $\mathrm{S}_{\mathrm{H}}=1.9$ meters followed by the significant decrease in FOS was not established. Further, at a dilation angle $\psi=19.6^{\circ}$ there was only a slight overall decrease in the FOS, varying from 0.94 to 0.89 as the horizontal soil nail spacing varied from $S_{H}=0.5$ meters to $S_{H}=5.0$ meters, respectively; these FOS values indicate a failure condition.

In an effort to understand the influence of the Dilation Angle $(\psi)$ on the FOS, additional models were completed using Soil 1, Soil 2, and Soil 3, presented in Table 5.3. Figures 7.95 to 7.97 present the results of this study. For Soil 1, the Angle of Friction $(\phi)$ and Cohesion (c) values were $19.6^{\circ}$ and $3 \mathrm{kPa}$, respectively. The results of the Dilation Angle $(\psi)$ study using Soil 1 are presented in Figure 7.95. Using this soil the FOS reached a maximum value for horizontal soil nail spacing's $\mathrm{S}_{\mathrm{H}}=0.5$ meters to 2.0 meters at a Dilation Angle $(\psi)$ of about $10^{\circ}$ to $10.5^{\circ}$. Further, there was no noticeable variance in the FOS values for horizontal soil nail spacing's $\mathrm{S}_{\mathrm{H}} \leq 1.9$ meters. At a horizontal soil nail spacing's $\mathrm{S}_{\mathrm{H}}=3.0$ meters, the maximum FOS value was obtained at a Dilation Angle $(\psi)$ of $12.5^{\circ}$. Further, at a horizontal soil nail spacing's $\mathrm{S}_{\mathrm{H}}=5.0$ meters, the FOS steadily increased to a maximum FOS value obtained at a Dilation Angle $(\psi)$ of $19.6^{\circ}$, which assumes a fully 
associative plastic flow assumption $\left(\psi=\phi=19.6^{\circ}\right)$. Also, using Soil 1 , there was very little variance in the FOS value for any horizontal soil nail spacing $\left(\mathrm{S}_{\mathrm{H}}\right)$ when a fully associative plastic flow assumption was modeled.

For Soil 2, the Angle of Friction $(\phi)$ and Cohesion (c) values were $31^{\circ}$ and $10 \mathrm{kPa}$, respectively. The results of the Dilation Angle $(\psi)$ study using Soil 2 are presented in Figure 7.96. This increase in the Mohr-Coulomb strength parameters yielded a significant FOS increase, overall, as compared to Soil 1. Similar to the results using Soil 1, the use of Soil 2 yielded a similar relationship between FOS values and the Dilation Angle $(\psi)$. The FOS using Soil 2 reached a maximum value for horizontal soil nail spacing's $\mathrm{S}_{\mathrm{H}}=0.5$ meters to 2.0 meters at a Dilation Angle $(\psi)$ of about $10^{\circ}$, and once again, there was no noticeable variance in the FOS values for horizontal soil nail spacing's $\mathrm{S}_{\mathrm{H}} \leq 1.9$ meters. At horizontal soil nail spacing's $S_{H}=3.0$ meters and $S_{H}=5.0$ meters, the maximum FOS value was obtained at a Dilation Angle $(\psi)$ of $12.5^{\circ}$ and $15^{\circ}$, respectively. Finally, and also similar to the results obtained using Soil 1, there was very little variance in the FOS value for any horizontal soil nail spacing $\left(\mathrm{S}_{\mathrm{H}}\right)$ when a fully associative plastic flow assumption was used.

For Soil 3, the Angle of Friction ( $\phi)$ and Cohesion (c) values were $18^{\circ}$ and $35 \mathrm{kPa}$, respectively. The results of the Dilation Angle $(\psi)$ study using Soil 3 are presented in Figure 7.97. The significant increase in the Cohesion value for Soil 3 yielded a notable difference in the results. While there was not a significant increase in the maximum FOS values, results for all horizontal soil nail spacing's studied $\left(\mathrm{S}_{\mathrm{H}}=0.5\right.$ meters to $\mathrm{S}_{\mathrm{H}}=5.0$ meters) were consistent in behavior, without much variance in the FOS values. In addition, at all horizontal soil nail spacing's studied, the maximum FOS value was obtained at a 
Dilation Angle $(\psi)$ of about $5^{\circ}$. For Dilation Angles $\left(\psi>5^{\circ}\right)$, the FOS values steadily decreased.

The results of this study indicate that the Dilation Angle can have a significant effect on the FOS when evaluating the horizontal soil nail spacing $\left(\mathrm{S}_{\mathrm{H}}\right)$ of soil-nailed slopes. In general, regardless of the soil strength parameters used, the FOS value slightly increases with an increase in the Dilation Angle $(\psi)$ and then steadily decreases. As discussed in Section 3.4.2, in most of the analyses, the Dilation Angle $(\psi)$ is considered to be equal to $0^{\circ}$, assuming a non-associative plastic flow rule, or the Dilation Angle $(\psi)$ is considered to be equal to the Angle of Friction $(\phi)$ which assumes a fully associative plastic flow rule. The results of this investigation indicate very little variance in the FOS values for all horizontal soil nail spacing $\left(\mathrm{S}_{\mathrm{H}}\right)$ studied $\left(\mathrm{S}_{\mathrm{H}}=0.5\right.$ meters to $\mathrm{S}_{\mathrm{H}}=5.0$ meters $)$ when the Dilation Angle $(\psi)$ was set equal to the Angle of Friction $(\phi)$. These results support the use of non-associative plastic flow rule $\left(\psi=0^{\circ}\right)$ used in this research. 


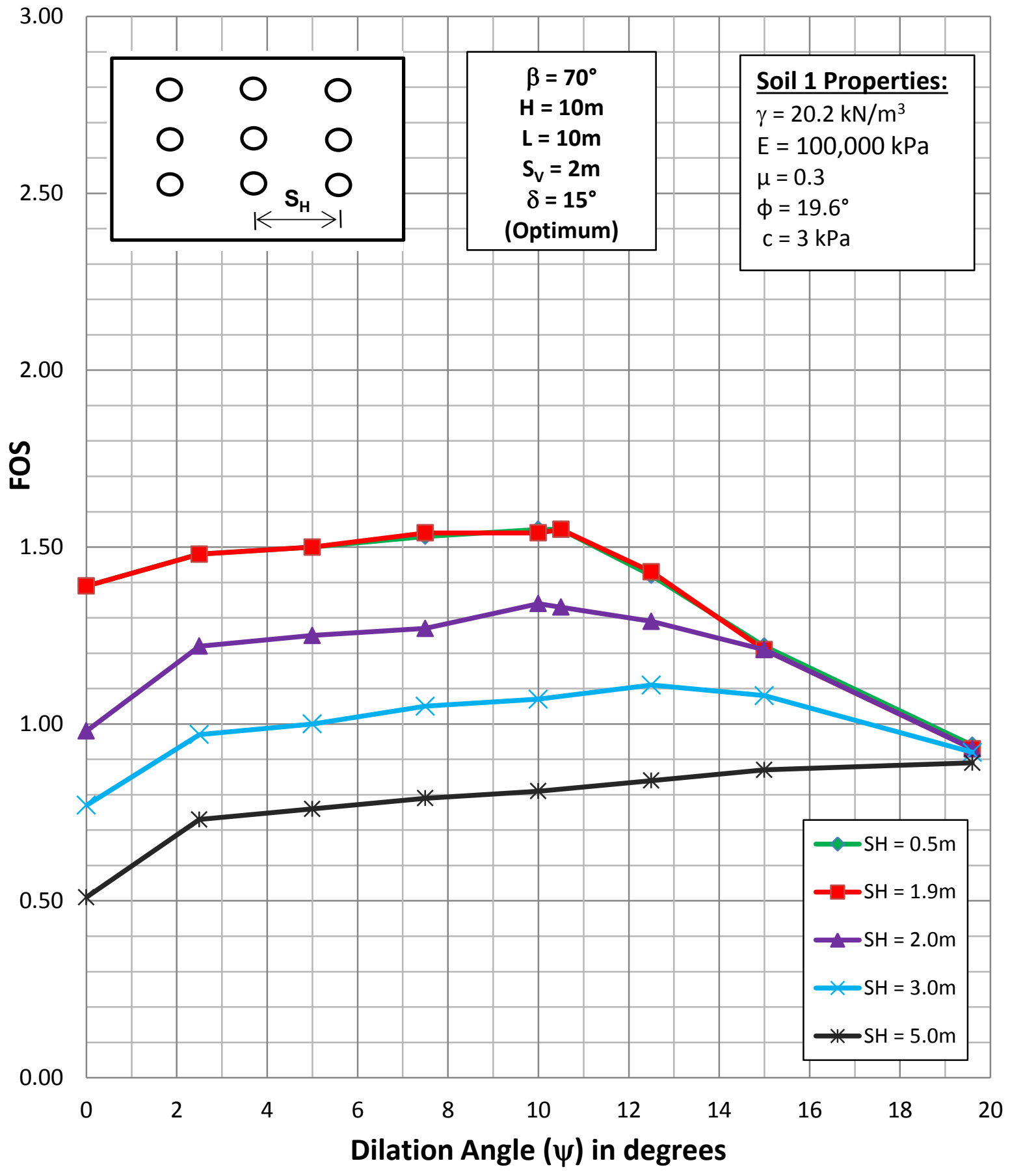

Figure 7.95 Influence of Dilation Angle $(\psi)$ on FOS for Select Horizontal Nail Spacing $\left(\mathrm{S}_{\mathrm{H}}\right)$ for a $70^{\circ}$ Slope Angle $(\beta)$ - Soil 1 


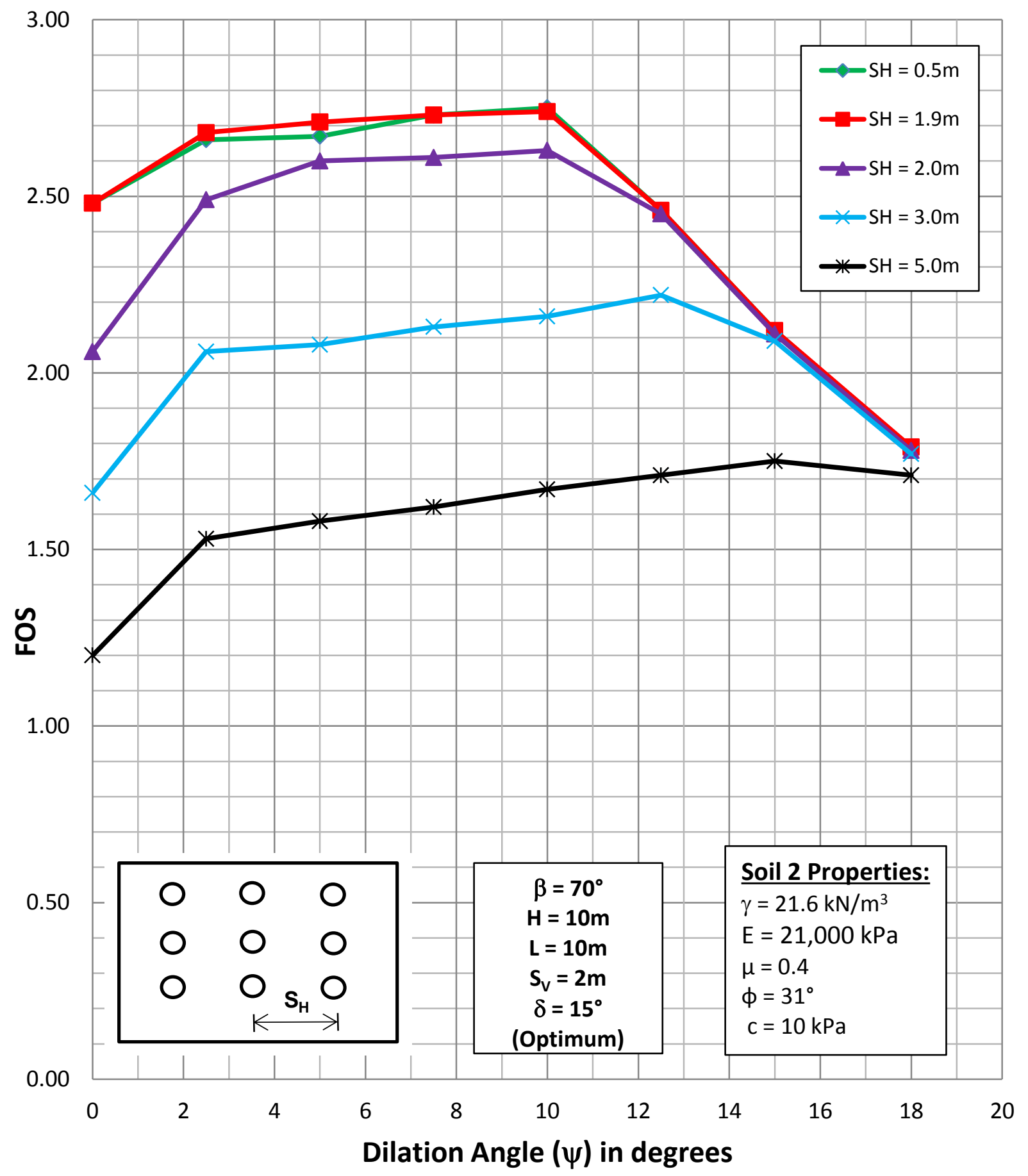

Figure 7.96 Influence of Dilation Angle $(\psi)$ on FOS for Select Horizontal Nail Spacing $\left(\mathrm{S}_{\mathrm{H}}\right)$ for a $70^{\circ}$ Slope Angle $(\beta)$ - Soil 2 


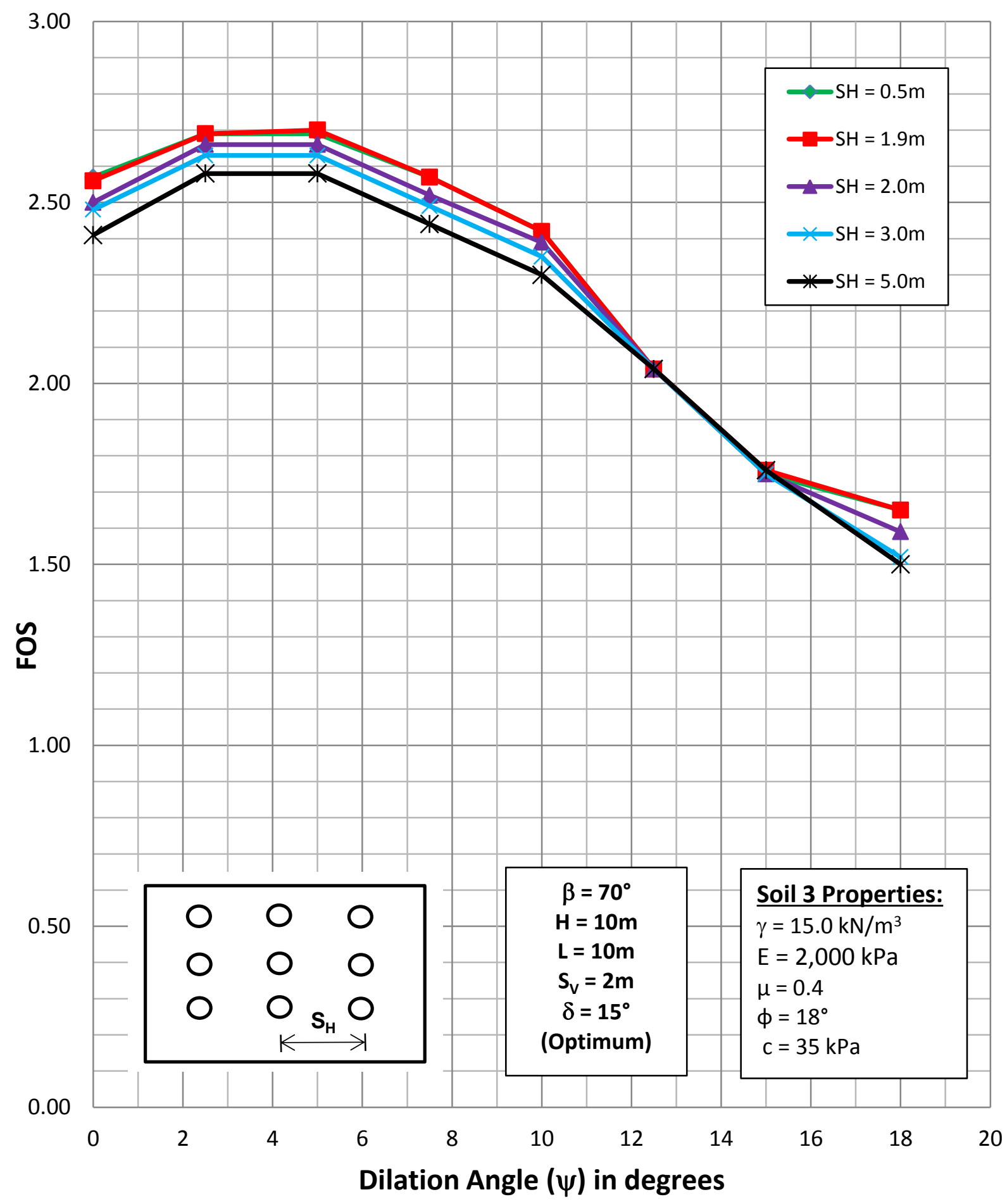

Figure 7.97 Influence of Dilation Angle $(\psi)$ on FOS for Select Horizontal Nail Spacing $\left(\mathrm{S}_{\mathrm{H}}\right)$ for a $70^{\circ}$ Slope Angle $(\beta)$ - Soil 3 
According to the results of this study, three-dimensional FEM modeling of reinforced slopes is relatively insensitive to a soil's Elastic Modulus (E), Unit Weight $(\gamma)$, and Poisson's Ratio ( $\mu$ ) value, with respect to the slope's overall FOS. Conversely, threedimensional FEM modeling of reinforced slopes is sensitive to a soil's Dilation Angle $(\psi)$, Cohesion (c) and Angle of Friction ( $\phi$ ) value, with respect to the slope's overall FOS.

In order to study the individual impact of Cohesion (c) and Angle of Friction $(\phi)$, additional models were completed. Combinations of high and low Cohesion (c) and Angle of Friction $(\phi)$ values were modeled. All other material and slope parameters were as presented in Table 7.5. Figure 7.98 presents the combined results of Cohesion (c) and Angle of Friction $(\phi)$ when considering horizontal soil nail spacing $\left(\mathrm{S}_{\mathrm{H}}\right)$ on the FOS value.

The results of this study indicate that the Angle of Friction $(\phi)$ has a significant impact on the relative FOS value. FOS values below 1.0 resulted for a very low Angle of Friction value $\left(\phi=1^{\circ}\right)$ despite a relatively high Cohesion value $(\mathrm{c}=30 \mathrm{kPa})$. Further, FOS values above 2.0 resulted for a high Angle of Friction value $\left(\phi=30^{\circ}\right)$ despite a relatively low Cohesion value $(\mathrm{c}=3 \mathrm{kPa})$. While the impact of the Cohesion (c) value does affect the overall FOS value, it is not as significant as the Angle of Friction $(\phi)$. However, the Cohesion (c) value does noticeably affect the magnitude of decrease in the FOS value at $S_{H}$ $>1.9$ meters (about 6 feet). For Cohesion (c) values less than $10 \mathrm{kPa}$, the FOS drop was substantial, especially at higher Angle of Friction $(\phi)$ values. For higher Cohesion values (c $\geq 10 \mathrm{kPa}$ ), PEEQ contour plots for $\mathrm{S}_{\mathrm{H}}>1.9$ meters resembled Figure 7.87 with a typical circular failure surface. For Cohesion (c) values less than $10 \mathrm{kPa}$, PEEQ contour plots for $\mathrm{S}_{\mathrm{H}}$ $>1.9$ meters demonstrated a localized slope failure between the soil nail columns, as presented in Figure 7.88. 


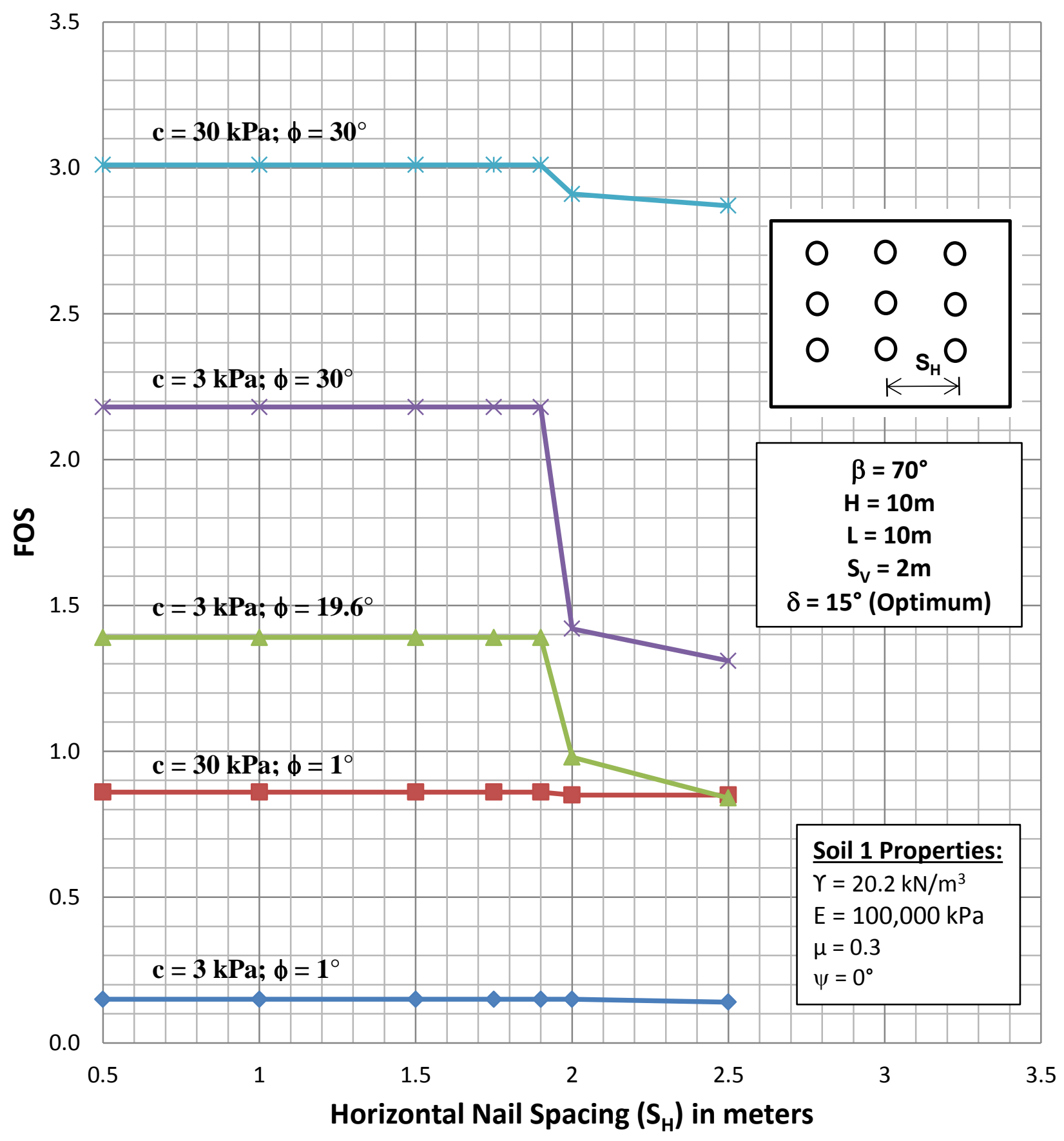

Figure 7.98 Influence of Combined Cohesion (c) - Friction $(\phi) \&$ Horizontal Nail Spacing $\left(\mathrm{S}_{\mathrm{H}}\right)$ on FOS for a $70^{\circ}$ Slope Angle $(\beta)$ - Soil 1 
7.5.5 Influence of Surcharge Location (x) and Magnitude (q)

Ultimately, surcharge loads are often the reason for a steepened slope that needs additional stability provided by soil nails. This study evaluated the position ( $\mathrm{x}$ ) and magnitude (q) of surcharge loads applied to the top of soil-nailed slopes. This study included slope angles $(\beta)$ from $90^{\circ}$ to $50^{\circ}$ using Soil 1 . Surcharge loads from $\mathrm{q}=0 \mathrm{kPa}$ (No surcharge) to $\mathrm{q}=500 \mathrm{kPa}$ were evaluated at distances (location $(\mathrm{x})$ ) measured from the top of the slope. The distance ranged from 0 (full coverage of top of slope) to a no surcharge load condition. Figure 7.99 presents a schematic for the slope and soil variables used in the surcharge location and magnitude study. Figures 7.100 through 7.104 present the results.

As a general observation, the FOS was not influenced greatly by the distance of the surcharge load from the top of slope. The results did support the basic logical deduction that the flatter slopes had generally higher ranges of FOS values. In addition, there was a consistent difference in FOS values between the $\mathrm{q}=10 \mathrm{kPa}$ and the $\mathrm{q}=500 \mathrm{kPa}$ surcharge load for all slope angles $(\beta)$. The relative difference in FOS values between these two surcharge loads generally decreased as the slope angle increased.

For all the slope angles, at surcharge load magnitudes of $\mathrm{q}=10 \mathrm{kPa}, \mathrm{q}=50 \mathrm{kPa}$, and $\mathrm{q}=100 \mathrm{kPa}$, it was evident that as the surcharge location (x) increased, as measured from the top of the slope, the FOS value moved towards the FOS value without a surcharge load present $(\mathrm{q}=0)$. At the $\mathrm{q}=250 \mathrm{kPa}$ and $\mathrm{q}=500 \mathrm{kPa}$ surcharge loads, which equates to about 5,221 pounds per square foot (psf) and 10,442 psf, respectively, the PEEQ contour plots indicate a local "bearing" failure on the top surface when the surcharge load location (x) exceeds about $x=4$ meters for most slope angles $(\beta)$. This is especially true as these large surcharge loads are placed beyond the influence of the soil-nailed reinforced soil mass. 


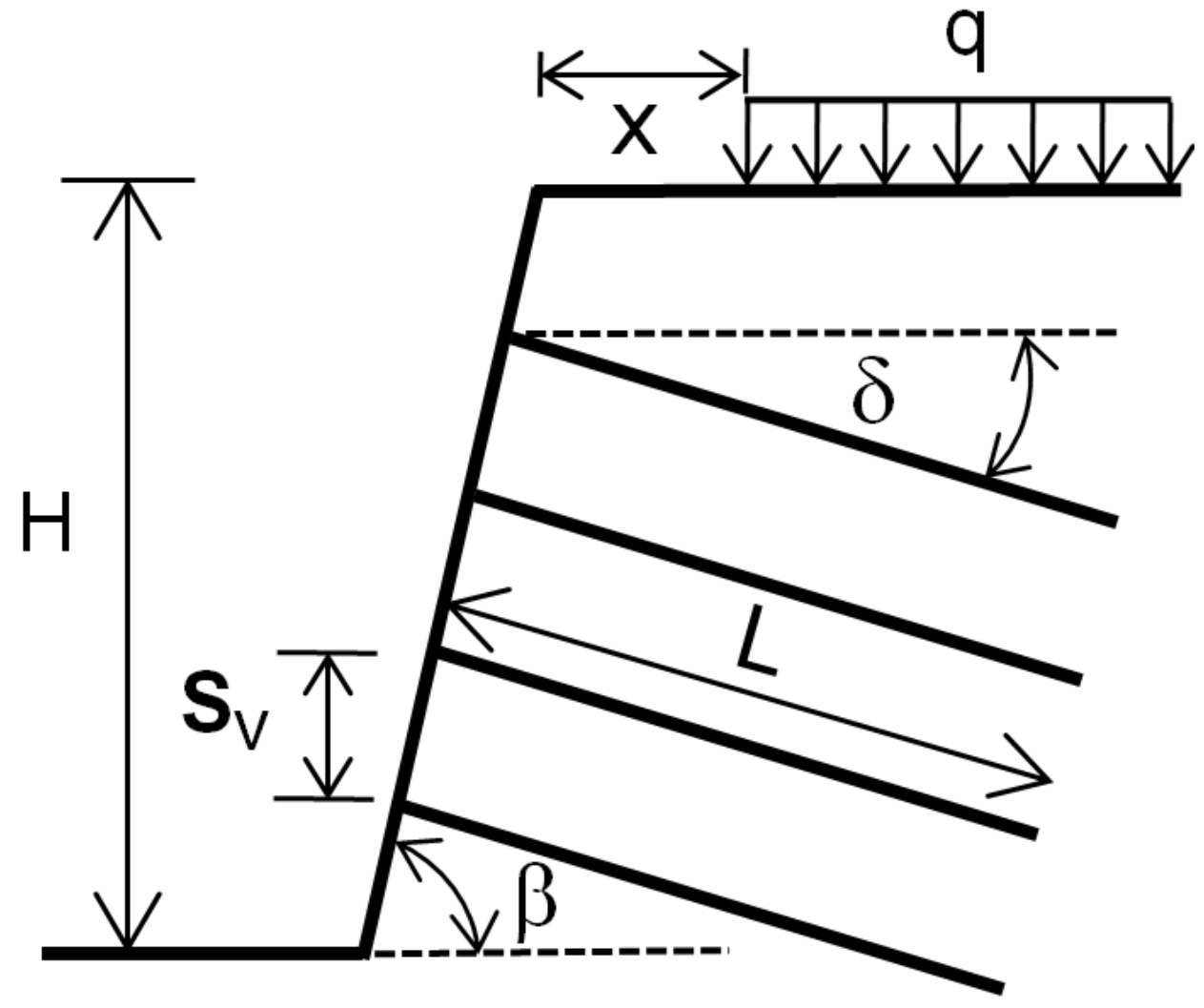

Where: Slope Height $(H)=10$ meters

Soil Nail Length $(\mathrm{L})=10$ meters

Soil Nail Orientation $(\delta)$ was set at optimum (See Table 7.4)

Soil Nail Vertical Spacing $\left(\mathrm{S}_{\mathrm{V}}\right)=2.0$ meters

Slope Angle $(\beta)$ was varied from $50^{\circ}$ to $90^{\circ}$

Surcharge Location (x) was varied from 0 meters to 20.0 meters

Surcharge Magnitude (q) was varied from $10 \mathrm{kPa}$ to $500 \mathrm{kPa}$

Figure 7.99 Schematic of Slope and Soil Nail Parameters Used in Surcharge Location (x) and Magnitude (q) Study 


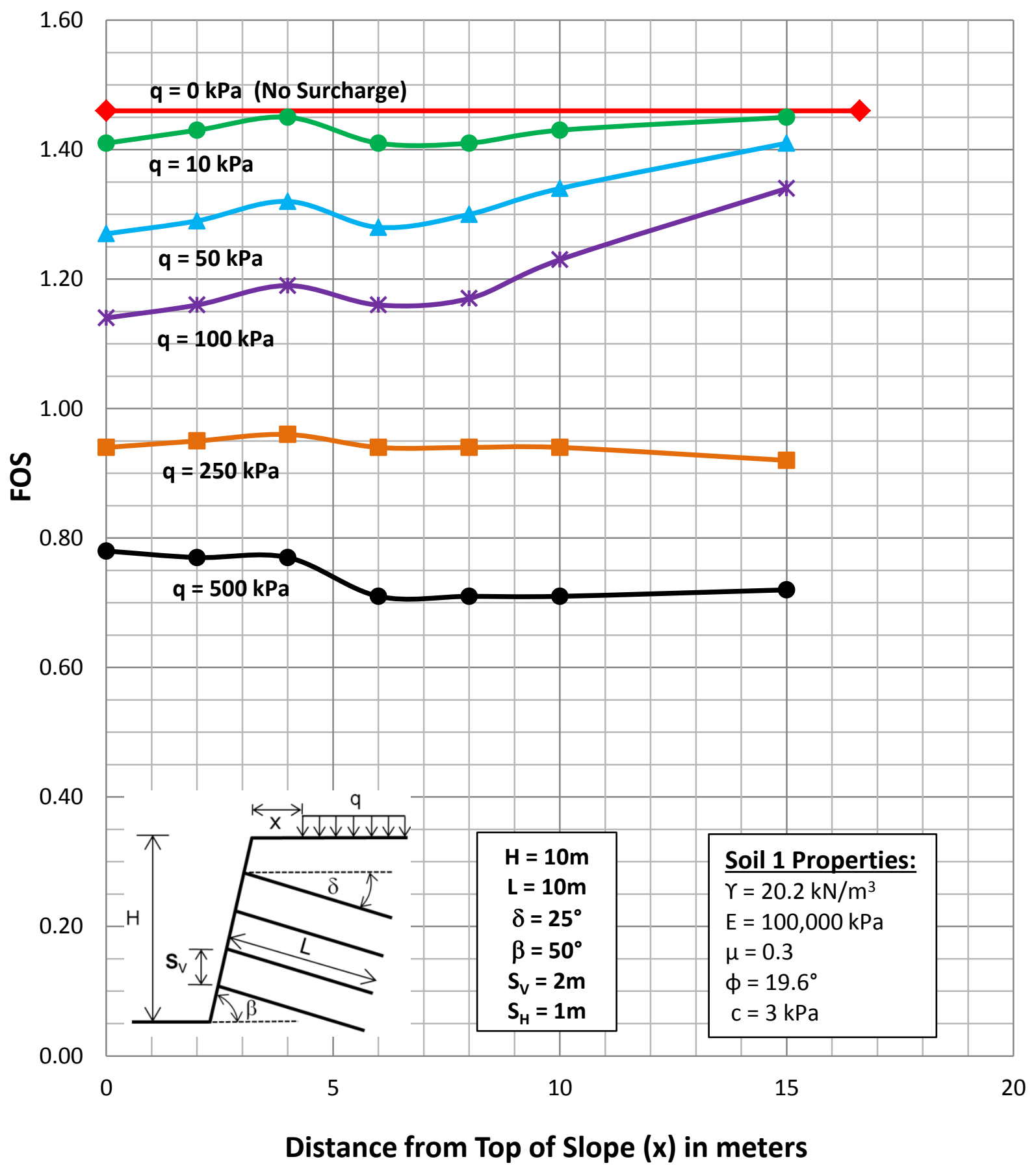

Figure 7.100 Influence of Surcharge Position (X) and Magnitude (q) - 50 Slope Angle 


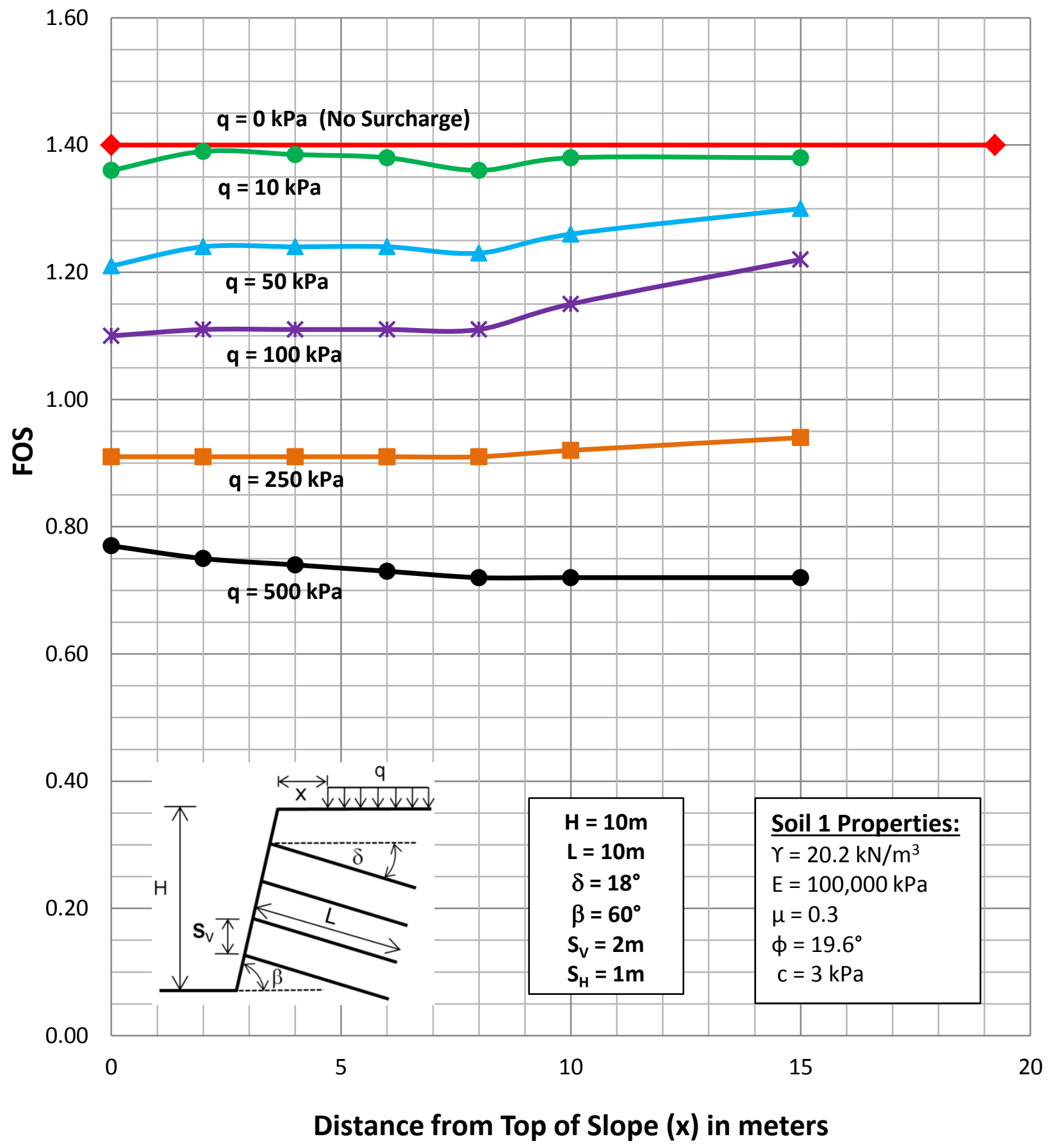

Figure 7.101 Influence of Surcharge Position (X) and Magnitude (q) $-60^{\circ}$ Slope Angle 


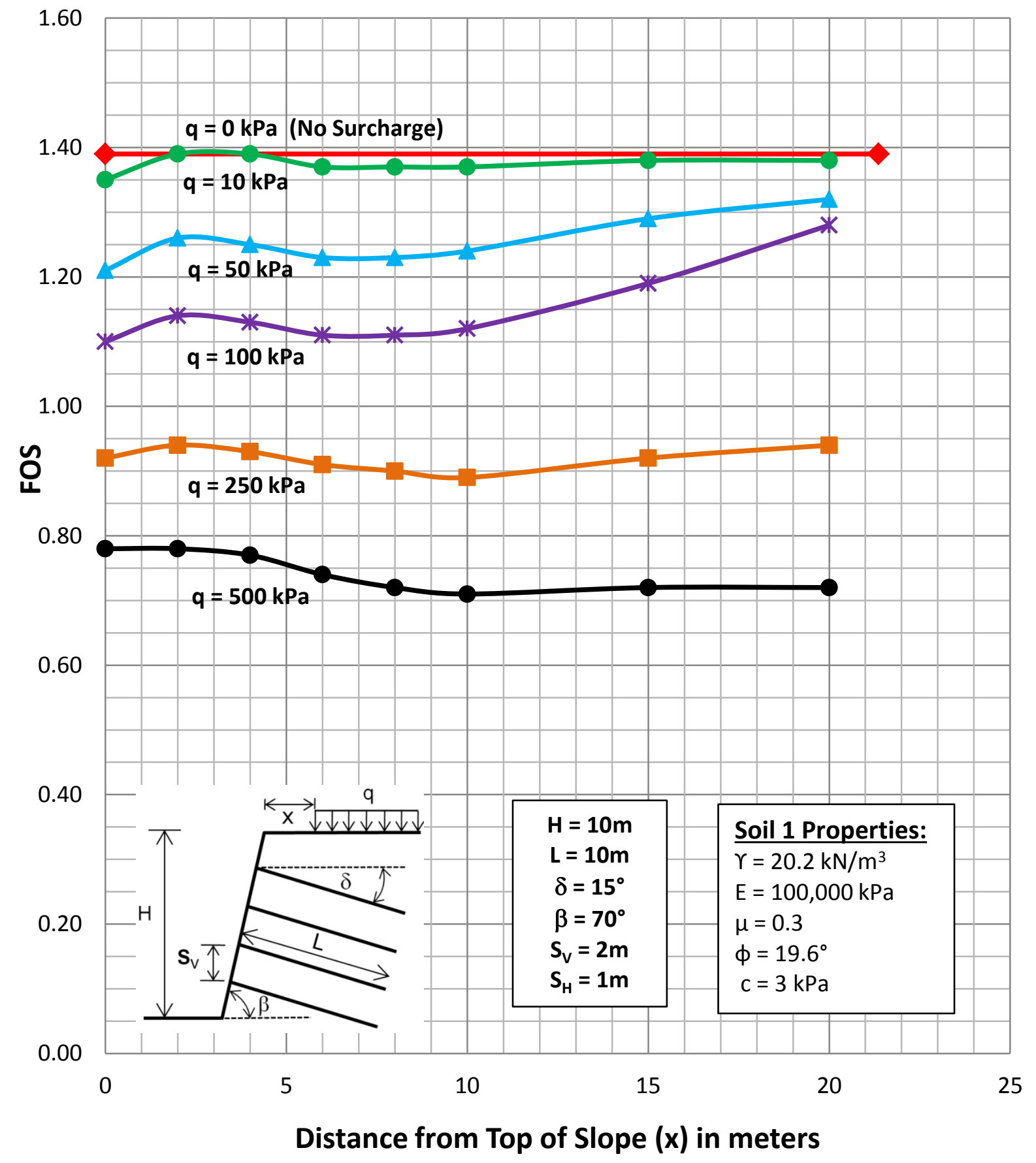

Figure 7.102 Influence of Surcharge Position (X) and Magnitude (q) - 70 ${ }^{\circ}$ Slope Angle 




Figure 7.103 Influence of Surcharge Position (X) and Magnitude (q) - $80^{\circ}$ Slope Angle 


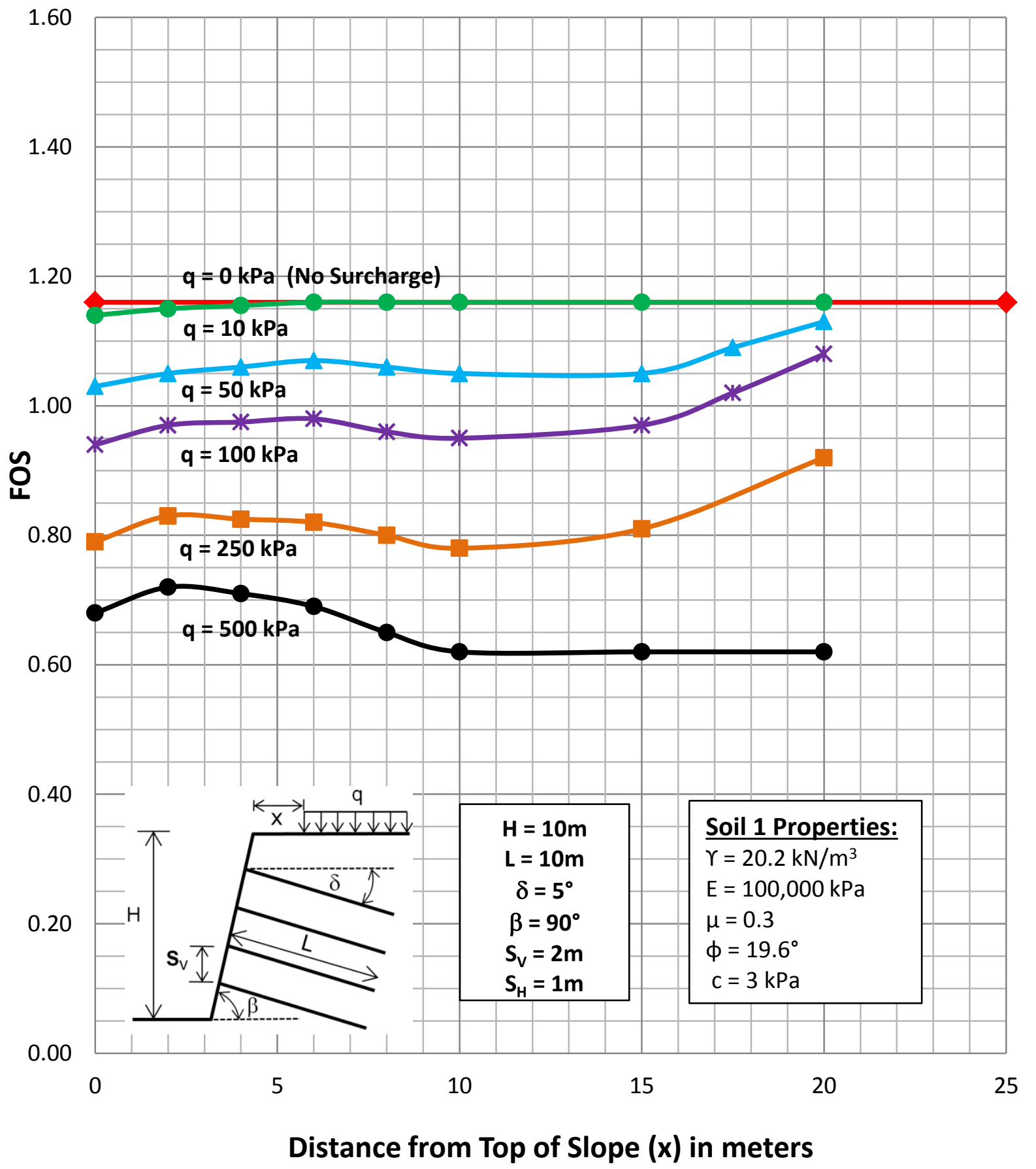

Figure 7.104 Influence of Surcharge Position (X) and Magnitude (q) - $90^{\circ}$ Slope Angle 
7.5.6 Surcharge Location (x) and Magnitude (q) - Two-Dimensional L-E Comparison

In order to compare results, two-dimensional L-E models were developed for a reinforced, $70^{\circ}$ slope with a surcharge load (q). The same methodology as described in Section 7.5.5 was used. The results are presented in Figure 7.105 below. Once again, it is evident that generally the three-dimensional FEM models yielded consistently higher FOS values. However, for the surcharge loads of $250 \mathrm{kPa}$ and $500 \mathrm{kPa}$, the two-dimensional L-E models yielded slightly higher FOS values when the surcharge load location (x) exceeded values of 11 and 13 meters, respectively. As noted above, for these relatively heavy surcharge loads, the PEEQ contour plots indicate a local "bearing" type of failure on the top surface of the slope. Unlike the FEM modeling, the two-dimensional L-E Slide slope stability program is not capable of analyzing this type of failure. Select FEM PEEQ contour plots and L-E critical circle results are presented as Figures 7.106 through 7.109.

\subsubsection{Influence of Typical Soil Types}

An upper/lower limit range of soil properties for three cohesive soils was investigated to determine the FOS's on slope angles ranging from $50^{\circ}$ to $90^{\circ}$. The soil properties used covered upper and lower limit soil parameters for Clay, Silt, and Sandy Clay soil types. These properties were obtained from various sources (Das, 2013; McCarthy, 2007; MnDOT, 2007; NAVFAC, 1986) and are presented in Table 5.4.

As noted from the sensitivity analysis completed during the horizontal soil nail spacing study in Section 7.5.4, the Angle of Friction ( $\phi)$ and Cohesion (c) soil properties are the critical parameters entered in the FEM, Mohr-Coulomb model for soil slopes when considering FOS. Figure 7.110 presents the results. 
The "Silt" soil has the largest variation in FOS values due to the relatively large range in Angle of Friction $(\phi)$ values, with the lower limit Angle of Friction $\left(\phi=18^{\circ}\right)$ and the upper limit Angle of Friction $\left(\phi=37^{\circ}\right)$. Also, since the upper limit Angle of Friction $(\phi$ $=37^{\circ}$ ) used for "Silt" was the highest studied, it also yielded the highest FOS values. The "Clay" soil properties studied covered a similar range for the Angle of Friction $(\phi)$ with a lower limit Angle of Friction $\left(\phi=18^{\circ}\right)$ and the upper limit Angle of Friction $\left(\phi=31^{\circ}\right)$. However, the Cohesion values for the "Clay" soil were slightly greater than those of the "Silt" soil, with a range of $10 \mathrm{kPa}$ to $35 \mathrm{kPa}$. This upper limit of Cohesion $(\mathrm{c}=35 \mathrm{kPa})$ for the "Clay" soil increased its FOS values slightly above those of the "Sandy Clay" soil, although the upper limit Angle of Friction $(\phi)$ value for the "Clay" soil was slightly less than that of the "Sandy Clay" soil. Due to the relatively narrow upper and lower limit Angle of Friction values for the "Sandy Clay" soil $\left(\phi=31^{\circ}\right.$ to $\left.34^{\circ}\right)$, its FOS range is relatively narrow as compared to the other two soil types studied.

The logical deduction between FOS and slope angle ( $\beta$ ) is supported by the results of this study, as the FOS values increase with decreasing slope angles $(\beta)$. However, the results of this study do not show a significant benefit in designing soil-nailed reinforced slopes with slope angles $(\beta)$ less than about $80^{\circ}$, as the increase in the FOS for any soil type and slope angle tested was less than $10 \%$. 


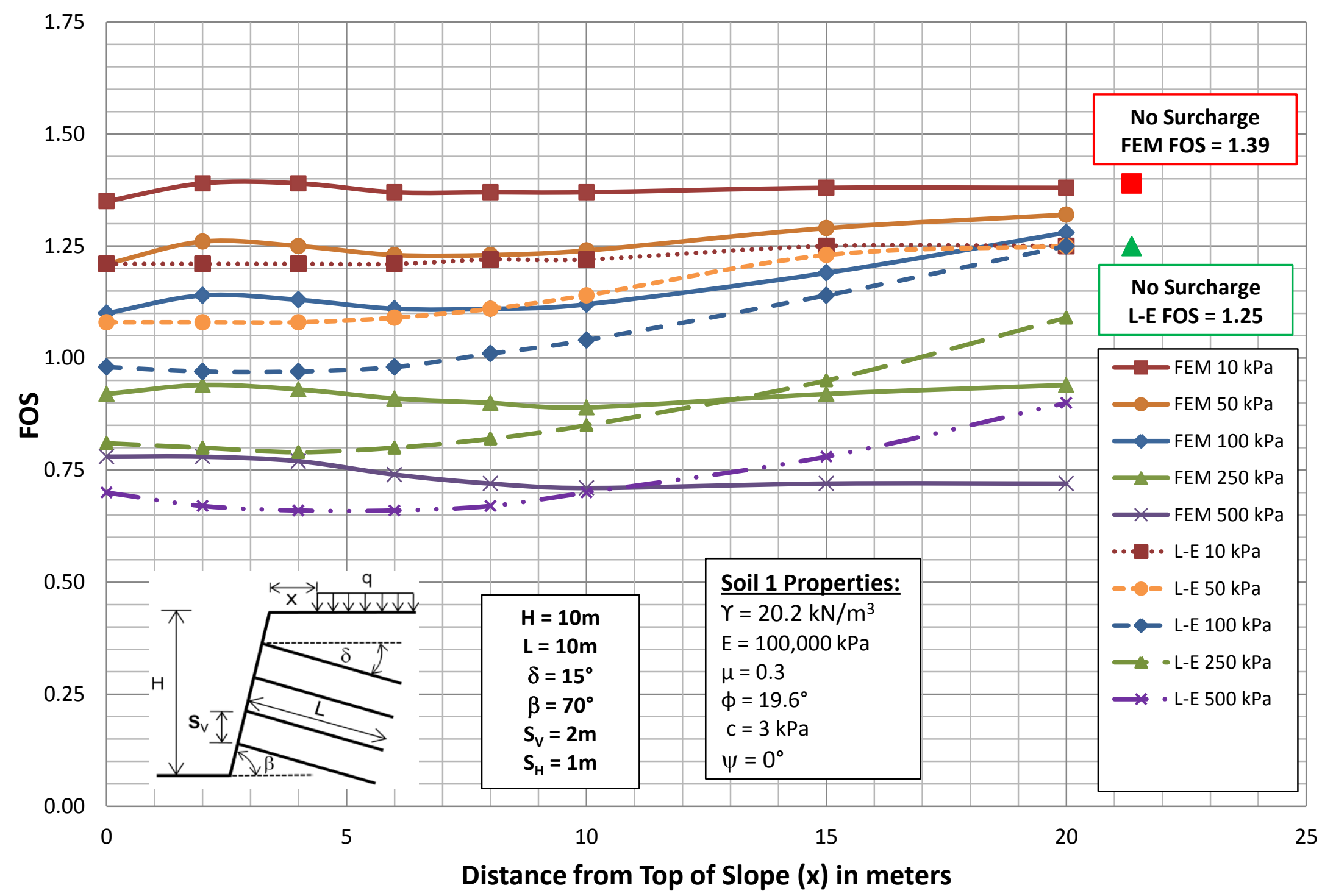

Figure 7.105 3-D FEM and 2-D L-E FOS Results for Surcharge Location and Magnitude - 70 Slope Angle 


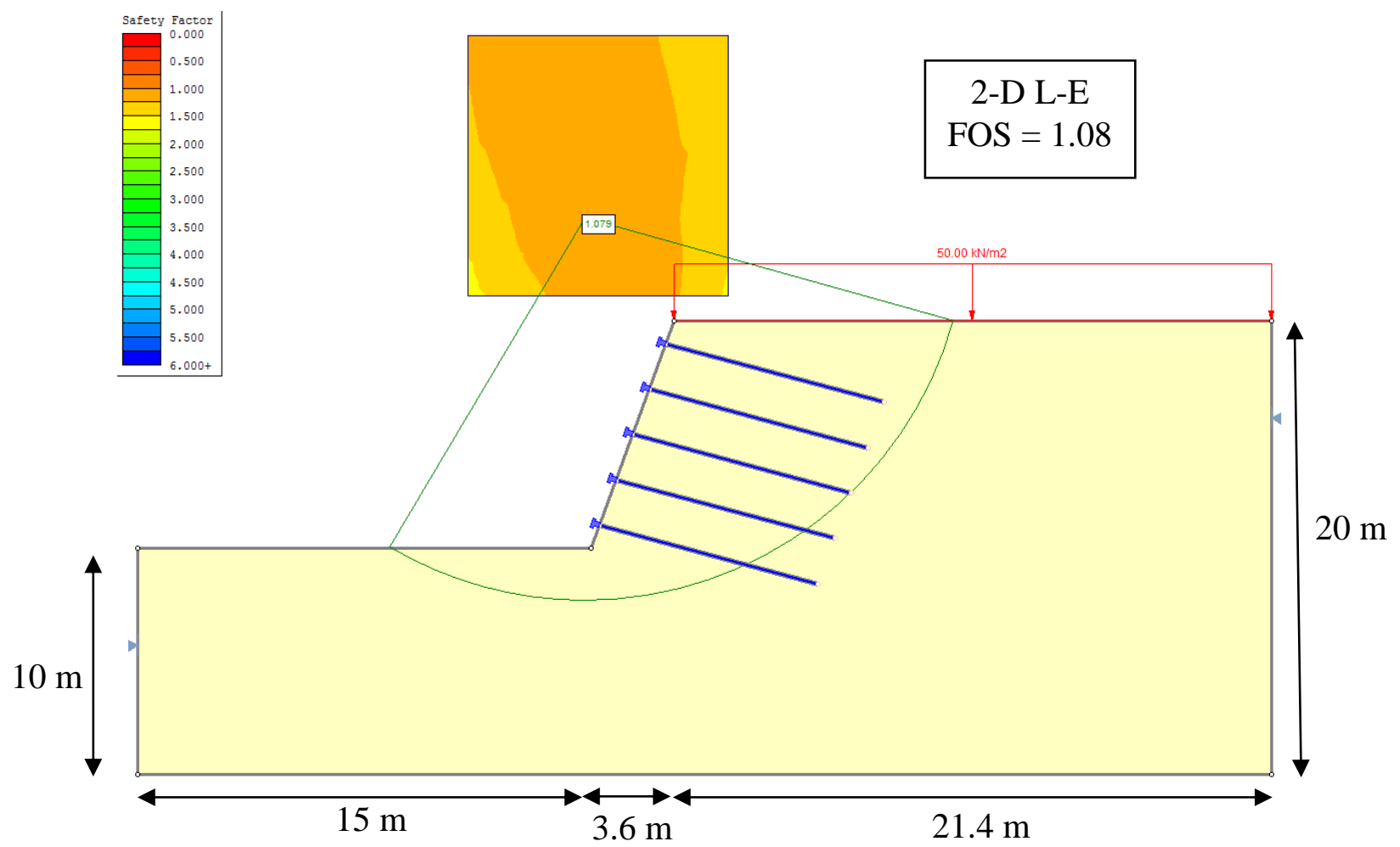

Figure 7.106 L-E Two-Dimensional Critical Surface for Reinforced Slope with Surcharge $70^{\circ}$ Slope $(\mathrm{x}=0 ; \mathrm{q}=50 \mathrm{kPa})$

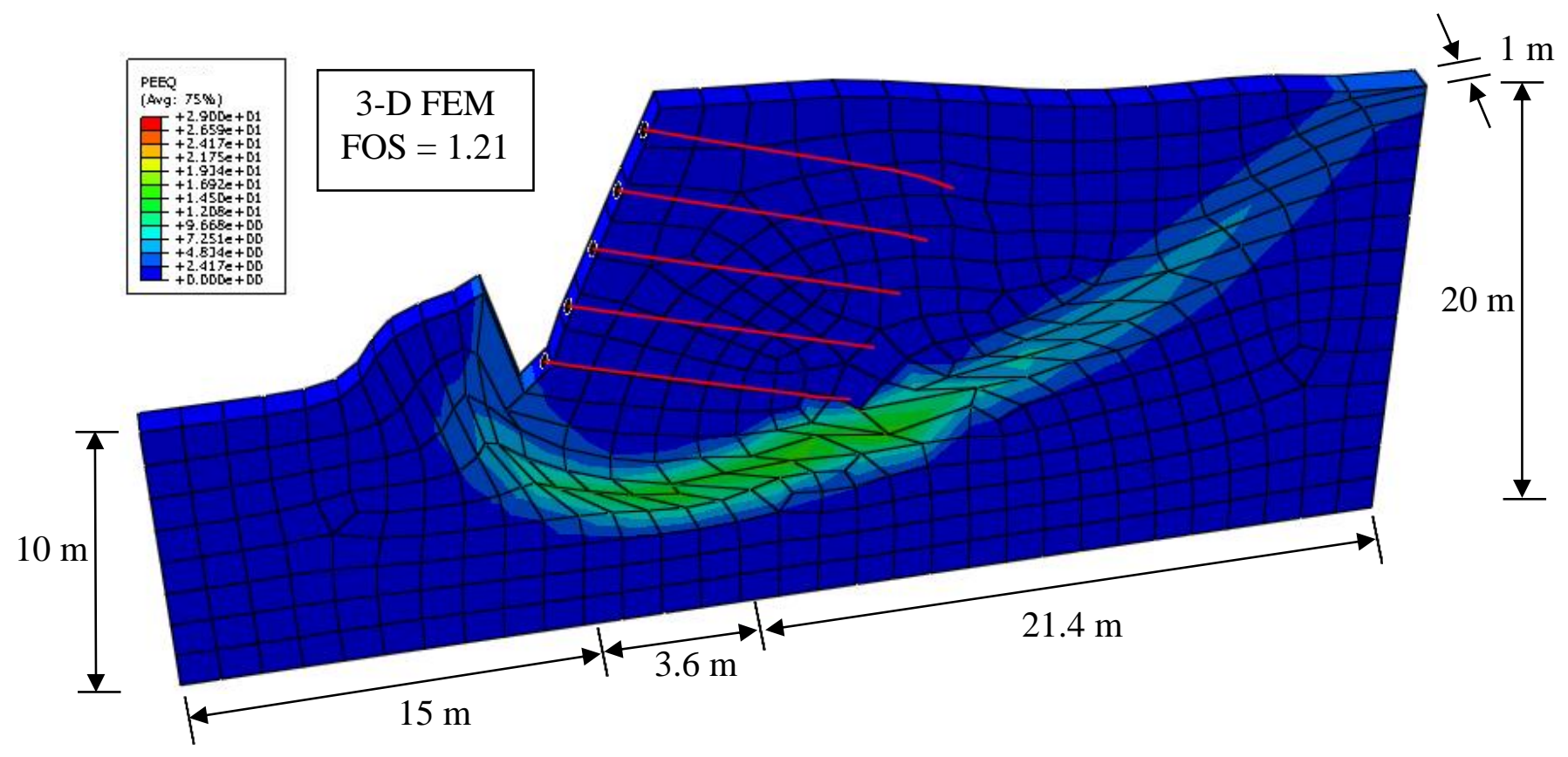

Figure 7.107 FEM Three-Dimensional PEEQ Contours for Reinforced Slope with Surcharge $70^{\circ}$ Slope $(\mathrm{x}=0 ; \mathrm{q}=50 \mathrm{kPa})$ 


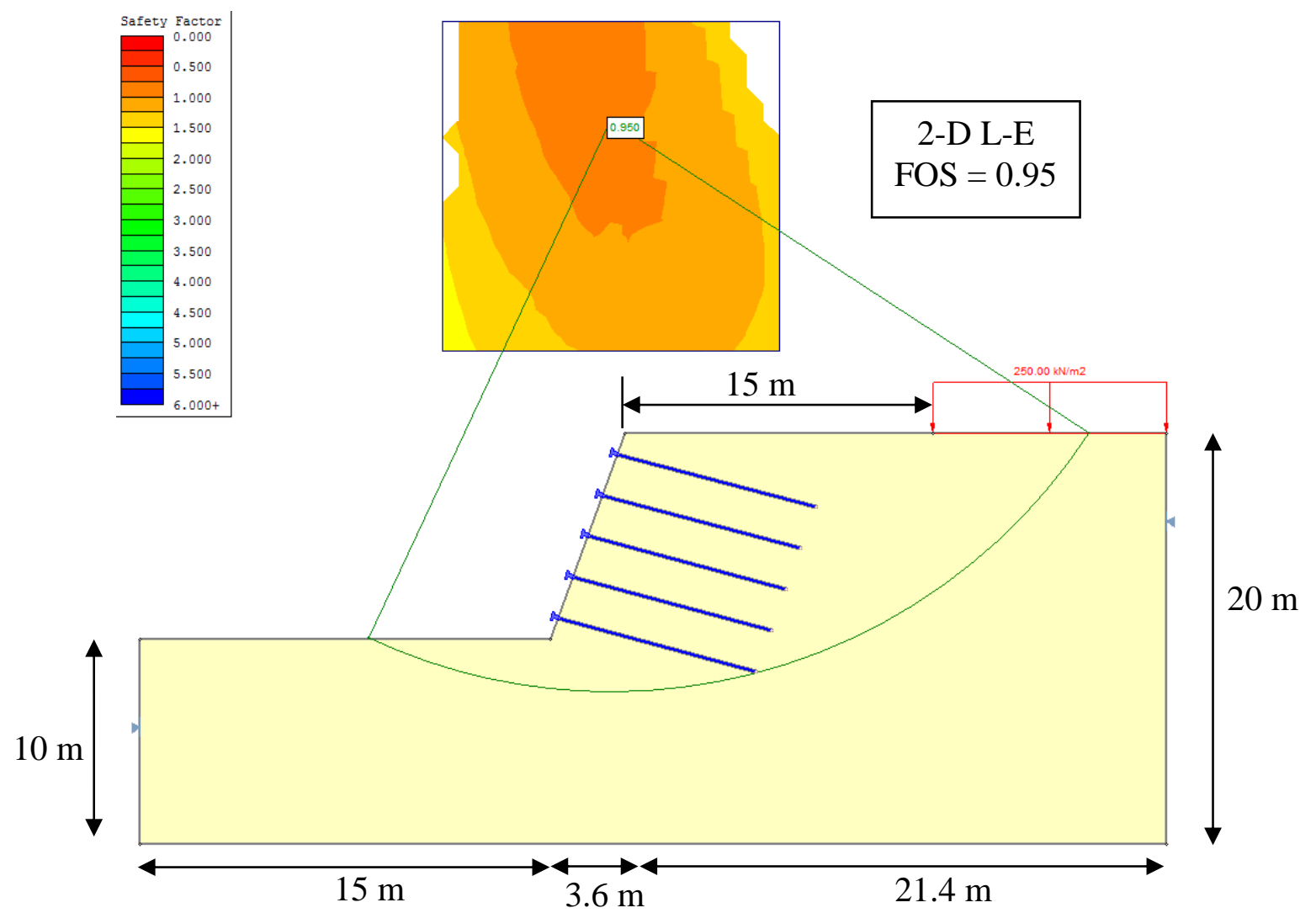

Figure 7.108 L-E Two-Dimensional Critical Surface for Reinforced Slope with Surcharge $70^{\circ}$ Slope $(\mathrm{x}=15 ; \mathrm{q}=250 \mathrm{kPa})$

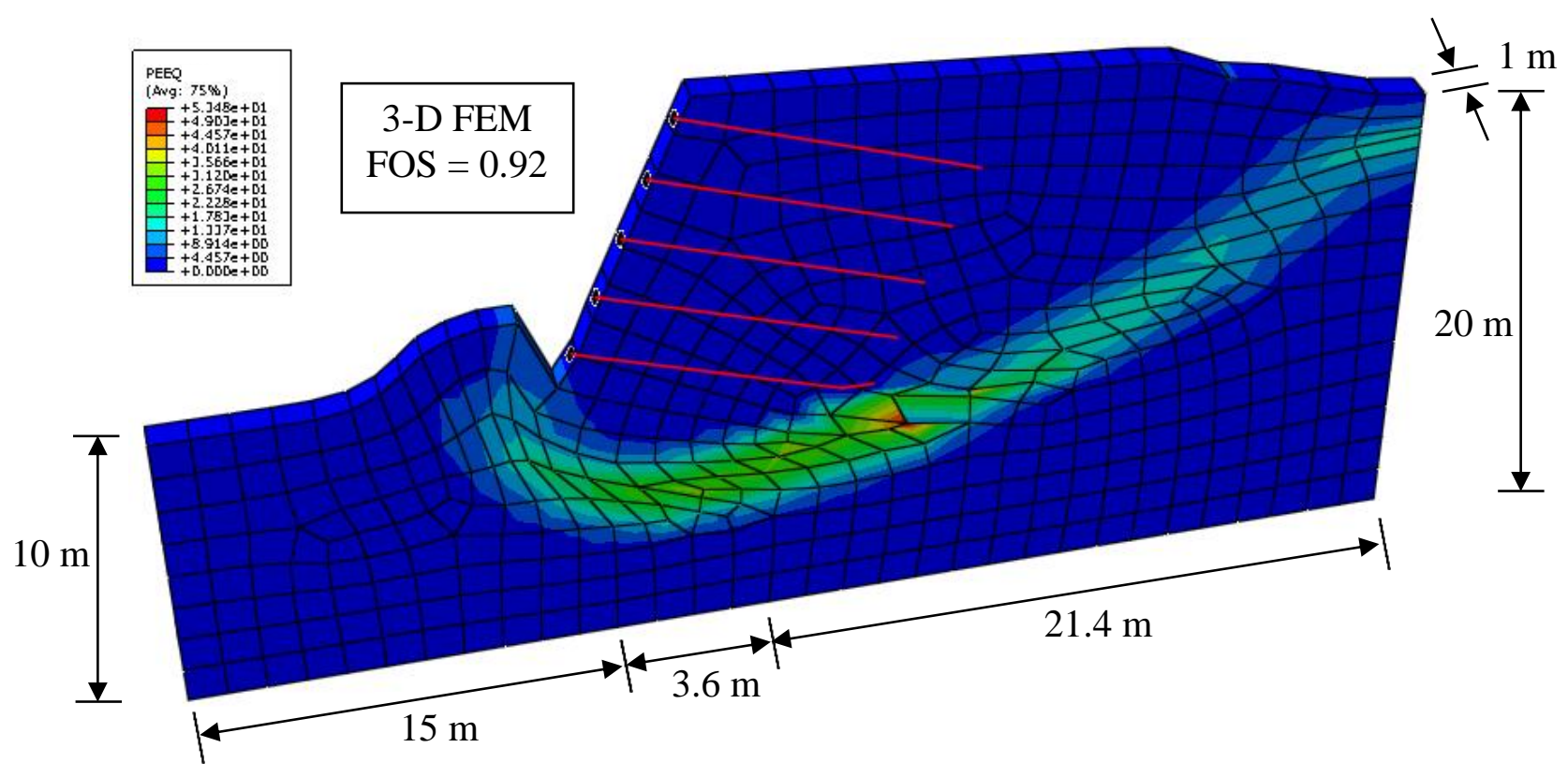

Figure 7.109 FEM Three-Dimensional PEEQ Contours for Reinforced Slope with Surcharge $70^{\circ}$ Slope $(x=15 ; \mathrm{q}=250 \mathrm{kPa})$ 


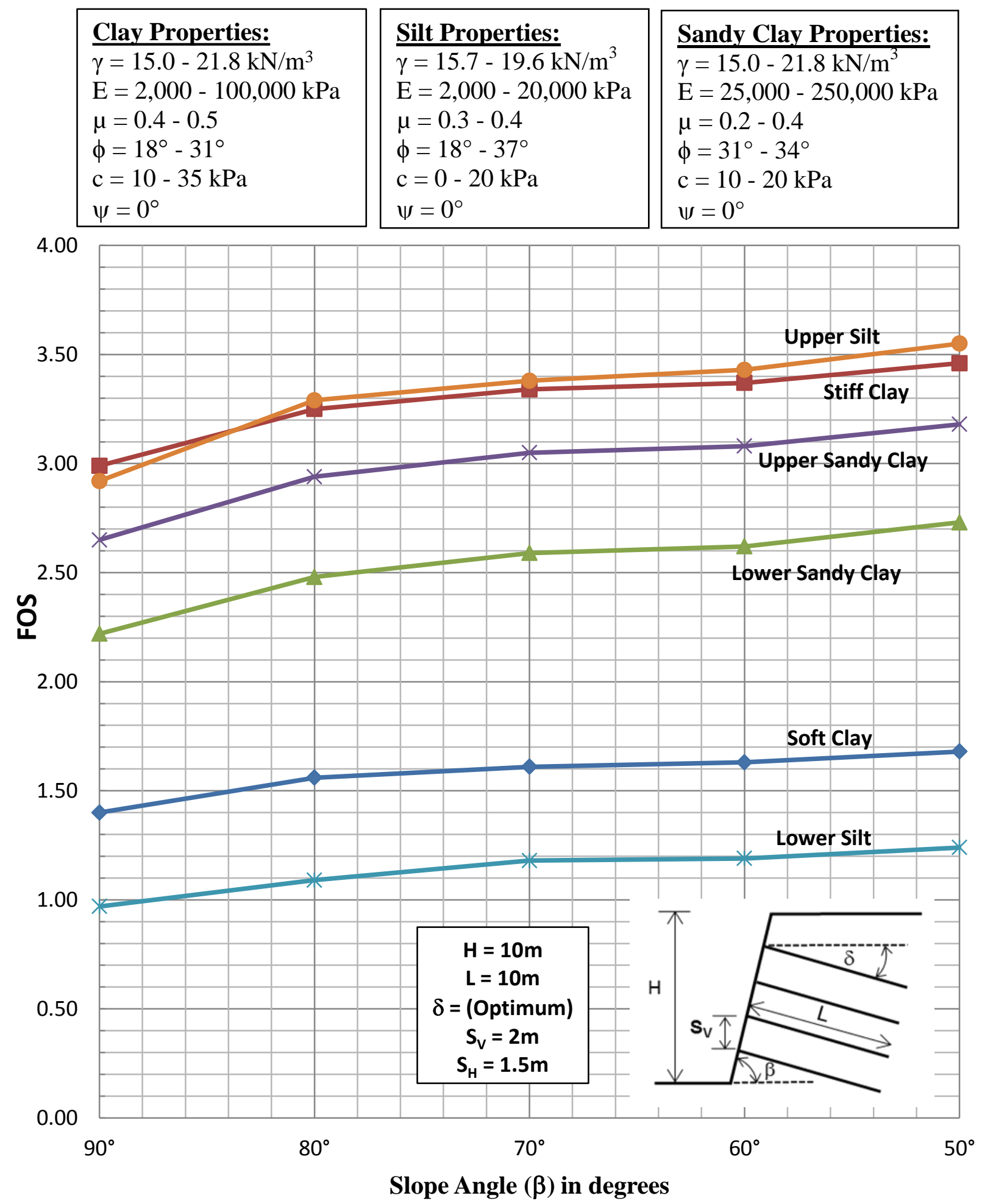

Figure 7.110 Influence of Typical Cohesive Soil Property Values on FOS 


\subsubsection{Influence of Rainwater Infiltration on Slope Stability}

Slopes often fail during periods of heavy rainfall. The decrease in shear strength is attributed to the rise in groundwater levels and associated decrease in effective stress. Using the Mohr-Coulomb failure criterion, the decrease in shear strength that results can be quantified using a soil's Cohesion (c) and Angle of Friction $(\phi)$. Both $\mathrm{c}$ and $\phi$ are potentially adversely affected by the decrease in effective stress and increased pore pressure (Duncan and Wright, 2005). The influence of these crucial soil parameters has been investigated in this study and was discussed extensively in Sections 7.5.4 and 7.5.7.

However, rainfall infiltration also adds to the driving force by increasing the unit weight of soil. In order to more fully understand the influence of rainwater infiltration on slope stability, a soil's Unit Weight $(\curlyvee)$ was considered. This study was accomplished using a $70^{\circ}$ unreinforced and soil-nailed reinforced slope. Soil 1 was used for all soil properties except the Unit Weight $(\Upsilon)$. The Unit Weight $(\curlyvee)$ was varied from $12.5 \mathrm{kN} / \mathrm{m}^{3}$ to 22.5 $\mathrm{kN} / \mathrm{m}^{3}$. Five, 10-meter long soil nails were placed along the centerline of the slope face using a vertical $\left(\mathrm{S}_{\mathrm{V}}\right)$ and horizontal $\left(\mathrm{S}_{\mathrm{H}}\right)$ soil nail spacing of 2 meters and 1.5 meters, respectively. The first (lowest) soil nail was placed 1.0 meter vertically from the toe of the slope. The soil nails were placed at an optimum orientation of $15^{\circ}$ (i.e. the orientation which yielded the highest FOS value for a $70^{\circ}$ slope, as presented in Section 7.5.1).

Figure 7.111 presents the results of this study. As presumed, the results clearly show an inverse relationship between a slopes FOS and the soil's Unit Weight $(\curlyvee)$. This result is consistent for both the unreinforced and soil-nailed reinforced slope; however, the decrease is not dramatic. The change in the FOS values is less than 0.08 for both the unreinforced and soil-nailed reinforced cases. 


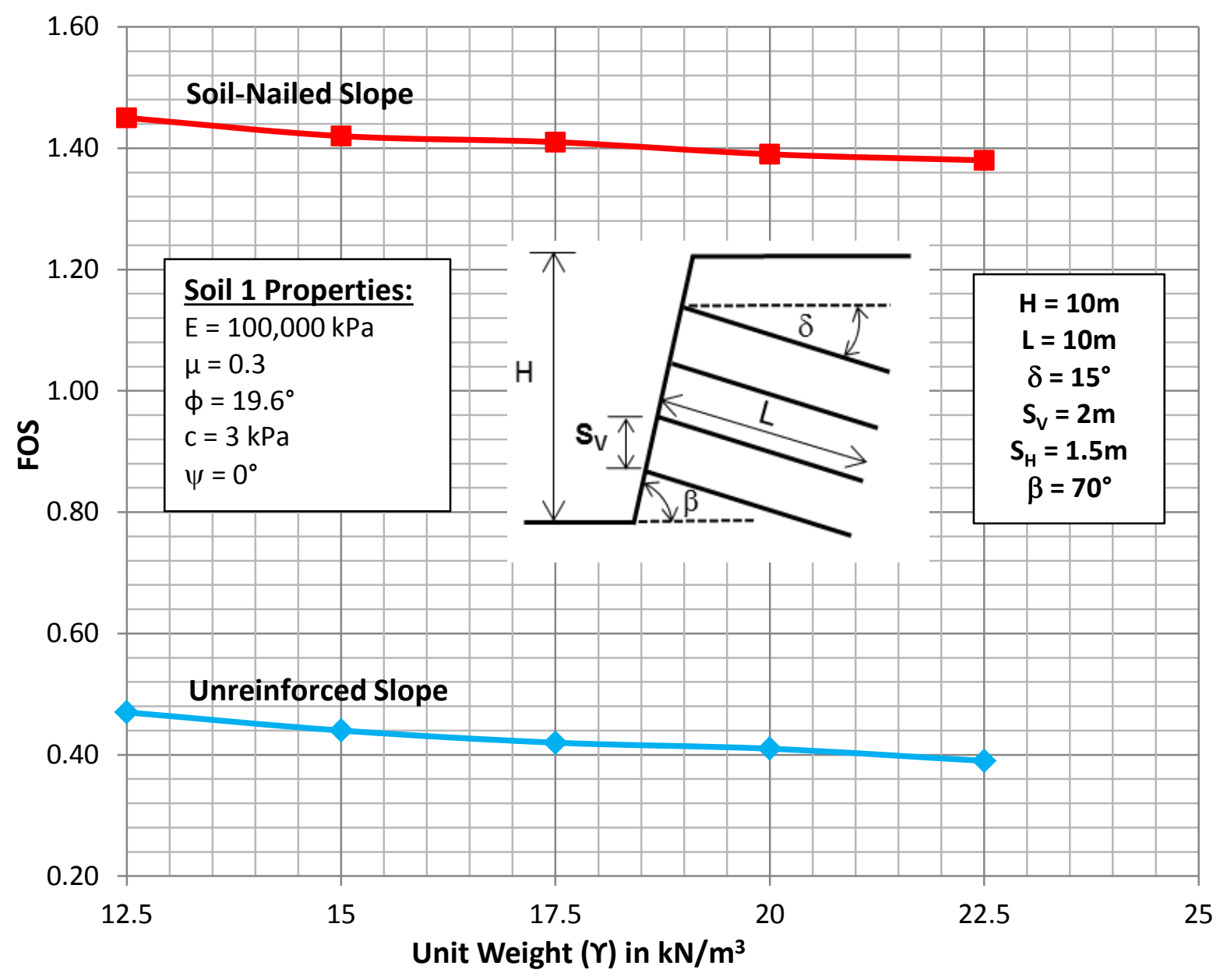

Figure 7.111 Influence of Unit Weight on FOS

\subsubsection{Influence of Pre-Tensioned Soil Nails on Vertical Deformation}

Pre-tensioned soil nails can be used in construction in an effort to reduce deformations. Figure 7.112 below presents the soil and slope geometry used in the pretensioned soil nail study. Deformation of a point just at the top of the slope was evaluated. Figure 7.113 presents the deformation results, with and without a surcharge load, for a pretensioned soil-nailed slope. In addition the FOS for both the slope with and without the surcharge load is presented. The results show a decrease in the vertical deformation for ranges of 0 to $10 \mathrm{MN}$ of pre-tensioning force, equating to a net difference in vertical 
deformation values approaching 0.25 inches for the surcharge case and just over 0.5 inches for the case without the surcharge load. Although practical limits are exceeded by the pretensioning forces in this plot, the advantages, or capabilities, of this modeling technique and its usefulness, especially in tightly controlled deformation environments, are evident.

Figures 7.114 and 7.115 present the PEEQ contour plots of soil-nailed slopes from this study with low and high levels of pre-tensioning force, respectively. When compared, the reinforcing action of the soil nails is certainly visible on the slope face when pretensioning levels are high. Note that the presence of a surcharge load did not obviously change the trend of the deformation reduction. As the pre-tensioning force is increased, the vertical deformation decreases.

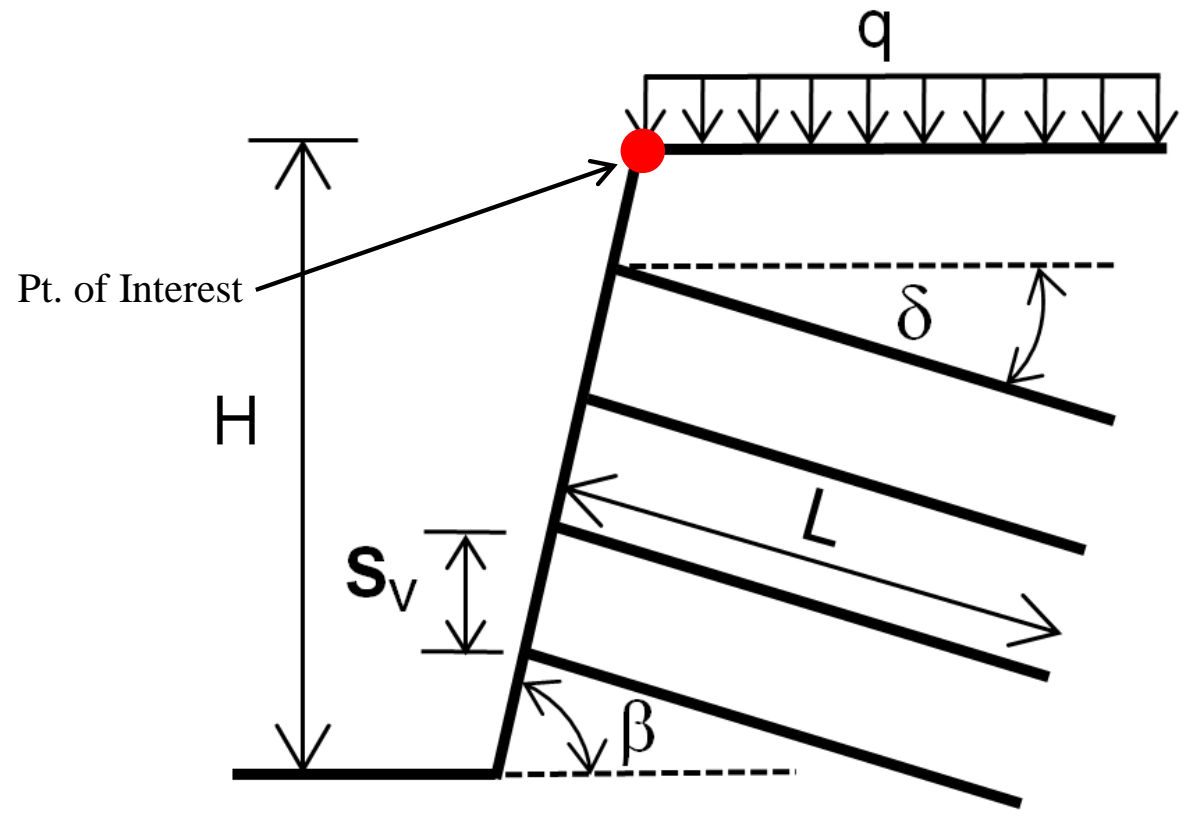

Where:

Slope Height $(\mathrm{H})=10$ meters Soil Nail Length $(\mathrm{L})=10$ meters Soil Nail Orientation $(\delta)=5^{\circ}$ Surcharge Magnitude (q) $=250 \mathrm{kPa}$ Slope Angle $(\beta)=90^{\circ}$

Soil Nail Vertical Spacing $\left(\mathrm{S}_{\mathrm{V}}\right)=2.0$ meters Horizontal Soil Nail Spacing $\left(\mathrm{S}_{\mathrm{H}}\right)=1.0$ meters

Figure 7.112 Schematic of Slope and Soil Nail Parameters Used in Pre-Tensioned Study 


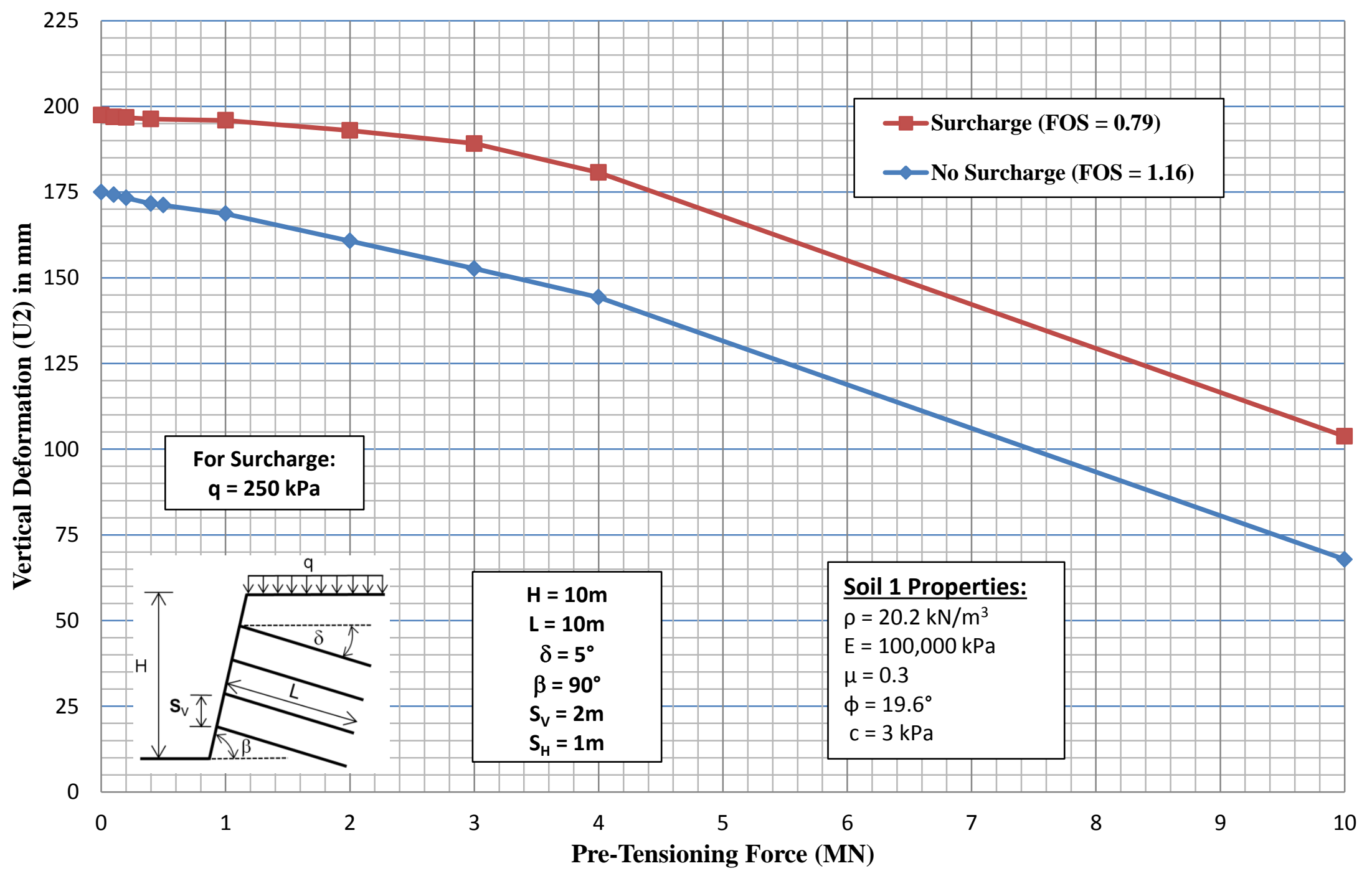

Figure 7.113 Vertical Deformation Results for Pre-Tensioned Soil Nails 


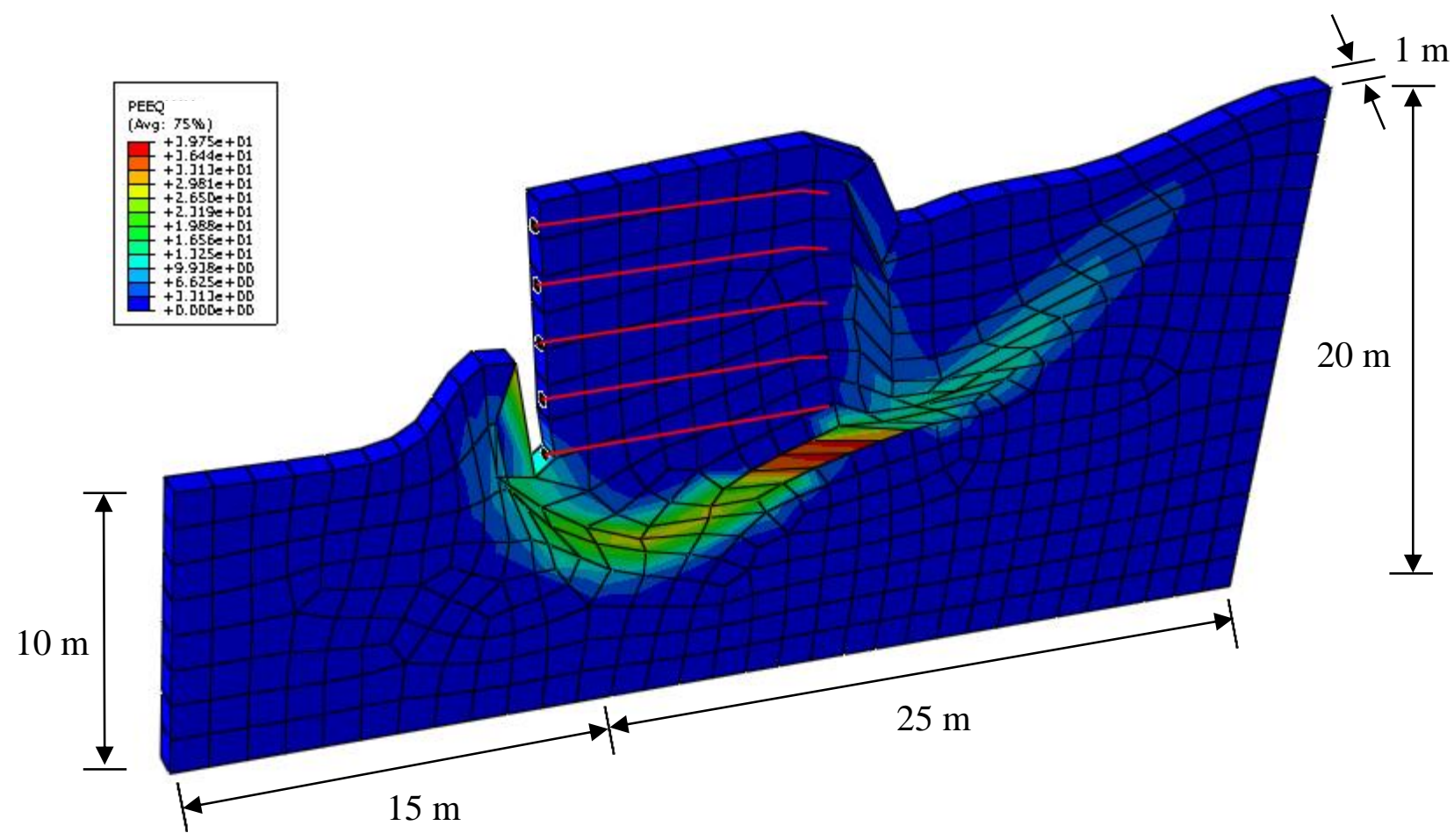

Figure 7.114 PEEQ Contour Plot for Pre-Tensioned Soil Nails with Low Pre-Tension Force

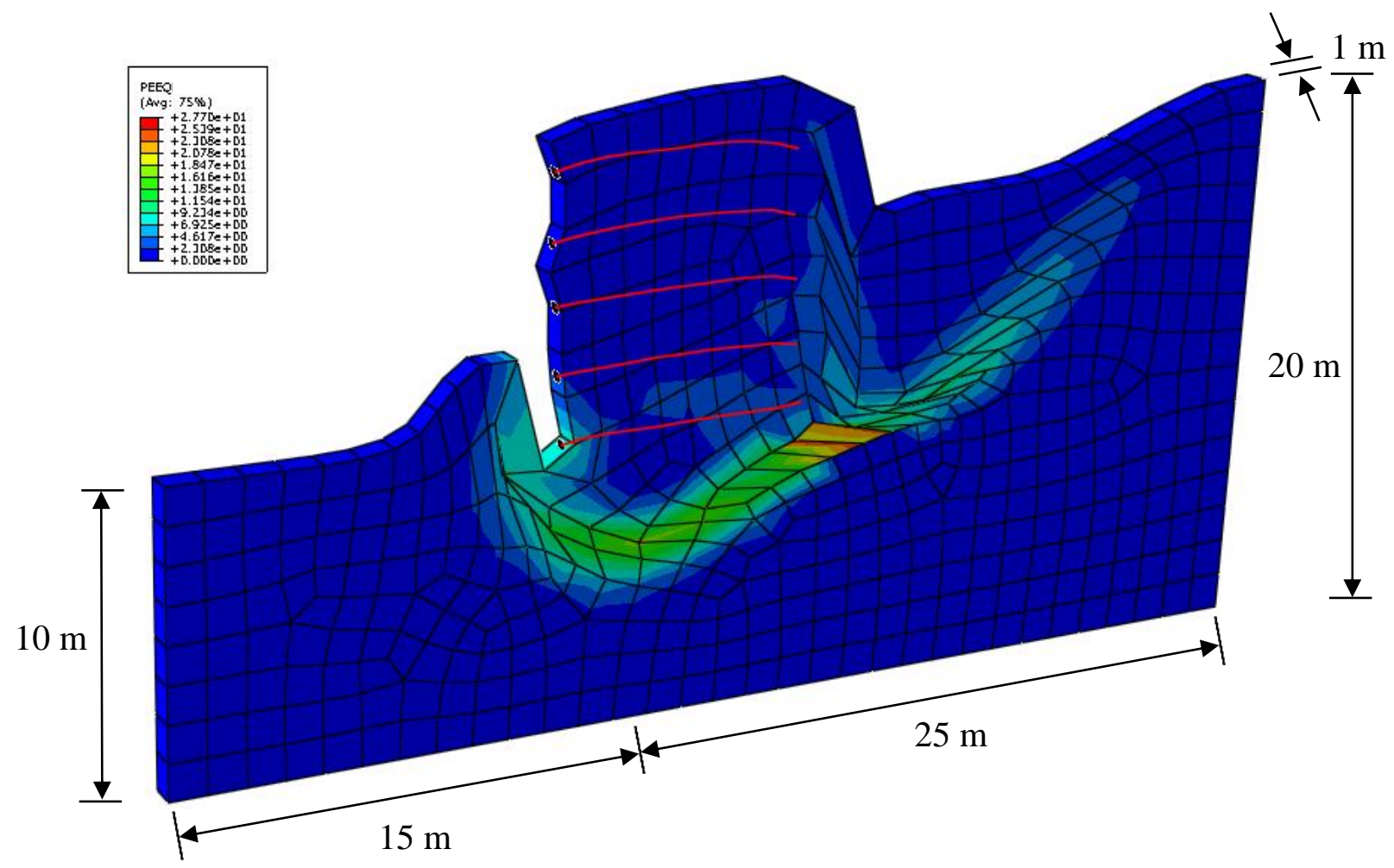

Figure 7.115 PEEQ Contour Plot for Pre-Tensioned Soil Nails with High Pre-Tension Force 


\subsubsection{Results for Full Slope Modeling}

To illustrate the applicability of the modeling technique for full scale modeling, three slopes were modeled and the results compared to three-dimensional, unit-width results, and two-dimensional limit-equilibrium (L-E) results. The slopes were modeled unreinforced and reinforced. The soil properties used in this study are for a Soft Clay, as presented in Table 5.5. The first slope (Full Slope Model No. 1) considered the effect of end conditions for a slope that reduces in height (from $\mathrm{H}=10 \mathrm{~m}$ to $\mathrm{H}=0 \mathrm{~m}$ ) on both sides. The front-face slope angle was $90^{\circ}$ and the side-slopes followed a 1(H):1(V) angle (See Figure 7.116). Ten meter long $(\mathrm{L})$ soil nails were placed at 1.5 meter and 2.0 meter horizontal $\left(\mathrm{S}_{\mathrm{H}}\right)$ and vertical soil nail spacing $\left(\mathrm{S}_{\mathrm{V}}\right)$, respectively. The first row of soil nails was placed at a vertical distance of 1.0 meter vertically from the toe of the slope at a $5^{\circ}$ orientation.

The second and third slopes (Full Slope Model No. 2 and No. 3) modeled in this study replicated an elevated site with a rounded, $90^{\circ}$ corner in plan view. The corners for the models were developed using a 5.0 meter and 25.0 meter radius, respectively. To accomplish the larger radius, Full Slope Model No. 3 was larger in plan view. The frontface of both slopes was $90^{\circ}$ and ten meter long (L) soil nails were placed at 1.5 meters and 2.0 meters horizontal $\left(\mathrm{S}_{\mathrm{H}}\right)$ and vertical soil nail spacing $\left(\mathrm{S}_{\mathrm{V}}\right)$, respectively for the reinforced case. The first row of soil nails was placed at a vertical distance of 1.0 meter vertically from the toe of the slope at a $5^{\circ}$ orientation.

For comparison, a three-dimensional unit-width slope and a two-dimensional L-E slope were developed with an "equivalent" cross-section. The cross-section is presented in Figure 7.117. 


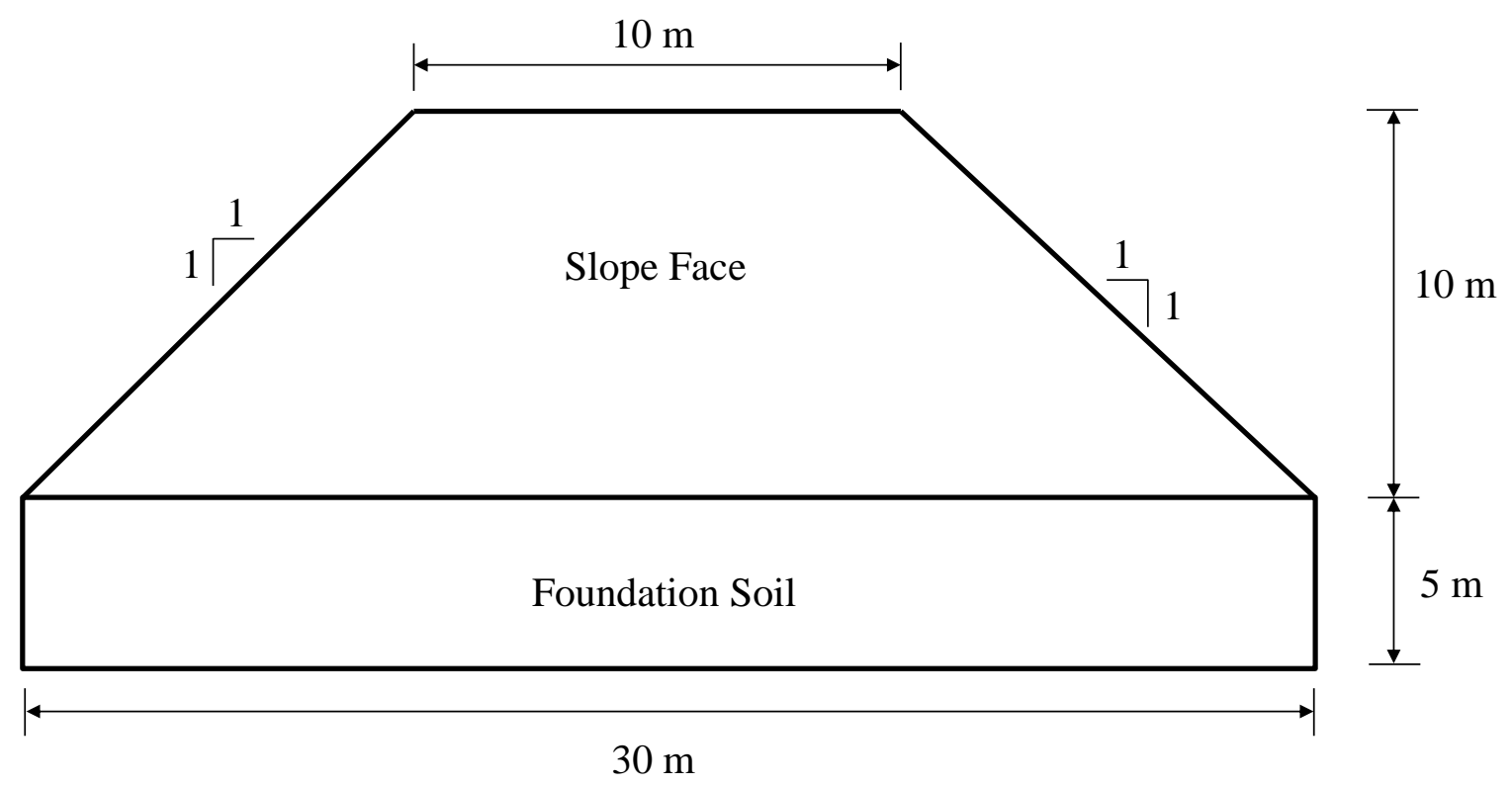

Figure 7.116 Schematic of Full Slope Model No. 1 Geometry - Elevation View

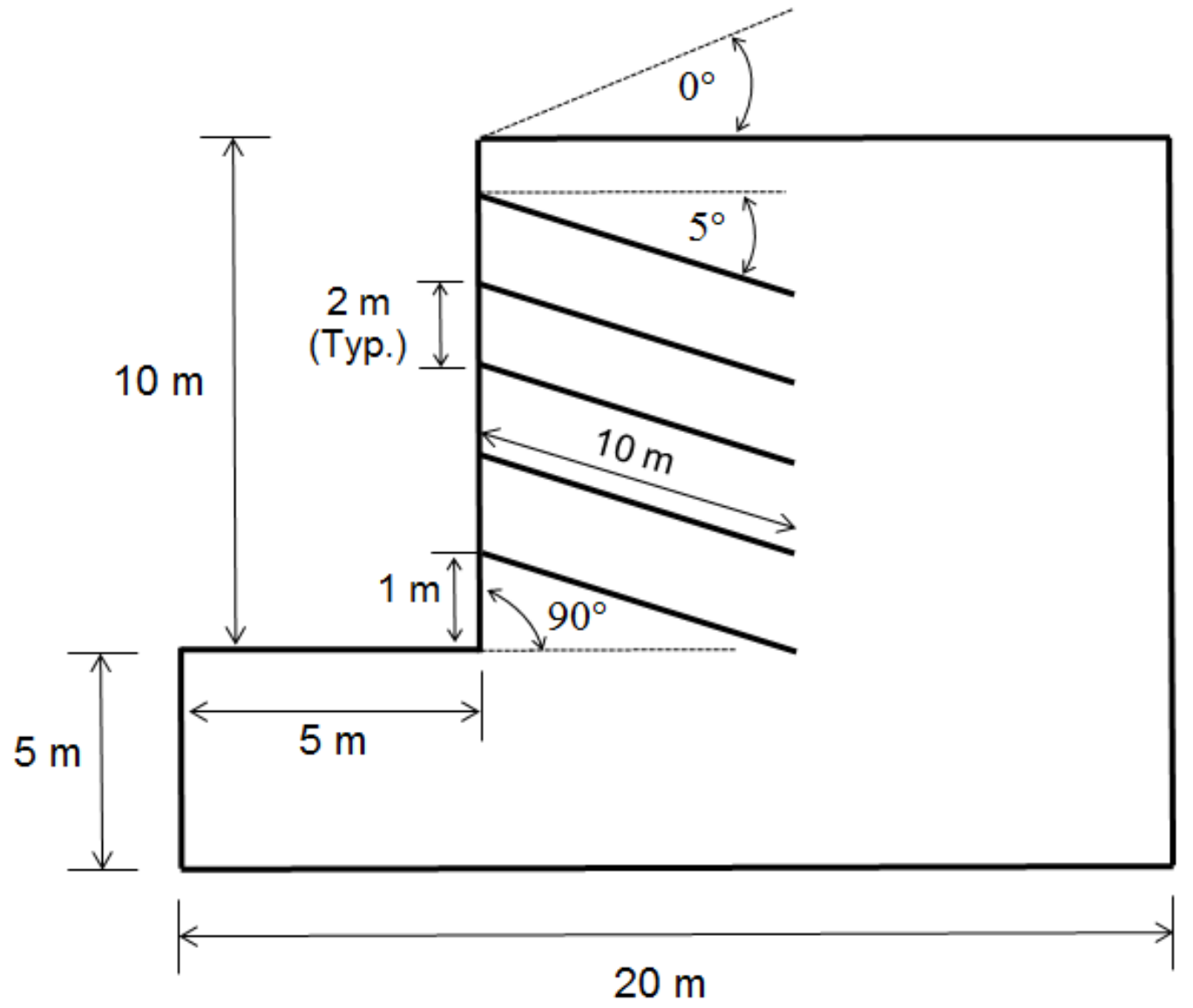

Figure 7.117 2-D "Equivalent” Cross-Section Schematic for Comparison to Full Slope Models 
FOS results for unreinforced and soil nail reinforced, three-dimensional FEM Full Slope Model Nos. 1, 2, and 3 are presented in Table 7.6. For comparison, FOS results for the three-dimensional FEM unit-width models and the two-dimensional L-E models are also presented. For the unreinforced cases, the FOS values for the tree-dimensional FEM Full Slope models were both higher than the three-dimensional FEM, unit-width model and the two-dimensional L-E model. For the reinforced cases, however, the resulting FOS values for the FEM Full Slope models were both lower than the three-dimensional FEM, unit-width model and the two-dimensional L-E model.

Figures 7.118 and 7.119 present the critical failure surface for the two-dimensional, L-E slope and the PEEQ contour plot for the three-dimensional FEM, unit-width model, respectively. Figures 7.120a and 7.120b present PEEQ contour plots for the unreinforced, three-dimensional FEM Full Slope Model No. 1. A significantly deformed slope face can be seen in Figure 7.120a. The cut section shown as Figure $7.120 \mathrm{~b}$ is intended to provide a clearer picture of the potential failure region within the unreinforced model. Figure 7.121 presents a PEEQ contour plot for the soil-nailed reinforced, three-dimensional FEM Full Slope Model No. 1. The perspective provided demonstrates the restrained deformation of the slope face. Figure 7.122 presents a clear view of the soil nail pattern for this slope, including the soil nail orientation.

Figures 7.123a and 7.123b present the PEEQ contour plots for the unreinforced, three-dimensional FEM Full Slope Model No. 2. Once again, it can be seen that bulging is present along the free surface. Figure 7.124 displays the soil nail pattern used for this model. As discussed in Section 5.5.10, soil nail intersections were avoided using a small 
translational offset. Figure 7.125 presents the PEEQ contour plot for this slope. The benefit of the soil nails is clearly evident.

Figures 7.126a and 7.126b present the PEEQ contour plots for the unreinforced, three-dimensional FEM Full Slope Model No. 3. As with the Full Slope Model No. 2, bulging and plastic strain are evident at the toe of the slope. Figure 7.125 displays the soil nail pattern used for this model. As discussed in Section 5.5.10, soil nail intersections were avoided with the larger corner radius (25.0 meters). FOS values for Full Slope Model No. 3 were nearly identical to those of Full Slope Model No. 2.

Table 7.6 FOS Values for Fully Modeled Slopes and Comparable Section Methods

\begin{tabular}{|c|c|c|}
\hline Model & Unreinforced FOS & Reinforced FOS \\
\hline 2-D L-E & 0.45 & 1.11 \\
\hline $\begin{array}{c}\text { 3-D FEM } \\
\text { (Unit Width) }\end{array}$ & 0.49 & 1.20 \\
\hline $\begin{array}{c}\text { 3-D FEM } \\
\text { Full Slope Model No. 1 }\end{array}$ & 0.56 & 1.01 \\
\hline $\begin{array}{c}\text { 3-D FEM } \\
\text { Full Slope Model No. 2 }\end{array}$ & 0.52 & 1.06 \\
\hline $\begin{array}{c}\text { 3-D FEM } \\
\text { Full Slope Model No. 3 }\end{array}$ & 0.51 & 1.04 \\
\hline
\end{tabular}




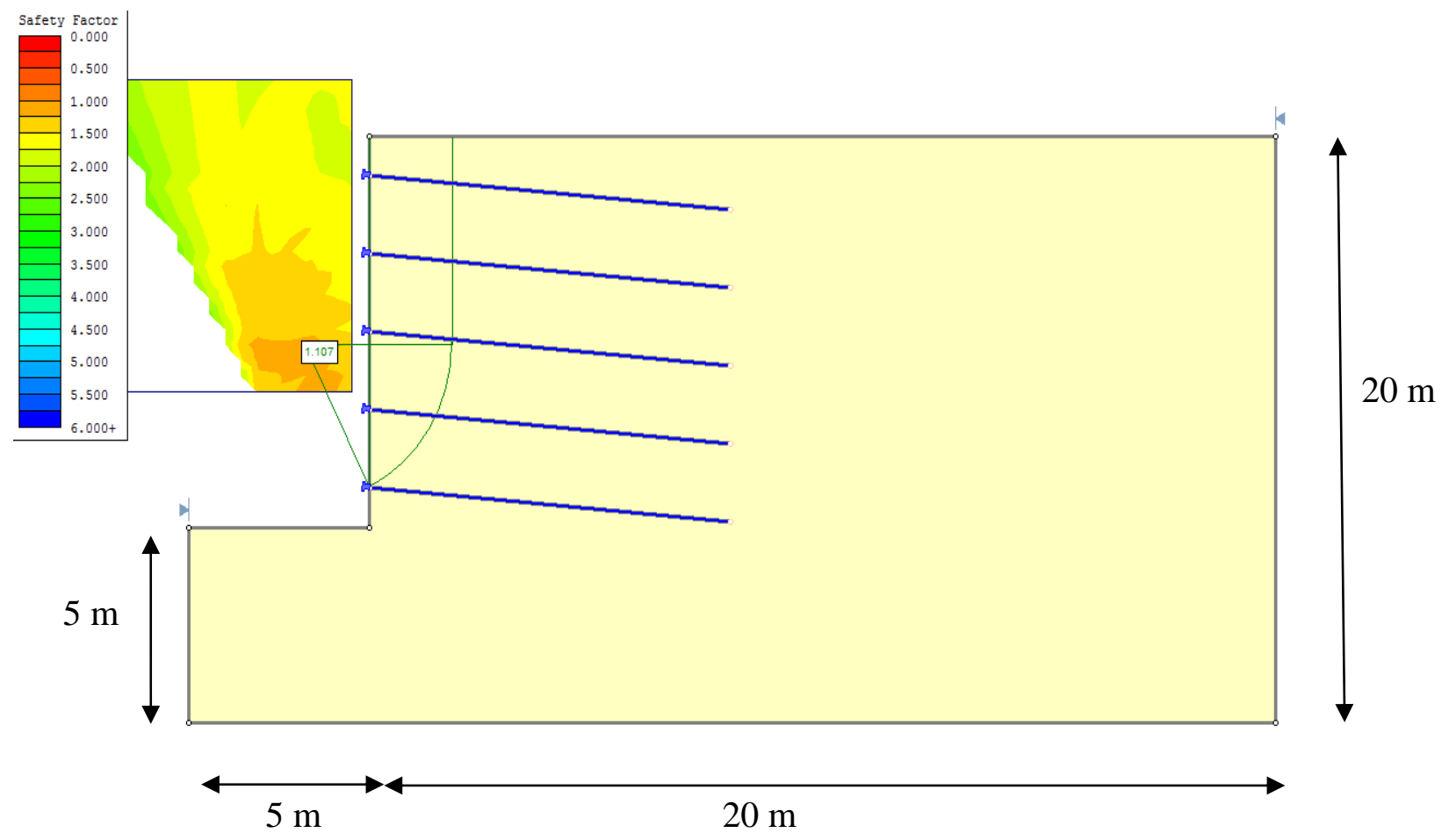

Figure 7.118 2-D L-E Reinforced Slope Result for Comparison to Full Slope Models

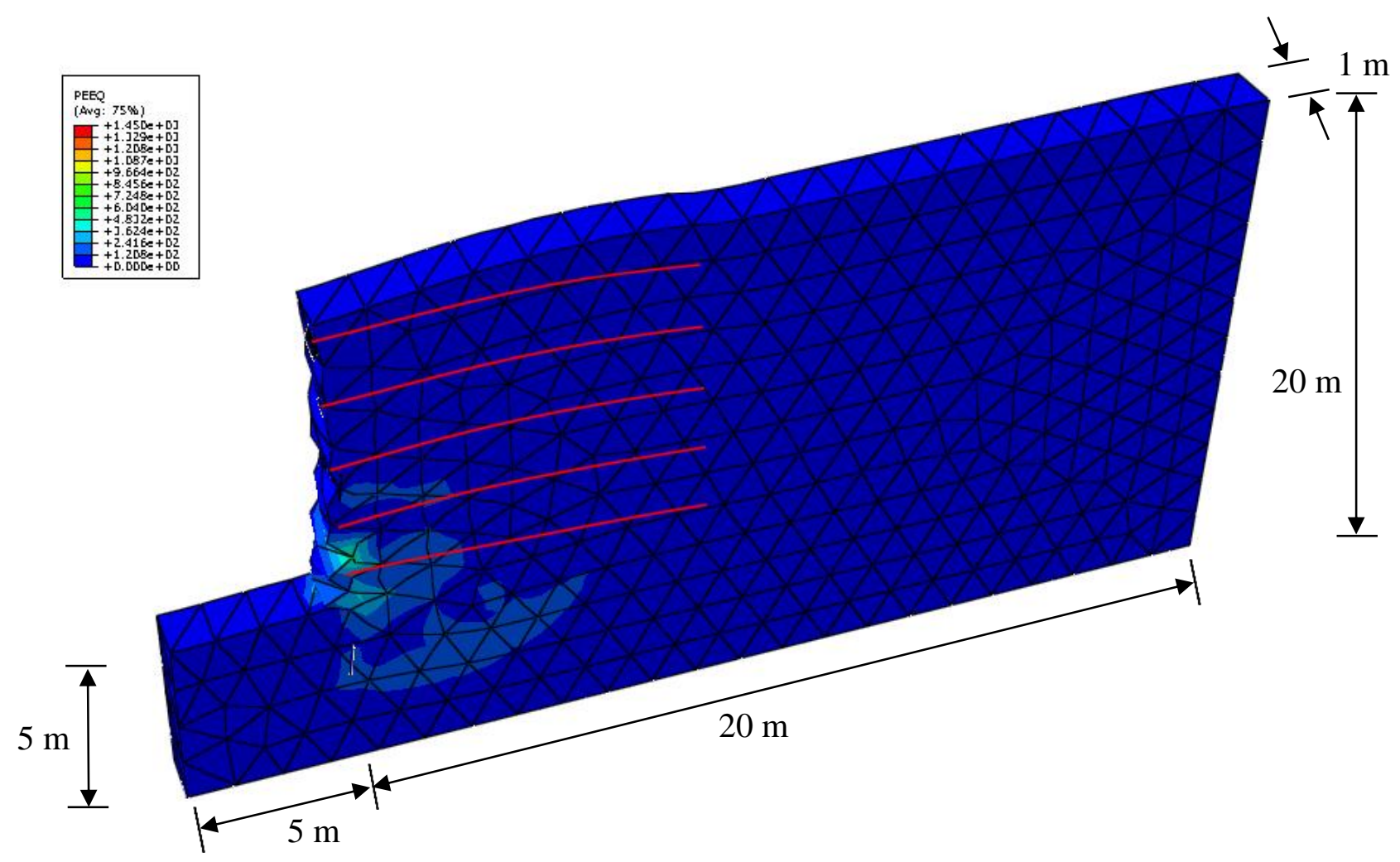

Figure 7.119 PEEQ Contour Plot for 3-D FEM, Unit-Width Reinforced Slope for Comparison to Full Slope Models 


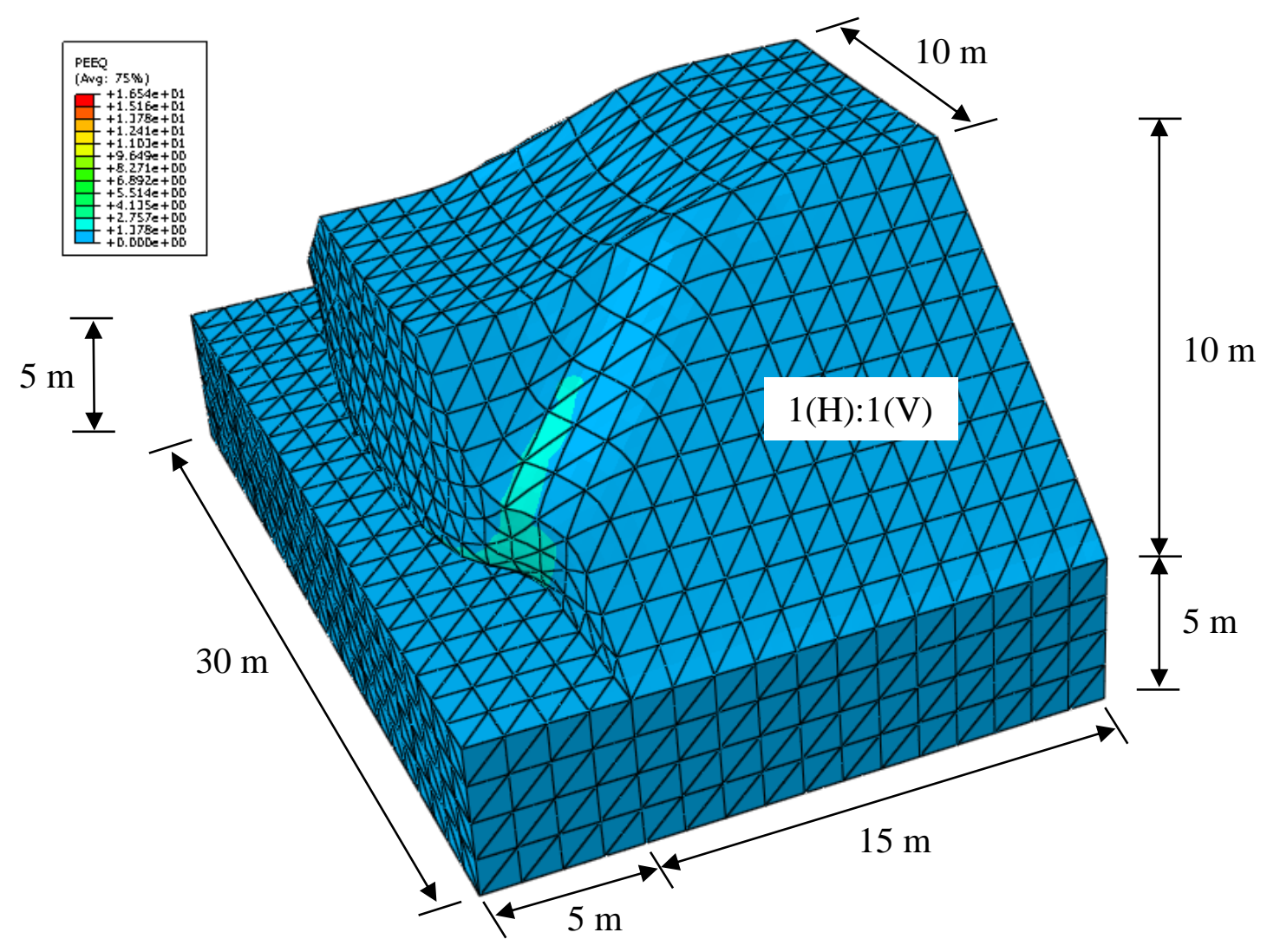

Figure 7.120a PEEQ Contour Plot for 3-D FEM, Unreinforced Full Slope Model No. 1 (Entire Slope)

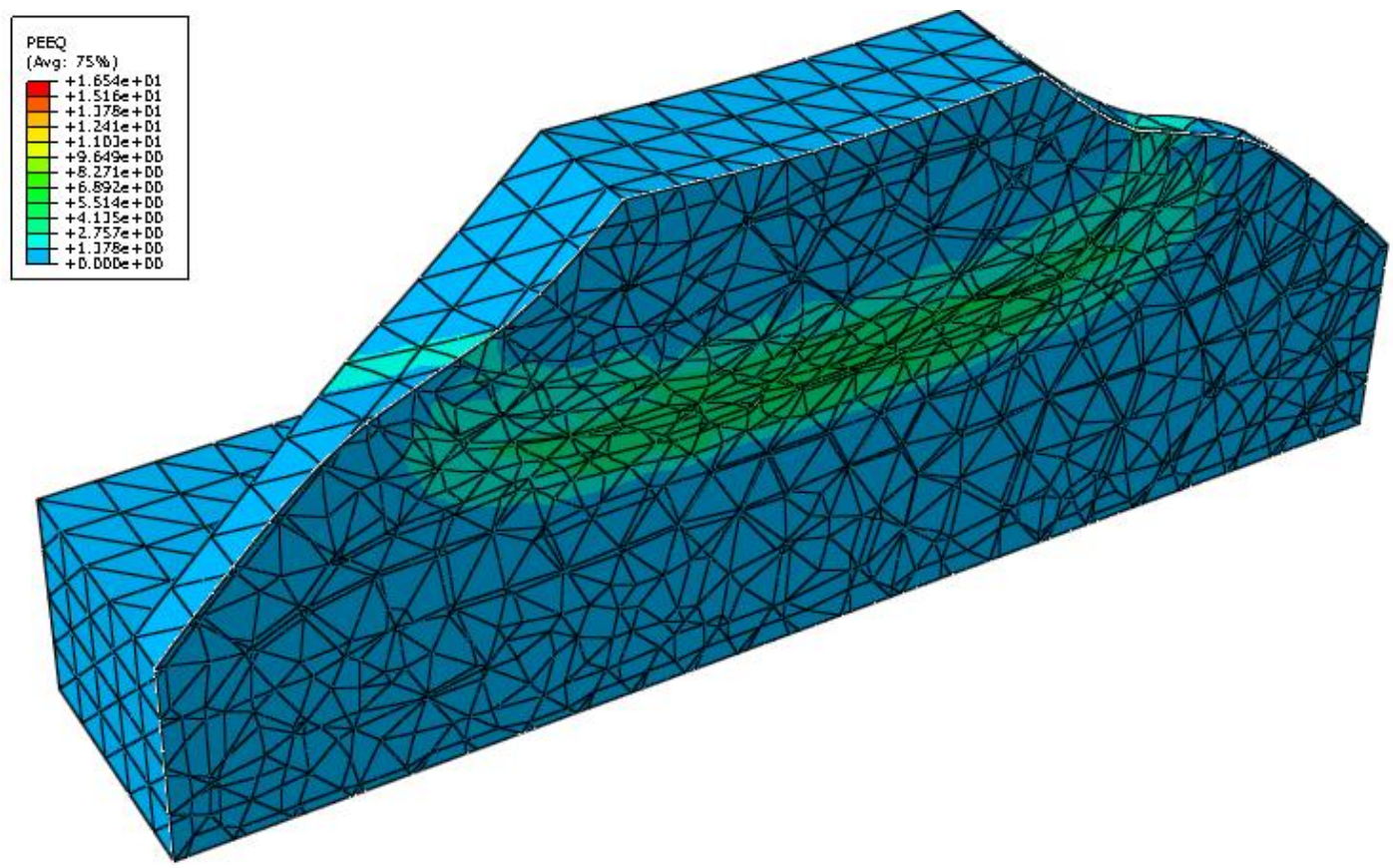

Figure 7.120b PEEQ Contour Plot for 3-D FEM, Unreinforced Full Slope Model No. 1 (View Cut Section - X Axis) 

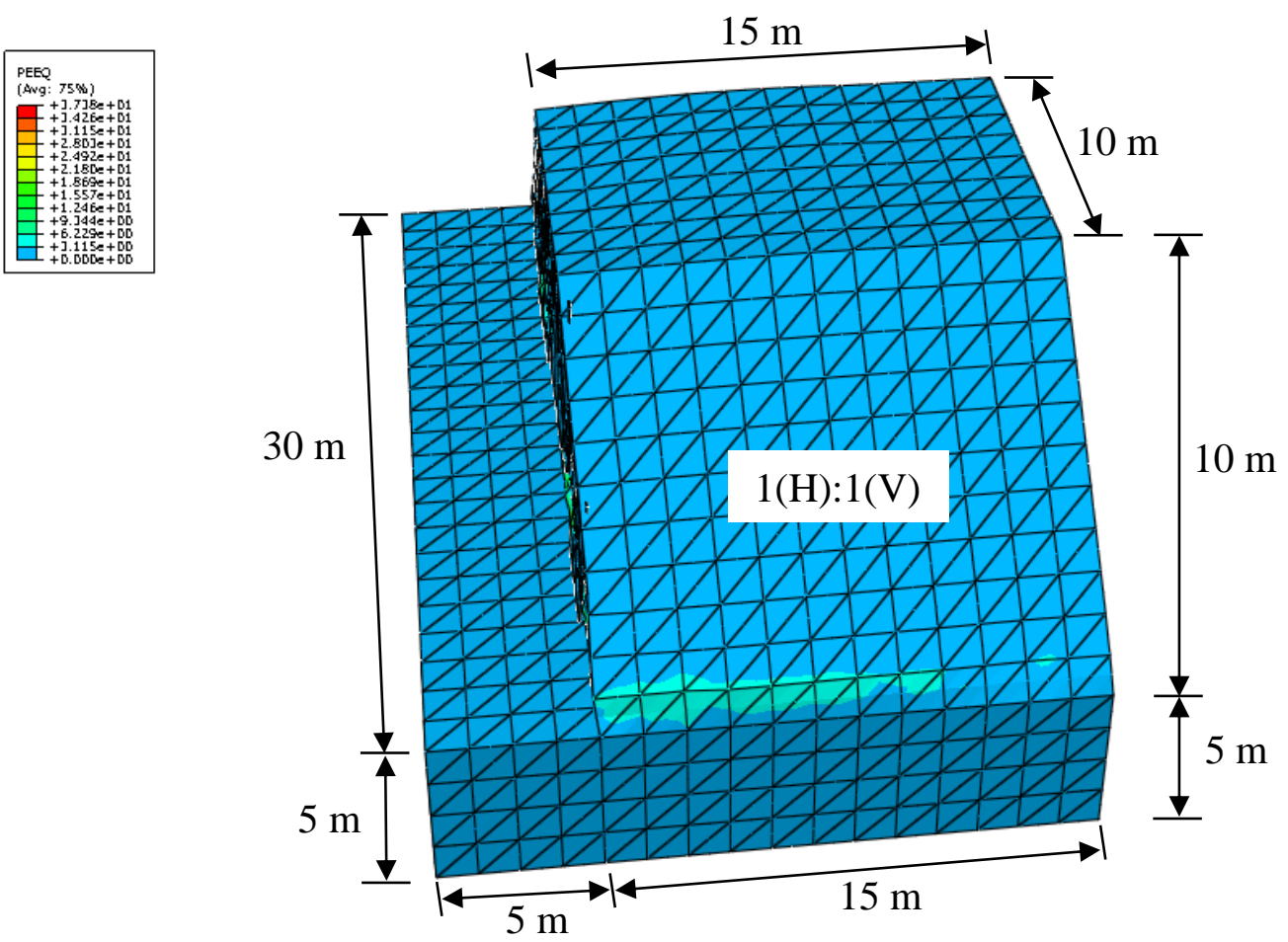

Figure 7.121 PEEQ Contour Plot for 3-D FEM, Reinforced Full Slope Model No. 1 (Entire Slope)

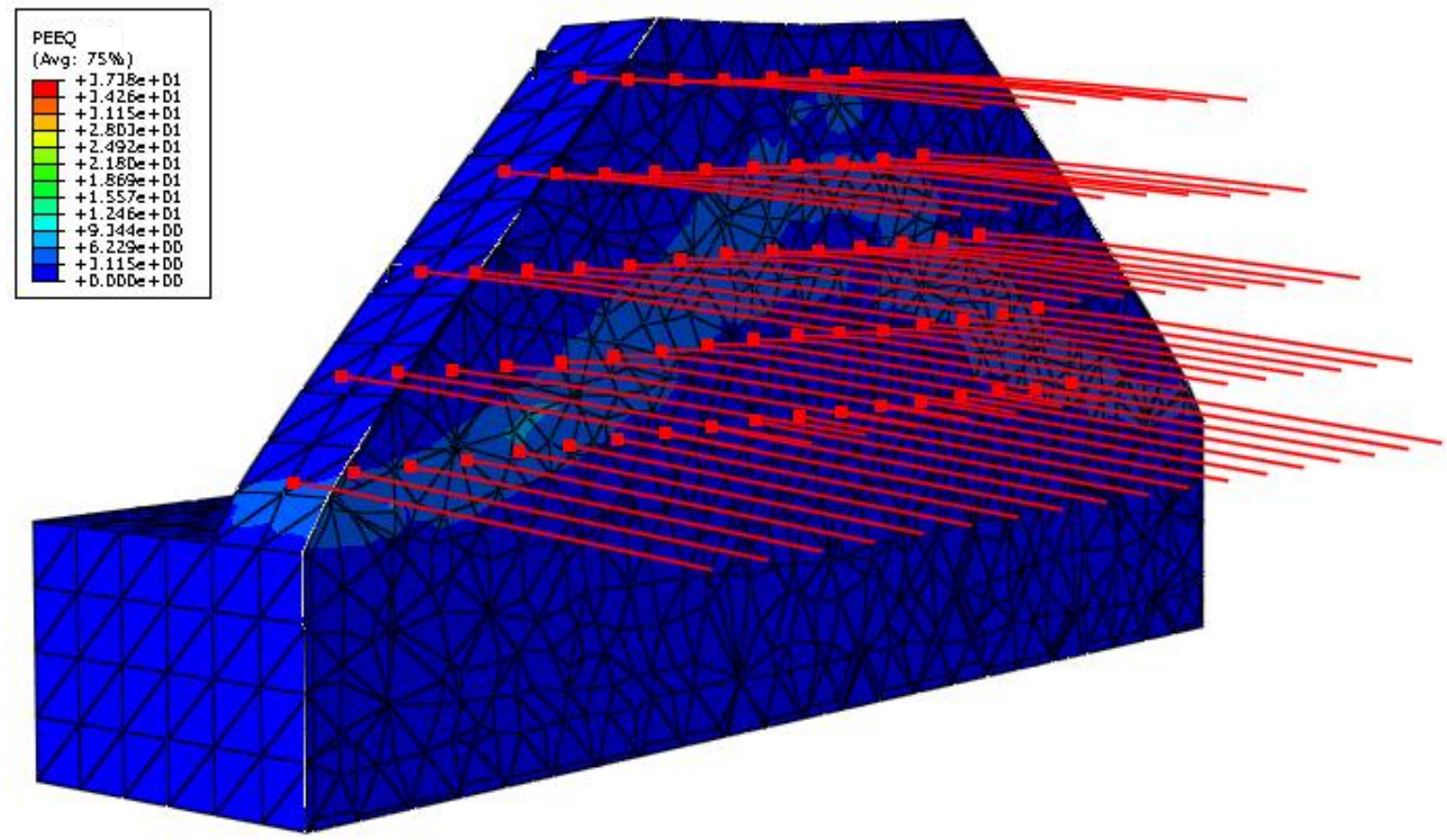

Figure 7.122 Soil Nail Pattern for 3-D FEM, Reinforced Full Slope Model No. 1 (PEEQ Contour Plot; View Cut Section - X Axis) 


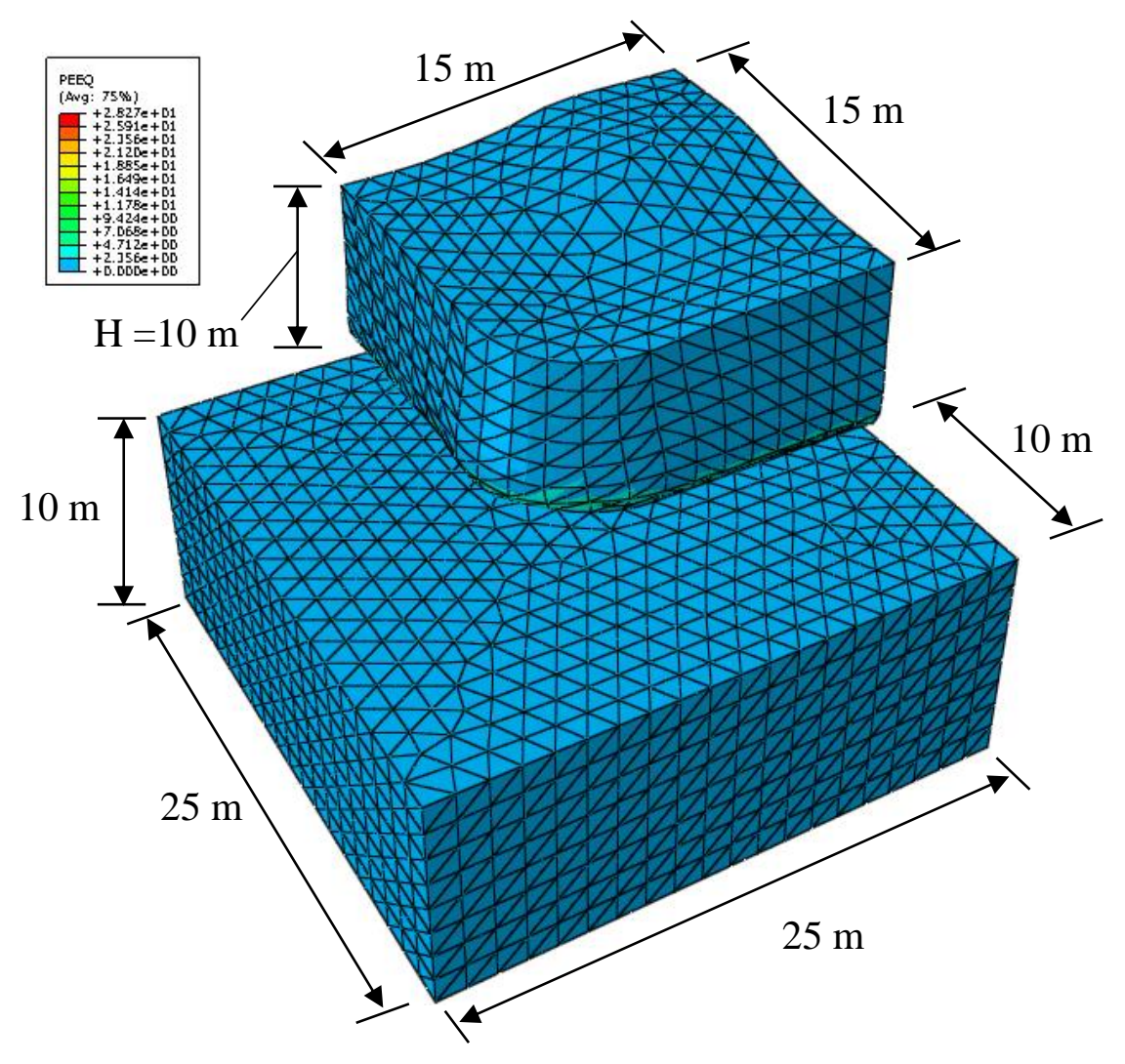

Figure 7.123a PEEQ Contour Plot for 3-D FEM, Unreinforced Full Slope Model No. 2 (Entire Slope)

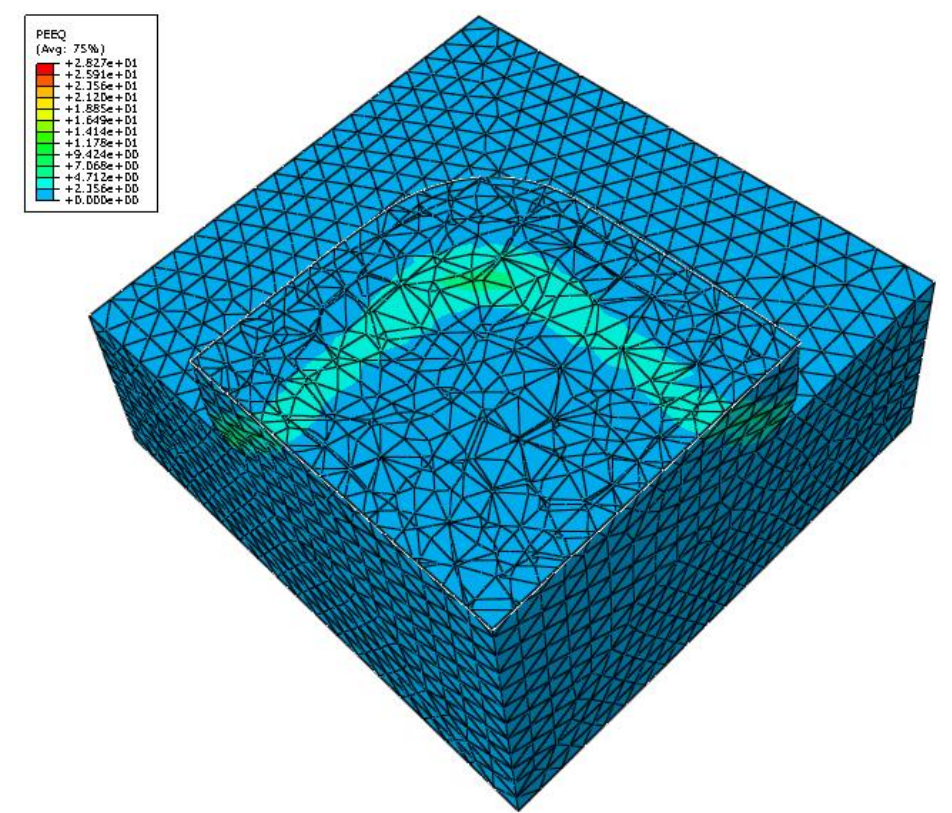

Figure 7.123b PEEQ Contour Plot for 3-D FEM, Unreinforced Full Slope Model No. 2 (View Cut Section - Y Axis) 


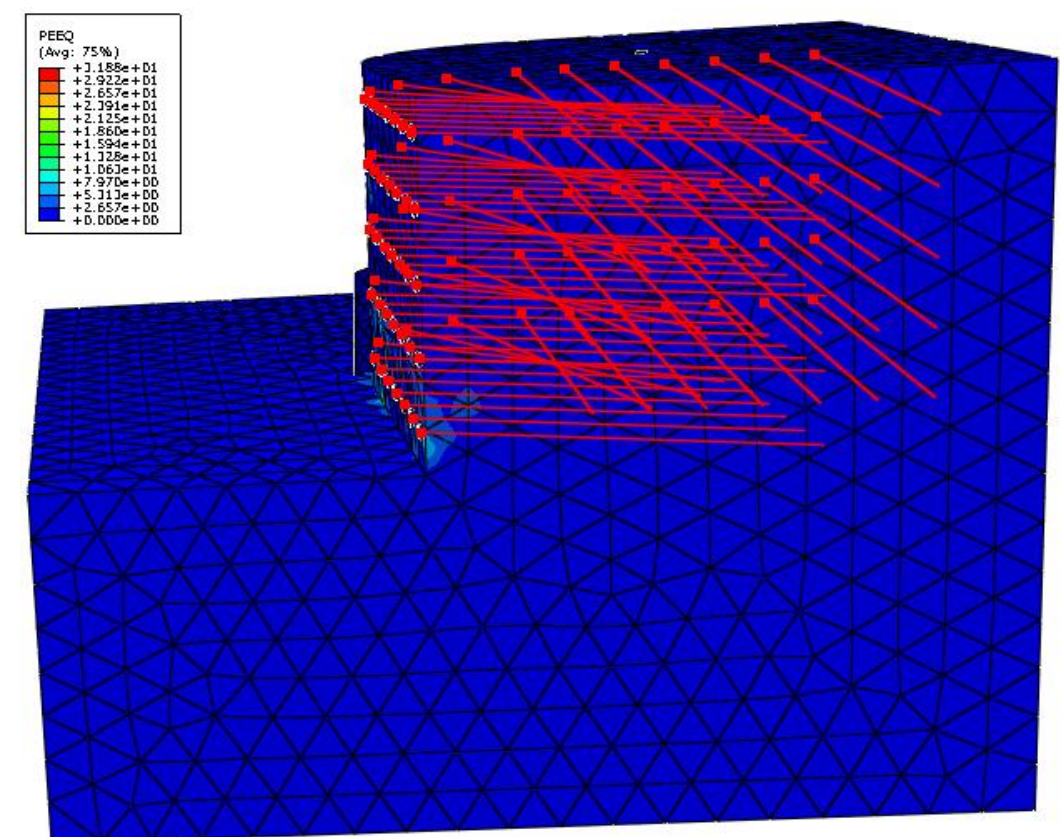

Figure 7.124 Soil Nail Pattern for 3-D FEM, Reinforced Full Slope Model No. 2 (PEEQ Contour Plot)

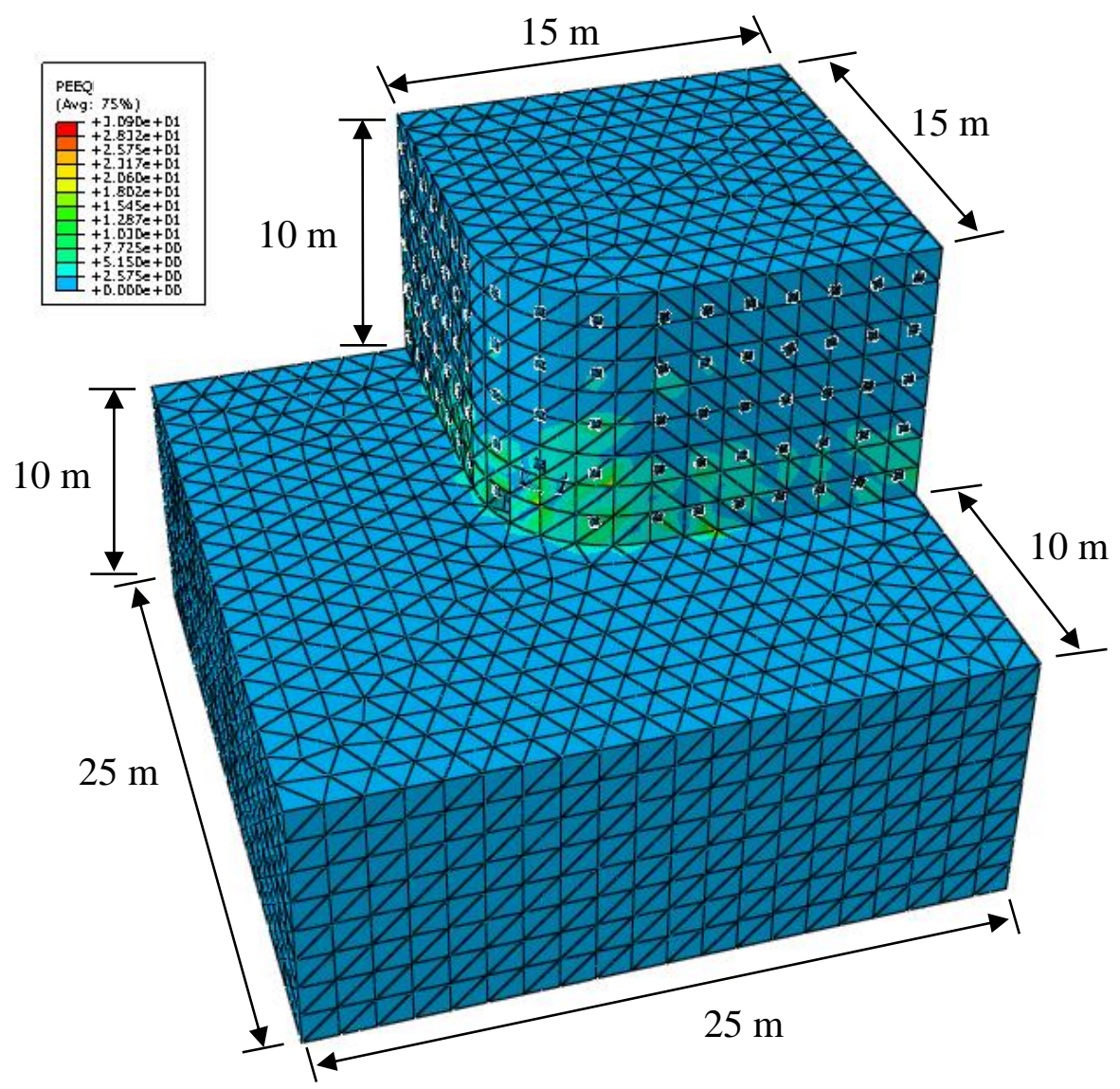

Figure 7.125 PEEQ Contour Plot for 3-D FEM, Reinforced Full Slope Model No. 2 (Entire Slope) 


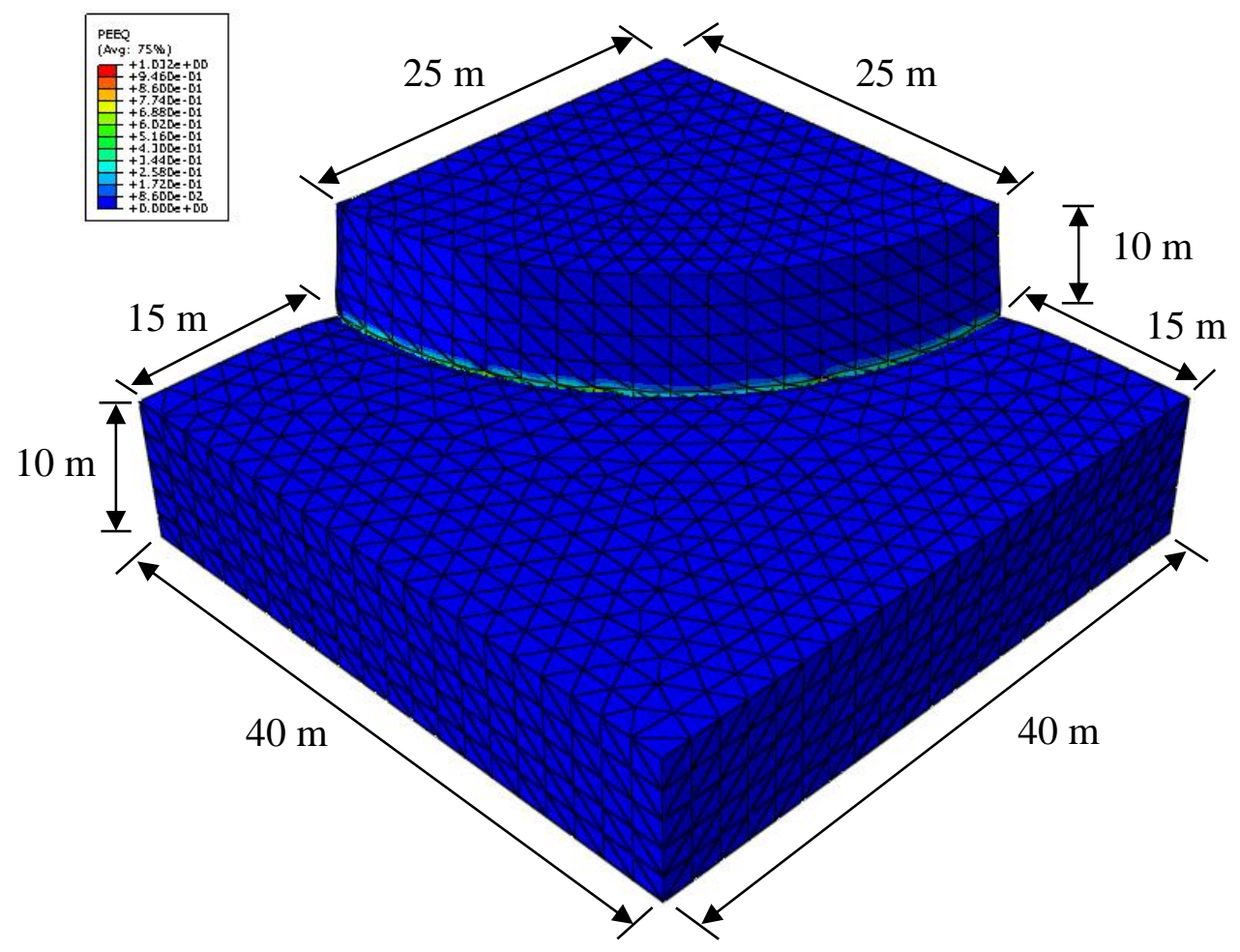

Figure 7.126a PEEQ Contour Plot for 3-D FEM, Unreinforced Full Slope Model No. 3 (Entire Slope)

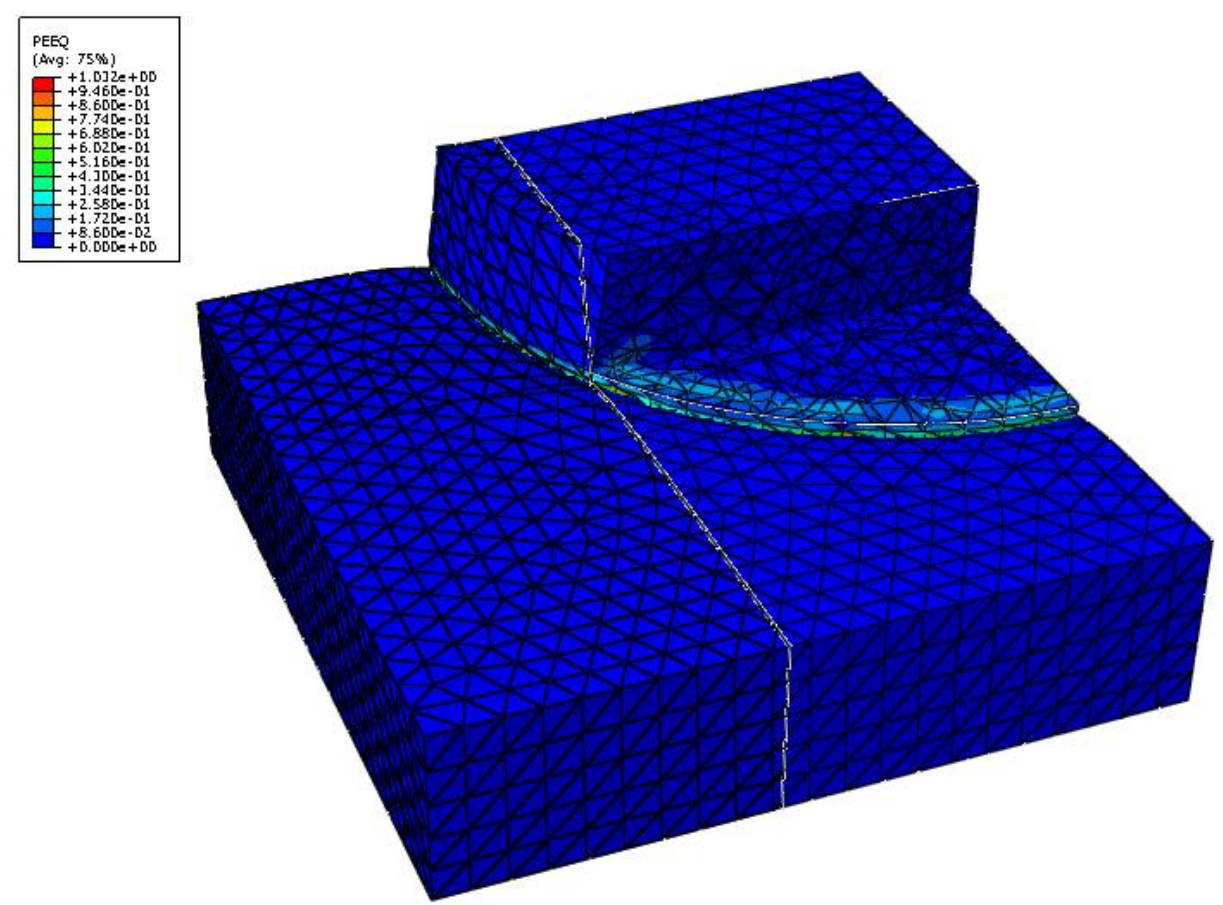

Figure 7.126b PEEQ Contour Plot for 3-D FEM, Unreinforced Full Slope Model No. 2 (View Cut Section - Y \& Z Axis) 


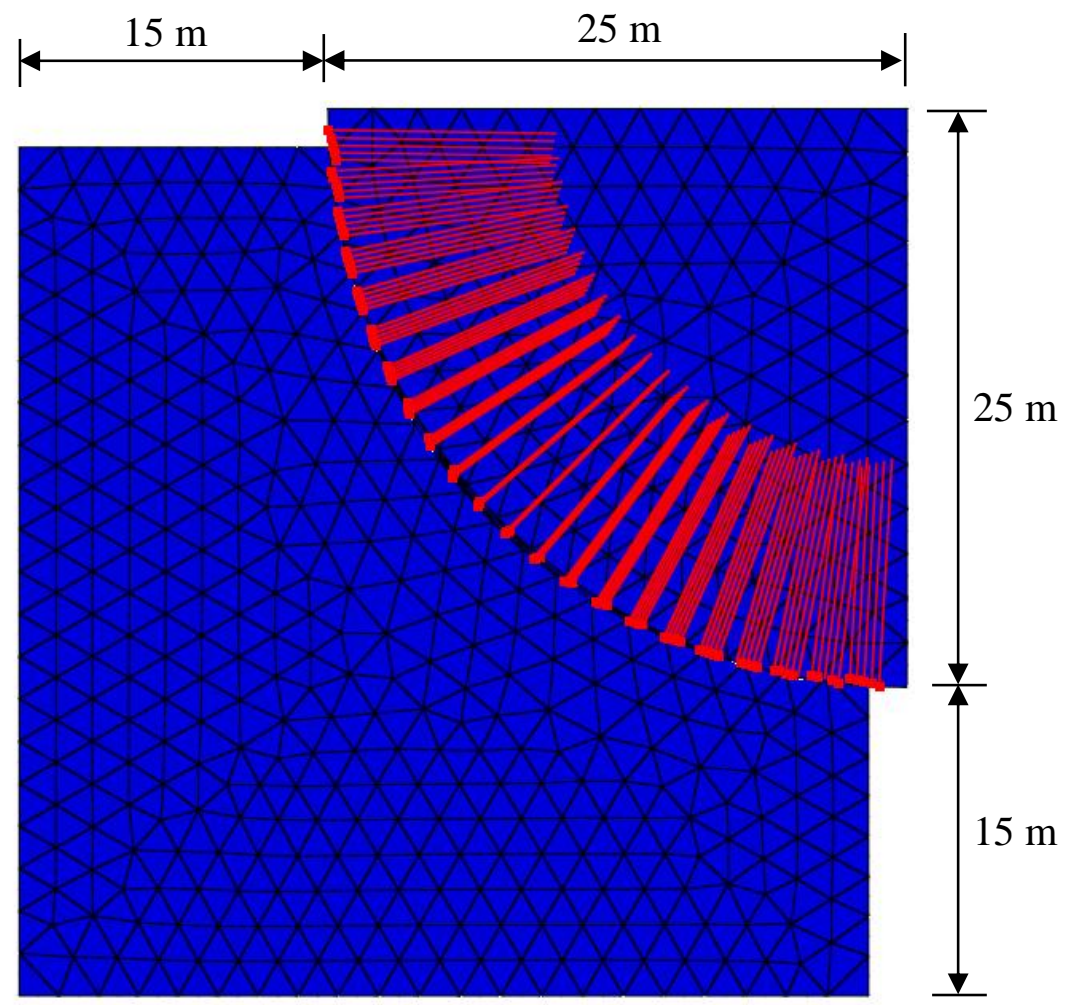

Figure 7.127 Soil Nail Pattern for 3-D FEM, Reinforced Full Slope Model No. 3 (Plan View)

The results of this study indicate that modeling soil-nailed reinforced slopes with a three-dimensional FEM analysis may yield lower FOS values than using a two-dimensional "section" technique (i.e. the two-dimensional section that results in the lowest FOS), as is commonly practiced. Due to complex site geometries often encountered in practice, many slope failures do not fail along a circular path (Cornforth, 2005). The lower FOS values generated from the three-dimensional FEM analysis may be due to the consideration afforded to non-circular failure surfaces included in the three-dimensional FEM slope models. Three-dimensional FEM analysis does not assume, or force, a particular failure surface (i.e. circular) like many two-dimensional L-E analyses. A minimum FOS value using three-dimensional FEM analysis considers any failure modes that result in a nonconvergent solution, as discussed in Section 3.9. These failure modes may include circular failures, wedge failures, slope bulging, and finite slope failures. 


\section{CHAPTER 8: SUMMARY AND CONCLUSIONS}

\subsection{Summary}

The primary objective of this study was to evaluate the use of finite element method for slope stability analyses for both two- and three-dimensional models, including both unreinforced slopes and slopes reinforced with soil nails. The numerical approach in this study utilized the Shear Strength Reduction (SSR) method in order to calculate a Factor of Safety (FOS). This study assessed the accuracy and efficiency of two-dimensional and three-dimensional finite element types used to model slope failures during slope stability analyses. Using three-dimensional models, several parametric studies were completed including the influence of soil nail orientation, soil nail length, and vertical and horizontal soil nail spacing on slope stability was investigated. This study also assessed the influence of surcharge location and its magnitude on slope stability. FOS values were also determined for some typical soils and their associated soil property ranges encountered in soil nailing applications. Further, the potential use for three-dimensional FEM modeling of pretensioned and fully modeled soil-nailed slopes was considered.

\section{Recapitulation}

- FEM can be used to analyze the slope stability of both two-dimensional and three-dimensional slopes, both unreinforced and with soil nail reinforcement. 


\subsection{Two-Dimensional Finite Element Models}

Two-dimensional FEM models were studied in order to connect with previous research as well as to study finite element types that may be used to model soil within a slope stability analysis. For an unreinforced, $26.5^{\circ}[2(\mathrm{H}): 1(\mathrm{~V})]$ slope, sixteen different element types were used in separate models to evaluate their efficiency, accuracy, and failure surface suitability based on equivalent plastic strain (PEEQ) contour plots. Both Mohr-Coulomb (M-C) and Drucker-Prager (D-P) soil yielding models were evaluated. Table 8.1 summarizes the results of this study.

The element types that proved to be most efficient, accurate, and produced an acceptable failure surface using the Mohr-Coulomb yielding criteria included the CPE4, CPE4H, CPE4R, and the CPE4RH. The CPE4 element is a solid (continuum) element utilized in two-dimensional analyses. It is a rectangular element suitable for plane strain conditions and utilizes first-order bilinear interpolation. The element has 4 nodes that have two translational degrees-of-freedom (Abaqus, 2011; Hutton, 2004). The CPE6, CPE6H, and the CPE6M (of which the benchmark model with a FOS $=1.00$ was based upon) also performed very well overall. The CPE6 is also a solid (continuum) element utilized in twodimensional analyses. It is a triangular element suitable for plane strain conditions and utilizes second-order quadratic interpolation. The element has 6 nodes that have two translational degrees-of-freedom (Abaqus, 2011; Hutton, 2004).

Using the Drucker-Prager yielding criteria, once again the CPE4 and the CPE4H proved to process quickly and accurately and generate and acceptable failure surface. Also, the CPE6, CPE6H, CPE6M, and the CPE6MH performed very well overall. In addition, the CPE8 and CPE8R produced acceptable failure surfaces and relatively accurate FOS values. 
Table 8.1 Results Summary for Two-Dimensional Element Selection Study

\begin{tabular}{|c|c|c|c|c|c|}
\hline No. & $\begin{array}{c}\text { Element } \\
\text { Type }\end{array}$ & $\begin{array}{c}\text { Failure } \\
\text { Criterion } \\
\text { (M-C/D-P) }\end{array}$ & $\begin{array}{l}\text { Acceptable } \\
\text { Failure } \\
\text { Surface }\end{array}$ & $\begin{array}{c}\text { Processing } \\
\text { Time } \\
\text { (Sec.) }\end{array}$ & $\begin{array}{l}\text { Accuracy } \\
\text { (FOS) }\end{array}$ \\
\hline \multirow{2}{*}{1} & \multirow{2}{*}{ CPE3 } & $\mathrm{M}-\mathrm{C}$ & Yes & 0.5 & 1.23 \\
\hline & & D-P & No & 1.7 & 0.97 \\
\hline \multirow{2}{*}{2} & \multirow{2}{*}{ СРE3H } & M-C & Yes & 0.5 & 1.23 \\
\hline & & D-P & No & 1.9 & 0.97 \\
\hline \multirow{2}{*}{3} & \multirow{2}{*}{ CPE4 } & $\mathrm{M}-\mathrm{C}$ & Yes & 2.9 & 1.03 \\
\hline & & D-P & Yes & 3.5 & 0.96 \\
\hline \multirow{2}{*}{4} & \multirow{2}{*}{ CPE4H } & $\mathrm{M}-\mathrm{C}$ & Yes & 3.0 & 1.01 \\
\hline & & D-P & Yes & 3.8 & 0.96 \\
\hline \multirow{2}{*}{5} & \multirow{2}{*}{ CPE4R } & M-C & Yes & 6.6 & 0.98 \\
\hline & & D-P & Yes & 2.5 & 1.37 \\
\hline \multirow{2}{*}{6} & \multirow{2}{*}{ CPE4RH } & $\mathrm{M}-\mathrm{C}$ & Yes & 6.0 & 0.98 \\
\hline & & D-P & Yes & 2.7 & 1.37 \\
\hline \multirow{2}{*}{7} & \multirow{2}{*}{ CPE4I } & M-C & No & 7.0 & 0.95 \\
\hline & & D-P & No & 5.5 & 0.93 \\
\hline \multirow{2}{*}{8} & \multirow{2}{*}{ CPE4IH } & $\mathrm{M}-\mathrm{C}$ & No & 6.6 & 0.66 \\
\hline & & D-P & No & 20.1 & 0.58 \\
\hline \multirow{2}{*}{9} & \multirow{2}{*}{ CPE6 } & M-C & Yes & 12.6 & 0.97 \\
\hline & & D-P & Yes & 5.3 & 0.94 \\
\hline \multirow{2}{*}{10} & \multirow{2}{*}{ СРE6H } & M-C & Yes & 22.3 & 0.97 \\
\hline & & D-P & Yes & 8.9 & 0.94 \\
\hline \multirow{2}{*}{11} & \multirow{2}{*}{ CPE6M } & M-C & Yes & 9.0 & 1.00 \\
\hline & & D-P & Yes & 5.5 & 0.96 \\
\hline \multirow{2}{*}{12} & \multirow{2}{*}{ CPE6MH } & M-C & No & 3.6 & 0.86 \\
\hline & & D-P & Yes & 4.0 & 0.98 \\
\hline \multirow{2}{*}{13} & \multirow{2}{*}{ CPE8 } & M-C & No & 19.0 & 0.97 \\
\hline & & D-P & Yes & 3.2 & 0.94 \\
\hline \multirow{2}{*}{14} & \multirow{2}{*}{ CPE8H } & M-C & No & 44.4 & 0.86 \\
\hline & & D-P & No & 43.8 & 0.86 \\
\hline \multirow{2}{*}{15} & \multirow{2}{*}{ CPE8R } & M-C & No & 11.0 & 0.94 \\
\hline & & D-P & Yes & 6.2 & 0.93 \\
\hline & & M-C & No & 33.9 & 0.71 \\
\hline 16 & CPE8RH & D-P & No & 34.1 & 0.72 \\
\hline
\end{tabular}


The CPE8 is a solid (continuum) element utilized in two-dimensional analyses. It is a rectangular element suitable for plane strain conditions and utilizes second-order quadratic interpolation. The element has 8 nodes that have two translational degrees-of-freedom (Abaqus, 2011; Hutton, 2004). However, the CPE8 element types were not as efficient as the others mentioned, as processing times were relatively large.

From the results of this study, when modeling two-dimensional, unreinforced soil slopes, the most efficient and accurate element type, that provides an acceptable failure mechanism, is the CPE4 element type. The CPE4 element types were more efficient than the CPE6 element types when using either the Mohr-Coulomb or Drucker-Prager soil yielding criteria. Further, the CPE4 element type was most efficient when used in conjunction with the Mohr-Coulomb soil yielding criteria. For comparison, a popular FEM computer program called "PLAXIS" limits users to either a 6- or 15-noded triangular element type for two-dimensional FEM modeling (PLAXIS, 2014). While the 6-noded triangular element did perform well, the results of this study indicate that the 4-noded bilinear quadrilateral element type was more efficient. A 15-noded triangular element was not evaluated in this study. However, due to its higher order interpolation, one could assume a longer processing time with its use.

\section{Recapitulation}

- When modeling two-dimensional soil slopes, the CPE4 (4-noded bilinear quadrilateral) and CPE6 (6-noded quadratic triangle) element types perform efficiently, accurately, and provide an acceptable failure mechanism when using either the Mohr-Coulomb or Drucker-Prager soil yielding criteria.

- Overall, when modeling two-dimensional soil slopes, the most efficient and accurate element type that provides an acceptable failure mechanism is the CPE4 element using the Mohr-Coulomb soil yielding criteria. 


\subsubsection{Analysis of Two-Dimensional Reinforced Slopes}

The benchmark, $26.5^{\circ}$ slope was reinforced with one, two, and three soil nails. The resulting FOS values were compared to two-dimensional, L-E models. These results were identical for the 1 nail case, and were $1.9 \%$ and $4.3 \%$ variance in the two and three nail cases, respectively. In slope stability analyses, these differences are considered very small. Like the traditionally accepted L-E method, the FEM approach provides acceptable FOS results. Additionally, the FEM provides opportunities for the evaluation of complex soil slopes while the Limit-Equilibrium (L-E) approach can only consider simple cases.

\section{Recapitulation}

- Two-dimensional FEM results compared well with two-dimensional LimitEquilibrium (L-E) results for soil-nailed reinforced slopes.

\subsection{Three-Dimensional Finite Element Models}

Many three-dimensional slope stability analyses were completed in this study, as discussed in Chapter 7. Similar to the two-dimensional study, three-dimensional element types were evaluated to determine their suitability for use in slope stability analyses based on their efficiency, accuracy, and failure surface correctness using equivalent plastic strain (PEEQ) contour plots. Moreover, several soil nailing design parameters were also evaluated. The results of some of these models were compared to the results using traditional two-dimensional, L-E methods in an effort to assess their validity. 


\subsubsection{Influence of Depth in Three-Dimensional Analysis of Unreinforced Slopes}

Using three-dimensional FEM, the depth in the Z-direction was varied for a $26.5^{\circ}$ unreinforced slope in an effort to confirm the use of a unit-width approach for threedimensional modeling of soil slopes when performing parametric studies of soil-nailed reinforced slopes. Varying depths of 1.0 meter out to 50.0 meters was evaluated. The results showed consistent Factor of Safety (FOS) values and PEEQ contour plots for all slope depths studied. Thus, when end conditions are not considered, a three-dimensional, unit-width FEM approach provides identical results to FEM slope models with depth. Using a unit-width approach provides a useful exercise for designers when considering soil nail parametric studies such as soil nail orientation, soil nail length, and soil nail vertical spacing.

\section{Recapitulation}

- For unreinforced slopes, a three-dimensional, unit-width FEM approach provides identical results to FEM slope models with depth (when end conditions are not considered) and can be processed much more efficiently, providing a useful tool in performing parametric studies.

\subsubsection{Three-Dimensional Element Type Study}

Once again, the benchmark, $26.5^{\circ}$ slope was modeled with Mohr-Coulomb and Drucker-Prager yielding criteria using twenty-one different three-dimensional finite element type options for the soil. Table 8.2 summarizes the results of this study. 
Table 8.2 Results Summary for Three-Dimensional Element Selection Study

\begin{tabular}{|c|c|c|c|c|c|}
\hline No. & Element Type & $\begin{array}{c}\text { Failure Criterion } \\
\text { (M-C/D-P) }\end{array}$ & $\begin{array}{c}\text { Acceptable } \\
\text { Failure Surface }\end{array}$ & $\begin{array}{l}\text { Processing Time } \\
\text { (Sec.) }\end{array}$ & $\begin{array}{c}\text { Accuracy } \\
\text { (FOS) }\end{array}$ \\
\hline \multirow{2}{*}{1} & \multirow{2}{*}{ C3D4 } & $\mathrm{M}-\mathrm{C}$ & Yes & 1.2 & 1.22 \\
\hline & & D-P & No & 7.4 & 0.94 \\
\hline \multirow{2}{*}{2} & \multirow{2}{*}{$\mathrm{C} 3 \mathrm{D} 4 \mathrm{H}$} & $\mathrm{M}-\mathrm{C}$ & No & 89.2 & 0.86 \\
\hline & & D-P & No & 53.4 & 0.96 \\
\hline \multirow{2}{*}{3} & \multirow{2}{*}{ C3D6 } & M-C & Yes & 0.7 & 1.22 \\
\hline & & D-P & Yes & 0.6 & 1.06 \\
\hline \multirow{2}{*}{4} & \multirow{2}{*}{ C3D6H } & $\mathrm{M}-\mathrm{C}$ & Yes & 0.8 & 1.20 \\
\hline & & D-P & Yes & 0.8 & 1.06 \\
\hline \multirow{2}{*}{5} & \multirow{2}{*}{ C3D8 } & M-C & Yes & 2.5 & 1.04 \\
\hline & & D-P & Yes & 7.5 & 0.97 \\
\hline \multirow{2}{*}{6} & \multirow{2}{*}{ C3D8H } & M-C & Yes & 9.2 & 1.00 \\
\hline & & D-P & Yes & 8.6 & 0.97 \\
\hline \multirow{2}{*}{7} & \multirow{2}{*}{ C3D8R } & $\mathrm{M}-\mathrm{C}$ & Yes & 4.9 & 1.01 \\
\hline & & D-P & Yes & 2.9 & 1.02 \\
\hline \multirow{2}{*}{8} & \multirow{2}{*}{ C3D8RH } & $\mathrm{M}-\mathrm{C}$ & Yes & 5.5 & 1.01 \\
\hline & & D-P & Yes & 16.0 & 0.95 \\
\hline \multirow{2}{*}{9} & \multirow{2}{*}{ C3D8I } & M-C & Yes & 48.8 & 0.95 \\
\hline & & D-P & Yes & 3.2 & 1.02 \\
\hline \multirow{2}{*}{10} & \multirow{2}{*}{ C3D8IH } & $\mathrm{M}-\mathrm{C}$ & No & 23.8 & 0.67 \\
\hline & & D-P & No & 42.3 & 0.60 \\
\hline \multirow{2}{*}{11} & \multirow{2}{*}{ C3D10 } & $\mathrm{M}-\mathrm{C}$ & Yes & 82.7 & 0.97 \\
\hline & & D-P & Yes & 41.7 & 0.94 \\
\hline \multirow{2}{*}{12} & \multirow{2}{*}{$\mathrm{C} 3 \mathrm{D} 10 \mathrm{H}$} & M-C & No & 338.3 & 0.63 \\
\hline & & D-P & No & 269.1 & 0.61 \\
\hline \multirow{2}{*}{13} & & $\mathrm{M}-\mathrm{C}$ & Yes & 125.0 & 0.99 \\
\hline & C3DIOM & D-P & Yes & 52.8 & 0.94 \\
\hline 14 & & $\mathrm{M}-\mathrm{C}$ & No & 1050.3 & 0.72 \\
\hline 14 & C3D10MH & D-P & No & 546.9 & 0.92 \\
\hline 15 & C2D10I & $\mathrm{M}-\mathrm{C}$ & No & 21.9 & 0.79 \\
\hline 15 & C3DI0I & D-P & No & 478.8 & 0.70 \\
\hline & & $\mathrm{M}-\mathrm{C}$ & Yes & 56.0 & 0.98 \\
\hline 16 & C3D15 & D-P & Yes & 33.4 & 0.94 \\
\hline 17 & עי150 & $\mathrm{M}-\mathrm{C}$ & No & 166.2 & 0.82 \\
\hline $1 /$ & С $3 D 15 H$ & D-P & Yes & 39.1 & 0.94 \\
\hline & & $\mathrm{M}-\mathrm{C}$ & Yes & 91.2 & 0.98 \\
\hline 18 & C3D20 & D-P & Yes & 67.5 & 0.94 \\
\hline 10 & עינחבים & $\mathrm{M}-\mathrm{C}$ & No & 334.3 & 0.79 \\
\hline 19 & C $3 \mathrm{D} 20 \mathrm{H}$ & D-P & No & 322.5 & 0.82 \\
\hline & & $\mathrm{M}-\mathrm{C}$ & No & 58.0 & 0.96 \\
\hline 20 & C3D20R & D-P & No & 33.7 & 0.93 \\
\hline 21 & מסתרמתו & $\mathrm{M}-\mathrm{C}$ & No & 144.8 & 0.71 \\
\hline 21 & C3D $\angle 0 R H$ & D-P & No & 31.2 & 0.66 \\
\hline
\end{tabular}


For the Mohr-Coulomb failure criterion, element types C3D8, C3D8H, C3D8R, and C3D8RH all proved to provide an acceptable failure surface with FOS results that processed fast and accurate. While the C3D10, C3D10M, C3D15, and C3D20 element types yielded relatively accurate results with acceptable failures surfaces, they had slower processing times. The C3D8 is a solid (continuum) element utilized in three-dimensional analyses. It is a brick element utilizing first-order linear interpolation. The element has 8 nodes that have three translational degrees-of-freedom (Abaqus, 2011; Hutton, 2004).

For the Drucker-Prager failure criterion, three-dimensional element types C3D6 and $\mathrm{C} 3 \mathrm{D} 6 \mathrm{H}$ processed fast; however, their accuracy and failure surface validity was questionable. Once again, the C3D8 group, including the C3D8, C3D8H, C3D8R, C3D8RH, and C3D8I all proved to process fast, with accurate FOS values and acceptable failure surfaces based on the PEEQ contour plots. The element types C3D10, C3D10M, C3D15, C3D15H, and C3D20 gave reasonably accurate values of FOS, but with slower processing speeds, and some exhibited questionable failure surfaces.

From the results of this study, when modeling three-dimensional, unreinforced soil slopes, the most efficient and accurate element type, that provides an acceptable failure mechanism, is the C3D8 element type. In addition, the C3D8 element type was most efficient when used in conjunction with the Mohr-Coulomb soil yielding criteria. For comparison, the PLAXIS (2014) computer program limits users to a 10-noded tetrahedral element type (PLAXIS, 2014). The results of this study indicate long processing times for the 10-noded quadratic tetrahedron as the C3D8 brick element was much more efficient. Further, while it was initially thought that the smoother, potentially non-circular Drucker- 
Prager yield surface would be advantageous in processing three-dimensional slope stability analyses, the results of this study show no benefit from its use.

\section{Recapitulation}

- When modeling three-dimensional soil slopes, the C3D8 (8-noded linear brick) element types perform very efficiently, accurately, and provide an acceptable failure mechanism when using either the Mohr-Coulomb or Drucker-Prager soil yielding criteria.

- Overall, when modeling three-dimensional soil slopes, the most efficient and accurate element type that provides an acceptable failure mechanism is the C3D8 element using Mohr-Coulomb soil yielding criteria.

- Although the Drucker-Prager soil yielding criteria assumptions seem to offer more potential for three-dimensional applications, this study found no significant benefit from its use. In addition, the Mohr-Coulomb soil yielding criteria, which is slightly easier to use and much more common, proved to be more time efficient, and just as accurate, while providing an acceptable failure mechanism.

\subsubsection{Comparison of Three-Dimensional FEM with Two-Dimensional L-E Analysis for} Unreinforced Slopes

Finite element analyses were performed for unreinforced slopes with slope angles of $26.5^{\circ}$ up to $90^{\circ}$. The results were compared with two-dimensional L-E results. These results were presented in Table 7.3 in Chapter 7. The two-dimensional, L-E FOS results were consistently lower than the three-dimensional, FEM results. This relationship is expected based on the results of the three-dimensional finite element type study. The C3D8 element type, which was used in the three-dimensional modeling of unreinforced slopes, yielded slightly higher FOS values when compared to the benchmark model. For clarity, Table 8.1 includes the percentage difference in the yielded FOS values between the two 
methods. As shown below, reasonably comparable results were yielded for slopes up to $80^{\circ}$. For the $90^{\circ}$ slopes, the FOS values were relatively low so that the percent difference seems falsely inflated. A slope height $(\mathrm{H})$ of 10 meters was used for all slopes in this study. For large slope angles (i.e. $\beta=90^{\circ}$ ), when slope heights $(\mathrm{H})$ increase beyond 10 meters, FOS values will decrease for both three-dimensional FEM and two-dimensional L-E models.

The results of this study confirm the use of three-dimensional, unit-width FEM modeling for unreinforced slope stability analyses. The resulting FOS values were consistently slightly higher for all slope angles studied as compared to traditionally accepted two-dimensional, L-E modeling. This difference is considered negligible for most slope stability studies.

Table 8.3 Comparison of 3-D FEM with 2-D L-E Results for Unreinforced Slopes

\begin{tabular}{|c|c|c|c|}
\hline $\begin{array}{c}\text { Slope Angle } \\
(\boldsymbol{\beta})\end{array}$ & $\begin{array}{c}\text { 3-D FEM } \\
\text { FOS }\end{array}$ & $\begin{array}{c}\text { 2-D L-E } \\
\text { FOS }\end{array}$ & $\begin{array}{c}\text { \% } \\
\text { Difference }\end{array}$ \\
\hline $\begin{array}{c}26.5^{\circ} \\
\text { (Benchmark Slope) }\end{array}$ & 1.04 & 0.99 & 4.8 \\
\hline $50^{\circ}$ & 0.57 & 0.54 & 5.3 \\
\hline $60^{\circ}$ & 0.46 & 0.43 & 6.5 \\
\hline $70^{\circ}$ & 0.40 & 0.38 & 5.0 \\
\hline $80^{\circ}$ & 0.33 & 0.29 & 12.1 \\
\hline $90^{\circ}$ & 0.26 & 0.18 & 30.8 \\
\hline
\end{tabular}

\section{Recapitulation}

- Unreinforced, unit-width, three-dimensional FEM models compared well to two-dimensional, L-E models, yielding Factor of Safety (FOS) values marginally higher for all slope angles. 


\subsection{Three-Dimensional Reinforced Slopes}

Three-dimensional slopes were reinforced with soil nails in order to evaluate the usefulness of the FEM for several soil nailing design parameters. The orientation of soil nails was investigated using three-dimensional FEM in an effort to determine the orientation that yielded the highest Factor of Safety (FOS) for construction of a soil-nailed slope. The orientation that yielded the highest FOS was named the "optimum" soil nail orientation $\left(\delta_{\mathrm{OPT}}\right)$. Slope angles from $26.5^{\circ}$ to $90^{\circ}$ were evaluated. The results of this study are presented in Table 7.4. From the results of this study, the optimum soil nail orientation $\left(\delta_{\text {OPт }}\right)$ for slopes of $26.5^{\circ}, 40^{\circ}, 50^{\circ}, 60^{\circ}, 70^{\circ}, 80^{\circ}$, and $90^{\circ}$ were $35^{\circ}, 34^{\circ}, 25^{\circ}, 18^{\circ}, 15^{\circ}, 10^{\circ}$, and $5^{\circ}$, respectively. Overall, these results compared well to previous research completed by Fan and Luo (2008) and Rotte et. al. (2007). Although Fan and Luo (2008) and Rotte et. al. (2007) did not study a $26.5^{\circ}$ slope angle, by extrapolation it is evident that discrepancies in the resulting optimum soil nail orientation values were slightly more significant at the lower slope angles $\left(\beta<40^{\circ}\right)$. In addition, when two-dimensional, L-E models were developed using the same conditions, the computed FOS values also compared well at steeper slope angles $\left(\beta \geq 60^{\circ}\right)$ and began to depart at the lower slope angles $\left(\beta \leq 50^{\circ}\right)$. As a practical note, soil nailing is rarely necessary at low slope angles.

By plotting the results of the optimum soil nail orientations $\left(\delta_{\mathrm{OPT}}\right)$ versus the slope angles from this study (See Table 7.4 in Chapter 7), combined with the results from the study completed by Fan and Luo (2008) and Rotte et. al. (2007), a well-defined relationship is apparent, as presented in Figure 8.1. The resulting relationship can be expressed by the linear equation presented as Equation 8.1. This equation provides an efficient and effective 
approach for designers when beginning to analyze a soil-nailed slope for the optimum soil nail orientation $\left(\delta_{\mathrm{OPT}}\right)$.

$$
\delta_{O P T .}=58^{\circ}-0.6 \beta
$$

Where:

$\delta_{\mathrm{OPT} .}=$ Optimum Soil Nail Orientation measured down from horizontal (degrees)

$\beta=$ Slope Angle (degrees)

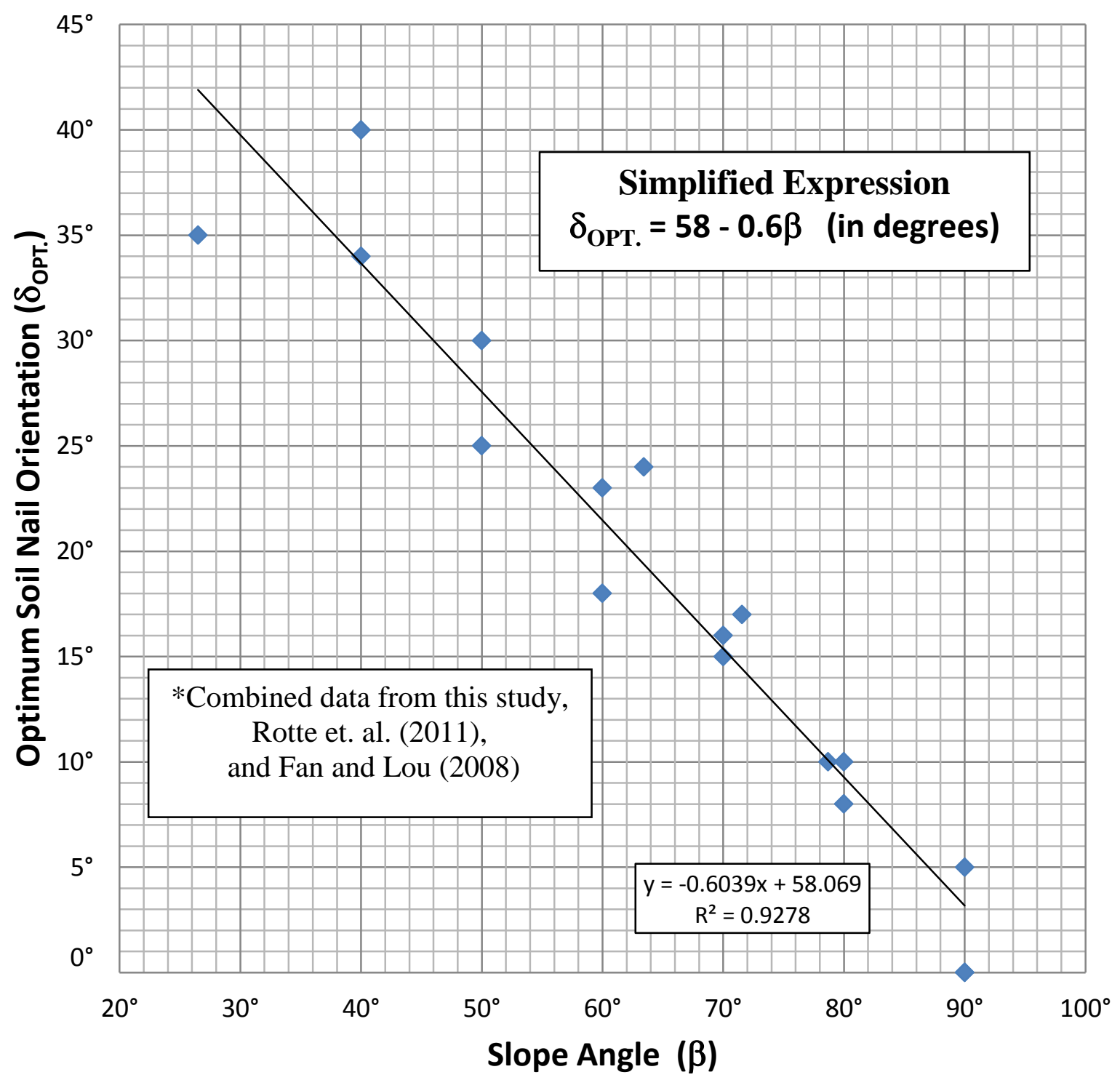

Figure 8.1 Combined Results for Optimum Soil Nail Orientations of Various Slope Angles 


\section{Recapitulation}

- Three-dimensional FEM models can be used to effectively determine the optimum soil nail orientation $\left(\delta_{\mathrm{OPT}}\right)$ for slopes reinforced with soil nails. For a slope with a level backfill, the optimum soil nail orientation (in degrees measured downward from horizontal) can be first approximated using the equation $\mathbf{5 8}^{\circ}-\mathbf{0 . 6 \beta}$, where $\beta$ is the slope angle in degrees.

\subsubsection{Influence of Soil Nail Length}

Influence of soil nail length (L) on the Factor of Safety (FOS) was evaluated in this study. The soil nail length (L) was increased from 0 meters (unreinforced) to 20.0 meters, which was twice the slope height $(\mathrm{H})$ of 10.0 meters. Once again, slope angles $(\beta)$ from $26.5^{\circ}$ to $90^{\circ}$ were studied. FOS values steadily increased for all slope angles ( $\beta$ ) up to nail lengths of about 10 meters. For soil nail lengths (L) greater than 10 meters, FOS values did moderately increase for most slope angles $(\beta)$; however, the FOS increase was slight $(<$ $10 \%$ ) for all slope angles except $\beta=26.5^{\circ}$. For a slope angle of $\beta=26.5^{\circ}$, the FOS value continued to increase, providing a $13.6 \%$ increase at a soil nail length ( $\mathrm{L}=20$ meters).

For every slope angle $(\beta)$ investigated, steady gains in FOS values were clearly evident up to a certain soil nail length (L), where increases in length from this point were not advantageous. This point is considered the most efficient soil nail length and can easily be determined using three-dimensional FEM methods. For the $26.5^{\circ}$ and $90^{\circ}$ slope, this value was around 12.5 meters. For slope angles of $50^{\circ}, 60^{\circ}, 70^{\circ}$, and $80^{\circ}$, the most efficient soil nail length was about 10 meters. Thus, for most slope angles $(\beta)$, when beginning to analyze a soil-nailed slope, a soil nail length to slope height ratio $(\mathrm{L} / \mathrm{H})$ of 1.0 is a practical place to start. 


\section{Recapitulation}

- Three-dimensional FEM models can be used to effectively determine the most efficient soil nail length (L) for slopes reinforced with soil nails. The most efficient soil nail length can be first approximated using a soil nail length to slope height ratio $(\mathrm{L} / \mathrm{H})$ equal to 1.0 .

\subsubsection{Influence of Vertical Spacing of Soil Nails}

Soil nail vertical spacing $\left(\mathrm{S}_{\mathrm{V}}\right)$ was investigated in this research. Slope angles were varied from $90^{\circ}$ to $26.5^{\circ}$ and the vertical soil nail spacing was evaluated from 0.5 meters up to 5.0 meters. Decreases in FOS values were marginal for the lower slope angles $\left(\beta=26.5^{\circ}\right.$, $50^{\circ}$, and $\left.60^{\circ}\right)$ up to a vertical soil nail spacing $\left(S_{V}=2.5\right.$ meters $)$, where significant decreases in FOS values began. For steeper slope angles $\left(\beta=70^{\circ}, 80^{\circ}\right.$, and $\left.90^{\circ}\right)$, this significant drop in FOS values began to occur at a soil nail vertical spacing $\left(\mathrm{S}_{\mathrm{V}}=2.0\right.$ meters $)$ and continued to a soil nail vertical spacing $\left(\mathrm{S}_{\mathrm{V}}=3.0\right.$ meters $)$. For soil nail vertical spacing $\left(\mathrm{S}_{\mathrm{V}}>3.0\right.$ meters), slight decreases in FOS values resulted for these steeper slopes.

Overall, the results of this study indicate that the most efficient soil nail vertical spacing $\left(\mathrm{S}_{\mathrm{V}}\right)$ is about 2.5 meters $( \pm 8$ Feet $)$ for flatter slope angles $\left(\beta<60^{\circ}\right)$. For steeper slopes $\left(\beta>60^{\circ}\right)$, soil nail vertical spacing $\left(\mathrm{S}_{\mathrm{V}}\right)$ should be limited to about 2.0 meters ( \pm 6.5 feet). These values agree with those reported by Lazarte et. al. (2003), stating that typical soil nail vertical spacing $\left(\mathrm{S}_{\mathrm{V}}\right)$ ranges from 1.25 meters to 2.0 meters.

\section{Recapitulation}

- A vertical soil nail spacing $\left(\mathrm{S}_{\mathrm{V}}\right)$ up to 2.4 meters $(\leq 8$ feet $)$ is recommended for soil-nailed slopes with slope angles $\left(\beta \leq 60^{\circ}\right)$ and up to 1.9 meters $(\leq 6$ feet) for slope angles $\left(\beta>60^{\circ}\right)$. 


\subsubsection{Influence of Horizontal Spacing of Soil Nails}

Soil nail horizontal spacing $\left(\mathrm{S}_{\mathrm{H}}\right)$ was investigated for slope angles $(\beta)$ from $50^{\circ}$ up to $90^{\circ}$. Horizontal soil nail spacing $\left(\mathrm{S}_{\mathrm{H}}\right)$ was evaluated from 0.5 meters to 5.0 meters. FOS values remained nearly constant out to a horizontal soil nail spacing $\left(\mathrm{S}_{\mathrm{H}}=1.9\right.$ meters $)$ where a consistent, significant decrease in FOS occurred (for most of the soil parameters used in this study), followed by a steady decrease in FOS out to $S_{H}=5.0$ meters. From the evaluation of the equivalent plastic strain (PEEQ) contour plots, it was clear that the mode of failure changed from an overall circular failure to a localized failure between the columns of soil nails from a $S_{H}=1.9$ meters to $S_{H}=2.0$ meters, respectively.

Further study was completed in an effort to identify the primary soil property variable that triggered this response. From the results of this study, it was apparent that neither the Elastic Modulus (E), the Poisson's Ratio $(\mu)$, nor the Unit Weight $(\gamma)$ had a significant effect on the sudden FOS decrease or the overall FOS value. However, the results of this study indicated that the FOS value, when considering horizontal soil nail spacing $\left(\mathrm{S}_{\mathrm{H}}\right)$ of soil-nailed reinforced slopes, is sensitive to Dilation Angle $(\psi)$, the Angle of Friction $(\phi)$, and the Cohesion (c) value.

The results of this study indicate that, depending on the Angle of Friction $(\phi)$ and the Cohesion (c) value used, the Dilation Angle $(\psi)$ can have a significant effect on the FOS value when evaluating the horizontal soil nail spacing $\left(\mathrm{S}_{\mathrm{H}}\right)$ of soil-nailed slopes. Generally, this study indicates that the FOS value slightly increases with an increase in the Dilation Angle $(\psi)$ to a maximum, depending on the $\phi$ and c values, and then steadily decreases. When a fully associative plastic flow rule was modeled $(\psi=\phi)$, the results indicate very little variance in the FOS values for all horizontal soil nail spacing $\left(\mathrm{S}_{\mathrm{H}}\right)$ studied $\left(\mathrm{S}_{\mathrm{H}}=0.5\right.$ 
meters to $\mathrm{S}_{\mathrm{H}}=5.0$ meters). These results support the non-associative plastic flow assumption $\left(\psi=0^{\circ}\right)$, which was used throughout this research

The results of this study show that the Angle of Friction $(\phi)$ value has a significant impact on the overall magnitude of the FOS value, as relatively low FOS values resulted for low Angle of Friction $(\phi)$ values and relatively high FOS values resulted for high Angle of Friction $(\phi)$ values.

When the Cohesion (c) value was investigated, it was found that it does not significantly affect the overall FOS value, as compared to the Angle of Friction $(\phi)$; however, it does appreciably affect the magnitude of decrease in the FOS value consistently present for horizontal soil nail spacing's from $S_{H}=1.9$ meters to $S_{H}=2.0$ meters. Large decreases in the FOS values resulted in this horizontal soil nail spacing range when Cohesion (c) values were low and relatively small decreases in FOS values resulted when the Cohesion (c) values were high.

Overall, the results of this study indicate that horizontal soil nail spacing $\left(\mathrm{S}_{\mathrm{H}}\right)$ values should be limited to $S_{H}<1.9$ meters $(\leq 6$ feet) for all slope angles $(\beta)$. According to Lazarte et. al. (2003), typical soil nail horizontal spacing's $\left(S_{H}\right)$ also range from 1.25 meters to 2.0 meters. In addition, the results of this study emphasize the importance of the proper and accurate determination of the Mohr-Coulomb strength parameters $\phi$ and $\mathrm{c}$, as indicated by other researchers (Duncan and Wright, 2005; Cornforth, 2005). 


\section{Recapitulation}

- A maximum horizontal soil nail spacing $\left(S_{H}\right)$ less than 1.9 meters $(\leq 6$ feet $)$ is recommended for soil-nailed slopes for all slope angles $(\beta)$.

- When performing three-dimensional FEM modeling of reinforced slopes, the FOS value is relatively insensitive to a soil's Elastic Modulus (E), Unit Weight $(\gamma)$, and Poisson's Ratio $(\mu)$ value. The most significant soil parameters are the Angle of Friction $(\phi)$ and the Cohesion (c).

- A non-associative plastic flow rule assumption $\left(\psi=0^{\circ}\right)$ is recommended for slope stability analyses using FEM.

\subsubsection{Influence of Surcharge Location and Magnitude}

The influence of a surcharge load applied to the top of a soil-nailed slope was evaluated with respect to the location and the magnitude of the surcharge load. This study included slope angles $(\beta)$ from $50^{\circ}$ to $90^{\circ}$. Surcharge loads from $10 \mathrm{kPa}$ to $500 \mathrm{kPa}$ were evaluated at distances measured from the top of the slope. This range easily covers most surcharge loads from light traffic to heavy building construction (Huang, 2014). The distance, or location of the surcharge load, ranged from 0 (i.e. full coverage of top of slope) to 20 meters. In addition, a no surcharge load $(q=0)$ condition was also modeled.

As expected, the FOS values were consistently lower for the larger surcharge magnitudes for all slope angles $(\beta)$ studied. The FOS values were also lower for the steeper slope angles $(\beta)$ under surcharge loading. The change in FOS value for a given surcharge load magnitude $(q)$, at any slope angle $(\beta)$, did not change by more than $15 \%$ for any surcharge load location (x) evaluated. In addition, at lower surcharge magnitudes, the FOS values trended towards a slope with no surcharge load; however, this was not the case for the larger surcharge loads. When the large surcharge loads were modeled beyond the 
influence of the soil-nailed reinforced soil mass, the equivalent plastic strain (PEEQ) contour plots indicated a local "bearing" failure on the top surface for most slope angles $(\beta)$.

For comparison, two-dimensional, L-E models were developed using the same methodology. Generally, two-dimensional L-E models yielded FOS values about 10\% lower than the FEM models, for surcharge locations out to a surcharge location $(\mathrm{x}=10$ meters), measured from the top of the slope. At surcharge location distances beyond this, the results became closer for the lower surcharge magnitude loads. Some L-E models produced FOS values greater than the FEM models for the higher surcharge magnitudes.

Unlike two-dimensional L-E modeling, three-dimensional FEM modeling for slope stability analyses enables comprehensive modeling capabilities. FEM modeling can evaluate slope stability problems with surcharge loads and indicate bearing type failures.

\section{Recapitulation}

- Three-dimensional FEM models can be used effectively to evaluate unreinforced and soil-nailed reinforced slopes with a surcharge load.

\subsubsection{Influence of Typical Soil Properties and Rainwater Infiltration}

The influence of typical soil properties that are encountered in many soil nailing projects on the Factor of Safety (FOS) of soil-nailed reinforced soil slopes was investigated. The study used an upper/lower limit approach to determine the variation in FOS for given slope angles $(\beta)$ ranging from $50^{\circ}$ to $90^{\circ}$, which covers most soil nailing projects. Cohesive soil types including Clay, Silt, and Sandy Clay were evaluated.

For all soil types studied, there was a consistent increase in FOS values from 17\% to $22 \%$ as the slope angle $(\beta)$ decreased from $90^{\circ}$ to $50^{\circ}$. The most significant increase in FOS 
values was consistently present as the slope angle $(\beta)$ changed from a slope angle $\left(\beta=90^{\circ}\right.$ to $\beta=80^{\circ}$, with relatively minor increases for slope angles $\left(\beta<80^{\circ}\right)$. Thus, the results of this study do not show a significant benefit in designing soil-nailed reinforced slopes with slope angles $(\beta)$ less than about $80^{\circ}$. For highway applications, Lazarte et. al. (2003) document that soil-nailed reinforced slopes are typically designed and constructed at slope angles from $\left(\beta=90^{\circ}\right.$ to $\left.\beta=80^{\circ}\right)$.

Overall, the pattern of change in FOS values for each soil was consistent. Since the "Silt" soil had the largest upper/lower combination of Angle of Friction $(\phi)$ and Cohesion (c) values, it yielded both the highest and lowest FOS values. The "Clay" soil properties studied also covered a broad FOS range, due once again to the relatively large difference in the upper/lower strength parameter combination. Similarly, the "Sandy Clay" soil yielded the narrowest range of FOS values due to the relatively narrow range in the upper/lower strength parameter combination.

Due to the frequent nature of slope failures during periods of heavy rainfall, this study investigated slope stability as it relates to soil properties for both unreinforced and soil-nailed reinforced slopes. The results of this investigation support the findings documented by other researchers; the proper and accurate determination of the MohrCoulomb strength parameters $\mathrm{c}$ and $\phi$ are vital to the determination of an accurate FOS value when performing a slope stability analysis (Duncan and Wright, 2005; Cornforth, 2005). This result was prominent in the horizontal soil nail spacing study which included a soil parameter sensitivity study, as discussed in Section 7.5.4. In addition, this study also found that the increase in a soil's Unit Weight $(\curlyvee)$ due to rainfall infiltration does decrease the slopes stability, for both an unreinforced and a soil-nailed reinforced slope. 


\section{Recapitulation}

- When performing three-dimensional FEM modeling of reinforced slopes, relatively high FOS values result for relatively high Angle of Friction $(\phi)$ and cohesion (c) values, and vice-versa.

- The decrease in a soil's Cohesion (c) and Angle of Friction $(\phi)$ and the increase in a soil's Unit Weight $(\curlyvee)$ during rainfall infiltration cause a decrease in a slope's FOS for both unreinforced and soil-nailed reinforced slopes.

- There is no significant increase in the FOS for soil-nailed reinforced slopes with slope angles $(\beta)$ less than $80^{\circ}$, regardless of the soil type.

\subsubsection{Influence of Pre-Tensioned Soil Nails}

A $90^{\circ}$ slope angle was used in this study to demonstrate the usefulness of the FEM for analyzing pre-tensioned soil-nailed slopes for the specific application of evaluating vertical deformation of a soil-nailed slope with a surcharge load. The deformation of a point just at the top of the slope was evaluated as various pre-tensioned force levels were applied.

On projects where deformation is tightly controlled, even small values of deformation could be significant. While the pre-tensioning forces used in the study were beyond the practical range for conventional soil nails, the effect of pre-tensioning forces for use in reducing deformation was clearly evident when these forces were applied, which demonstrates the capabilities of the FEM approach. Deformation values decreased as the pre-tensioning force was increased. Limit-Equilibrium computer programs are not capable of performing an analysis that considers deformation or the effect of pre-tensioned soil nails.

\section{Recapitulation}

- Pre-tensioned soil nails can be modeled using an FEM approach. 


\subsubsection{FEM for Full Slope Modeling}

To illustrate the applicability of three-dimensional FEM for full scale modeling, three slopes were modeled and the results compared to three-dimensional, unit-width results, and two-dimensional L-E results. The slopes were modeled unreinforced and reinforced. For the unreinforced slopes, the FOS values for the three-dimensional FEM fully modeled slopes were slightly higher than those of the FEM unit-width model and the twodimensional L-E model. This supports the previous results from this study for unreinforced slopes, summarized in Section 8.3.3. However, the soil-nailed reinforced slopes showed the contrary. The FOS values for all three of the three-dimensional FEM fully modeled, soilnailed reinforced slopes were lower than those of the FEM unit-width model and the twodimensional L-E model. This opposes the commonly held view that it is a conservative approach to model the steepest, or "worst case" section only. The FOS results for the unreinforced and soil-nailed reinforced models, for all cases studied, were within $20 \%$ and 16\%, respectively (See Table 7.6).

The results of this study indicate that fully modeling soil-nailed reinforced slopes with a three-dimensional FEM analysis may yield lower FOS values than using a conventional "section" technique, whether using a FEM three-dimensional, unit-width section or a two-dimensional L-E section, where the inclusion of lateral stresses and deformation are not accounted for and the failure may not be circular. In any case, this study demonstrates that in some types of slope stability analyses, using a "worst case" section may not be a conservative approach, as generally assumed. Further, since vertical deformation, horizontal deformation, or slope face "bulging" may be a governing criterion, 
fully modeled slopes using a three-dimensional FEM approach is superior to the other methods.

\section{Recapitulation}

- Fully modeled, three-dimensional FEM slope stability analyses can be developed and executed to analyze complex, real-world site geometries.

- Three-dimensional, soil nail reinforced slopes that are fully modeled using FEM, may yield FOS values that are lower than traditional section methods that use a "worst case" section technique.

- Three-dimensional FEM slope stability modeling is superior to other methods due to its capabilities and overall versatility.

\subsection{Conclusions}

Based on the results of this research, the following conclusions are drawn:

- FEM can be used to analyze the slope stability of both two-dimensional and threedimensional slopes, both unreinforced and with soil nail reinforcement.

- When modeling two-dimensional soil slopes, the CPE4 (4-noded bilinear quadrilateral) and CPE6 (6-noded quadratic triangle) element types perform efficiently, accurately, and provide an acceptable failure mechanism when using either the Mohr-Coulomb or Drucker-Prager soil yielding criteria. Overall, when modeling two-dimensional soil slopes, the most efficient and accurate element type that provides an acceptable failure mechanism is the CPE4 element using MohrCoulomb soil yielding criteria.

- Two-dimensional FEM results compared well with two-dimensional LimitEquilibrium (L-E) results for soil-nailed reinforced slopes.

- For unreinforced slopes, a three-dimensional, unit-width FEM approach provides identical results to FEM slope models with depth (when end conditions are not considered) and can be processed much more efficiently, providing a useful tool in performing parametric studies. 
- When modeling three-dimensional soil slopes, the C3D8 (8-noded linear brick) element types perform very efficiently, accurately, and provide an acceptable failure mechanism when using either the Mohr-Coulomb or Drucker-Prager soil yielding criteria. Overall, when modeling three-dimensional soil slopes, the most efficient and accurate element type that provides an acceptable failure mechanism is the C3D8 element using Mohr-Coulomb soil yielding criteria.

- Although the Drucker-Prager soil yielding criteria assumptions seem to offer more potential for three-dimensional applications, this study found no significant benefit from its use. In addition, the Mohr-Coulomb soil yielding criteria, which is slightly easier to use and much more common, proved to be more time efficient, and just as accurate, while providing an acceptable failure mechanism.

- Reinforced and unreinforced, unit-width, three-dimensional FEM models compared well to two-dimensional, L-E models, yielding Factor of Safety (FOS) values marginally higher for most slope angles.

- Three-dimensional FEM models can be used to effectively determine the optimum soil nail orientation $(\delta)$ for slopes reinforced with soil nails. For a slope with a level backfill, the optimum soil nail orientation (in degrees measured downward from horizontal) can be first approximated using the equation $58^{\circ}-0.6 \beta$, where $\beta$ is the slope angle in degrees.

- Three-dimensional FEM models can be used to effectively determine the most efficient soil nail length (L) for slopes reinforced with soil nails. For slopes with a slope height $(\mathrm{H})$ of about 10 meters, the most efficient soil nail length can be first approximated using a soil nail length to slope height ratio $(\mathrm{L} / \mathrm{H})$ equal to 1.0.

- A vertical soil nail spacing $\left(\mathrm{S}_{\mathrm{V}}\right)$ up to 2.4 meters $(\leq 8 \mathrm{feet})$ is recommended for soilnailed slopes with slope angles $\left(\beta \leq 60^{\circ}\right)$ and up to 1.9 meters ( $\leq 6$ feet) for slope angles $\left(\beta>60^{\circ}\right)$.

- A horizontal soil nail spacing less than 1.9 meters $(\leq 6$ feet) is recommended for soil-nailed slopes for all slope angles $(\beta)$.

- When performing three-dimensional FEM modeling of reinforced slopes, the FOS value is relatively insensitive to a soil's Elastic Modulus (E), Unit Weight $(\gamma)$, and Poisson's Ratio $(\mu)$ value. The most significant soil parameters are the Angle of Friction $(\phi)$ and the Cohesion (c).

- The decrease in a soil's Cohesion (c) and Angle of Friction $(\phi)$ and the increase in a soil's Unit Weight $(\curlyvee)$ during rainfall infiltration cause a decrease in a slope's FOS for both unreinforced and soil-nailed reinforced slopes. 
- A non-associative plastic flow rule assumption $\left(\psi=0^{\circ}\right)$ is recommended for slope stability analyses using FEM.

- There is no significant increase in the FOS for soil-nailed reinforced slopes with slope angles $(\beta)$ less than $80^{\circ}$, regardless of the soil type.

- Three-dimensional FEM models can be used effectively to evaluate unreinforced and soil-nailed reinforced slopes that have a surcharge load. Three-dimensional FEM models can be used to estimate the deformation of unreinforced and soil-nailed reinforced slopes with and without a surcharge loading, even prior to failure. FEM modeling can accurately evaluate slope stability problems and also indicate bearing type failures.

- Pre-tensioned soil nails can be modeled using an FEM approach.

- Fully modeled, three-dimensional FEM slope stability analyses can be developed and executed to analyze complex, real-world site geometries.

- Three-dimensional, soil nail reinforced slopes that are fully modeled using FEM, may yield FOS values that are lower than traditional section methods that use a "worst case" section technique.

- Three-dimensional FEM slope stability modeling is superior to other methods due to its capabilities and overall versatility.

\subsection{Recommendations}

During the course of this research and while the results were disseminated and the conclusions drawn, several additional areas of research became apparent and include the following:

- This study evaluated the finite element type options available for modeling unreinforced soil slopes. More research is needed to confirm the accuracy and suitability of the recommended finite element types for other soil types and slope geometries.

- More research needs to be completed and field research results compiled to verify the accuracy of the equation provided to determine the optimum soil nail orientation.

- More research needs to be completed and field research results collected to verify the accuracy of the ratio provided to determine the most efficient soil nail length. 
- More research needs to be completed and field research results gathered to confirm the recommendations for soil nail vertical and horizontal spacing.

- More research needs to be completed and field research results compiled to investigate the effects of surcharge loads on soil-nailed slopes, especially considering end effects and areal extent. Fully modeled slopes should be evaluated and compared.

- More research needs to be completed and field research results collected to substantiate the accuracy and usefulness of FEM for the prediction of slope deformation, especially slopes induced to surcharge loads.

- More research is needed to evaluate the potential use of pre-tensioned soil nail walls, especially when deformation under surcharge loads/structures is a design consideration.

- Most of the parametric studies performed in this research were completed using three-dimensional slopes with a unit-width approach. The comparative results for fully modeled slopes in this research leads one to infer that more research needs to be completed on fully modeled slopes in comparison to extracted cross-sections that do not consider end conditions.

- While the primary focus in this research was to study the effect of soil nail reinforced slopes, the strength and integrity of the actual soil nail and soil nail head was not considered a part of this study and additional research should be performed to include these components.

- More research needs to be completed to develop a universal, reliable design method for the design of soil-nailed wall systems for seismic considerations. 


\section{REFERENCES}

1. ABAQUS (2011). ABAQUS User's Manual, Abaqus version 6.11. Dassault Systemes Simulia Corp. (SIMULIA), Karlson \& Sorensen, Inc., Pawtucket, RI.

2. Abdulrahman, A. (2006). Finite Element Based Design Procedures for MSE/Soil nail Hybrid Retaining Wall Systems. Dissertation Submitted to the Department of Civil Engineering, Texas Tech University.

3. Abramson, L., Lee, T., Sharma, S., and Boyce, G. (2002). Slope Stability and Stabilization Methods. Second Edition, John Wiley \& Sons, Inc., Hoboken, N.J.

4. Andrew, R., Hume, H., Hansen, S., Arndt, B., Macklin, P., Rock, A., Zhang, R. (2010). Soil Nail Analysis Program (SNAP) User's Manual. FHWH-CFL/TD-10004, Federal Highway Administration, Washington, D.C.

5. Ann, T., Cheang, W., Hai, O., and Tan, D. (2004). Finite Element Analysis of A Soil-nailed Slope-Some Recent Experience. Proceedings of the GeoAsia 2004 Conference, Third Asian regional conference on Geosynthetics, Seoul, Korea, June 21-24, pp. 183-189.

6. Banerjee, S., Finney, A., Wentworth, T. and Bahiradhan, M. (1998). Evaluation of Design Methodologies for Soil-nailed Walls. Volume 3: An Evaluation of Soil nailing Analysis Packages. FHWA Publication No. WA-RD 371.1, pp. 154.

7. Barley, T., Mothersille, D. (2006). The Actively Stressed Soil Nail System Complete with Corrosion Protection. Proceedings of the Conference on Slope Engineering Kuala, Lumpur, August 6-9.

8. Byrne, R. J., Cotton, D., Porterfield, J., Wolschlag, C., and Ueblacker, G. (1998) Manual for Design and Construction Monitoring of Soil Nail Walls. Report FHWASA-96-69R, Federal Highway Administration, Washington, D.C.

9. Chen, W. F., Han, D. J. (2007). Plasticity for Structural Engineers. J. Ross Publishing, Inc., 5765 N. Andrews Way, Fort Lauderdale, FL.

10. Chow, C.M., Tan, Y.C. (2003). Deep Excavations for Basement via Soil Nailing Method". Retrieved from http://www.gnpgeo.com.my. Extracted August, 2014.

11. Choi, Y.G., Shin, B.W., Park, S.S., Kim, H.T. (2004). An Experimental Study on Behavior Characteristics of the Pretension Soil Nailing Systems. Journal of the Korean Geotechnical Society, Volume 20, No. 2, pp. 87-96.

12. Clague, J.J., Stead, D. (2012). Landslides: Types, Mechanisms and Modeling. Cambridge University Press, New York, N.Y. 
13. Clough, R. W. (1990). Original formulation of the finite element method. Finite Elements in Analysis and Design, Volume 7, Issue 2, pp. 89-101.

14. Cornforth, D. (2005). Landslides in Practice - Investigation, Analysis, and Remedial/Preventive Options in Soils. John Wiley \& Sons, Inc., Hoboken, N.J.

15. Coulomb, C. A. (1776). Essai sur une application des regles des maximis et minimis a quelquels problemesde statique relatifs, a la architecture. Mem. Acad. Roy. Div. Sav., Vol. 7, pp. 343-387.

16. Curran J.H., Hammah, R.E., Yacoub, T.E., Corkum, B. (2006). Investigating the Performance of the Shear Strength Reduction (SSR) Method on the Analysis of Reinforced Slopes. Proceedings of the $59^{\text {th }}$ Canadian Geotechnical and $7^{\text {th }}$ Joint CGS/IAH-CNC Groundwater Specialty Conference, Vancouver, British Columbia, Canada.

17. Das, B. M. (2013). Principles of Geotechnical Engineering. Eighth Edition, Cengage Learning, 200 First Stanford Place, Suite 400, Stanford, CT.

18. Dawson E.M., Roth W.H., Drescher A. (1999). Slope stability analysis by strength reduction. Geotechnique, Volume 49, No. 6, pp. 835-840.

19. Duncan, J. M., Wright, S. G. (2005). Soil Strength and Slope Stability. John Wiley \& Sons, Inc., Hoboken, N.J.

20. Duncan, J.M. (1996). State of the art: limit equilibrium and finite-element analysis of slopes. Journal of Geotechnical Engineering, Vol. 122, No. 7, pp. 577-596.

21. Duncan, J.M., Brandon, T.L., Wright, S.G., Vroman, N. (2008). Stability of I-Walls in New Orleans during Hurricane Katrina. Journal of Geotechnical and Geoenvironmental Engineering, Volume 134, Special Issue: Performance of GeoSystems during Hurricane Katrina, pp. 681-691.

22. Durgunoglu, H. T., Keskin, H. B., Kulac, Ikiz, S., Karadayilar, T. (2008). Performance of soil-nailed walls based on case studies. Bogazici University and ZETAS Zemin Teknolojisi A.S., Istanbul Turkey.

23. Drucker, D. C., Prager, W. (1952). Soil mechanics and plastic analysis for limit design. Quarterly of Applied Mathematics, Vol. 10, No. 2, pp. 157-165.

24. Elias, V., Christopher, B., Berg, R., (2001). Mechanically Stabilized Earth Walls and Reinforced Soil Slopes Design and Construction Guidelines. FHWA -NHI-00-043, Federal Highway Administration, Washington D.C. 
25. Elias, V. and Juran, I. (1991). Soil Nailing for Stabilization of Highway Slopes and Excavations. Publication FHWA-RD-89-198, Federal Highway Administration, Washington D.C.

26. Fan, C-C., and Luo, J-H. (2008). Numerical study on the optimum layout of soilnailed slopes. Computers and Geotechnics, Vol. 35, pp. 585 - 599.

27. Geoslope, (2008). Stability Modeling with Slope/W 2007 Version, Fourth Edition, Geo-Slope International Ltd., Calgary, Alberta, Canada.

28. Gitirana, Jr., G., Santos, M.A., Fredlund, M.D. (2008). Three-Dimensional Slope Stability Model Using Finite Element Stress Analysis. GeoCongress 2008: Geosustainability and Geohazard Mitigation, pp. 191-198.

29. Griffiths, D. V., Lane, P. A. (1999). Slope stability analysis by finite elements. Géotechnique 49, No. 3, pp. 387-403.

30. Halabian, A.M., Sheikhbahaei, A.M., and Hashemolhosseini, S.H. (2012). Three dimensional finite difference analysis of soil-nailed walls under static conditions. International Journal of Geomechanics and Geoengineering, Volume 7, No. 3, September, 2012.

31. Hammah, R.E., Yacoub, T.E., Corkum, B., Curran J.H. (2005). A Comparison of Finite Element Slope Stability Analysis with Conventional Limit-Equilibrium Investigation. Proceedings of the $58^{\text {th }}$ Canadian Geotechnical and $6^{\text {th }}$ Joint CGS/IAH-CNC Groundwater Specialty Conference, Saskatoon, Saskatchewan, Canada.

32. Houlsby, G.T. (1991). How the Dilatancy of Soils Affects Their Behavior. Soil Mechanics Report Number 121/91, University of Oxford, Department of Engineering Science, Oxford, U.K.

33. Huang, Y.H. (2014). Slope Stability Analysis by the Limit Equilibrium Method: Fundamentals and Methods. American Society of Civil Engineers, ASCE Publications, Reston, VA.

34. Hutton, D.V. (2004). Fundamentals of Finite Element Analysis. McGraw Hill Companies, Inc., 1221 Avenue of the Americas, New York, N.Y.

35. Kutschke, W.G., Tarquinio, F.S., Petersen, W.K. (2007). Practical Soil Nail Wall Design and Constructability Issues. Proceedings from Deep Foundation Institute's (DFI) $32^{\text {nd }}$ Annual Conference on Deep Foundations, Colorado Springs, Colorado.

36. Lazarte, C., Elias, V., Espinoza, D. and Sabatini, P. (2003). Geotechnical Engineering Circular No.7- Soil Nail Walls. Report No. FHWA0-IF-017, 182pp. 
37. Ling, H. I., Liu, H. (2009). Deformation analysis of reinforced soil retaining wallssimplistic versus sophisticated finite element analyses. Acta Geotechnica, Vol. 4, pp. 203-213.

38. Littlejohn, G.S., (1985). Underpinning and Retention. Soil anchorages, proceedings...., Blackie Academic \& Professional, Wester Cleddens Road, Bishopbriggs, Glascow G64 2NZ, UK, pp. 292-338.

39. Liu, C., Evett, J.B. (2008). Soils and Foundations. $7^{\text {th }}$ Edition, Prentice Hall, Upper Saddle River, N.J.

40. Manzari, M. T., Nour, M. A. (2000). Significance of Soil Dilatancy in Slope Stability Analysis. Journal of Geotechnical and Geoenvironmental Engineering, Vol. 126, No. 1, pp. 75-80.

41. Marotta, T.W., Coffey, J.C., LaFleur, C.B., LaPlante, C. (2011). Basic Construction Materials. $8^{\text {th }}$ Edition, Pearson Education, Inc., Upper Saddle River, N.J.

42. McCarthy, D. (2007). Essentials of Soil Mechanics and Foundations. $7^{\text {th }}$ Edition, Prentice Hall, Upper Saddle River, N.J.

43. Mitchell, J. K., Soga, K. (2005). Fundamentals of Soil Behavior. John Wiley \& Sons, Inc., Hoboken, N.J.

44. MnDOT (2007). Pavement Design Manual. Subgrade Soils, Section 3-2.0, Table 32.10, Minnesota Department of Transportation, St. Paul, MN.

45. NAVFAC (1986). Soil Mechanics, Design Manual 7.01. U.S. Naval Facilities Engineering Command, Alexandria, Virginia

46. Oñate, S. (2013). Structural Analysis with the Finite Element Method - Linear Statics. Volume 2: Beams, Plates and Shells, $1^{\text {st }}$ Edition, Artes Gráficas Torres S.A., Barcelona, Spain.

47. Park, S.S., Kim, H.T. (2006). Design and Stability Analysis of a Novel Pretensioned Soil Nailing System in Korea. Advances in Earth Structures: Research to Practice, Proceedings of the GeoShanghai International Conference, ASCE, pp. 302-309.

48. PLAXIS (2014). PLAXIS Reference Manual, PLAXIS 2D Anniversary Edition 02/PLAXIS 3D Edition 01. PLAXIS Company, 2600 AN DELFT, Netherlands.

49. Plumelle, C. Schlosser, F., Oclage, P., and Knochenmus, G. (1990). French National Research Project on Soil Nailing: CLOUTERRE. Geotechnical Special Publication No. 25, American Society of Civil Engineers, pp. 660-675. 
50. Porterfield, J. A., Cotton, D.M., and Byrne, R.J. (1994). Soil Nailing Field Inspectors Manual, Project Demonstration 103. Publication No. FHWA-SA-93-068, Federal Highway Administration, Washington, D.C.

51. Rotte, V.M., Viswanadham, B.S. (2013). Influence of nail inclination and facing material type of soil-nailed slopes. Proceedings of the Institution of Civil Engineers, Ground Improvement, Issue G12, May 2013, pp 86-107.

52. Rotte, V.M., Viswanadham, V.M., Chourasia, D. (2011). Influence of slope geometry and nail parameters on the stability of soil-nailed slopes. International Journal of Geotechnical Engineering, Vol. 5, pp. 267-281.

53. Sakr, C. T., Kimmerling, R. (1995). Soil Nailing of a Bridge Embankment, Report 2: Design and Field Performance. Oregon Department of Transportation Experimental Features Project, OR-80-07.

54. Salgado, R. (2006). The Engineering of Foundations. McGraw Hill Companies, Inc., 1221 Avenue of the Americas, New York, N.Y.

55. Sanderson, E. (2011). Life's Little Mysteries. TechMediaNetwork; Gift Edition, ISBN-10: 0983301301.

56. Shaw-Shong, L. (2005). Soil Nailing for Slope Strengthening. Geotechnical Engineering 2005, Gue \& Partners Sdn Bhd, Kuala Lumpar, Malaysia.

57. Shiu, Y.I., Chang, G.W.K. (2005). Effects of Inclination, Length Pattern and Bending Stiffness of Soil Nails on Behaviour of Nailed Structures. Geo Special Report No. SPR 6/2005, Reprinted as Geo Report No. 197, Hong Kong Special Administrative Region, Homantin, Kowloon, Hong Kong.

58. Shukla, S. K. (2011). Handbook of Geosynthetic Engineering, $2^{\text {nd }}$ Edition, ICE Publishing, ISBN-10:0727741756.

59. Singh, V. P., Babu, G. L. (2010). 2D Numerical Simulations of Soil Nail Walls. Geotechnical and Geological Engineering, Volume 28, Number 4, pp. 299-309.

60. Singla, S. (1999). Demonstration Project 103: Design \& Construction Monitoring of Soil Nail Walls, Project Summary Report. Report FHWA-IF-99-026, Federal Highway Administration, Washington, D.C.

61. Slide (2012), Slide User's Manual, version 6.020, Rocscience, Inc., Toronto, Ontario Canada.

62. Tamboli, A. R. (1997). Steel Design Handbook. LRFD Method, McGraw Hill Companies, Inc., 1221 Avenue of the Americas, New York, N.Y. 
63. Thompson, S.R., Miller, I.R. (1990). Design, Construction and Performance of a Soil-nailed Wall in Seattle, Washington. Design and Performance of Earth Retaining Structures (P.C. Lambe and L.A. Hansen, Eds.), Geotechnical Special Publication No. 25, American Society of Civil Engineers, NY, pp. 629-643.

64. Tuozzolo, T. (2003). Soil Nailing: Where, When, and Why - A Practical Guide. $20^{\text {th }}$ Central Pennsylvania Geotechnical Conference, Hershey, Pennsylvania.

65. Turner, J., Jensen, W. (2005). Landslide Stabilization Using Soil Nail and Mechanically Stabilized Earth Walls: Case Study. Journal of Geotechnical and Geoenvironmental Engineering, ASCE, 131(2), 141-150.

66. Varnes, D. J. (1978). Slope Movement Types and Processes. Transportation Research Board Special Report, Issue Number 176, TRB, 500 Fifth St., NW, Washington, D.C.

67. Wanstreet, P. (2007). Finite Element Analysis of Slope Stability. Thesis submitted to College of Engineering and Mineral Resources, Department of Civil and Environmental Engineering, West Virginia University.

68. Wei W. B., Cheng Y. M. (2010). Soil-nailed slope strength reduction and limit equilibrium methods. Journal of Computers and Geotechnics, Volume 37, pp. 602618.

69. Zhang, M., Song, E., and Chen, Z. (1999). Ground movement analysis of soil nailing construction by three-dimensional (3-D) finite element modeling (FEM). Computers and Geotechnics, Vol. 25, pp. 191-204.

70. Zhou, Y., Xu, K., Tang, X., and Tham, G. (2013). Three-Dimensional Modeling of Spatial Reinforcement of Soil Nails in a Field Slope under Surcharge Loads. Journal of Applied Mathematics, Volume 2013, Article ID 926097, Hindawi Publishing Corporation.

71. Zhou, Y., Cheuk, C., Tham L.G. (2009). An embedded bond-slip model for finite element modeling of soil-nail interaction. Journal of Computers and Geotechnics, Volume 36, pp. 1090-1097. 


\section{APPENDIX A}

Using the 16 available element options in Abaqus (2011) for 2-D modeling, models were created and evaluated that utilized both the M-C and D-P soil yielding criteria for the benchmark slope. The results of this study were presented in Table 6.2 and 6.3, respectively. These results included PEEQ visualization plots that were developed using Abaqus (2011) default values for Deformation Factor and PEEQ color contour limits. A summary of the default values used and the final element type recommendations are presented in Table A.1 and A.2 for the M-C and D-P yielding criteria, respectively.

Table A.1 Summary Table of Default PEEQ Plot Values and Recommendation for 2-D Element Selection Study using M-C Yielding Criteria

\begin{tabular}{|c|c|c|c|c|c|}
\hline $\begin{array}{c}\text { Element } \\
\text { Type }\end{array}$ & $\begin{array}{c}\text { Default } \\
\text { Deformation } \\
\text { Factor }\end{array}$ & $\begin{array}{c}\text { Default } \\
\text { PEEQ } \\
\text { Limits } \\
\text { (Min-Max) }\end{array}$ & $\begin{array}{c}\text { Default } \\
\text { Acceptable } \\
\text { Failure }\end{array}$ & FOS & $\begin{array}{c}\text { Recommended } \\
\text { Based on Default } \\
\text { Values }\end{array}$ \\
\hline CPE3 & 26.5 & $0-0.71$ & Yes & 1.23 & $\mathrm{NO}$ \\
\hline CPE3H & 19.4 & $0-1.09$ & Yes & 1.23 & $\mathrm{NO}$ \\
\hline CPE4* & 1.04 & $0-20.2$ & Yes & 1.03 & YES \\
\hline CPE4H* & 1.49 & $0-16.6$ & Yes & 1.01 & YES \\
\hline CPE4R & 237.8 & $0-0.48$ & Yes & 0.98 & $\mathrm{NO}$ \\
\hline CPE4RH & 1869.6 & $0-0.46$ & Yes & 0.98 & $\mathrm{NO}$ \\
\hline CPE4I & 52.9 & $0-0.03$ & No & 0.95 & $\mathrm{NO}$ \\
\hline CPE4IH & 54.0 & $0-0.0005$ & No & 0.66 & $\mathrm{NO}$ \\
\hline CPE6 & 155.8 & $0-0.11$ & No & 0.97 & $\mathrm{NO}$ \\
\hline CPE6H & 182.0 & $0-0.08$ & Yes & 0.97 & YES \\
\hline CPE6M* & 59.4 & $0-0.54$ & Yes & 1.00 & YES \\
\hline CPE6MH & 258.8 & $0-0.01$ & $\mathrm{No}$ & 0.86 & $\mathrm{NO}$ \\
\hline CPE8 & 231.2 & $0-0.02$ & No & 0.97 & $\mathrm{NO}$ \\
\hline CPE8H & 260.0 & $0-0.01$ & No & 0.86 & $\mathrm{NO}$ \\
\hline CPE8R & 238.6 & $0-0.03$ & $\mathrm{No}$ & 0.94 & $\mathrm{NO}$ \\
\hline CPE8RH & 290.9 & $0-0.002$ & No & 0.71 & NO \\
\hline
\end{tabular}

*Elements selected for uniformity comparison (Results presented in Table A.3). 
Table A.2 Summary Table of Default PEEQ Plot Values and Recommendation for 2-D Element Selection Study using D-P Yielding Criteria

\begin{tabular}{|c|c|c|c|c|c|}
\hline $\begin{array}{c}\text { Element } \\
\text { Type }\end{array}$ & $\begin{array}{c}\text { Default } \\
\text { Deformation } \\
\text { Factor }\end{array}$ & $\begin{array}{c}\text { Default } \\
\text { PEEQ Limits } \\
\text { (Min -Max) }\end{array}$ & $\begin{array}{c}\text { Default } \\
\text { Acceptable } \\
\text { Failure }\end{array}$ & FOS & $\begin{array}{c}\text { Recommended } \\
\text { Based on } \\
\text { Default Values }\end{array}$ \\
\hline CPE3 & 188.1 & $0-0.001$ & No & 0.97 & $\mathrm{NO}$ \\
\hline CPE3H & 191.9 & $0-0.001$ & No & 0.97 & $\mathrm{NO}$ \\
\hline CPE4* & 20.5 & $0-0.09$ & Yes & 0.96 & YES \\
\hline CPE4H & 3.79 & $0-0.52$ & Yes & 0.96 & YES \\
\hline CPE4R & 0.03 & $0-15.05$ & Yes & 1.37 & $\mathrm{NO}$ \\
\hline CPE4RH & 0.03 & $0-15.05$ & Yes & 1.37 & $\mathrm{NO}$ \\
\hline CPE4I & 191.7 & $0-0.01$ & No & 0.93 & $\mathrm{NO}$ \\
\hline CPE4IH & 304.7 & $0-0.0001$ & No & 0.58 & $\mathrm{NO}$ \\
\hline CPE6 & 143.6 & $0-0.007$ & Yes & 0.94 & YES \\
\hline CPE6H* & 57.8 & $0-0.04$ & Yes & 0.94 & YES \\
\hline CPE6M* & 53.5 & $0-0.05$ & Yes & 0.96 & YES \\
\hline CPE6MH & 95.8 & $0-0.009$ & Yes & 0.98 & YES \\
\hline CPE8 & 139.5 & $0-0.007$ & Yes & 0.94 & $\mathrm{NO}$ \\
\hline CPE8H & 227.1 & $0-0.002$ & $\mathrm{No}$ & 0.86 & $\mathrm{NO}$ \\
\hline CPE8R & 157.2 & $0-0.01$ & Yes & 0.93 & $\mathrm{NO}$ \\
\hline CPE8RH & 345.6 & $0-0.001$ & $\mathrm{No}$ & 0.72 & $\mathrm{NO}$ \\
\hline
\end{tabular}

*Elements selected for uniformity comparison (Results presented in Table A.4).

For comparison, select 2-D element types were plotted with a uniform Deformation Factor and PEEQ color contour limits. The selected element types possessed similar Deformation Factors and PEEQ limits and were included in those elements that were recommended. The results are presented in Table A.3 and A.4 for the M-C and D-P yielding criteria, respectively. 
Table A.3 Comparison of 2-D Element Type for M-C - Uniform Deformation Factor and PEEQ Limits

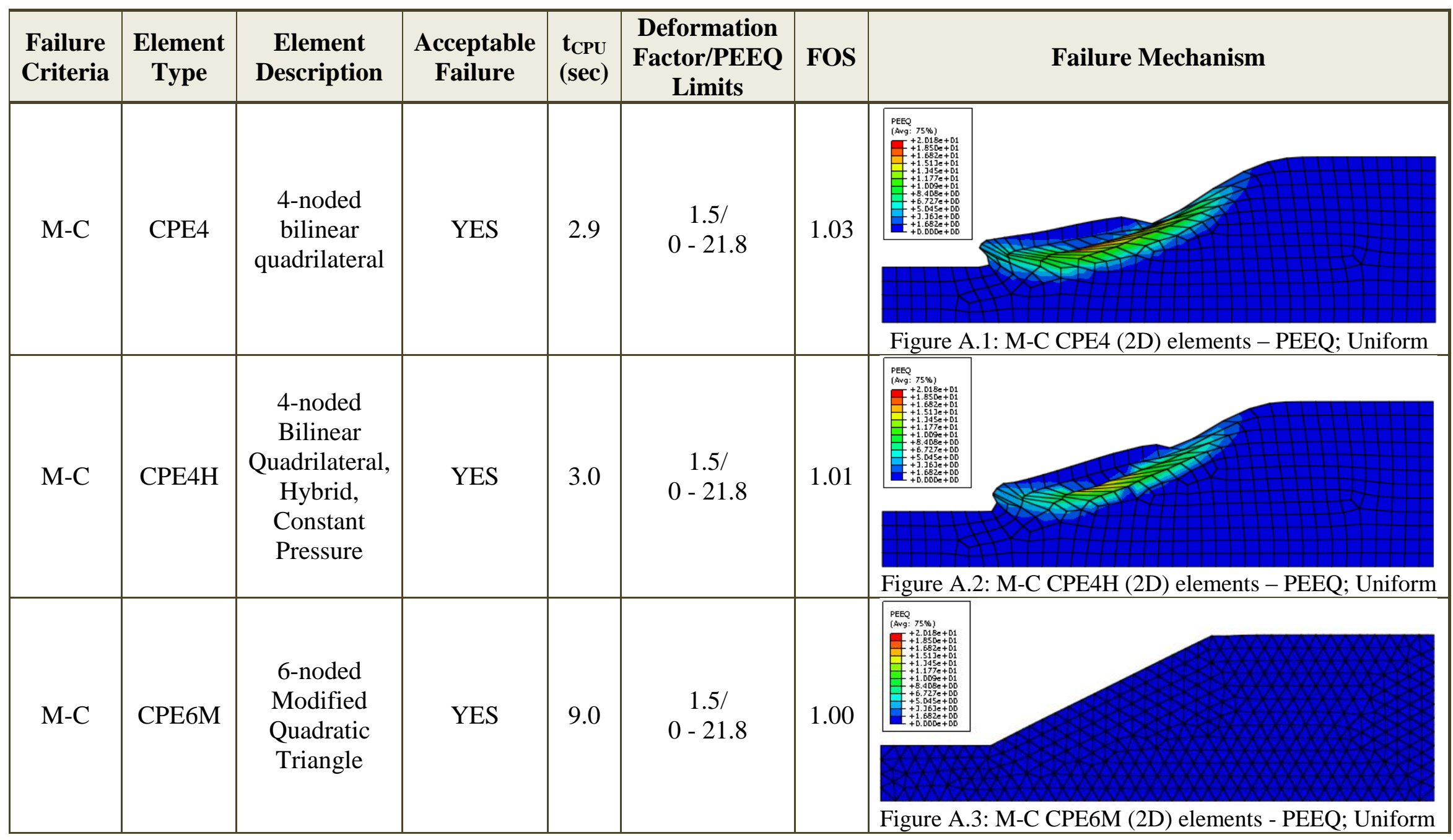


Table A.4 Comparison of 2-D Element Type for D-P - Uniform Deformation Factor and PEEQ Limits

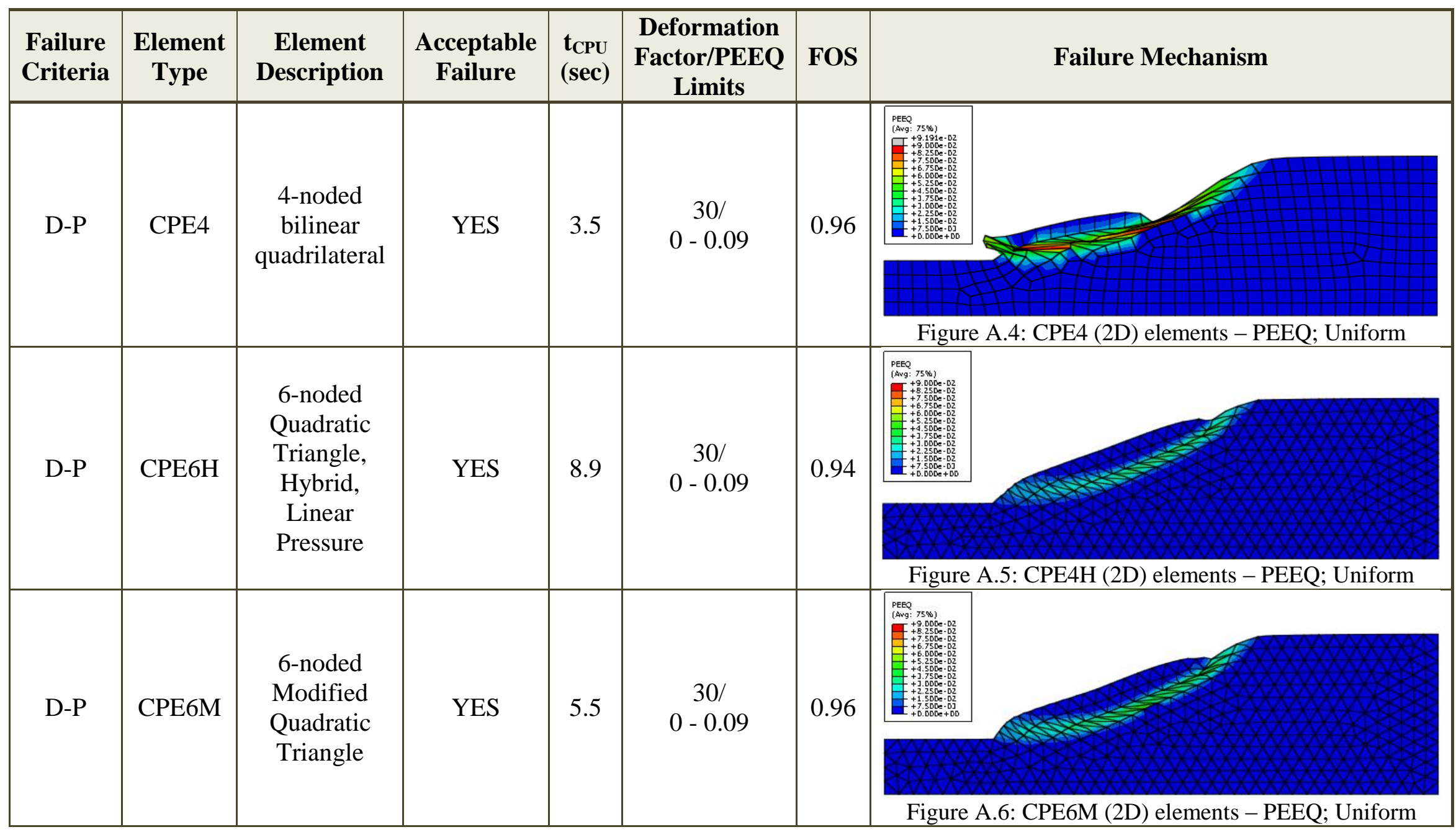


Using the 21 available element options in Abaqus (2011) for 3-D modeling, models were created and evaluated that utilized both the M-C and D-P soil yielding criteria for the benchmark slope. The results of this study were presented in Table 7.1 and 7.2, respectively. These results also included PEEQ visualization plots that were developed using Abaqus (2011) default values for Deformation Factor and PEEQ color contour limits. A summary of the default values used and the final element type recommendations for three-dimension FEM modeling are presented in Table A.5 and A.6 for M-C and D-P yielding criteria, respectively.

Table A.5 Summary Table of Default PEEQ Plot Values and Recommendation for 3-D Element Selection Study using M-C Yielding Criteria

\begin{tabular}{|c|c|c|c|c|c|}
\hline $\begin{array}{c}\text { Element } \\
\text { Type }\end{array}$ & $\begin{array}{c}\text { Default } \\
\text { Deformation } \\
\text { Factor }\end{array}$ & $\begin{array}{c}\text { Default } \\
\text { PEEQ Limits } \\
\text { (Min-Max) }\end{array}$ & $\begin{array}{c}\text { Default } \\
\text { Acceptable } \\
\text { Failure }\end{array}$ & FOS & $\begin{array}{c}\text { Recommended } \\
\text { Based on Default } \\
\text { Values }\end{array}$ \\
\hline C3D4 & 18.0 & $0-2.10$ & Yes & 1.22 & $\mathrm{NO}$ \\
\hline C3D4H & 270.4 & $0-0.008$ & No & 0.86 & $\mathrm{NO}$ \\
\hline C3D6 & 32.6 & $0-0.61$ & Yes & 1.22 & $\mathrm{NO}$ \\
\hline $\mathrm{C} 3 \mathrm{D} 6 \mathrm{H}$ & 53.6 & $0-0.24$ & Yes & 1.20 & NO \\
\hline C3D8* & 1.3 & $0-18.52$ & Yes & 1.04 & YES \\
\hline C3D8H* & 4.2 & $0-7.13$ & Yes & 1.00 & YES \\
\hline C3D8R & 59.1 & $0-0.41$ & Yes & 1.01 & YES \\
\hline C3D8RH & 59.1 & $0-0.41$ & Yes & 1.01 & YES \\
\hline C3D8I & 237.5 & $0-0.03$ & No & 0.95 & $\mathrm{NO}$ \\
\hline C3D8IH & 294.1 & $0-0.0006$ & No & 0.67 & $\mathrm{NO}$ \\
\hline C3D10 & 141.6 & $0-0.16$ & Yes & 0.97 & YES \\
\hline C3D10H & 290.6 & $0-0.001$ & No & 0.63 & $\mathrm{NO}$ \\
\hline C3D10M* & 95.9 & $0-0.42$ & Yes & 0.99 & YES \\
\hline C3D10MH & 350.8 & $0-0.004$ & No & 0.72 & $\mathrm{NO}$ \\
\hline C3D10I & 279.0 & $0-0.01$ & No & 0.79 & $\mathrm{NO}$ \\
\hline C3D15 & 176.1 & $0-0.07$ & Yes & 0.98 & YES \\
\hline C3D15H & 273.4 & $0-0.009$ & No & 0.82 & $\mathrm{NO}$ \\
\hline C3D20 & 160.4 & $0-0.07$ & No & 0.98 & $\mathrm{NO}$ \\
\hline C3D20H & 278.4 & $0-0.008$ & No & 0.79 & $\mathrm{NO}$ \\
\hline C3D20R & 228.8 & $0-0.05$ & No & 0.96 & $\mathrm{NO}$ \\
\hline C3D20RH & 290.9 & $0-0.002$ & No & 0.71 & $\mathrm{NO}$ \\
\hline
\end{tabular}

*Elements selected for uniformity comparison (Results presented in Table A.7). 
Table A.6 Summary Table of Default PEEQ Plot Values and Recommendation for 2-D Element Selection Study using D-P Yielding Criteria

\begin{tabular}{|c|c|c|c|c|c|}
\hline $\begin{array}{l}\text { Element } \\
\text { Type }\end{array}$ & $\begin{array}{c}\text { Default } \\
\text { Deformation } \\
\text { Factor }\end{array}$ & $\begin{array}{c}\text { Default } \\
\text { PEEQ Limits } \\
\text { (Min -Max) }\end{array}$ & $\begin{array}{c}\text { Default } \\
\text { Acceptable } \\
\text { Failure }\end{array}$ & FOS & $\begin{array}{l}\text { Recommended } \\
\text { Based on } \\
\text { Default Values }\end{array}$ \\
\hline C3D4 & 201.1 & $0-0.001$ & No & 0.94 & $\mathrm{NO}$ \\
\hline $\mathrm{C} 3 \mathrm{D} 4 \mathrm{H}$ & 174.6 & $0-0.002$ & No & 0.96 & $\mathrm{NO}$ \\
\hline C3D6 & 110.3 & $0-0.005$ & Yes & 1.06 & $\mathrm{NO}$ \\
\hline C3D6H & 110.4 & $0-0.005$ & Yes & 1.06 & $\mathrm{NO}$ \\
\hline C3D8* & 29.1 & $0-0.07$ & Yes & 0.97 & YES \\
\hline C3D8H* & 30.9 & $0-0.06$ & Yes & 0.97 & YES \\
\hline C3D8R & 42.7 & $0-0.04$ & Yes & 1.02 & YES \\
\hline C3D8RH & 5.3 & $0-0.19$ & Yes & 0.95 & YES \\
\hline C3D8I & 129.5 & $0-0.02$ & Yes & 1.02 & YES \\
\hline C3D8IH & 304.0 & $0-0.0001$ & No & 0.60 & $\mathrm{NO}$ \\
\hline C3D10 & 156.3 & $0-0.005$ & Yes & 0.94 & YES \\
\hline C3D10H & 285.2 & $0-0.0006$ & No & 0.61 & $\mathrm{NO}$ \\
\hline C3D10M* & 147.1 & $0-0.01$ & Yes & 0.94 & YES \\
\hline C3D10MH & 202.8 & $0-0.003$ & No & 0.92 & $\mathrm{NO}$ \\
\hline C3D10I & 467.2 & $0-0.0004$ & No & 0.70 & $\mathrm{NO}$ \\
\hline C3D15 & 137.9 & $0-0.008$ & Yes & 0.94 & YES \\
\hline C3D15H & 144.7 & $0-0.007$ & Yes & 0.94 & YES \\
\hline C3D20 & 147.0 & $0-0.006$ & Yes & 0.94 & YES \\
\hline C3D20H & 243.3 & $0-0.001$ & No & 0.82 & $\mathrm{NO}$ \\
\hline C3D20R & 184.9 & $0-0.004$ & No & 0.93 & $\mathrm{NO}$ \\
\hline C3D20RH & 275.7 & $0-0.0007$ & $\mathrm{No}$ & 0.66 & $\mathrm{NO}$ \\
\hline
\end{tabular}

*Elements selected for uniformity comparison (Results presented in Table A.8).

For comparison, select three-dimensional element types were plotted with a uniform Deformation Factor and PEEQ color contour limits. The selected element types possessed similar Deformation Factors and PEEQ limits and were included in those elements that were recommended. The results are presented in Table A.7 and A.8 for the Mohr-Coulomb and Drucker-Prager yielding criteria, respectively.

The results of the comparison studies for 2-D and 3-D element type selection that utilized uniform Deformation Factors and PEEQ color contour limits support the recommendations presented in Section 8.2 and 8.3 of this study. 
Table A.7 Comparison of Three-Dimensional Element Type for Mohr-Coulomb Uniform Deformation Factor and PEEQ Limits

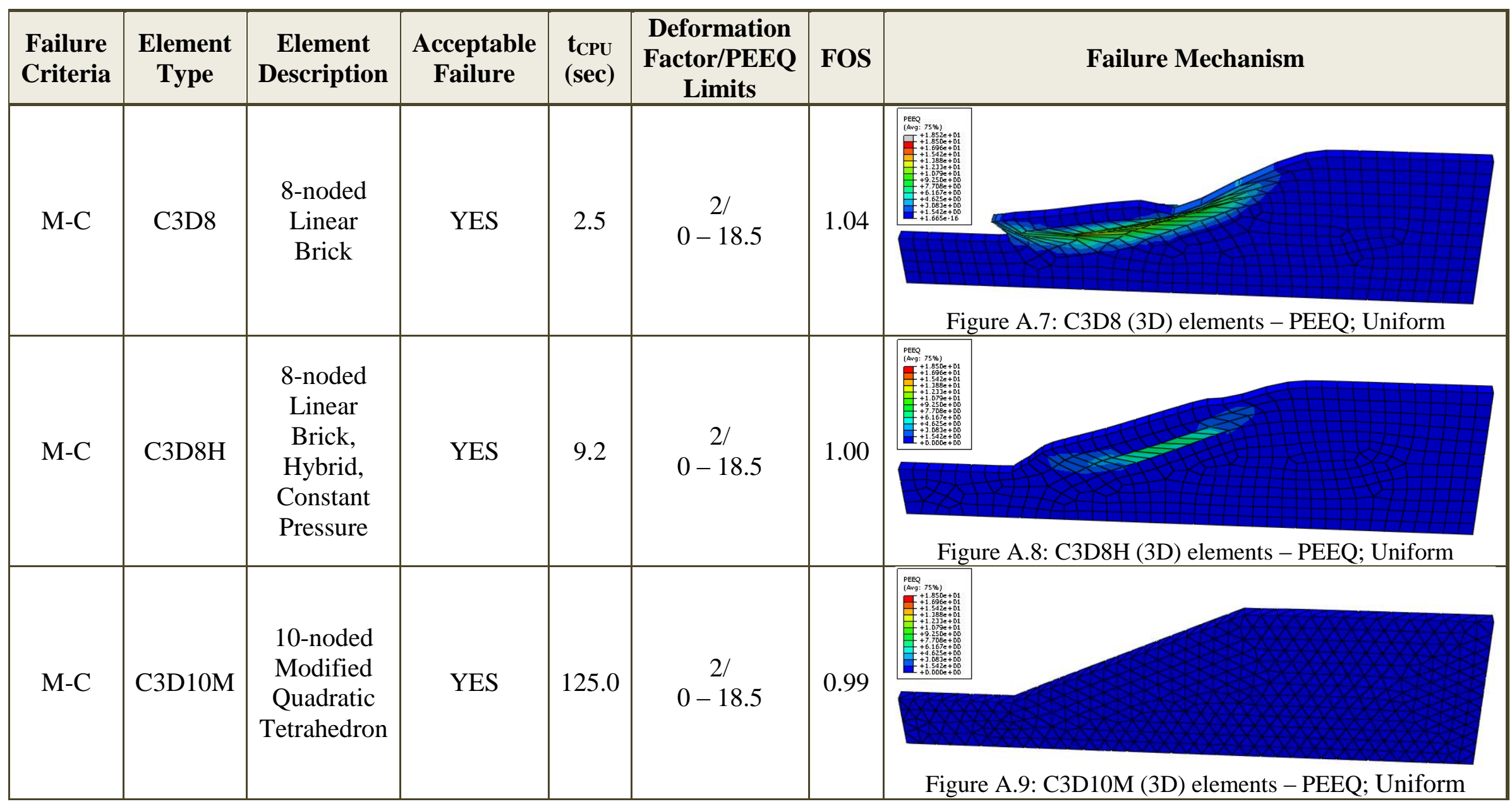


Table A.8 Comparison of Three-Dimensional Element Type for Drucker-Prager Uniform Deformation Factor and PEEQ Limits

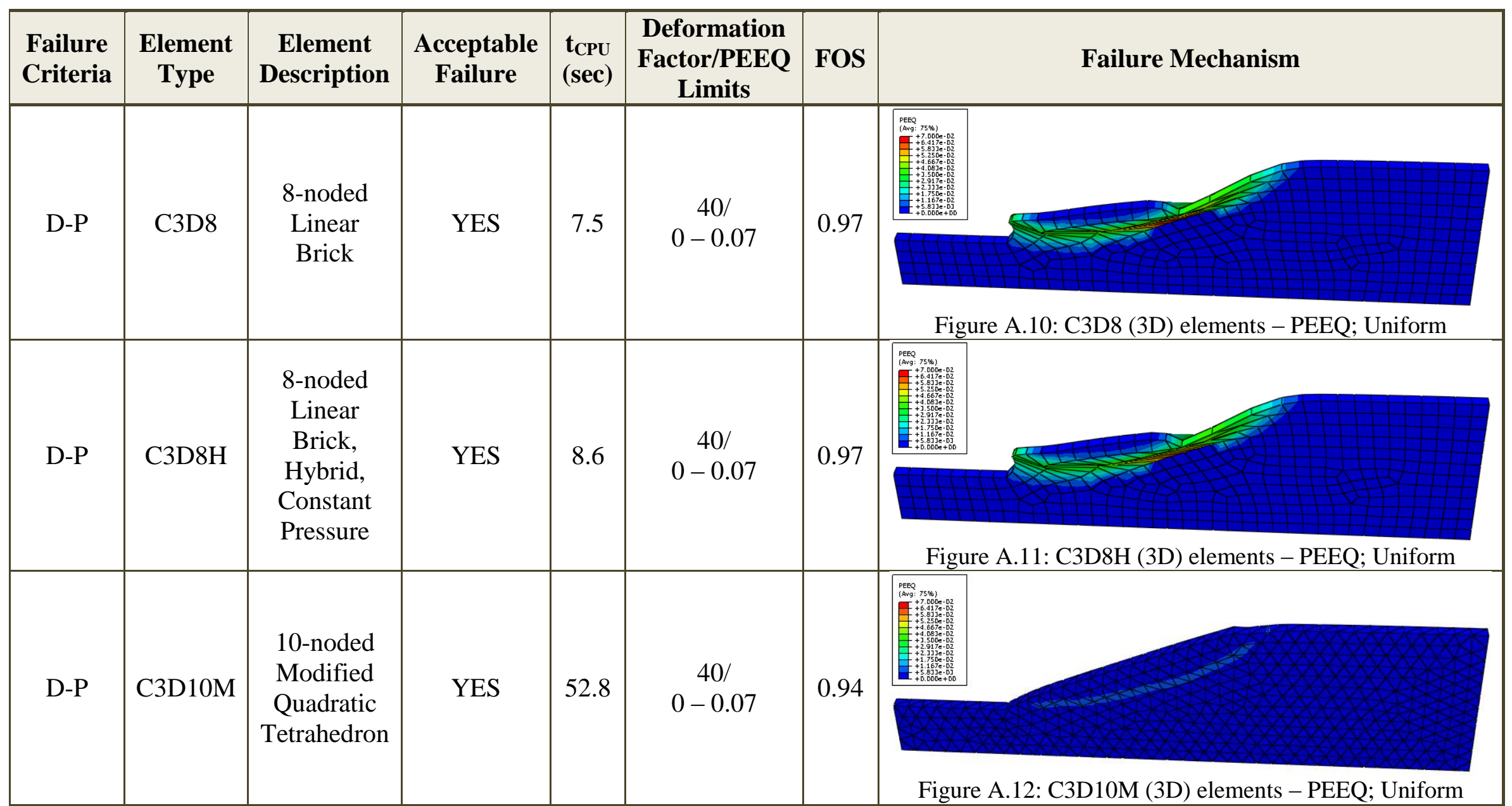

